\title{
Perspectives on uncertainty and risk : the PRIMA approach to decision support
}

Citation for published version (APA):

van Asselt, M. B. A. (2000). Perspectives on uncertainty and risk : the PRIMA approach to decision support. [Doctoral Thesis, Maastricht University]. Kluwer Academic Publishers. https://doi.org/10.26481/dis.20001012ma

Document status and date:

Published: 01/01/2000

DOI:

10.26481/dis.20001012ma

Document Version:

Publisher's PDF, also known as Version of record

\section{Please check the document version of this publication:}

- A submitted manuscript is the version of the article upon submission and before peer-review. There can be important differences between the submitted version and the official published version of record.

People interested in the research are advised to contact the author for the final version of the publication, or visit the DOI to the publisher's website.

- The final author version and the galley proof are versions of the publication after peer review.

- The final published version features the final layout of the paper including the volume, issue and page numbers.

Link to publication

\footnotetext{
General rights rights.

- You may freely distribute the URL identifying the publication in the public portal. please follow below link for the End User Agreement:

www.umlib.nl/taverne-license

Take down policy

If you believe that this document breaches copyright please contact us at:

repository@maastrichtuniversity.nl

providing details and we will investigate your claim.
}

Copyright and moral rights for the publications made accessible in the public portal are retained by the authors and/or other copyright owners and it is a condition of accessing publications that users recognise and abide by the legal requirements associated with these

- Users may download and print one copy of any publication from the public portal for the purpose of private study or research.

- You may not further distribute the material or use it for any profit-making activity or commercial gain

If the publication is distributed under the terms of Article $25 \mathrm{fa}$ of the Dutch Copyright Act, indicated by the "Taverne" license above, 


\title{
Perspectives on Uncertainty and Risk
}

\section{The PRIMA Approach to Decision Support}

\author{
by
}

Marjolein B.A. van Asselt

International Centre for Integrative Studies (ICIS),

Maastricht University,

Maastricht, The Netherlands

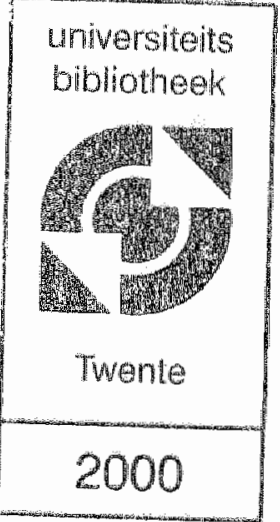

KLUWER ACADEMIC PUBLISHERS

BOSTON/DORDRECHT / LONDON 
Published by Kluwer Academic Publishers, P.O. Box 17, 3300 AA Dordrecht, The Netherlands.

Sold and distributed in North, Central and South America by Kluwer Academic Publishers,

101 Philip Drive, Norwell, MA. 02061, U.S.A.

In all other countries, sold and distributed by Kluwer Academic Publishers,

P.O. Box 322, 3300 AH Dordrecht, The Netherlands.

Printed on acid-free paper

Cover and graphic design by Zwaarwater, Esther Mosselman, Amsterdam, The Neiherlands

\section{All Rights Reserved}

(C) 2000 Kluwer Academic Publishers

No part of the material protected by this copyright notice may be reproduced or utilized in any form or by any means, electronic or mechanical, including photocopying, recording or by any information storage and retrieval system, without written permission from the copyright owner.

Printed in the Netherlands 


\section{Errata}

p.6 and p. 21: a wrong reference is mistakenly copied from our Endnote library. Radford et al. (1976) (footnote 15 and p. 21) is not used in this thesis.

p. 196: Table 7 should have been referred as Figure 7. The figure presented here as Figure 7 is actually Figure 8 (see p. 198).

p. 311: The remark $\left({ }^{*}\right.$ check $\left.^{*}\right)$ should be read as "the decrease of $\mathrm{NO}_{\mathrm{x}}$-emissions in the cities and the decrease of hydrocarbon and the $\mathrm{NO}_{\mathrm{x}}$-level on regional and European scale".

Furthermore, some typing errors throughout the thesis have survived checks and double checks.

This book is dedicated to all active dreamers 



\section{Contents}

Acknowledgements

page xim

снаттев Introduction and research methodology

$\begin{array}{lc}\text { page } & 1 \\ \text { page } & 3 \\ \text { prage } & 4 \\ \text { page } & 6 \\ \text { page } & 7 \\ \text { page } & 9 \\ \text { page } & 9 \\ \text { page } & 10 \\ \text { page } & 11 \\ \text { page } & 11 \\ \text { page } & 12 \\ \text { page } & 12 \\ \text { page } & 12 \\ \text { page } & 14 \\ \text { page } & 14 \\ \text { page } & 95 \\ \text { page } & \$ 7 \\ \text { page } & 19 \\ \text { page } & 19 \\ \text { page } & 21\end{array}$

1. Complexity, uncertainty and risk

2. Decision-support

3. Integrated Assessment

4. Research perspective

5. Aim of the thesis

5.. PROBLEM DEFINITION

5.2. RESEARCH HYPOTHESES

5.3. R ESEATCH QUESTIONS

5.4. TARGRTED OBUECTIVE

6. Research approach

6.1. RESBARCH PHILOSOPHY

6.2. RESEARCH METHODOLOGY

6.3. PROBLEM ANALYSIS

6.4. DESIGN OF PLURALISTIC FR AMEWORK

6.5. CASE-STUDY

6.6. EXPERIMENTING

6.7. EVALUATION

7. Structure of the book

REFERENCES CHAPTER ।

page al

chapter 2 Integrated Assessment

1. Key features of Integrated Assessment

$\begin{array}{ll}\text { puge } & 23 \\ \text { page } & 23 \\ \text { page } & 28 \\ \text { page } & 32 \\ \text { page } & 37 \\ \text { page } & 38 \\ \text { page } & 41 \\ \text { page } & 44 \\ \text { page } & 51 \\ \text { parge } & 54 \\ \text { page } & 54 \\ \text { page } & 56 \\ \text { page } & 62 \\ \text { page } & 66 \\ \text { page } & 67\end{array}$

2. The policy dimension of IA

3. Taxonomy of IA studies

4. IA methodology

4.I. ANALXTICAL METHOD: IA MODELLING

4.2. ANA LYTICAL METHOD: SCENARIOS

4.3. PARTICIPATORY METHODS

4.4. TOWARDS AN INTEGR ATED ASSESSMENT TOOL-KIT

5. Good practice and high quality

5.I. DHLEMMAS

5.2. ROUGH GUIDELINES FOR PR ACTISE

5.3. QUALITY CRITERIA

6. Challenges

REFERENCES CHAPTER 2

page 67 
1. Uncertaincy in a historical perspective

1.1. TEE ENIIGHTENMENT'

1.2. THE CRISIS OF POSITIVISM

1.3. POST-MODER NISM

1.4. SOCIAL-CONETRUCTIVISM

1.5. WACING INHERENT UNCERTAINTY

2. "Typology of uncertainty

2.I. TRANS-SCIENTIFIC QUESTIONS

2.2. SOURCES AND TY PES OF UNCERTAINTY

2.3. WOURCES OF UNCERTAINTY

2.4. TYPES OF UNCERTANTTY

2.5. UNCERTAINTY, MEASUR ABILITX AND SUBJECTIVITY

3. State of the art in uncertainty analysis

3.I. SENSITIVITY ANALYSIS

3.2. PROBABILITY-BASED METHODS

3.3. FORMAL SCENARIO ANALYSIS

3.4. HEDGING-ORIENTED METHODS

3.5. WALIDATION

3.6. QUALITATIVE UNCERTAINTY ANALYSIS

3.7. LIMITS

4. Towards uncertainty management

4.1. APPROACHES TO SELECTING SALIENT UNCERTAINTIES

4.2. SUBJECTIVITY, CONTROVERSY AND PLURALISM

4.3. CHALLENGES POR UNCER'AINTY MANAGEMEN'T"

5. Perspective-based uncertainty management

5.1. PERSPECTIVES

5.2. MULTIPLE MODEL. ROUTES

5-3. LESSONS LEARNED

6. Framework for uncertainty management

7. Conclusions

REFERENCES CHAPTER 3 A

1. The risk debate

1.1. THE DEBATE ON RISK DEFINITIONS

1.2. THE DEAATE ON THE RISKINESS OF MODERN HAZARDS

1.3. THE MANGE OF SCHOLARLY VIEWS

2. Towards an integrated risk analysis

2.1. WHE NEED FOR AN INTEGRATED RISK NOTION

2.2. THE NEED FOR PARTICIPATION

2.3. THE CHA LLENGE

3. Defining and classifying 'risk'

page 147

pouge 150

pange $15 \mathrm{I}$

page 156

page $15^{8}$

pange 760 .

page 163

pange $\quad 165$

parge $\quad 169$

page riza

4. Participatory risk analysis

paige 179

5. Multiple risk assessments

page 1.84 
6. Risk statements

6.1. HOW TO COMMUNICATE RISK STATEMENTS?

matris

6.2. HOW TO INTEGRATE PLUR ALISTIC RISK ASSESSMENTS INTO ROBUST RISK STATEMENTS?

7. Conclusions

page 194

page 198

REFERENCES CHAPTER 36

page 200

Chapter 4 Uncertainty and risk in perspective

1. Uncertain risks and risky uncertainties

2. Pluralism

page 206

3. Pluralism as a fact

page 209

4. Pluralism in perspective

page 213

5. Towards pluralistic methods

page 215

REFERENCES CHAPTER 4

page 220

page 225

сннетres Pluralistic framework for Integrated uncertainty Management and risk Analysis (PRIMA) page 227

1. General framework page 228

2. Starting perspective page 2 go

3. Uncertainty in perspective page 2,36

4. Scenarios in perspective page 242

5. Risks in perspective page 243

6. Quality assessment page 256

7. Conclusions REFERENCES CHAPTER 5 page 250 page 261

снаттев 6 Exploring the need for prima:

$$
\text { a case-study approach }
$$

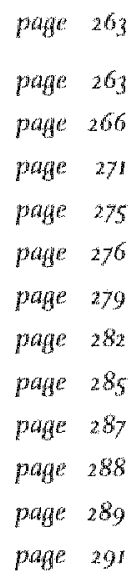

prage 282

1. Selection of the case

2. RIVM

3. RIVM's Environmental Outlooks

4. The case-study methodology 4.I. ARGUMENTATION ANALYSIS

4.2. HORIZONTAL DOCUMENT ANALYSIS

4.3. NNTERWIEWS

4.4. CHANGE OF CONTEXT-THE DE KWAADSTENIET AFYAIR

4.5. FOCUS GROUP 
CHAPTERY Searching for uncertainty in

\section{RIVM's Environmental Outlooks}

page 293
page 293
page 294
page 296
page 30 r
page 305
page 310
page 313
page 313
page 379

page 328
page 329
page 330
page 337
page 342
paige 344
page 349
page 350

1. Document analyses

2. Argumentation analysis

2.H. RXAMLE OF A WEAKCONCUUSION

2.2. EXAMPLE OE A STRONG CONCHUSION

2.3. SUMMARY OF THE WERTICAL DOCUMENT ANALYSIS

3. Searching for sources of uncertainty

4. Horizontal document analysis

4.1. LINGUISTIC ANALYSIS

4.2. ANALYSIS OP THE SCENARIOS

4.3. RIWM'S UNCHRTAINTY MANAGEMENT

AS DEDUCED FROM THE DOCUMENT ANALYSES

5. Empirical research

5.1. UMCERTAINTY IN THE ENVIRON MENTAL. OUTLOOK PRACTISE

5.2. EXPRESSED ATTITEDDE TOWARDS UNCERTAINTY

5.3. RIYM"S LEARNING PROCESS

6. A need for the prima approach?

7. Conclusions

REFERENCES CHAPTER 7

page 350

Chapter \& Exploring PRIMA's first steps in practice the case of the $5^{\text {th }}$ Environmental Outlook

1. Research approach

2. Definition phase

3. Uncertainty in perspective - workshop 3. II SUREACING IMPORTANT UNCERTAINTIES

3.2. UNGETIAINTHES IN PERSPIGTIVE

33. OUTPUT OF THE CONTROLLIST WORKUNG GROUP

3.4. OUTPUT OF THE MARKET OPTIMIST WORK NG GROUP

3.5. THE ENVIRONMENTAL WOREY WART

4. Analysis of the workshop

4.1. ANALYSIS OF 'THW WORKING GROUPS' OUTPUT

4.2. EVALUATKON OF THE PROCESS:

LESSONS FOR IMPLEMEN'TING PRIMA IN PRACTISE

page 353

page 354

page 357

pager 360

page $36 \mathrm{r}$

page 360

page 367

page 372

page 377

page 381

page $38 x$

page 390

4.3. USE OF PRIMA OUTPUT IN $5^{\text {Tii }}$ ENVIRONMENTAL OUTLOOK

page wos

page 399

page 40 I

page 405

6. Conclusions

REFERENCES CHAPTER 8 
Chapier 9 Perspectives on uncertainty and risk:

conclusion and discussion

page 407

1. Summary of findings

page 408

2. Reflection

page 413

3. A look ahead

page 414

4. Epilogue

poge 16

\footnotetext{
AlPPENDIX I Letter to the Trouw editor

APPENDIX 2 Track record of DeKwadsteniet affair

APPENDIX 3 Aggumentation analysis schemes
}

page 419

page 421

page 425 


\section{Acknowledgements}

Writing an interdisciplinary book alone is a contradiction in terms. Probably for that reason interdisciplinary $\mathrm{PhD}$ theses are still rare. I am not even able to pretend that this piece of work was a solo-activity. The scientific mores, however, requires that I am the one and only author of this thesis. The compromise is that my name stays solitarily at the cover. However, I will use the plural 'we' throughout this thesis to indicate that most of the inspiration and creativity arose out of teamwork and that all thoughts and ideas presented in this thesis have been thoroughly improved through discussion with colleagues.

First and for all, it is hard to express how grateful $l$ am to Jan Rotmans. Without his expertise, vision and endless encouragement and enthusiasm, I would have certainly lost the faith that I could write a thesis that would be worth the effort. In the course of time, we grew into a team in which each of us has a clear role to play. It is no exaggeration to state that alone I would have done less than half of what we did together. My two PhD supervisors, Jan Rotmans and Rob Hoppe, shared an exceptionally critical attitude, but in a complementary way. With the result that no single sentence was left uncriticised. I would like to thank Rob Hoppe for his contribution to this thesis and my scientific development. Thanks for helping me to make this thesis at least interesting to social scientists, and for preventing me to fall into the trap of naiveté on political and policy matters.

There are some senior colleagues who probably do not realise how important they have been in my scientific carreer, both as role models and mentors. First of all, II would like to thank Steve Rayner for his prophetic words "You will get a lot of criticism, but never forget..." and for the private advanced study course in Cultural Theory. In one way or the other, Silvio Funtowicz has given crucial support at critical moments, apart from the inspiration he and Jerry Ravetz gave me through their writings on post-normal science. I would like to thank John Robinson and Timothy O'Riordan for reminding me that being "undisciplined" does not imply "unscientific" at moments in which I was seriously discouraged. Furthermore, I would like to thank both Steve Schneider and Hadi Dowlatabadi for taking me serious at the time I was not (yer) convinced that I could contribute something to the field of Integrated Assessment. Their stimulus through opening doors has provided 
me with important opportunities to learn from leading people in the field. Last but not least, I would like to thank two female role models, José van Eijndhoven and Jill faeger. They have shown me that it is possible to stand with one foot in science as well as to held an advisory position while being respected in both worlds, and all of that without being seen as a man in female cloths.

I thank RIVM for the trust that my research on their assessment activities would go beyond simple criticism. I take it as a compliment that they were willing to sponsor my $\mathrm{PhD}$ research and to prowide all the hellp we needed in carrying out the empirical research on the Environmental Outlooks and the assessment process. I would like to thank all people from RIV m who contributed to this thesis either as interviewees (January-Eebruary 1999), or as participants in the focus group (April r999) and the uncertainty workshop (June r999). Above all, I would like to thank Klaas van Egmond, Fred Langeweg, Rob Maas, Leon Braat and Jean-Paul Hettelingh for giving me a second opportunity to serve as a "change-agent".

It would have been much more difficult to write this thesis without the team-work I encountered throughout my career. I would like to thank my former colleagues in the so-called 'globo-team' around Jan Rotmans at RIVM, where I took some first steps on the road that would ultimately resulted in this thesis. I learned a lot from their expertise on sustainable development issues. I owe a special word of thanks to Arthur Beusen and Henk Hilderink, who were always willing to help with the necessary modelling work and experiments needed to advance the concept of perspectivebased model routes. Furthermore, ] would like to thank Esther Mosselman, who apart from making wery functional art that helped to communicate my ideas, turned out to be a room-mate in the best sense of the word.

I would like to thank Carlo Jaeger for fulfilling my wish to work and live abroad for sonne time. I learned a lot during my one-year stay in Switzerland. I thank him, my former colleagues at EAWAG and all people involved in the ULYSSES project for initiating me in the world of participation. The year in Carlo Jaeger's group provided a stronger social scientific base for this PhD endeavour. I owe a special word of thanks to Claudia Pahl-Wostl and Bernd Kasemir. I am happy that we did write down our inspiring exchange of thoughts in some collective papers. 
The actual PhD research was carried out at the International Centre for Integrative Studies (ICIS), Maastricht University, Ther Netherlands, established by Jan Rotmans and myself about $2 \frac{1}{2}$ years ago. The major advantage was that this context provided me with the opportunity to organise support. I would like to thank Chantal Timmermans-Storms, Bastien Clement and Maud Huynen for their supportive literature surveys on risk, pluralism and specific literature requests, respectively. I am more than grateful to Rian Langendonck and Frank van Asten. Together we carried out the case-study work on Rrvm's Environmental Outlooks. Through thard work and almost endless commitment, they have both produced a very good master thesis that served as very valuable input to Chapters 6,7 and 8 . The whole ICIS-team has been very supportive, both through their interest and by providing a helping hand when necessary. I would explicitly like to thank those colleagues who took the time and effort to comment on previous drafts, i.e. Pim Martens, Dale Rothman, Nicole Rijkens-Klomp, Bas Amelung, Philip van Notten, Janneke Hoekstra and Debby Jochems. Furthermore, I would like to thank the secretariat - Simone Pittie, MarieLou Mestrini and Debbie ten Berge - for taking care of the procedural aspects of the PhD trajectory and the communication with the faculty and the university, the review committee, the graphical designer and the publisher.

Apart from the support from direct colleagues, I was in the fortunate circumstance that also external scholars, either within Maastricht University or from other universities and research institutes in the Netherlands and abroad, were willing to review previous drafts. I would like to thank Ruth Mourik, Roland Bal and Rein de Wilde from the department of Cultural Sciences (Maastricht University). Furthermore, I would like to thank Bruna de Marchi, Leen Dresen, Baruch Fischhoff, Silvio Funtowicz, Chris Hope, Leen Hordijk, Rob Lempert, Jerry Ravetz, Tim O'Riordan, Jeroen van der Sluijs, Charles Vlek and Warren Walker. Also the discussions at the EFIEA Uncertainty workshop in Baden (July 1999) organised by jill Jäger and Carlo Jaeger provided valuable input to this thesis.

Apart from the professional acknowledgements, I would like to thank those in my personal life that gave me the support and energy needed for such an intensive activity as producing a $\mathrm{PhD}$. 
Saskia, thanks for the way you were my sister and friend during my PhD period. Arjet, Birgit, Diederik, Eric, Esther, Fieke, Ilse, José, Marlo, Monique, Peter, Simone, Tess, and their partners: it is good to know that for being friends, it would not have made any difference whether I succeeded in finishing my PhD or not. At the same time you supported me in one way or the other more than you probably realised. I know that the period in which I was writing my $\mathrm{PhD}$ weighted on the time-slots available for sharing our friendship. Thanks for your support and understanding. In this context, I owe a very special word of thanks to Daniel Gerdes, who read the whole thesis to check the English. I would also like to thank my girl-scouts and colleague staff members for guaranteeing the necessary distance to my research in the weekends.

Finally, I would like to thank the families that adopted me in various periods in my life. I would like to thank my uncle Ton and aunt Gerda, and their children Chris and Astrid for the family warmth they gave and give to me. Frances, Derek and Gael served as my Enschede family. At the time I was wondering whether I would ever graduate, Frances already predicted that I would do a PhD. Heidi, Franz and their kids Nina, Eva and Tim were my Swiss home. Especially abroad, such a warm and comfortable friendship and being treated as member of the family are a gift for which I can never be grateful enough. Last but not least, Cor and Leida, you are outstanding in the role of parents of a mature, quasi-independent and busy woman. Thanks.

The world isn't always that beautiful, but life is a wonder. In sum, I want to thank everyone who inspired me and coloured my world. I hope this thesis gives you something back.

Marjolein B.A. van Asselt

Maastricht, November 1997 - July 2000 


\section{Introduction and}

\section{research methodology}

In a nutshell

The decisions of modern life are complex, giving rise to often intractable uncertainty in decision making. This uncertainty can take several forms. Different perspectives lead people to perceive and seek to manage the world in different ways. The approach proposed in this thesis enhances awareness of this pluralism and helps Integrated Assessment practitioners to consider the possibilities and consequences of various equally legitimate possible development parhways and, hence, avoid being over deterministic and positivistic in their practice. 
In face of complexity, decision-makers usually just muddle along. Why?

First of all, what is a complex problem? A decision-making issue is complex, if it satisfies the following characteristics' (see also Figure I):

- there is not one problem, but a tangled web of related problems (multiproblem).

- the issue lies across or at the intersection of many disciplines ${ }^{2}$, i.e. it has an economic, environmental, socio-cultural and institutional/political dimension (multi-dimensional).

- the underlying processes interact on various scale levels (local, regional, national, continental and global) and on different temporal scales ${ }^{3}$ (multiscale).

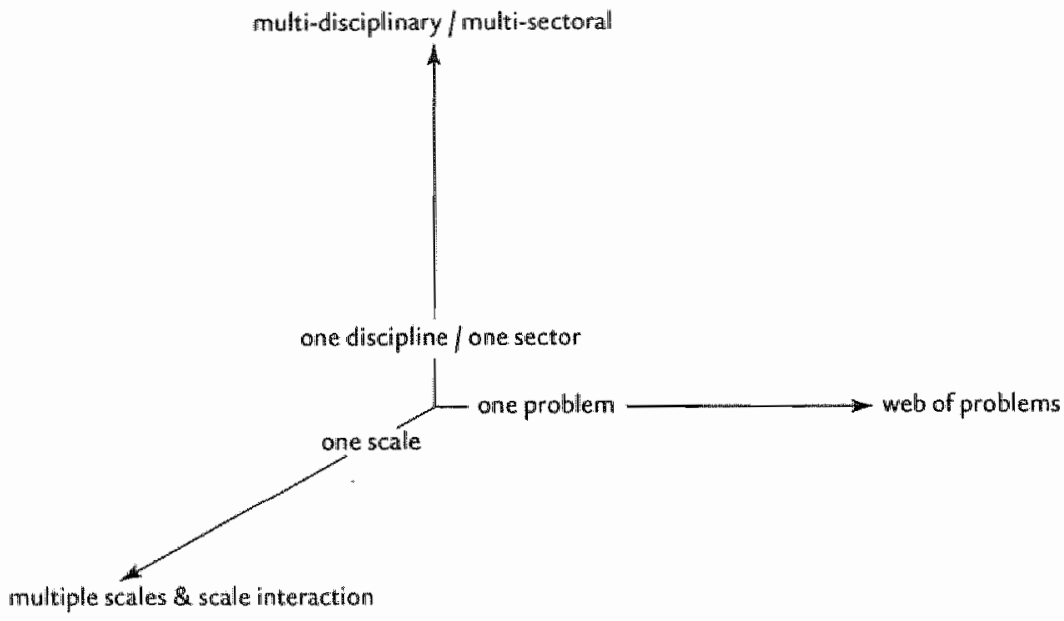

FIGURE, The three dimensions of complexity

We do not argue that previous societies were not complex or that life used to be easy. The Inca-culture is an obvious example of a very complex society in ancient times. However, this culture was bound to a specific geographical area, and can thereby be considered as a kind of independent subsystem. We argue that the essence of today's complexity lies in the vanishing of geographical borders and subsystem boundaries. Nowadays, changes at one place on Earth can impact on the 
lives of people and the state of the environment around the globe due to mutual interactions and interrelations between social, economic, institutional, technological and ecological processes.

The number of complex issues swells, due to scale-enlargement, globalisation, technological innovation and an increased interconnectedness. However, our society is not prepared to manage complexity: governments are subdivided in ministries, science is organised along disciplines, business is structured into sectors, and NGOs defend a specific stake. Although the words intergovernmental, interdeparmental and interdisciplinary belong to our vocabulary, they have not really developed into common practise.

Decision-makers are and will be increasingly confronted with complex issues. Muddling along doesn't seem to be the best strategy. It is not fair to blame decisionmakers. They are not adequately equipped for this task. They lack tools, methods and strategies that enable them to do the job. They lack adequate decision-support. Why?

\section{Complexity, uncertainty and risk}

Complex issues are complicated. There are two major reasons. Due to the scope of complexity, more and more actors are involved, either directly or indirectly. Decision-making on complex issues thus implies consideration of an increasing variety of, often conflicting and contradictory, perspectives, interests and needs. Notwithstanding the apparent success of the "poldermodel", decision-making bodies, whether governmental or business, struggle with this consequence of complexity. Second, as will be argued in this thesis, complexity goes hand in glove with fundamental uncertainty. Important complex phenomena like climate change, technological innovation, and war, and tunderlying processes (like biogeochemical processes, market mechanisms, and human behaviour) are not fully understood. As will be argued in this thesis, in such cases uncertainty cannot be banned. Decisionmaking on complex issues is thus decision-making in uncertainty. Uncertainty is a feature our society feels uncomfortable with ${ }^{6}$. As will be argued in this thesis, no methods and tools are currently available to manage uncertainty in decision-making in an adequate manner.

Dutch model of consultation and negotiation-economy

5 See allso (RMAHO 1998)

6 Compare (Hofstede 991 ) 
Complex issues are important. The risks associated with complexity can be quite substantial. Due to the character of complexity, the risks cannot be limited in space, nor in time. Furthermore, there are different perspectives on risk - e.g. risk-seeking, risk-accepting and risk-aversive ${ }^{7}$-, which makes it difficult to define risks unequivocally: multiple risk definitions are equally legitimate. As will be argued in this thesis, the current tools and methods for risk analysis are not adequate to evaluate risks associated with complex issues. Complexity demands a new 'risk logic' and a new form of risk analysis.

\section{Decision-support}

Due to uncertainty and multiple risk definitions, science cannot come up with definite recommendations for complex issues. On the one hand, this may be seen as good, because it frees society from 'technocratic patronising.8. On the other hand, it may lead to irresponsible management if uncertainty is used to postpone decision-making.

In the face of complexity, the way knowledge and science are currently used in decision-support is problematic ${ }^{9}$. On the one hand, because in general uncertainty is hidden, ignored or even denied. On the other hand, because risks are usually estimated from one perspective. The way in which science handles uncertainty and risk affects the manner it communicates uncertainty and risk to decision-makers ${ }^{10}$. The traditional methods and tools are inadequate to address and communicate inherent uncertainty and plural perspectives in scientific knowledge. And even worse, applying these classical methods is likely to reinforce the denial of uncertainty and 'mono-thinking' about risk.

Although the fears for a technocratic society ruled by scientific experts are still alive, in our point of view it is much more likely that decision-makers will turn their back on scientific experts, either explicitly or implicitly. The latter by using/abusing scientific advice selectively as 'underpinning' of taken views ${ }^{\text {nt. }}$. Due to uncertainty and pluralism, the ideal of prediction and truth is corroded. However, in the current web of engagements between decision-makers and scientists, the latter still claim, or are forced to claim, levels of certainty that the human stock of knowledge does not support. Both seem to be kept in the paradigm of "science-speaking-truth-to-power".

See Chapter 318

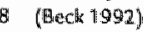

9 See also (Hoppe 1999 )

10 (ORiordan and Langford 1999 )

H (RAMO 1998) 
Scientists may have the feeling that they cannot make uncertainties explicit in their recommendations, because it deprives them of credibility (and power). But in the current setting every disclosed 'wrong prediction' undermines the trust in science. And, due to complexity, the number of "wrong predictions" will only increase. Such a negative spiral may in the end put science at the margins of societal debates.

Due to uncertainty and risk, the ideal of finding the "optimal, most effective and most efficient solution' vanishes into thin air. In the face of uncertainty and risk, the challenge is to find strategies that are robust, i.e. strategies that appear to trigger a favourable future, that seem to avoid highly undesirable ones, and that are flexible enough to be changed or reversed if new insights emerge. Scientific knowledge, an informed awareness of the limits to knowing, and the systematic way of thinking associated with science can be useful in the common search for robust strategies that address societal problems and make the most of opportunities. Scientific decisionsupport in principle thus has a role to play.

'Taking the above into account, decision-support is thus not simply the provision of knowledge per se. The quality of decision-making does not necessarily increases if more knowledge is available. Decision-support should therefore not limit itself to communicating the relevant scientific insights, but it should also enable decisionmakers to form their opinion on the associated uncertainty and risk ${ }^{12}$.

Complex issues, such as transport, infrastructure and mobility, cannot be studied by a single scientist behind a desk in an ivory tower. Due to the scope of complex issues, actor"s perceptions, expectations, attitudes, perspectives, norms and values do matrer. This implies that scientists can (and should) learn from the experience, expertise and views of non-academics as politicians, civil servants, business people, representatives from NGOs, artists and ordinary citizens. The implication is that decision-support on complex issues should be participatory ${ }^{13}$.

The challenge for decision-support is thus to find ways to use knowledge and to understand uncertainty in such a way that it enables to inform societal debates about risks. Taking the above considerations into account, the aim of scientific decisionsupport in face of complexity can be formulated as:

Decision-support is a structured and participatory search process that aims to provide robust insights that facilitate decision-makers to act consciously in a complex, and thus uncertain and risky, world. 
To that end, new assessment methods which enable to address and communicate uncertainty and risk are necessary. The current thesis aims to make a valuable and constructive contribution to this methodological challenge.

\section{Integrated Assessment}

This thesis builds upon the tradition of Integrated Assessment (IA). In this context, IA is considered as a particular form of decision-support. IA can probably best be described as a structured process of dealing with complex issues, using knowledge from various scientific disciplines and/or stakeholders, such that integrated insights are made available to help responsible decision-makers to think about problems and/or to evaluate possible actions ${ }^{14}$. The principle of Integrated Assessment is that birs and pieces from different knowledge domains are combined into one puzzle in order to gain relevant insights for decision-making that go beyond the reach of separate disciplines. Integrated Assessment distinguishes itself from intuitively-based processes through the usage of formal frameworks, systematic procedures and scientific knowledge. It is distinct from interdisciplinary research by its a-priori decision. support ambition.

Approaches currently available in Integrated Assessment suffer from either one or two of the following disadvantages:

- the methods do not allow to address the most salient uncertainties and risks

- the associated uncertainty and risk measures are not understandable to nonscientists in general and decision-makers in particular.

Both disadvantages are undermining the key ambitions of Integrated Assessment: to analyse and interpret complex issues, and to communicate integrated insights to society and decision-makers in particular. How to deal with inherent uncertainty currently plays a key role in actual methodological debates in the IA community ${ }^{25}$. Against this background, the current thesis aims to provide a substantial contribution to lA methodology. The intention is that the thesis is also of interest to neighbouring fields of decision support, such as risk analysis, technology assessment, impact assessment ${ }^{16}$, life-cycle analysis, policy analysis and operations research.

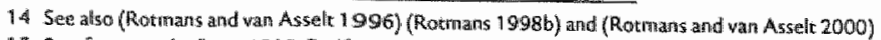

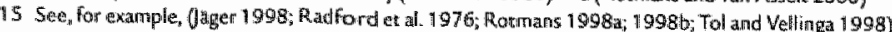

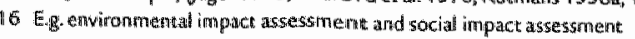




\section{Research perspective}

It will be argued further on in this thesis that science is a creative process in which social and individual values interfere with observation, analysis and interpretation. In this view a scientist is a societal actor. So before outlining the research approach, we consider it necessary to clarify our research perspective and attitude.

The research attitude can be characterised as moderately social-constructivist ${ }^{37}$, in the sense that we accept that science is a social process, however the existence of facts and reality is not fully denied. We argue that in case of complex societal issues objective scientific assessment is impossible, without arguing that science is just another way of argumentation.

The issue of decision-support can be addressed from either the supply-side (i.e. the scientists and analysts) or the demand-side (i.e. the decision-makers and the stakeholders) ${ }^{8}$. The perspective guiding the current thesis can be characterised as 'supply-driven'. There are several reasons for this choice, both principal and practical.

We are more and more convinced that profound knowledge of the policy sciences" literature and/or substantial experience with the decision-making practise is needed to be able to gain a sufficiently rich and realistic understanding of the demand-side. It is at the moment beyond our competence to reason adequately from a demand-driven perspective in this particular thesis. If the thesis would have taken such a perspective, it is more than likely that it would have resulted in a naive and caricatural exercise of no use for decision-support. Having worked at RrvM, the Dutch Enwironmental Planning Agency, having participated in two large projects for the European Commission ${ }^{\text {th }}$ and being involved in various IA consultancy projects ${ }^{20}$ at the Intermational Centre for Integrative Studies (ICIS), the primary researcher is rather knowledgeable of and experienced with the supply-side of decision-support.

The principal, and thus the decisive, reason for choosing a supply-driven perspective, is that we are convinced that there are 'clues' on the supply-side. The majority of the decision-makers still expects certainty from science and will therefore not have an a-priori interest in decision-support that takes uncertainty as starting point. The first step towards a new mode of decision-support is that the decisionsupport suppliers acknowledge inherent uncertainty and pluralism. This already

\footnotetext{
17 See also Chapter $3 A, 3 B$ and 4 .

1 See Chapter 2.

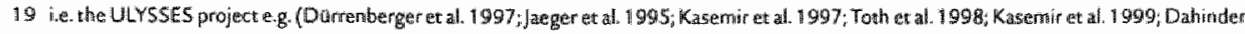

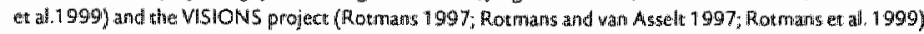

20 E.g for the Province of Limburg (the so-Called POL-project) (1C15 ; 99 ;
} 
requires a kind of paradigm-shift on the supply-side. The next step is to sketch alternative strategies to deal with uncertainty and risk in the practise of decisionsupport. Such a practical translation is necessary to consolidate support with the practitioners. In sum, we argue that a promising avenue towards improved decisionsupport is to attempt to gain support on the supply-side for the need for change, and secondly to develop an alternative approach that seems feasible to the practitioners in decision-support.

As a theoretically sound and practically feasible alternative approach to decision-support is available as a prototype, the next step would be to discuss such an example study with the demand-side, with the aim to raise consciousness on the impossibility to escape uncertainty and risk. As argued in technology assessment ${ }^{21}$, preferences and expectations are shaped by the interaction with a prototype. This implies that concrete alternatives are needed in order to facilitate a sensible discussion between the supply and the demand-side. Otherwise it is difficult to imagine what would be the consequences of a new interplay between science and policy for the practise of decision-making.

The current thesis can be considered as an attempt to build a protorype that may enhance a consciousness-raising process and thus an alteration of current preferences and expectations. First on the supply side and, in a lacer stage, on the demand side. The current thesis aims both to be a contribution to scientific methodology and to serve as a catalyst in the decision-support community. The longterm objective is to encourage and promote a fundamental transformation of the interplay between decision-making and science. The research actitude underlying this thesis can thus be characterised as that of an active intervenor as opposed to a passive observer. We consciously choose to act as a change agent, instead of being an outsider to the process.

The research perspective can also be considered as 'science-driven", because it holds, as follows from the introduction so far, that scientists and scientific knowledge have something to offer to decision-makers. In our point of view, a society that doesn't use the available stock of knowledge and the specific competence of experts ignores a valuable resource. And in doing so, it may head towards an undesirable future that could have been avoided. Without this conviction, the present thesis would have never been written.

2) Seet for examplet, (Rip 1995) 


\section{Aim of the thesis}

Central to this thesis is the acceptance of uncertainty and plural risk definitions as being inherent to complex issues. The above detour around complexity, uncertainty, risk, decision-support and Integrated Assessment serves as basis for our problem definition, which on its turn sets the scope for the research hypotheses and questions.

Complexiry provides room for different interpretations of uncertainty and different definitions of risk. As a consequence, science cannot come up with definite recommendations for decision-making. This has severe consequences for decisionsupport. In view of inherent uncertainty and risk, the rask of decision support is then to assist decision-makers to act consciously in an uncertain and risky world by structuring and facilitating the search process for robust strategies. However, there is a yawning gap between this theoretical ideal and the current practise of decisionsupport, including Integrated Assessment. The goal of this thesis is to provide a contribution to bridging this gap through development of Integrated Assessment methodology.

\section{I. PROBLEM DEFINITION}

The overall ideal of our research programme is to improve the interplay between science and decision-making in order to allow the human stock of knowledge to be used in an effective and adequate manner. Effective means that scientific decision-support really facilitates decision-making in taking robust decisions. Adequate in this con* text signifies that decision-support recognises both the potency and the limits of scientific advice, and that it doesn't claim levels of certainty or plausibility that the evidence doesn"t support.

The umbrella purpose of this thesis is to address the following overarching question: What are theoretically sound and practically feasible approaches to Integrated Assessment that enable to handle and deal with uncertainty and risk in an adequate and effective manner?

or to phrase it in a more accessible manner:

How to bridge the observed gap between the theoretical ideal and the practise of Integrated Assessment? 


\subsection{RESEARCH HYPOTHESES}

Because the way in which science handles uncertainty and risk frames the manner scientists communicate with decision-makers, a methodological approach to the above research purpose is both legitimate and promising. Furthermore, it seems that the traditional assessment methods and tools are inadequate to deal with uncertainty and risk in decision-support endeavours. Our research hypothesis therefore holds:

\section{Hypothesis}

There is a need for new assessment methods for managing and analysing uncertainty and risk.

This hypothesis is falsified in case an assessment method exists that enables to address both all cypes and sources of uncertainty as well as all relevant risk definitions and perceptions in such a way that decision-makers understand the quality and the impact of the derived recommendations. Furchermore, testing the above hypothesis implies analysing whether the available methods are problematic in view of uncertainty and risk.

Multiple interpretations of uncertainty and plural definitions of risk imply pluralism. Pluralism refers to the existence of different viable and legitimate perspectives. This implies that the approaches for managing and analysing uncertainty and risk have to consider multiple perspectives. The basic requirement guiding this thesis involves that perspective-based/pluralistic methods are in principle able to deal with inherent uncertainty and risk.

\section{Requirement}

Assessment methods addressing uncertainty and risk have to effectively and adequately deal with pluralism.

The above requirement is normative. It would be falsified if it can be convincingly argued that there is at least one 'mono-istic' (positivist) method that adequately addresses multiple interpretations of uncertainty and plural risk perceptions. Testing the hypothesis and the above requirement will enable to convincingly demonstrate in a scientific way both the need for, and the main features of, new approaches to deal with uncertainty and risk analysis in Integrated Assessment. 


\section{5*3. RESEARCH QUESTIONS}

The above hypotheses form one comerstone for the current thesis. Testing the above hypotheses will create a basis for an alternative to decision-support, by identifying the criteria new assessment methods have the satisfy. But it would not result in a. bridge, not even a prototype of a bridge, between the theoretical ideal and actual practise. To that end, the following research questions will also be addressed in the current thesis:

- What concepts, tools and methods would a pluralistic framework for integrated uncertainty management and risk analysis deploy and what steps would it involve?

- How can this theoretically sound pluralistic framework be used in actual decision-support?

- In what way and to what extent is this pluralistic framework a feasible and adequate alternative for decision-support?

Addressing these questions will enable to explore the practical feasibility of pluralistic assessment.

\subsection{TARGETED OBJECTIVE}

The aim of the thesis is to advance improvement of the practise of Integrated Assessment by enriching the current methodology" (tool kit"). Our effort is specifically directed to approaches that enable to address and communicate inherent uncertainty and risk. The ambition is thus to develop an alternative assessment methodology, that satisfies the criteria associated with uncertainty management, The targeted concrete objective guiding this thesis is thus:

to develop a pluralistic framework for integrated uncertainty management and risk analysis that is theoretically sound and to explore whether it is practically feasible. 


\section{Research approach}

In this section we will delineate our research approach. The research approach signifies how the above research hypotheses will be tested and how the research questions are addressed in order to realise the research objective. It furthermore describes which methods will be used, and how. It will be argued that the chosen approach is valid, legitimate and sound in view of the research purpose and the ultimate objective.

\subsection{RESEARCH PHILOSOPHY}

We will argue on theoretical and empirical grounds that uncertainty and risk are problematic issues in decision-support. A framework for pluralistic uncertainty management and risk analysis will be proposed. The aim is to apply this framework in practice in order to explore its practical feasibility. These experiences will then be used to draw lessons for Integrated Assessment (see Figure 2).

\subsection{RESEARCH METHODOLOGY}

The following steps will be taken in order to test the hypotheses and to answer the research questions:

- problem analysis

- design of a pluralistic framework

- case-study on uncertainty management and risk analysis in the practise of decision-support

- experimenting with the pluralistic framework in the practise of decisionsupport

- evaluation

The different steps will be discussed in more detail in the following subsections in order to make explicit which research methods are chosen and why. 


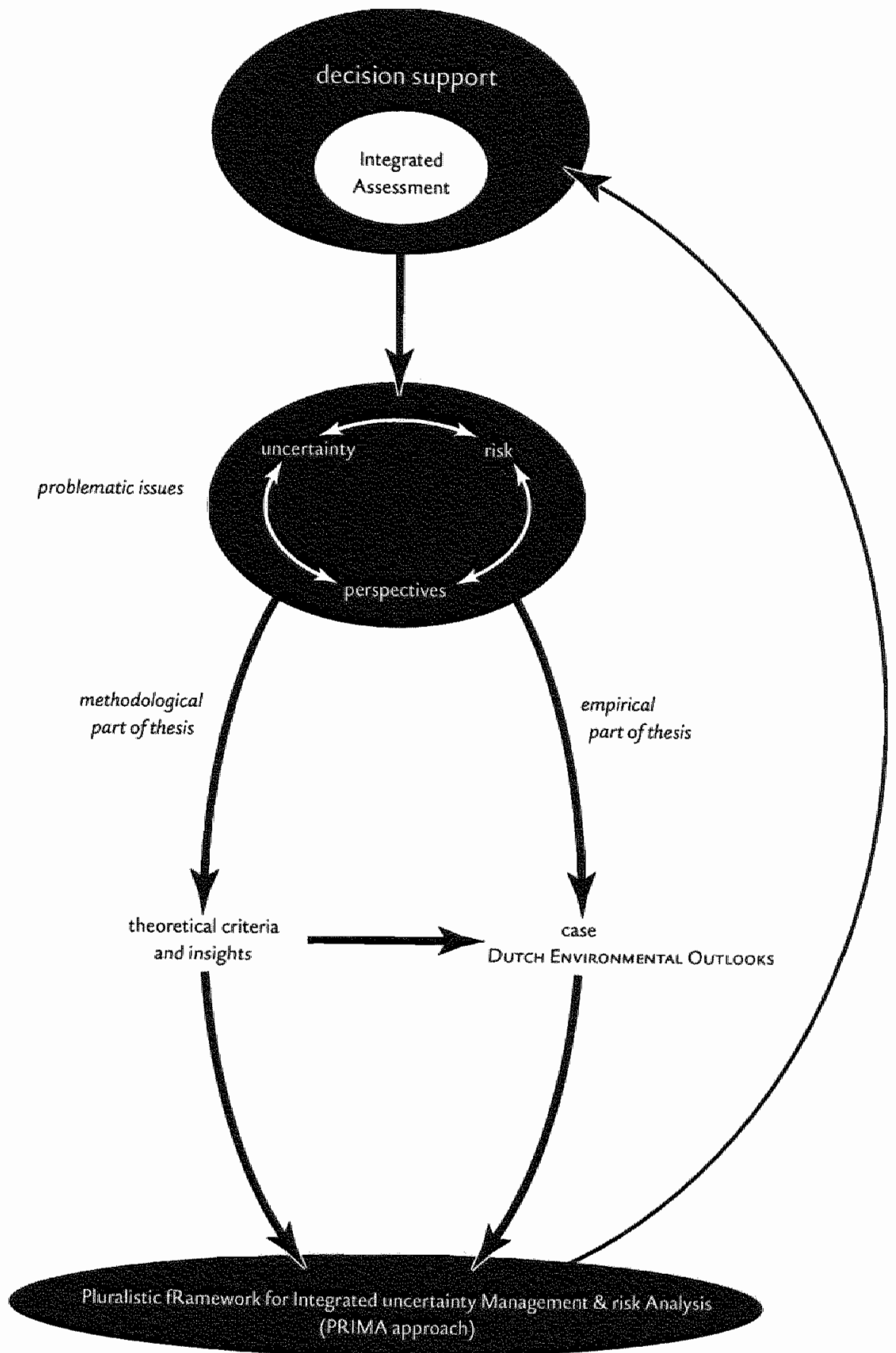

FIGURE 2 Research philisophy 


\subsection{PROBLEM ANALYSIS}

This first step involves a theoretical investigation of the concepts 'uncertainty' and 'risk' in relation to decision-support. The theoretical part of this thesis involves an interdisciplinary literature review and analysis involving the following scientific disciplines or felds of research:

- uncertainty analysis (mathematics)

- risk analysis (assessment, management and communication)

- history of science

- philosophy

- social studies of science

- sociology

- psychology

- economics

- anthropology

- policy sciences

- technology assessment

The literature assessment will allow conceptualisations of the concepts uncertainty and risk. The theoretical analysis will furthermore yield criteria which have to be satisfied in view of inherent uncertainty and risk. Against this background, ideas on pluralism, perspectives, participation and robustness as expressed in the scholarly literature will be evaluated. This evaluation will yield theoretical building blocks that can be used to sketch an assessment approach in which uncertainty and risk are the guiding principles. This step involves on the one hand targeted literature analysis, and on the other hand systematic creative and interdisciplinary thinking.

\subsection{DESIGN OF PLURALISTIC FRAMEWORK}

Theorising about uncertainty, risk and perspectives will be used to develop a theoretically sound framework for decision-support. To give a foretaste of the contents of this thesis, the major principles that result from the theoretical endeavour are outlined here.

Central in the proposed framework is to disentangle controversies on complex issues in terms of salient uncertainties and relevant risk dimensions. The salient uncertainties are then 'coloured' according to various perspectives. Starting from these perspective-based interpretations, we arrive at various legitimate and consistent 
narratives. This set of narratives then indicates a variety of possible futures. Integrated analysis of this set of fucures allows to evaluate autonomous and policydriven developments in terms of plausibility and risk. In this way, the level of uncertainty of the underlying knowledge can be made explicit in terms of risk. Based on such an integrated assessment, the perspective-based approach is supposed to reveal robust insights relevant for decision-making. The proposed framework for decision-support will be referred to as the PRMA-approach, an acronym for Pluralistic $\mathrm{R}$ amework for Integrated uncertainty Management and risk Analysis.

In order to be of practical use, one of the challenges the present thesis faces is to translate this framework into concrete stages and steps, and in concepts and tools that can be be used to implement a particular step and in terms of deliverables. Although the framework will be generic, which implies a certain level of generality, the aim is that it has to lend itself quite easily into use for particular assessment pruposes. This ambition will be explored through experiments with the PRIMA approach in practice, which empirical research constitutes the second part of the study.

This research step belongs to the heart of methodology development. In a certain way, it can be considered as a design activity and thus shares some key features with engineering. The end product of this endeavour will be a framework that describes different steps and stages.

\subsection{CASE-STUDY}

The empirical perspective involves exploring how uncertainty and risk are currently treated and managed in actual decision-support and why in this way. A case-study is the preferred strategy when "how" and "why" questions are being posed about a contemporary phenomenon over which the investigators have no control ${ }^{22}$. It is clear that we are not interested in the "dead past", (i.e. that is when no relevant persons are alive to report, even retrospectively, what occurred), but in contemporary decisionsupport processes. In studying assessment practices, it is obvious that it is beyond our reach to set up "controlled experiments" or to manipulate behaviour.

Before choosing the case-study approach as the strategy for empirical inquiry, it is important to reflect on the kind of scientific conclusions that can be derived from case-study research. Case-studies in principle yield conclusions that are analytical 
generalisable, i.e. to theoretical propositions, and not to populations or universes (statistical generalisation). For our purpose, we are interested in insights that enable us to draw conclusions about the nature of the assessment practice in the light of our theoretical understanding of uncertainty and risk. This implies that our interest is in analytical generalisation. Evaluating our ambitions, the case-study approach seems to be the appropriate research strategy.

We decided to do one in-depth case-study instead of a series of case-studies. We realise that this implies that the conclusions may be biased by the specifics of the particular case. However, because of the fundamental character of uncertainty and risk, it is to be expected that a qualified case-study is demanding and timeconsuming. In view of our purpose, it is highly important to ensure that we are able to gain a multi-dimensional understanding of actual decision support practise. This implies that in this context it is prudent to opt for one in-depth case study. The idea is that the in-depth case-study will shed some light on how uncertainty and risk are managed and analysed in practice. In view of the theoretical analysis of uncertainty and risk, it will be evaluated wherher the adopted approach(es) are adequate.

We have selected the Dutch Environmental Outlooks (in Dutch: Millieuverkenningen) for our case. The Environmental Outlooks ${ }^{23}$ are produced by rrvm, the National Institute for Public Health and the Environment, being the official decision-support institute on environmental policy. Rrvm has the status of environmental planning agency (in Dutch: Milieuplanbureau). Since the publication of the first environmental outlook, well-known as "Concern for Tomorrow" these environmental forecasts play a key role in Dutch environmental policymaking. The Environmental Outlook endeavour can be adequately characterised as institutionalised decision-support. The Environmental Outlooks aim to provide an analysis of the environmental and health impacts associated with a particular evolving of societal pressures (e.g. in terms of economic growth, demographic developments, and consumption and production patterns). Due to the complexity of these dynamics, the analysis is beset with uncertainty. On the other hand, by aiming to provide recommendations for environmental policy, the Environmental Outlooks touch upon the issue of societal risks. The Environmental Outlook process is generally considered to be a decision-support activity that can be characterised as Integrated Assessment. These features imply that the Dutch Environmental 
Outlooks constitute a relevant case in the context of this thesis. Furthermore, RIVM's Environmental Outlooks inspired decision-support activities in orher countries, at the European level ${ }^{25}$ and even at the global level ${ }^{16}$. Because of this, the case of the Dutch Environmental Outlooks is also an attractive one: because it played an exemplary role in the past, this case-study is an interesting one in view of its potential for analytical generalisation.

So far, Rrvm has produced four Environmental Outlooks. We propose a multiple-case approach, i.e. the four Environmental Outlooks are considered to be separate cases that are independently studied (vertical analysis). This enables to address in a second instance to question whether, and if so how, the way uncertainty and risk are dealt with changed over time (horizontal analysis). The case-study will comprise $^{27}:$ i) document analysis, ii) interviews with the analysts involved in the Environmental outlook process, iii) a focus group with the interviewees and some additional RIVM executives to check the conclusions in an interactive manner, and iv) questionnaires among a broader group of RrvM analysts participating in the environmental assessments.

The retrospective case-study has primarily a deconstructive character. The assessment practice is deconstructed in order to assess the fundamental character of inherent uncertainty and plural risks in relation to decision-support in an empirical manner. The aim of this empirical investigation is to evaluate whether the current practise of decision-support in case of complex issues is problematic and to signify whether there is a practical need for new approaches.

\subsection{EXPERIMENTING}

As indicated above, the practical usefulness of the generic framework can only be explored through use. In order to explore whether the proposed framework is practically feasible, experience has to be gained with the application of this framework in an actual assessment context. Feasibility in this context implies that practitioners themselves indicate that this approach has a surplus value compared to current practise and that it can in principle be applied within the limits of their practical constraints. 
In this step, the proposed method for integrated uncertainty management and risk analysis is applied to the $5^{\text {th }}$ Environmental Outlooks. This prospective approach has the advantages that problematic characteristics of current practise observed in the retrospective case-study can be dealt with in a constructive manner. In this way, the thesis goes beyond superficial (easy) criticism on Rrvm's practise. The case-study material enables to understand the current practise, its strengths and weaknesses, and allows to build up credibility, mutual respect and trust. Active participation of the professionals involved in the Environmental Outlook processes in the course of this research phase is a pre-requisite. Only with help of the analysts it will be able to evaluate whether, and if so in what way, the pluralistic approach lends itself to implementation in practise.

This research phase is partly methodological (i.e. drafting a case-specific version of the PrIMA framework) and partly empirical. Empirical methods used in this part of the study are a secondary analysis of the case-study interviews, a focus group with the interviewees supplemented by some senior professionals, and a participatory workshop with analysts involved in the preparation of the $5^{\text {th }}$ Environmental Outlook. It is intended to use additional questionnaires at the workshop to complement the social process with individual observations, experiences and preferences.

The intended participatory process is meant to be a mutual learning exercise. The aim is that we encounter the practical criteria and boundary conditions to pluralistic decision-support, while Rrvm get acquainted with an alternative approach to decision-support that enables them to manage and analyse uncertainty and risk in a way that is more in accordance with theoretical and epistemological insights. This intention has become quite opportune in the course of the research described in this thesis, due to a public debate on the way RIVM is dealing with uncertainty in their decision-support endeavours ${ }^{28}$.

We have to be careful with the conclusions that can be drawn about feasibility, because the outlined research approach implies a limited group of practitioners will be involved all employed by the same the decision-support institute.

28 See Chapter 6 and (yan Asten 2000). 


\subsection{EVALUATION}

The experiences gained will enable us to improve the proposed framework. The experiences in the empirical phase of the research thus feed back into the proposed framework, either in terms of improvement and refinement, or in terms of specifying critical aspects of the assessment context that guides some specific implementation choices, or by concluding that the proposed framework is a theoretical ideal that has norhing to offer to the practise of decision-support.

This last research phase will involve a critical evaluation in which the strengths and weaknesses of the proposed approach for Integrated Assessment are addressed. With regard to the latter, it is worthwhile to explore whether and in what way the proposed approach can be used in a complementary way with existing assessment methods, and it is essential to evaluate if this proposed approach in principle elevates the quality of Integrated Assessment.

\section{Structure of the book}

It is difficult to reflect the cyclical and iterative nature of our research into the most linear form of communication, i.e. a book that is supposed to be read from the beginning till the end. Nevertheless.... Where this first Chapter discusses the research philosophy and the research approach, Chapter 2 sets the scope of the thesis by providing a state-of-the-art overview of Integrated Assessment in terms of current practises and challenges for the future.

As argued above, uncertainty and risk can be considered as two sides of the same coin. It depends on the perspective of the reader which angle s/he prefers. It turned out to be a mission impossible (and probably a wild-goose chase) to integrate the two modes of thinking into one theoretical overview. For that reason, we have chosen to produce two variants of Chapter 3 , i.e. one reasoning from the concept of uncertainty (Chapter $3 \mathrm{~A}$ ) and the other from the notion of risk (Chapter $3 \mathrm{~B}$ ). The first is supposed to be primarily of interest for IA modellers and interested natural scientists, where the second one is expected to comply initially with the social scientists in Integrated Assessment and decision-makers' conceptualisations. Both chapters result in theoretical criteria for addressing and communicating uncertainty and risk in Integrated Assessment. Notwithstanding the fact that the variants share the same conclusions, they differ, so it may be interesting to read both after all. 
In Chapter 4 the relationship between uncertainty and risk is explored in order to assess how the two notions can supplement each other. The theoretical criteria that result from the previous Chapters, i.e pluralism, participation and robustness, are studied in more depth and the interlinkages between these criteria are explored in order to provide a basis for crystallising the ideas. The theoretical endeavour in this and the previous chapters then culminates into defining integrated uncertainty management and risk analysis in a way that is theoretically sound.

In line with the theoretical criteria and conditions discussed in the previous part of the thesis, in Chapter 5 a pluralistic framework for integrated uncertainty management and risk analysis is proposed, referred to as the Pluralistic fRamework for Integrated uncertainty Management and risk Analysis (PRIMA). The proposed stages and steps are discussed as concrete as possible. The aim is that this general framework can be used as a kind of 'ideal plan' that inspires and challenges practitioners to set up pluralistic assessment processes tailored to their specific case and circumstances.

The second part of the thesis has an empirical flavour and concentrates on the case of the Dutch Environmental Outlooks. Chapter 6 describes the background and introduces the approach followed in the empirical research. Chapter 7 reports the results of the retrospective case-study. It will assess how uncertainty and risk are dealt with in the previous Environmental Outlooks, and whether this approach is problematic. Chapter 8 summarises the experiences with the first phases of the PRIMA in the context of the $5^{\text {th }}$ Environmental. Outlook process. It will evaluate the practical constraints and challenges associated with putting uncertainty and pluralism at the heart of the assesment job.

Chapter 9 closes the thesis with concluding remarks and a discussion on decision-making on complex issues in the light of the insights gained. In doing so, the thesis hopes to communicate that there may be alternatives to muddling along.

It is our intention that this thesis may serve as a kind of manual for pluralistic integrated assessment. 


\section{REFERENCES CHAPTER I}

- Beck, U. (1992). "From Industrial Society to the Risk Society: Questions of survinal, social structure and ecological entightment: "Theory, Culture and Society, 9(1),97-123.

- Dahinden, U., Querol, C., Jager, ). and Nilsson, M. (1999). "Using Computer Models in Participatory Integrated Assessment." ULYSSES WP-99-2, Darmstadt University of Technology, Darmstadt Ciermany.

- Dürrenberger, D., Behringer, , Dahinden, U., Gerger, A, Kasemir, B., Querol, C., Schule, R., Tabara, D., Toth, F., van Asselt, M, Vassilarou, D. Willi, N., and Jaeger, C. (1997). "Focius Groups in Integrated Assessmient: A Martual for a Participatory Tool." ULYSSES work ing paper WP-97-2, Darmstadt University of Technology, Darmstadt, Cermany.

- EEA. (1995) "Environment in the European Union: Report for the rewiew of the fifth environmental action programme." ,European Enwironment. Agency, Copenhagen, Denmark.

- Fischhoff, B. (1995). "Ranking Risks." Risk: Health, safety and enwironment, 6(Summer), $191-201$.

- Gezondheidsraad. (1995). "Not All Risks are Equal (in Dutch with English summary)." 1995/06, Health Council of the Netherlands $s_{0}$ The Hague, the Netherlands.

- Gezondheidsraad. (1996). "Risk is More than Just a Number (in Dutch with English summary)." 1996/03, Health Council of the Netherlands, The Hague, the Netherlands.

- Hofstede, G. (1991). Cultures and Organization: Software of the mind, McGraw-Hill, London, UK.

- Hoppe, R. (1999). "Rethinking political judgement and science-based texpertise: argumentative practices and boundary work for policy-oriented learning?".

- ICIS. (1998). "Limburg in Perspective" A first imventory (in Dutchy." ,ICIS, Maastricht.

- ICIS. (1999a). "Future on its way: City wision and planning tool for Maastricht on its way to 2030.", ICIS, Maastricht, the Netherlands.

- ICIS. (1999b). "The Thinkmodel for POL (in Dutch).", ICIS, Mlaastricht.

- Jaeger, C. C., Chadwick, M., Wynne, B., Funtowicz, S, Giaoutzi, M., Giner, S., Toth, F, Jager, J., Durrenberger, G., Ravetz, J. R.y and Casill, C. (1995). "ULYSSES - Urbar Lifestyles, Sustainability and integrated Environmental Assessment - RTD proposal for the European Community Framework Programme IV.", Darmstadt Technical Uniwiersity, Darmstadt, Germany.

- )äger, ), (1998). "Current Thinking on Using Scientific Findings in Environmental Policy Malking." Environmental Modeling and Assessment, 3\{3, Special issue: Challenges and Opportunities for Integrated Environmental Assessment, J. Rotmans and P. Wellinga, eds.). 143-1153.

- Kasemir, B., Behringer, J, de Marchi, B., Dewker, C, Durrenberger, D., Funtowicz, S., Gerger, A, Giaoutzi, M., Haff. ner, $Y_{,}$Nillson, M. Querol, $C$, Schule, R, Tabara, D., van Asselt, M., Vassilarou, D. Willi, N. and jaeger; C. (1997). "Focus Groups in Integrated Assessment: The ULYSSES pilot experience." ULYSSES WP-97.4, Darmstadt University of Technology, Darmstadt, Germany.

- Kasemir, B., Dahinden, U. Gerger, A, Schüle, R, Tabara, D., and Jager, C. C. (1999) "Fear, Hope and Ambiguity: Citizens' perspective on climate change and energy use." ULYSSES WP-99-1, Darmstadt Uriversity of Tech. nology, Darmstadt, Germany.

- O'Riordan, $T_{r}$ and Langford ${ }_{p}$ 1. (1999). "Dealing with Scientific Uncertainty in a Future World (in press)." Health Impacts of Clobal Environmental Change: Concepts and methods, P. Martens and A. McMichael, eds., Cambridge University PRess, Cambridge.

- Radford, A., wan Leeuwen, H., and Christian, S. (1976). "Social alspects in the changing epidemiology of malaria in the highiands of New Guinea" Ammals of tropical medicine and parasitology, $70(1)_{1} 11-23$

- Rip. A. (ed.) (1995). Managing Techuology in Society: The approach of Constructive Technology Assessment, Plinter, London, UK.

- RIVM. (1988). Concern for Tomorrow, Samson H.D. Tjeenk Willink, Alphen aan de Rijn, The Netheriands.

- RIVA. (1991). National Environmental Outlook 2 1990-2010, Samsom H.D. Tjeenk Willink, Alphen aan der Rijn, the Netherlands. 
- RIVM. (1993). National Environmental Outlook 3 1993-2015, Samsom H.D. Tjeenk Willink, Alphen aan den Rijn, the Netherlands.

- RIVM. (1997). National Environmental Outlook 41997-2020 (in Dutch), Samsom H.D. Tjeenk Willink, Bilthoven, the Netherlands.

- RMNO. "Towards a Better Use of Knowledge in Large Projects (in Dutch)." Knowledge and policy: Towards an optimal relationship.

- Rotmans, J. (1997). "Integrated Visions for a Sustainable Europe: An Integrated Assessment proposal." "European Union, DG XIl, Work Programme Environment and Climate (second phase), Brussells, Belgium.

- Rotmans, J. (1998a). "Integrated thinking and acting: a necessary good (in Dutch).", ICIS, Maastricht, the Netherlands.

- Rotmans, J. (1998b). "Methods for IA: The challenges and opportunities ahead." Environmental Modelling and Assessment, 3(3, Special issue: Challenges and Opportunities for Integrated Environmental Assessment, J. Rotmaris and P. Vellinga, eds.), 155-179.

- Rotmans, f., and van Asselt, M. B. A. (1996). "Integrated Assessment: A growing child on its way to maturity." Climatic Change, 34(3-4), 327-336.

- Rotmans, , and wan Asselt, M. B. A. "From scenarios to visions. A long way to go. Lessons learned from two decades scenario dewelopment." "Open meeting of the Hurnan Dimensions of Glabal Environmental Change Research Community, Laxenburg, Austria.

- Rotmans, I. and van Asselt, M. B. A. (2000). "Integrated Assessment: Current Practises and Challenges for the Future." Ecological Economics and Integrated Assessment: A participatory process for including equity, efficiency and scale in decisionmaking for sustainability, R. Constanza and 5. Tognetti, eds., SCOPE, Paris, France.

- Rotmans, J, van Asselt, M. B. A., Peters, 5., and Miellors, J. (1999). "VISIONS Progress Report.", ICIS, Maastricht.

- Schneider, S. (1997). "Integrated Assessment Modeling of Climate Change: Trarisparent rational tool for policy making or opaque screen hiding value-laden assumptions?" Environmental Modelling and Assessment, 2(4), 229.250.

- Tol, R. S. J., and Vellinga, P. (1998). "The European Forum on Integrated Environmental Assessment." Environmental Modelling and Assessment, 3(3, Special issue: Challenges and Opportunities for Integrated Environmental Assessment, J. Rotmans and P. Vellinga, eds. ., 181-191.

- Toth, F. L., Kasemir, B., and Masing, V. (1998). "Climate Policy as a Business Opportunity for Venture Capital in Europe." ULYSSES WP-98-2, Darmstadt University of Technology, Darrnstadt, Germany.

- UNEP. (1997). Globall Environmental Outlook, Oxford University Press, Oxford, UK.

- van Asten, F. (2000). "Uncertainty in Practise: Application of the PRIMA approach to the 5th Environmental Outlook, "master thesis, Maastricht Uniwersity, Maastricht, the Netherlands.

- Yin, R. K. (1994), Case Study Research: Design and methods, Sage Publications, Thousand Oaks, California. 


\section{Integrated Assessment ${ }^{1}$}

Integrated Assessment (IA) has been a rapidly evolving field during the last decade. This does not imply that Integrated Assessment is something new. In an earlier publication ${ }^{2}$, we argued that the Egyptian farmers in pre-Christian times were already performing integrated assessments. For decades, scientists have been working with decision-makers to address local and regional problems, especially in the field of environmental policy, though it was not necessarily called "Integrated Assessment". It is only recently that Integrated Assessment has been recognised as a profession in its own right and as a specific branch of scientific research. The current state can be considered as the culmination of a multi-decade process that involved both the changing nature of the issues on the societal agenda as well as the evolution of the ways these issues have been analysed by scientists and managed by decision-makers.

\section{Key features of Integrated Assessment}

Integrated Assessment is still in the phase of development in which many definitions and interpretations circulate 4 . Notwithstanding this diversity, these definitions have two elements in common, i.e. its interdisciplinary character and its decision-support aim $^{5}$. "Integrated" conveys the message of interdisciplinarity, and "assessment" that of policy relevance ${ }^{6}$. "Integrated" means that the information is assembled from a broader set of domains than a single discipline. "Assessment" does not mean doing new research -although this is not excluded-, but it does mean making knowledge relevant and helpful to decision-makers ${ }^{7}$. IA has thus the explicit purpose to inform

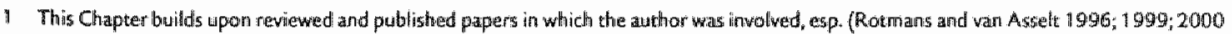

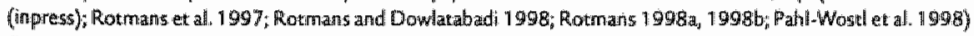

2 Rotmans and valn Asselt 1996 ):

3 Tokh and Hizsnyik 1998)

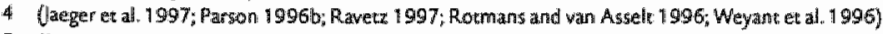

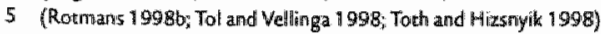

6 Tol and Wellinga 1998 )

7 (Jager 1998; Parson 1995; 1997* Toth and Hizsnyil 1998) 
policy and to support decision-making. Integrated Assessment is accordingly viewed as a process, including but not restricted to its formal products, in which the scientific quality is central. Taking this into account, IA can probably best be described as:

a structured process of dealing with complex issues, using knowledge from various scientific disciplines and/or stakeholders, in such a manner that integrated insights are made available to responsible decision-makers.

IA thus involves an interdisciplinary process of gathering, combining, interpreting and communicating knowledge from diverse scientific disciplines and knowledge domains to allow a better understanding of complex phenomena. The aim is to analyse and explore past, current and future developments in terms of plausibility, desirability and feasibility. Integrated assessments should have added value compared to insights derived from disciplinary research. An integrated approach ensures that key interactions, feedbacks and effects are not inadvertently omitted from the analysis. The implicit conviction is that some kind of synergy will emerge from the integrative process. In a way, Integrated Assessment can be considered as a form of policy analysis ${ }^{8}$ applied to particularly complex societal problems.

Integrated Assessment attempts to shed light on complex issues by illuminating different aspects of the societal issue of concern: from causes to impacts, from options to strategies. Integrated assessments thus involve a scale of aspects and a set of intricate interlinkages ${ }^{9}$. IA aims to create a more holistic picture by integrating the separate components into one framework ${ }^{10}$. A holistic perspective presupposes that there are manifold causal relationships between different hierarchical levels, as opposed to a reductionist model in which cause-effect chains are uni-directional (see Figure I)". Furthermore, a holistic approach addresses multiple dimensions, while a reductionistic one is usually restricted to a single dimension.

Although participation of stakeholders is not a necessary prerequisite, the conviction in the IA community has grown that participation of stakeholders is a vital element in $1 \mathrm{~A}^{12}$. The engagement of non-scientific knowledge, values and preferences into the IA process through social discourse will improve the quality of IA by giving access to practical knowledge and experience, and to a wider range of perspectives and options. Communication should be at the very heart of IA. Integrated Assessment aims to be an iterative, continuing process, where integrated

8. Sec, for example. (Majone ard Quade 1980; Weimer and Winung 1989; Parsons 1995; Quade and Carter 19189)

9 (Kates a all, 1985 )

10 (Romans 1990; 1998 a)

11 (Rotrmans 1998a)

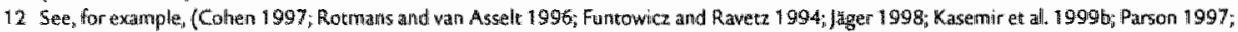
tol and Vieztinga 1998 ; Toth and Hizstyil 1998 ) 
REDUCTIONISM

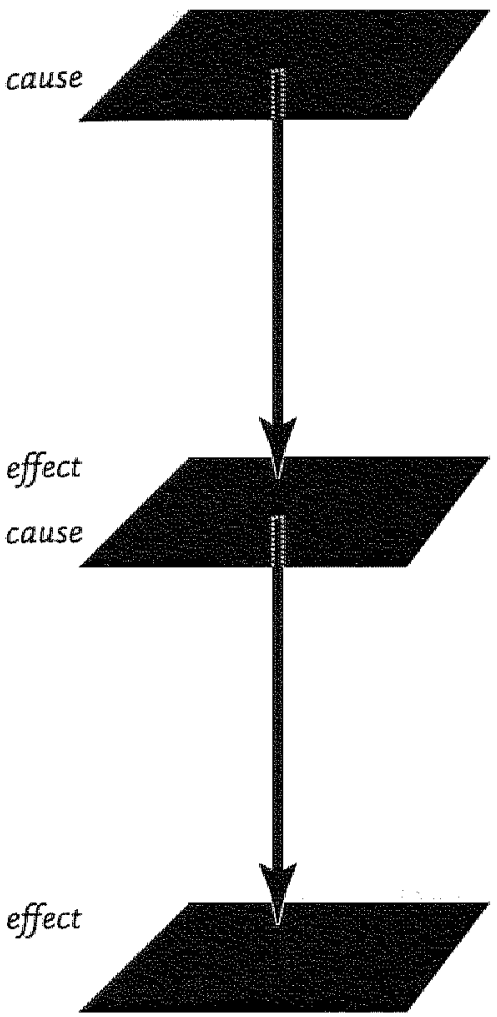

HOLISM

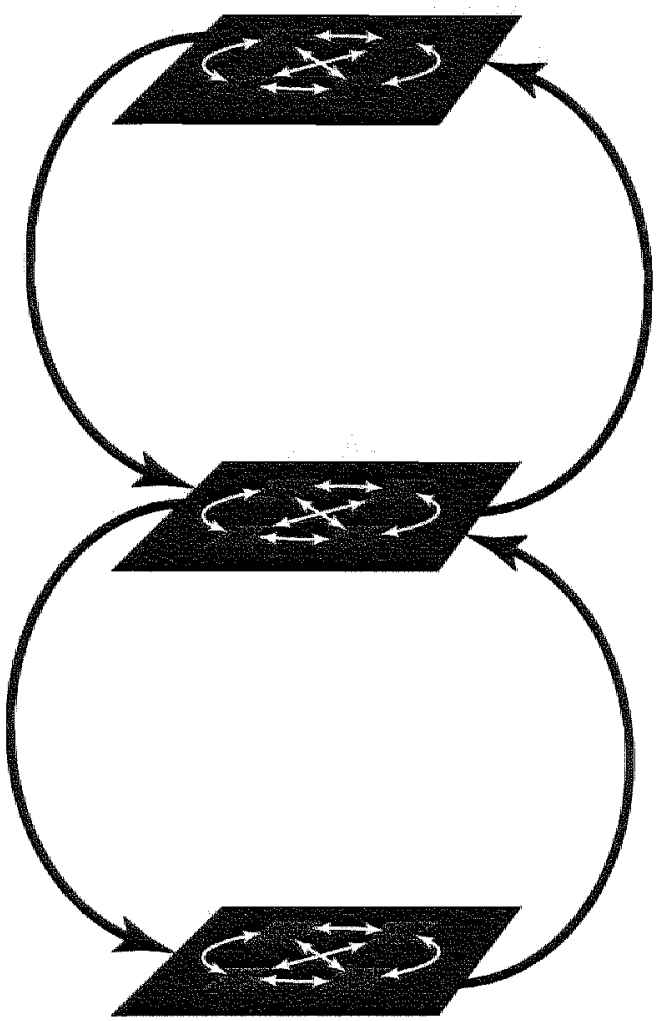

FIGURE, Holism wersus reductionism

insights from the scientific and stakeholder communities are communicated to the decision-making community, and experiences and learning effects from decisionmakers form an input for scientific and social assessment. IA aims to be a forum in which interdisciplinary science outlines the state-of-the-art knowledge pertaining to the issue of concern, including the inherent uncertainties, value judgements and preferences. The stakeholcers indicate what is desirable and acceptable, and what is not. They can also provide knowledge other than that of the "experts'. Ideally, together they come out with visions and recommendations that satisfy societal constraints. This does not necessarily mean consensus: the integrated assessments can also highlight conflicts and differences of opinion. The visions and insights resulting from this participatory process may then facilitate the decision-making processes.

The ideal picture of Integrated Assessment is a cyclic and participatory process comprising various parallel actions and a wide diversity of actors as summarised 


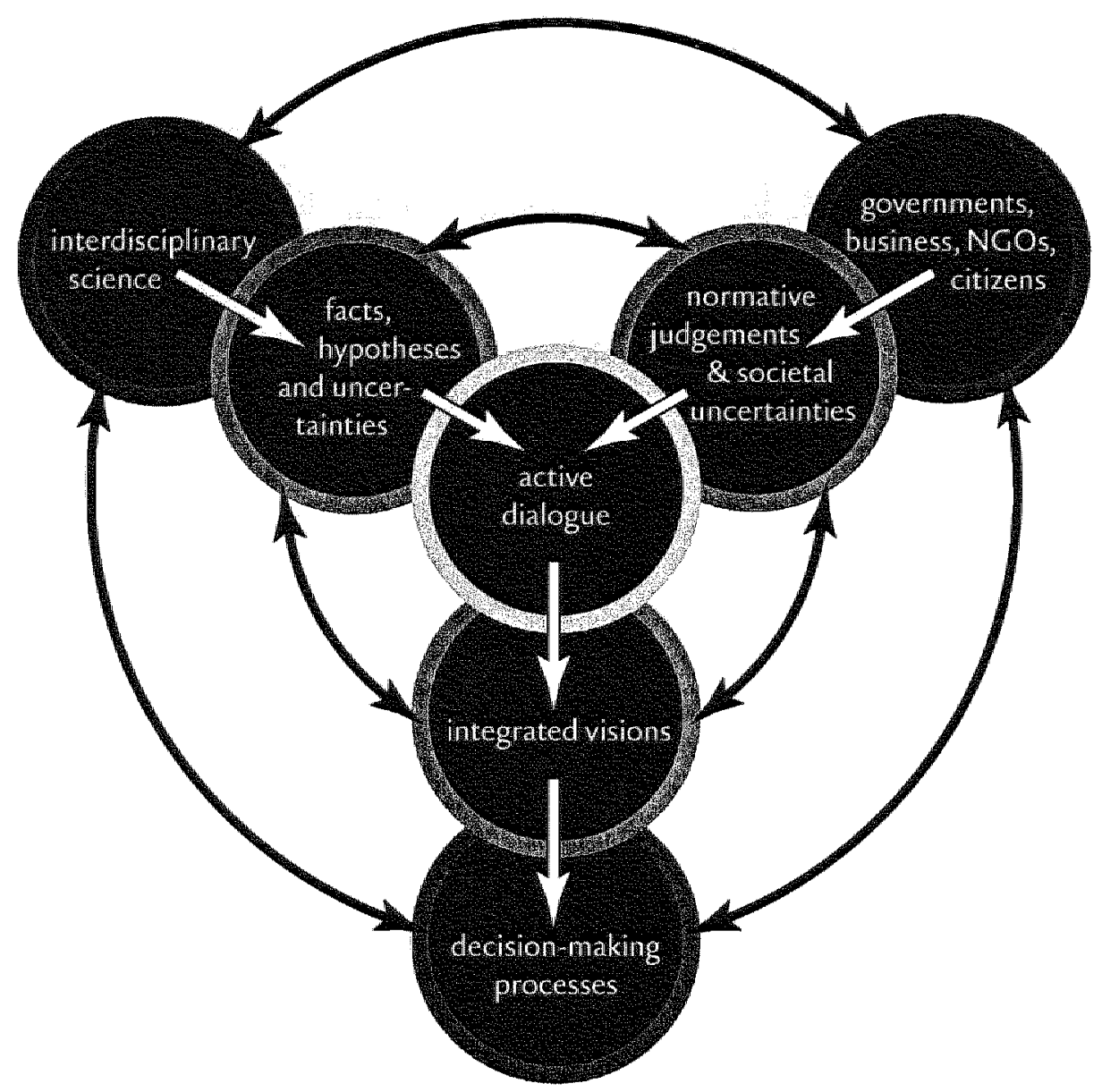

Figurez 2 Aapracess

in Figure 2. The two pillars are i) the participation of scientists in the form of interdisciplinary research, and ii) the participation of societal actors, such as the policy community, the business community, non-governmental organisations (NGOs) and the general public.

IA has a number of advantages. In general terms, it may help to:

- put a complex problem in the broader context of other problems, by exploring rhe interrelations of the specific problem with other issues

- identify major uncertainties in the underlying cause-effect chains

- set priorities for research topics by identifying and prioritising decision-relevant gaps in knowledge

- shape the decision-making agenda

- assess robust response strategies to complex problems 
There is a growing interest in Integrated Assessment, both from the scientific and from the policy side. The scientific interest is, for example, revealed by the initiation in 1996 of a new journal called 'Environmental Modelling and Assessment', with Integrated Assessment as a flourishing section, the establishment of the European Forum for Integrated Environmental Assessment (EFIEA) in 1998 in which over 30 European research institutes participate, the first informal initiatives to set up a global society for Integrated Assessment, and the increasing number of research programs, workshops, seminars and conferences devoted to Integrated Assessment ${ }^{14}$.

There is a growing recognition for Integrated Assessment in the policy realm. In the United States, the notion of IA is used to scope the governmental nationwide programme on climate change impacts ${ }^{15}$. In Europe, the policy interest in Integrated Assessment is primarily clear at the European level. The European Environment Agency (EEA) characterises its activities as Integrated Assessment ${ }^{16}$, and the European Commission ${ }^{67}$ sponsors and stimulates a number of $1 A$ endeavours, ranging from advanced study courses ${ }^{18}, R \& D$ programs, conferences, to the above mentioned EFIEA. In the context of policy interest in $I A$, it is important to note that decision-makers participate in EFIEA alongside scientists.

Integrated Assessment is not a panacea for all societal problems. As argued above, it is in principle pre-eminently suitable for complex problems. Furthermore, it is important to realise that notwithstanding this growing interest, Integrated Assessment is at the moment more a research principle than an established approach. Many of the methods employed are relatively immature and the application of established methods in IA is not straightforward. There are some good examples of studies which can guide new endeavours, however, a kind of textbook that enables us to learn (and to teach) Integrated Assessment is lacking. At the moment, the art of Integrated Assessment is mainly tacit knowledge ${ }^{19}$. There is a clear need for codes of practise to set up and assess IA processes, and for quality rules to design and

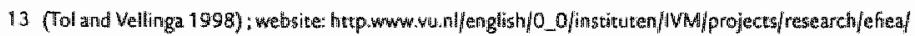

14 For example, the sessions and plenary lectures on Integrated Assessment in the context of the Open meetings of the International Human

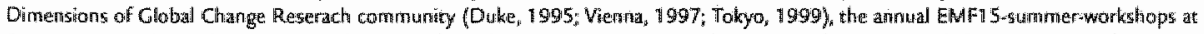
Snowmass since 1994, the Scope-workshop on ecological economics and integrated assessment (Boston, 1996), the European conference on integrated Assessment in Toulouse (1996), the large IPCC conference on Inategrated Assessmement modelling, (Tokyo, 1997), the synapositum of the Anerican Association of Geographers sponsored by, among athers, whe. Wariomal Science fousndation (Wastaington, 1998 ), the meeting

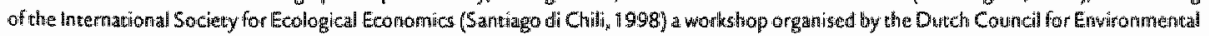
and Nature Research (RMNO) (̧ the Netheriands, 1999) on lintegrated Assessmento

15 US Global Change Research Programme (see hetpl/hwww:usgcrpgowh)

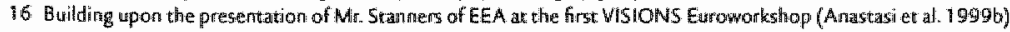

17 Esp. within the Fifth Framework. Programme on Environment and Climatie, OC Xllt.

18. For example, the 1999 advanced study courses Tools and methods for Initegrated Assersment' (Mllastriche, the Netherlands) and the course 'Decision tools and processes for Integrated Erwironmental Assessment' (Biarcelone, Spaim).

19 (Brand 1994) 
evaluate the products delivered by IA endeavours. Transparency is needed, so that the process and the products can be judged by an extended peer community ${ }^{20}$, involving other IA practitioners, disciplinary experts, users and affected publics. Without such maturation, IA is doomed to degenerate to a (popular) buzzword.

The aim of this Chapter is twofold. On the one hand, it gives an overview of the state-of-the-art in Integrated Assessment. On the other hand, it scopes the thesis by identifying the crucial methodological challenges that IA currently faces. To that end, this Chapter first discusses the policy dimension of IA. Then a taxonomy to characterise IA-studies is proposed. In the following section, IA methodology is discussed in more depth, and ideas are explored how the various methods could be used in a fruitful, complementary manner. The issue of quality is crucial, both in terms of the state of the art as well as methodological challenges. This Chapter concludes with identifying key challenges that clarify the ambitions this thesis aims to fulfil.

\section{The policy dimension of IA}

It is the explicit aim of IA to assist decision-makers and to facilitate decisionmaking. That does not necessarily imply that it has done so in the past. Good intentions do not guarantee success. IA has contributed to the climate change debate in exploring impacts of climate change, mitigation and abatement strategies, issues in co-operative implementation, the likely equity effects of candidate policies, and complicating factors such as aerosols ${ }^{21}$. It has continuously underpinned the policy discussion on the questions: when do we have to act, what kind of action and in what pace? IA has also proven to be useful in the field of acid rain, where the IA model RAINS played a guiding and supportive role in the negotiating process of emission reductions of $\mathrm{SO}_{2}{ }^{22}$. But little understanding exists regarding what sorts of assessment processes have been most effective, or why others have failed ${ }^{23}$.

The Global Environmental Assessment project ${ }^{24}$ is the first systematic endeavour to evaluate the impact of integrated assessments and to learn from accumulated experience about the policy dimension of IA. The questions studied in the GEA project are:

\footnotetext{
20 A concept introduced and pute forward by Funtowicy and Ravetz, see for example (Funtowicz and Rawerz 1992a; $1992 \mathrm{~b} ; 1993 \mathrm{a}_{*}$ 1993b; $1994)$.

21 (Rotmans 1998 a)

22 (Hordi), 1991 al, 19976 )

23. (GEA 1998)

24. (GEA 1997, 1998) (Clark et al. 1997) (Clark and Dickson 1998)

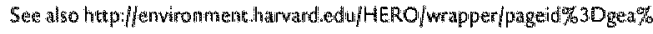


- Why are some kinds of assessments performed, while others are not?

- How have assessments actually affected society's understanding of global environmental issues and scientific research?

- Under what conditions and in what ways have assessments been able to influence preferences, behaviours and policies of significant actors?

- What makes a specific assessment credible?

- How can assessments be designed and implemented to better serve specific needs?

This project that runs until 20or will hopefully in the end, shed clearer light on the policy dimension of IA.

On the one hand, the demand for policy relevant science to illuminate policy issues seems to be greater than ever ${ }^{25}$, on the other hand there seems to be quite a lot of scepticism regarding the relevance of Integrated Assessment for decisionmaking ${ }^{26}$. Integrated Assessment suffers from a technocratic image. Outsiders have the feeling that the underlying thought is that if complex problems were left to rational scientists and all the irrationality associated with policy-making was eliminated, then better decisions would have been taken ${ }^{27}$. This image is strengthened by the harsh attacks of some social scientists ${ }^{28}$ on the IA community in general and on IAmodellers in particular. We cannot vouch for all IA practitioners, but in our informed view the majority of the IA-practitioners does not consider, and does not even want, Integrated Assessment to be a substitute for political and decision-making processes. Integrated Assessment is generally viewed as a multi-step process that may provide a bridge between science and decision-making ${ }^{29}$.

There is a broad literature that discusses the linkages between science and policy. Policy sciences, for example, explicitly study how political judgement can be informed by scientific expertise in view of the inherent limits to human understanding $^{30}$. Policy science is thus concerned with the production and application of knowledge in policy. Much of this literature is relevant for IA in order to gain "political awareness ${ }^{33}$ and sufficient understanding of decision-making processes. It is beyond the scope of this thesis to give a comprehensive synthesis of this scholarly literature.

25 (Clath andilichickon 1998)

26. See, for example, (Haigh 1998)

27 (Hiaigh 1998)

28. for example (Darier 1999; Jasanof and Wiynme 1998)

29: (Uager 1998)

30 (Dror 1971 ; Lasswell $197 \%$; Lirdblom 1968 ) arad compare (Hoppe 1999)

31 (Hajg 1998) 
We restrict ourselves to summarising some major lessons that can be learned from that literature ${ }^{32}$.

First, it is misleading to think that science and policy take place in two largely distinct realms. Mutual interactions between science and policy are prevalent, esp. in the field of Integrated Assessment. For example, due to personal contacts, financial ties, institutional commitments, political pressure, and scientific activists the two realms evolve into a rather seamless web $b^{33}$. Scientists are also citizens with a political opinion. These linkages create a field of tension between policy relevance and scientific mores. Integrated Assessment faces the danger of falling between two stools in lacking credibility on both sides. That this is a possibility that IA practitioners should not ignore is evident from the RIVM-case ${ }^{34}$. On the one hand, the policy-makers doubted whether RIvM's assessments were scientific enough, while on the other hand, scientists blamed the institute of being too involved with policymaking.

Furthermore, it is also clear that the interactions between science and policy cannot be viewed as entirely linear. The constructive, active character of scientific knowledge in decision-support, as opposed to the linear view of knowledge simply being transferred from science to policy, should be emphasised ${ }^{35}$. The mutual construction of science and policy can be characterised by the "politisation of science ${ }^{35}$ and 'scientification of policy'. These imply that scientific research is subject to political pressures, while at the same time, science has 'cognitive authority ${ }^{\text {t37 }}$ in, and privileged access to, policy domains.

Another important lesson from this body of literature is that the relevance of Integrated Assessment differs over the course of the policy process. Although in practise the policy process is not a smooth sequence in stages, steps or phase ${ }^{38}$, it is useful to think in terms of a "policy life cycle" ${ }^{34}$ in order to illuminate the contribution IA in principle can have in the decision-making process (see Figure 3). Roughly speaking, four phases can be distinguished: i) ignition, ii) strategic policy formulation, iii) political decision-making and iv) implementation. Haigh ${ }^{40}$ argues that in the first phase the public opinion plays a crucial role in raising the temperature

\footnotetext{
32 Sete also (brest 1998 )

33 Compare (vain Assult 1994 )

34 See Chapter 6 and Appendix 1.

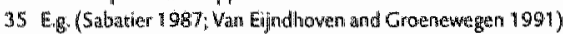

36 (Neirngatert 1983)

37 (Hoppe 1999 )

38 See, for example, Jager 1998; Kingdon 1984)

39 Winsentwits 1986)

40 (Haigh 4998;
} 
sufficiently for politicians to feel able to act. Rotmans ${ }^{41}$ argues that Integrated Assessment can facilitate this consciousness-raising process, either by helping to identify the problem or by helping to excite public conscience. It is generally accepted that Integrated Assessment can play a vital role in the policy formulation phase. Tol and Vellinga ${ }^{42}$ argue that one of the important contributions IA can make to the decision-making process lies in defining the problem and spelling out the various views on the problem at stake. The policy formulation phase necessitates an assessment of the issue at stake in order to figure out the characteristics of the problem and what strategies would address the problem and optimally use opportunities. In the last phases, i.e. the political decision-making and the implementation phases, there is a greater need for detailed sector- or theme-specific studies, that provide an in-depth study of specific decision options, than for broad integrated studies. In Rotmans et al. ${ }^{43}$, we argued that the integrated character of the ultimate decision options is in principle guaranteed by the integrated feature of the preparing phases.

There is a risk that, notwithstanding the actual need for science-based expertise in decision-making, the policy dimension of IA primarily serves to legitimise the work of the IA community to outsiders. The key challenge for Integrated Assessment is effectively facilitating and supporting policy-oriented learning ${ }^{44}$. In order to understand what are the necessary features of IA, both evaluations of previous

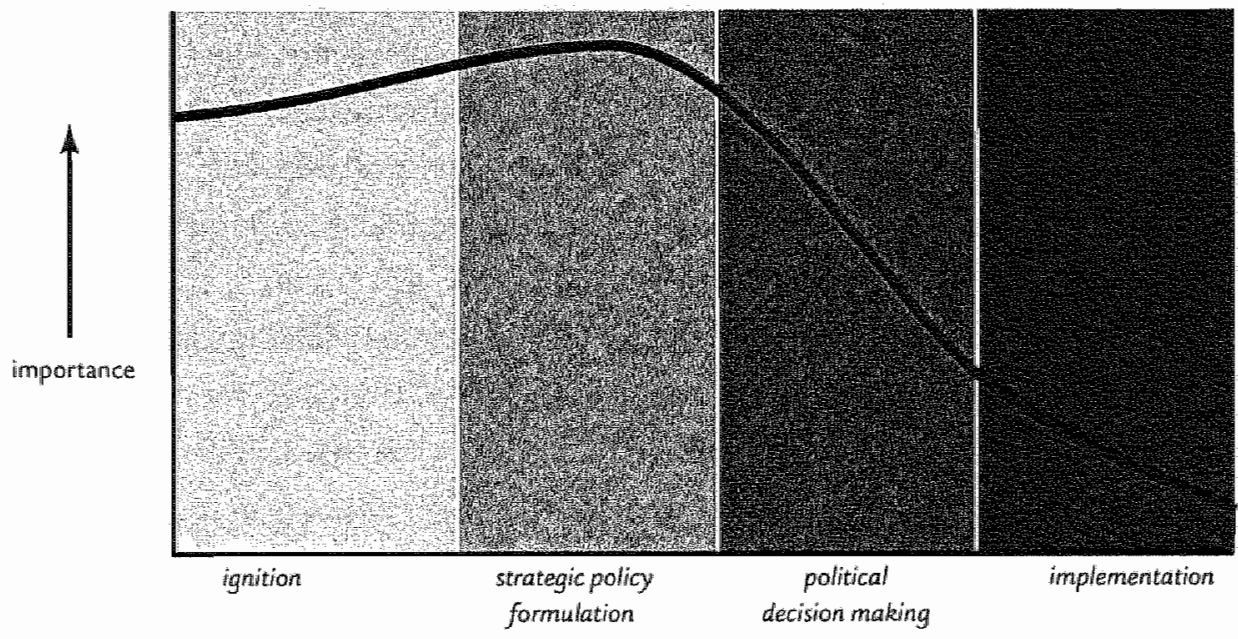

FIGLARE 3 Integrated Assessment related to statger in policy making

41 (Rotmans 1998a)

42 Tol and Wellinga 1998)

43 (Toliandi Wellinga 1998

44 e.g. (Weyant et al. 1996), (Rokn ang and Dowlatabadi 1998, (Parson and Fisher-Wanden 1997) For literature on policymoriented learning see (Sabatier and Jenkinsi-Smith 1993) 
assessments, and the involvement of policy scientists and decision-makers in the constituent debates in the IA community are pre-requisites. In that context, the IA community is currently following a promising avenue: the European Forum for Integrated Environmental Assessment (EFIEA) has the explicit aim to address such issues and to bring together IA practitioners, policy scientists and decision-makers.

\section{Taxonomy of IA studies}

The variety of assessments that are or can be characterised as 'Integrated Assessment' is rather heterogeneous. Most efforts to characterise this variety are outdated ${ }^{45}$, because they were restricted to IA modelling studies. In order to characterise the whole spectrum, it is useful to identify major differences allong the following dimensions:

- research perspective

- focus

- adopted method

With regard to the dimension research perspective, the distinction between supplydriven and demand-driven is crucial (see Figure 4$)^{46}$ :

- In supply-driven IA studies, a group of scientists anticipates the societal relevance of a complex theme. The scientific problem definition frames the assessment.

- Demand-driven IA is a participatory endeavour in which decision-makers and stakeholders (and scientists) explore which complex issues are highly relevant to a future society. The resulting common agenda and exploratory assessment then frames the integrated assessment.

The major difference between the two thus involves "who is defining the problem?" The majority of IA studies so far have been supply-driven. The most prominent example is Integrated Assessment of climate change, which was dictated at the start by the (multi-) disciplinary research agenda, rather than the policy agenda.

The focus of IA studies can also be used as distinctive feature. We propose to distinguish between global IA studies, regional IA studies and theme-specific IA studies. Global integrated assessments address the world as a whole, regional IA studies $^{47}$ concentrate on a particular geographical area, such as a world region, a

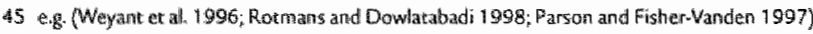


SUPPLY-DRIVEN

societal aspirations, constraints \& public knowledge

facts, hypotheses \& uncertainties

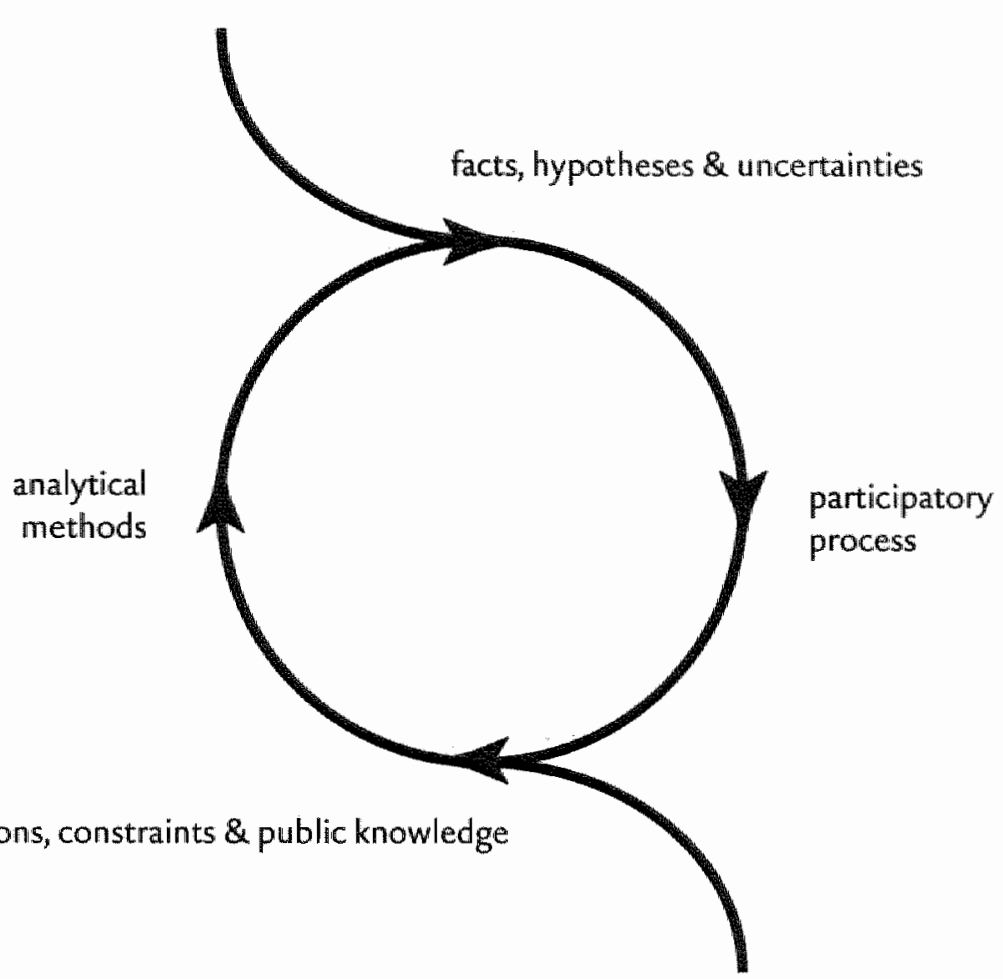

DEMAND-DRIVEN

FIGURE 4 Demand-driwen versus supplyadiriven: $\| A$

country, a city or a river basin, and theme-specific integrated assessments focus on a particular issue or sector like acidification or energy.

Thus far, most IAs operate on the global level. There have been only a few examples of integrated regional studies, most of which are climate impact studies, such as the MacKenzie Basin impact study ${ }^{48}$, the MINK impact study ${ }^{49}$, the regional US impact study ${ }^{50}$ and the CLEAR-study ${ }^{51}$. A notable exception is the integrated study on the future of Canada ${ }^{52}$. Where global assessments are useful to create a rough, but holistic picture, working at the regional scale level has two advantages: i) IAs can focus on concrete issues at stake; and ii) IAs can be made geographically-

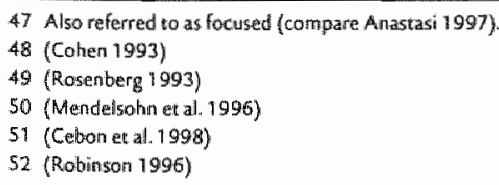

52. (Robimson 1996) 
explicit, which allows for analysing trade-offs between problems, sectors, resources and scale levels.

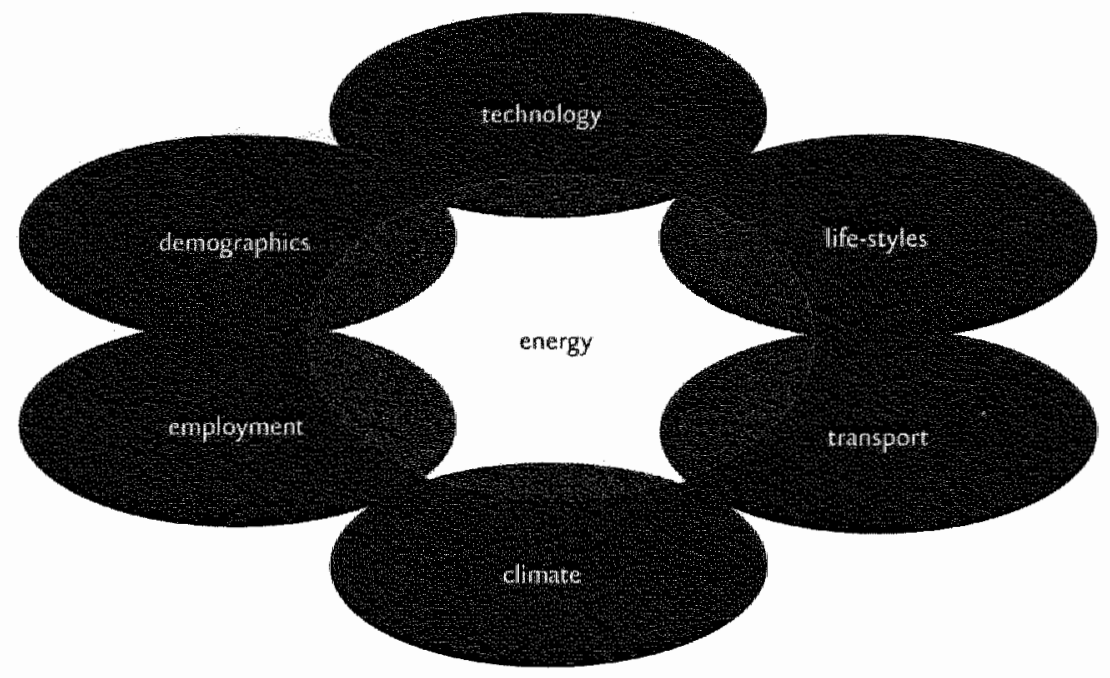

Figure 5A Visualisation of theme-specific $I A$

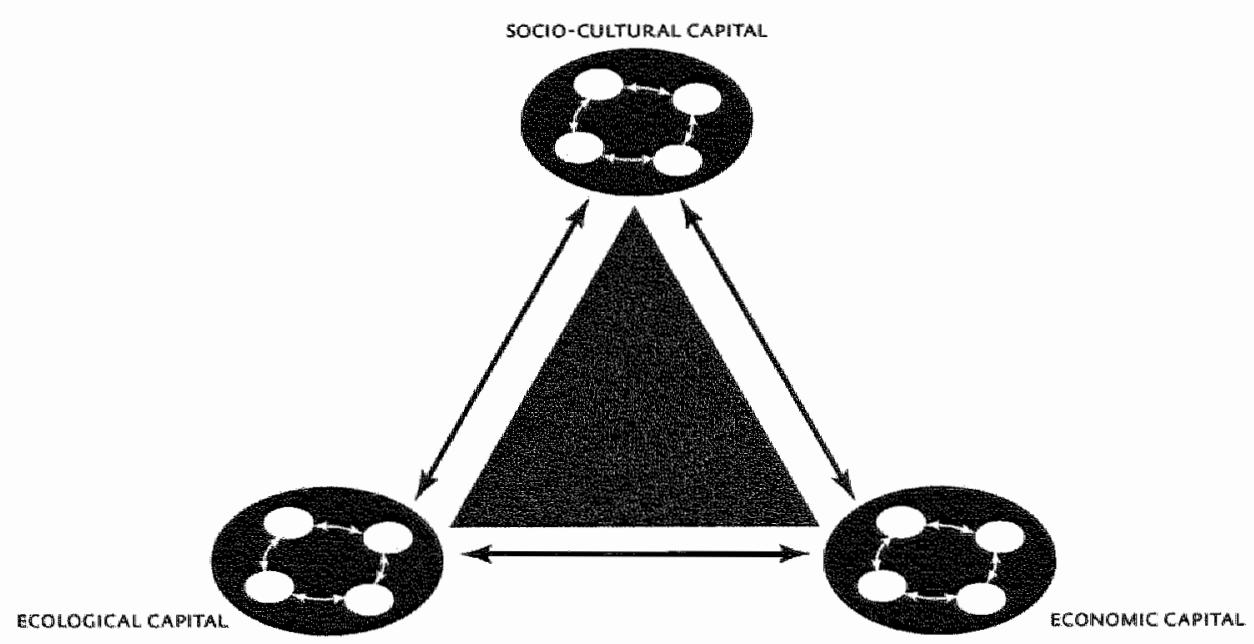

FIGURE $5^{\text {e }}$ Visualisation of general IA 
The majority of current IA-studies are theme-specific; most being devoted to climate, and some to acidification. The difference between theme-specific and general integrated assessments is visualised in Figure $5^{53}$. Examples of general integrated assessments are studies addressing global change and/or sustainable development ${ }^{54}$.

The advantage of a theme-specific approach is that it has a clear focus and it is easier (although not necessarily simple) to define the targeted problem. Integrated assessment in this context means evaluating the whole cause-effect chain of the problem from a synoptic perspective. For example, in the case of acidification this implies that an integrated assessment should cover the pathway from economic and industrial factors affecting emissions, to the ecological impacts resulting from emissions ${ }^{55}$. In the case of climate change, an integrated assessment should comprise the full cycle of cause-effect relationships ranging from socio-economic development, the associated greenhouse-gas emissions, atmospheric concentrations of these substances, to the resulting climate change, the induced biophysical impacts, economic damages and societal and ecological risks ${ }^{56}$. Other examples ${ }^{57}$ of complex themes addressed by IA-studies are biodiversity ${ }^{58}$, human health ${ }^{59}$ and water ${ }^{60}$, and IA-projects are currently under way addressing tourism ${ }^{{ }^{6}}$, transport $^{62}$, and desertification ${ }^{6_{3}}$.

The distinction between regional and theme-specific studies is not murually exclusive; there are regional, theme-specific studies. However, in practise there is a clear difference between regional theme-specific studies and theme-specific regional studies. The first will be classified as regional studies and the latter as themespecific. The ESCAPE-model $6^{4}$ is a climate model, but with the specific purpose of investigating effects and possible response strategies for Europe. The RAINS model has Europe as its scale level, however, it is first and foremost an integrated study on acidification.

Another common way to characterise IA studies is by means of the adopted method. Various techniques have been and are used in Integrated Assessment ${ }^{65}$, e.g.

53 See for a description of the triangular model 1 C 15 (1999).

54 5ee, for example, (Robinson 1998, Rotmans and de Wiles 1997 and Rotmans and var Asselt 2000 (in press)) Compare the resieardin agenda

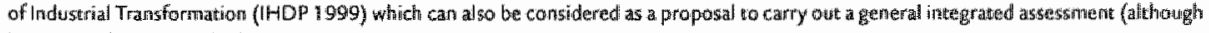
hit us not explicitly natmed so).

55 (Alcamo et al. 1990)

56 (Rotmans 1990; Dowallababati and Morgan 1993a; Toth 1997 )

57 Compane (Roumans 1998a)

58 (Ratmans et al. 1994 )

50 (Martens 1997; MCMichael 1997)

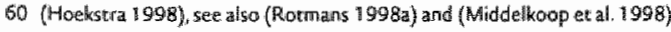

64 (Rournans and Dowlatiabadii 1998 ),

62 (EEFEA and IEEP'1998)

63 (Hairota a al. 1998)

64 (Rowntans at. 1994)

65 see (Parson 1996 a thotm 1998 ar Weyant et al. 1996) 
i) mulridisciplinary expert panels, ii) collaborative interdisciplinary research teams who exchange and share knowledge across their fields, iii) modelling, iv) individual essays by authors with multidisciplinary competence, v) scenario-studies and vi) participatory methods. In general, two types of Integrated Assessment methods are distinguished $^{66}$ : analytical methods ${ }^{67}$ and participatory methods ${ }^{68}$.

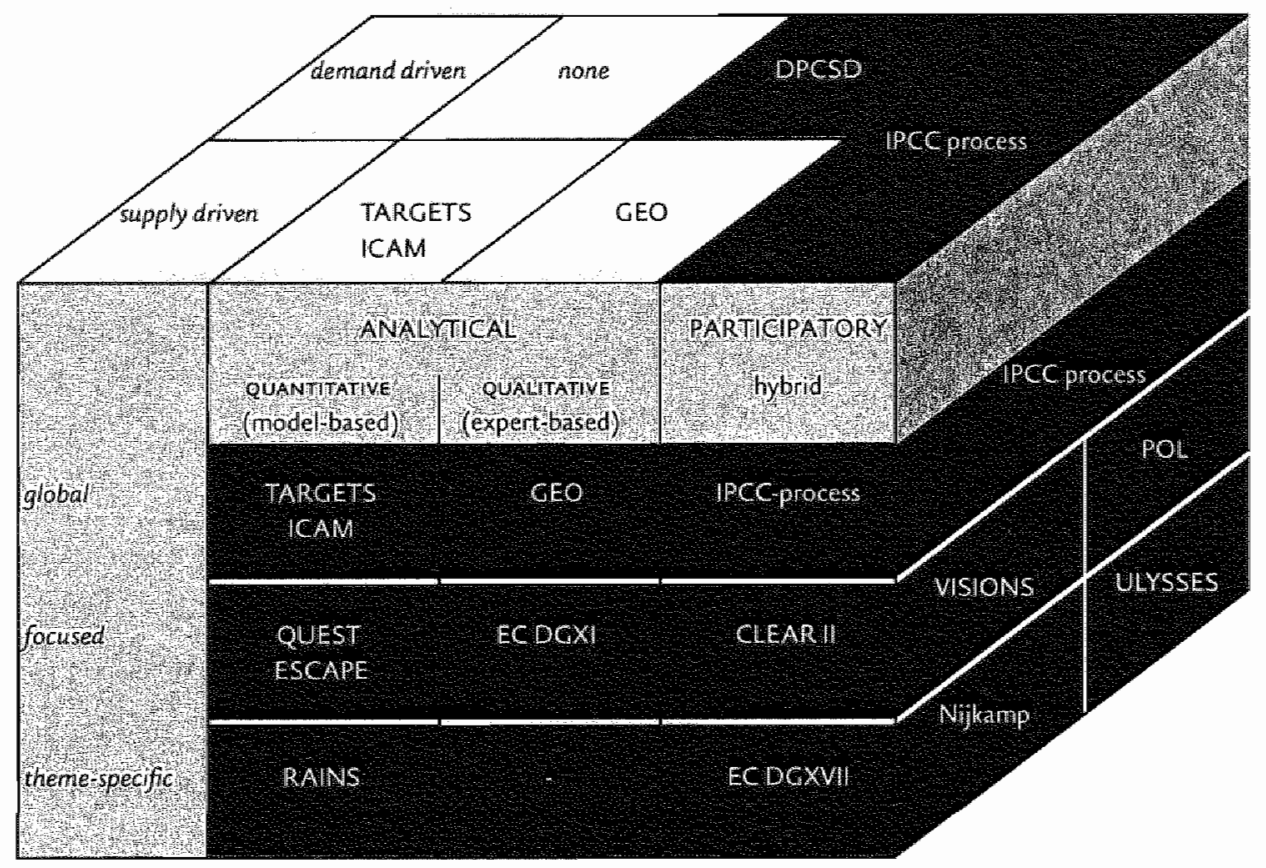

Fligure 6 3-dirmensional taxonomy of 1 A-studies with some examples ${ }^{\text {63 }}$

66 (Rotmans $1998 \mathrm{~b}$; Tol and Wellinga 1998; Toth and Hizsnyilk 1998)

67 Also referred to as expert-lixased methods or modelling methodis.

68. Also labelled as interactive or cominunicative methods.

69 Legend: TARCETS: (Rotmains and de Vies 1997): KCAM: (Dowlatabadi and Morgan 1993b): QUEST: (Biggs et al. 1998 ; (in press); Rothman er al. 1998 (in press), ESCAPE: (Rocmans et al. 1994); RAINS: (Alcano et al. 1990); OPCSD: (UN-DPCSD 1997); CEO: (UNNEP

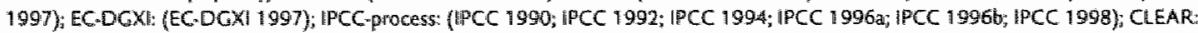

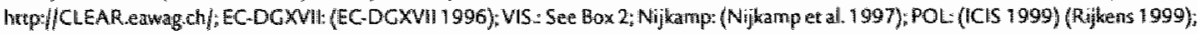
ULYSS: See Bow 1 
Analytical methods are generally rooted in the natural sciences. What they share is their provision of analytic frameworks for representing and structuring scientific knowledge in an integrated manner. They have the common aim of collecting expert judgements of scientists whose knowledge and expertise span the domains relevant to the issue(s) of concern and to gather these insights into an integrated picture. Knowledge elements from various disciplines are combined in an analytical framework, to assess the socio-economic and environmental consequences of human activities. The group of analytical methods is reasonably well defined and basically includes model-based analysis and scenario studies. Analytical methods can result in either quantitative or qualitative assessments. The first type of assessments is model-based. To make a distinction between qualitative assessment resulting from participatory processes and those resulting from analytical work, the latter can be characterised as expert-based assessments.

Participatory methods stem from the social sciences, in particular sociology, anthropology and geography. Participatory methods explicitly involve non-scientists in the assessment effort. The group of participatory methods involves a plethora of techniques, varying from expert panels, in-depth interviews, to gaming, policy exercises and focus groups. In its extreme form, the whole IA is considered to be a participatory process. What these participatory methods have in common is the aim to set up stakeholder involvement. Participatory techniques are particularly relevant for problem structuring, communication and in analysing qualitative aspects.

Figure 6 provides some examples of different types of IA-studies along the lines of the above distinctions.

\section{IA methodology ${ }^{70}$}

Because neither a unifying theory nor clear recipe for integration is available, the choice of a method or a combination of methods is crucial in any integrated assessment. For that reason we will discuss the two classes of methods - analytical and participatory methods - in some more depth. We will furthermore discuss how these methods could be used in a complementary manner.

70 This section bullds upon (Rotrrans 1998b; Rotmans and van Asselt 2000 (in press)) 


\section{I. ANALYTICAL METHOD: IA MODELLING}

Integrated Assessment models are formal, quantitative frameworks that describe as much as possible of both the cause-effect relationships of a specific issue (vertical integration) and the interlinkages and interactions among different issues (horizontal integration). Current projects in (A modelling build on a tradition started in the early seventies by the Club of Rome? . In this context the first global computer simulation model, the World3 model, was developed. This model describes links between the major social and physical components of the world system. This model inspired the development of numerous global models, focusing on resource depletion, population and pollution ${ }^{\prime 2}$.

The next generation of IA models explicitly addressed environmental issues. The first among these models emerged in the late 1970 s and the early 80 s from earlier energy modelling ${ }^{43}$. Meanwhile, the RAINS model of acidification in Europe was developed ${ }^{74}$. The phenomenon of global climate change has prompted the development of a new series of IA models ${ }^{75}$. The first model that comprised a fully integrated representation of climate change from sources to impacts was the IMAGE .o model ${ }^{6}$. Since then approximately 40 IA models of climate change have been developed ${ }^{7}$.

There is general agreement that two types of IA models can be distinguished. Weyant et al ${ }^{7 / 2}$ classify them as:

- policy optimisation models, which try to optimise key policy variables given certain policy goals;

- policy evaluation models which try to evaluate the environmental, social and economic consequences of specific policy strategies.

However, a number of IA-models that are characterised as policy evaluation models can also be used for optimisation experiments (e.g. RAINS). The two schools of modelling can also be classified according to their origins ${ }^{7 \%}$.

- Macro-economic oriented school, that represents simple, fully parameterised decision-analytic formulations of a policy-relevant complex problem;

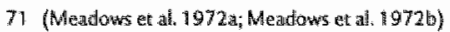

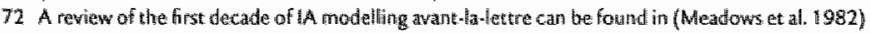

73 (Edmonds and Reilly 1985 ; Nordhaus 1979).

74 (Alcamo et al. 1990)

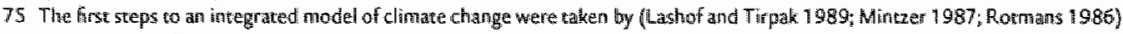

76 (Romans 1990$)$

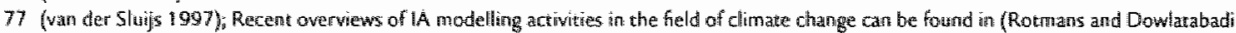

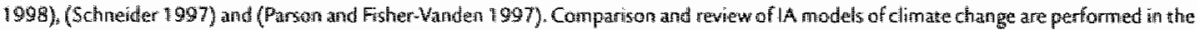

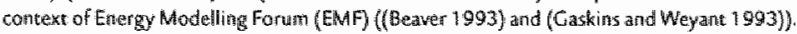

78 (Mvyant at. 1996)

79 (Romans 1998 ; Romans and Dowlatabadi 1998 ) 
- Biosphere oriented school, that represents a more comprehensive, processoriented description of a policy-relevant complex problem.

Most macroeconomic-oriented models are neo-classical models based on an equilibrium framework, using traditional economic concepts regarding optimisation and capital accumulation, largely ignoring environmental dynamics. The most wellknown example of the macro-economic oriented school is the DICE model ${ }^{80}$. Two variants have been developed later on, namely a regionalised version $\mathrm{RICE}^{\mathrm{B}_{1}}$, and another with uncertainty ranges in key parameter values, i.e. PRICE ${ }^{82}$. Other wellknown examples of this school are the CETA model ${ }^{8_{3}}$ and the MERGE model ${ }^{8.4}$.

Biosphere-oriented models, however, focus on a systems-based description of the geophysical and biogeochemical processes and feed backs, but do not adequately represent the socio-economic system. Representatives for the biosphere-oriented school of IA modelling are the IMAGE models (IMAGE $1.0^{8_{5}}$, IMAGE 2.0 $0^{86}$ ). Another model in this school is AIM ${ }^{\mathrm{A}}$.

Meanwhile, some attempts are being made to combine the best of both worlds, yielding a hybrid of the two categories above. These hybrid models may contain a detailed general equilibrium model for the economy that interacts with a dynamic environment, such as GCAM ${ }^{88}$ and the MIT model ${ }^{89}$. They may also use complexity and uncertainty as guiding modelling principles for both the human and natural system, of which ICAM ${ }^{90}$ and TARGETS ${ }^{91}$ are examples. Therefore, the macroeconomic IA models and the biospheric IA-models can be considered as polar ends of a continuum populated by many IA modelling efforts, with in the middle IA models in which the various aspects are treated on an "equal footing"syz.

Any attempt to fully represent a complex issue and its numerous interlinkages with other issues in a quantitative model is doomed to fail. Nevertheless, even a simplified but integrated model can provide a useful guide to complex issues and complement disciplinary models. Among the major strengths of IA models are:

\footnotetext{
80 (Nondhats 1992; 1994)

81 (Nordhaus and Yang 1995)

82 (Wordhats and Popp 1997)

83 (Reck and Teistwerg 1992)

84 (Hatrine ex al. 199.4)

(Romans 1990)

86 (Alcamo 1994 ) (Leemans al. 1998)

87 (Morita et a $1994 ;$; 1995 )

g8 (Edrutonds et al. 1994b)

89 (Primet all 1996)

90 (Dowatabadi and Morgan 1993.)

9] (Rommans and de Vries 1997)

92. (Tol and Vellinga 1998 )
} 
- tracing assumptions to conclusions: whereas humans are relatively weak in making large numbers of calculations, this is exactly the area where computers excel.

- exploration of interactions and feedbacks. explicit inclusion of interactions and feedback mechanisms between subsystems can yield insights that disciplinary studies cannot offer;

- Rexible and rapid simulation tools: the simplified nature and flexible structure of 1 A models permit rapid prototyping of new concepts and scientific insights;

- consistent frameworks to structure scientific knowledge: critical uncertainties, gaps in scientific knowledge and weaknesses in discipline-oriented expert models can be identified;

- tools for communication: IA models $\operatorname{can}^{93}$ be useful tools for communicating and discussing complex scientific issues among decision-makers, disciplinary scientists, stakeholders, and the general public.

Obviously, IA models allso have limitations and weaknesses, some of which are insolvable, because they are inevitable mirror-drawbacks of some of the advantages. Other disadvantages are in principle surmountable. Among the most important current deficiencies are:

- high level of integration: many processes occur at a micro level, far below the spatial and temporal aggregation of current LA models;

- limited calibration and validation: the high level of aggregation implies an inherent lack of empirical variables and parameters, and current data sets are often too small and/or unreliable to be able to apply;

- inadequate treatment of uncertainties: IA models are prone to an accumulation of uncertainties and to a variety of types and sources of uncertainty;

- absence of stochastic behaviour: most IA models describe processes in a continuous, deterministic manner, excluding extreme conditions that may signifi. cantly influence the long-term systems behaviour.

The latter two can in principle be overcome by innovations in the modelling practise. These weaknesses will be addressed in detail in the following Chapter.

93 It should be noted that most of the curren model interfaces are too complex or the models ton slow to be useful in an initeractive way and tiso that most current lA-models are not explicitly designed with non-scientific users in friad. in practise this implies that a mew generation of iA models seem to be necessary to realise the potency of iA models as broad commurvication tools (see ULYSSES experience, Bax 7 ). 


\subsection{ANALYTICAL METHOD: SCENARIOS}

Thinking about the future is often done by means of scenarios. Theoretically speaking, scenarios are hypothetical sequences of events, constructed for the purpose of focusing attention on causal processes and decision points ${ }^{94}$. In practice, scenarios are coherent descriptions of alternative images of the future, created from mental maps or models that reflect different perspectives on past, present and future developments. Ideally, they should be internally consistent, plausible and recognisable stories exploring a path into the future ${ }^{95}$. Although many scenario definitions exist, most of them share the following characteristics:

- scenarios are hypothetical, describing possible future pathways;

- scenarios describe processes, representing sequences of events over a period of time;

- scenarios consist of states, events, actions and consequences which are causally related;

- scenarios start from an initial state (usually the present), depicting a final state at a fixed time horizon.

Scenarios are perhaps most effective when seen as a powerful tool to broaden perspectives, raise questions, and challenge conventional thinking. However, that is not the way they have been used. Many scenarios developed in the past had a rather dogmatic and predictive character. Looking back at developments over the past 25 years, however, one clear lesson can be learned from scenario-based assessments made in the 1970s: dogmatic predictions regarding the earth's future are unreliable and can be politically counterproductive ${ }^{96}$.

Nowadays, it is generally accepted that scenarios do not predict, but rather paint pictures of possible futures and explore the different outcomes that might result if basic assumptions are changed, for example, regarding policy interventions. So the only relevant questions that scenarios can address are not whether an event will happen in the future, but how might it happen, what we could do if it does and what we might be able to do to prevent it from happening.

During the last decade, this increased understanding has resulted in a number of well-thought out scenario exercises, which have proven their value in a particular 
context ${ }^{97}$. For example, the IPCC ${ }^{98}$ has developed two sets of scenarios, which illustrate the impacts of specific developments in population growth, energy use and technology in terms of resulting emissions and atmospheric concentrations of greenhouse gases and its associated patterns of climate change. Currently a new scenario-process is well under way ${ }^{59}$. Shell ${ }^{100}$ has produced a number of world scenarios, where three alternative societal visions have been formulated and weighted against their economic robustness. The World Energy Council ${ }^{\text {not }}$ developed global scenarios focusing on energy that underlined the importance of diversity of supply, assuming shifts in the energy system due to autonomous technological developments and market forces and not through government interference. The Global Scenario Group has recently produced three classes of global scenarios, based on alternative social visions ${ }^{102}$ : Conventional Worlds, Barbarisation, and Great Transitions, described in terms of economic scale, equity, environmental quality, technological change, and degree of social and geopolitical conflict. One of the more comprehensive scenario studies has been undertaken by Robinson et al. ${ }^{103}$, sketching a desirable, sustainable future for Canada in 2030 , and the changes that would need to occur to let this future vision evolve. At the European scalle a number of scenario studies have been performed ${ }^{104}$, e.g. by EC-DGXI ${ }^{\text {ras }}$ resulting in narratives of European citizens in the year 2010, in the field of energy by the European Commission DG-XVII ${ }^{106}$, and on political and institutional developments by Smith $^{107}$.

Different subdivisions of scenarios exist ${ }^{108}$. First, subdivision can be made between forecasting and backcasting scenarios, or exploratory versus anticipatory scenarios. Forecasting or exploratory scenarios are forward directed, i.e. they explore future consequences of a sequence of assumptions, with or without policy efforts. The majority of recent scenario studies can be characterised as forecasting exercises. Backcasting or anticipatory scenarios on the other hand, are backward directed, i.e. they start from some assumed (desired) final state, and explore the preconditions that could lead to this state, including a palette of strategies.

97 Apart from the examples discussed in this paragraph, it is inkeresting to mote that the Dutch Scientific Council for the Government devel. oped a number of scennario-studies on behalf of the Dutch gowersument. Somze examples af recent studies are: (WRR 1992; 1998) (wan Latestein 1999)

98. (PPC 1990; 1993)

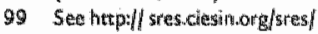

100 (Kassler 1994)

101 (WEC and IIASA 1995)

102 (Gallopin et al. 1997)

103 (Robinson 1996)

104 For a comprehensive. owerview of sce?krio-studies for Europe during the last decade, see (van Asselt et al. 1998)

105 (EC-DGX11996)

106 (ECDCXVI 1990; 7996 )

107 (Smith 1997)

108 See (van Asselt et al. 1998) 
Secondly we can distinguish between descriptive and normative/targeted scenarios. Descriptive scenarios state an ordered set of possible events irrespective of their (un)desirability, whereas normative scenarios take values and interests into account. Current scenario studies mostly have a descriptive character. Some of them are normative or have normative elements, but this is usually not explicitly acknowledged.

Finally, trend and peripheral scenarios can be set out against each other. $A$ trend scenario represents extrapolations of past and current trends, while a peripheral scenario includes bifurcations or surprises. Many recent scenario studies are hybrid, in the sense that they are neither trend nor peripheral scenarios. This has to do with the fact that they include deviations of current trends, but these anticipated changes are merely incremental.

Scenarios can in principle be useful tools to:

- articulate key considerations and assumptions: scenarios can help to envision a range of possible futures if we follow a key set of assumptions and considerations;

- blend quantitative and qualitative knowledge: scenarios are powerful frameworks for using both data and model-produced output in combination with qualitative knowledge elements;

- identify constraints and dilemmas: exploring the future often yields indications for constraints in future developments and dilemmas for strategic choices. to be made;

- expand thinking beyond the conventional paradigm: exploring future possibilities that go beyond conventional thinking may result in fresh and innovative insights.

Current scenarios are also characterised by a number of deficiencies:

- lack of diwersity: scenarios are often developed from a narrow, disciplinary based perspective, resulting in a limited set of standard economic, technologi$\mathrm{cal}_{n}$ and to a lesser extent environmental assumptions;

- extrapolations of current trends: many scenarios have a 'business-as-usual' character, assuming that current conditions will continue for decades, excluding surprises;

- inconsistency: sets of assumptions made for different sectors, regions, or issues, are often not consistent with each other;

- lack of transparency: key assumptions and underlying implicit judgements and preferences are often not made explicit. The same holds for the issue of 
exogenous and endogenous factors, and to what extent societal processes are autonomous or influenced by policies.

\subsection{PARTICIPATORY METHODS}

"Participatory methods" is an umbrella term describing approaches for assessment in which non-scientists, such as decision-makers, stakeholders or citizens, play an active role. In the late seventies, Holling ${ }^{\mathrm{ran}}$ proposed the idea of using participatory approaches in assessment efforts. Brewer ${ }^{100}$ repeated and rephrased this plea some ro years later. However, LA practitioners only recently sought to apply such methods.

Participatory methods are thus not new ${ }^{\prime \prime}$. Focus groups, for example, have been applied in market research since the seventies ${ }^{112}$, while consensus conferences were used in technology assessmen ${ }^{\text {[13 }}$. Gaming approaches have been prominently used for training purposes (e.g. millitary and business games) since the early seventies ${ }^{\text {In }}$. Teaching and training games for environmental management have been around since the $80 \mathrm{~s}^{1: 5}$. There is no major difference in using such methods in $1 \mathrm{~A}$. However, LA's complexity, interdisciplinary character, and the heterogeneity of societal actors involved present speciall challenges. The use of participatory methods in IA, therefore, requires substantial adjustment of existing procedures and the development of new tools and methods. Projects like the ULYSSES project ${ }^{\text {th6 }}$, the IIASA policy-exercise effor ${ }^{117}$, the Mackenzie Basin Impact Study ${ }^{18}$ and more recently the COOL-project ${ }^{\text {"19 }}$ explore the necessary features of participatory methods for IA. Within the VISIONS project $^{20}$, various participatory methods are used in the process of envisioning European and regional futures, which will yield further insights into the strengths and weaknesses of participation of non-scientists in Integrated Assessment efforts.

\footnotetext{
109 (Holling 1978 (rexisicon 1990 )

110 (8rewer 1986$)$

111 See for recent owerviews of parciciparory methods: (henn at al. 1995) (Crin et at. 1997) (Joss and Durant 1995) (Din renberger tet al. 1997)

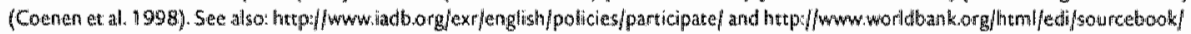

112 (Com et all 1976 )

113 For example, on the issue of predictive genetic research (Platform-on-5cience-and-Ethics i 995 )

114 see, for exarnple, (Hausrath 1971)

115 (Meadows 1985)

$116 \sec B$ Bow 1

117 (Parson 1996a)

118 (Cohen 1997)

119 (Berk ek al. 1999)

120 (Rotmans et al. 1999; 2000; van Atsselle et all 1998; 1999; Gough et all. 1999; Funeowicz and Peneim 1999). See allso

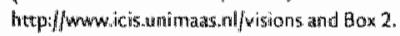


Participatory methods for $\mathrm{A}$ differ with regard to the profile of the participants, the goal of participation and the degree of participation. We distinguish three classes of methods:

- policy exercises

- dialogue-methods

- mutual learning methods

Policy exercises build upon the tradition of simulation games. A policy exercise can be described as a flexibly structured process designed as an interface between scientists and decision makers ${ }^{12 !}$, in which a complex system is represented by a simpler one with relevant behavioural similarity, and from which decision-making is part through human participants ${ }^{62}$. In general, a game is set up that represents a negotiation process in which the different teams are responsible for a certain country or region. Policy exercises quite often make use of computer support. A computer model can be used as a consulting device or as tool to convert the negotiated agreements into a new 'state of affairs'.

Policy exercises differ from the other participatory approaches in the following ways: i) the participants play roles, and ii) the participants do not explicitly take part in the assessment process. A policy exercise is a way to get information on human behaviour and policy preferences necessary for the assessment the analysts produce. Two examples of policy exercises in $\mathrm{IA}^{\mathrm{L2}}$ are the climate pollicy-exercises ${ }^{124}$ and RrVM's SusClime-exercises ${ }^{125}$. Both efforts made use of IA models, respectively a "tailor-made" version of the GCAM model" and a preliminary version of the TARGETS model ${ }^{127}$. Experiences with policy exercises in Integrated Assessment thus far are discussed in Parson ${ }^{128}$, and Toth and Hisznyik ${ }^{129}$.

The dialogue-method is applied in cases where the intended users are considered as a source of information beyond behaviour and preferences necessary for the analysts to perform the assessment. The goal of participation is to extract this essential information from the intended users. Within this class, we can discriminate between continuous dialogues, and cases in which the dialogue takes place in a specific phase of the assessment. In the first case, the role of the intended users

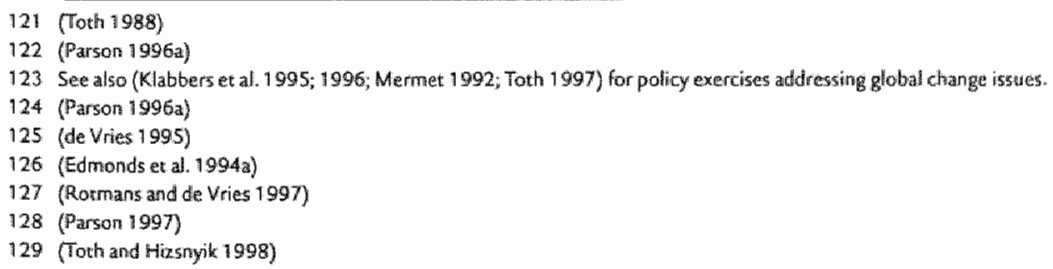


can be described as that of co-designer. In adaptive ecological modelling ${ }^{\text {t30 }}$, the aim is for the crucial choices to be co-designed by the user community. The epistemic community involving scientists and policy makers in the RAINS project realised that the involved stakeholders actually played the role of co-designer ${ }^{135}$. In cases where the dialogue takes place in the design phase, the role of the intended users is to contribute to the design principles by sketching their wants and needs. This type of dialogue can be described as a user-platform. In earlier work ${ }^{132}$, we decribed how a 'dialogue ${ }^{133}$ was intended to serve as a user-platform. If the dialogue is part of the final stage, the participants serve as a test-group that helps to determine how the results of the assessment will be brought to the fore. The Delft process around the IMAGE model ${ }^{134} \mathrm{can}$ be considered as an example of a test group.

The principle behind mutual learning is that participation of stakeholders and citizens enriches the assessment by a multiplicity of perspectives, skills and competence. The participants are considered as co-producers of knowledge. They are not selected dependent on whether the assessment is of use, but whether their perspectives, skills or competence complement the scientists' expertise and knowledge.

We distinguish two forms of mutuall learning:

- the focus group approach, in which scientists play the role of facilitator and observer, and in which stakeholders are the real participants, and

- the interactive approach, in which scientists are actively involved as participants among other stakeholders like policy makers, business people, and representatives from NGOs.

In the first case, special groups are typically composed of citizens, policy makers and/or other stakeholders who are provided with scientific input. The assessments of these groups are then used in a broader IA process. In interactive analysis ${ }^{135}$, problem definitions and proposed solutions are integrated into a joint assessment that makes sense to both stakeholders and scientists. The ULYSSES project involves IA focus groups with citizens (Box I). The VISIONS project (Box 2) can be considered as a first example of the interactive approach in Integrated Assessment.

\footnotetext{
130 Eg (Costanzand Ruth 1996, Holling 1978 (rewision 990$)$ )

131 (Hordije 19911 a 19916)

132 (wan Asselt 7994 )

133 Analysts and inten ded wsers ir the policy commuficy did not meet directly, but got informed abnut eart others' perspectives and artitudes wial interexiews.

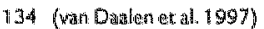

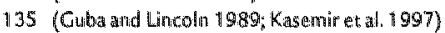




\section{BoX I The ULYSSES project}

While an increasing number of researchers are trying to design suitable computer models for the task of Integrated Assessment (IA), to date there have been severe difficulties in translating the outputs of emvironmental science into appropriate inputs for policy formation. This does not come as a surprise, as the two worlds -of scientific inquiry and of political decision making, are dissimilar in both their cognitive and social aspects. In this context the European research project ULYSSES, short for Urban Lifestyles, Sustainability, and Integrated Environmental Assessment ${ }^{136 i}$, which ran from 1996 until 1999, is relevant. This project aimed at bridging the gap between environmental science and policy by including a monitored social process in the form of so-called IA-focus groups in the assessment method. Designing an interface between IA focus groups and computer models was the central research task of ULYSSES.

The procedures for public participation in IA developed within the ULYSSES project were tested with regard to issues of urban lifestyles and sustainability. These experiments have been carried out in different European regions. The goal was to shape the participatory procedures in such a way that the cultural heterogeneity within Europe could be taken into account while also maintaining some comparability. Experiences have been gained with IA focus groups in Barcelona, Venice, Zurich, Frankfurt/Rhine-Main, Manchester, Athens and Stockholm.

\section{BOX 2 VISIONS project}

"Integrated Visions for a Sustainable Europe", commonly known as VISIONS, is an Integrated Assessment project that will run from 1998 to 2001, under the auspices of DGXII of the European Commission (Research and Development). The project is part of the Fourth Framework Programme, Environment and Climate, Theme 4, Human Dimensions of Environmental Change of the European Community. 
$30 \times 2$

THE MAIN OBJECTIVES OF VISIONS ARE:

- to develop a range of alternative visions, comprising European and regional scenarios for future sustainable development paths, up to 2020 and 2050

- to provide a point of reference and practical tools for key-decision makers and stakeholders

- to raise awareness of sustainable development by increasing the understanding of the many links between socio-economic and environmental processes and improving the assessment of the consequences for Europe from an integrated viewpoint

research methodology

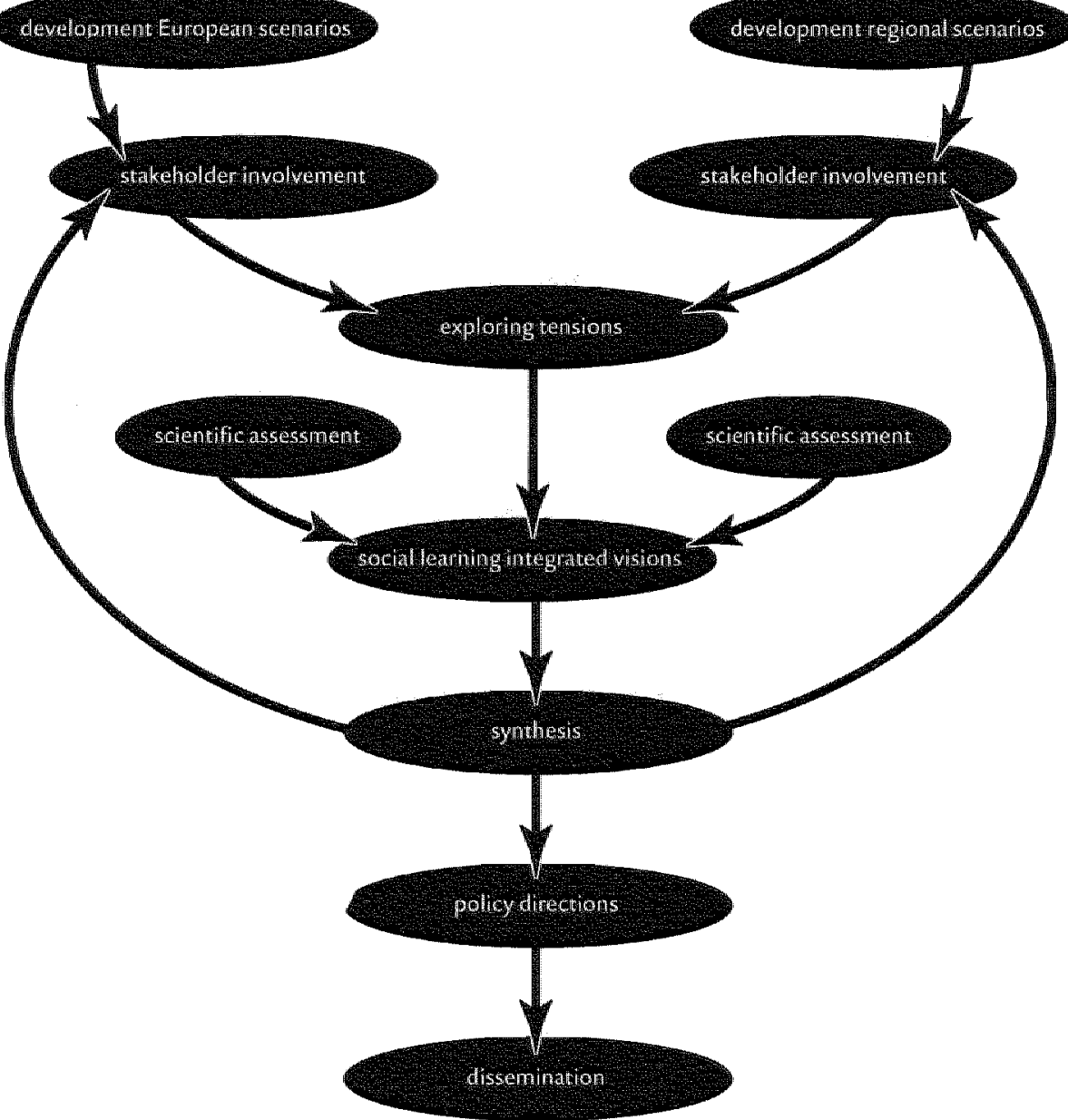




\section{KEYISSUES}

In order to create a balance between depth and broadness, VISIONS focuses on the following key European policy issues: equity, employment, consumption behaviour, degradation of the natural resource basis, in relation to developments in energy, water, transport and infrastructure.

\section{PROJECT METHODOLOGY}

Post normal science

The overall research philosophy is provided by "post-normal science", in which scientific process and dialogue is enhanced to include all those who have an interest in or are affected by decisions, associated with the particular issue/set of issues of concern.

Integrated assessment

The overall research activity is that of Integrated Assessment (IA), where a set of assessment tools will be used in an iterative and participatory process of planning for sustainable development.

\section{RESEARCH STEPS}

The following concrete research steps can be identified for VISIONS:

- to develop scenarios for Europe and the selected regions

- to integrate those scenarios into a range of altermative integrated visions for a sustainable Europe

- to test new and existing scientific tools and participatory methods for scenariobuilding

- to develop a framework for integration of toolls for sustainable development

- to identify and evaluate consensus and conflict between multiple perspectives in alternative scenarios

THE VISIONS WILL BE TESTED BY:

- Scientific experts

- State of the art modelling tools

- Participatory methods 


\section{SCENARIOS}

The scenarios will cover a European-wide perspective as well as three selected regions, which are representative for the different types of problems that are relevant within the context of sustainable development, i.e.

- The Green Heart (NL): a non-urban region, threatened by increasing expansion from the surrounding urban areas

- Greater Manchester: a typical industrial region in transformation

- Venice: a flourishing economic region, characterised by tensions between a further economic expansion, degradation of the natural resource base and an increasing deterioration of the water quality

PARTNeRs IN ThE VISIONS PROJEct ARE:

ICIS, The Netherlands (co-ordinator); C3ED, France; UMIST, UK; EAWAG, Switzerland; Manchester University, UK; RIKS, The Netherlands; JRC of the EU, Italy; RIVM, The Netherlands; RMC, UK

The set of participatory methods discussed above can be considered to constitute a spectrum with on the one extreme scientists controlling the assessment and on the other methods in which the stakeholder participants perform the core of the assessment assisted by scientists (see Figure 7). There are participatory methods available in which scientists do not participate ${ }^{137}$ at all; however, these are not relevant in the context of Integrated Assessment, because it would impair the ambition of building a bridge between science and decision-making.

$$
\text { Y.7. }
$$

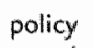

exercises

test
group
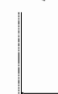

user platform co-designer

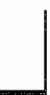

dialogue methods

mutual learning 
Participatory methods are useful for:

- setting up a communication process between scientists and stakeholders

- structuring the IA process

- integrating public opinion and attitudes of stakeholders into the assessment

- integrating abstract, highly aggregated knowledge with local knowledge

- integrating quantitative with qualitative knowledge ${ }^{13^{8}}$

The major weakness is that the use of participatory techniques in Integrated Assessment is in its infancy, which means that there are not (yet) established procedures and work-packages for using participatory processes, whereby making it difficult to judge the quality of participatory-based assessments at this stage.

\subsection{TOWARDS AN INTEGRATED ASSESSMENT TOOL-KIT}

The issues Integrated Assessment aims to address are far too complex and too diverse to be dealt with by only a single approach. Multiple approaches are needed, employing combinations of analytical methods and participatory processes. The simultaneous use of various methods can improve the quality and adequacy, because each method has its own strengths and weaknesses. This is more easily said than done: in the worst case we end up with the disadvantages of both. Whether choosing an analytical or a participatory perspective, the crux of Integrated Assessment is to provide a framework that can put the methods to work to address the complex issue under concern in a fruitful way. This implies a two-level structure of IA methodology ${ }^{139}$ (see Figure 8 ) in which the base level consists of primary disciplinary elements ${ }^{140}$ (such as theories, expert models and data) and primary integration tools (such as checklists, IA-models, scenarios and participatory techniques) (see Figure 8). The methodology used in a particular integrated assessment depends on the issue, the context of the assessment and the requirements of the IA clients. IA frameworks will then differ by the ways and means in which they select, assemble and blend a suitable set of primary elements and tools.

Analytical and participatory methods are thus not, and should not be, mutually exclusive methods for integrated assessment. Models can be used as tools to develop scenarios. On the other hand, models and scenarios can also be the

138 See, for example, (Renin 区t al. 1995)

139 Thoth and Hizsny 1998 )

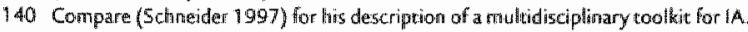


$\$ 2$

CHAPTER 2

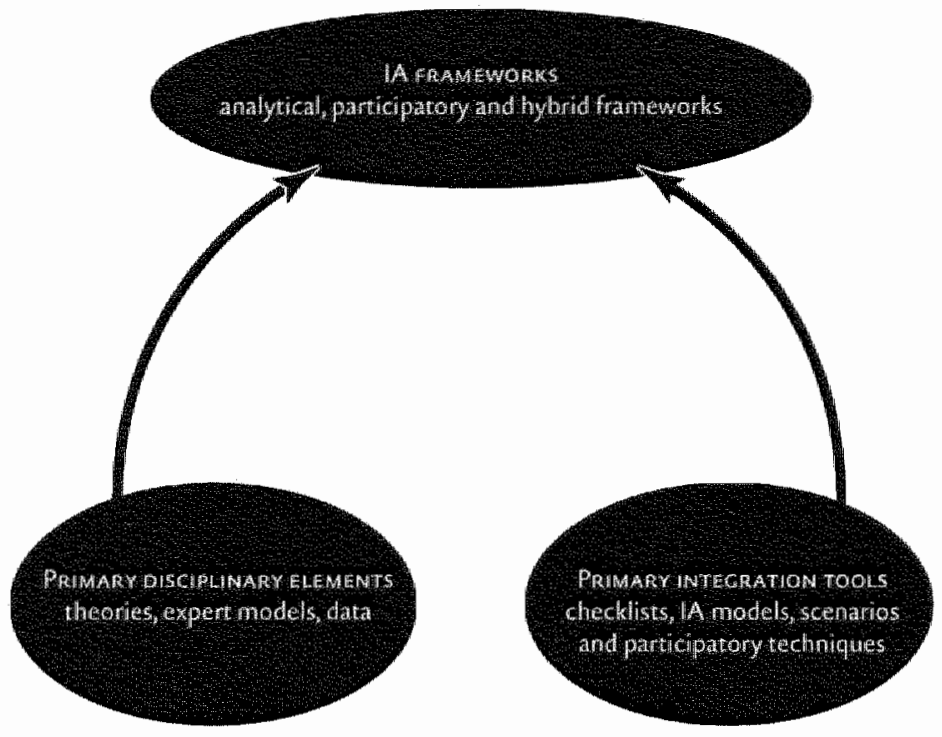

FIGURE 8 IA methodology $y^{341}$

result of participatory processes. Dialogue approaches can be oriented towards the development and/or use of IA models. Within policy exercises, models can be used as reference frameworks. In the ULYSSES focus groups, IA models were used as expert input for the group discussions. In mutual learning approaches, models might be helpful for comparing scenarios developed by participants with scientific insights.

A major methodological challenge for IA is to take advantage of the existence of multiple methods. Figure 9 suggests one way how the various methods can be used in a complementary manner:

41 Adapted from (Thoth and Hizsnyik 1998) 


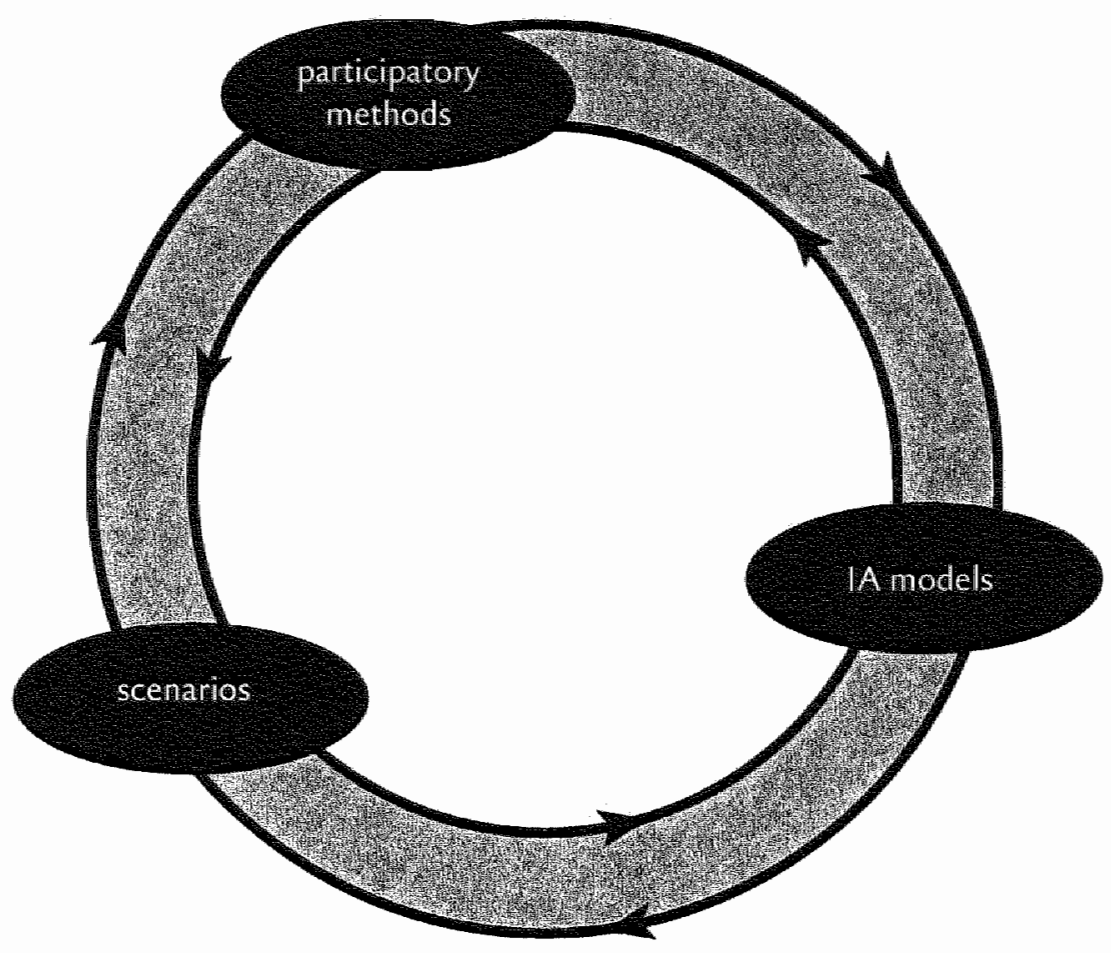

FIGUREg IA methods cycle

This cyclic scheme can thus serve as a heuristic to design a variety of sensible procedures using both analytical and participatory approaches. Starting with participatory methods and then turning clockwise, the scheme sketches a project in which participatory methods provide the basis for the development of an IA model that, in turn, is used to develop scenarios. These scenarios are then used as input for the next round of participatory meetings, where the developed models are adjusted, etc. Starting with IA models and turning anti-clockwise results in the following iterative process: an IA model is developed as a multidisciplinary scientific effort and is then used as scientific input to participatory processes in which a variety of scenarios are developed. The consistency and plausibility of these scenarios are then checked using IA-models. These checked scenarios serve as input for participatory processes, etc. The development of European scenarios in the VISIONS project (see Box 2) envisages an anti-clockwise combined use of participatory approaches, scenarios and IA-models starting from participatory methods. 


\section{Good practice and high quality}

An important challenge for $I A$, and the most crucial one if $I A$ wants to grow into a makure approach, is the development of codes for good practise and quality criteria. Critical reflection on the practice and results of IA activities is not a luxury, but an urgent need ${ }^{142}$. Codes of practise and quality criteria are necessary to evaluate and compare IA studies. Where codes of good practice mainly address the assessment process itself, quality criteria are needed to judge the products associated with IA. An accepted set of codes for practise and quality criteria that enable evaluation and comparison of IA studies will in the end improve the credibility of Integrated Assessment as an approach to decision-support on complex issues.

\section{I. DILEMMAS}

Why not simply apply standard scientific criteria to evaluate integrated assessments? First, the interdisciplinary nature of IA hampers the application of disciplinary standards on IA. This can be demonstrated at three different levels. First, the ambitions of disciplinary research and Integrated Assessment fundamentally differ. The disciplinary enterprise is focused on new knowledge, while the innovative chanacter of IA is not new knowledge per se. Integrated Assessment aims to provide new and innovative insights through synthesis of available knowledge. Second, because of the multitude of disciplinary processes to be combined in an integrated assessment, simplified representations of disciplinary knowledge are preferable. Notwithstanding the general scientific ideal of parsimony, such a process of simplification by definition does not fully satisfy advanced disciplinary standards. Third, IA by its very nature involves combining different processes usually studied in isolation from other disciplinary fields. However, when the constraints of isolation are removed, there is a variety of ways in which to connect the pieces of disciplinary knowledge. There is neither a unifying theory nor a clear recipe how to integrate the various knowledge elements. An integrated assessment is more than just the sum of its knowledge components, which, in view of the lack of an 'integration theory", adds an artistic component to the endeavour ${ }^{1+3}$. 
The critical standards applied to IA can thus not simply be the intersection of the standards from the constituent domains. To do so would reduce all evaluation of the IA endeavour to cheap shots ${ }^{144}$ and would by definition ignore the added value of the synthesis. However, disciplinary-based standards are necessary to evaluate the quality of the inputs from the various disciplines on which the integrated assessment builds. The theories, data and expert models used, and the assumptions made should be recognised as valid by the disciplinary community.

Integrated assessment also differs from interdisciplinary research due to its decision-support purpose. If IA is considered as a kind of "decision-aid", it should be tested through use. However, what does "use" mean in the context of IA? And how does one judge that the use of IA improves decision-making? It takes decades or more before the effects of present decisions can be discerned, and that those changes are only partly policy-driven ${ }^{145}$. So if it is difficult to judge the quality of a decision, how can we then recognise if the assessment supports decisionmaking? IA practitioners ${ }^{146}$ argue that studies that correspond to the decisionmakers' perceptions and political agenda have a greater likelihood to be considered by decision-makers. But are such assessments better? If so, factors such as political utility and timeliness would overrule scientific criteria. Such criteria deprive Integrated Assessment of going beyond current political interests. But taking the decision support aim seriously, this implies that notwithstanding the above difficulties, we need to find ways to evaluate the "political quality' ${ }^{147}$ of integrated assessments.

Another feature of IA complicates the quality issue even further. Integrated Assessment aims to clarify complex issues. Due to the character of complex issues " every Integrated Assessment study is by definition incomplete and at best only partially integrated. The level of integration ${ }^{148}$ may serve as quality criteria, however full integration as yardstick makes any integrated assessment a mission impossible. There seems to be no way to prove that the assessment is correct. The future is likely to be influenced by assessment activities. Assessments may foster decisions that prevent forecasts from taking place. Malthus' fears and the 'Limits to Growth' dooms have clearly influenced political thinking and decision-making. The current state of the world (e.g. no mass starvation nor depleted resources) does not make those past assessments of a poor quality.

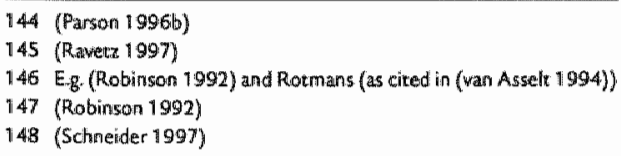


These dilemmas indicate that the design of codes of practise and quality criteria for LA is not an easy jab. It is nevertheless urgently needed in order to be credible in the long term. It is too difficult and would probably even be counter-productive, to formulate strict rules and hard criteria. Nevertheless, we will attempt to formulate rough guidelines and a kind of checklist. It is important to realise that these guidelines and this checklist do not represent the current state of the art. These quality aspects first and foremost aim to provide a heuristic for designing and evaluating $\mathbb{I A}$ research.

\subsection{ROUGH GUIDELINES FOR PRACTISE}

Different authors writing about $\mathbb{A}$ A have recently addressed the issue of developing guidelines for practise. Ravetz ${ }^{149}$ states that the quality of integrated assessment is assured only by the quality of its production. Risbey et al..$^{150}$ emphasise that process-based criteria should be developed. Bailey et al. ${ }^{\text {5it }}$ seek to identify key aspects of good practice in IA. Morgan and Dowlatabadi ${ }^{42}$ propose hallmarks of a good integrated assessment. Clark and Majone ${ }^{153}$ derived four 'meta-criteria' that capture what practitioners and users have in mind when they cite a particular assessment noteworthy or important. Others like Parson ${ }^{154}$, Schneider ${ }^{155}$ and äger $^{156}$ in turn have interpreted and extended these contributions.

It is commonly recognised that good practice primarily depends on craftsmanship. An IA study is designed with a particular function or policy question in mind. To know what to do when and what to leave aside is a crucial part of the craft. In the case of Integrated Assessment, the context, time frame, costs and conditions of use condition "best".

The above authors agree that the general functions assigned to IA imply that the IA process should involve a dialogue between users and analysts. Good practice thus means that $\mathbb{I A}$, at least in crucial stages, embraces communication between IA practitioners, stakeholders and the broad audience. This implies that participatory methods are needed in the IA process. Ideally, the various societal actors should

\footnotetext{
$149(\mathbb{R}$ iawex, 1997)

150 (Risbey et al 1996)

151 (Bailey al. 1996)

152 Hougan and Dowlatabadi 1996 )

15. (Clatk and Majone 1985)

154 (Parson 1996b)

155 (Scheider 1997)

"156 (inger 1998)
} 
participate in all stages of the IA process, but we should keep in mind that this may be too demanding for both the IA practitioners and the stakeholders. Within the VISIONS-project, we observed that it is difficult to get stakeholders 'on board', irrespective of the participatory methods used and the scalle of the assessment ${ }^{157}$. Fair management is needed to ensure that the different participants are good discussion partners and that solutions are worked out that do not entirely ignore the interest of anyone across the spectrum of societal actors. Furthermore, stakeholders are not used to this kind of science-society interactions, so the structure of the participatory process and the process facilitators should provide something to go on ${ }^{158}$. In this context, it is extremelly important that more experience is gained with participatory methods in IA in order to find out which methods seem to be suitable for what kind of contexts and to develop appropriate procedures and formats for their application.

On the other hand, it is commonly felt that IA is more than a participatory process. The analytical dimension, i.e. gathering and synthesising knowledge elements from different disciplines and knowledge domains, is as crucial as the participatory process. Building on the state of the art in IA, we conclude that the following analytical steps are essential in any IA process $^{59}$ (see Figure 10) (in italic sources of inspiration and examples that can be turned to):

- A scan of the relevant economic, socio-cultural, environmental and institutional dimersions to get a first rough outline of the issues and processes that should be considered. This step can be considered as the problemstructuring phase.

See, for example, Figure or for a simple diagram of an integrated perspective on the climate change issues. Within the TARGETS project ${ }^{\text {tio }}$, we made an overview of the global change issues addressed in major studies to select key issues in addressing sustainable development on a global scale ${ }^{451}$. As a first step in our regional assessment of the Province of Limburg, we listed the key economic, environmental and socio-cultural issues as identified in sectorspecific studies on Limburg ${ }^{\text {*6 }}$.

- Design and selection of indicators that are crucial for the analysis. Ideally, this step should be taken as a participatory effort. In this context the distinction

157 (Rotryans et at. 1999)

158 See, also, (Rotmians et al. 1999)

159 Compare (Rotmans 19986), (1CIS 1998; 1999).

160 (Rottrnans and de Vries 1997 )

161 (Rotmans 1997)

162 (ICIS 1998) 


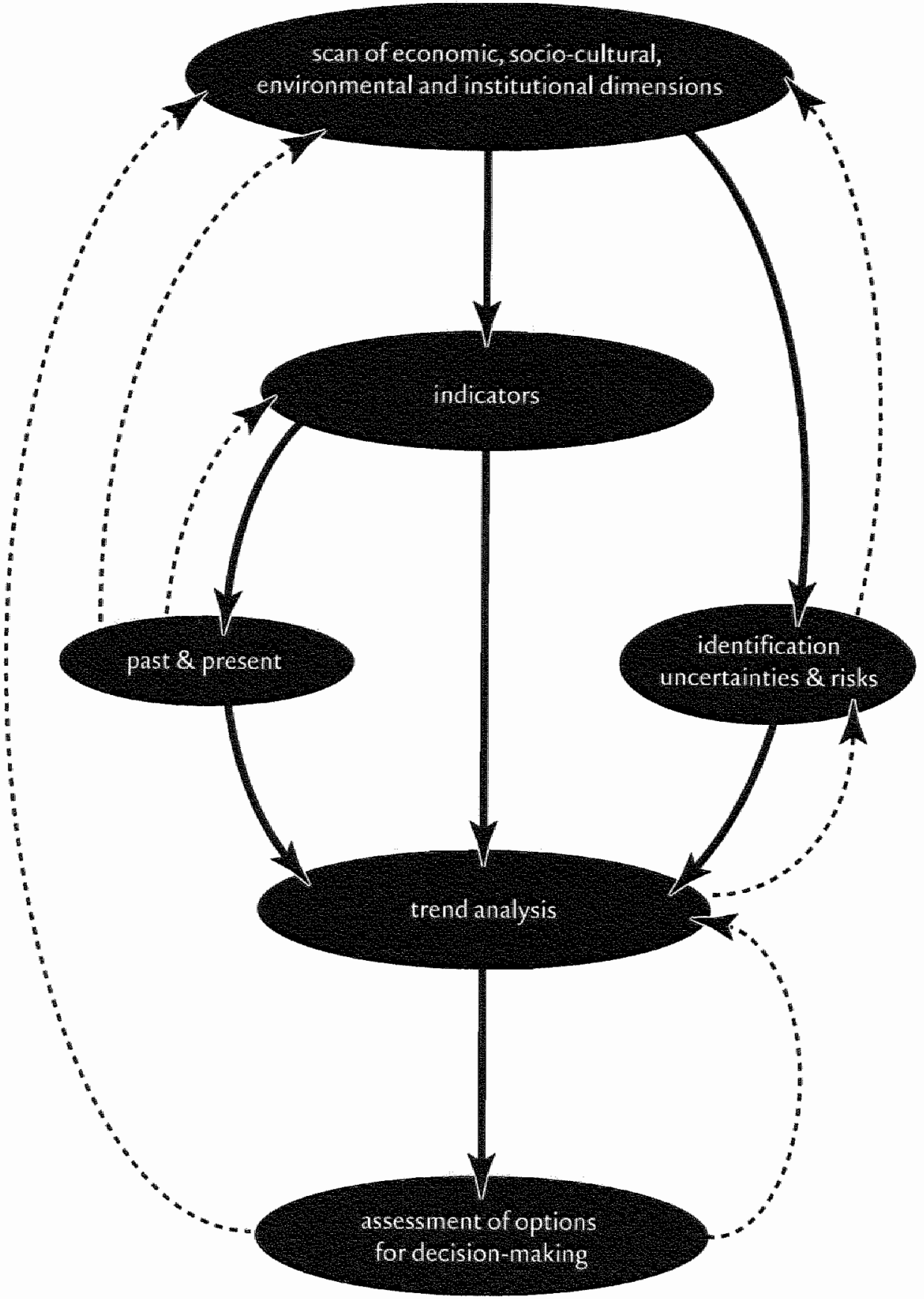

Some likely iterations are indicated by dotted arrows. 


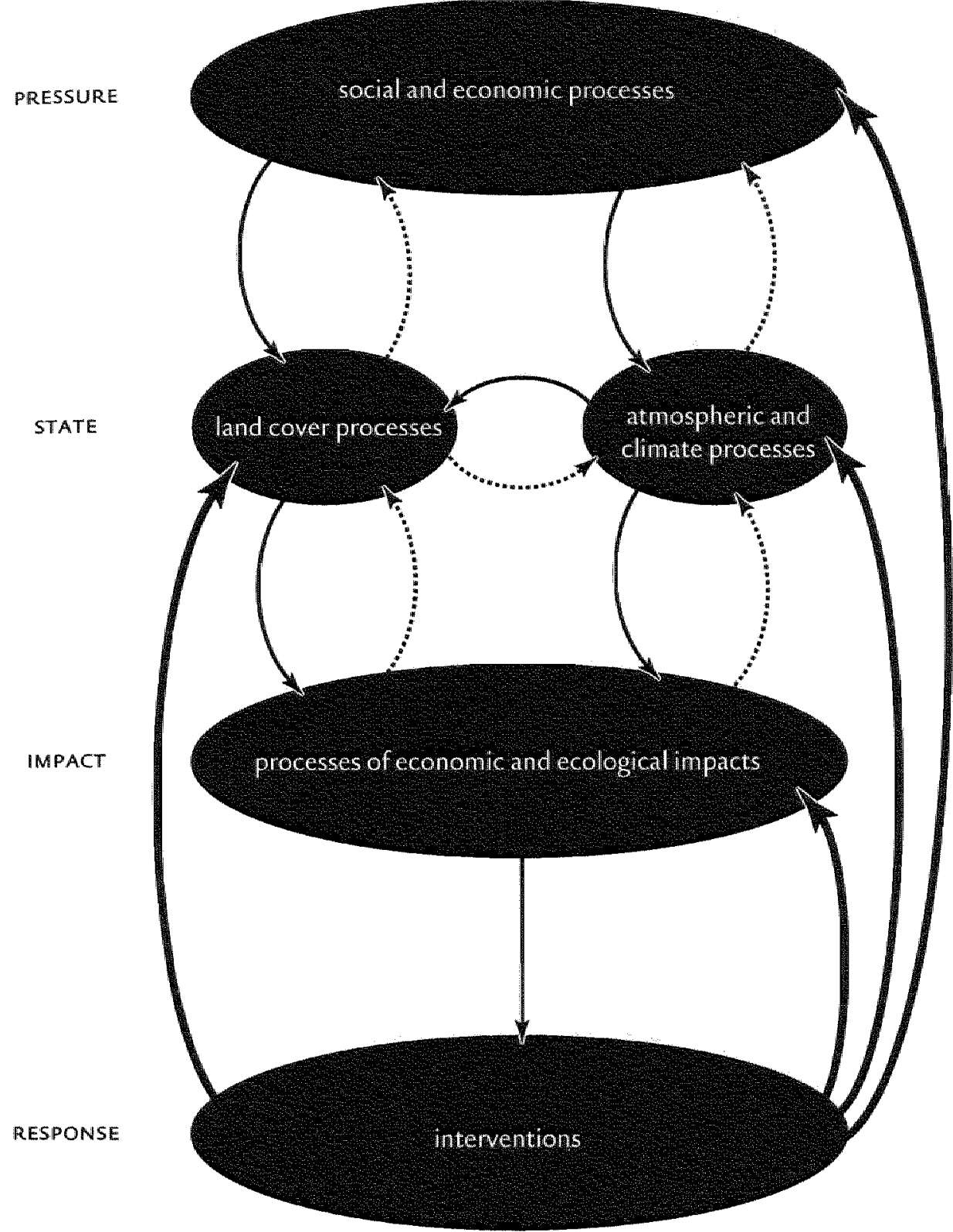

actions by human directed altering the process involwed

forcing

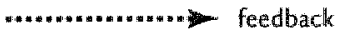

FIGURE 1 A conceptual scherne for ann integrated analysis of climate change ${ }^{\text {q63 }}$

163 Source (Rotrzans and Dowlatabadi 1 998 ) 
between stock and flow indicators is relevant. Flow indicators indicate the shortterm changes, while stock indicators describe long-term developments ${ }^{164}$.

For an illustration of this step, see the discussion report and the workshop report for the Green Feart case study in the VISIONS project ${ }^{\text {its }}$ or the report documenting the participatory process with the Province of Limburg in which indicators were designed and selected ${ }^{\text {rto }}$. See also the IA study on a sustainable future for Canada ${ }^{\text {:67 }}$.

- A historical analysis of the development of the selected indicators, in order to be able to understand the crucial dynamics and to clarify cause-and-effect chains. Part of this step involves an inventory of data pertaining to the key issues and processes to be able to sketch the state-of-the-art.

Interesting example of data inventories are those carried out in the context of VISTONS, both of key characteristics of Venice $e^{\text {a68 }}$ and of the Green Heart ${ }^{\text {t69. }}$. An example of such a historical analysis can be found in the Trend report of the United Nations, prepared by the Division for Policy Co-ordination and Sustainable Development (DPCSD) ${ }^{170}$. Other issue specific historical analysis can be found in the background documents to the TARGETS-model ${ }^{17}$.

- Trend analysis to get a feel for the future prospects.

See the Trend report of the United Nations, prepared by the Division for Policy Co-ordination and Sustainable Development (DPCSD) ${ }^{72}$. A recent example of stuch a trend analysis in the context of an IA endeavour can be found in Anastasiet al ${ }^{\text {rza }}$.

- Identification of salient uncertainties and risks.

Examples of IA studies that explicitly identify salient uncertainties include Lave and Dowlatabadi" and Rotmans and de Vries ${ }^{775}$.

\section{- Articulation of possible futures.}

This can be dome by using models (see the wide variety of scenario-exercises by means of $\mathrm{LA}$ models for climate change $\left.{ }^{i 76}\right)$, by means of an intelligent

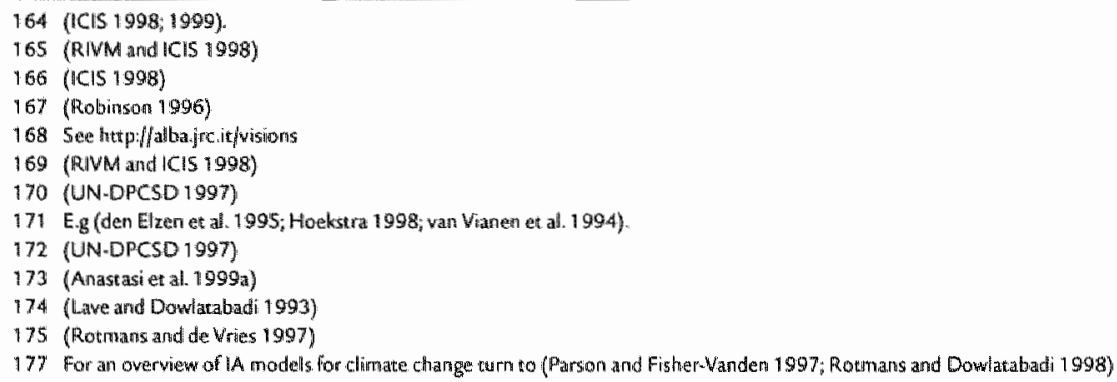


synthesis of previous trend analysis, or in a narrative manner, either informed by participatory processes (see ULYSSES experience) or as an expert-based exercise (see, for example $S$ mith ${ }^{n 77}$ ).

- Assessment of insights for decision-making in the view of historical developments, the current state-of-the-art, the future outlooks, the salient uncertainties and future risks.

This step is the most difficult and the most crucial one in any assessment. However, it is difficult to provide case studies, because this step can certainly be characterised as the 'art of integration'. An example in which it is attempted to make the assessment step explicit can be found in Rotmans and van Asselt ${ }^{178}$. The assessment step can involve the evaluation of policy options. Policy analysis offers some good methods for option generation ${ }^{779}$.

There is agreement within the IA community that the step of identifying major uncertainties and risks is crucial, but problematic. It is commonly felt that IA lacks the methods or procedures that enable the incorporation of uncertainty into trend analysis in an adequate way and to use the concept of risk in the final assessment. The current thesis aims to provide an in-depth study of the issue of uncertainty and risk in Integrated Assessment. Although uncertainty and risk are just one of the critical quality issues, the current research is thus relevant in the context of good practise.

Notwithstanding the different steps identified above, it is agreed that Integrated Assessment can never be a linear endeavour. This implies that the followed approach should be iterative and cyclical (see also Figure 10). Furthermore, it is important to realise that the distinct steps can be interpreted and performed differently depending on the context in which the assessment effort is carried out ${ }^{180}$ and the type of complex issue addressed. "The analytical steps above identified serve to outline the analytical dimension of IA.

\footnotetext{
\#77 (Smith 1997 )

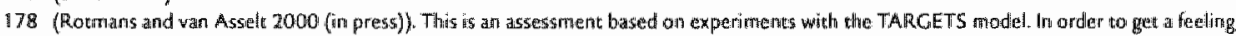
for differences between richer and poorer assessments compare this assessment with (die Vries et al. 1997 ), in which the forst symthesis of the TARGETS experiments is described. See also (Roumanis and van A sseli 1999)

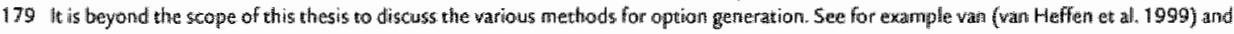
(Hoppe 1998)

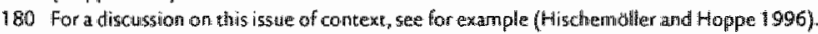




\subsection{QUALITY CRITERIA ${ }^{18 .}$}

What applies to the process, also applies to the product: the quality of the products is dependent of the purpose and context of the study in question. It is thus by definition impossible to come up with general quality standards that measure all IAs with the same yardsticks. Nevertheless, it is useful to think about rough rules for assessing the quality of LA studies within the scope of their own purpose.

Building upon Robinson ${ }^{182}$, we distinguish three types of quality criteria: i) analytical quality ${ }^{183}$, iii) methodological quality and iii) usability ${ }^{184}$ that can be defined as follows ${ }^{\text {is: }}$ :

- analytical criteria concern the credibility of the underlying data sources and theories, the validity of techniques or models used, the level of integration, and the logic of the conclusions.

- methodological criteria address the quality of the methods and approaches adopted.

- usability criteria involve the degree of relevancy of the assessment for decision-making.

The latter category is unique and reveals the explicit decision-support aim of IA. For this reason IA-studies are subject to additional criteria that go beyond interdisciplinarity. Analytical and methodological quality are necessary, but insufficient conditions for every IA study. We can thus distinguish between two hierarchical levels ${ }^{186}$, i.e. internal quality of the assessment ${ }^{187}$ ("have we done a good

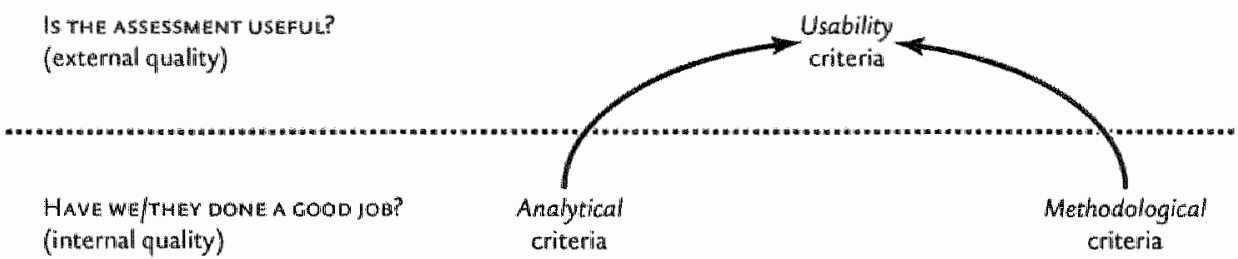

FquURe in Two levels of qualinty

181 In this effiort to propose giality criteria, the Bellagio principlas as formulated by the intemational Irstitu te for Sustainable Developme:ne

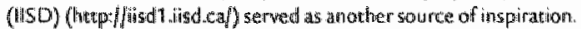

182 (Robinson 1992)

183 also keferred to as 'scientific quality' (Towh and Hizssyik 1998) or 'tectinical actequacy' (Clank and Aajone 1985).

184 also feferred to as 'practicill achiewennent' (Toth and Hibsmyik 1998)

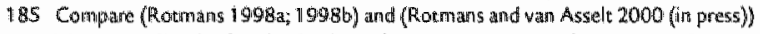

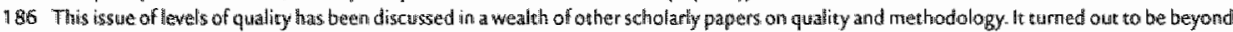
the scope of this thessis to per form a proper linerature rewiew.

187 (Clark and Majone 1985) refer to internal qualty as "technical adequacy". 
job?") and external quality ("is the assessment useful?") (see Figure 12). The aim is a balanced quality judgement, that inwolving both internal and external quality, would enable us to distinguish between "better" and "worse" studies, to separate the sheep from the goats.

In order to arrive at a checklist, it is necessary to investigate what kind of specific items the different types of quality include. On the orher hand, we should not aim at an exhaustive checklist. For each type of criteria, we have tried to identify 7 key questions ${ }^{188}$.

Analytical quality criteria involve what Risbey et al. ${ }^{189}$ call 'discipline-based criteria to evaluate IA components'. An assessment of the analytical quality thus involves addressing ${ }^{100}$ :

- What are the data-sources (field data, survey data, laboratory experiments, statistical data, computer simulations, educated guesses, etc.), how credible are they and are the data confirmed by different studies?

- Are the theoretical assumptions derived from state-of-the-art theory, are the concepts and laws used, interpreted and formulated in accordance with disciplinary standards, and are the models used in the assessment calibrated ${ }^{\text {to }}$ and validated ${ }^{\text {ig? }}$ ?

- Is there a balance between aggregation and disaggregation, and is it based on a sound protocol?

- Is the adopted time-horizon long enough to capture the relewant time-scales, and how is this long-term perspective related to short-term decision-making?

- Are autonomous processes and processes that are or may be affected by human activities and/or policy strategies distinguished in the assessment?

- To what extent is the study integrated: are the key social, economic and environmental dimensions addressed in a balanced way and does the assessment adequately address mutual interactions as well as positive and negative feedbacks?

- Is the study consistent, are the conclusions supported by evidence and/or logical and plausible argumentation ${ }^{93}$, can the results be generalised (either analytically

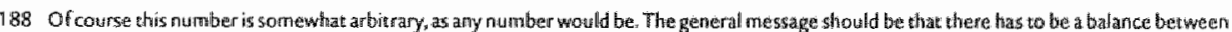
the three rypes, and for that reason we wanted to have the same amownt of issues for each type of criteria. The only fustification for 7, may be that this number has the cultural (religious) meaning of representing complieteness.

189 (Risbey et all 1996)

190 Compare (Funtowicz and Rawetz 1990)

191 Calitratiom is defined as the procedure to gauge the most important parameters in such a way that the model simulations come clarse to the observations.

192 Validation is diefined here as tescing model performance.

193 l.e. to what extent are the cond usions compatibile with data, modtel resistes and qualitati we insights? 
or statistically) and do the conclusions transcend disciplinary insights and provide innovative findings?

Methodological quality addresses the quality of the Integrated Assessment process and the methods and approaches adopted. Therefore, the guidelines for good practise reappear to a greater or lesser extent as methodological criteria. Questions relevant in this context are:

- Are the research questions and the research priorities appropriate in view of the aims, time frame, costs and conditions of use?

- Does a framework that is integrated and comprises the essential analytical steps as indicated under codes of good practice guide the research?

- Are the chosen analytical and participatory methods and approaches state-ofthe-art, appropriate and legitimate in the context of the aim of the study?

- Is the study of an interdisciplinary or multi-disciplinary nature?

- Is the use of disciplinary knowledge elements and the simplification of this knowledge into building blocks for the IA study done in close collaboration with disciplinary experts (disciplinary peer review)?

- What is the level of participation by what kind of stakeholders, and how were they selected?

- How is uncertainty dealt with and are values, preferences and bias made explicit so that it is clear to what extent value judgements influence the scientific conclusions?

Usability addresses the relevance of the IA study for society in general, and decisionmaking in particular, and the usefulness for disciplinary research in terms of advancing knowledge. As discussed before, it is difficult, if not impossible, to come to a definite judgement taking into account the nature of decision-making processes and the delayed response to actual decisions. However, the key following questions may help to arrive at an indication of the usability of $1 \mathrm{~A}$-studies:

- Does the problem formulation make sense to the stakeholders and the decisionmakers, and does the study address important decision-making issues?

- Are the stakeholders, views and dimensions relevant for the decision-making process taken into account?

- Is the assessment comprehensible to the audience and users, and are the recommendations concrete?

- Is the study useful for disciplinary sciences in the sense that it helps to set disciplinary research agendas? 
- To what extent has the IA study been able to address societal concerns and needs, and if, and in what way, do stakeholders and the general public benefit from the integrated assessment?

- Does the study facilitate in any way one or more of the following decisionmaking processes: framing the issue(s), agenda setting, scenario development, analysis of policy options, evaluation of consequences, identification and exploration of scientific uncertainties or evaluation in terms of equity ${ }^{194}$ ?

- To what extent is the study effective, in terms of changing, stabilising and/or advancing the relevant debate(s)?

- Is the assessment timely?

The above checklist is summarised in Table 1 , where the major items associated with the various quality criteria are listed. Three levels of items can be distinguished, i.e. criteria that hold for any scientific study (normal), criteria pertaining to interdisciplinary research in general (italic) and criteria that hold for IA in particular (bold) ${ }^{\text {ngs }}$ "

\begin{tabular}{|c|c|c|}
\hline ANALYTICAL QUALITY & METHODOLOGICAL QUALITY & USABILITY \\
\hline credibility of datarsources & suitability of research agenda & $\begin{array}{l}\text { value of probllem } \\
\text { definition }\end{array}$ \\
\hline $\begin{array}{l}\text { disciphltury quality of } \\
\text { used knowledge elements: }\end{array}$ & $\begin{array}{l}\text { integrated character of } \\
\text { research methodology }\end{array}$ & legitimacy $^{196}$ \\
\hline balance aggregation-disaggregation & choice of methods & transparency \\
\hline integitation of time-horizons & interdisciplinatity & tusefint to disciplinary science \\
\hline $\begin{array}{l}\text { distinction between autonomous } \\
\text { \& policy-driven }\end{array}$ & level of collaboration with disciplines & societal benefit \\
\hline level of integration & levell of participation & effectivenes \\
\hline $\begin{array}{l}\text { consistency and "transdisciplinary" } \\
\text { character of conclusions" }\end{array}$ & uncertainty treatment & rimeliness \\
\hline
\end{tabular}

TABLE, Quality checklist 


\section{Challenges}

The aim of this chapter has been to set the scope for the thesis by providing a stateof-the-art overview of Integrated Assessment in terms of current practices and challenges for the future. Building upon the above overview, some important conclusions can be drawn:

- Notwithstanding its explicit decision-support aim, the policy relevance of IA is being questioned. The challenge for $I A$ is to investigate how it can be more responsive to the needs of decision-makers.

- There are different analytical methods and participatory methods available or being developed, but IA lacks frameworks that enable practitioners to use different methods in a complementary and sensible way. The need for such frameworks that can guide IA endeavours is commonly recognised.

- The above overview indicates that the treatment of uncertainty and the incorporation of different perspectives in IA are vital issues in the context of quality. It is broadly felt that uncertainty and pluralism are currently problematic issues in IA.

- Integrated Assessment, so far, has not explicitly addressed risks in the assessment effort. It would be interesting to explore which risk approaches can be useful within the context of $\left[\mathrm{A}^{\text {ny }}\right.$.

In view of the above, the goal of the thesis is to provide a significant contribution to Integrated Assessment methodology. The intention of this thesis is to address uncertainty and risk in relation to pluralism. The explicit aim is to explore a framework for uncertainty management and risk analysis that can be used to perform Integrated Assessment in a way that is theoretically sound and practically feasible. As becomes clear from the current state-of-the-art detour in this Chapter, such a contribution to IA methodology would be highly welcomed in view of the quality of IA as an approach to scientific decision-support.

197 Sae also (Rotmanns 1998; 1998b) 


\section{REFERENCES CHAPTER 2}

- Alcamo, I. (ed.) (1994). MACE 2.0. Integrated Modefing of Giobal Climate Change, Kluwer Academie Publishers, Dordrechi, The Netherlands.

- Alcamo, I. Shaw, R., and Hordijk, L. (eds.). (1990). The RAINS Model of Acidification. Science and Strategies in Europe, Kluwer Academic Publishers, Dordrecht, The Netherlands.

- Anastasi, C. "Lessons Learned from Two Decades Scenario Development." Open meeting of the Human Dimensions of Global Envirionmental Change Research Communty, Laxenburg, Austria.

- Anastasi, C., Rotmans, J, van Assell, M. B. A., Greeuw, S., Mellors, J., Peters, S, and Rothrnan, D. (1999a). "Global Format: Position Paper." , ICIS, Mastricht Uniwersity, Maastricht, The Wetherlands.

- Anastasi, C., wam Asselt, M. B. A., Peters, S. S. M., Mellors, J., Ravezz, J., and Rotmans, J (1999b) "From Wild Storyline Material to Integrated Visions: The first steps have been taken."

- Bailey, P., Gough, $C_{y}$ Chadwich, M, and McGranahan, G. (1996). "Methods for Integrated Environmental Assessment: Research directions for the European Union." Stockhoim Erviromment Institute (SE), Stockholm, Sweden.

- Beaver ${ }_{2}$ R. (1993). "Stluctural Comparison of the Models in GMF 12." Energy Policy, 21, 238-248.

- Berk, M. M., Hordijk, L., Hisschemoller, M., Kok, M. T. J, Liefferink, D., Swart, R.)., and Tuinstra, W. (1999), "Climate OptiOns for the Long term (COOL): Interim report." 410200028 , NOP, Bilthowen, the Netherlands.

- Biggs, B., Robinson, J. B., Tague, C, and Walsh, M. (1998 (in press)). "Tools for Linking Choices and Consequences." Sustainability Issues and Choices in the Lower Fraser Basin: Resolving the Dissonance, M. Healley, ed., UBC Press, Vancouver, Canada.

- Brand, A. l. (1994). "Tacit leaning in Transnational Organisations.".

- Brewer, C. D. (1986). "Methods for Synthesis: Policy Exercises" Sustainable Dewelopment of the Biosphere, W. C. Clark and R. E. Munn, eds., Cambridge University Press, Cambridge, UKK, 455-473.

- Cebon, P.s Dahinden, U., Davies, C. D., Imboden, D., and Jaeger, C. C. (eds.). (1998). Views from the Alps: Regional perspectives on climate change, The MIT Press, London.

- Clark, W., Dickson, N., and Parson, E (1997). "The Global Environmental Assessment Project: An overwiew." A critical evaluation of global environmental assessments: The dimate experience, GEA, ed, Center for the Application of Research on the Environment, Boston, USA.

- Clark, W. C. and Dickson, N. M. (1998). "The Global Environmental Assessment Project: Overwew for 1998.", Harvard University, Boston, USA.

- Clark, W. C., and Majone, G. (1985). "The Critical Appraisal of Scientific Enquiries with Policy Implications." Sci. ence, Technology and Human Vahes, $10(3), 6-19$.

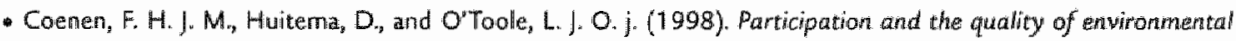
decision-making, Kluwer Academic Publishers, Dordrecht, the Netherlands.

- Cohen, 5. 1. (ed.) (1993). Mackertzie Basin Impact Study: Interim Report 1, Enwironment Canada, Downsview, Cartada

- Cohen, S.). (1997). "Scientist-stakeholder collaboration im integrated assessment of climate change: Lessons from a case study of Nortthwest Canadd" Environmental Modelling and Assessment, 2(4), $281-293$.

- Costanza, R., and Ruth, M. "Dynamic Systems Modelling for Scoping and Consernsus Building "European Chapter of the International Society for Ecological Economics, University of Versalles, Paris, France.

- Cox, K. Ku, Higginbotham, J. B, and J., B. (1976). "Application of Focus Croup Interview in Marketing." Journal of Marketing $(40), 77-80$.

- Dahinden, U, Querol, C., Jager, 1., and Nilsson, M. (1999). "Using Computer Models in Participatory Integrated Assessment." ULYSSES WP-99-2, Darmstadt University of Technology, Daurmstadt, Germany.

- Darier, E. (1999). "Computer Madeling of Climate Change (submitted)." Science as Culture.

- de Vries, H.).M. (199.5). "SusClime." Globo report series 11, RIVM Bilthoven, The Netherlands. 
- de Vries, H. . M. Romans, J.,Beusen, A. H. W, den Eizen, M. G. J. Hilderink, H. B. M. Hoelkstra, A. Y., Janssen, M. A. Niessern, L. W. Strengers, B. I. and wam Asseli, M. B. A. (1997) "Clobal Change: Fresh insights, no simple answers." Perspectives on Global Change: The TARGETS approach, ). Rotmans and H. J. M. de Vries, eds., Cambridge University Press, Cambridge, UK

- den Elzen, M. Beusen, A. and Rotmans, J. (1995). "*Modelling Global Biogeochemical Cycles: An integrated assessment approach." 461502007, RIVM, Bilthoven.

- Dowlatabadi, H., and Morgan, M. G. (1993a). "Integrated Assessment of Climate Change." Science, 259, $1813-1814$

- Dowlatabadi, H.z and Morgan, M. G. (1993b). "A Model Framework for lintegrated Studies of the Climate Problem." Energy Policy(March), 209-221.

- Dror, Y. (1971). Design for polioy sciences, American Elsevier Publishing Company Ine., New York.

- Dürnenberger, D., Behringer, I, Dahinden, U., Gerger, A., Kasemir, B., Queroll, C, Schüle, R., Tabara, D., Toth, F, van Asseht, M., Vassilarou, D, Willi, N., and jaeger, C. (1997). "Focus Groups in Integrated Assessment: A Manual for a Participatory Tool." ULYSSES working paper WP-97-2, Darmstadt University of Technology, Darmstadt, Germany.

- EC-DGXX1.(1996). "Vision 2020: Scenarios for a Sustainable Europe."X1-120-97, European Commission, Directorate Ceneral XI, Environment, Aluclear Safety and Civil Protection, General Consultative Forum, Brussels.

- EC-DCXII. (1997). "Vision 2020. Scenarios for a sustainable Europe-Summary and recommendations agreed on by the General Consultative Forum." European Commission Directorate-Gieneral XI Enwironment, Nuclear Safety and Civili Protection, Brussels, Belgium.

- EC-DCXVII: (1990)."Energy for a new century: Energy in Europe-The European perspective." European Commission, Luxembourg, Luxembourg:

- EC-DGXVII.(1996). "Energy in Europe: European energy to 2020-A scenario approach.", European Commission, Luxembourg, Luxembourg.

- Edmonds, J., Pitcher, H. Rosenberg, $N_{2}$ and Wigley, T. "Design for the Global Change Assessment Model. "Integratiwe Assessment of Mitigation, Mmpacts and Adaptation to Climate Change, Laxenburg, Austria.

- Edmonds, J, and Reilly, J. M. (1985). Global Entergy: Assessing the Future, Oxford University Press, Oxford, UK

- Edmonds, I., Wise, M., and MacCracken, C. "Advanced Energy Technologies and Climate Change: An analysis using the global change assessment model (GCAM)." Air and Waste Martagement Meeting, Pittsburgh, USA.

- EFIEA, and IEEP. (1998). "Assessment of transport issues relewant to the policy programme of the European forum on Integrated Enwironmental Assessment (EFIEA)."

- Funtowicz, S. O, and Ravetz, J. R. (1990). Uncertaincy and quality in science for policy, Kluwer, Dord reicht, the Netherlands.

- Funtowicz, $S_{1} O_{3}$ and Ravetz, ). R. (1992a). "Risk Management as a Postmormal Science." Risk Anabysis, 12(1), 95-97.

- Fumtowicz, S. O., and Ravetz, ). R. (1992b). "Three Types of Risk Assessment and the Emergence of Post-Narmall Science." Social Theories of Risk, S. Krimsky and D. Golding, eds., Greenwood, Westport.

- Funtowica, S. O., and Ravetz, ). R. (1993a). "The Emergeruce of Post-normal Science." Science, Politics and Morality: Scientific uncertainty and decision-making. R. von Schomberg, ed., Kluwer Academic Publishers, Dor. drecht, the Netherlands.

- Funtowicz, S. O, and Ravetz, J. R. (19936) "Science for the Post-Normal Age." Futures, 25(7), 739-755.

- Funtowic, S. O, and Ravetz, ). R. (1994). "Thye Wortlly of a Songbird: Ecological Economics as a Prost-Normal Science" Ecological Economics(10), 197-207.

- Funtowica, S., Guimaraes Pereira, A. "WISIONS report" Interim Report, September, 1999. JRC, 1spra, Italy.

- Gatlopin, G. Hammond, A., Raskin, P., and Swart, R. (1997). "Branch Points: Global Scenarios and Human Choice A Resource Paper of the Global Scenario Group." Polestar Series Report fo. 7. Stockholm Environment Insti" tute, Sweden. 
- Gaskins, D. W., and Weyant, J. P. (1993). "Model Comparisons of the Costs of Reducing CO2 Envissions" American Economic Revies, Papers and Proceedings, 83,318-323.

- GEA. (1997). A critical ewaluation of global environmental assessments: The climate experience, Center for the Application of Research on the Environment; Boston, USA.

- GEA. (1998). A Critical Evaluation of Global Environuental Assessments: Tropospheric pollutants and climate change., Harvard University, Cambridge.

- Gough, C., Shackley, S., Ravetz, . (1999) "VISIONS for the North West" Interim Report, September 1999. Manchester School of Mamagement, UMIST \& Department of Planning and Landscape, Manchester University, UK.

- Griri, l., wan de Graaf, H, and Hoppe, R. (1997). Technology Assessment through interaction: A guide, STV Transla. tions, translator, SDU, The Hague, The Netherlands.

- Guba, E. Gi, and Lincoln, Y. S. (1989). Fourth Generation Evaluation, Sage, Newbury Park, USA.

- Haght, N. (1998). "The European Forum on Integrated Enwironmental Assessment." Environnuental Modelling and Assessment, 3(3, Special issue: Challenges and Opportunities for Integrated Environmental Asserssment $\left.{ }_{s}\right)$. Rotmans and P. Vellinga, eds.), 135-142.

- Hausrath, A. (1971). Venture Simulation in War, Business and Politics, MCGraw-Hill, New York, USA.

- Hisschemoller, M., and R. Hoppe (1996). "Coping with lntractable Controversies: the case for problem structuring in policy design and analysis." Knowledge and Policy $8(4)_{n} 40-60$.

- Hoekstra, A. Y. (1998). Perspectivers on Water: An integrated model-based exploration of the future, International Books, Utrecht, the Netherlands.

- Holling, C. S. (ed.) (1978 (revision 1990)). Adaptive envirommental assessment and management, Willey, London, UK: New York, USA.

- Hoppe, R. (1998). Effective Policy Documents: A guide for successful decision support (in Dutch), Coutinho, Bussum, the Netherllands.

- Hoppe, R. (1999) "Rethinking political judgement and science-based expertise" argumentative practices and boundary work for policy-riented learning?"

- Hordijk, L. (1991a). "An Untegrated Assessment Madel for Acidification in Europe,", Free University of Amsten" dam, Amsterdam, The Netherlands.

- Hordijk L. (1991b). "Use of the RAINS Model in Acid Rain Negotiations in Europe." Environmental Science and" Techrology. 25(4), 596-603.

- $\|$ CIS. (1998). "Limburg in Perspective A first inventory (in Dutch).", ICIS, Maastricht.

- $\| C I S$. (1999). "The. Thiinkmodel for POL (in Dutch)." "ICIS, Maastricht.

- HDP. (1999). "Indistrial transformation-research directions.".

- IPCC. (1990), Climate Change: The IPCC Scientific Assessment, Cambridge University Press, Cambridge, UK.

- IPCC. (1992). Climate Change 1992. The Sapplementary Report to The IPCC Sciemtific Assessment, Cambridge University Press, Cambridge, UK.

- IPCC. (1994). Climate Change 1994. Radiative Forcing of Climate Change and an Evaluation of the IPCC 1992 Emission Scenario, Cambridge University Press, Cambridge, UK.

- IPCC. (1996a). Climate Change 1995: Inpacts, Adaptations and Mitigation of Clinate Change: Sicientific-Technical Anatyses, Press Syndicate, Cambridge.

- IPCC. (1996b). Chmate Change 1995: The Science of Climate Change, Cambridge Uniwersity Press, Cambridge, UK

- IPCC. (1998). The Regionall Impacts of Climate Change: An Assessment of Vulmerability, Cambridge University Press, Cambridge.

- Jaeger, C. C, Barker, T", Edenhofer, O., Fancheux, S., Hourcade, 1.C. Kasemir, B. O'Connor, M., Parry, M., Peters, I. Ravetz, ), and Rotmans, J. (1997). "Procedural leadership in Climate Policy" a European Task." Globall Envi. rommental Change, $7(3), 195-203$ 
- Jaeger, C. C., Chadwick, M., Wynne, B., Funtowicz, S, Giaoutzi M., Giner, 5., Toth, F., Jäger, I, Dürenberger, C., Ravet2, I. R, and Casilli, C. (1995). "ULYSSES - Uriban Lifestyles, Sustainability and Integrated Environmental Assessment - RTD proposal for the European Community Framework Prograrnme HV." Darmstadt Technical University, Daminstade, Germany.

- Jäger, (1998) "Current Thinking on Using Scienth́ Findings in Environmental Policy Making." Environmental Moduling and Assessment, 3(3, Special issue: Challenges and Opportunities for Integrated Enwironmental Assessment, I. Rotmats and P. Vellinga, eds.), 143-153.

- Jasanoff, S, and Wynne, B. (1998) "Science and Decision making. Human Choice and Climate Change, S. Rayner and E. L. Malone eds, Battelle Press, Washington D.C., US.A.

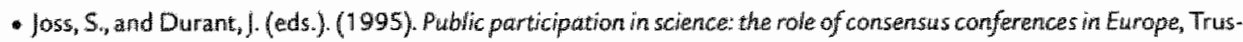
tees of the Science Museum, London.

- Kahn, H., and Wiener, A. (1967). The Year 2000, MacMillain, New York.

- Kasemir, B., Behringer, J, de Marchi, B., Deuker, C, Durrenberger, D., Funtawicz, S., Gerger, A., Gizoutzi, M., Hatfner, $Y_{*}$ Nillson, M., Querol, C., Schule, R., Tabara, D., van Asselt, M., Vassilarou, D., Willi, $N$,, and jaeger, C. (1997). "Focus Groups in Integrated Assessment: The ULYSSES pilot experience." WLYSSES WP-97-4, Darmstad Universitity of Technology, Darmstadt, Germany.

- Kasemir; B., Dahinden, U., Gerger, A., Scholle, R., Tabara, D. and jaeger, C. C. (1999a). "Fear, Hope and Ambiguity: Citizens' perspective on climate change and energy use." ULYSSES WP.99-1, Darmstadt University of Technology Darmstadt, Germany.

- Kasemir, B., van Asselt, M. B. A., Dürrenberger, G. and jaeger, C. C. (1999b). "Integrated Assessmert: Multiple Perspectives in: Interaction. "International journal of Environment and Pollution, 11(4), 407-425.

- Kassler, P: (1994). "Energy for Development." Shell Selected Paper, Shell London, UK.

- Kates, R. W. A Ausubel, ).H., and Berberian, M. (eds.). (1985). Climate Impact Assessment, John Willey \& Sons ${ }^{\text {Chich- }}$ ester.

- Kingdon, J. (1984). Alternatives and Public Policies, Little Brown, Boston MA.

- Klabbers, J., Bernabo, C. Hisschemsller, M., and Moomaw, B. (1996). "Climate Change Policy Dewelopment: Enthencing the science/policy dialogue." Simulation nowl Learning Through Experience: The challenge of change, $F$. Watts and G. Crabonell, eds, Diputacio de Valencia, Valencia, 285-297.

- Kiabbers J. H. C., Swart, R. J., Van Ulden, A. P., and Vellinga, P. (1995). "Climate Policy: Management of organised corraplexity through gaming." Simulation and Gaming aCross Disciplines and Cultures: ISACA at a watershed,

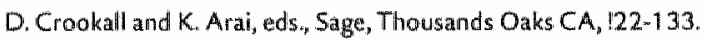

- Lashof, D. A.s and Tirpak, D. A. (1989). "Policy Options for Stabilising Clobal Climate.", US Environmental Protec. tion Agency, Washington, USA.

- Lasswell, H. D. (1971). A preview of polkcy sciences, Elsevier, New York.

- Lave, L B. and Dowlatabadi, H. (1993). "Climate Change: The effects of personal beliefs and scientific uncertainty." Enwironmental Science and Technology, 27(10), 1962-1972.

- Leemants, R., Kreileman, R. E, Zuidema, G., Alcamo, J. Berk, M, van den Born, G. I., den Elzen, M., Hootsmans, R., Janssen, M., Schaeffer, M., Toet, S., and de Vries, B. (1998). "Global Change Scenarios from IMAGE 2.1 - the IMAGE User Support System." RIVM Publiciations, Bilthoven.

- Lindblom, C.E (1968). The policy -making process, Prentice Hall, Englewood Cliffs, N.).

- Mazrota, P., Thornes. J. B., and Geeson, N.. (eds.). (1998). Atias of Mediterranean Enwironments in Europe: The deser. tification context, Joha Wiley \& Sons, Chichester, UK.

- Majone, G, and Quade, E. S. (1980). Piffalls of analysis, Wiley, Chichester, USA.

- Manine, A. S. Mendelsohn, R., and Richels, R. C. "MERGE. A Model for Eval luating Regional and Global Effects of CHC Reduction Policies." Integrative Assessment of Mitigation, Impacts and Adaptation to Climate Change, Laxenburg, Austria. 
- Martens, W. ). M. (1997) "Health impacts of climate change and ozone depletion: An eco epidemiologital approach, ${ }^{2}$, Malastricht University Maastricht, the Netherllands.

- McMichael, A. ). (1997). "Integrated Assessment of Potential Health limpacts of Cllobal Envirommental Change: Prospects and limitations." Environmental Modelling and Assessment, 2(3).

- Meadows, D. H. (1985). “User's manual for STRATEGEM-M. A microcomputer based management traiming game on energy-enwironment unteractions. " Resource Policy Center, Hanover, N.H.

- Meadows, D. H., Meadows, D. L., Randers, I- and Behrens, W. W. (1972a). The Limits to Curowth, Universe Books, New York, USA.

- Meadows, D. H., Richardson, ., and Bruckrnann, C. (1982). Groping in the Darte: The first decade of global modelling; John Wiley \& sons, New York, USA.

- Meadows, D. L., Meadows, D. H, and Randers, I. (1972b). Dynamics of Growth in a Finitie World, Wright-Allen Press, Cambridge, UK.

- Mendelsohn, R, Morrison, W., Schlesinger, M., and Andronowa, NN. (1996). "Country-specific Market imparts of Climate Change, unpublished manuscript."

- Mermet, L. (1992). "Policy Exercises on Global environmental Probllems." Global Interdependence: Simulation and gaming perspectives, d. Crookall and K. Arai, eds., Springer, Tokyo, 216-222.

- Middellkoop, H., Rotmans, J., Kwadijk ${ }_{n}$ ). C. I. wan Deursen, W. P. A., and Konnen, G. P. (1998). "Integrated water management strategies for the Rhine and Meuse basins in a changing environment." NOP project destiption, The Netherlands.

- Mintzer, 1. (1987). "A Matter of Degrees: The potential for controlling the greenhouse effect." Research repart No. 5. World Resource Institute, Washington, USA.

- Morgan, M. G., and Dowlatabadi, H. (1996) "Learning from "ntegrated Assessment of Climate Change." Climatic Change(34), 337-368.

- Morita, T, Kaihuma, Y, Harasawa, $H_{\text {, }}$ Kail, K., Dong-Kun, $L_{\text {s, }}$ and Matsuoka, Y. (1994). "Asian-Pacific lntegrated Model for Evaluating Policy Options to Reduce GHG Emissions and Global Warming Impacts." "National Institute for Enwironmental Studies, Tskuba, Japan.

- Morita, T. Kainuma, M., Harasawa, H., Kai, K, Dong-Kun, L, and Matswoka, Y. (1995). "The Asian Pacific integrated model, what can it predict? A collection of AlM simulation results." , National Institute for Environmental Studies, Tskuba, Japan.

- Nökamp, P., Owwersloot, H., and Rienstra, S. A. (1997). "Sustainable Urban Transport Systems: an expert-based strategic scenario approach." Urban studies, Vol. 34, 693-712.

- Nordhaus, W. D. (1979). The Efficient Use of Energy Resources, Yale University Press, New Haven, USA.

- Northaus, W.D. (1992). "The DICE Model Background and Structure of a Dymamic Integrated Climate Economy." , Yale University, USA.

- Nordhans, W. D. (1994). Managing the Cilobal Cormmons. The Economics of Climate Change, MIT Press, Cambridge, USA.

- Nordhaus, W. D, and Popp, D. (1997) "What is the value of scientific knowledge? An application to global warming using the PRICE madell." Energy journal, 18(1), 1-45.

- Nordhaus, W. D. and Yang, Z. (1995). "RICE; a regional dynamic general equilibrium model of optimal climatechange policy.".

- Pah-Wostl, C., Jaeger, C. C., Rayner, S., Schaer, C, wan Asselt, M. B. A., Imboden, D., and Vckovski, A. (1998). "Regional Integrated Assessment and the Problem of lindeteminacy. Views from the Alps: Regional Perspec" tives on Climate Change, P. Cebon, U. Dahinden, H. C. Davies, D. Umboden, and C C. Jaeger, eds., MIT Press, Cambridge USA. $_{\text {A }}$.

- Parson, E. A. (1995). "Integrated Assessment and Environmental Policy Making: In the Pursuits of Usefuliness." Energy Policy, 23(4/5), 463-475. 
- Parson, E. A. (1996a). "How Should We Study Cilobal Environmental Problems: A plea for unconventional methods of assessment and synthesis." WP-96-157, hiternational Institute for Hoplied Systems Analysis (IIASA), Lawenburgig Austria

- Parson, E. A. (1996b) "Thnee Dilemmas in the Integrated Assessment of Climate Change." Climatic Change(34), $315-326$.

- Parson, E. A. (1997). "Informing global environmental policy-making: A plea for new methods of assessment and synthesis. Enwironmental Modelling and Assessmen, 2(4), 267-280.

- Parson, E. A ${ }_{x y}$ and Fisher-Vanden, K. (1997). "Integrated Assessment of Glabal Climate Change." Annual Review of Energy and the Enviromment, 22

- Parsons, W. (1995). Public policy: An introduction to the theory and practise of palicy analysis, Edward Elgar, Aldershot, USA.

- Peck, S. C., and Teiisberg, T. 1. (1992). "CETA: A Model for Carbon Emissions Trajectory Assessment." The Energy jountal, 13(1),55-77.

- Platform-on-Scieruce-and-Ethics. (1995). "Workshop reports on the societal debate on genetic research." W43, Rathenau institute $e_{n}$ The Hague, The Netherlands.

- Prinn, R. H. J., Sokolow, A., Wand, C., Xiao, X., Yang, Z, Eckaus, R., Stone, P, Ellerman, D., Melillo, J., Fitzmaurice, J. Kicklightiter, D., and Liu, Y. (1996). Integrated global system model for climate policy analysis, L: model frame. work and sensitivity situdies, Globall Change Center, Massachusetts Institute of Technology.

- Quade, E. S, and Carter, G. M. (1989). Analysisfor Public Decisions, North-Holland, New York, USA.

- Ravetz, \. R. (1997). "Integrated Envirommental Assessment Forum: Developing Guidelines for Good Practise." ULYSSES WP-97-1, Darmstadt University of Technology, Darmstadt, Germany.

- Renn, O., Webler, T., and Wiedemann, P. (eds.). (1995). Fiainess and Competence in Citizen participation, Kluwer Academic Publishers, Dardrecht, the Netherlands.

- Rijkens, IN. "The Participatory Dewelopment of a Thinkmodel for Regional Planning" Participatory Appraisal Workshop, Edinburgh, UK

- Risbey, 1., Kandlikar, M., and Patwardhan, A. (1996). "Assessing lintegrated Assessments" Climatic Change(34), 369-395.

- RIVM and ICIS. (1998). "The Green Heart in Broader Perspective: Initiation report scenarios and indicators for the visions workshop.", Maastricht.

- Robinson . 3. (1992). "Of maps and territories: The use and abuse of socio-economic modelling in support of decision making." Technological farecasting and social change(42), 147*164.

- Robinson, ). B. (ed.) (1996). Life in 2030: Exploring a sustainable future for Canada UBC Press, Vancouver, Canada.

- Rosenberg, N. J. (ed.) (1993). Towards ar Integrated Assessment of Climate Charge: The WHNK study, Kuwer Acadenics, Dordiecht, The Netherlands.

- Rothumar, D., Robirson, J, and Biggs, D. (1998 (in press)). "Signs of Life: Linking Indicators and Models in the Context of QUEST." Ecological Economics and Integrated Assessment: A participatary process for including equity, efficiency and scalle in decision-making for sustainability, R. Costanza and S. Tognetti, eds., SCOPE, Paris, France.

- Rotmans, 1. (1986). "The Development of a Simulation Modell for the Globall CO2 Problem (in Dutch)." 840751001, RIVM, Bitthowen, The Netherlamds.

- Rotmans, I. (1990). MACE: An integrated Model to Assess the Greenhouse Effect, Kluwer Academics, Dordrecht, The Netherlands.

- Rotmans. J. (1997). "Indicators for Sustainable Development." Perspectives on Global Change: The TARGETS approach, J. Rotmans and H. I. M. de Vries, eds, Cambridge University Press, Cambridge, UK.

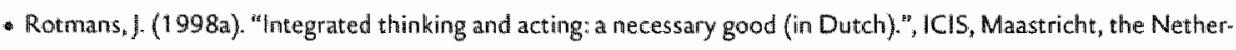
ands. 
- Rotmans, J. (1998b). "Methods for $\mid \mathrm{A}$. The challenges and opportumities ahead." Environmental Modeling ard Assessment, 3(3, Special issue: Challenges and Opportunitives for Integrated Environmental Assessment, J. Rotmans and P. Vellinga, eds. 1 , $155-179$.

- Rotinans, J., Anastasi, C, wan Asselt, M.B.A. Greeuw, S., Mellors, J, Peters, S., and Rothman, D. (1999) "WS1ONS for Europe" Interim Report, September, 1999. ICIS, Maastricht, the Netherlands.

- Rotmans, J, and de Vries, H. J. M. (eds.). (1997). Perspectives on Global Change: The TARGETS approach, Cambridge University Press, Cambridge, UK.

- Rotmans, I, and Dowlatabadi, H. (1998). "Integrated Assessment of Climate Change" Evaluation of Methods and Strategies." Human Choice and Climate Change: An international Social Science Assessment, S. Rayner and E. Malone, eds., Battelle Press, Washington ${ }^{\prime \prime}$ USA.

- Rotmans, 1. Hulme, M., and Downing, T. (1994). "Climate Change Implications for Europe: An Application of the ESCAPE Model." Global Environmental Change 4(2), $97-124$.

- Rotmans, J, and van Asselt, M. B. A. (1996). "Integrated Assessment: A growing child on its way to maturity." Climatic Change, $34(3-4), 327-336$.

- Rotmans, l, and van Asselt, M. B. A. (1999). "Perspectives on a Sustainable Future." International Journal for Sustainable Development, $1(3)$

- Rotmans, ل., and wam Asselt, M. B. A. (2000 (in press)). "Integrated Assessment: Current Practises and Challenges for the Future." Ecological Economics and Integrated Assessment: A participatory process for ineluding equity, efficiency and scale in decision-making for sustainability, R. Constanza and S. Tognetti, eds., SCOPE, Paris, France.

- Rotmans, J., van Asselt, M. B. A., and de Vries, H. ). M. (1997). "Global Change and Sustainable Devellopment." Perspectives on Clobal Change: The TARGETS, approach, J. Rotmans and H. ل. M. de Wries, eds, Cambridge University Press, Cambridge, UK.

- Rotmans, I., wan Asselt, M. B. A, Peters, S., and Mellors, J. (1999). "WISIONS Progress Report., "\#CIS, Maastricht.

- Rotmans, I., van Asselt, M.B.A., Anastasi, C., Greeuw, S., Mellors, J., Peters, 5., Rothrman, D. and Rijkens, N. (2000). "VISIONS for a sustainable Europe." Futures (in press).

- Sabatier, P. A. (1987). "Knowledge, policy-oriented learning and policy change. An advocacy coalition franthework" Knowledge: creation, diffusion, utilization, 8(4), 649-692.

- Sabatier P. A., and Jenkirss-Smith, H. C. (1993). Policy change and learning: an advocacy coalition approach, Westview Press, Boulder.

- Schneider, S. (1997) "Integrated Assessment Modeling of Climate Change: Transparent rationall tool for policy making or opaque screen hiding value-laden assumptions?" Environmental Modelling and Assessment, 2(4), $229-250$.

- Smith, D. (1997). Eurofutures: Five scenarios for the next millenmüum, Capstone Publishing Limited, Oxford, UK.

- Tol, R. S. . and Vellinga, P. (1998). "The European Forum on lntegrated Enwironmental Assessment." Environmen. tal Modelling and Assessmemt, 3 (3,5pecial issue: Challenges and Opportunities for Irntegrated Environmental Assessment, J. Rotmans and P. Vellinga, eds.), 181-191.

- Toth, F. L. (1988). "Policy Exercises." Simulation and Games, 19(Sieptember), 235-276.

- Toth, F. L. (1997). "Beyond Costs and Benefits of Climate change; A workshop overview." Cost-Benefit analyses of Climate Change: The broader perspective, F. L. Toth, ed., Birkhauser, Bael, $1-16$.

- Toth, F. L., and Hizsnyik, E. (1998). "Integrated Envirommental Assessment Methods: Evollution and applications." Enwironmental Modeling and Assessment, 3 (3, Special issue: Challenges and Opportunities for Integrated Environmental Assessment, J. Rotimans and P. Vallinga, eds.), 193-207.

- Toth, F. L., Kasemir, B., and Masing, V. (1998). "Climate Policy as a Business Opportunity for Vemture Capital in Europe." ULYSSES WP-98-2, Darmstadt University of Technology, Darmstadt, Germany.

- UN N-DPCSD. (1997). "Critical Trends: Global Change and Sustainable Development", Department for Policy Coordination and Sustalinable Development - United Mations, New York, USA. 
- UNEP. (1997). Globul Environmental Outlook, Oxford University Press, Oxford, UK

- van A.sselt, M. B. A. (1994). "Glotall Integrated Asgessment Models as Policy Support Tools: A Triangular Approach" "University of Twente, Enschede, the Netheriands.

- Van Asselt, M.8.A. Greeww, S., de Niet, Rotmans, J. (1999) "VISIONS for the Green Heart" Interim report, Sep. tember 1999. ICIS, Maastricht, and RIVM, Bithovem, The Netherlands.

- vam Asselt, M. B. A. Storms, C. A. H. M., Rijkens-Klomp, N., and Rotmans, J. (1998). "Towards Visions for a Sustainable Europe: An overview and assessmert of the last decade of European scenario studies." 198-E001, ICIS, Maastricht, the Netherlands.

- van Dalem, C. E.,Thissen, W. A. H., and Berk, M. M. (1997). "The Delft Process: Experiences with a dialogue between policy makers and global modellers. "R. Leernans and J. Alcamo, eds.

- van der Sluijis, J. P. (1997). "Anchoring amid uncertainty." "Utrecht University, Utrecht, the Netherlands.

- Van Eijndhoven, J. P. C. and Groenewegen, P. (1991). "The Construction of Expert Advise on Health Risks." Social Studies of Science, 21, 257-278.

- van Heffen, O. Maassen, P., and Rip, A. (1999). Social science: From desigm practise to design methodology, Twente University Press, Enschede, The Netherlands.

- van Latestejun. H. C. (1999). Land use in Europe, Sdu Uitgevers, The Hague, The Netherlands.

- van Vianen, H. A. W., Williekens, F. J., Hutter, I, van Asselt, M. B. A. Hillderink, H. B. M., Niessen, L. W., and Rotmans, 1. (1994). "Fertility Change: A Global lritegrated Perspective." RIVM-Report no. 461502008, National Insti. tute of Public Health and the Environment (RIVM), Bilthoven, The Netherlands.

- WEC, and IIASA. (1995). "Global energy perspectives to 2050 and beyond." WEC, London, UK.

- Weimer, D. L., and Vining, A. R. (1989). Policy Analysis: Concepts and Practise, Prentice Hall, Upper Saddle River, USA.

- Weingart, P. (1983). "Scientification of society - Politisation of science (inn German)." Zeitschrift fur Sozrologie, $12(3), 225-41$.

- Weyant, I., Davidson, O., Dowlatabadi, H., Edmonds, I., Grubb, M., Parson, E. A. Richels, R., Rotmans, l., Shukla, P, Tol, R. S. J, Cline, W., and Frankhauser, 5. (1996). "Integrated Assessment of Climate Change: An overview and comparison of approaches and results." Economic and Social Dimensions of Climate Change, J. P. Biruce, H. Lee, and E. F. Haites, eds., IPCC, Cambridge University Press, Cambridge, UK.

- Wirnsemitus, P. (1986). Gwest at Home: Views on emwironmental management (in Dutch), Samson Tjeenk Willink, Alphen aan de Rijn, the Netherlands.

- WRR. (1992), Ground for choices: four perspectives for the rural areas in the European Community (in Dutch), Sdu Uitgevers, The Hague, The Netherlands.

- WRR (1998). State withow Land (in Dutch), Sdu Uitgevers, The Hague, The Netherlands. 


\section{Uncertainty $^{1}$}

Much has been said and written about what the public expects from science: resolving, or at least reducing, uncertainty. Scientists are requested to give definite answers to societal questions. There are simple and one-dimensional questions that can be unambiguously answered by science, such as effects of smoking on lung functions. However, the majority of urgent societal questions pertain to complex issues, such as increasing poverty, climate change and European integration. Such complex issues involve inherent uncertainty. Scientists are, for example, unable to give confident answers about the magnitude of global climate change or even whether a region will warm or cool. Uncertainty thus has major political and ethical impacts, as the need to decide whether or not to act, as well as what kind of action to take, requires deciding about uncertainty ${ }^{2}$.

Uncertainty in science has led to much confusion among the public ${ }^{3}$. Due to inherent uncertainty, scientists come up with different recommendations to decision-making in accordance with their particular argumentation ${ }^{4}$. Confronted with scientific disagreement, the common public reaction is distrust in science. Citizens conclude that scientists contradict each other, and they feel misled ${ }^{5}$. In its extreme form, such emotions may result in the conclusion that science has no value at all. Jasanoff $f^{6}$ points out that the unproductive response is that scientists are invited to press the evidence to produce levels of precision that cannot be supported. This societal pressure causes that scientists, recognising the uncertainty in their study of (aspects of) complex issues, feel forced to conceal what is unknown or indeterminate.

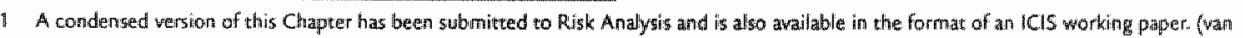
Asselt 1999) 
The gap between what society expects and what science can provide hampers the interaction berween science and society. Facilitating this interplay is the central task of all branches of science for decision-making, including Integrated Assessment. The current Chapter discusses the issue of uncertainty and its implications for decision-support. The aim of the Chapter is to develop concrete ideas for management of

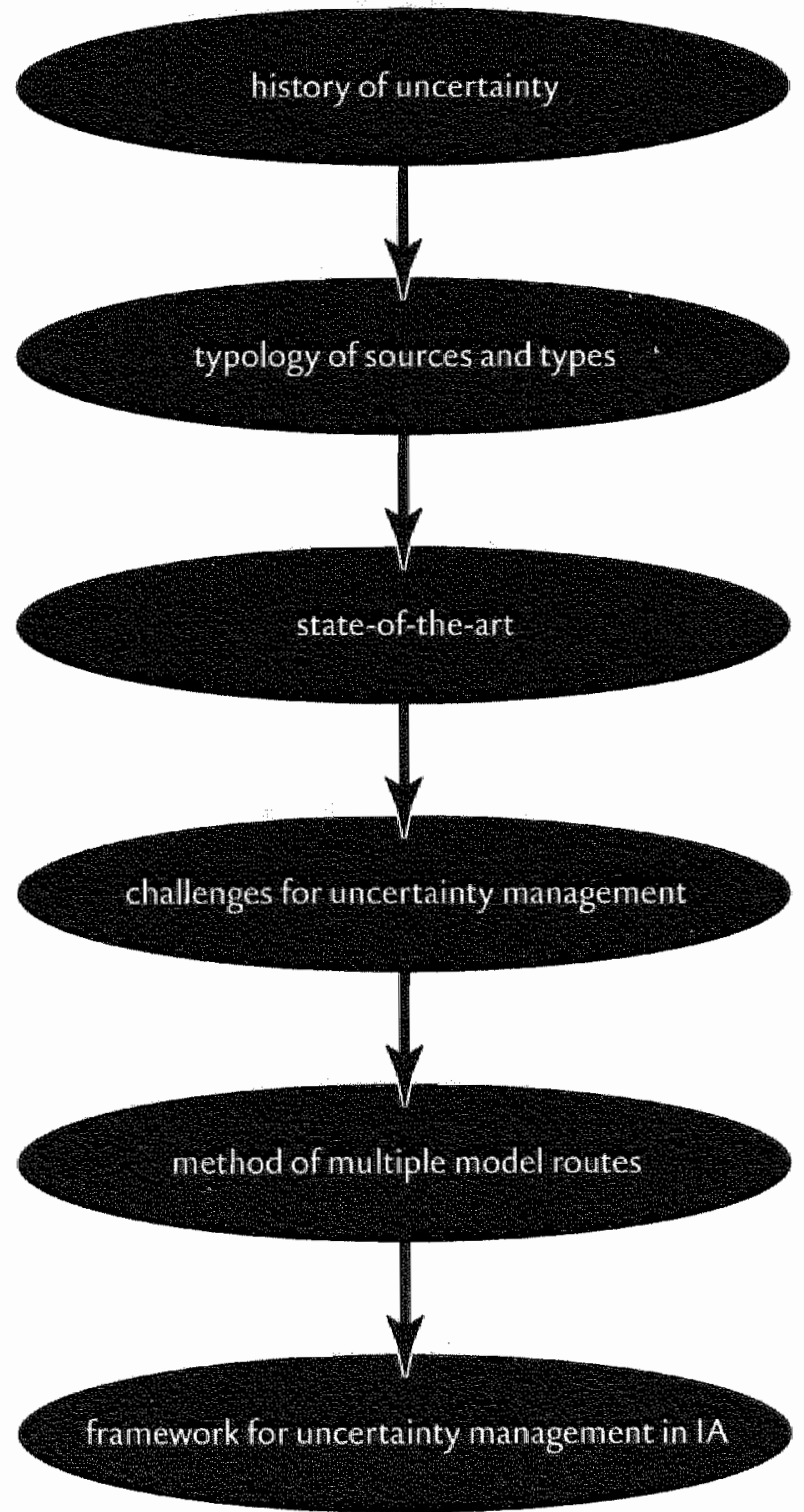


inherent uncertainty in Integrated Assessment. To this end, the following steps are taken:

- The role of science and the issue of uncertainty are put in a broader, historical context.

- The various types and sources of uncertainty are identified and synthesised into a typology.

- The state of the art in uncertainty analysis applied in Integrated Assessment activities is discussed. The tension between prevalent types and sources of uncertainty and the scope of the current approaches for uncertainty analysis is addressed.

- Crucial challenges for management and communication of uncertainty are identified.

- A new approach to uncertainty management in Integrated Assessment, i.e. perspective-based multiple model routes, is discussed in the context of these chall. lenges.

- A framework for uncertainty management is sketched, which enables us to address the various types and sources of uncertainty in a systematic way.

The structure of our attempt to develop a sound methodology for uncertainty management is summarised in Figure $\mathbb{I}$.

\section{Uncertainty in a historical perspective}

What are the tasks and aims of science in the light of the contradistinction certaintyuncertainty? 'This issue has bothered thinkers and academics ever since intellectual activities are part of society. It is beyond the scope of this Chapter to give a comprehensive overview of the development of ideas pertaining to science and uncertainty since the Greek philosophers. We restrict ourselves to describe milestones in this evolution in a nutshell.

\subsection{THE ENLIGHTENMENT}

The rolle ascribed to science as the "provider of certainty" is deeply influenced by the epistemology ${ }^{7}$ of what is known as the Enlightenment or the Age of Reason. The

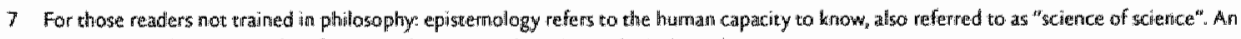
atcitude towards science is therefore rooted in a particular epistemalogical stand. 
notion 'Enlightenment' came into use by the end of the $18^{\text {th }}$ century ${ }^{8}$. Enlightenment thinking traces back to $17^{\text {th }}$ and $18^{\text {th }}$ century thinkers in Europe, especially in England (Freethinkers, esp. Locke), in France (Encyclopedists, esp. Diderot, Voltaire, Rousseau and d'Alembert) and in Germany (esp. Kant and Hegel). In a certain sense, Enlightenment thinking built upon the theories of Descartes (1596-I650). Descartes' plea for methodological examination of knowledge before the "forum of Reason" marked a clear break with medieval religious thinking. The Enlightenment movement has carried forward this ideal of systematic investigation. Reason and objectivity are the key values associated with the Enlightenment movement. The imperative is to draw a fixed boundary between the objective realm of facts and the subjective realm of opinions. The conviction is that systematic inquiry using mathematical and quantitative methods will lead to certain knowledge about reality. In other words, science, if conducted in the right way, yields the truth.

Enlightenment thinking grew into what is generally referred to as 'positivism'. Positivisn can be defined as the search for, and prediction of, empirical regularities to make universal, true statements. The quantitative method of natural science is the adopted approach to gather objective knowledge. In the positivist epistemology, uncertainty is considered as something unscientific ${ }^{10}$. These positivist absolutisms have dominated science far into the $20^{\text {th }}$ century.

\section{I.2. THE CRISIS OF POSITIVISM}

Notwithstanding the dominance of the positivist values in the last three centuries, it is important to realise that these epistemological principles have always been questioned. The most important dissident in the $18^{\text {th }}$ century was Hume (171-1776). He attacked the thesis that empirical observations and rational investigations lead to true knowledge. His conclusion was that the gap between observations and reality could not be bridged by reason. The pretensions of true knowledge were even challenged within the Enlightenment movement itself. The German variant, of which Hegel ( $1770-1831$ ) was the most important representative, argued that systematic inquiry leads to knowledge, but not to perfect and complete knowledge.

The first major crisis of positivism was in mathematics. By the beginning of the $20^{\text {th }}$ century, contradictions at the logical foundations of mathematics were revealled. 
The emergence of statistical mechanics at the beginning of this century enhanced some serious study of uncertainty and its role in science. In r905 Einstein proposed his 'new physics', in which the basic concepts of science, i.e. time, space and mass, are relative, instead of absolute, notions. Notwithstanding these developments, positivism remained the dominant paradigm in guiding scientific endeavours.

However, in the second half of the $20^{\text {th }}$ century, the positivist approach to science was more, and more strongly, criticised. The hegemony of the natural science method was questioned from both philosophy and the social sciences. An early publication that also played a key role in this dethroning process is the seminal work "Risk, uncertainty and profit" ence are thoroughly discussed. What can be called 'the sceptical crisis ${ }^{\text {t2 }}$ was initiated in the turbulent 1960 s. The most extreme antagonists of positivist epistemology, which can be grouped as 'conventionalists' or 'subjectivists', hold that knowledge is nothing but 'conventions' of what given groups of scholars deem to be 'true'. Two influential anti-positivist movements are post-modernism and social-constructivism. Post-modernism originates from philosophy, while social constructivism has its origins in sociological studies of science and technology.

\section{I.3. POST-MODERNISM}

Post-modernism ${ }^{13}$ can be considered as the most extreme attack on the Enlightenment project. Foucault (1926-1984) and Derrida (1930-) are the most important representatives of this school of thought. They both build upon work of Nietzsche (1844-1900) and Heidegger (1889-1976). Post-modernism denies the possibility of any certain knowledge. Post-modernists question the ability to represent reality in any objective manner. The search for truth is an illusion. The post-modernist argument is that reality is not directly available to us. Facts do not present themselves directly to the investigators. Post-modernists argue that scientists pick and choose among them, guided by ideological presuppositions. Scientists do not discover as the positivists have it, but they invent. Post-modernism furthermore deconstructs central authority, which implies the loss of a central perspective. Post-modernists challenge all endeavours to explain processes and events, and, in doing so, they undermine the traditional claims in both natural and social sciences. If post-modern claims 
are taken to the extreme, there are no grounds for systematic investigation, analysis and interpretation.

\subsection{SOCIAL-CONSTRUCTIVISM}

Social constructivism ${ }^{14}$ challenges the positivist claim that scientific knowledge can be produced according to purely rational, cognitive factors. Social constructivism claims that the production of science is a social process. Scientific knowledge is constructed and negotiated. Empirical underpinning for this claim is found in historical studies $^{15}$ and laboratory ethnographies ${ }^{16}$. Rationality is defined by the beliefs of a specific discipline or scientific community, and thereby socio-cultural. Social constructivist epistemology can be deduced to the following theses ${ }^{17}$ :

- What knowledge is produced and how it is to be used are socially driven decisions. Social factors play a large role in the direction of research, the drawing of boundaries between acceptable and unacceptable, relevant and irrelevant research, and so on.

- Key processes in theory building such as consensus formation, assessments of credibility, the acceptance and rejection of theories are entirely social.

- What scientists expect to observe, are able to observe, and want to observe are outcomes of social negotiations.

- There is no single scientific method to which all scientists can refer. Decisions on appropriate methods are influenced by social factors such as rhetoric, politics, disciplinary cultures, and personal reputations.

Social constructivism argues that it is possible to distinguish between valid and invalid scientific statements, but the criteria for making such judgements cannot be derived from an "abstract and universal faculty of reason", but have to be sociallyconstructed.

\footnotetext{
14 See for an overview (lasanoff and Wynne 1998; Knoir-Cetina and Mellkay 1983; Pickering 1992). The jowrnal associated with this selwool of though is Social Studies of Science.

15 E.g. (Barnes and 5hapin 1979)

16 E.g. (Larour and Woolgar 1979)

17 Compare (Hess 1995)

18 (Hess 1995 )
} 


\section{I.5. FACING INHERENT UNCERTAINTY}

Both post-modernism and social constructivism raise interesting questions about truth, objectivity and certainty. They have helped to (re)vitalise discussions about methods, goals and the foundation of science. The main messages propagated by these conventionalist movements are:

- Science is not a purely objective, value-free activity of discovery: science is a creative process in which social and individual values interfere with observation, analysis and interpretation.

- Knowledge is not equivalent to truth and certainty.

The above principles have dethroned the absolutisms that have reigned since the Enlightenment ${ }^{\text {ts }}$.

We have to realise that uncertainty is not simply the absence of knowledge. Uncertainty can still prevail in situations where a lot of information is available. Furthermore, new information can either decrease or increase uncertainty. New knowledge on complex processes may reveal the presence of uncertainties that were previously unknown or were understated. In this way, more knowledge illuminates that our understanding is more limited or that the processes are more complex than thought before. In other words, more knowledge does not mean less uncertainty and vice versa.

Heisenberg explained another dimension of the problematic relationship between knowledge and uncertainty. His uncertainty principle ${ }^{20}$ has it that:

We could not, in fact, obtain all the information we need, since the act of getting information often changes the phenomena being studied.

No amount of information will ever be able to entirely eliminate uncertainty. Or as Shackle phrased it in his theory of "unknowledge "21: "There would be no uncertainty if a question could be answered by seeking additional knowledge. The fundamental imperfection of knowledge is the essence of uncertainty". In other words, there are inherent limitations to the reduction of uncer tainty ${ }^{22}$.

The notion that scientific knowledge is inherently imperfect is becoming more common. The fundamental role of uncertainty in science is more broadly recognised, both in the disciplines reflecting on knowledge and scientific practice, and in

19 See also (Nowotry 1993).

20 (Heisenberg 1962)

21 (Stackle 1955)

22. (Funtowicz and Ravetz 1 993a) 
the disciplines that aim to describe and explore reality. The interest in uncertanty is enhanced by the recognition that the world around us is becoming more and more complex ${ }^{23}$. There are different causes for this increasing complexicy ${ }^{24}$ :

- increase in scale: global and international processes increasingly interact with developments on the national and regional scale, and vice versa.

\section{- technologicaldevelopments}

- acceleration of processes, implying that turnover rates decrease.

The resulting web of social, economic, technological and environmental processes forms a complex system that is beser with new uncertainties.

In such a situation of inherent uncertainty and imperfect knowledge, truth is not what science can deliver to the public. In such cases, "it seems that the only certain aspect of science is that it is uncertain" ${ }^{* 25}$. The aim of prediction is eroded. On the other hand, if reality were fully indeterminate, there would be no grounds for scientific investigation. "The adage that "most phenomena and occurrences have one or more causes" is the basic principle of science. In the light of uncertainty, this implies that plausibility of scientific explanations and claims is the key issue.

Practitioners in science for decision-support in general and Integrated Assessment in particular, realise that uncertainty is and will be central to their endeavours. This increasing interest in uncertainty in the Integrated Assessment community is, for example, revealed by the international workshop on uncertainty organised by the European Forum on Integrated Environmental Assessment (summer 1999).

\section{Typology of uncertainty}

In order to be able to consider uncertainty as a challenge for science in general and for scientific decision-support in particular, it is necessary to analyse sources and types of uncertainty. Such an understanding of uncertainty is needed to be able to distinguish berween highly uncertain and less uncertain issues ${ }^{26}$, as well as to understand which types and sources of uncertainty pertain to particular decision-making issues.

23 (Geck 1986; Rotmans 1998 a)

24 (Rotmans 7998 )" see also Chapher 1.

25 (Rolnen 19.88 )

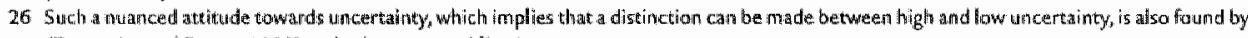
(Funtewisz and Ravetz 1990) and subsequent problications. 
A better understanding of uncertainty and how uncertainty is dealt with analytically is a prerequisite for improved decision-support in situations with high uncertainty. Below various characterisations and classifications of uncertainty are discussed, which are synthesised into a typology of uncertainty.

\section{I. TRANS-SCIENTIFIC QUESTIONS}

Weinberg ${ }^{27}$ addressed uncertainty by identifying societal questions that cannot unambiguously be answered by science and thus 'transcend' science, i.e.:

- Questions that require impracticably expensive or lengthy, or even impossible experiments.

- Questions that refer to human behaviour.

- Questions pertaining to the future.

- Questions that involve value judgements.

These trans-scientific questions are unanswerable due to inherent uncertainty ${ }^{28}$. A closer look at these questions yields which sources of uncertainty complicate scientific investigation. The first type of question refers to cases for which necessary historical records or monitoring systems are lacking to fulfil data-requirements and to cases being too abstract or too demanding to satisfy empirical needs. This holds for example for open systems, such as the global biosphere, which do no allow for controlled experiments.

The second type of question is unanswerable, because the behaviour of human beings does not allow such a strict rationalisation as the behaviour of atoms and molecules does. There is inherent uncertainty with respect to the adaptive and innovative capability of humans.

Questions pertaining to the future, i.e. the third type of question, are unanswerable, because there is always uncertainty in extrapolating current knowledge to new and untried circumstances. For example, natural systems may adlapt to changes.

27 (Weönberig 1972)

28 (Funtowice and Ravetz 1993a) argued that Weinberg's demarcation criterion was ane of seala, te. the feasibility of a project in relation to

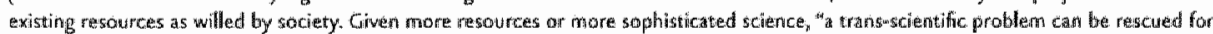

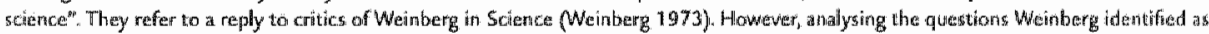

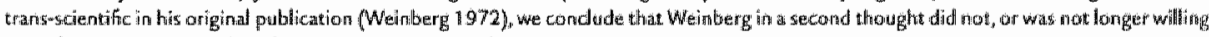

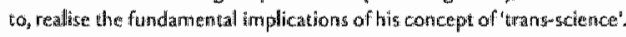

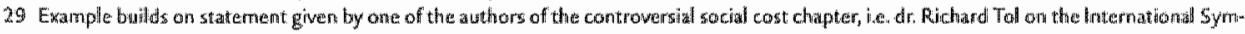

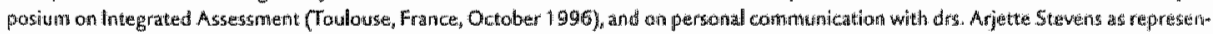

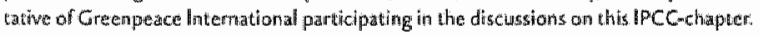


to estimate the social costs of climate change. To that end, estimates of the monetary value of human lives were used to express anticipated loss of lives in dollars. According to these estimates, human life in developed countries is worth more dollars than a human life in developing countries. A similar difference can be observed berween the estimates in dollars for male versus female lives. Societal actors heavily attacked this scientific 'answer' to a societal question. Estimating human life involves value judgement that cannot simply be solved in an objective manner in a monetary exercise by economists ${ }^{30}$. This example shows how diversity in values contributes to uncertainty in scientific endeavours. This type of trans-scientific questions shows similarities with what Hisschemöller and Hoppe ${ }^{31}$ call 'unstructured problems'.

Issues dealt with in science for decision-making are usually trans-scientific $c^{32}$. Although the issue of uncertainty pertains to science in general, our focus will be on the scientific analysis of trans-scientific issues with an explicit decision-support purpose.

\subsection{SOURCES AND TYPES OF UNCERTAINTY}

It can be argued that uncertainty as such does not exist, but it only exists through human mediation. Whether uncertainty is taken as a factual or as a social construction, it is nevertheless interesting to try to understand the origins of uncertainty. Just as scientists investigate the sources of climate change, we would like to investigate the sources of uncertainty to explain why uncertainty occurs in scientific decisionsupport on complex, trans-scientific issues. We aim at a comprehensive taxonomy of sources of uncertainty, in the sense that no important class of sources is overlooked. The latter means that any source of uncertainty that cannot be traced to the generic sources of uncertainty should not be found in any empirical decision-support case. A proposed taxonomy of sources of uncertainty can thus in principle be falsified by empirical testing. In other words, it is legitimate to hypothesise that a taxonomy of sources can be universally valid. Our aim is to develop such a universally valid taxonomy that can serve as a benchmark in analysing particular and concrete sources of uncertainty in actual decision-support.

In developing a kind of taxonomy of uncertainty the difference between source and type of uncertainty matters. "Source" refers to the origin of uncertainty, which

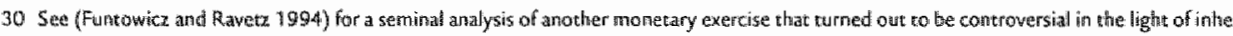
eqte uncertainay.

31 (Hisschem diller and Hoppe il 996)

32 Compare (jasianoff and Wynne 1998 )
} 
implies that such a classification is preferably universally valid. "Type" refers to the way in which uncertainty manifests itself in a particular context. The consequence is that any typology of types of uncertainty is by definition context-dependent or method-dependent. A typology of types of uncertainty can help in decision-support endeavours to single out in which step of the analysis, in which part of the model, in which component of the relevant issue, and in which phase of a process uncertainty may be expected. A typology of types of uncertainty can thus never be falsified; its potential usefulness for the quality of the practise of decision-support can only be tested through use and best practise examples.

The aim of our research on the concept of uncertainty is to develop a generic taxonomy of sources of uncertainty and to provide some examples of typologies of types of uncertainty that may be relevant and useful in the context of decision-support in general, and Integrated Assessment in particular.

\subsection{SOURCES OF UNCERTAINTY}

From the above analysis of trans-scientific questions, it can be concluded that there are various sources of uncertainty prevalent in the science for decision-support. Building upon a recent inventory of classifications of uncertainty ${ }^{3.3}$ and our own review of the scholarly literature on uncertainty, we conclude that on the highest level of aggregation the two major sources of uncertainty are $\mathrm{e}^{34}$;

- wariability, also referred to as 'objective uncertainty"35, 'stochastic uncertainty" ${ }^{36}$, 'primary uncertaincy ${ }^{137}$, "external uncertainty"3, or 'random uncertainty"39; the system/process can behave in different ways or is valued differently. Variability is an attribute of reality.

- lack of knowledge, also referred to as "subjective uncertainty" , "incompleteness of the information" "informative uncertainty" " "secondary uncertainty" or "internal uncertainty" ${ }^{44}$. Lack of knowledge is a property of the analysts" performing the study and/or of our state of knowledge.

\footnotetext{
33 (van der Sluijs 1997)

34 Compare (Hof fman and Hammonds 199.4)

35 (Natke and Ben-Hiam 996 )

36. (Helton 1994 )

37 (Koophonans 1957)

38. (Kanturman and Tversky 1982)

39. (Henrion and Fischhoff 1988 )

40. (Helton 1994; Narke and Ben-Haim 1996)

41 (won Schomberg 1993 )

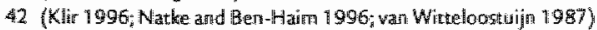

43 (Koopmans 1957)

44. (Kahrueman and Tversky 1992 )
} 
Uncertainty thus has both an ontological ${ }^{45}$ (variability) and an epistemological ${ }^{46}$ (lack of knowledge) dimension. As a consequence, there are theoretical and practical limitations to the reduction of uncertainty.

Different sources of variability can be distinguished, i.e. ${ }^{47}$ :

- inherent randomness of nature ${ }^{48}$ (natural randomness)

- value diversity ${ }^{49}$ (cognitive variety)

- human behaviour (behavioural variety)

- social, economic and cultural dynamics ${ }^{50}$ (societal randomness)

- technological surprises (technological randomness)

Variability as defined by the above sources goes beyond established seasonalities. Due to variability, reality inhibits inherent uncertainty and unpredictability. As such, it contributes the to lack of knowledge, because due to variability perfect, certain knowledge is unattainable in any event. Variability, especially if it is random, can thus be considered as a source of inherent lack of knowledge.

Lack of knowledge is partly a result of variability, but knowledge with regard to deter ministic processes can also be incomplete. There are different degrees of lack of knowledge. A continuum can be described that ranges from inexactness to irreducible ignorance:

- inexactness ${ }^{51}$, also referred to as metrical uncertainty ${ }^{52}$, measurement errors ${ }^{53}$, or precise uncertainties ${ }^{54}$. "We roughly know".

- lack of observations or measurements: the data could have been collected, but have not been. "We could have known".

- practically immeasurable: the data can in principle be measured, but it is not practical to do so (too expensive, too lengthy). "We know what we do not know".

- conflicting evidences: different data sets are available and can be interpreted in competing manners. "We do not know what we know".

45 concerning the gutenerial properties of objects

46 concerning the human ability to know.

4) campare (Rowe 1994)

48 see also (Morgan and Henrion 1990 , also referred to as (unnobserved) seasonal thies (van Wlimmerery tet 1991)

49 allso referred to ass subjective judgement: and di sagreement. (Morgan and Herairion 1990) or moral uncertainties (de Marthi 1995).

So The need to consider societal and institutional processes als a major contributer to uncertainty due to variability can be inferred from various: papers of Funtowict, Rawietz and de Marchi. See for example: (de Marchi 1995; de Marchi et al. 19933).

51 (Funtowica and Ravera 1990; Zinmermann 1996). The dassical theory of measuring errors postulated by Gauss (1777-1855) has it thath ewery ine asturement of a physical quantity is affected by measiring errors of a random character, which are unknown.

52. E. [Rowe 1994)

53 e.g. (Beck 1987; var Vlirnmeren et al. 1991 )

54 eford (Wallsten 1990)

55 (Zimmernann 1996). 
- reducible $t_{3}$ norance ${ }^{36}$ : there may be processes and interactions between processes out there that we do not observe, nor theoretically imagine at this point of time, but probably in the future. "We do not know what we do not know".

- indeterminacy ${ }^{57}$ : there may be processes of which we understand the principles and laws, but which can never be fully predicted. "We will never know".

- irreducible ignorance ${ }^{58}$ : there may be processes and interactions between processes that cannot be (or not unambiguously) determined by human capacities and capabilities. "We cannot know".

The first three degrees of lack of knowledge (i.e. inexactness, lack of observations/ measurements and practically immeasurable) are also referred to as unreliability The latter four degrees are also referred to as structural uncertainty ${ }^{60}$ or systematic uncertainty ${ }^{61}$,

The hierarchy of sources and degrees of uncertainty is visualised in Figure 2.

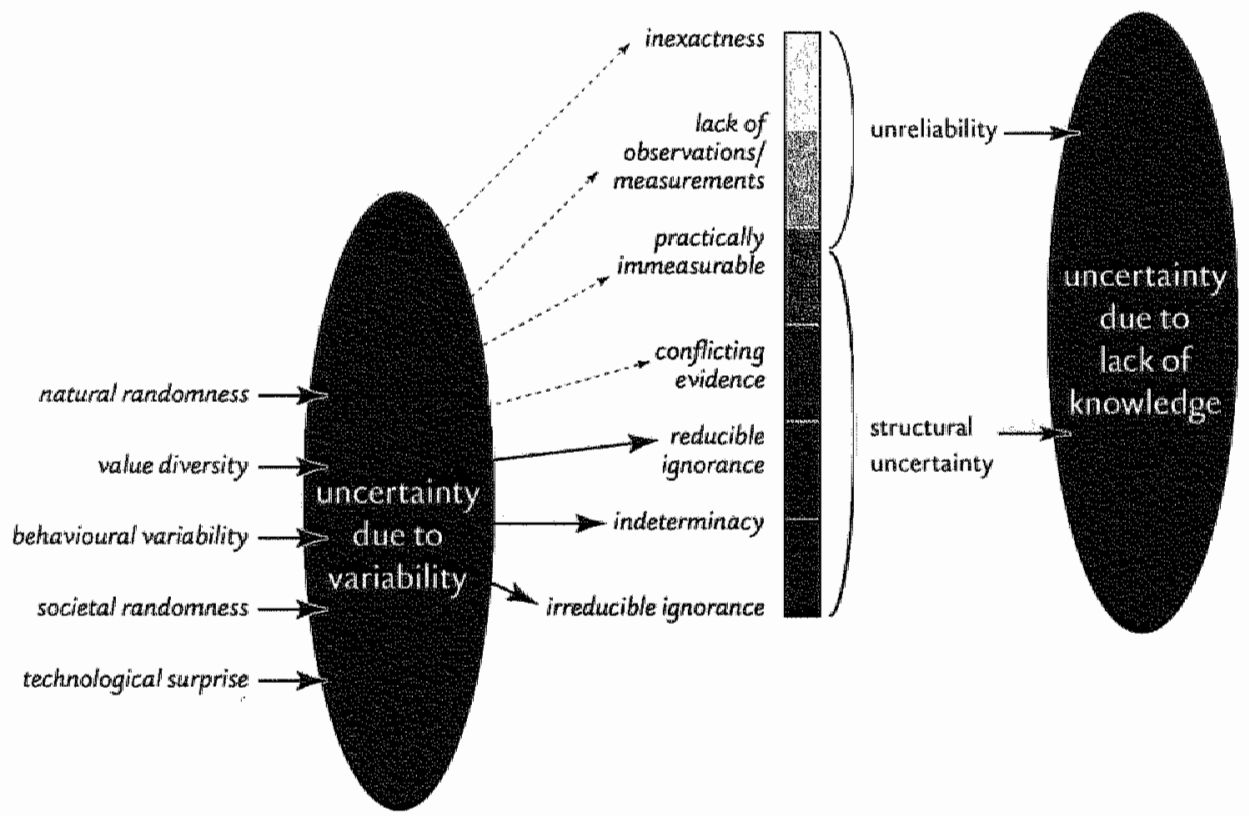

PICURE 2 Typology of sources of uncertainty

56 (Funtrwica and Raverz 1990, Wynnes 7992)

57 e.gis (Wrane 1992 )

58 lowe the distinction between reducibie and irreducible ignorance to a fascinating discussion with, amnorag others, Sreve Manson, Brian Narton and Jan Roumans.

59 e.g. (Fubtowica and Ravetx 1990 )

60 e.g. (Rowe 1994 )

61 ex. (Hemrion and Fischhoff 1986 ; Morgan and Helntion 1990) 
In sum, uncertainty can be defined as the entire set of beliefs or doubts that stems from our limited knowledge of the past and the present (esp. uncertainty due to lack of knowledge) and our inability to predict future events, outcomes and consequences (esp. uncertainty due to variability) ${ }^{62}$.

\subsection{TYPES OF UNCERTAINTY}

Due to variability and lack of knowledge, both our understanding of processes, past and present states of the relevant complex system and our predictive capability in terms of future states are limited. The knowledge of a system or issue is quite often described by means of a model, which can be a theory, a conceptual model, a mathematical model, an optimisation model or a computer simulation model. The latter three types of models can be clustered to 'formal models'. Due to inherent uncertainty, no framing of the issue is neutral, nor are models. However, downplaying the usefulness of models as structuring devices by claiming that modelling by definition denies the essence of uncertainty, as Jasanoff and Wynne $e^{6_{3}}$ do, is throwing away the baby with the bath water. A more constructive approach would be to analyse how uncertainty materialises in modelling.

Uncertainty enters warious steps of the modelling process. One way to describe how uncertainty manifest itself in modelling is by means of the following classification of types of uncertainty ${ }^{64}$ :

- technical uncertainties

- methodological uncertainties

- epistemological uncertainties

These three types of uncertainty imply different levels of uncertainty as is visualised in Figure 3.

Technical uncertainties arise from the quality or appropriateness of the data used to describe the system, from aggregation ${ }^{65}$ (temporal and spatial) and simplification as well as from lack of data and approximation. In other words, technical uncertainties primarily result from uncertainty due to unreliability. Due to lack of knowledge, methodological uncertainties arise. In case of such inherent uncertainty, what analytical tools and methods are appropriate? In view of incomplete understanding of the processes, how does one model causall relationships? What is an adequate frame 


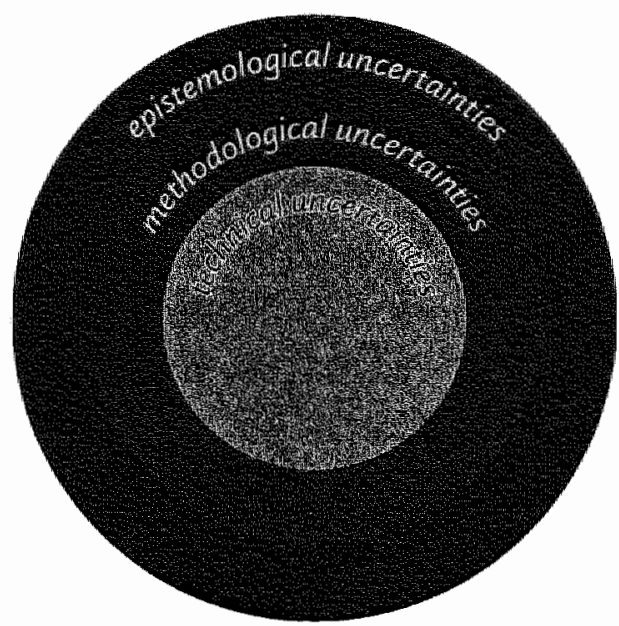

FICURE 3 Levels of uncertainty

to structure what we know and what is uncertain? How to interpret the uncertainties? Epistemological uncertainties concern the conception of a phenomenon. This type of uncertainty arises from structural uncertainty and variability. The key question with regard to this type of uncertainty is whether the description, theory or model relates to the real, variable world.

In formal modelling, technical, methodological and epistemological uncertainties materialise as ${ }^{66}$ uncertainties in model quantities, uncertainty about model form ${ }^{67}$ and uncertainty about model completeness/adequacy of the model ${ }^{6.8}$ respectively (see also Figure 4). Parameters, inputs and initial states ${ }^{69}$ are uncertain model quantities. Uncertainty about model form comprises uncertainty pertaining to model structure, uncertainties about the functional relationships ${ }^{70}$ and uncertainties with regard to the choice of algorithms. Uncertainty abour model completeness is the most fundamental and crucial for the quality of the model. Uncertainty about model completeness is addressed in the validation phase ${ }^{71}$. However, complete validation is impossible in case of complex systems due to inherent uncertainty (especially due to ignorance and indeterminacy) ${ }^{72}$. To express the limits to validation exercises, model validation is also referred to as testing model performance ${ }^{7 x}$. A fourth rype of uncertainty relevant in formal modelling

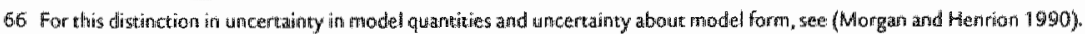

6.7 Compare (Alcamo and Bartricki 1987 ; (aeck 1987).

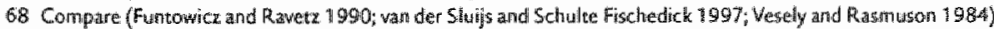

69 See (Alcamo and Bartmicki 1987 ;Beck 1987 ; Morgan and Hentrion 1990)

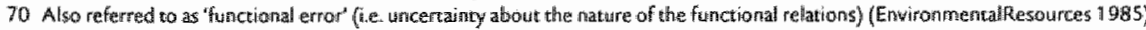

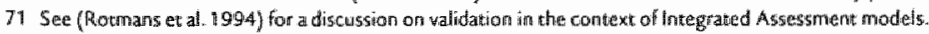

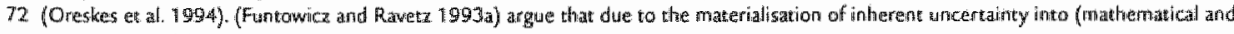

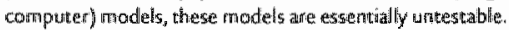

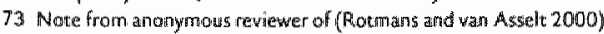


includes so-called model operation uncertainties ${ }^{74}$. These uncertainties occur partly due to the hidden flaws in the technical equipment (especially numerical errors and bugs in hard-and software ${ }^{75}$ ), but above all due to accumulation of uncertainties propagated through the model ${ }^{\text {th }}$.

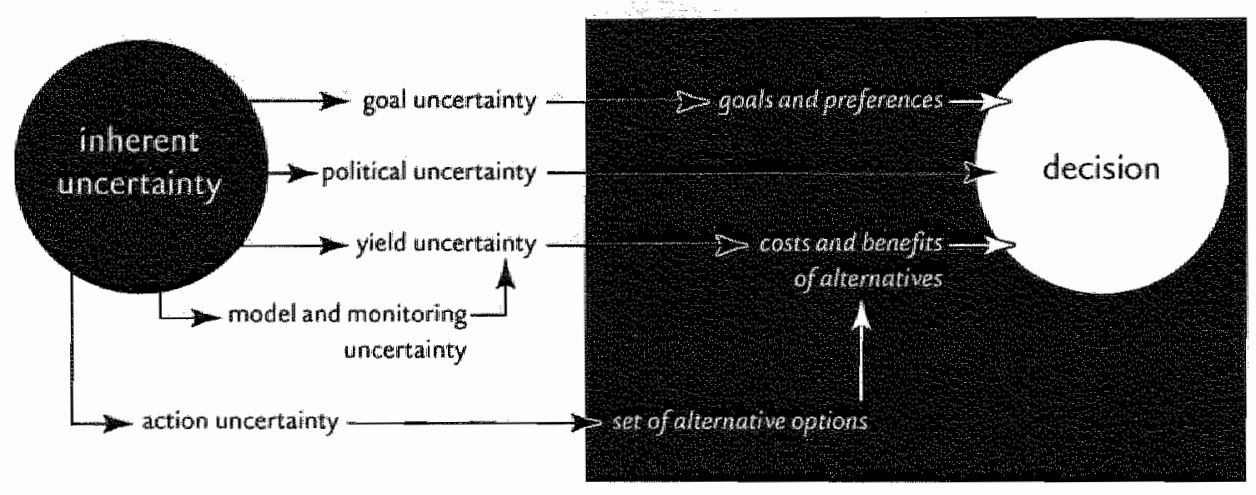

FHGURE 4 Uncertainty in the decision-making process

Another typology of uncertainty relevant in the context of science for decisionsupport is a classification of uncertainty by its focus in the decision-making process ${ }^{77}$ (see Figure 4 and 5). Due to inherent uncertainty, a decision-maker may be uncertain with respect to the composition of the set of alternative options ${ }^{78}$ (action uncertainty) and the costs and benefits of those alternatives ${ }^{79}$ (yield uncertainty ${ }^{80}$ ). Model and moniroring uncertainty, i.e. the decision-makers' doubt on the validity of the model and the data sets that they employ, may contribute to yield uncertainty. Another focus of uncertainty relevant in the decision-making process is goal uncertainty ${ }^{{ }^{8}}$, i.e. uncertainty or ambiguity about the preferences or goals the decision-maker aims to satisfy. Because there are so many conflicting objectives, priorities and interests, there is furthermore political uncertainty ${ }^{\mathrm{y}_{2}}$ complicating decision-making. Political uncertainty means that the decision-maker struggles with uncertainty as to the political acceptability of options in the relevant decision-forum ${ }^{8_{3}}$.

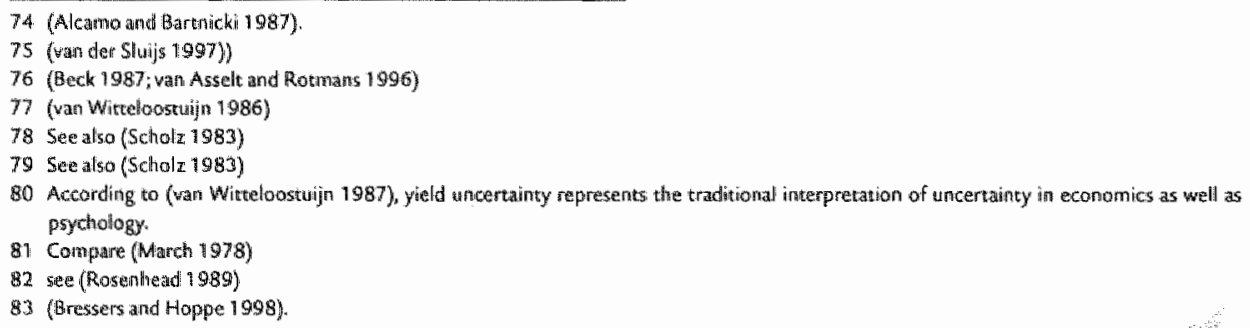


modellers

decision-makers"

view on uncertainty

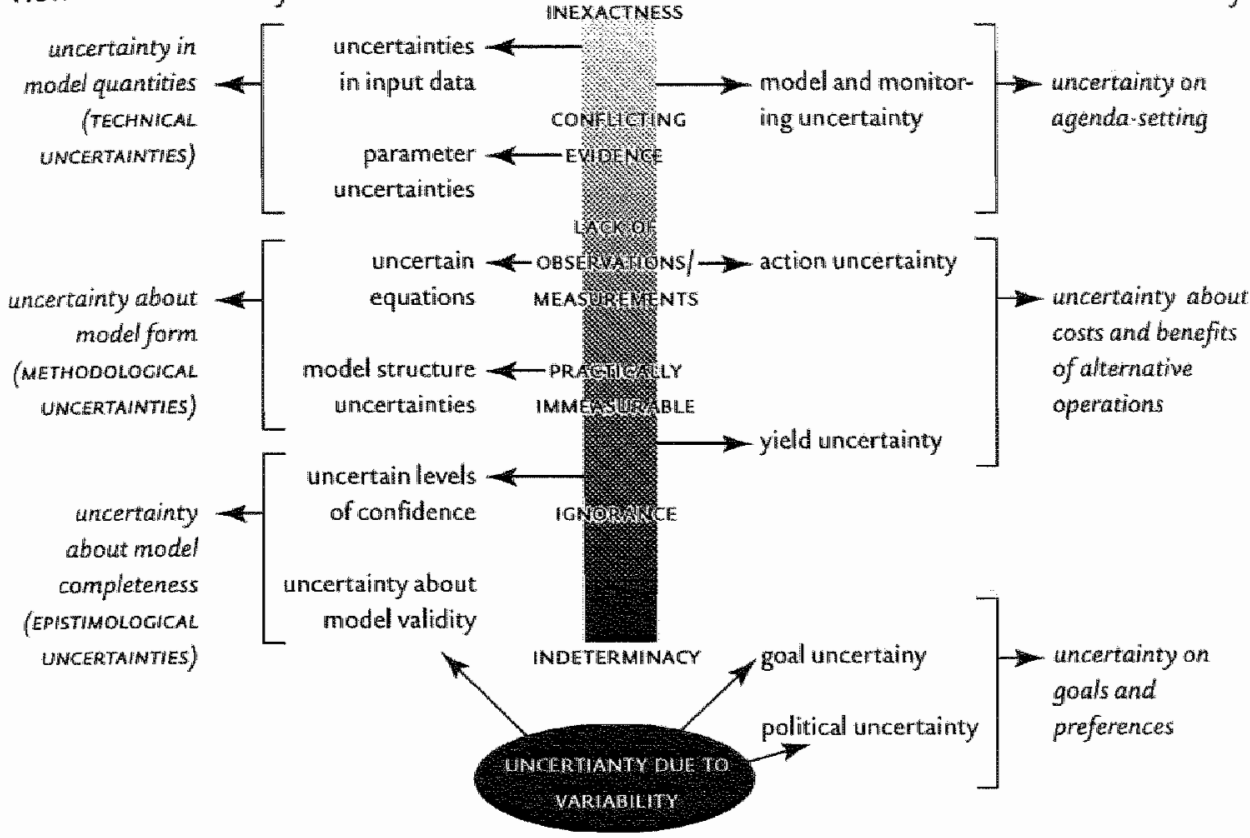

FIGUREE 5 Uncertainty in the modeller"s and decision-makers view

Various types of uncertainty in decision-making ${ }^{84}$ may play a different role in the decision-making cycle ${ }^{85}$. Model and monitoring uncertainties are usually dominant in the ignition and agenda setting phase. Action and yield uncertainties may play a vital role in the assessment phase, while political uncertainties dominate in the actual decision-making process.

\subsection{UNCERTAINTY, MEASURABILITY AND SUBJECTIVITY}

Some uncertainties are measurable ${ }^{86}$ and can be calculated, in the sense that they stem from well-understood systems or processes ${ }^{87}$. These uncertainties generally fall into the categories of technical uncertainties and uncertainty due to unreliability. This implies that either margins (in case of unreliability) or seasonalities can be established, so that

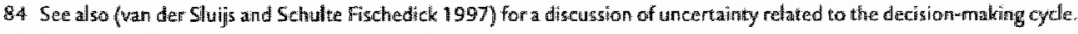

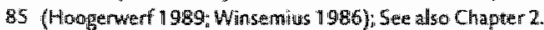

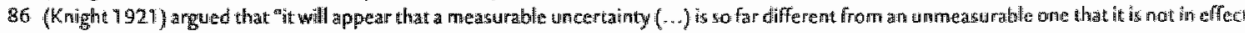

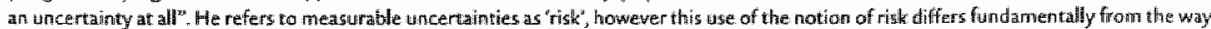

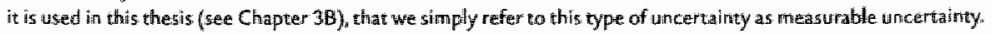

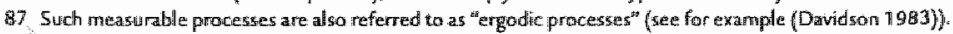


the uncertainty can be described quantitatively (either in terms of a domain or as stochastic equation). However, trans-scientific questions by definition inhibit immeasurable uncertainties that are crucial for the analysis. Such immeasurable uncertainties are also referred to as "radical uncertainties" ${ }^{88}$. Radical uncertainties are thus uncertainties that can at best be roughly estimated. Radical uncertainties generally arise due to structural uncertainty and uncertainty due to variability. It is even likely that the most salient uncertainties in the analysis of trans-scientific questions are radical.

Assessment of complex, trans-scientific issues cannot be a purely objective exercise. Due to radical uncertainty, no analysis is possible withour a long sequence of decisions based on the analysts' subjective judgement ${ }^{89}$. Subjectivity affects the way analysts deal with uncertainty. It enters the stage already in the conceptual phase in deciding which elements will be included in the assessment, and which will be left out. Decisions in formal modelling involving subjectivity ${ }^{90}$ range from which value is used for uncertain parameters to the choice of algorithms, from the treatment of problematic data sets to definitions of functional forms.

Inherent uncertainty thus evokes subjectivity in the assessment process. On the other hand, subjective judgements in the analysis will result in value diversity, which is a source of variability. This implies that an analyst studying and interpreting inherent uncertainty also contributes to inherent uncertainty. Furthermore, it is beyond the human capability to deal with all the phenomena at one time simultaneously. Also in Integrated Assessment, fragmentations are made to describe the physical and social reality. However, these fragmentations are in itself sources of uncertainty, because it is not possible to construct a system that in reality is not influenced by its surroundings, or from which the relationships between the system and the surroundings are completely known or controllable. So the analysts are themselves a source of inherent uncertainty in science ${ }^{*}$.

Furthermore, stakeholders participating in the IA process ${ }^{9 z}$ will apply different value systems. So value diversity and associated subjectivity are both a consequence of, and input to, the IA process. The mutual interplay between inherent uncerrainty and the IA process is visualised in Figure 6.

\footnotetext{
88 (Fintowicz and Ravetz $1993 \mathrm{a})$

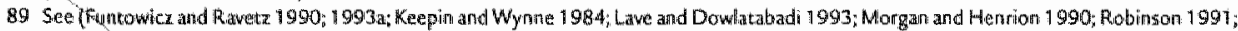
Shackley and Wynae 1995).

90 (Panl-Wost et al. 1998)

\$1 (Rohen igg8)

92. See Chapter 2.
} 


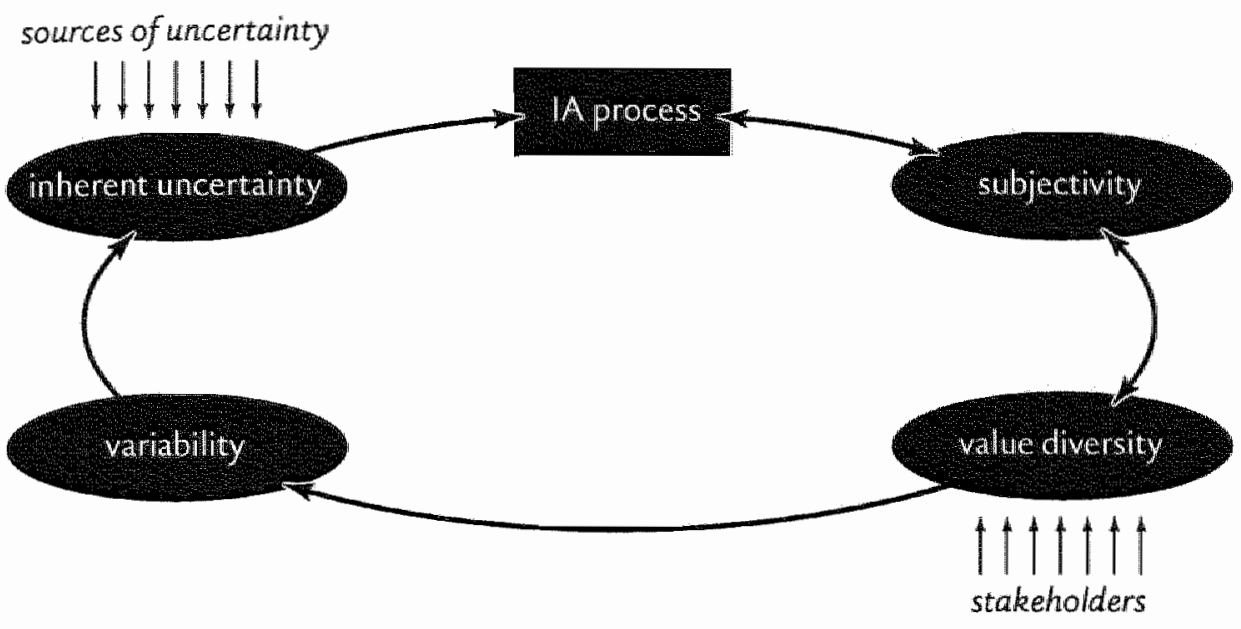

FICURE 6 Mutual interplay between inherent uncertainty and the IA process

\section{State of the art in uncertainty analysis}

A better understanding of, and insight in, uncertainty by means of a taxonomy enables structured thinking about how to deal with uncertainty in the analysis of complex issues in generall and in Integrated Assessment in particular. In this section, we will discuss methods for uncertainty analysis currently in use, in the light of the above taxonomy of sources of uncertainty.

We can distinguish between quantitative and qualitative approaches for dealing with uncertainty in science for decision-support. Quantitative approaches to uncertainty analysis are used in combination with formal models. In the following, we would like to illustrate quantitative approaches to uncertainty by means of the current practise in Integrated Assessment modelling. Integrated Assessment Models $(\mathrm{IAMs})^{93}$ are built to address trans-scientific questions on complex issues. As a consequence, such models describe inherently uncertain systems. Furthermore, as IAMs are end-to-end approaches, they suffer from accumulation of uncertainty propagated throughout the models. Last but not least, the majority of these models are used for forecasting purposes, which introduces another level of uncertainty. In sum, these models inhibit different types of uncertainties that arise from different sources. As a consequence, such models are no truth-machines, but act as heuristic tools for systematic exploration of complex issues.

93 See chapter 2 for an overview of IAlMs. 
In view of the above, the logical next question is then 'how is uncertainty managed in IA modelling?". O' Neill ${ }^{94}$ appears to have been the first to call for uncertainty analysis in the context of environmental modelling ${ }^{95}$, which is one of the roots of Integrated Assessment modelling. Since then more and more attention is paid how to deal with uncertainty in integrated modelling.

The aim of current uncertainty analysis in Integrated Assessment modelling is to evaluate to what extent particular uncertainties impact upon the conclusions. The standard practise is that uncertainty analysis is performed as a final step in the model cycle. The following approaches are currently used for uncertainty analysis in LA modelling ${ }^{\text {gt: }}$

- sensitivity analysis

- probability-based methods

- formal scenario analysis.

- hedging-oriented methods

- validation

The different approaches will be discussed below, especially in relation to the various types and sources of uncertainty.

\section{I. SENSITIVITY ANALYSIS}

Sensitivity analysis is the study of the influence of variations in model parameters and initial values on madel outcomes". In order to determine whether these variables have a significant effect on the model output, and to determine their relative importance, statistical techniques are usually applied in sensitivity analysis. Some methods for sensitivity analysis are individual parameter variation, differential sensitivity analysis, response-surface method ${ }^{98}$ and meta modelling ${ }^{99}$. Standard software packages, employing these methods, are widely available.

'The role of sensitivity analysis in the context of uncertainty analysis is to estimate the relarive importance of uncertain parameters and initial values on the model output. Fowever, one has to realise that there is not a one-to-one mapping possible from the degree of sensitivity to the salience of the uncertainty. Sensitivity analysis

\footnotetext{
94 (0'Neill 1971; ONvill and Cardner 1979)

95 (Hettelingh 1989 )

96 Compare (Kani 1998)

97 (Danssen et a 1990; Rohven 1988)

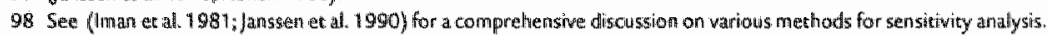

99 Sice for an exmple (Oradieck ot al. 1994).
} 
does nothing more and nothing less, than providing insights of the role of uncertain parameters and initial values in model runs.

\subsection{PROBABILITY-BASED METHODS}

In economics, engineering and psychology, the probability concept is advanced as the formal representation of uncertainty that can be dealt with in a mathematical manner. Probability is not uniquely defined. The most frequently used probabilistic approach in IA modelling is the Bayesian approach ${ }^{100}$, in which probabilities are interpreted as subjective "degrees of beliefs". The information required to apply probability calculus are distributions for uncertain inputs/parameter, which expresses how likely the analyst or group of experts ${ }^{101}$ considers a particular value for that variable. The uncertainty expressed in this way is propagated through the model, so that the output variables also feature probability distributions ${ }^{102}$ or statistical measures as the 95-percentile (see Box I). Usually 'intelligent' sampling techniques, generally Monte Carlo techniques ${ }^{\text {103 }}$, are applied to reduce the computing requirements.

Probability-based methods thus give an indication of the likelihood of outputs dependent on the (subjective) likelihood attached to uncertain model inputs/ parameters. Probability-based methods solely address uncertainty in model quantities and ignore uncertainty in model structure. In case of lack of knowledge beyond the level of inexactness, it is questionable whether probability distributions can cover the range of possibilities. In practise, modellers apply uniform distributions, because probability distributions are unknown. Furthermore, the method requires a complete covariance matrix, but in many cases the correlations between the uncertainties are unknown ${ }^{\text {ind }}$. This means that the outputs do not signify the probability of a certain development or event in reality, but merely indicate how the model propagates probability distributions.

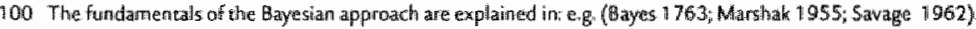

101 Examples of IA nodelling project iry which probability distributions wefe deriwed firoun elicitation processes within a group of experits are: (Horgan and Keith 1995; Nordhatis 1994 ).

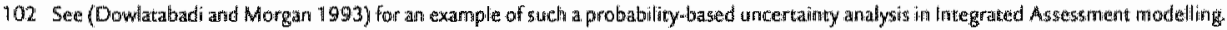

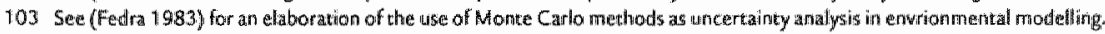

104 (Rohen 1988)
} 


\section{BOX I Results of probability-based uncertainty analysis}

The different outcomes of a large set of model runs performed with probabilitybased techniques are collected and aggregated in terms of 95-percentiles (see Figure 7 for an example). This range has just statistical meaning; namely it indicates the range that comprises the trajectories of $95 \%$ of the outcomes. The remaining $2.5 \%$ beyond both the upper and lower bound are considered to be 'outliers' that should not be taken into account. Apart from this statistical meaning the upper and lower bound as well as the range in between do not explain the adopted interpretation of the underlying uncertainties.
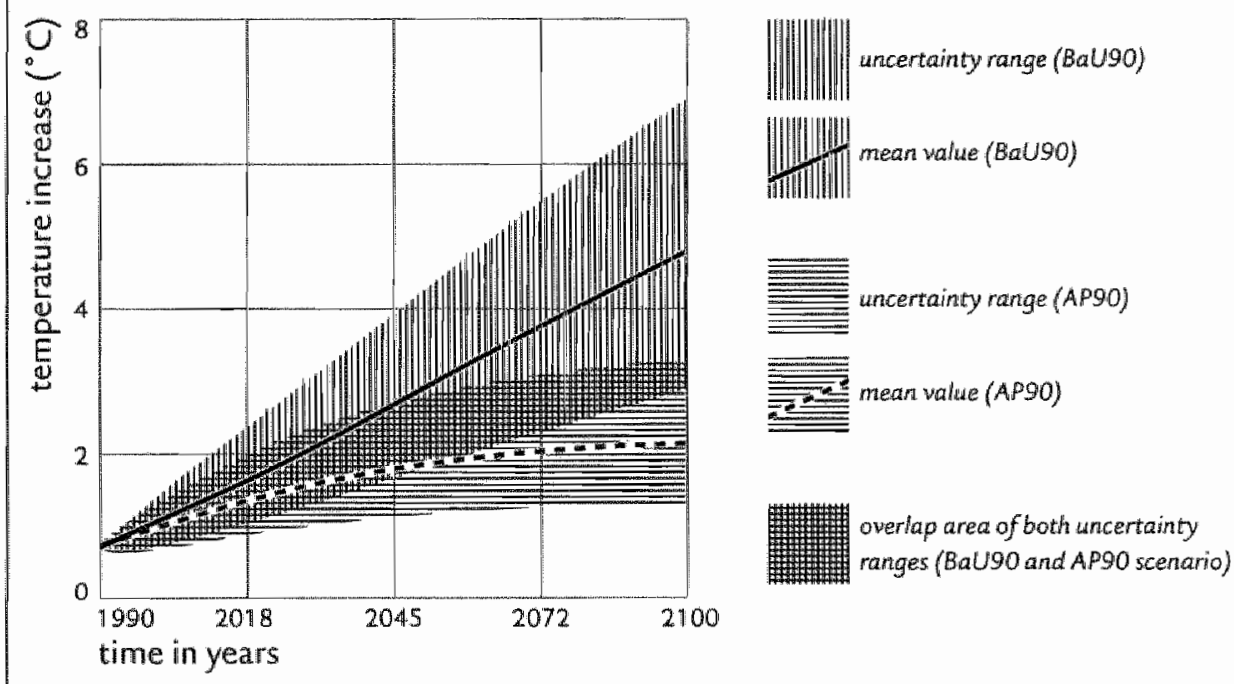

Ficume Output associated with current methods for formal uncertanty analysis (based on den Elzen 1994)

\subsection{FORMAL SCENARIO ANALYSIS}

Formal scenario analysis involves assessing sets of different assumptions of possible future states, which are parameterised in the model. Scenario analysis thus implies performing model runs for sets of parameter values and/or time-series, and comparing the results. Scenario analysis aims to investigate interesting, meaningful and varied future states, and in that way in terms of uncertainty analysis it has a considerable advantage above random sampling methods. Table I gives an example of the kind of scenario-variables currently used in IA modelling. These variables are central 
in the scenario-analysis involving the use of different IA-models ${ }^{105}$ in the context of the IPCC Third Assessment report process.

Scenario wariables

Population (humans)

GNP (\$)

GNP/capita (\$/cap)

Energy intensity (M)/\$)

Forests (ha)

table 1 Scenario-variables as proposed by scenario-working group in IPCC third Assessment Report process (preliminary version) $)^{\text {to6 }}$

In performing scenario analysis, IA modellers implicitly or explicitly draw the distinction between scientific uncertainties occurring in the environmental system and socio-economic uncertainties. The latter are uncertainties occurring in the human system, e.g. with respect to future geopolitical, socio-economic and demographic developments ${ }^{107}$. As the IPCC example illustrates, scenario input sets used in Integrated Assessment modelling merely comprise socio-economic variables. Used in this way, scenario-analysis merely addresses uncertainties in model inputs. In terms of the above distinction, this means that scenarios created in this way assess the consequences of socio-economic uncertainties on projections for the environmental system, but they neglect the scientific uncertainties in the environmental system itself.

Furthermore, scenario-analysis exercises quite often fall in the attractive pitfall to classify one of the scenarios as the most likely scenario or best-guess scenario. In this way the output of scenario-analysis then mask inherent uncertainty, which was originally the starting-point of the analysis.

105 Namely AIM Maria, IMACE 2, IASA Message, ASE, MiniCam

106 As presented by Dr. Hisgh Pitcher at the Association of American Geographers meeting on lntegrated Assessment in Washingeon D.C. (9-10 Jully 998). See also 1PCC Open process welositte: thttp// sres.ciesir.orgls res/

107 See fior example (Rotrnams et al. 1964).

108 (Kann 1998) 


\subsection{HEDGING-ORIENTED METHODS}

This class of method is the most recent approach for dealing with uncertainty in Integrated Assessment models. Hedging can be viewed as building contingency plans and responding to opportunities and risks, as they become apparent ${ }^{108}$. Hedgingoriented methods aim to identify strategies, which balance the risks of waiting with premature action $^{\text {tox }}$. In this type of modelling, the value of decision-variables in the model is determined based on a joint distribution on the possible outcomes that may occur in the next period. This approach does not assume that uncertainty is completely resolved at a certain point in time, but rather that due to progress in knowledge a probability distribution is adjusted. In this approach, the adjustment of probability distributions of the outcomes is central. Such distributions can either be inspired by probability-based methods (see above) or subjectively determined by the analysts. By using outputs derived from probability-based methods, hedging-oriented exercises inherit the disadvantage of solely addressing uncertainties in model inputs. However, hedging-oriented techniques are slightly more sophisticated than the previous methods for quantitative uncertainty analysis, because they do not only address uncertainty in the model, but by incorporating action and yield uncertainties, they also try to keep uncertainties within bounds of credibility for decisionmakers. In other words, these techniques are not just about analysing uncertainty; they are about bounding uncertainty ${ }^{110}$.

\subsection{VALIDATION}

It is unusual to place validation approaches under the heading of uncertainty analysis. Validation implies testing model performance. With validation techniques, modellers aim to assess to what extent the model is an adequate representation of reality, and as a derivative to what extent it is in accordance with empirical observations and theoretical insights. In terms of our typology of uncertainty, validation is the analysis of uncertainty on model completeness, which type of uncertainty is caused by ignorance, indeterminacy and variability. In this broader perspective, it is therefore legitimate to consider validation as uncertainty analysis.

109 (Manne and likichens 1995)

110 (Berescers and Hoppe 1998) 
PERSPECTIVES ON UNCERTAINTY AND RISK 
Because validation is used in combination with modelling, it is described under formal uncertainty analysis. However, validation may be semi-quantitative and/or participatory. Approaches employed for validation comprise review meerings, comparison with data not used for calibration, comparison with other models and model outputs, and the so-called Strategic Cycling Approach" ${ }^{\text {"I }}$. The latter involves iterative cycling between large-scale and small-scale assessments.

A qualified validation exercise should yield insights in how well the model matches observations and hyporheses. It aims to confirm the model by demonstrating agreement between observations and the model 'predictions', but such a confirmation is anyhow inherently partial ${ }^{112}$. That does not necessarily imply that the model is complete enough or whether it is an adequate representation of reality. Models can only be evaluated in relative terms. Validation exercises, which in principle address the epistemological dimension, are not systematically used to assess and discuss radical uncertainties. The results of validation are generally solely used to 'sell' the model as being scientifically credible.

\subsection{QUALITATIVE UNCERTAINTY ANALYSIS}

The term 'uncertainty analysis' is generally confined to quantitative approaches. However, there are good reasons to classify qualitative (or narrative) scenario development, interactive problem and uncertainty structuring, and the NUSAP method as uncertainty analysis techniques. These methodologies share a focus on uncertainty and ways of managing it: they do not seek to analyse uncertainty by scientific means. alone. Only qualitative scenario-development is currently really applied in the context of Integrated Assessment. Van der Sluijs ${ }^{113}$ proposed a procedure for applying NUSAP in Integrated Assessment modelling, but no applications followed so far. Interactive uncertainty and problem structuring is described to offer insight into qualitative uncertainty analysis methods currently available in neighbouring fields of science for policy.

Qualitative scenario-exercises take uncertainties in societal and environmental processes as starting point. The role of scenario-exercises is to imagine how these processes can develop. The ultimate challenge of scenario-development is to manage uncertainty by judging which mutually exclusive images of the future are possible in 
the face of a given amount of knowledge and degree of uncertainty. The concept of scenario as a tool to explore the future came into use since the seminal publication of Kahn and Wiener in $1967^{134}$. Although many definitions of scenarios circulate, they share the following features ${ }^{115}$ :

- scenarios are hypothetical, describing possible future pathways.

- scenarios describe processes, representing sequences of events over a period of time.

- scenarios consist of states, events, actions and consequences that are causally related by the above processes.

- scenarios start from an initial state (usually the present), depicting a final state at a fixed time horizon.

Qualitative scenario exercises are either developed by means of participatory approaches, or they are expert-based. In this way, scenarios in principle address uncertainty due to variability and lack of knowledge. However, actual scenario-studies $^{216}$ are often developed from a narrow, disciplinary-based perspective. Such studies employ in a limited set of standard assumptions, which are implicitly or explicitly treated as certainties ${ }^{117}$. Many narrative scenarios do have a 'business-as-usual' character, assuming those current conditions will continue for decades, thereby excluding variability and hiding ignorance and indeterminacy. Scenarios quite often do not incorporate surprises. Key assumptions and judgements are often not made explicit, so that it is difficult to trace back which salient uncertainties were the starting point for the scenario exercise and how the uncertainties were interpreted.

To illustrate the basic features of interactive uncertainty and problem structuring, we describe two examples of methods that can be grouped under this heading: the strategic choice approach ${ }^{118}$ and robustness analysis ${ }^{119}$. The reader should keep in mind that comparable approaches could be found under a variety of headings.

The strategic choice approach can be characterised as an interactive method for representing the structure of complex decision-making problems and the various sources of uncertainty, which make them difficult to resolve ${ }^{120}$. The strategic choice

\footnotetext{
14 (Kathin arat Wianer 1967 )

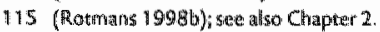

116 See for example corr evaluation of the last decade of European scenario-studies (van Asselt et al. 1998),

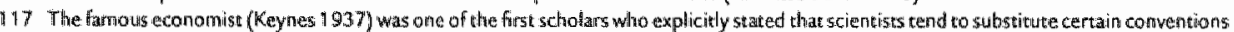
for the knowitgdge that is unatainable.

113 Thus description is based on the owerview paper of (Friend 1989). See djo (Friend and Hickling 1987).

119 This descripkion is based on the owerview papers of (Rosenthead 1989)

120 (EnvionmentalResources 1987; Hickling 1989; var de Graf 1985) thescribe examples of the strategic cholce approach to high-lewe: national policy-malking.
} 
approach involves different stages, i.e. shaping the issue in terms of a complex of related problems, designing possible courses of action, comparing implications of different courses of action and choosing a strategy.

Robustness analysis ${ }^{121}$ provides a framework to structure problem situations in which uncertainty is high, and where decisions can or must be staged sequentially. It is an approach to identify decisions early in the sequence, which keeps open a range of options for the future. The participatory process of robustness analysis involves characterising the decision-problem in terms of sequential stages, valuation of alternative initial decisions, deternining sets of compatible initial decisions and future states, and selecting robust initial decisions.

Funtowicz and Ravet ${ }^{122}$ developed the NUSAP method as a scheme that would enable evaluation of uncertainties in such a way that both the quantitative and the qualitative aspects are addressed. NUSAP stands for Numeral, Unit, Spread, Assessment and Pedigree. The idea is to characterise each part of the analysis in these terms. Numerical, unit and spread are rather familiar concepts and enable to characterise estimate in quantitative terms. Assessment and Pedigree represent levels of uncertainty that go beyond technical uncertainties. They are the most qualitative categories in the scheme. See Box 2 for an application of the NUSAP scheme as a way to characterise uncertainties.

\section{BOX 2 Application of NUSAP}

The NUSAP method can be illustrated by means of an example ${ }^{123}$, i.e. the economic value of shrimps in the wetlands in Louisiana ${ }^{124}$. A "willingness to pay" method was used to derive an estimate for the annual value per acre, i.e. $\$ 10.85$ (rounded of to one digit: $\left.10=1 E_{1}\right)$. The shrimp production estimate was based on a theoretical model relating wetland area to shrimp catch, using statistical data from the National Marine Fisheries and a regression analysis procedure that has high peer acceptance. Pedigree was determined by using Table 2.

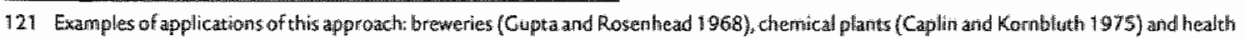
systerms (Best et al. 1985).

122 (Funtowicz and Rayetz 1990) 
$\operatorname{arc} 2$

\begin{tabular}{l|l|l|l} 
code & $\begin{array}{l}\text { Quality of model } \\
\text { theoretical structure }\end{array}$ & Quality of data & Degree of peer acceptance \\
\hline 4 & Established theory & Experimental data & Total \\
\hline 3 & Thieoretical model & Historical/field data & High \\
\hline 2 & Computational model & Calculated data & Mediun \\
\hline 1 & Statistical processing & Educated guesses & Low \\
\hline 0 & Definitions & Uneducated guesses & None \\
\hline
\end{tabular}

TAELE 2 Pedigree matrix.

The assessment grade is based on the average codes in the pedigree (i.e. the sum of the codes divided by the maximum grade (i.e. 12)). The full NUSAP representation of the willingness-to-pay estimate for shrimps in the wetlands in Louisiana then holds:

N:U:S:A:P $=1 E I: \$$ /acre/year $: \pm 10 \%: 0.7:(3,3,3)$

The willingness-to-pay estimates for menhaden, oyster and blue crab can be represented in the same way. Funtowicz and Ravetz building upon work done by Costanza and colleagues ${ }^{125}$ gave the following estimates:

\begin{tabular}{|c|c|c|c|c|c|}
\hline Element & Numeral & Unit & Spread & Assessment & Pedigree \\
\hline Shrimp & $1 \mathrm{EL}$ & \$facre/year & $10 \%$ & 0.7 & $(3,3,3)$ \\
\hline Menhaden & $6 \mathbb{E 0}$ & Syacre/year & $\pm 20 \%$ & 0.5 & $(2,2,2)$ \\
\hline Oyster & $8 \mathrm{EO}$ & \$facre/year & $\pm 30 \%$ & 0.6 & $(2,3,2)$ \\
\hline Blute crab & $1 \mathrm{EO}$ & Shacre/year & $\pm 40 \%$ & 0.6 & $(3,2,3)$ \\
\hline
\end{tabular}

TABLE 3 NUSAP representation of demvents of fishery in wetlands in Lowisiana

Funtowicz and Ravetz used these grades to determine the NUSAP score for the total commercial value of fishery on these four kinds of fish. Numeral is the sum of the numeral of the components, i.e. $N: U=2.5 \mathbb{E}$ : $\$$ /acre/year. Its Spread is defined as the weighted average of the percentage spreads of the elements, i.e. total sum of Numeral multiplied by Spread of the components divided by Numeral of fishery:

$\left(I E_{1} * 0.1+6 E_{0}^{*} 0.2+8 E_{0}^{*} 0.3+1 E_{0}^{*} 0.4\right) / 2.5 E_{1}=0.2= \pm 20 \%$ 
and the grade for Assessment is determined as the weighted average of its component grades, i.e. total sum of Numeral multiplied by Assessment per component divided by Numeral of fishery:

$\left(\mathrm{EE}_{\mathrm{I}}^{*} 0.7+6 \mathrm{EO}^{*} 0.5+8 \mathrm{Eo}^{*} 0.6+\mathrm{EO} * 0.6\right) / 2.5 \mathrm{El}=0.6$

So the NUSA(P) representation for the total commercial value of fishery in wetlands of Louisiana according to these calculations holds:

N:U:S:A $=2.5 \mathrm{Er}: \$$ /acre/year: $\pm 20 \%: 0.6$

The advantage of the NUSAP-method is that it enables to characterise the quantitative, the qualitative, and the subjective aspects of uncertainty in a formal way. The disadvantage is that it concentrates on uncertainty in variables and it does not address uncertainty in relationships between different variables. Furthermore, notwithstanding its usefulness to roughly characterise salient uncertainties, performing a comprehensive NUSAP is probably a rather time-consuming effort. Last but not least, the question is how to interpret the results. NUSAP produces a judgement of the analysis in terms of "how (un)certain are the underlying sources?". But does this imply that an analysis that solely includes uncertainties with low spread and high grades on assessment and pedigree is 'better' than an analysis that includes uncertainties with high spread, and low grades on assessment and pedigree? Van der Sluij] ${ }^{126}$ interprets NUSAP in the context of Integrated Assessment modelling in this way, with the implication that modellers who restrict themselves to 'hard' data and certain equations are "rewarded" with a high NUSAP grade. The consequence is that from this NUSAP perspective uncertainty-avoiding behaviour of the positivist scientist turns out to be the 'best' strategy. However, NUSAP' has been developed in the context of post-normal science that argues that uncertainty is inberent in Integrated Assessment and that it should be at the heart of the analysis. So it can never be the intention that NUSAP reinforces the positivist paradigm. So apart from the practi-

126 (vam der Stuijs 1997) 
cal limitations to NUSAP, there is a fundamental question how to use this approach. as tool for uncertainty analysis.

\subsection{LIMITS}

Because uncertainty is multi-dimensional, it is unlikely that a single approach will suffice to capture all the salient forces of uncertainty ${ }^{127}$. Different approaches address $d$ ifferent types and sources of uncertainty in different ways. If we use the above classification of types of uncertainty in modelling, Table 4 summarises which types of uncertainty are analysed by the discussed methods. "Table 5 summarises which sources of uncertainty can be addressed by the above approaches. We make the reservation that not all methods in any application are currently used to such a full extent. In Table 5 NUSAP is not mentioned, because it is actually a method to articulate sources of uncertainty and the degree of uncertainty in the components of the analysis.

A complementary use of various methods is needed in order to be able to provide a comprehensive insight into the extent and the scope of uncertainty. Such combinations of uncertainty analysis methods are applied in Integrated Assessment modelling. For example, as follows from the description above, hedging-oriented

\begin{tabular}{|c|c|c|}
\hline \multicolumn{2}{|c|}{ uncertainty } & method \\
\hline \multirow[t]{2}{*}{ tuncentainty in model quantiries } & uncertainties in input datal & $\begin{array}{l}\text { - sensivivity analysis } \\
\text { - probability-based methods } \\
\text { - formal scenario-analysis } \\
\text { - hedging-oriented methods } \\
\text { - NUSAP }\end{array}$ \\
\hline & parameter uncermanties & $\begin{array}{l}\text { - sensinivity atualysis } \\
\text { - probabiliry-based methods } \\
\text { - hadging-or tented merhods } \\
\text { - NUSAP }\end{array}$ \\
\hline \multirow[t]{2}{*}{$\begin{array}{l}\text { uncertainy about } \\
\text { model form }\end{array}$} & uncerkin equations & $\begin{array}{l}\text { - sensirivity analysis in the form of } \\
\text { meta-modelling }\end{array}$ \\
\hline & model strucrure uncertainties & nomethods \\
\hline \multirow[t]{2}{*}{$\begin{array}{l}\text { morertainty on } \\
\text { model completeress }\end{array}$} & uncertuin levels of confidence & - NUSAP \\
\hline & $\begin{array}{l}\text { uncertainty about } \\
\text { model validity }\end{array}$ & - validarion \\
\hline
\end{tabular}

TABLE A (ABOVE AND RACHT) Mithods of uncertainty analysis in terms of types of uncertainty 
methods are combined with probability-based methods. Sensitivity analysis is quite often used to filter out those uncertain parameters that will be subjected to probability-based uncertainty analysis. Exploratory modelling ${ }^{23}$ is an example of an approach that explicitly aims to incorporate a combination of the above methods in order to address uncertainty explicitly. In its general form it combines sensitivity analysis with both quantitative and qualitative scenario approaches and ir is usually applied in a participatory set-up.

However, even if the available methods for uncertainty analysis are combined in a systematic manner, crucial sources and types of uncertainty are ignored as become apparent in Table 4 and 5. The current methods suffer from the fact that they only address uncertainties in model quantities and neglect the structure of the model itself. In doing so, significant uncertainties are 'exogenised' and thereby become invisible $e^{\text {tay }}$. Current uncertainty analysis techniques thus merely address technical uncertainties. Furthermore, sources of variability are difficult to address with the current methods. Scenario approaches in principle allow inclusion of behavioural variability and societal randomness, however in practise this is seldom the case. As can be concluded from Table 5, there are no methods available yet to deal with value diversity and technological surprise in Integrated Assessment.

\section{output}

- role of uncertainties in input data in model run

- propagation of probabilities in input data to outcomes

- effects from uncertaín sociomeconomic inputs on outcomes

- assessing effects uncertainty reduction in ínput daca

- insight in the qualitative and quanticative mature of the uncertainty in the inputs

- role of uncertainties in parameters in model runs

- propagation of probabilities in parameters to outcomes

- assessing effects uncertalnty reduction in parameters

- insight in the qualitative and guantitative nature of the uncercainty in the parameters insights into crucial equarions

insight in the level of comfidence in terms of the quality of the underlying sources

insights in model performance 


\begin{tabular}{|c|c|}
\hline source & method \\
\hline Inexacmess & $\begin{array}{l}\text { - Probabilicy-based methods } \\
\text { - Formal scenario-analysis }\end{array}$ \\
\hline Lack of observations/ measurements & $\begin{array}{l}\text { - Probability based methods } \\
\text { - Formal scenario-analysis } \\
\text { - Hedging-oriented methods }\end{array}$ \\
\hline Practically immeasurablet & $\begin{array}{l}\text { - Probability-based methods } \\
\text { - Formal scenario analysis } \\
\text { - Hedging oriented merhods }\end{array}$ \\
\hline Conflicting exidence & $\begin{array}{l}\text { - Formal scenatio-analysis } \\
\text { - Hedging oriented methods }\end{array}$ \\
\hline Igrorance & $\begin{array}{l}\text { - Validation } \\
\text { Qualitative scenario-development } \\
\text { - Iriteractive problem and uncertaing structuring }\end{array}$ \\
\hline Indleterminalcy & $\begin{array}{l}\text { - Interactive problem and uncertaingy structuring } \\
\text { - Qualitative scenario-dewelopment }\end{array}$ \\
\hline Natural randomness & Stochastic modellhng \\
\hline Value diversiry & nomethods \\
\hline Behavioural variability & Scenario-approaches \\
\hline Societal randomness & Scenario-approaches \\
\hline Technological stur prise & Ho methods \\
\hline
\end{tabular}

TABLE 5 Potential of discussed methods in addressing different sources of uncertainty

At the moment, uncertainty is not at the heart of scientific assessment. Notwithstanding modellers' claims, in the practise of Integrated Assessment modelling, uncertainty is treated as a marginal issue that could unfortunately not be resolved yet. Uncertainty is treated as if it were an additional physical variable ${ }^{31}$, as a mathematical artefact. Current uncertainty analysis techniques implicitly inherit positivist thinking; i.e. these methods remain ambiguous as to the acknowledgement of subjectivity and inherent uncertainty. Uncertainty analysis merely involves evaluation of the impacts of 'certain uncertainties', i.e. uncertainties for which estimates or probability distributions are available. The more fundamental, and probably the most salient, uncertainties are ignored. As a consequence, formal uncertainty analysis is in a sense hiding inherent uncertainty.

On the other hand, the inevitability of uncertainty is increasingly recognised in the IA community. But the formal uncertainty analysis techniques applied originate from principles that are incompatible with this recognition of inherent uncertainty.

130 Not meintioned thus far, because it is too specific to ereat it on a simillar lewel as the dether uncentaingy analysis methodls.

131 (Funtowitz and Ravetz 1993a) 
The available formal techniques do not allow addressing inherent uncertainty adequately. The use of qualitative methods for uncertainty analysis in Integrated Assessment is relatively rare. Only qualitative scenario-development is used, but in a very limited manner. The present situation in IA can therefore be characterised by the tension between objectivity and truth as guiding principles for actual uncertainty analysis on the one hand and the recognition of the inevitable uncertainty on the other hand ${ }^{132}$.

To date, there is no alternative crystallised portfolio of methods that enables conscious integrated assessors to deal adequately with inherent uncertainty in their daily practise. There is no ready-made kit of tools, recipes, techniques and models available.

The above evaluation teaches us that as uncertain situations become more imminent, the ability to analyse uncertainty decreases ${ }^{133}$. We conclude that:

Uncertainty analysis lacks a tool-kit that enables to address salient technical, methodological and epistemological uncertainties in an adequate manner as the central activity in scientific assessment ${ }^{134}$.

As a consequence of the above inconsistency between epistemological principles and the tools and methods used, it is even more difficult to discuss the relative value of scientific insights with societal actors. Current methods give them no indication regarding the magnitude and the sources of the underlying uncertainties, with NUSAP as notable exception. The way scientists handle uncertainty affects the manner in which they communicate lack of knowledge and variability to the public ${ }^{135}$. Furthermore, scientists fail to translate uncertainty into notions that are understandable by non-scientists, and vice versa. Such communication problems in explaining uncertain results and in interpreting characterisations of uncertainty are referred to as "translational uncertainties" ${ }^{m 6}$.

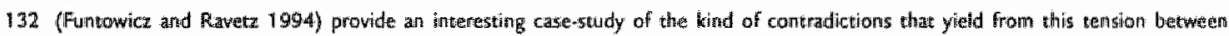
epastemology and practisen.

133 Compare (Rowe 1994 )

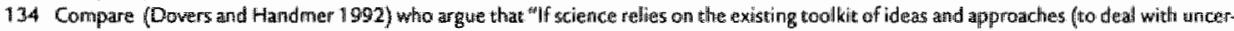

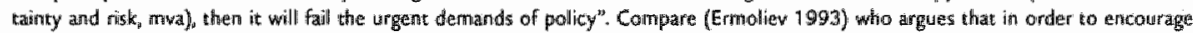

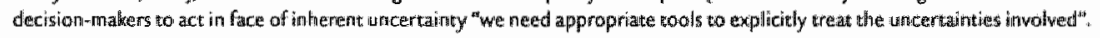

135 (ORiordan et al. 1997 )

136 (Rowe 1994) 


\section{Towards uncertainty management}

If we do not change the way uncertainty is treated in science for decision-making, uncertainty is a problem that has the potential to sap the role science may play in facilitating decision-making processes. Uncertainty can also be considered as a challenge, and as an invitation to develop new approaches. Suggestions for how science may play a relevant and useful role in society within its irherent limits are provided in the scholarly literature under denominators as trans-science, realism and post-normal science. These attempts share that they aim to reconcile the notion to improve the scientific basis for decision-making (which is actually a remainder of the positivist model of science) ${ }^{137}$ with the constructed character of that scientific basis (which is the central claim of the conventionalist model of science) ${ }^{138}$.

The aim then has to shift from analysing the impact of uncertainty on the conclusions to treating uncertainty as intrinsic and key facet of the issue under concern. Uncertainty should not longer be treated as marginal issue or a closing entry in the analysis, but it should be at the heart of the assessment ${ }^{139}$. In this perspective, science is no longer understood as steadily advancing certainty of knowledge. Science for decision-making is conceived as a search process that aims to provide insights that facilitate conscious acting in an uncertain world. This implies a switch from the technical discourse of problem-solving and definite answers, to puzzling and insights. In order to mark this shift in orientation, the notion 'uncertainty-management' is introduced $^{\text {14t. }}$.

Uncertainty management should encompass the various types and sources of uncertainty in an adequate manner. Due to inherent uncertainty, bias is pervasive in the analysis of trans-scientific issues. It is expert judgement, but judgement nevertheless. For example, Lave and Dowlatabadi ${ }^{14 t}$ argued that the actual estimates of the effects of climate change on people and the environment "depends on whether one is optimistic, moderate or pessimistic". An important step towards uncertainty management is the acknowledgement of irreducible subjective diversity in science ${ }^{142}$.

\footnotetext{
137 Sest (van der Slupis and Schulte Fischedick 1997)

138 Phrasing inspired by (Jasanolit 1990), See also (Nowotry 1987) (Funcowict and Ravetz 19g Ja).

139 (Funtowicz and Ravete 1993a)

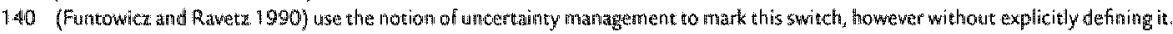

141 (Lave and Dowlatabiadi 1993 )

142 Wording inspired by Hadi Dowlatabadi, personal communication.
} 
Funtowicz and Ravetz ${ }^{143}$ argue that quality assurance ${ }^{144}$ and the fostering of skills necessary for this are crucial elements in uncertainty management. The issue of quality assurance is usually ignored in dealing with uncertainty. And it is furthermore not well understood that uncertainty and quality are two distinct attributes. High quality does not imply low uncertainty and vice versa. Information of lesser certainty may be yet of good quality for its intended function. Building upon Funtowicz and Ravetz ${ }^{145}$, quality can be defined as "the totality of characteristics of a particular process-product combination that bears its ability to satisfy an established use". In the context of uncertainty management, quality implies that the salient uncertainties crucial for the decision-making process are considered and that legitimate interpretations of these uncertainties are brought to the fore.

Uncertainty management can then be defined as an approach to decision-support that reasons from inherent uncertainty and that provides a framework in which the salient uncertainties are used as building blocks to arrive at insights relevant for the decision-making process. The ultimate aim of uncertainty management is to facilitate the search for the most robust alternative. Robust implies that the identified strategy is one that appears to trigger a favourable future, that seems to avoid highly undesirable ones, and that is flexible enough to be changed or reversed if new insights emerge ${ }^{\mathrm{t} 46}$.

In the following, we aim to provide concrete suggestions for uncertainty management. To that end, we will suggest approaches for selecting salient uncertainties, i.e. the key items of the analysis, and we will argue how a pluralistic approach enables to deal with vallue diversity and subjectivity in an adequare and constructive manner.

\section{I. APPROACHES TO SELECTING SALIENT UNCERTAINTIES}

Probably, it is not worthwhile investing serious efforts in analysing uncertainties of lower salience, as long as the more salient ones remain. So the first step towards uncertainty management is a heuristic that enables to select the most salient ones. Checklists have been proposed to rank uncertainties in terms of salience $\mathrm{e}^{147}$. In earlier work ${ }^{14^{8}}$, we proposed to use magnitude, degree and time-variability as indicators of importance:

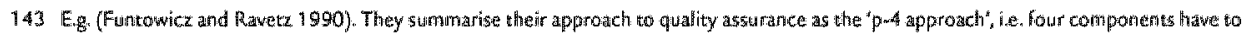
be consideredt the purpose, the person the pirocess and the product.

144 See also Chapter 2.

145 (Furtowicz and Rawetz 1990 ) (Funtowicz and Rayetz 1993 b)

146 Compane (Collingridge 1989) (Colgharier 1991) fard (Lempert iand Bonomo 1998).

177 See for example (de Marchi et al. 1993)

148 (van Aswelt and Rotmans 1995)
} 
- magnitude: the relative contribution of the specific uncertain component to the uncertainty of the full analysis.

- degree the range of uncertainty of a specific component of the analysis.

- time-variability: whether the rate of uncertainty is fluctuating over time.

The three indicators can be used to assess the components of the analysis in a qualitative way ${ }^{149}$. Using Table 6 the components can be classified as uncertainties of low, middle and high importance.

\begin{tabular}{|c|c|c|c|}
\hline magnicude & degree & time-variability & importance \\
\hline $\begin{array}{l}\text { large } \\
\text { large } \\
\text { large } \\
\text { medlum } \\
\text { medium }\end{array}$ & $\begin{array}{l}\text { high } \\
\text { medium } \\
\text { low } \\
\text { high } \\
\text { medium }\end{array}$ & $\begin{array}{l}\text { high/medium/low } \\
\text { high/medium } \\
\text { high } \\
\text { high/medium } \\
\text { medium }\end{array}$ & HIGH \\
\hline $\begin{array}{l}\text { large } \\
\text { large } \\
\text { medlum } \\
\text { medium } \\
\text { small }\end{array}$ & $\begin{array}{l}\text { medium } \\
\text { low } \\
\text { high } \\
\text { medium } \\
\text { high }\end{array}$ & $\begin{array}{c}\text { low } \\
\text { medium/low } \\
\text { high/medium/low } \\
\text { medium } \\
\text { high/medium }\end{array}$ & MEDIUM \\
\hline $\begin{array}{l}\text { medium } \\
\text { small } \\
\text { small } \\
\text { small }\end{array}$ & $\begin{array}{l}\text { medium/low } \\
\text { high } \\
\text { medium } \\
\text { low }\end{array}$ & $\begin{array}{c}\text { low } \\
\text { low } \\
\text { high/medium/low } \\
\text { high/medium/low }\end{array}$ & Low \\
\hline
\end{tabular}

TABLE 6 Classification of importance $\mathrm{e}^{\text {iso }}$

As argued in the section on formal uncertainty analysis, sensitivity analysis may be useful in this ranking effort. Inspired by post-normal science reasoning, Van der Sluys ${ }^{\text {tst }}$ proposed a participatory sensitivity analysis that can be used in a selection process (see Figure 8).

We have to realise that due to the nature of uncertainty, ranking the most salient uncertainties is always a judgmental exercise, notwithstanding the usefulness of checklists and techniques for sensitivity analysis for doing it in a systematic way.

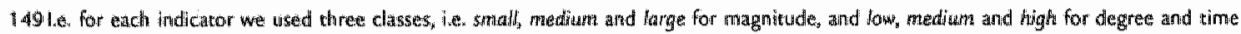
variabilithy. Magnitude is weighted highest, then degree and than time-variability.

150 Source: (van Asselt and Rotmans 1995)

151 (van der S1 wijs 1997)
} 


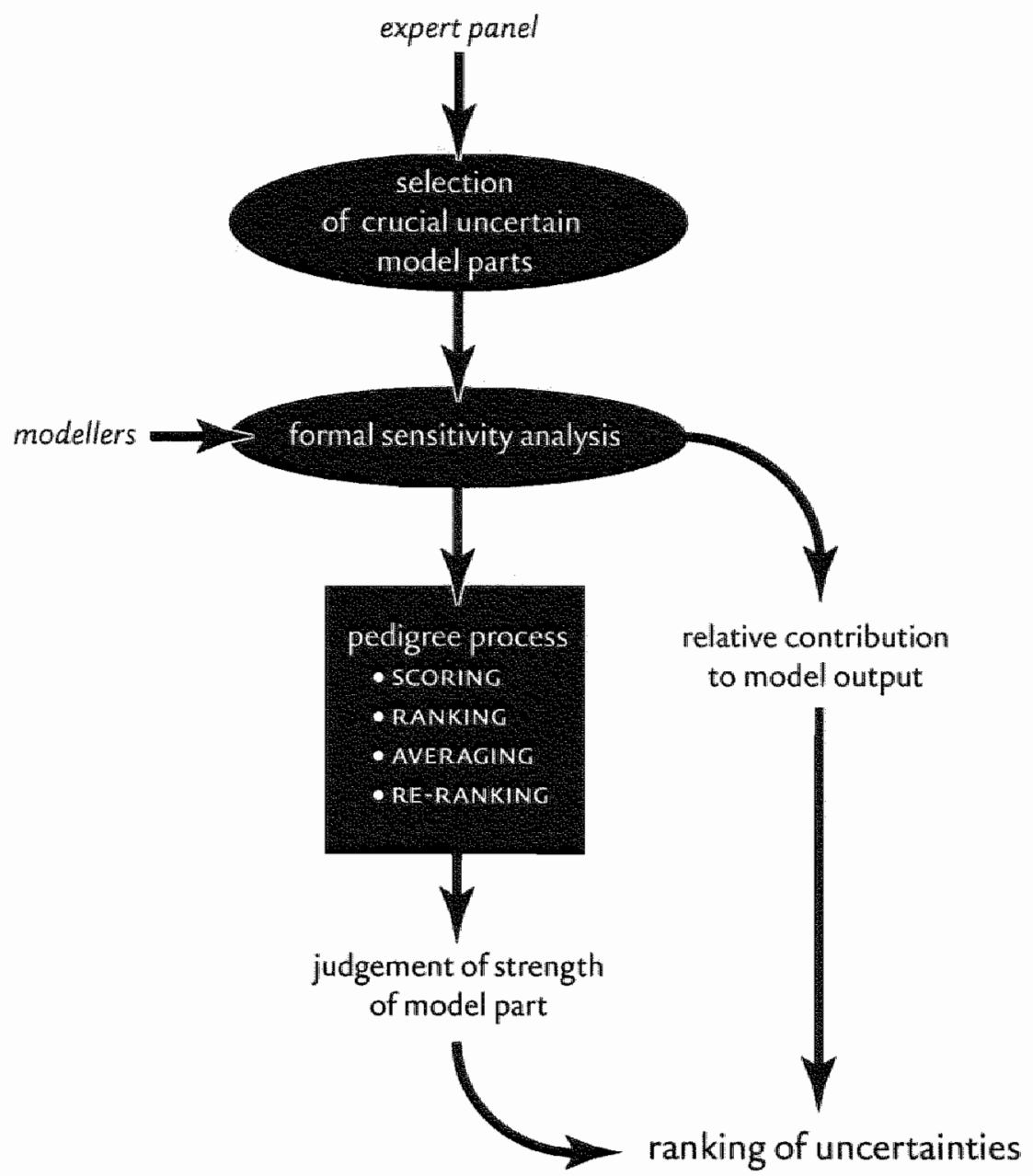

FGGRE 8 Participatory sensitivity analysis as derived from van der Sluijs (1997)

\subsection{SUBJECTIVITY, CONTROVERSY AND PLURALISM}

In case of value diversity, scientific disagreement and controversy are persistent. Scientific disagreement on its turn encourages controversy, because it enables different stakeholders to arrive at competing scientific conclusions ${ }^{152}$. Furthermore, scientific consensus on trans-scientific issues has often been wrong ${ }^{153}$. Due to inherent uncertainty, controversy should not be treated as something that should or could be avoided. In face of inherent uncertainty, scientific consensus is not a substitute for 
knowledge ${ }^{154}$. Controversy involves counterfactual arguments that articulate uncertain and inadequate knowledge ${ }^{155}$. Controversy between schools of thought and types of knowledge are signals of inherent uncertainty. Taking this into account, controversy can be used in a constructive manner to identify disagreement, and thereby different interpretations of the underlying uncertainties. Analysis of controversy is one way to grasp uncertainties and different legitimate perceptions composed of facts and coloured interpretations of uncertainty ${ }^{15}$.

Since the r97os, procedural suggestions have been made to deal with scientific disagreement and inherent controversy. The common denominator is that scientific controversy should be openly admitted. In the I970s, the idea of a Science Court was launched ${ }^{157}$, i.e. an occasional body analogous to a law court, where scientists from different fields would reach consensus on the basis of the best available evidence and the most plausible argumentation. Weinberg ${ }^{158}$, for example, argued that a type of adversary procedure seems to be the best alternative, involving face-to-face confrontation, juxtaposing experts and counter-experts, and opportunity for cross-examination ${ }^{159}$. The idea did not develop into standard practise, but it is still an inspiring analogy in the Integrated Assessment community ${ }^{160}$.

Reasoning from value diversity and subjectivity, we argue that a science has to accept the differences in perspectives, and utilise them consciously as resource. This requires willingness to open the scientific black boxes and to consider their internal construction $^{65}$. In line herewith, we argue that uncertainty management should be pluralistic. This implies that uncertainties are considered from different legitimate perspectives in order to articulate multiple manifestations of a problem ${ }^{462}$. Such an approach is in line with the insight from social psychology ${ }^{163}$ that biased interpretations are seldom fully arbitrary, but tend to relate to frames, value-systems or perspectives.

Regarding the controversy that transcends science and affects society, scientists can no longer deal with these issues alone. In such cases, not only the perspectives prevalent in the scientific conmunity count. In addressing such unfamiliar issues sci-

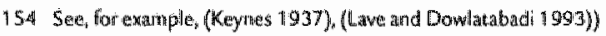

155 (won Schomberg 1993)

156 Compane (van Eaten 1999)

$15 \%$ See (ron Schombeng 1993 ) for a discussion on the concept of Science Court.

158 (Weinberin 1972)

159 See also (Neinberge 1972)

160 For example, during the meeting on Integrated Assessment orgarised by the American Association of Ceogriaphers (fing 1998 , Washingron) Schlessinger suggested that an athenative way of dealing with controversy would be: an analogy to the Sup reme: Court. Furthermore, in the origiral proposal for the ULYSSES project (Jatger et al. 1995). The wording IA jumes was used to refer to the role of participatory lintegraced Assessmant.

16: (Nyme 1992)

162 Wording is inspired by Khalid Saced, Symposim Environument, Energy and Econony A sistumable füture, Rome, $12-13$ October 1998.

163 F.g. (Twersky and Kalmeman 1974; 1980; 1981 )
} 
entists are like amateurs, with a training that is useful, but without a secure framework. Science is challenged to become conversant with mature citizens and to address certain of the public's legitimate demands. Knowledge then becomes alive by the force of conflict and contradiction ${ }^{164}$. It is argued that the different parties in the participatory processes should be granted equal power, and function like an externally 'extended peer-community ${ }^{1165}$. This implies that uncertainty management involves participatory processes including scientists, decision-makers, stakeholders and the general public ${ }^{166}$.

In such a participatory process, qualified scientists possess unique knowledge and useful skills. According to Weinberg ${ }^{167}$, scientists can and should inject some intellectual discipline into the, often chaotic, trans-scientific debates by:

- making the contestants (more) aware of the consequences of any decision and of alternatives,

- showing them what the implications are in terms of other values,

- ensuring that they are aware of the values implied in their choices.

It is beyond the scope of this Chapter, to discuss participation in depth ${ }^{168}$. We touch upon it, because it is an important feature of uncertainty management. In our attempt to sketch a framework for uncertainty management in the remaining of this Chapter, participation will be included as one of the constituting characteristics, without going into much details of implementation.

\subsection{CHALLENGES FOR UNCERTAINTY MANAGEMENT}

In sum, the state-of-the-art review of current methods for uncertainty analysis and scholarly thoughts on uncertainty management teaches us that the challenges for uncertainty management are:

- to develop methods for addressing methodological and epistemological uncertainties.

- such methods for uncertainty management have to be pluralistic (i.e. including different perspectives, expertise and counter-expertise).

- to seek ways for participatory uncertainty management.

- quality assurance is centrall to uncertainty management.

- to find ways to communicate uncertainty in a way understandable to non-scientists.

164 (Funtowicz and Raverz 1993b)

165. (Funtowicz and Ravetz 1990; 19936)

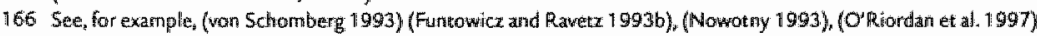

757 Weinberg 1972)

158: See Chapters 2, 38 and 5 for a more extended discussion on participation. 


\section{Perspective-based uncertainty management}

Attempts have been made to incorporate multiple perspectives in Integrated Assessment modelling ${ }^{\text {thy }}$ as a way to assess the most salient uncertainties, both as manifested in model quantities and in model structure. Such a pluralistic approach implies that an IA model does not merely include one (hidden) perspective, but comprises a set of perspectives. Our contribution to this endeavour has been the development and application of 'multiple perspective-based model roures ${ }^{170}$. In this approach uncertainty is "marked" and communicated by different interpretations according to different perspectives. A perspective is reflected in choices concerning model inputs, parameter choices, model structure and equations. In this way, experimenting with the model implies choosing among perspective-dependent options. A perspective-based model route is thus a chain of interpretations of the salient uncertainties coloured with the bias and preferences of a certain perspective. In this way, uncertainty and subjectivity are not hidden, but are made explicit.

In the following pages the method of perspective-based model routes is described. The methodology of model routes has been developed within the scope of Rrvm's research project ${ }^{171}$ 'Global Dynamics and Sustainable Development' that involved the development of the Integrated Assessment model TARGETS, which is an acronym for Tool to Assess Regional and Global Environmental and health Targets for Sustainability. To a certain extent the method is tied to, or constrained by, features of the TARGETS model ${ }^{172}$. For that reason, we first describe this particular method for pluralistic uncertainty management by means of the application to the TARGETS model. Secondly, we will use the experiences and lessons learned to draw the contours of pluralistic uncertainty management.

\section{I. PERSPECTIVES}

The first step in developing the model route strategy has been to define the concept 'perspective'. The definition of perspective adopted in this thesis holds:

\footnotetext{
169 E.g. (Liawe and Dowlatabadi 1993), (Wan Assett and Rotmans 1995; 1996), (Rothman et al. 1998 (im press)) and (Biggs et al. 1998 (in press)

170 (wan Asselic et al 1996; wan Asselt and Rotmans 1995; 1996; 1997)

171 (Rotmass and de Vries 1997; Rotmans et al, 1994)

$172 \mathrm{Sec}$, for example. (Geels 1996$)$ for a discussion how model choices framed the multiple model route strategy-
} 
A perspeCtive is a COHERENT and CONSISTENT description of the PERCEPTUAL SCREEN through which (groups of) people INTER PRET or make sense of the WOR LD and its SOCIAC DIMENSIONS, and which guides them in ACTING.

A perspective thus comprises both a worldview (i.e. how people interpret the world) and a management style (i.e. how they act upon it) ${ }^{173}$.

Involving the endless number of individual preferences to account for variety in perspectives would turn any pluralistic endeavour into a mission impossible. Furthermore, some social scientists argue that the variability in values can be covered by a limited number of value combinations ${ }^{174}$. The challenge then is to find a typology of perspectives that sufficiently covers the pluralism in value-systems. To implement the concept of multiple perspective-based model routes, such a typology should satisfy the following conditions:

- It should be social scientifically credible.

- It should be structured in a systematic manner.

- It should be generic, i.e. applicable to different temporal and geographical scales and different levels of aggregation.

- Each perspective should comprise both a worldview and a management style. Unfortunately, the social sciences do not provide a ready-to-hand, generally accepted typology of perspectives that is independent of time and scale. Social sciences have it that people think and act on the basis of a 'situation-logic ${ }^{175}$. Generic typologies would violate this broadly shared conviction. For the development of TARGETs, a topdown approach has been chosen whereby the analysis addresses the global level. Taking genericity as opposed to the specificity social sciences presumes as the aim, a typology of global top-down perspectives is needed. However, social sciences usually prefer a bottom-up perspective in understanding actual pluralism ${ }^{176}$. As far as our knowledge extents, no credible typology is available that explicitly addresses the global level and that mirrors the top-down perspective adopted in the modelling effort. The challenge left to us was to find a systematic typology of perspectives that includes both a world view and a management style dimension, that can be considered to be credible in social sciences and that is phrased in sufficiently general terms to allow application to the

\footnotetext{
173 A similir distinction can be found by (Sabarier 1987).

174 (Rayme 1987)

175 Wording inspired by Hoppe, persoryal comrmutuhication.

176 See, for examples (foe 1998).
} 
global level and the diversity of issues covered in the TARGETS model (i.e. population \& health, economy, energy, food, water and environmental change).

Cultural Theory as developed by anthropologists and widely used in political science, has been a basic source of inspiration. Cultural Theory does not represent social science as a whole. We realise that its scheme is rigid and that it cannot fully take account of the reall world variety of perspectives. The typology associated with Cultural Theory is nothing more, but also nothing less, than an attempt to systematically address the complex issue of different perspectives at a rather general level. As any model it is merely a limited and defective reflection of reality. However, in spite of the lacunae and inconsistencies, we did not find a typology that better satisfied the criteria mentioned above ${ }^{\mathrm{n} 7}$. In the context of our aims, it seems therefore legitimate and reasonable to use the types put forward in Cultural Theory to characterise the spectrum of perspectives and to use the associated typology to implement multiple perspective-based model routes in Integrated Assessment models. In Van Asselt and Rotmans $s^{178}$, we have attempted to motivate that this typology served our purpose and that it was a legitimate choice in this particular context to chose Cultural Theory as heuristic. Furthermore, it falls beyond our competence, as is also argued by our colleagues Parsion ${ }^{179}$ and Risbey et al. ${ }^{180}$, to test Cultural Theory. Although Cultural Theory is controversial it is a theoretical model that has passed the test of peer review and that is used by social scientists. So apart from the criticism, there are also social scientific scholars arguing that Cultural Theory provides an enriched framework for the perceptions of the various participants in trans-scientific issues ${ }^{18:}$. It is up to social science experts ${ }^{182}$ to test its validity. Parson's ${ }^{18_{3}^{3}}$ remark pertaining to the limits of IA in connection to disciplinary research is relevant here:

IA cannot be held liable for the general incompleteness of relevant knowledge. (.) IAs can help - they may reveal or characterise the need, motwate the research effort, perhaps even provide hints about fruitful ways to proceed-but they cannot do the job.

With our work, we have tried to encourage social scientists to develop typologies that enable IA practitioners to apply the concept of perspective-based model routes

177 In (vali Asselt and Rotrians 1999) we provide an overview of other general typologes that have been considered, ege acting perspectives by (WRR 1994). Ethical positions by (Coward and Hurka 1993) and (Dotto 1993), and views on sustainable development (de Vries 1989)).

178 (wan Asselt and Rotmans $1996 ; 1997$ )

179 (Parson 1996 )

180 (Risbey et al. 1996)

181 (Fumbowicz and Rawetz 19936), (laeger et al. 1999), (O'Riondan et al. 1997), (Hoppe and Peterse 1998), (Pendergraft 1998)

182 For example, in the way as done by (O'tiondan et al. 1997 ), (Martis et al. 1997)), (Crendstad and Selle 1997), (uager et al. 1999)

183 (Parson 1996) 
in a way that does justice to both empirical observations and social science theorising. Crucial in our effort was to develop a strategy that enabled practitioners to take account of pluralism (and thus of inherent uncertainty and subjectivity) in IA modelling. In this context, we will use the application of cultural theory-based in the TARGETS model first and for all to illustrate pluralistic uncertainty management.

In the present context, we thus limit ourselves to a brief description of the three active perspectives (see Box 3 ), i.e. hierarchist, egalitarian and individualist, which have been used as stereotypes to develop multiple model routes that represent fundamentally different, but legitimate perspectives. The hierarchist, egalitarian and individualist are considered as extremes. The resulting spectrum that these extreme stereotypes define comprises a variety of less extreme, or rather hybrid, worldviews and management styles.

\section{Bо 3 Cultural Theory's typology of perspectives ${ }^{184}$}

EGalitarians hold that all humans are born "good", but that they are highly malleable. Just as human nature can be 'corrupted' by bad influences, it can be positively guided by an intimate relationship with nature and other people. Self-realisation lies in spiritual growth rather than in the consumption of goods. The egalitarian worldview implies a risk-averse attitude. The associated management style can therefore be characterised as preventive. With regard to the capitalistic economic system, drastic structural social, cultural, and institutional changes are advocated. The egalitarian has it that nature is very fragile. Small disturbances may have catastrophic results. Any man-made change is likely to be detrimental to the environmental system. Nature is in a delicate balance. Activities that are to a greater or lesser extent likely to harm the environment should be abandoned.

For the INDIVIDUALIST, human nature is based on self-seeking behaviour. Human beings are considered to be rational self-conscious agents seeking to fulfill their ever- 
3

increasing materialistic needs. Individualists holl that changes in principle provide opportunities for human ingenuity that will be revealed through market mechanisms. The individualist can be characterised as risk seeking. Eventual highly unlikely negative consequences of human activities will be resolved by technological solutions. The management style of the individualist can therefore be described as adaptive. Seen from an individualist perspective, nature is very robust. Anthropogenic perturbations, even if they are large, will do no more than result in mild and harmless disruptions. The ind ividualist considers humans the centre of the universe, whille nature is seen as providing resources that are there to be exploited.

HIERARChISTS consider humans to be born sinfull, but that they can and should be educated by good institutions. The role of management is to prevent serious problems by careful control, i.e. by keeping the system within its limits. This management style of control can be associated with a risk-accepting attitude. Hierarchists believe that nature is robust within certain limits. Nature is able to cope with small disturbances. However, as soon as a threshold is passed, anthropogenic disturbances pose a threat to the functioning of nature. The hierarchist can be associated with an attitude towards the relationship between man and nature in which the mutual dependency between humans and nature is stressed. A balance between human and environmental values has to be ensured.

Cultural Theory describes 4 , and at times even 5 , perspectives, i.e. hierarchist, egalitarian, individualist, fatalist and hermit. The first three perspectives, are also referred to as "active perspectives", because they share an action oriented world view and management style, although they fundamentally differ with regard to the type of action and the effectiveness thereof. Because the TARGETS model envisioned policy action, the fatalist and the hermit were not of primary interest. For simplicity reasons, those two were not included in the perspective-based model route application to the TARGETS model ${ }^{185}$. However, in a project that ran parallel to the TARGETS project in which we have tried to model different types of consumer and consumer behaviour, the fatalist perspective was explicitly taken into account ${ }^{186}$. 


\section{- nature fragite \\ - people good and mallable \\ - ecocentrism \\ Egalitarian $1 \mathrm{~A}$ - pquity and equality}

\section{Hierarchist +24}

- nature toleraint within limits

- people sinful

- partnership

- control

- stability

- risk-accepting

Ficure 9 Main features of perspectives
Individualist

- nature robust

- people self-seeking

- anthropocentrism

- adaption

- growth

- risk-sereking

\subsection{MULTIPLE MODEL ROUTES}

Model routes consist of chains of alternative formulations of model relationships and model quantities. Implementing model routes in an Integrated Assessment model is a collaborative and iterative effort involving at least modellers, analysts, disciplinary experts and Cultural Theory experts. The various implementation steps are summarised in a flow chart (Figure 10).

In the following sections, we will illustrate the implementation steps by referring to aspects of the application in TARGETS ${ }^{187}$.

185 See also (wan Asselit and Rotmams 1996; 1997).

186 (joger er al. 1995; 1999 )

187 See (Romass and te Vries 1997) for a comprehensiwe overview: 


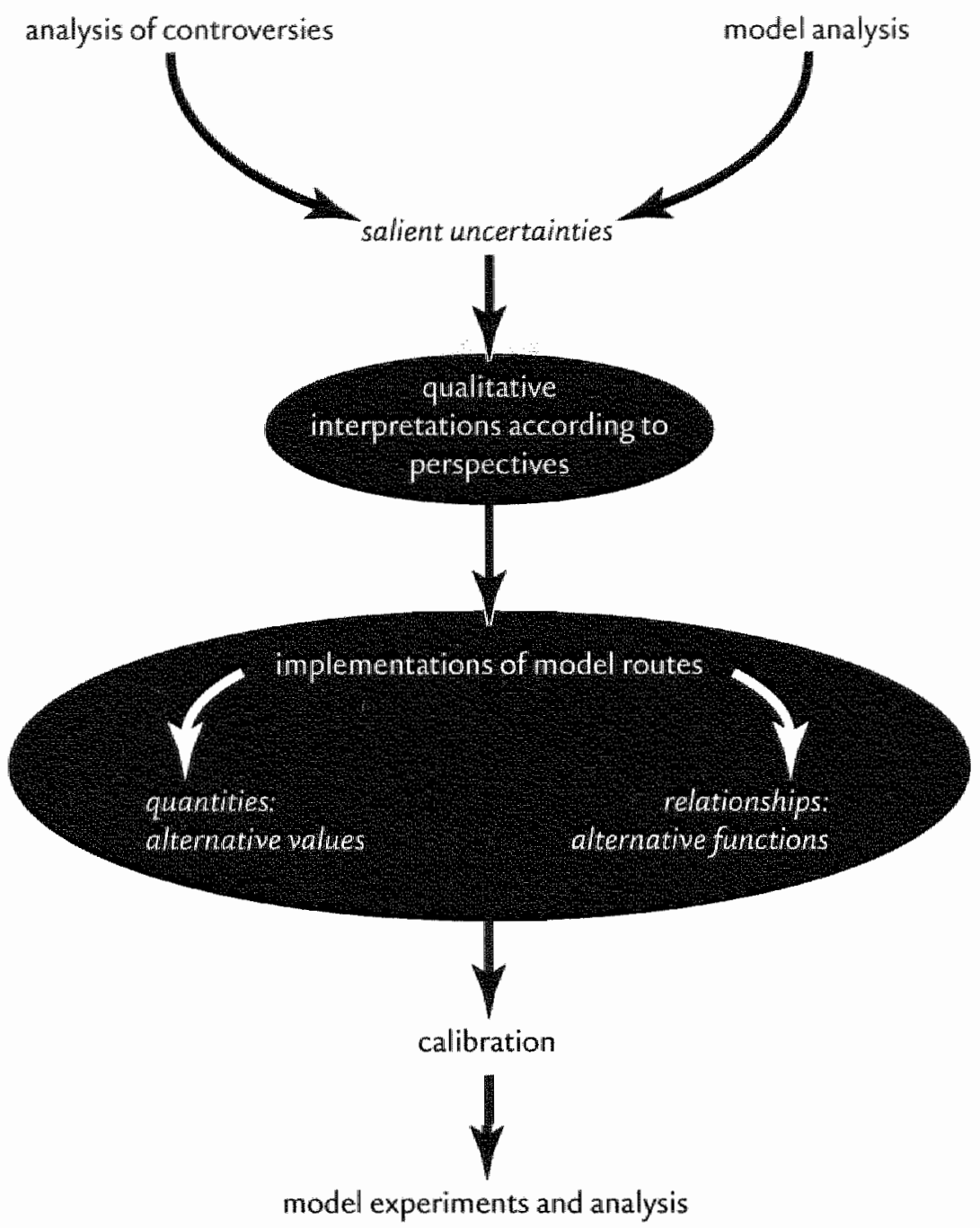

FIGURE 10 Flowchart of methodology of multiple model soutes

\section{STEP I ANALYSIS OF CONTROVERSY}

In the previous section, it was argued that the analysis of controversy could be a way to identify salient uncertainties. The first step in the multiple model route method builds upon this argument. Relevant scientific debates are analysed in order to identify the major controversy within the scientific community. To give an example: the key question that underlies the controversy in the climate community can be summarised as: 
Is the global climate disturbed in a serious and irreversible way; and if so to what extent, at what rate of change and with what regional pattern, and what are the human and environmental consequences? ${ }^{128}$

This question includes all the controversial elements around which the actual controversy abounds. The above question can therefore be considered as embracing and representing the major controversy in the climate community.

The next step is to unravel this controversy in terms of facts, hypotheses and uncertainties. To this end, a study of the scientific literature and intensive collaboration with experts is needed. Crucial in this step is to decide which literature is included, in other words whose opinions are considered, and what falls beyond the inventory. In the present application, the heuristic guideline was to restrict the inventory to official publications in peer reviewed media and to research reports that were seriously considered in such official publications (e.g. the Greenpeace scenarios on energy as produced by the Stockholm Environment Institute $\left.{ }^{489}\right)$. This explains why Simon's controversial opinion ${ }^{190}$ is considered and why Böttcher's opinion ${ }^{k 31}$ is left out. Constraint by this heuristic, the inventories performed in the context of the TARGETs reveal fundamental uncertainties underlying the debate in the scientific community as discussed in official scientific bodies.

\section{STEP 2 MODEL ANALYSIS}

The inventory of the salient uncertainties enables to identify which model components are necessarily influenced by subjective judgement. All model choices on inherent uncertainties by definition represent a particular interpretation of uncertainty. By going back and forth between the inventory of uncertainties and the model, a list of crucial model components that involve subjectivity is produced. Sensitivity analysis is used to check how critical these model components are for the assessment activities. Based on this evaluation, the most salient uncertain model components are selected.

This step can be illustrated by means of the example of the analysis of the water submodel in the TARGETS model. As a result of the above procedure, water scarcity, potential water supply and water demand were selected as the key uncertain issues in forecasting whether the world population can be provided in the long term. 
with sufficient and clean fresh water without threatening the ecological functions of water. In an iterative process between the water modeller and the analyst, the following model components were selected ${ }^{192}$ as being crucial in terms of inherent uncertainty and its impact on the model output: MODEL STRUCTURE

- Modelling of water scarcity

- Modelling of water quality EQUATIONS

- Water supply-cost curves

- Water demand equation (esp. in terms of growth and price elasticity) MODEL QUANTITIES

- Diffusion of technology

- Fraction consumptive water use

- Climate sensitivities of ice sheets and glaciers

\section{STEP 3 QUALITATIVE INTERPRETATIONS}

The next step involves defining alternative interpretations of the uncertain model components reasoning from the above framework of perspectives. The perspectives were used to develop mutual coherent sets of responses on the following questions that represent the salient uncertainties addressed in the TARGETS model:

- What level of economic growth is desired?

- What are the limits to population growth and what are the major driving forces?

- What derer mines health?

- How will rechnology develop in the energy sector?

- What is the role of feedbacks in the climate system?

- What are the determinants of water demand and supply?

- What will the future diet be?

- What is the area land available for agriculture and what will the quality of arable land be in view of global change?

- What policy measures are preferred?

Qualitative descriptions of the perspective-based interpretations of the salient uncertainties should be the result of intensive and iterative dialogue. Table 7 
summarises the participatory-developed interpretations for the hierarchist, individualist and egalitarian perspective, in terms of both world views and management styles as was used to implement the perspectives in the TARGETs model ${ }^{193}$.

\begin{tabular}{|c|c|c|c|}
\hline & Hierarchist & Egalitariam & Individualist \\
\hline economy & $\begin{array}{l}\text { moderate desired } \\
\text { economic growth }\end{array}$ & $\begin{array}{l}\text { low desired } \\
\text { economic growth }\end{array}$ & $\begin{array}{l}\text { - high desired } \\
\text { economic growth }\end{array}$ \\
\hline $\begin{array}{l}\text { population } \\
\text { \& health }\end{array}$ & $\begin{array}{l}\text { - physical limits } \\
\text { - family planning programs } \\
\text { as driving force } \\
\text { - healith as human capital } \\
\text { - health services }\end{array}$ & $\begin{array}{l}\text { - environmental and } \\
\text { sociallimits } \\
\text { - societal dewelopments } \\
\text { as driving force } \\
\text { - health as human asset } \\
\text { - social economic and } \\
\text { environmental health } \\
\text { determinants }\end{array}$ & $\begin{array}{l}\text { no limits } \\
\text { - individual possibilities } \\
\text { as driving force } \\
\text { - health as consumption } \\
\text { good } \\
\text { ageing }\end{array}$ \\
\hline energy & $\begin{array}{l}\text { - moderate technology } \\
\text { development }\end{array}$ & - enwironmental technology & - energy-efficient technology \\
\hline$\overline{\text { climate }}$ & $\begin{array}{l}\text { - amplifying effect of } \\
\text { geophysical feedbacks } \\
\text { - moderate cooling of aerosols }\end{array}$ & $\begin{array}{l}\text { - strong amplifying effects } \\
\text { of geophysical feedbacks }\end{array}$ & $\begin{array}{l}\text { - radiative effects are } \\
\text { strongly dampening effects }\end{array}$ \\
\hline water & $\begin{array}{l}\text { - supply oriented } \\
\text { stable runoff as potential } \\
\text { water supply } \\
\text { medium response to } \\
\text { dimate change }\end{array}$ & $\begin{array}{l}\text { - demand oriented } \\
\text { - clean fresh water stock } \\
\text { as potential supply } \\
\text { - ligh response } \\
\text { to climate change }\end{array}$ & $\begin{array}{l}\text { - market oriented. } \\
\text { - no limits } \\
\text { - low response to } \\
\text { climate change }\end{array}$ \\
\hline land \& food & $\begin{array}{l}\text { - present diet } \\
\text {-3.3 Gha arable land } \\
\text { - middle recuper ative power } \\
\text { of degraded land }\end{array}$ & $\begin{array}{l}\text { - vegetarian diet } \\
\text { - } 2.8 \text { Gha arable land } \\
\text { - low recuperative power } \\
\text { of degraded land } \\
\text { - negative affect of } \\
\text { temperature increase }\end{array}$ & $\begin{array}{l}\text { - American diet } \\
\text { - } 3.8 \text { Gha arable land } \\
\text { - high recuperative power } \\
\text { of degraded land } \\
\text { - positive CO2 fertilisation } \\
\text { effect }\end{array}$ \\
\hline
\end{tabular}

TABLE 7A Perspective-descriptions in terms of worldview

193 As. synthesised from the various publications on the TARCETS model, see (van Assele 1997). 


\begin{tabular}{|c|c|c|c|}
\hline & Hierarchist & Egallitarian & Indingualist \\
\hline population \& health politcy & $\begin{array}{l}\text { - fanily planning } \\
\text { - anti-abortion" } \\
\text { - selective health care } \\
\text { pollicy (cure) }\end{array}$ & $\begin{array}{l}\text { - human dewelopment (esp } \\
\text { - legulistation of abortion } \\
\text { - comprehernsive health } \\
\text { care policy (prevention) }\end{array}$ & $\begin{array}{l}\text { - legalisarion of abortion } \\
\text { market-oriented } \\
\text { health policy }\end{array}$ \\
\hline energy policy & $\begin{array}{l}\text { - no uarbon tax } \\
\text { moderate } R \& D \\
\text { programs for new } \\
\text { energy supply and } \\
\text { efficiency options }\end{array}$ & $\begin{array}{l}\text { - carbon tax towards } \\
500 \$ / \mathrm{tC} \text { in } 2020 \text {, } \\
\text { constane afrerwards } \\
\text { - R\&D programs on } \\
\text { renewable resources }\end{array}$ & - no carbon tas \\
\hline water management & $\begin{array}{l}\text { - increasing charges } \\
\text { on water }\end{array}$ & $\begin{array}{l}\text { - water-taxing } \\
\text { - active policy on public } \\
\text { water supply and } \\
\text { coverage } \\
\text { R\&D programs on } \\
\text { small-scale technology }\end{array}$ & $\begin{array}{l}\text { - market pricing of water } \\
\text { - high-tectu R\&D } \\
\text { programs if water gets } \\
\text { scarce (eg. desalmation) }\end{array}$ \\
\hline land management & $\begin{array}{l}\text { - reforestation policy } \\
\text { agricultural planning } \\
\text { (ind. irrigation, } \\
\text { fertilisers, deforest- } \\
\text { arion, reforestation) }\end{array}$ & $\begin{array}{l}\text { eco-forestry } \\
\text { (e.g-reforestation) } \\
\text { eco-agriculture (less } \\
\text { dearing, no fertilisers) }\end{array}$ & $\begin{array}{l}\text { - protection of wood } \\
\text { sector } \\
\text { - incensive agriculture } \\
\text { (ind genetic } \\
\text { engineering) }\end{array}$ \\
\hline
\end{tabular}

* the issue of abortion tur ned to be very difficult to interpret in terms of the different perspectives. Wirth reference to the Roman Catholic Church, which can be considered as an exemplar of hierarchic culture, the hierarchist is interpreted as ant:abortion; while with reference to China, which can in a certain way also be considered as a hierarchist culture, the hierarchist is interpreted as pro-abortion. "This was the most ewident example we encountered of ambiguity of Cultural Theory, also by Cultural Theorists themselwes (personat communication with Steve Rayner and Michate) Thompson).

TABLE gB Perspectiwe-descriptions in terms of management style

The above descriptions were used as starting point in the implementation of multiple model routes in the TARGETS model.

\section{STEP 4 IMPLEMENTATION OF MODEL ROUTES}

The crucial next step involves translation of these qualitative descriptions into model terms. In the case of model quantities, this means that alternative values have to be determined. This is achieved by estimating inputs and parameter values so that they reflect the interpretation from this perspective. If the scientific literature provides a range of quantitative estimates for a parameter or input, this range can be used to arrive at reasonable model choices. In case no specific quantitative 
estimates are available, the team has to decide upon representative quantitative values.

In the case of uncertain relationships, functional forms need to be reformulated. This means changing the function, or deleting, adding or changing the function's arguments. Notwithstanding their mathematical simplicity, such changes are fundamental in a conceptual sense. Alternative formulations change the dynamics of the system. Ideally, different equations are provided by the scientific literature, which can be assigned to the perspective-based interpretations of the underlying uncertainty. In practise, it is rather likely that alternative interpretations are not spelled out in the literature in explicit mathematical terms. In this case, modellers and experts have to study the perspective-based interpretation of the uncertain issue and search for an adequate translation into model terms.

Figure I I schematically represents different perspective-based model formulations in the water submodel in TARGETs ${ }^{194}$. Another example of different functional forms is the relationship between net primary production and global mean temperature in the biogeochemical cycles submodel. This relationship is modelled as a parabolic function in both the hierarchist and egalitarian model route, where it is a continuously increasing function in the model route representing the individualistic perspective. An example of alternative quantities in perspective-based model route is the value for the $\mathrm{CO}_{2}$-fertilisation factor $\beta$, which ranges from o (i.e. no effect) in

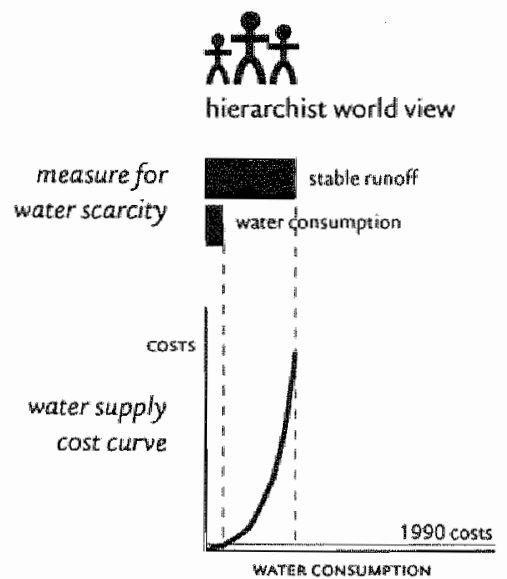

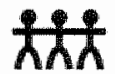

egalitarian world view

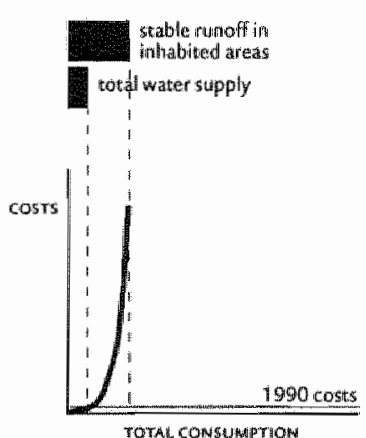

‡ individualist world wiew

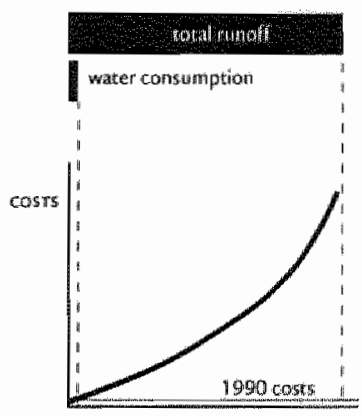

WATER COMSUMPTION

FIGURE Is Schematic representations of perspective-based formulations in water submodel 
the egalitarian model route, to 0.7 (i.e. substantial effect) in the individualistic model route. In this case, a range was provided in the scientific literature ${ }^{195}$.

\section{STEP 5 CALIBRATION}

The multiple model routes have to represent historic trends and should match available data. However, we should realise that the data is not always hard, but may contain uncertainties. The TARGETs model runs from 1900-2100, which allows for calibration on historical evidence. Each model route is calibrated on historical data ${ }^{196}$, in which effort we took uncertainty bounds into consideration. Figure 12 illustrates that notwithstanding the fundamental differences between the three model routes in the land and food-submodel of TARGETs, the historical trajectories calculated with each model route correspond with the actual historical development, while the future pathways differ significantly.

arable land - total and irrigated

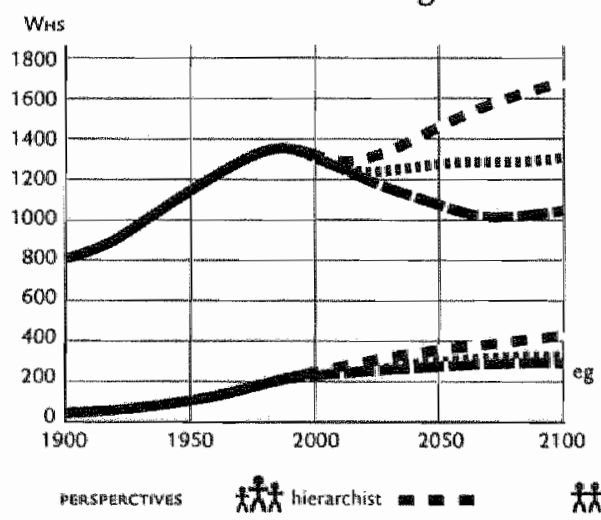

vegetable and animal food intake KCan, CaptTa pen Dar

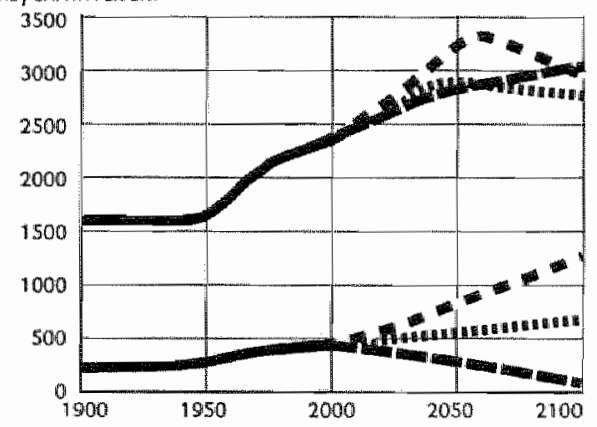

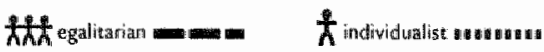

FIGURE 1 .3. Historical similarities and future divergence

\section{STEP 6 MODEL EXPERIMENTS}

The implemented and calibrated model routes allow for systematic experimentation. To this end, the distinction between world view and management style is relevant. Matching the management style of each perspective to its respective worldview is a 
technique used to assess the utopias. A utopia is a world in which a certain perspective is dominant and the world functions according to the reigning worldview.

We realise that the concept 'utopia' is normative and that use of the concept is highly controversial. It is beyond the scope of this thesis to provide a well-founded underpinning that does justice to the state of the art in political philosophy ${ }^{197}$. In this Chapter, we restrict ourselves to a short motivation why we think 'utopia' is a proper label for this particular kind of experiments. A utopia is a description of an ideal future. In that sense, it is a kind of scenario, but one that is a highly normative. A utopia reasons from a radical model of society and nature that serves as a blueprint of the future. Utopias are characterised by the trust that the imagined future will be without problems. In political philosophy, utopias are considered as a kind of thought experiments, that are logical and internally consistent ${ }^{\text {tg8 }}$. As discussed before, each perspective involves a certain worldview and a certain management style. From the viewpoint of a particular perspective, a human and an environmental system mirroring the adopted world view and management style would yield the preferred future. The utopian experiments that we propose to carry out with an IA model thus reflects the basic characteristics associated with the utopian tradition.

In the philosophical tradition, dystopias, or anti-utopias ${ }^{199}$, describe terrifying visions of the future. In terms of our dichotomy, dystopias describe either what would happen to the world if reality proved not to resemble the adopted world view following adoption of the favoured strategy, or vice versa, i.e. where reality functions in line with one's favoured world view, but opposite strategies are applied. Thus in terms of model experiments, dystopias are scenarios involving mismatches between worldviews and management styles (Figure I3) $_{3}$

future according to world view

\begin{tabular}{|c|c|c|c|}
\hline $\begin{array}{l}\text { future according to } \\
\text { management style }\end{array}$ & 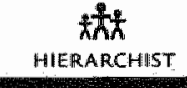 & $\begin{array}{c}\text { HAt } \\
\text { ECALITARIAN } \\
\end{array}$ & $\begin{array}{c}\hbar \\
\text { INIDIVIDUALIST } \\
\end{array}$ \\
\hline AXt HIERARCHIST & The utopla & dystopia & dystopia \\
\hline HAN EGALITARIAN & dystopia & Ahin utopia & dystopia \\
\hline finOIVIDUALIST & dystopia & dystopia & A utopha \\
\hline
\end{tabular}

FIGURE 13 Utopias and dystopias

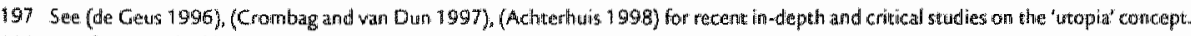


This way of generating scenarios is rather crude. The above scheme was used for the first set of scenarios. Building upon the insights gained, we systemarically explored scenarios in which the model routes varied per submodel; for example in the population and health submodel the world view was egalitarian and the management style hierarchist, while the energy submodel featured the hierarchist perspective for world view and management style and the other submodels were entirely put on the individualistic model route. Furthermore, we have also experimented with changes in perspective over time in developing scenarios ${ }^{200}$.

The result of performing utopian and dystopian model experiments is a flow of outputs representing various pathways into the future. There are different strategies for analysing these projections. One way is to evaluate whether the outcomes differ significantly from previous qualitative or model scenario studies. The next step then involves explanation of these differences. Box 4 provides an example of such an assessment. In this example population projections generated with multiple perspective-based model routes are compared with the authoritative population projections of the United Nations.

\section{Box 4 Comparison of perspective-based population scenarios with UN projections ${ }^{201}$}

The spectrum emanating from the three utopias generated with the population submodel of TARGETS runs from 7.9 to 13.0 billion people in 2100 for population, while the life expectancy projected for 2100 varies between 76 and 86 years. Comparison of our projections with the current UN projections ${ }^{202}$, of which the 2100 values range from 6.4 billion in the low projection to 17.6 in the high projection, shows a smaller range provided with perspective-based model experiments.

Why do the perspective-based projections significantly differ from the ones provided by the UN? First of all, the utopian projections all assume that the fertility transition succeeds, it is only the onset and the transition rate that differ among the three perspectives. By the end of the 2 st century the utopian projections 


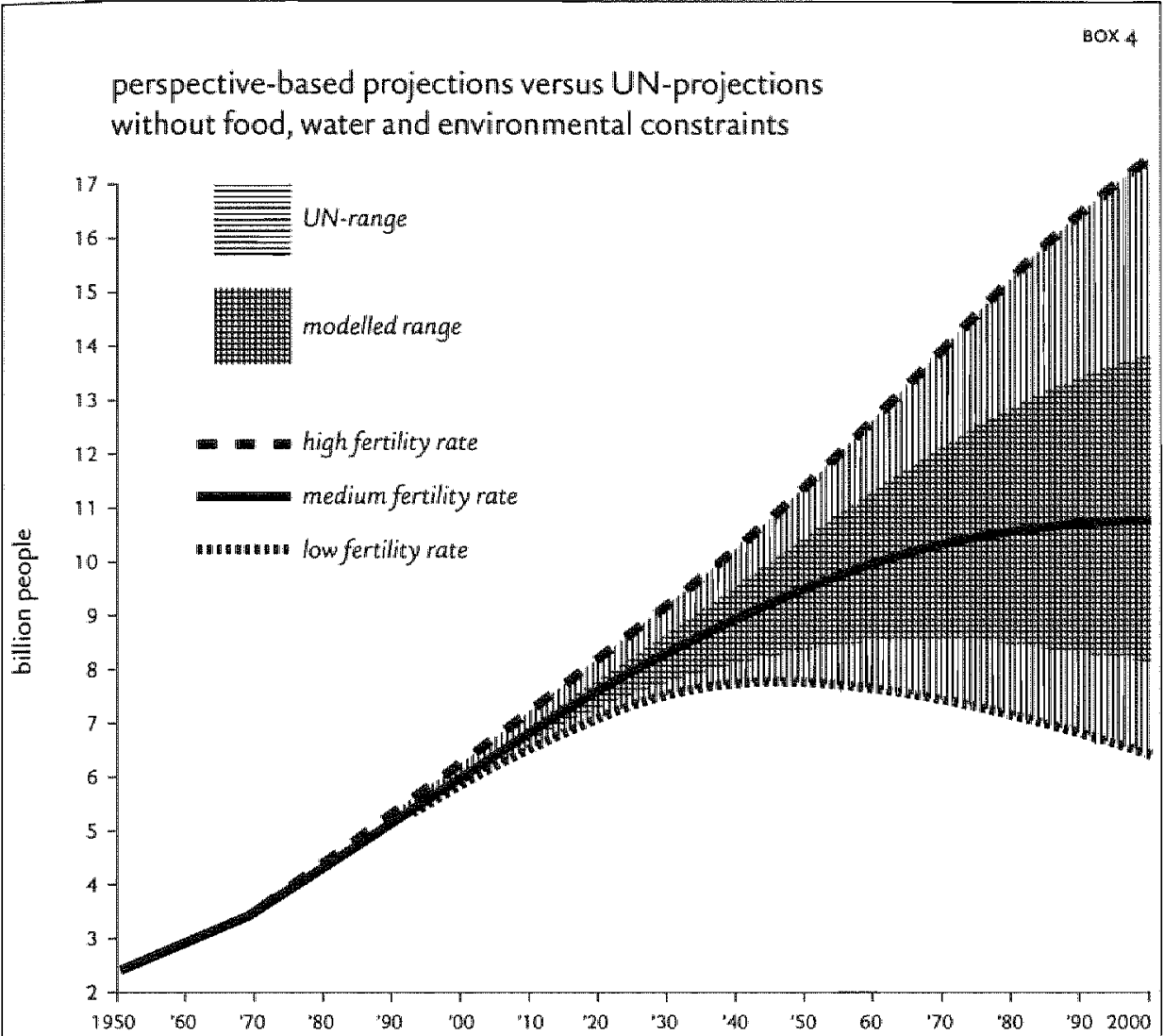

FIGURE 14 Population projections with TARGETS compared to UN range

show a fertility level approaching replacement level ( 2.1 children per woman), which eventually causes stabilisation of the population on the condition that the mortality level also stabilises. In designing their scenarios, the UN chose fertility levels which are taken constant for the next 50 to 100 years. Their assumptions with regard to fertility levels for the second half of the next century wary between 1.6 in the lowfertility case to 2.6 in the high-fertility case. The high UN projection thus comprise of futures in which the fertility level is far above replacement level, and thus yields a higher population projection than our utopian projections reveal. Secondly, the population and health submodel in TARGETS accounts for the recognised mutual relationships between fertility and mortality. The assumptions with respect to food, water and environmental circumstances underlying the utopian population projections reason from a secure food supply, access to clean fresh water for 
BOX 4

everyone and moderate environmental changes. The result is that the major health determinants, i.e. food security, safe drinking water supply and health services, evoke in any perspective an epidemiological transition towards low mortality levels. A low mortality level implies a high life expectancy, which, in turn, increases the level of human development, stimulating a decrease in fertility leve ${ }^{203}$. On the other hand, a lower fertility level causes a smaller increase in the population, thereby enhancing the availability of resources per capita, which in turn results in better health conditions. These causal relationships imply that high life expectancy excludes a high fertility level for the world at large. The perspective-based projections therefore do not comprise a scenario that describes a large excess of births over deaths for a healthy population. The high UN projection seems to presuppose such an implausible development.

The low UN projection provides a picture in which the population declines very fast, i.e. a decline of 1.4 billion in 50 years during the second half of the $215 t$ century, which corresponds to an average decline of 30 million persons per year. None of the utopian projections show a decline that can be compared to such a fast decrease. The rapid and huge decline in population as described in the low UN projection presupposes an excess of deaths over births. None of the stages of the demographic transition features a situation in which the crude death rate exceeds the crude birth rate. In other words, the low UN projection assumes a very low fertility level (i.e. a global average of 1.6 children per woman as early as 2050 , which is supposed to remain constant for the next 50 years) and/or an extraordinary situation featuring very high mortality levels. One can probably imagine a large number of deaths due to famine and severe water shortages. As said before, the utopian projections do not account for grave lack of food and water ${ }^{204}$. Other potential factors that influence mortality, such as wars and natural disasters, are ignored in our model due to them only accounting for a negligible part of the total mortality. When, for example, the Gulf War, and wars in Rwanda, Sudan, Uganda, Angola and Liberia raged in 1990, only a mere $0.6 \%$ of the total mortality could be attributed to wars ${ }^{205}$.

203 See (Niessen and Hilderink 1998 )

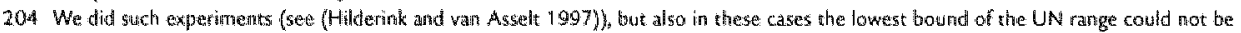
reppoduced.

205 (Worldd Bank 1993) 
Another way to analyse the model experiments, is to concentrate on differences between the various utopias. Do they significantly differ and are the differences counter-intuitive? What do these differences teach us about possible futures? Box 5 illustrates this kind of comparison by means of an analysis of the integrated utopian experiments.

\section{Box 5 Comparison of utopias ${ }^{206}$}

Figure 15 presents the three integrated utopias in 2100 . The differences between these scenarios are salient. Whereas the individualistic utopia has the highest-pressure values and the highest social and economic impact values for the selected indicators, the state of the environment is the least deteriorated, and water and energy prices are lowest. The reason is that this is a world of abundance and resilience: energy, land and water resources are huge and the environmental system is supposed to be quite insensitive to human disturbances. The egalitarian utopia shows the opposite picture: at much lower pressure and impact levels, and despite rather radical response measures, parts of the environment, notably land and climate, are in worse shape. The hierarchist utopia has high energy-related indicators, which means that this scenario symbolises an energy-intensive future. The environmental impacts are considerable, i.e. the environment is more deteriorated than in the individualist utopia, however less than in the egalitarian one.

The intriguing aspect that arose from the simulated utopias briefly described above, is that these utopias are not strictly utopian: not all is rosy, as expected beforehand. This is due to the variety of choices over widely differing issues, which has to be internally consistent. The internal consistency may result in counter-intuitive trends that contain positive and negative trends. This observation is also interesting from a philosophical point of view. Critics from the utopian tradition ${ }^{207}$ argue that the realisation of any utopia does not bring the ideal society it imagines. Also in this sense, the label 'utopian experiments' seems to be adequate in our context where these experiments show those tensions. 
$80 \times 5$

hierarchist

egalitarian

individuallist $\hbar$
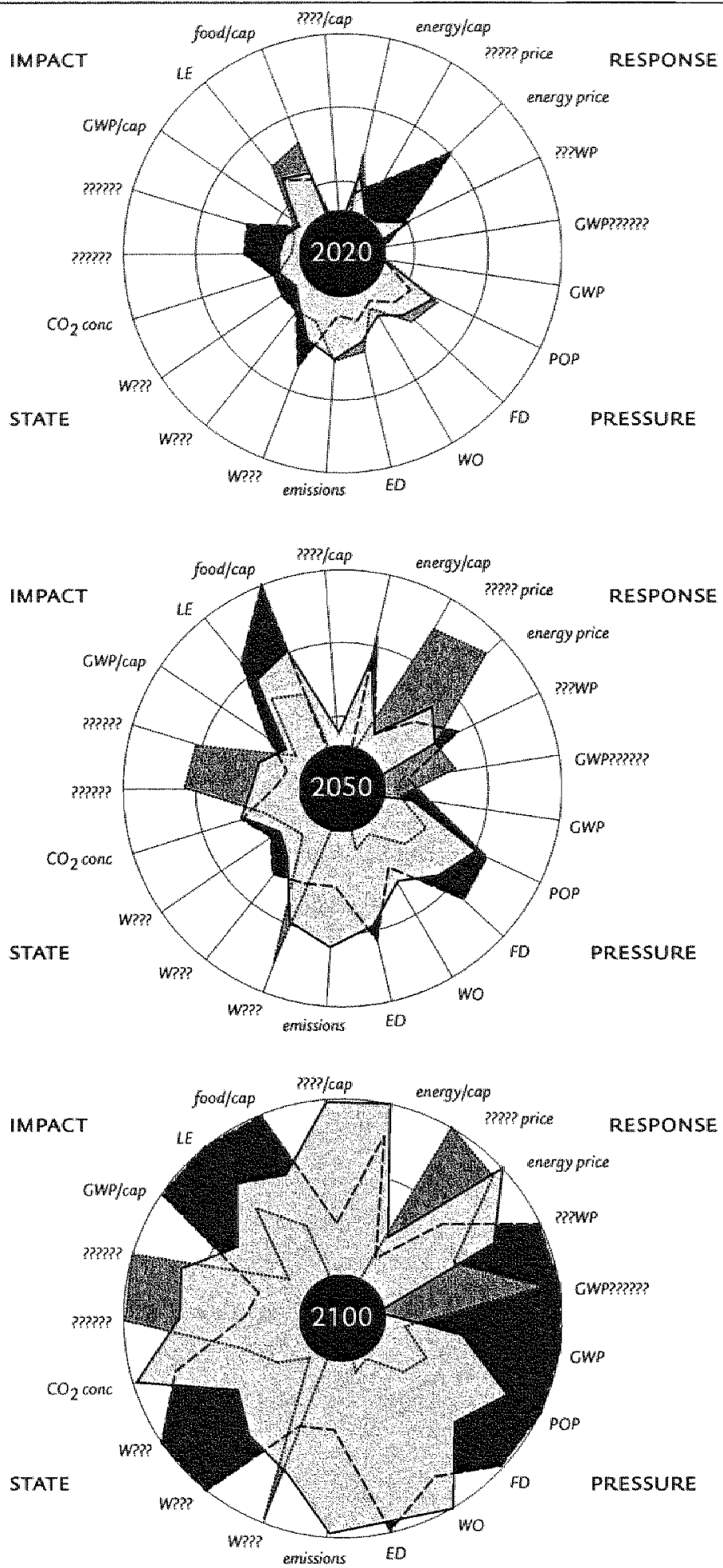

Ficure 15 Multistar representation of the three utopias over time 
By means of multiple model routes, we create a set of model runs that spans the space of possible arguments, constrained by what is known ${ }^{208}$.

\subsection{LESSONS LEARNED}

The method of perspective-based model routes is tied to formal modelling and is framed by the features of the TARGETS model. What did we learn from applying pluralistic uncertainty management in IA?

Whether right or not, the most eye-catching element of our approach was the choice of our typology. In some cases the controversial character of Cultural Theory was probably used to discredit the pluralistic approach where as in fact it seemed to be dismissed for deeper reasons. Nevertheless, this experience yields that although a typology is primarily a means to express pluralism, the level to which the typology is acceptable is crucial for the usefulness of the actual assessment. Our recommendation would be that the way in which the choice for a typology is made or the process in which a set of perspectives is developed is participatory in order to ensure that the perspectives are familiar and valid to at least the users of the assessment. Furthermore, we would like to challenge social scientists to engage in this endeavour. Such engagement is needed in order to guarantee that the variety of perspectives covers to a sufficient extent the plurality observed by social scientists. Only with help of social scientists could such a perspective-based approach go beyond superficiality ${ }^{2019}$.

The experience with TARGETS yields that it is difficult both for colleague integrated assessors, for other scientists, for the policy audience and the public at large to interpret the results. With hindsight this is not surprising if we evaluate the learning processes that took place within the TARGETs team over the course of three years. It is such a fundamental different way of dealing with knowledge and uncertainty that it takes time to understand both the principle and the outcomes, and to grasp how such insights can be used for decision support. We have underestimated the revolutionary aspect of our approach. Participating in the process seems to enhance the capability to deal with the outcomes. However, not all the intended users can participate in the development process, even not in case of a participatory set-up, so it is necessary to put a lot of effort in communicating the insights in transparent and understandable ways. To that end also new ways of summarising the insights are 
needed. Traditional representations are not suitable for communicating non-traditional outcomes.

The way perspective-based model routes were implemented was very scienceoriented. We just allowed scientific interpretations of salient uncertainties. For some of them it can be argued ${ }^{2 i s}$ that scientific knowledge of the relevant issue is necessary to arrive at a valid interpretation of the given uncertainty. However, many of the uncertainties involved in the analysis were rrans-scientific and implicitly or explicitly deal with societal developments, human behaviour or value diversity. One of the major lessons of the experiences with TARGETs is that such a trans-scientific exercise should be participatory in order to allow a mutual learning process in which those uncertainties and risks are selected that are salient in societal terms.

\section{Framework for uncertainty management}

Building upon our efforts to deal with inherent uncertainty in Integrated Assessment modelling as reported in the previous section, we can envision a framework for uncertainty management that is both pluralistic and participatory. The first step in such uncertainty management would be to unravel controversies on trans-scientific issues. The next step is to identify salient uncertainties, and to colour them according to different perspectives. The different interpretations of the sallient uncertainties can then be used to envision allternative futures, either by means of modelling or by means of scenario-exercises. The concept of utopias and dystopias, and variations on this basic scheme, can be useful in exploring tensions and conflicts in a participatory manner. The next step is then to synthesise the knowledge encountered in this systematic exercise of exploring uncertainty into robust insights and recommendations for decision-making.

The above describes a systematic procedure for exploring uncertainty in a participatory manner. Roughly speaking, two strategies for performing the different steps can be distinguished ${ }^{21:}$ :

210 Sece for example, (Ermoliev 1993).

211 Compare (Romans 19986); see Chapter 2. 


\section{A SUPPLY-DRIVEN STRATEGY}

- the controversies are defined building on literature review and document analysis.

- salient uncertainties are identified by means of sensitivity analysis or systematic ranking exercises to articulate expert judgement.

- scientists prepare different internally consistent perspective-based interpretations reasoning from an inventory of different scientific opinions ${ }^{2 n z}$, a typology or building upon analysis of prevailing perspectives (e.g. using questionnaires, discourse analysis, Delphi-methods ${ }^{2 / 3}$, etc.)

- the participants in the process enrich and extent the qualitative interpretations and suggest which ones (or combinations) are interesting from a societal point of view.

- participatory assessment of the future in terms of utopias and dystopias ('what-if'-exercises).

\section{A DEMAND-DRIVEN STRATEGY}

- the controversies are framed in a participatory process.

- the salient uncertainties associated with the controversies are identified.

- the participants colour the uncertainties, either by means of group processes or by a systematic analysis of the individual perspective-based interpretations of uncertainty the number of qualitative descriptions is reduced to a manageable number.

- scientists check the qualitative descriptions in terms of consistency and whether they do not contradict established facts.

- the identified perspectives are used to assess the future.

The above descriptions are just meant to illustrate how pluralistic uncertainty management might be set-up. Variations and combinations are imaginable.

The framework for participatory pluralistic uncertainty management is summarised in Figure $\mathbf{1} 6$.

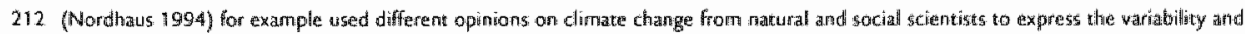

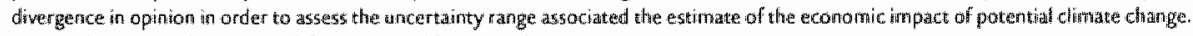
See allso (Norgan and Keith 1995 ) for a comparable approath.

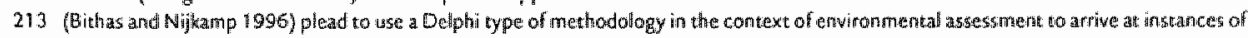
urneertain causal relationships. 


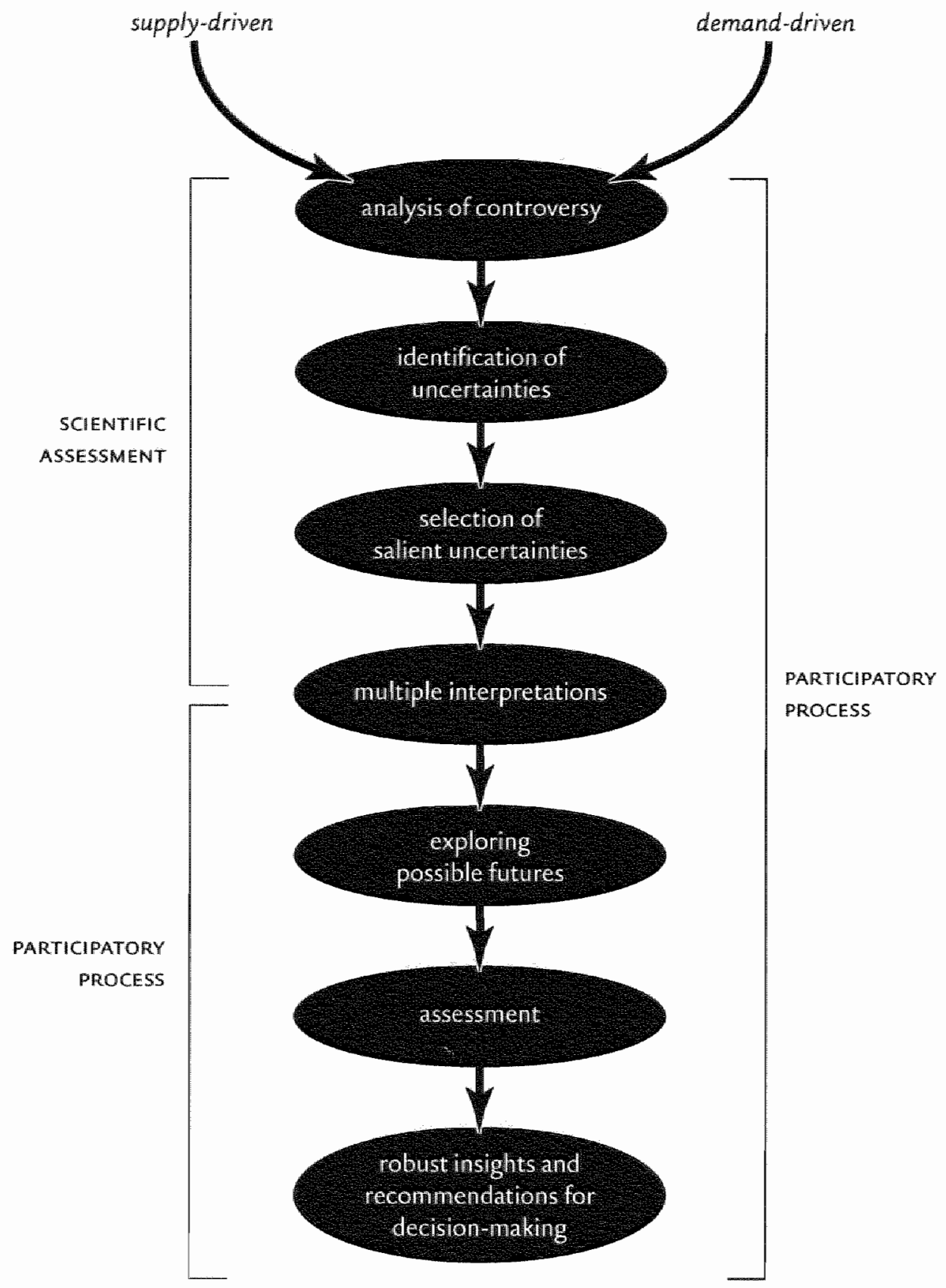

FIGURE 16 Framework for participatory pluralistic uncertainty management

In this way, uncertainty is at the core of the assessment, and remains there. This approach has considerable advantages compared to existing approaches in uncertainty analysis: 
- Pluralistic uncertainty management focuses on the most salient uncertainties.

- This approach is able to address sources of uncertainty that are not addressed by other methods for uncertainty management, esp. conflicting evidence and uncertainty due to variability.

However, notwithstanding its advantages pluralistic uncertainty management is not a panacea. Other methods of uncertainty analysis can serve as complementary tools to allow for a more comprehensive evaluation of uncertainty. In the above description we already suggested how scenario approaches could be applied in the framework of pluralistic uncertainty management. Furthermore if applied in the form of modelling, the combination with sensitivity-analysis or probability-based methods could enable to evaluate uncertainty due to inexactness compared to other sources of uncertainty.

\section{Conclusions}

Regarding complex issues, it is important to include a number of alternative views of the future in an analysis, because due to inherent uncertainty, one can never be sure which view is correct. In this Chapter we have tried to go beyond the abstract and general notion of uncertainty by identifying sources of uncertainty. The taxonomy of uncertainty as proposed in this Chapter enables to characterise uncertainty, and thereby renders it more tangible. The hypothesised generic validity of this taxonomy can in principle be tested empirically. A sound empirical testing is beyond the current thesis, but it may become a leitmotiv in future research.

Building upon the insight into uncertainty, the present Chapter outlines an approach pluralistic uncertainty management. "This approach builds on epistemological principles advocated under denominators as trans-science, realism and postnormal science, which accept uncertainty as being inherent to knowing.

The use of multiple model routes in the IA model TARGETs is discussed as a first application of the idea of pluralistic uncertainty management in Integrated Assessment. By means of this example we wanted to illustrate the potential of the pluralistic approach to uncertainty management. In this way, the methods and building blocks provided in this Chapter may be of help for integrated assessors to recognise uncertainty and to deal with it in their research efforts in an adequate manner. The challenge is to test the soundness of the approaches in concrete studies of complex issues. We hope that the example of perspective-based model routes in the TARGETS model illustrates that the framework we propose can in principle be implemented. As this 
example illustrates, this type of uncertainty management has the potential to yield new and challenging insights on complex issues: insights that will be informative and highly relevant for societal decision-making.

The aim of the following Chapters is to use the proposed insights on uncertainty in an effort to arrive at methodological improvements of decision-support on complex issues. From the analysis provided in this Chapter, we can conclude that key notions for such an endeavour are ${ }^{214}$.

- PLURALISM

- partecipation

- ROBUSTNESS 


\section{REFERENCES CHAPTER 3A}

- Achterhuis, H. (1998). The legacy of the utopia (in Dutch), Ambo, Amsterdam.

- Alcamo, J.n and Bartnicki, .) (1987). "A Framework for Error Analysis of a Long-range Transport Model with Emphasis on Parameter Uncertainty." Atmospheric Ervironment, 21(10), $2121-2131$.

- Bankes, 5. (1994). "Computational Experiments and Exploratory Modeling" CHANCE, 7(1), 50-57.

- Barnes, B, and Shapin, S. (1979). Natural Order: Historical studies of scientific culture, Sage, Beverly Hills, USA.

- Bartels, J. (1993). The history of the subject, Descartes, Spinoza, Kant (in Dutch), Agora, Kampen, the Netherlands.

- Bayes, T. (1763). "An Essay Towards Solving a Problem in the Doctrines of Chances." Phil. Trans, 53, 370-418.

- Bieck, M. B. (1987). "Water Quality Modelling: A review of the analysis of uncertainty." Water Resources Research, 23(8), $1393-1442$

- Beck, U. (1986). Risk Society: Towards a New Modiernity, Sage, London, UK.

- Beck, U. (1997). "Fatalists in the labyrinth of the risk society." The World as. Risk Society". Essays about the ecological crisis and the politics of progress (in Dutch), U. Beck, ed, De Balie, Amsterdam, the Netherlands.

- Best, $C_{\text {. }}$ Parston, $\mathrm{C}_{\text {., }}$ and Rosenhead, . . (1986). "Robustness in Practice: The regional planning of health services." 1. Opl Res. Soc, 37, 463-478.

- Biggs, B., Robinson, J. B., Tague, C., and Walsh, M. (1998). "Tools for Linking Choices and Consequences." Sustain. ability Issues and Choices in the Lower Fraser Basin: Resolving the Dissonance ${ }_{s}$ M. Healey, ed, UBC Press, Vancouver, Canada.

- Bithas, K., and Nijkamp, P. (1996). "Environmental Impact Assessment under Scientific and Informational Uncertainty." T1 96-94/5, Tinbergen Institute, Amsterdam, Rotterdam, the Netherlands.

- Boritz, J. E. (1990). "Approaches to Dealing with Risk and Uncertainty.", The Canadian Institute of Chartered Accountants, Toronto, Canada.

- Braddlock, R., Fillar, J, Rotmans, J., and Elzen, M. G. J. d. (1994). "The IMAGE Greenhouse Model as a Mathematical System." Applied Mathernatical Modelling, 18(May), 234-254.

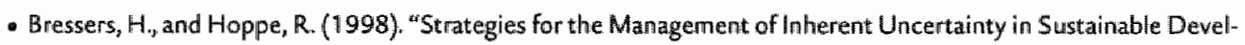
opment: Links between the cognitive and political structure of uncertainty and risk." , University of Twente, Enschede, the Netherlands.

- Caplin, D. A, and Kornbluth, J. S. H. (1975). "Multiple Investment Planning under Uncertainty." Omega, 3, 423-441.

- Colglazier, E. W. (1991). "Scientific Uncertainties, Public Policy and Global Warming: How Sure is Sure Enough?" Policy Studies Journal, 19(2), 61-72.

- Collingridge, D. (1980). The Social Control of Technology, Frances Printer, London, UK.

- Costanza, R., Farber, S., and Maxwell, J. (1989). "The Valuation and Marnagement of Wetland Ecosystems." Ecologicaf Economics.

- Coward, H.t, and Hurka, T. (1993). "Ethics and Climate Change: The greenhouse effect.", Wilfrid Laurier University" Press, Waterloo, Canada.

- Crombag, $H_{2}$ and van Dum, F. (1997). The Utopian Temptation (in Dutch), Contact, Amsterdam, the Netherlands.

- Davidson, P. (1983). "Rational Expectations: A fallacious foundation for studying crucial decision-making processes." Journal of Post-Keynesian: Economics, 5, 182-198.

- den Elizen, M. (1994). "GLobal Environmental Change: An integrated modelling approach", International Books, Utrecht, The Netherlands.

- de Geus, M. (1996). Ecological Utopias: Ecotopias and the enviranmental debate (in Dutch), Jan van Arkel, Utrecht, the Netherlands.

- de Marchi, B. (1995). "Uncertainty in Environmental Emergencies: A diagnostic tool." Journal of Contingencies and" Crisis Management, 3(2), 103-112.

- de Marchi, B., Funtowicz, S. O., and Ravetz, J. R. (1993). "The Management of Uncertainty in the Communication of Major Hazards." CEC JRC EUR 15268 EN, CEC joint Research Centre; Ispra, ttaly. 
- de Vries, H. J. M. (1989). "Sustainable resource use: An inquiry imto modelling and planning" "University of Groningen, Groningen, the Netherlands.

- den Elzen, M. C. I, Beusen, A.H. W. Rotmans, ), and van Asselt, M. B. A. (1997) "Hiuman disturbance of the global biogeochemical cycles." Perspectives on Clobal Change: The TARCETS approach, I. Rotmans and B. de Vries, eds., Cambridge University Press, Cambridge, UK.

- Dotto, L. (1993). Ethical choices and global greenhouse warming, Wilfrid Launier Uniwersity Pres, Waterloo, Canada

- Douglais, M. (1969). "Environments at risk." Ecology: The Shaping Enquiry, I. Beuthall, ed., Longman, London, UK.

- Douglas, M. (1982). "Essays in the Saciology of Perception." ,Routledge and Kegan Pauli, London U.K.

- Douglas, M., and Wildavsky, A. (1982). Risk and Culture: Essays on the Selection of Technical and Environmental Dangers, University of California Press, Berkley, USA.

- Dovers, S. R., and Handmer, J. W. (1992). "Uncertainty, Sustaimability and Change." Global Enwironmental Change. December, $262 \cdot 276$.

- Dowlatabadi, H., and Morgan, M. G. (1993) "Integrated Assessment of Climate Change." Sicience, 259, $1813-1814$.

- EnvironmentalResources. (1985). "Handling Uncertainty in Ervironmental Impact Assessment." Enwironmental Resources Ltd., London, UK.

- EnvironmentalResources. (1987). "Risky Decisions: A management strategy." "Environmental Resiources, London, UK.

- Ermoliev, Y. M. (1993). "Uncertainties and Decision Making." WP-93-22, International Institute for Applied Systems Analysis (llASA), Laxenburg; Austria

- Farber, S, and Costanza, R. (1987). "The Economic Value of Wetland Systems." fournal of Enwironmental Managernent, 24, 41-51.

- Fedra, K. (1983). "Environmental Modeling under Uncertainty: Monte Carlo Simulation:" , International Institute for Applied 5ystems Analysis (IIASA), Laxenburg, Austria.

- Friend, J.(1989). "The Strategic Choice Approach." Rational Analysĭs for a Problematic World: Problem structuring methods for complexity, uncertainty and conflict, J. Rosenhead, ed., John Wiley \& Sons, Chichester, UKK.

- Friend, 1 , and Hickling, A. (1987). Planning under Pressure, Oxford.

- Funtowicz, 5. O., and Ravetz, J. R. (1989). "Managing Uncertainty in Policy-related Researciz." Les experts sonit formels: Controverse scientifques et Decisions Politiques dans le domaine de l'enwironment, Arc-et-Semauns, France.

- Funtowicz, 5. O., and Ravetz, ). R. (1990). Uncertainty and quality in science for policy, Klwwer, Dordrecht, the Nethertands.

- Funtowicz, S. O., and Ravetz, 1. R. (1993a). "The Emengence of Post-normal Science" Science, Politics and Morality: Scientific uncertainty aryd decision-making, R. won Schomberg, ed., Kluwer Academic Publishers, Dordrecht, the Netherlands.

- Funtowicz, 5. O., and Ravetz, J. R. (19936). "Science for the Post-Normal Age." Futures, 25(7), 739-755.

- Funtowicz, 5. O., and Ravetz ${ }_{4}$ ). R (1994). "The Worth of a Sangbird: Ecological Economics as a Post-Normal Science." Ecological Economics(10), 197-207.

- Geels, F. (1996). "The Miraculous Comeback of Uncertainty and the End of Modernity" "University of Twente, Enschede, the Netherlands.

- Grendstad, G., and Selle. P. (1997). "Cultural Theory, Postmaterialism and Environmental Attitudes." Culture Matters: Essays in Memory of Aaron Willdavsky, R. J. Elis and M. Thompson, eds., Westview Press, Boulder, USA.

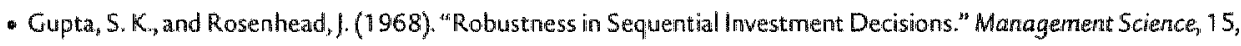
$18-29$.

- Heisenberg, W. (1962) Physics and Philosophy: The revolution in modern science, Harper and Row, New York, USA. 
- Helton, f. C. (1994) "Treatment of Uncertainty in Performance Assessments for Complex Systems." Risk analysis" $14(4), 483-511$.

- Herrion, $M_{3}$, and Fischhoff, B. (1986). "Assessing Uncertainty in Physical Constants." Annual jourtal of Physics. $54(9), 791-797$

- Hess, D. ). (1995). Science and Technology in a Multicultural World: The cultural politics of facts and artifacts, Collombia University Press, New York, USA.

- Hettelingh, J.-P. (1989). "Uncertainty in Modelling Regionall Enwironmental Systems: The generalization of at watershed acidification model for predicting broad scale effects." RR*90-3, IIASA, Laxentburg, Austria.

- Hickling, A. (1989) "Gambling with frozen fure?" Rational Analysis for a Problematic World: Problem structuring methods for complexity, uncertainty and confict, ). Rosenhead, ed, John Wiley, Chichester, UK.

- Hilderink, H. B. M., and van Asselt, M. B. A. (1997). "Population and Health in Perspective" Perspectives on Gllobal Change: The TARGETS approach, I. Rotmans and H.). M. de Vries, eds, Cambridge University Priess; Cambridge, UK.

- Hisschemöller, M., and Hoppe, R. (1996). "Coping with Intractable Controversies: the case for problem structuring in policy design and analysis." Knowledge and Policy, 8(4), 40-60.

- Hoekstra, A. Y. (1998). Perspectives on Water: An integrated nodel-based exploration of the future, International Books, Utrecht, the Netherlands.

- Hoekstra, A. Y., Beusen, A. H. W. Hilderink, H. B. M, and van Asselt, M. B. A. (1997). "Nater in crisis?" Perspectives

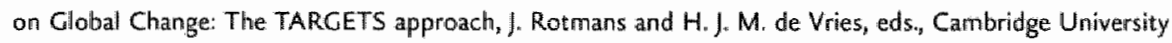
Press, Cambridge, UK.

- Hoffman, F. O., and Hammonds, J. S. (1994). "Propagation of Uncertainty in Risk Assessment: The need to distinguish between uncertainty due to lack of knowledge and uncertainty due to wariability." Risk Analysis, $14(5), 707-712$.

- Hoogerwwerf, A. (1989), "Gowernment policy: An introduction to policy science (in Dutch)." , Tjeenk Willink, Alphen aan de Rujini, the Netherlands.

- Hoppe, R., and Peterse. A. (1998). "Building stones for argumentative policy analysis (in Dutch)." "Elsevier Bedrijfsinformatie, Den Haag.

- Iman, R. L., Heiton, J. C., and Campbell, J. E. (1981). "An Approach to Sensitivity Analysis of Computer Models:" Journal of Quality Technology; 13(3), 174-183, 232-240.

- Jaeger, C. C., Chadwick, M. Wyrne, B. Funtowicz, S., Giaoutzi, M., Ginner, S., Toth, F. Jager, Jo, Durrenberger, G., Ravetz, I. R, and Casili, C. (1995). "ULYS5ES - Urban Lifestyles, Sustainability and Integrated Enwironmental Assessment - RTD proposal for the Europearn Community Framework Programme IV." "Darmstadt Technical Uluiversity, Darmstadt, Germany.

- Jaeger, C. C., Grendstad, G., van Asselt, M. B. A., Beck, A , Bieri, Lo, Dürenberger, G., Selle, P, and Stromsnes, K. (1999). "Environmental Risks and Myths of Nature: A Test Of The Cultural Theory Of Risk." Risk Analysis (stibmitted).

- Jager, W., wan Asselt, M. B. A, Rotmans, l, and Vlek, C. (1999). "Consumer Behaviour A modelling perspective in the context of integrated assessment. of global change." Sustainability in Question: The search for a concept wal framework, ]. Köhn, I. Cowdy, F. Hinterberger, and J. van der Straaten, edls., Edward Elgar, Cheltenham, UK.

- Jager, W., van Asselt, M. B. A., Rotrnans, J., Vlek, C. A. l, and Costerman_Boodt, P. (1997). "Consumer biehaviour: A modelling perspective in the context of integrated assessment of global change" 461502017 , RIMM, Bilthoven, the Netherlands.

- Janssen, M. A. (1996). "Meeting Targets," Maastrict University, Maastricht.

- Janssen, P. H. M., Slob, W, and Rotmans, J. (1990). "Uncertainty Analysis and Sensitivity Analysis: An lnwentory of Ideas, Methods and Techniques from the Literature." 95880500 , National institute of Public Health and Environmental Protection (RIVM), Bilthover, The Netherlands.

- Jasan off, 5. (1990). The fifth branch: Science advisers as palicy makers, Harvard University Pres5, Cambridge, USA. 
- Jasanoff, 5. (1991). "Acceptable evidence in a pluralistic soctety." Acceptable evidence: Science and values in risk manageinent, D. G. Mayo and R. D. Hollander, eds, Oxford University Press, New York, USA.

- Jasanoff, 5.y and Wymne, B. (1998). "Science and Decision-maling." Human Choüce and Climate Change, S. Rayner and E. Lalone, eds. Battelle Press; Washington D.C., USA.

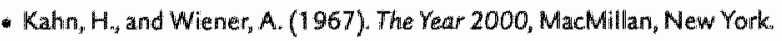

- Kahneman, D., and Twersky, A. (1981), "Variants of uncertainity. Judgement under Uncertainty: heuristics and biases, D. Kahneman, P. Slvic, and A. Twersiky, eds., Cambridge University Press, Cambridge, UK.

- Kann, A. (1998). "A Comparison of Approaches for Performing Uncertainty Analysis in Integrated Assessment Madels." 14.4, Energy Madeling Forum, Stanford Unüversity ${ }^{\text {USA. }}$

- Kant, 1. (1783). Prolegoma to rational metaphysics (in German), Riga.

- Keepin, B., and Wynne, B. (1984). "Techmical Analysis of the IIASA Energy Scenarios." Nature, 312, 691-695.

- Keynes, \#. M. (1937). "Some economic consequences of a dedining population." The Eugenics Review.

- Klir, G. ). (1996). "Uncertainty Theories, Measures and Principles." Uncertainty: Models and Measures, H. G. Natke and Y. Ben-Haim, eds, Akademie Verlag, Berlin, Germany.

- Knight, F.H. (1921). Risk, uncertainty and profit, Houghton Mifflin, Boston, USA.

- Knorr-Cetina, K, and Mulkay, M. (1983). "Science Observed." "Sage, Beverly Hills, USA.

- Koopmans, T C. (1957). Three Essayss on the State of Economic Science, ?????, New York, USA.

- Kumar, K. (1991). Utopia and Anti-Ltopia in Modern Times, Bsil Blackwell, Oxford, USA.

- Latour, B., and Woolgar, S. (1979). Laboratory Life: The social construction of scientific facts, Sage, Beverly Hills, USA.

- Lave, L. B., and Dowlatabadi, H. (1993). "Climate Change: The effects of personal beliefs and scientific uncertainty." Enwironmental Science and Techuology, 27(10), 1962-1972.

- Lazarus, M. (1993). "Towards a Fossil Free Energy Future: The next energy transition." Stockhom Enviranment Institute for Greenpeace International, Boston, USA.

- Lempert, R. I. Schlesinger M. E, and Bankes, S. C. (1996). "When We Don't Know the Costs or the Benefits: Adaptive Strategies for Abating Climate Change." Climatic Change, 33(2), 235-274.

- Lempert, R. J., and Bonomo, J. L. (1998). "New Methods for Robust Science and Technology Planning." DB-238DARPA, RAND, Santa Manica, USA.

- Manne, A., and Richels, R. (1995). "The Greenhouse Debate: Economic efficiency, burden sharing and hedging strategies." Dept. of Operations Research, Stanfiord University, Stanford, USA.

- March, ). G. (1978). "Bounded Rational ity: Ambiguity and Engineering of Choice." Bell Journal of Economics, 9, $587-608$.

- Marris, C., Langford, I., Saunderson ${ }_{\mathrm{k}}$ T., and O'Riordan, T. (1997). "Exploring the Psychometric Paradigm: Comparisons between aggregate and individ wal analyses." Risk Analysis, 17(3), 303-312.

- Marshak, ل. (1955). "Probability in the Social Sciences." Mathematical Thinking in the Social Sciences, P. F. Lazarsfeldt, ed, Clencoe.

- Morgan, G. M, and Henrion, M. (1990). Uncertainty - A Guide to Dealing with Uncertainty in Quantitative Risk and Policy Analysis, Cambridge University Press, New York, USA.

- Morgan, M. G. and Keith, D. W. (1995). "Subjective Judgements by Climate Experts." Environmental Science and Technology, $29(10), 468-46$.

- Natke, H. G., and Ben.Haim, Y. (1996). "Uncertainty: a discussion from various points of view." Uncertainty: Models and measures, H. G. Natke and Y. Ben-Haim, eds., Akademie Verlag, Berlin, Germany.

- Niessen, L. W. and Hilderink, H. (1997). "The Population and Health Submodel." Perspectives on Global Change: The TARGETS approach, J. Rotmans and B. de Vries, eds., Carnbridge University Press, Cambridge, UK.

- Nordhaus, W. D. (199.4). "Expert Opinion on Climate Change." American Scientist, 82, 45-51.

- Nowotny, H. (1987) "Concepts of Science for policy." Science, Politics and Morality" Scientific Uncertainty and Decision Making, R. Von Schombeing, ed., Kluwer Academic Publishers, Dordrecht, $63-78$. 
- Nowotny, H. (1993). "A New Branch of Science, Inc. Science, Politics and Morality: Scientife uncertainty and decision-making, R. von Schomberg, ed. Kluwer Academic Publishers, Dordnecht, the Netherlands.

- O'Neill, R. V. "Error analysis of ecological madels." Thima National Symposium on Radioecology, Oak Ridge, USA, 898-908.

- ONeill, R. V, and Gardner, R. H. (1979). "Sources of Uncertainty in Ecological Models." Methodology in Systems Modelling and Simulation, B. P. Zeigle; M. S. Elzas, G. I. Klir, and T. I. Oren, eds., North Holland Publishing Company, Amsterdam, the Netherlands.

- Oreskes, N., Shrader-Frechette, K., and Belitz, K. (1994) "Werfication, Validation, and Confrmation of Numerical Models in the Earth Sciences." Science, 263(February), 641.646.

- O"Riordan, T., and Jordan, A. (1999). "Institutions, Climate Change and Cultural Theory: Towards a common analytical framework." Clobal Enwironmental Change, 9, 81-93.

- ORiordan, T. Marris, C, and Langford, 1. (1997) " Irnages of Science Underlying Public Perceptions of Risk.",$R$. Society, ed.

- Pah-Wostl, C., Jaeger, C. C., Rayner, S., Schaer, C., van Asselt, M. B. A., Imboden, D., and Vckowski, A. (1998). "Regional Integrated Assessment and the Probiem of Indeterminacy." Vhews from the Alps: Regional Perspectives on Climate Change, P. Cebon, U. Dahinden, H. C. Dawies, D. Imboden, and C. C. Jaeger, eds., MIT Press, Cambridge, USA.

- Parson, E. A. (1996). "Three Dilemmas in the Integrated Assessment of Climate Change." Climatic Change(34), 315-326.

- Pendergraft, C.A. (1998). "Human Dimensions of Climate Change: Cultural Theory and collective action." Climatic Change, 39, 643-666.

- Pickering, A. (1992). "Science as Practise and Culture." "University of Chicago Press, Chicago, USA.

- Proctor, ). D. (1998). "The Meaning of Clobal Ervironmental Change: Re-theorizing culture in human dimensions research." Global Environmentaf Change, 8(3), 227-248.

- Raymer, S. (1984). "Disagreeing about Risk: The Institutional Cultures of Risk Management and Planning for Future Generations." Risk Analysis, Institution and Public Policy, S. C. Hadden, ed., Associated Faculty Press, Port Washington, USA.

- Rayner, S. (1991). "A Culturall Perspectiwe on the Structure and Implementation of Clobal Environmental Agreements." Evaluation Review, 15(1), 75-102.

- Rayner, S. (1992). "Cultural Theory and Risk Analysis. "Social Theory of Risk, G. D. Preagor, ed., Westport, USA.

- Rayner, 5. F. (19187). "Risk and relativism in science for policy." The social and cultural construction of risk, B. B. Johnson and V. T. Covello, eds., Reidel, Dordrecht, the Netherlands.

- Risbey, J., Kandlikar, M, and Patwardhan, A. (1996). "Assessing lintegrated Assessments." Climatic Change(34), 369-395.

- Robinson, J. B. (1991). "Modelling the interactions between human and natural systems." litternational Science Journal $(130), 629-6477$.

- Roe, E. (1998). Taking Complexity Seriously: A Policy Anatysis, Triangulation and Sustainable Development, Kluwer Academic Publishers, Boston, Dordrecht.

- Rohen, Y. (1988). Uncertainty Analysis, CRC Press Inc, Bioca Raton, USA.

- Root, T, and Schneider, 5. (1995). "Ecology and Clmate: Research strategies and implications." Science, 269(52), 334-341.

- Rosenas, P. M. (1992). Post-Modernism and the Social Sciences: mnsights, inroads, and intrusions, Princeton Uniwersity Press, Princetion, USA.

- Rosenhead, ). (1989) "Rational Analysis for a Problematic World: Problem structuring methods for complexity, uncertainty and conflict." ,John Wiley \& Sons, Chichester, UK. 
- Rathman, D. Robirson, In and Biggs, D. (1998 (in press)). "Signs of Life: Linking lndicators and Models in the Context of QUEST." Ecological Economics and tntegrated Asessment: A participatory process for including equity, effieiency and scale in decision-making far sustainabihity, R. Costanza and S. Tognetri „eds., SCOPE, Paris: Firance.

- Roumans, ). (1998a). "Integrated thinking and acting: a necessary good (in Dutch)." $1 \mathrm{ClS}$, Masatricht, the Netherllands.

- Rotmans, J. (19986). "Methods for 1A: The challenges and opportunities ahead" Enwironmental Modelling and Assessment, 3(3, Special issue: Challienges and Opportunities for lntegrated Environmental Assessment, $)$ Rotmans and P. Vellinga, eds.), $155-179$.

- Rotmans, ). and de Vries, H.J.M. (1997). "Perspectiwes on Gilobal Change: The TARGETS approach." Cambridge University Press, Cambridge, UK.

- Rotmans, $)_{\text {a }}$ and van Asselt. M. B. A. (1999). "Pierspectives on a Sustaimable Future." International journal for Sustainable Development, $1(3)$.

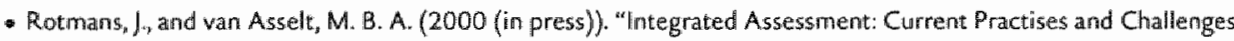
for the Future." Ecological Economics and Integrated Assessment: A participatory process for including equity, efficiency and scale in decision-making for sustainability, R, Constanza and S. Tognettit, eds, SCOPE, Paris $s_{i p}$ France.

- Rotrnars, J., wan Asselt, M. B. A., de Buinin, A. J., der Elzen, M. G. J., de Greef, J, Hilderink, H., Hoekstra, A. Y., Janssen, M. A., Koster, H. W., Martens, W. J. M., Niessen, L. W., and de Vries, H. J. M. (1994). "Culobal Change and Sustaimable Dewelopment: A Modelling Perspective for the Next Decade." RVMM-report no. 461502004, National linstitute of Public Health and the Environment (RIM), Bithoven, The Netherlands.

- Rowe, W. D. (1994) "Understanding Uncentainty." Risk analysis, 14(5), 7443-750.

- Sabatier, P. A. (1987). "Knowledge, policy-oriented learning, and policy change. An advocacy coal ition framework." Krowledge: creation, diffusion, wilization, $8(4), 649-692$.

- Savage L. J. (1962). "Bayesuar Statistics." Recent Dewelopments in Information and Decision Processes, Machol and Gray, eds. Nlew York, USA.

- Scholz, R. W. (1983). "Decisionamaking under Uncertainty." Elsevier scientific publishers, Amsterdam, the Netherlands.

- Schwarz, M., and Thompson, M. (1990). Divided We Stand: Redefining Politics, Technology and Sacial Choice, Harvester Wheatsheaf, New York, USA.

- Shackle, C.L. \$. (1955). Uncertainty in Economics and Other Reffections, Cambridge University Press, Cambridge, UK.

- Shackley, 5, and Wynne, B. (1995). "Integrating Knowledges for Climate Change: Pyramids, Nets and Uncertainties." Clobal Enwironmental Change, 5(2), 113-126.

- Silbergeld, $E_{n}$ K. (1991), "Rísk Assessment and Risk Management. An uneasy divorce." Acceptable Evidence: Science and Values in Risk Management, D. G. Mayo and R. D. Hollander, eds., Oxford University Press, New York.

- Simon, ). L. (1980). "Resources, Population, Environment: An Oversupply of Fallse Bad News." Science, 208, 1431.1137.

"Simon, J. L. (1981). "Against the Doomsdayers." The Ultimate Resource, Princeton University Press, Princeton, USA.

- Thompson, M., Ellis, R., and Wildavsky, A. (1990). Cultural Theory, Westwiew Press, Boullder, USA.

- Tversky, A. and Kahneman, D. (1974). "Judgement under Uncertainty: Heuristics and Biases." Science, 185, 1124.1131.

- Tversky, A, and Kahneman, D. (1980) "Causal Schemes in Judgements under Uncertainty." Progress in Social Psychology, M. Fisthbein, ed., Lawrence Ertbaum Associates, Hillsdalle, USA. 
- Tversky, A. and Kahneman, D. (1981). "The Framing of Decisians and the Psychology of Choice." Science, 211 , $453-458$.

- UN. (1993) "Word Population Prospects: The 1992 revision" ST/ESA/SER.A/135, United Nations, Department for Economic and Social Information and Policy Analysis, New York, USA.

- UN. (1995). "World Popullation Prospects: The 1994 revision." "New York, USA.

- van Asselt, M. B. A. (1997). "TARGETS for ULYSSES: Work package." "EAWAG, Dubendorf, Switzerland.

- van Asselt, M. B. A. (1999). "Uncertainty in Decision Support: From problem to challenge" Risk Analysis (submitted).

- van Asselt, M. B. A., Beusen, A. H. W. and Hiderink, H. B. M. (1996). "Uncertaimty in Integrated Assessment: A Social Scientific Approach." Enwironmental Modelling and Assessment, $1(1 / 2), 71-90$.

- van Asselt, M. B. A., and Rotmans, 1. (1995). "Uncertainty in Integrated Assessment Modelling" A Culltural Perspective-based Approach." RIVM-report no. 461502009, National Institute of Public Healith and the Environment (RVM), the Netherlands; Bïlthoven.

- van Asselt M. B. A., and Rotmans, J. (1996). "Uncertainty in Perspective." Global Envirormental Change, 6(2), $121-157$.

- van Asselt, M. B. A, and Rotmans, J. (1997). "Uncertainties in perspective." Perspectives on Clobal Change: the TARGETS approach, J. Rotmans and B. de Vries, eds., Cambridge University Press, Cambridge, UK.

- van Asselt, M. B. A, and Rotmans, ). (1999). "Perspectives and the subjective dimension in modelling" Climate Change: an integrated perspective, D. Janssen, W. J. M. Martens, J. Rotmans, and O. J. Vrieze, eds, Kluwer, Dordirecht, the Netherlands.

- van Asselt, M. B. A., Storms, C. A. H. M., Rijlkens-Klomp, N., and Rotmans, 1. (1998). "Towards Visions for a Sustainable Europe: An overview and assessment of the last decade of European scenario studies." 198-EO01, ICIS, Maastricht, the Netherlands.

- van de Graaf, R. (1985) "Strategic Choice in LPG policy." Evaluation of Complex Policy Problems, A. Faludi and $H$. Voogd, eds., Delftsche Uitgevers, Delft, the Nether|ands.

- wan der Sluijjs, I., and Schulte Fischedick, K. (1997). "Dealing with Uncertainty in Science for Enwironmental Policy: An inventory of theories and approaches (in Dutch)." 97017 , University of Utrecht: and the Rathenau Institute, Utrecht, the Netherlands.

- wan der Slü̈is, J. P. (1997). "Anchoring amid uncertainty," Utrecht Uniwersity, Utrecht, the Netherlands.

- van Eetten, M. (1999). Dialogues of the Deaf: Defining New Agendas for Environmental Deadlocks, Eburon, Delft.

- van Vlimmeren, $1 . C_{n} C_{y}$, Don, F. J. H, and Okker, V. R. (1991). Composition and pattern of forecast uncertainty due to unreliable data: further results." 81 , Cintral Planning Bureau, The Hague, the Netherlands.

- van Witteloostuijn, A. (1986). "Choice-theory versus Biehaviourism: A paradox." 187, Univer sity of Groningen, Groningen, the Netherlands.

- van Witteloostuijn, A (1987). "Uncertainty in Psychology: A look beyond the non-differentiated approach." RM 87-020, Maastricht University, Miasastricht, the Netherlandis.

- Vesely, W. E, and Rasmuson, D. M. (1984). "Uncertainties in Nuclear Probabilistic Risk Analyses." Risk Analysis, 4, $313-322$

- won Schomberg, R. (1993). "Controversies and Political Decision Making." Science, Politics and Morality: Scientific uncertainicy and decishon-making, R. von Schomberg, ed., Kluwer Academic Publisher, Dordrecht, the Netherlands.

- Wallsten, T. S. (1990). "Measuring Vague Uncertainties and Understanding their Use in Decusion Making" Acting under uncertainty: Multidisciplinary conception, G. M. von Furstenberg, ed., Kluwer Academics Publishers, Dordrecht, the Netherlands.

- Weinberg, A. M. (1972). "Science and Trains-Science." Minerua, 10, $209-222$

- Weimberg. A. M. (1973) "Letter to Science." Science, $180,1124$. 
- Winsemisus P. (1986). Gwest at Home: Views on enwironmental management (in Dutch), Samson Tjeenk Willink, Alphen aan de Rijn, the Netherlands.

- WorldBank. (1993), World Development Report 1993. Investing in Mealth, Oxford Uniwersity Press, New York, USA.

- WRR (1994). Sustained Risks: A Lasting Phenomenom, SDU Uitigeverij, The Hague, The Netherlands.

- Wynne, B. (1992). "Uncertainty and Enwironmental Learning; Reconceiwimg science and policy in the prewentive paradigm." Global Enwironmental Change, 2(june), 119-127.

- Zimmermann, H. J. (1996), "Uncertainty Modelling and Fuzzy Sets." Uncertainty: Models and Measures, H. G. Natke and Y. Ben-Haim, eds., Akademie Verlag, Berlin, Cermany. 


\section{Risk}

Risk refers to debates about the possibility that something might go wrong. Risks are rooted in human behaviour', or in natural surprises or extreme events (also referred to as external risks). The notion of 'risk' traces back to the $13^{\text {th }}$ century ${ }^{2}$. The word 'risk' is derived from the Italian word 'rischiare' that has its origins in the Greek notion 'rhiza' which literally means 'root' or 'cliff'. This word got the metaphorical meaning of everything that sticks out, and thereby can constitute a danger. The word risk circulated in Italy in the context of insurance against the loss of shiploads coming from the Orient through, for example, storms or piracy. The notion of 'risk' is still used in the context of insurance, but apart from that it has become a widely applied, often used and ambiguous notion. It is used in the field of business, technology, health, politics, sport, games, and even in love. 'Risk' originally had a negative connotation, as something dreadful (for example, in the case of nuclear energy). It is now also used positively, namely as a challenge (for example, in the case of stock exchange) or even as a kick that one is seeking (for example, bungy-jumping).

\footnotetext{
1 (Cezondheidsraad 1996)

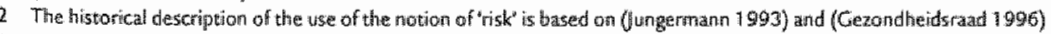

3 The latter two axamples do not build on extensiwe scientific research, but are derived from common life experience.
} 
Apart from this common use, risk is also used as a concept in scientific analysis for decision support. An early example of this kind of analysis ${ }^{7}$ dates back to the introduction of electricity at the end of the $19^{\text {th }}$ century: men like Edison and Thomsom made the first assessments concerning the risks associated with the use of electricity ${ }^{5}$. Since the early $19705^{6}$, risk analysis has become an established field of research. It was originally rooted in engineering and decisions sciences? ${ }^{7}$ During the seventies the notion of 'risk' was mainly confined to the natural sciences. Probabilistic risk assessment was the dominant method. "The rise of risk analysis is strongly connected with the nuclear energy controversy ${ }^{8}$ and a number of technological accidents" ${ }^{9}$, esp. the Bhopal accident in India (in 1984) and the Chernobyl disaster in the former USSR (in 1986). Since the 8os, 'risk' has gained importance as a concept in assessment activities ${ }^{\text {(t) }}$, esp. in technology assessment". In the 1980 , efforts have been made to define 'tolerable risks'.

The notion of risk is still central to societal debates on technology. Nowadays, all undesirable side-effects of modern technology are subsumed under the notion of 'risk", whether these are associated with a single system (e.g. a technological site) or product (e.g. an airplane, a medicine), technological innovations (e.g. gene-technology) or large-scale projects (e.g. water reservoirs, airports) ${ }^{12}$. The last decade, the concept of risk is also increasingly used to refer to environmental hazards, like ozone depletion and climate change ${ }^{13}$. Risk analysis is furthermore becoming part of assessment activities for the purpose of environmental policy making't. Since the beginning of the gos, it is advocated to use the concept of risk to address general aspects of decision-making in modern society ${ }^{15}$. These recent developments seem to onset a trend in risk analysis to extend beyond a specific case.

Contemporary risk analysis can be described as the scientific approach to risk for public policy making on technological, environmental and health issues ${ }^{\text {t6 }}$. It now

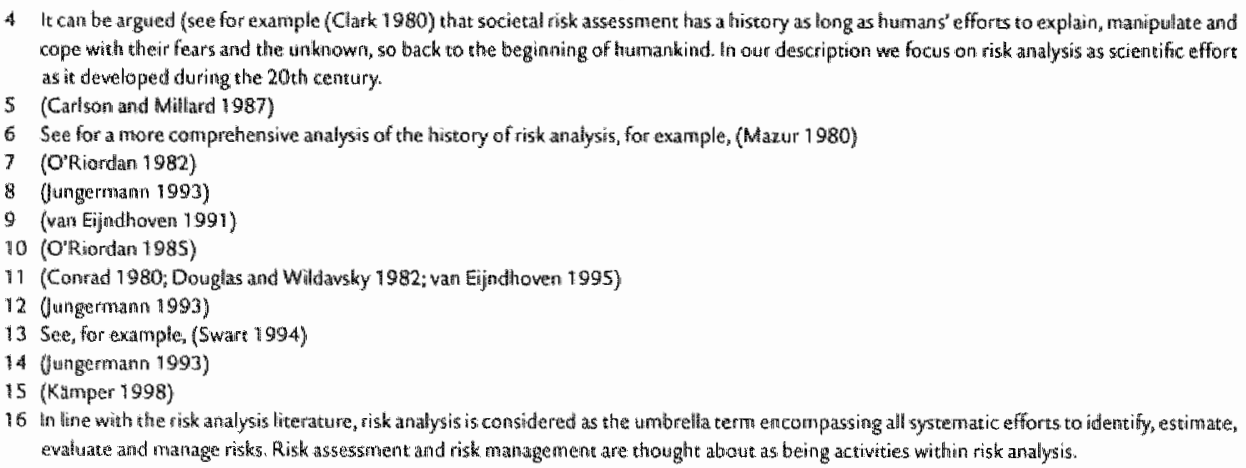

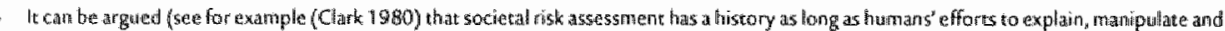

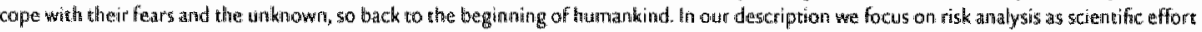

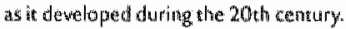

5 (Cirlonin and Mitlatid 1987)

6 See for a pore comprehensive analysis of the history of risk analyshs, for exarrple, (Mazur 1980)

(ORiardan 1982).

(Gumgermanin 1993)

(wank Eijnd howem 1991)

10 (ORikindan 1985)

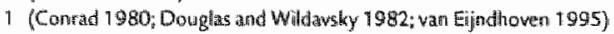

12 (Lumgranan 1993)

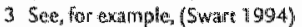

14 ("ungerman 1993)

15 (Kumper 1998)

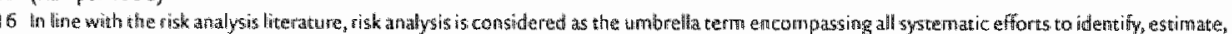

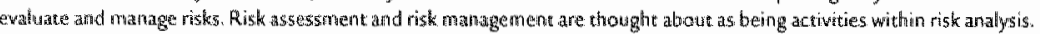


has become an active field involving disciplines as diverse as mathematics, statistics, epidemiology, toxicology, biology, engineering, technology studies, system analysis, environmental sciences, law, psychology, decision sciences, sociology, anthropology, geography, history, economics, management science, policy sciences and philosophy. Notwithstanding the involvement of so many disciplines, we can doubt whether the risk community is in fact interdisciplinary in the sense as expressed by Schneider ${ }^{17}$ : "Interdisciplinary implies an original combination from the integration of multidisciplinary ideas or methods that permits explanation or assessment not achievable of un-integrated application of multidisciplinary ideas or tools". There is a clear tendency to treat the issue of risk from the perspective of one's own discipline and speciality $^{18}$. There is not (yet) a universal definition of risk: the Society for Risk Analysis tried to arrive at an accepted unique definition of risk, but so far without success. It may therefore not be surprising that there is no common paradigm that integrates the different aspects of risk and that guides risk analysis.

This Chapter explores the risk concept and its relevance for decision-support on complex, incompletely known societal issues. The aim is to sketch a framework for integrated risk analysis. To that end, the following steps are taken:

- the debate in the risk community is analysed

- an attempt is made to explore whether, and if so, how the partial contributions of the different schools of thought can be synthesised into one framework, that may provide the basis for a new, integrated form of risk analysis

We do not stop here, but continue with exploring the features of such an integrated risk analysis. In this effort, we will argue in this Chapter that it is necessary to:

- classify risk

- (re)define risk

- develop methodologies that enable multiple risk assessments

- explore guidelines, tasks and tools for participatory processes

- design formats for risk statements

Building upon three decades of risk analysis, we will try to take the above issues a step further to concrete suggestions how to implement integrated risk analysis. The structure of our search towards an integrated form of risk analysis is summarised in Figure I.

17 (Schneider 1997)

18 (Conrad 1980), Jasanoff 1993) 


\section{analysis of different schools of thought}

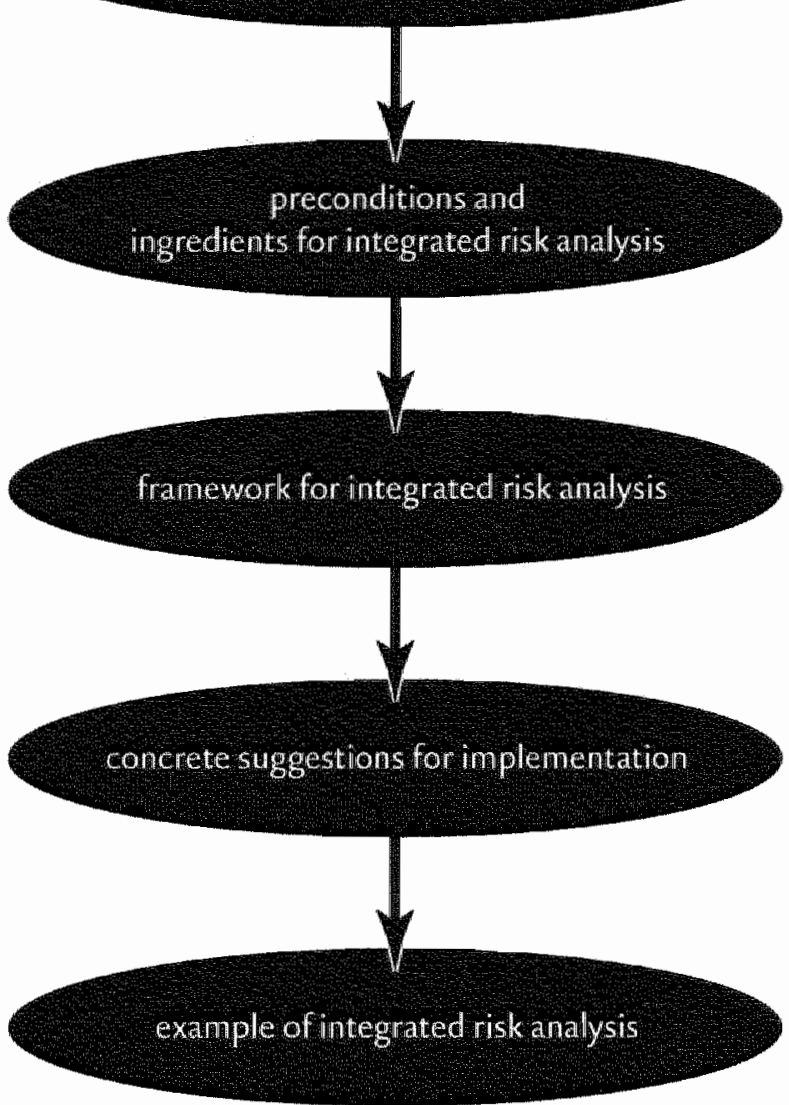

FIGURE I Structure of Chapter

\section{The risk debate}

Analysis of the scholarly literature on risk yields that there used to be a serious division of opinion concerning fundamentals. The risk community is still somewhat fragmented, although attempts are made to bridge the gaps. Out of the scholarly literature, two key issues emerge that underlie the differences of opinions, i.e.:

- How to define risk?

- How risky are modern hazards? 
On each question, roughly two extreme positions can be identified. In the discussions pertaining to defining risk, the objectivists and constructivists ${ }^{20}$ can be distinguished $^{21}$. Concerning the second issue, we find scholars holding the position that hazards have increased and are increasing versus those that argue that modern society is only more sensitive to risk. Both discussions have inyplications for risk analysis activities: thus far they have prevented the development of a common cognitive framework that can guide risk analysis and that would enable to compare specific risk analyses in terms of quality. It can be argued that the diversity of approaches is useful, because each framework has its pros and cons. On the other hand, a common basis would help to advance to a mature scientific method ${ }^{2 x}$.

It is beyond the scope of this Chapter, to provide a full account of all positions and viewpoints in the risk debate. For the sake of brevity and simplicity, we therefore limit ourselves to describe the extreme positions in a rather black and white manner, in order to highlight the major controversy. We aim to discuss the range of opinions by means of sketching the extreme, probably somewhat charicatural in view of the current state-of-the-art, positions related to the two controversial issues. Such an analysis can provide a basis for exploring the question whether, and if so, how the partial contributions can be synthesised.

\section{I.I. THE DEBATE ON RISK DEFINITIONS}

Risk is not a physical substance that can be directly measured. Risk is a kind of attribute ascribed to the unknown future: the real dangers and hazards are only known afterwards ${ }^{23}$. Risks exist only in the artificial world of risk analysis. Risk is a construct. The central question that underlies the debate on risk definitions is whether it is a construct that can be defined univocally, or whether it is a social construct, that is given a meaning through social processes.

We can distinguish between formal and informal definitions of risk. Formal definitions generally stem from especially statistics and economics. In most formal definitions, risk is defined as some function of probability (i.e. the likellihood of consequences) and negative utility (the seriousness of the impacts) ${ }^{24}$. An example of a

\footnotetext{
20 This fabelling is in accondance with the terminology as proposed by (Linnerooth-Bayer and Thompson 1997)

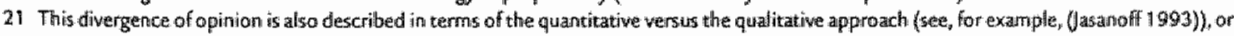
the naive positiwists wers us the cultural relativists (Shrader-Frechette 1991), or the seperatist versus sociological wew ((Mayo and Htollander 199:)

22 See for example (Jasanoff 1993)

23 (Douglas and Wildavsky) 1982; Wlek 1990)

24 (Hendriidoc 1991)
} 
formal definition is the one applied in the safety literature, in which risk is defined as the probability of an adverse future event multiplied by its magnitude ${ }^{25}$. Apart from these singular definitions, so-called 'combination functions' (i.e. aggregates of singular measures) have been proposed to assess risks ${ }^{26}$, such as the 'probability-weighted sum of possible undesired consequences'. An example of an informal definition is 'the set of undesired consequences associated with a certain activity" ${ }^{\prime 7}$. Informal definitions appeared in response to the vague sense that what is experienced as being risky may be not fully or nor adequately grasped by formal definition ${ }^{28}$. Informal definitions are generally proposed by social scientists or by societal actors in actual risk debates.

Empirical research on risk perception ${ }^{29}$ shows quite convincingly that the risky events "that kill people, are not necessarily the ones that anger and frighten citizens ${ }^{330}$. In other words, a gap between scientific estimates and risk estimates of lay people is observed. To discriminate between the 'scientific definition' and the 'lay perception', the distinction between 'objective' and 'perceived' risk was explicitly introduced by Starr" ${ }^{31}$, who is generally considered to be an important scholar belonging to the so-called 'objectivist' school of risk analysis. 'Objective risks' then are the "real, actual, objective, measurable risks that obey the formal laws of statistical theory"32. 'Perceived risks' are "subjective risks inaccurately perceived by non-experts"33. Differences between objective and perceived risks are attributed to simple misperceptions, biases or plain deviousness ${ }^{34}$. With reference to the confined finding in psychological research that citizens often overestimate involuntary risks, the objectivists have it that perceived risks are inherently wrong. In the same line of reasoning the distinction is made between 'risk assessment' and 'risk management ${ }^{35}$. Risk assessment is considered as the "hard" analysis that measures the "real" risks ${ }^{36}$. It is the process of estimating the risks associated with an activity, practise or substance ${ }^{37}$. Risk management comprises the "soft" administrative and political procedures to

\footnotetext{
2.5 See, for examples (Adians 1995)

2.5 See (Vlek 1990) for a comprehensive overwicw

27 (Tweedekamer 1989)

218 (N): 1990 )

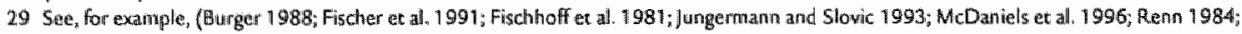
Slovic 1987; Slowic et á. 1982; Weinstein 1984; Winne 1982)

30 (Sandiman 1989)

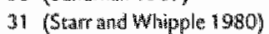

32 as quord from Chapter 5 of the 1992 Britas hoyall Sociedy repare on risk assessment (Royal Society 1992).

33 thitid.

34 (Oway and won Winterfeldt 1923 )

35 The distinction was jutroduced in the earfy 80 by the US Restarch Council (NationalResearchConncil 1983) and was elaborated on in (Russel and Cruber 1987 ).

37 (Malayo and Hoilander 1991)
} 
deal with risks ${ }^{38}$. It is the process of deciding what to do about such risks ${ }^{39}$. The vast and sophisticated literature in this objectivists' paradigm ${ }^{40}$ assumes that the right expert calculations would be enough to settle questions about worthwhile risks.

There are two major types of criticism on the above objectivists' paradigm:

- criticism within the framework sketched by the objectivists

- fundamental criticism on the objectivists' basic principles

Both types of criticism will be discussed below.

First, the measurability of the two components, i.e. probability and damage, is questioned, because of the unreliability of historical records ${ }^{41}$, uncertainty with regard to cause-effect relationships ${ }^{42}$, and the absence of an agreed scale for measuring the magnitude of damage ${ }^{43}$. According to the Bayesian school of thought ${ }^{44}$, probability is not a property inherent to the event, but a statement expressing an observer's judgement that it will occur. "There is no "correct" probability that resides somewhere in reality" 45 . Probabilities are thus subjective "degrees of belief" ${ }^{* 6}$. So if probability is inherently subjective, experts' risk estimates are not neutral and objective.

It is furthermore argued that it is controversial which probable events should be considered: only the major negative outcome(s), or all imaginable outcomes, whether positive or negative, direct or indirect effects? ${ }^{47}$ Merely casualities, deaths and material damage, or also environmental impacts, and social effects like social anxiety or even policical and social disorder ${ }^{4^{8}}$ How far to go in considering higher-order consequences? ${ }^{49}$ How to treat partial contributions to impacts, such as rendering people more susceptible to other risks? ?5 $^{\circ}$ And even if it is decided which damages to consider how to combine the relevant probabilities and magnitudes of damage into an overall risk estimate? A generally accepted aggregation rule is lacking ${ }^{51}$, and can probably any how not be established definitively.

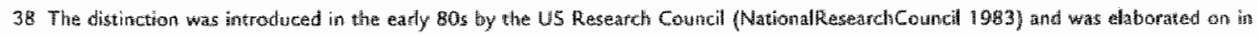
(Russel and Cruber 1987 ).

39 (Mayo and Hollander 1991)

40 see for example (Hafele 1976 ; Lowrance 1976 ; Starr 1969; Srarr and Whipple 1980)

41 See (Mdams 1995 ) for a comprehen sive discussion and illustrative examptles.

42 Exmples can be foumd in (Somers 1995). See for a discussion on the different types and sources of uncertainty relewant for risk analysis (Morgan and Hearion 1990),

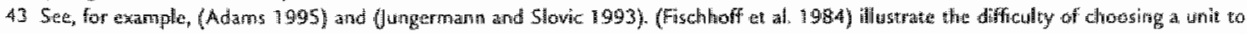
express the danage by bringing different choices found in the risk analysis literature to the for . The units of damiges ramige from ann wal death roll to the loss of thfie-expectancy.

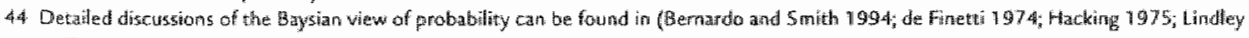
1973 ; Siwage: 1954 )

45 (Otway and von Winter feld $1982 b^{3}$ )

46. (Morgan and Herion 1990 )

47 (Herdick 1991 )

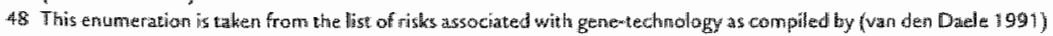

49 (Fischthotr et al 1984 )

50 ilion.

51 (Hendric 1991 )
} 
Besides, social scientific research, especially psychometric studies, shows that individuals on the one hand tend to discard low probabilities ${ }^{52}$, but, on the other hand, explicitly take the catastrophic potential (i.e. high damage cases) into account ${ }^{53}$. Empirical research on risk perceptions indicates that citizens seem to be more worried about cases with large effects at once (such as accidents in a nuclear plant), then repeated occurrences with little damage (such as accidents with electricity at home). The definition of risk as probability times effects is thus questioned, because it does not allow to discriminate between 'low probability - high damage' and 'high probability - low damage' situations ${ }^{54}$. These specifics of the human mind and psychological processing have to be considered in risk analysis.

This way of thinking about risk that can be derived from the above criticism on the objectivists be characterised as the subjective perspective on risk. This point of view can be considered a kind of middle position between the objectivists and the constructivists.

Furthermore, social scientists from a wide range of disciplines argue that the formal definition of risk as a function of probability and negative utility is not able to cover crucial psychological and social dimensions. From this point of view, risk analysis does not supply socially relevant results that can inform and facilitate societal decision-making on risk. Psychologist ${ }^{55}$ argue that risk analysis should address issues like the potential of catastrophe, the location of the impacts and contextual factors, such as voluntariness and the possibility of control as well as the cause of the risk (natural versus human-induced) ${ }^{56}$. In line with empirical findings on how individuals rate risks, risk estimates should be higher if a single occurrence leads to enormous impacts (in terms of deaths, for example), if one is personally likely to lose out and if the risks are human-induced and not attributable to specific societal actors. Risk estimates should be lower if one voluntarily runs the risks, and if one can control it. Anthropologists ${ }^{57}$ argue that risk estimates should comprise fairness considerations such as trust, liability distribution and consent. Other qualitative factors added by social scientists include organisational affiliations, community dynamics, institutional context, ideology and social interactions. For this reason, alternative

52 e.g. (Twersky and Kahnemar 1974; 1980, 198\%)

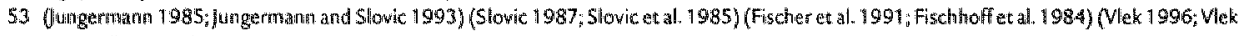
and Stallen 1980)

54 (Kaphar and Garrick 1981; Wek and Sallen 1981)

55 Se forthote 53 .

56 (fumgermann and Silowic 1993)

57 (Rxayner 1992, 1987) (Johmson, 1987) 
definitions of risk are proposed such as "lack of perceived controllability" that stems from social psychology and decision-theory ${ }^{58}$. The sour conclusion is that "the most powerful method of science, i.e. experimental observation, is inapplicable to the estimation of overall risk in exactly those instances where public policy most demands assessments of risks" ${ }^{\prime \prime 99}$.

The second type of criticism mainly stems from social studies of science and technology and fundamentally criticises the basic assumptions of the objectivists' paradigm. It questions whether risks are measurable and objective at all. 'Risk measurement" is inherently problematic because risk refers to the future, and we cannot collect future data. Interpretation and judgement of today's hard facts are needed to determine their relevance for the future ${ }^{60}$. Besides, selecting risk measures is complicated, because different measures of the same hazard exist and the same measure can lead to different perceptions ${ }^{61}$.

In this 'constructivist' ${ }^{62}$ school of thought which fundamentally questions the objectivists premises, one finds arguments like "there is not an objective definition of risk. There are only different definitions which are, dependent on the problem and the context, more or less appropriate" ${ }^{63}$. It is argued ${ }^{64}$ that risks are socially constructed, so there is no valid way of drawing the distinction between objective and perceived risks. According to the constructivists, risks are inherently subjective ${ }^{65}$. Mary Douglas' paper 'Environments of risk ${ }^{266}$ first introduced the idea that the definition and perception of risks are rooted in social and cultural conditions ${ }^{67}$. The constructivists have it that multiple legitimate risk definitions exist due to a wide variety of psychological factors, and social and cultural circumstances. They argue that any form of society and every individual produce their own selected view, which influences the choice of dangers worth attention. Constructivists therefore have it that risk analysis never should be an exercise performed by scientists alone. Societal stakeholders should participate in the risk analysis. According to the constructivists, participatory processes are an integral part of risk management.

\footnotetext{
58 see (W:k 1990 for a comprehensive discussion

59 (Weinbegn 1981 )

60. (Slovic et a 1985).

61 (5)कvic 1991 )

62 (Linnerocth-Bayer and Thompson 1997)

63) (uimgermann 1993)

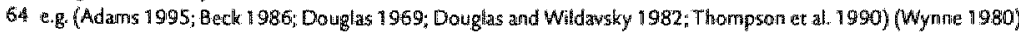

65 One of the fros dischisshon on the conncept of subjective risk can bie found in (Rowe 1977)

66 (Douglas 1969 )

67 See also (Douglias and Will dawsky 1982 )
} 
In Table the main characteristics of the objectivist and the constructivist ways of reasoning are summarised just as to indicate the variety of opinions in the risk community.

\begin{tabular}{|c|c|}
\hline objectrvists ${ }^{6 / 9}$ & conistruturivists ${ }^{69}$ \\
\hline Science is value free (i.e. positivism). & $\begin{array}{l}\text { Science is entirely social } \\
\text { (1.e. social or cultural relativismu) }\end{array}$ \\
\hline Distinction between objective and perceived risks. & $\begin{array}{l}\text { Risk is a social construct. There is no } \\
\text { objective definition of risk. }\end{array}$ \\
\hline $\begin{array}{l}\text { Objective risks are measurable in terms of } \\
\text { probability and utility. }\end{array}$ & $\begin{array}{l}\text { Risk arvalys is should involve qualitative factors } \\
\text { thar are difficult ro measure. }\end{array}$ \\
\hline $\begin{array}{l}\text { Risk assessment and } r \text { Histh management } \\
\text { have to be separated. }\end{array}$ & $\begin{array}{l}\text { Risk assessment and managemenc are inseparable } \\
\text { activities in which value differences are at the core. }\end{array}$ \\
\hline Right expert calculations can settle risk issues. & $\begin{array}{l}\text { Participatory processes are needed to } \\
\text { manage risk issues. }\end{array}$ \\
\hline
\end{tabular}

T.ABLE C Characteristics of the two major schools of thought in risk anallysis

\subsection{THE DEBATE ON THE RISKINESS OF MODERN HAZARDS}

The question whether contemporary hazards and dangers are larger than in the past is explicitly debated within the sociological segment of the risk community ${ }^{70}$, but it does have some impact on the community as a whole. The debate has been framed roughly by two extreme positions ${ }^{7}$. The first point of view ${ }^{7^{2}}$ holds that past generations were threatened by much more direct hazards and did not worry about it. In this perspective, a critical mass of citizens has become more sensitive to risk. Modern society seems to have become unusually risk-aware and does no longer accepts vital risks as belonging to fate or destiny ${ }^{73}$. As a result, risk issues have gained an enormous importance in modern society and have become foreground phenomena ${ }^{74}$.

The majority of the scholars in the risk community have it that the increasing complexity of modern technological society leads to severe risks ${ }^{75}$. This second point

68 or ntaive positivists or seperatists (sce lootnote 21)

69 or cullural relativist or sociological vienw (see footnote 21)

10 (Kamper 1998)

71 (Krohn and Kruecken 1993)

72 see for example, (Whipple 1905 ) jand (Douglas and Wildawsky 1982)

73 (Lublue 1993)

74 (Nlek 1996)

75 sex, for example (Kasper 1980 ; Nelkin 1982) 
of view can be characterised as the "R isk Society" ${ }^{376}$ school of thought. In the wake of the German sociologist Ulrich Beck" these scholars argue that humanity has moved, slowly and almost unnoticed, into a society shaped by risk and hazard. The nature of risks has changed in a significant way. The crucial contemporary risks are humancreated, i.e. large-scale nuclear, chennical, genetic and ecological hazards. In this view, present-day concerns about industrial pollution, radiation and the side effects of new drugs and chemicals are not comparable to concerns about pollution and impurity in less industrial societies ${ }^{78}$. The modern risks and hazards "surpass traditional human boundaries"79 and "transcend the capacity of our senses" "With this poetic expression Beck implies that, because of the global, long-term and universal character, contemporary risks cancel out our conventional notions of space, time and social differences. According to this point of view, increase in risk is inherent to economic, scientific and technological progress. Due to size and nature, current and fut ure threats are substantial.

In line with the issue concerning the riskiness of modern risk, the question arises 'how important are risks for modern governance?' According to Beck, risk permeates society. The crises in the modern world root in the inability to deal with modern risks: society deals with these omnipresent "normal accidents" ${ }^{87}$, normal in the sense of inherent to modern industrialism, as if they are excesses. Conventional institutions and organisations are specialised in denying risks and hazards, instead of being prepared for the "largest assumable accident ${ }^{\text {\$2 }}$. Beck characterises this situation as 'organised irresponsibility'.

The consequence of this 'institutionalised non-management' is that society may come into a negative spiral to the extent that it has nothing left to go on. The postmodern, nihilistic phantom might then become reality. Several authors ${ }^{\gamma_{3}}$ examine how societal mechanisms rooted in organised irresponsibility evolve, and how these processes on their turn impact upon society. A central issue is the role of scientific expertise. On the one hand, because of the 'transcending' character of risk, society heavily relies on scientific expertise. On the other hand, scientific experts just address probable risks. But, as for example the Tsernobyl-disaster showed, there is a wide gap

\footnotetext{
76. (Beck 79861

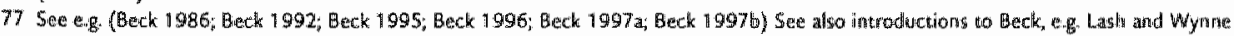
(1992), and (Hajer and Schwati 1997).

78. See for example (Kaprow 1948; Winwer 1982)

79 (Viek and Siallen 1981)

80 (Beck 9992)

81 (Perrow 1984 )

82. (Bedk 1992)

83 (Beck 1986 ) and foliowing puldolications (gasanoff 1991; Slowic 1991)
} 
between 'safety' and 'probable safety". "The calculations of experts remain true, even if some nuclear plants explode" ${ }^{q_{4}}$. The failure of scientists to indicate uncertainty in an understandable manner not only deprives society of needed information, but it will also lead to distrust towards science ${ }^{85}$. In the same time, the effort to bring an unattainable level of technical rationality to decisions that are fundamentally subjective and political will weaken trust in governmental institutions as well ${ }^{86}$.

It is a complex interplay of various societal mechanisms rooted in organised irresponsibility that may cause society to stumble into this negative spiral. Apart from the vicious cycle described above, Beck argues that we now live in an 'uninsured society ${ }^{87}$. The common strategy in case of uncertainty is collective agreements as insurance. However, due to the complexity and the nature of contemporary risks, the foundations of the established risk-logic are undermined ${ }^{88}$. According to Beck, this results in the strange situation in which the legal system regulates every detail of technically controllable small risks, but implicitly legalises large-scale, global and universal hazards. Paradoxically enough this implies that the more hazards increase, protection decreases. As a consequence, the "everything-under-control" mentality will either result in the return of insecurity or to rigid bureaucratic control that invades all aspects of life. Proponents of this point of view argue that to get out of this vicious circle, new institutions and arrangements are needed to deal with risk and uncertainty in a more intelligent way.

\subsection{THE RANGE OF SCHOLARLY VIEWS}

T range of opinions had severe implications for risk analysis activities. Over the last 25 years, the different points of view had fervent advocates and fierce proponents in and outside the risk community ${ }^{\text {s. }}$. With the result that there is neither agreement over appropriate methods for risk analysis nor acceptance of the outcomes of public processes. As a consequence measures of risk tend to fall into two categories ${ }^{90}:$ i) those that aim to calculate the risk of a process or a project, and ii) those that rely upon the perceptions of those assessing the risks. Measures of the first type employ

\footnotetext{
8.4 (Beck 19976)

Bis (Sllowic 1991)

8.6 Gasaiug 1991)

877 ithid.

8 It) Hid.

89 It is buyond the scope of this thesis to provide a detalled and comprehensiwe overview of the history risk analysis, antu a adiequate review of

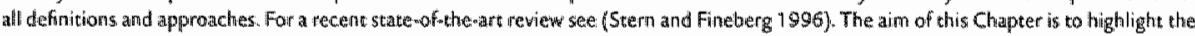
main controwersy and ies implications.

90 (Kasper 1980)
} 
experimental evidence, long term experience, and/or sophisticated analytical calculations to describe actual risks or project potential risks. This type of measure can be associated with the objectivist school of thought. Measures of the second type tell us what people think the risks of a particular activity are. This type of measures is advocated by constructivist risk analysis.

Till the 9 os the 'objectivist' perspective has dominated risk analysis, as can be concluded from the publications of prestigious bodies like the US Academy of Science $^{91}$ and the UK Royal Society ${ }^{92}$ in the midst of the 8 os. This resulted in a mechanistic approach to decision-making whereby "too great an emphasis is placed on quantification"'.3. The objectivist' view has come under increasing attack. As a result, the majority of risk-analysts now seem to agree on the following premises ${ }^{94}$ :

- experts perceive risk differently from lay men

- risk analysis is not a purely objective process: facts and values merge frequently

- cultural factors affect the way people assess risk

This shift signifies that the supremacy of the objectivist school is weakening. However, that does not mean that the constructivists have taken over. According to critics of the constructivist approach, many constructivsts mainly criticise the objectivists' way of doing it, without providing alternatives ${ }^{95}$. The constructivist school is criticised for going a step too far by downplaying the value of scientific and analytical methods, and scientific knowledge in general, in assessing and evaluating risks ${ }^{96}$ Those critics argue that risks are not merely social constructs. At least some hazards are real, and many of these are measurable, though within limits. According to the critics, not all disagreement about risk is entirely political as the constructivists suggest. Methodological and conceptual disagreements are often at stake. The constructivists deny the existence of objective grounds for criticising and scrutinising risk judgements. The critics argue that although no risk estimate is value free, some are more warranted than others. Not all risk attitudes can be justified. A critical scientific overview can indicate what the data do and do not say about a certain risk and what is biased by political and/or cultural values ${ }^{97}$. In other words, "one can admit

\footnotetext{
91 (NationalResearcil/3Coumcill 1983 )

92 (Royalsociesy 1992)

93 (Somers 1995 )

94 (Jasanoff 1993)

95 Nek 1990)

96 e.g. fillayo and Hollander 1991 ; Shrader-Frecheres 1991)

97 (Nayo and Holllander 1991)
} 
that risk judgements are not perfect and yet claim that it is possible to reason about them" ${ }^{\prime g}$ against the background of such a scientific overview.

What we see at the moment is on the one hand an increasing recognition of the constructivists' criticism on the objectivist framework. This can be observed from discussions in the scholarly journal Risk Analysis and from proceedings of conferences on risk assessment ${ }^{99}$. On the other hand, analysis of the contents of, for example, the Journal on Risk and Uncertainty, shows that the objectivists' paradigm is still playing a role in actual studies on risk for decision-making. Signs that the issues raised by the constructivists are recognised within this part of the risk community follow from attempts to address the issue of inherent uncertainty in a mathematical way. For example by bringing Bayesian statistics and subjective probability functions ${ }^{100}$, or fuzzy sets into risk assessments.

The risk community ${ }^{\text {tol }}$ is facing the dilemma that uncertainty takes away the security of science and that conflicts are inherent to risk issues. On the basis of our analysis of the scholarly literature on risk, we conclude that:

the risk community is confronted with the challenge to reconcile the limitations of scientific analysis, the special characteristics of the human mind, and sacial and cultural factors into one coherent umbrella paradigm.

\section{Towards an integrated risk analysis}

The relevance of the Risk Society concept in the broader context of risk analysis is that it reveals that risk management is essential to the governance of the complex societyenvironment system. As a result, the fact that an integration of the available knowledge on risk analysis is lacking ${ }^{102}$ has severe consequences for decision-making about risk $^{103}$. One approach to decision-making, reasoning from the objectivist paradigm, is to ignore public opinion and to insist on using solely calculated estimates of risk. But the result of such an approach is dissatisfaction on the part of the public, which in the long run may undermine the legitimacy of democracy. The other extreme, which can be associated with the constructivist point of view, is no more palatable: it may

\footnotetext{
98 (Shradentractuetwe 1997)

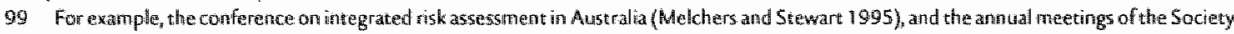

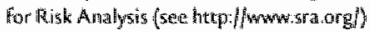

100 for example, (Morgan and Herrion 1990)

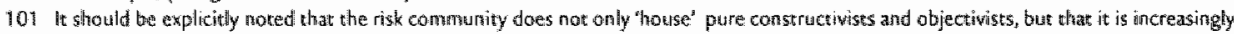
nommon to necogn ise the differences in opinion and to am to benefit from both approaches (Passehier, personal communication).

102 See also (Cerondheidstad 1995)

103 This section builds upon (Kasper 1980 )
} 
get stuck in satisfying public opinion in not-in-my-backyard type of discussions, and thereby deprive society of potential social, economic and environmental benefits.

Both positions err: roughly speaking, objectivists overemphasise facts and underestimate values, while constructivists overemphasise values and underestimate facts $^{104}$. In doing so, constructivists reduce all risk judgements to social constructs, and objectivists reduce all risk estimates to scientific calculations. If risk analysis is serious about the decision-support, it has to provide a form of risk analysis that addresses both 'fact' and "value"tos. The aim of systematic risk analysis is to support intelligent decision-making out of knowledge of the known and critical analysis of the uncertainties. The alternative to systematic risk analysis is governance inspired by fear of the unknown.

Notwithstanding the criticism on the actual practise of risk analysis, both proponents and opponents generally agree that the risk concept comprises a promising selection and evaluation instrument for policy strategies. The underlying argument holds that it is important to explore the subject of risk analysis in order to improve the quality of decision-making ${ }^{106}$. The acceptance or rejection of risky activities ${ }^{107}$ requires a dynamic decision-making process based on assessments made under uncertainty ${ }^{108}$. Risk analysis should enable society to consider trade-offs. To avoid that society will crawl in a sea of irrationality ${ }^{109}$, it would therefore be interesting to explore an "integrated approach to thinking about risk analysis" ${ }^{\text {"10 }}$, in order to arrive at "a framework that is both pragmatic and rational to help us cope with a largely irrational world"'". Without such an integrated approach to risk analysis, the knowledge of risks "will remain fragmentary and will serve at best as an imperfect guide to (.) decision-making" ${ }^{\text {"n }}$. In other words, there seems to be a societal need for a new 'risk-logic' and a new form of risk analysis. What we need is a framework in which alternative risk judgements can be developed, compared and criticised in terms of

104: (Shrader-frechetite 1991)

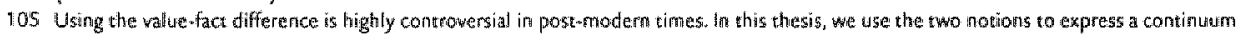

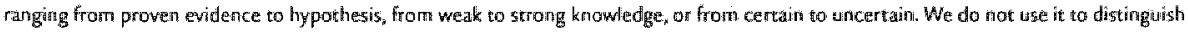

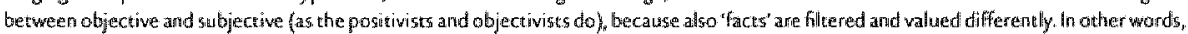

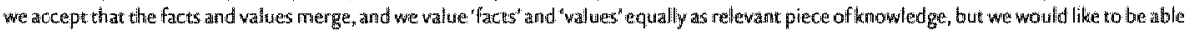

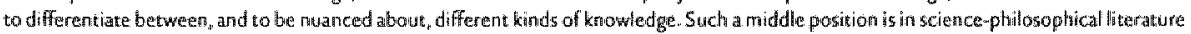

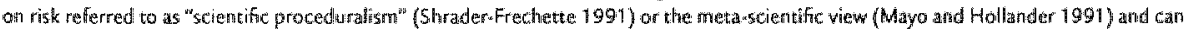

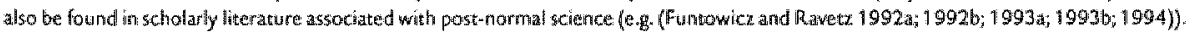
Compare Chapeer 1 on research perspective and Chapter 3 A on uncertainty.

106 Starr and Whipplo $(1980)$

107 Where we should realise that also inacrion can be risky (Dowghas and Wildawalky 1982 ).

108 (Nak 1990)

109 (Berk 1996)

710 (Jasanoff 1993)

11 (Somers 1995)

112 (lasanof 1993) 
coherence, completeness, plausibility and transparency ${ }^{113}$. Such a framework should allow for critical scrutiny of the uncertainties involved"4.

An integrated framework for risk analysis should comprise a consistent theoretical framework and sound methods to deal both with 'facts' and "values' in estimating risks. 'The ultimate challenge is to find ways to cope with the surprising world around us. The necessary approach to risk analysis accepts the inevitability of incomplete knowledge, seeks to accommodate the unknown and aims to coexist with uncertainty and surprise. So, integrated risk analysis should be designed in such a way that it uncovers facts and uncertainties and illuminates alternative judgements. An integrated approach to risk should enable us to reach robust ${ }^{115}$ conclusions, which in turn would help us to recognise, address and manage risk-conflicts ${ }^{\text {th }}$. In other words, integrated risk analysis may help society to avoid 'unmanageable risk conflicts" ${ }^{\text {"17 }}$ by identifying and creating public support that couples scientific facts with societal values and aspirations.

The search for an integrated approach towards risk is currently in the phase of individuals signalising the necessity for an integrated approach to risk analysis ${ }^{\text {t18 }}$, building relevant networks and searching for research commitments and funds ${ }^{\text {try }}$. In this context, the following part of the present Chapter aims to provide a methodological contribution to this search. Our starting-point is that the various current approaches to risk capture a different, and only partial, aspect of the complex and multi-dimensional reality ${ }^{120}$. For example, recognising the social context and societal substance of risk does not deny the value of formal sciences and approaches. The challenging task is to deduce those partial aspects that together can provide a basis for integrated risk analysis. To that end, we have to determine which requirements such an integrated risk analysis should satisfy:

- the process of risk analysis should be one that assures real involvement of scientists and stakeholders (i.e. decision-makers, the general public, non-governmental organisations and the economic actors)

- both 'facts", "values' and alternative judgements should be illuminated

This means that the following issues discussed in the risk literature are relevant in

1973 lbid:

114 Mayo and Hollander 1991)

115 (cliark 1980$)$

116 Hastartioff 1993)

117 (Bed 1992)

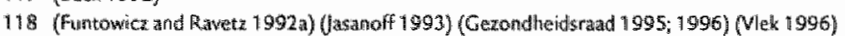

119 (himerooth: Bayer and Thompson 1997)

120 vasanoff 1993 ) 
our endeavour: i) social, psychological and physical aspects of risk, and ii) the need for participation.

\section{I. THE NEED FOR AN INTEGRATED RISK NOTION}

Key insights with regard to the quantitative risk aspects and how to calculate them can be found in the objectivist scholarly literature. The complementary value of public risk perceptions to scientific risk estimates ${ }^{127}$ is that the underlying conceptualisation of risk is much richer than that of the experts and reflects legitimate societal concerns that are typically omitted in risk estimates ${ }^{12 z}$. In lay perceptions, qualitative, indirect and long-term damages are taken into account ${ }^{123}$. As a result, societal aspects of risk can be derived from the social and behavioural research on risk perception. It is surprising how little objectivist risk analysts thus far have tried to benefit from the insights the state-of-the-art in social and behavioural research on risk provides. It is equally surprising that expert knowledge, experience and creative imagination about the future usually fall outside the scope of decision analysis of risk issues as practised in the social sciences ${ }^{124}$. Objectivist risk studies concentrate on scientific risk assessment, while psychometric studies focus on public risk perceptions. Policy sciences and technology assessment explicitly attempt to integrate scientific knowledge on facts and uncertainties, and public values and judgements. Building upon these efforts, the challenge is thus twofold. First, to use the complementary aspects of risk as addressed by both objectivist and constructivist literature. And second, to phrase the notion of 'risk' in such a way that it implies integration of various pieces and types of knowledge and the judgements of facts, uncertainties, and values into risk estimates and assessments.

Empirical research on risk perception shows that different 'fundamental moods of thought $t^{3125}$ exist that result in specific expectations concerning the riskiness of hazards. Some expectations are relatively permanent ${ }^{126}$. Especially these seemingly stable expectations have a profound effect on risk perception ${ }^{127}$. Such 'beliefs" about risks ${ }^{128}$, which can be interpreted as a priori risk attitudes, are embedded in general

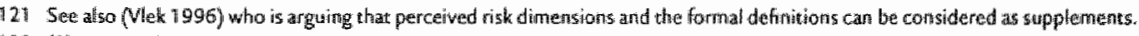

122 (showic 1991)

123 (Jumgermann and Slovic 1993 )

124. See, for example, (Vlek and Stallen 1981)

125 (Sillowich ext. 1985)

126 (Kahreman and Twersky 1982)

127 (Kahneman and Twersky" 1982)

129 (Cotgroure 1981) 
social orientations, such as short or long time horizons, and concentration on losses or gains ${ }^{229}$. At the highest level of abstraction these general social orientations can be described as worldviews ${ }^{134}$. The variety in risk attitudes is usually described in terms of risk avoiding, risk taking, and risk accepting ${ }^{13}$. These a priori risk attitudes in turn structure the way in which the uncertainties, accompanying a specific risky issue, are perceived ${ }^{32}$. This is not to say that risk attitudes of specific actors are deterministic and do not vary in time. However, it does mean that various biases result in different risk perceptions. The definitions of risk vary greatly, depending upon the chosen perspective. So 'risk' cannor have a generally shared meaning. Cultural variety implies inherently differing perspectives towards the interpretation of risk. Especially so-called 'cultural theorists' argue that each cultural group has its unique way of looking at the world. Social and cultural risk analysts have attempted to account for pluralistic interpretations of risk. Anthropologists, for example, have devised a variety of classificatory schemes that reduce the range of cultural variation to a number of useful types. Grid-group analysis, which evolved from Douglas and Wildavsky's pioneering book 'Risk and culture ${ }^{133}$, is such a scheme that has received prominence in social and cultural risk analysis since.

Furthermore, social and cultural analysis as well as the subjective probability school indicates that scientists cannot free themselves entirely of biases. A degree of subjectivity is inherent to risk assessment. As Fischhoff et al. explain: "in risk analysis, research requires the exercise of judgement. It is expert judgement, but judgement nonetheless ${ }^{1354}$. Not only about what is but what ought to be in the future ${ }^{135}$. Experts slide bias into the calculations unobserved ${ }^{136}$. Both scientific knowledge and value judgements are involved in the scientific assessment of risk. Case studies on decision-making on risks ${ }^{13}$ reveal diverging interpretations and conflict among experts. Within the social and behavioural segment of risk analysis there seems to be agreement that the perceptual biases of scientific experts do, at least partly, arise from social and cultural factors. As Jasanof $\mathrm{f}^{\mathrm{r}^{8}}$ concludes: "Cultural variation appears to influence (.) the way (..) scientists select among competing interpretations of data (.)

\footnotetext{
129 (Douglas and Wildawsky 1982 )

130 (Cotgrowe 1981)

i3i See also chapter 3 A

132 compare (Slovic 1987 , 5llowic at al, 1985; Dow glas and Wildaws ky 1982)

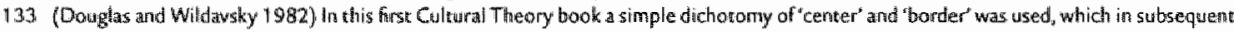
work ewaltued into the two-dinemsional gronop-grid classifucation.

134 (Fischioffet all 1984)

135 (Douglas and Widawsky 1.982 )

136 bid.

137 (Tarr and Jacobson 1987; asanoff $1987 ; 1997$ )

138 (Jasanof 1991)
} 
and the techniques for coping with uncertainty". Coping with that reality requires seeing the information from many perspectives ${ }^{139}$.

In sum, risk is thus multi-dimensional and variably defined among individuals ${ }^{40}$. Social research on risk indicates that both science and the public exhibit different legitimate perspectives towards risks. Conflicts are therefore inherent to risk issues. In this context, the role of risk analysis should be to provide evaluation of the major consequences arising in risky decisions that reflects plural risk perceptions, incl. conflicting expert opinions, interdisciplinary variety and public value systems ${ }^{14}$. By illuminating the variety of judgements, we may in principle be able to understand which policy differences with regard to risk can be reconciled and which not. Instead of favouring one risk perception, the challenge is to make the case for different views on risk ${ }^{142}$. Risk should thus be estimated from multiple perspectives with the idea that such a multiple perspective-approach "results in a balanced understanding of risk" "43.

\subsection{THE NEED FOR PARTICIPATION}

In order to organise risk analysis in such a way that it assures real involvement of stakeholders, it is argued that decision-makers, citizens, opinion leaders and representatives of interest groups should actively participate in the process. Especially in the constructivists risk community, we can find ideas on risk analysis as a participatory process. Participatory processes, also referred to as the "multiple-stakeholder approach" "provide a way to design a workable environment in which all parties can co-operate in addressing risk issues. Participation in risk analysis is not a new issue. Nelkin and Pollak ${ }^{145}$ reviewed various types of participation in evaluating the risks of technology as have been practised already in the 1970 s, such as public inquiries (e.g. the Berger Inquiry in Canada ${ }^{46}$ and the Windscale Inquiry in Britain ${ }^{477}$ ), complaint investigations (e.g. in France ${ }^{14}$ and in Germany), citizen advisory groups (e.g. in the USA), referenda (e.g. in Switzerland) and citizens' dialogues (e.g. in Sweden and in Germany). However, at that time no systematic attention was paid to participatory procedures, methods and the actual benefits of participatory involvement.

\footnotetext{
139 (Fischingeff 1995)

140 (Earle and Cwerovich 1985 )

141 Compare Becks's publications: see footnote 77, (Whipple 1985) (Fischthoff et al. 19.84)

142 (Douglas and Wildatusky 1982)

143 (jangermansa and Femers. 1995),

144 See, for example, (von Winterfeldit 1992)

145 Nelkin and Pollak (1980)

146 (Ciamble 1978)

147 (Wyrne 1978; 1982)

148 (Colson 1977)
} 
The first thorough analyses of the effectiveness of participation in risk issues are of a recent date ${ }^{19}$. So far, the need for participatory processes has generally been underpinned with theoretical arguments and with reference to anticipated benefits. Among the pleas for participatory risk analysis we have found:

- Risk analysis should be an iterative process ${ }^{450}$. Participatory methods in theory assure iterative analysis ${ }^{\mathrm{K}}$.

- Experts are too far removed from an appreciation of public attitudes and understanding. Participatory methods enable to integrate public knowledge and understanding in risk analysis. ${ }^{152}$

- Risk communication is more effective if it is structured as a two-way process than as a one-way transfer of facts from experts to the public is. Participatory processes involve such a two-way process. ${ }^{153}$

- Participatory methods are defended by the nature of democracy ${ }^{154}$. Risk decisions imply that citizens must accept the undesired consequences ${ }^{155}$, they must agree to do without some things and accept substitutes for others, they must obey specific rules, such as safery rules and environmental laws, etc ${ }^{156}$. People and communities have a right to participate in decisions that affect their lives, property and things they value. For this reason, all parties that have a stake in the risk issues concerned are legitimate partners in the risk analysis process ${ }^{157}$. Participatory methods are a way to inwolve stakeholders more directly in the formulation of policy ${ }^{\mathrm{r} \$}$.

- Risk analysis involves a normative judgement about what is desirable. Participatory risk analysis is considered to be one way to forge a societal dialogue addressing the $q$ uestion: How do we want to live?

- Participatory methods are considered to be the logical imperative for a pluralistic society. Due to legitimate pluralism, risk issues "must be necessarily resolved through negotiation and debate among many competing interests" is9.

\footnotetext{
149 (Ceurts and Mayer 1996; Rerin et al.1 1995) (Ceurts vet al. 1987)

150 (Rayner and Cantor 1987 )

151 Hoid.

152 (Sonners 1995 )

153 See, for example, (Covello et al. 1991; Jasanoff 1993; Renn et al. 1995; Stovic 1991)

154. See for example, (Kunrewther and Linnerooth 1983)

155. (Nvelkin and Pollak 1980)

1.56. (Slowic et all. 1985)

157 (Covello ot al. 1991)

158 This argument in Fawour of participatory methods is quite controversial, because in political theory and in the practise of representative democracy this type of direct participation is awoided (Hoppe, personal communication).

159 (asanoff 1991); The counter-argurnent is that there are other ways to onganise negotiation and debate among many competing interests that participatcory methods, such as a type of corporatism or ellite epluralisn (Hoppe, personal communication).
} 
In sum, proponents of participatory risk analysis see the following benefits of involving stakeholders and/or the general public: more creativity, improved production and diffusion of knowledge, integration of different sources of information and knowledge, mutual understanding between opposing groups, early co-ordination, improved legitimacy or enhancement of democracy, improved decision-quality, commitment of participants, and more effective communication between analysts and users of the analysis ${ }^{160}$.

Participation does not necessarily imply to turn over "research labs to untrained persons" "61. The aim of participation is "to bring the relevant parts of science into the public debate along with all the other issues affecting our society" ${ }^{\text {"nf }}$. In our point of view, scientific involvement is needed in participatory processes, in order to enable effective management of risks ${ }^{163}$. Only a societal debate 'armed ${ }^{154}$ with scientific arguments is able to separate the sheep from the goats. It could be argued that scientific information could be fed into the participatory process, without the scientists participating, however experienced risk communicators ${ }^{\text {tis }}$ argue that the following conditions have to be satisfied before non-academics feel able to judge and trust scientific information, i.e.:

\section{CONDITIONS CONCERNING CONTENT}

- familiarity with underlying science

- familiarity with assumptions, inputs and models

- familiarity with analytical perspectives

- ability to double-check

\section{SOCIAL CONDITIONS}

- familiarity with scientists/scientific community

- recognition of societal concerns

- respectful treatment

These conditions can only be satisfied if scientists are actively involved in the itera* tive and interactive process. Our conclusion is that both scientists and stakeholders are needed in participatory risk analysis in order to overcome a serious dilemma in complex risk analysis ${ }^{16,6}$ : "The experts should not control society's (..) choices, but

\footnotetext{
160 (Ceurts and Mayer 1996)

161 (Fintowicz and Ravecz 1992 b)

162 thid.

163 Conmare the type of participatory prowesses, which in Chapter 2 are described as mutual tearning

164. (Heck 1992)

165 En. (Fischhof 1996$)$

160 Quote from (won Winterfeldt 1992) see also (Wlek 1996)
} 
the public and their political representatives are not sufficiently informed to assume complete control themselves".

The challenge of participatory processes is to join different sorts of expertise and various perspectives, into a mutual learning process. Building upon Beck ${ }^{\text {nf }}$ and Fischhoff et al ${ }^{168}$, the following steps towards participatory risk analysis can be distinguished:

- risks should be revealed and be made subject of societal discussion.

- all parricipants, whether scientists, decision-makers, citizens, business people or interest groups, need to understand the limits to their own knowledge and expertise.

- politics should accept its limitations; it is not the only place where societal decisions are made.

- scientists should be self-critical; i.e. enough attention should be paid to (suppressed) scepticism.

- citizens, business people, scientists and other actors should admit that they make politics.

- non-academics need to understand the limits of advise provided by various experts.

- organisations and institutions should be organised in an open and pluralistic mamner.

The ideal of the participatory risk society is a society in which the public is informed, involved, interested, reasonable, thoughtful, solurion-oriented, co-operative ${ }^{\text {t69 }}$, nonacademics are co-producers of knowledge and heterogeneous coalitions are formed, composed of a 'strange' variety of participants. Participatory risk analysis would then imply a dialogue between such incidental and thematic 'coalitions of differences"

Participatory risk analysis is like a many-sided conversation in which being ultimately right or wrong is not the issue. What matters, is that the dialogue continues with new questions. New kinds of questions will inspire new insights, which in turn. will result in risk strategies that could not have been thought of before. Participatory risk analysis ideally is thus an iterative and continuous process, which can inform decision-making on risk issues by providing insights and suggesting risk strategies.

167 (Beck 1986) and his succeeding work (siee footnote 77)

162 (Fischorf et al 1997)

169 (Covello et al. 1991)

170 Beck 1996 


\subsection{THE CHALLENGE}

From the above assessment on concept of risk and literature on risk analysis, it can be concluded that integrated risk analysis has to satisfy the following requirements:

- Risk analysis should be organised as a participatory process.

- Risk analysis should reflect the variety of value judgements and perspectives.

- Risk analysis, being an iterative and continuous process, should nevertheless enlighten particular decision-making choices. The key task of risk analysis is to provide needed and appropriate information to decision-makers and the public $^{\text {i7r. }}$. Risk analysis should provide reliable and understandable information addressing the dimensions relevant to the public and decision-makers in a transparent manner.

From the above we can conclude that integrated risk analysis should be a processoriented approach. Integrated risk analysis is seen as a mutual learning process and is defined as:

A dynamic and participatory process in which inevitably incomplete, conflicting, uncertain and situated knowledge is evaluated and structured into alternative risk judgements in such a way that robust strategies can be explored with the best possible understanding of current knowledge, its limitations and implications $^{172}$.

Integrated risk analysis is not meant to be a panacea for all risk issues. Not all risk issues need to be settled in an integrated, participatory manner. Some risks are not so controversial and can be reasonably calculated by available methods. For that reason, it is necessary to explore and classify the different types of risk.

In order to develop a framework for integrated risk analysis the following issues. have to be settled:

- defining and classifying risk

- set-up for participatory risk analysis, incl. guidelines, tasks and tools.

- developing methodologies that enable multiple risk assessments

- designing formats for risk statements

Our ambition is to seek in the impressive body of risk analysis literature seeds that may blossom in an integrated framework. From the scholarly literature on risk discussed in the previous sections, we conclude that scientific assessment and participam

171 Comparie (Stert arid Fineberg 1996)

172 Phrasing is inspired by (Clarik 1980, Morgan 1978)

173 (Reotmans 1998), See also Chapter 2. 
tory processes have to be organised in an iterative and cyclical manner. There are two possibilities to structure such an iterative risk analysis effort, i.e. a demand-driven and a supply-driven approach ${ }^{173}$. The central issue underlying this difference is how much influence the participants have on the framing and structuring of the risk issue. In the supply-driven approach, scientists are framing the risk issue. The risk analysis effort in this mode starts with a scientific assessment of the risk issue at stake, which involves an assessment of the state-of-the-art knowledge and an overview of recognised risk perceptions. This scientific assessment is then evaluated in into a participatory process.

Risk analysis in a demand-driven mood reasons from the concerns expressed by stakeholders in a first participatory round. The stakeholders thus define the risk issue in this type of risk analysis. These concerns and the accompanying information needs are then, if possible, addressed in the scientific assessment of the risk issue at stake ${ }^{174}$. A demand-driven risk analysis differs from the supply-driven approach in the sense that stakeholders determine in the first round what risk issues are most pressing in societal terms and what developments and consequences should be taken into account in a risk analysis. In this way, the non-scientific participants frame the scientific assessment.

The framework for integrated risk analysis is presented in Figure 2, where the various components of such an integrated risk analysis are specified in the remaining of the present Chapter.

We would like to illustrate the various steps by means of an example, which builds upon the exemplary case of alternative technologies for electricity generation, provided by Fischhoff and colleagues ${ }^{175}$ in their seminal paper on defining risk. The strength of the work of Fischhoff and colleagues is that it illustrates some ideas of multi-dimensional definition of risk and of pluralistic risk assessments, although it did not involve participation. Furthermore, the case allows to discuss those ideas that were not already implicitly or explicitly proposed by Fischhoff and colleagues.

\section{C.ASE}

Six energy technologies were selected to consider, i.e. coal, hydropower, largescale wind power, small-scale wind power, nuclear power, and energy conservation. The latter can reduce the demand for electricity, where the others can increase the supply of electricity. 


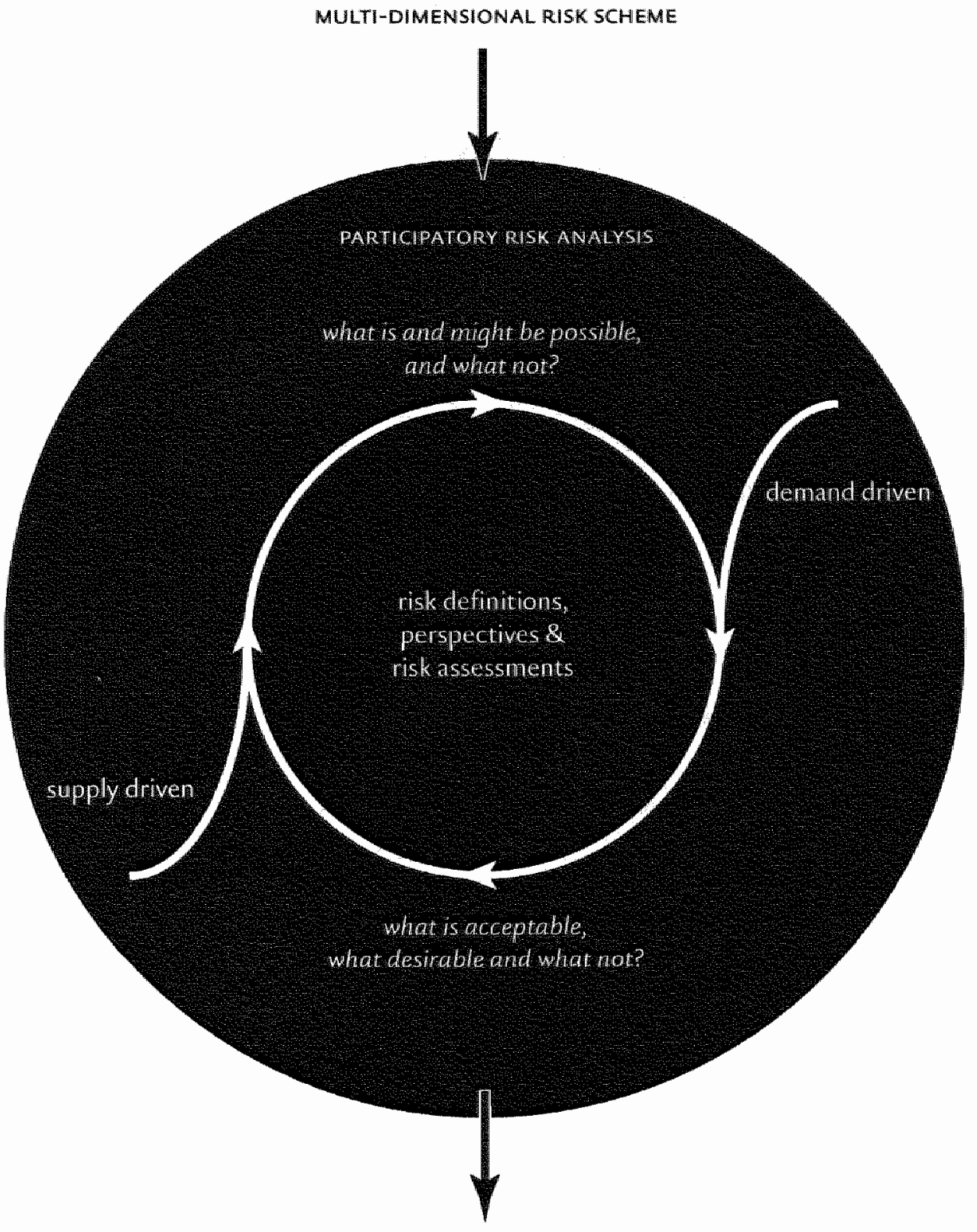

RIISK PROFILES AND STATEIMENTS

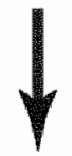

DECISION SUPPORT

FGunk 2 Framework for integrated risk assessment 


\section{Defining and classifying 'risk'}

Risks are so diverse, how do we decide which ones need to be addressed in an integrated manner? Risk issues fundamentally differ with regard to ${ }^{176}$ :

- the level of control: personal control versus collective affair

- the time-horizon: momentary, short-term, medium-term and long-term (i.e. inter-generational)

- the spatial scope: indiwidual, indoor, local, regional, narional, continental, and global

- the level of uncertainty

These aspects are usually linked together ${ }^{278}$, in the sense that collective risk issues that are long-term in character are usually inherently uncertain and quite often involve large scales. Conversely, personal risks are usually momentary or short-term, are small-scale and can be quite well estimated. The above risk aspects determine the level of public interest and societal importance ${ }^{7 \%}$, and thereby indicate whether the risk issue is policy-relevant. Building upon these aspects, risk issues can be classified as operational, tactical and strategic risks ${ }^{180}$ (see Figure 3 ).

Individuals cannot control strategic risks and the time horizon usually transcends the short-term. Usually, this sort of risks cannot be exactly located and the level of uncertainty associated with this type of risks is high. Such strategic risks are complex issues ${ }^{16}$; they generally comprise social-economic, environmental and institutional dimensions, that they involve multiple scales, and that pertain to a web of problems. In case of strategic risks, a variety of risk factors usually accumulate and interact. While in case of operational risks risk perceptions may converge, in case of such complex issues divergent and fundamentally different risk definitions and risk perceptions usually dominate the societal debate. Especially in the case of strategic risks, a participatory process is needed that enables to recognise different perspectives, to consider these perspectives in a systematic manner and to arrive at robust

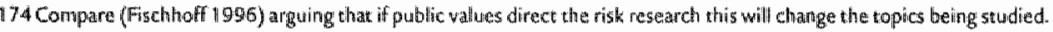

175 (Fochlwofer at. 1984)

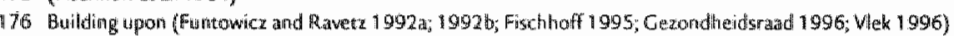

177 See Chaper 3 A for a comprehensive discussion of the levels of uncerainty. See Chapter 4 for an extended discussion an risk and uncertating.

178 (Gerondheidstowad 1995 )

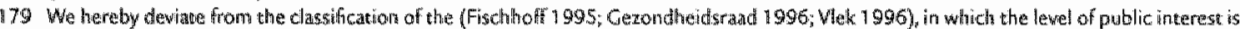
congidered to be ane of the constitiating uspects.

180 This rhrew+category classification resembles; the distinction made by (Funtowica and Ravetz 1990 ) and subsequent publications, in applied science, professional consuleancy and pose-normal science. Applied science deals with operatonal risks, profersional con wultancy with tactical risks and postonormal scierace with strategic risks.

181 Sea chapter 2 for the defnition of complex as adopted in this thesis
} 
level of control

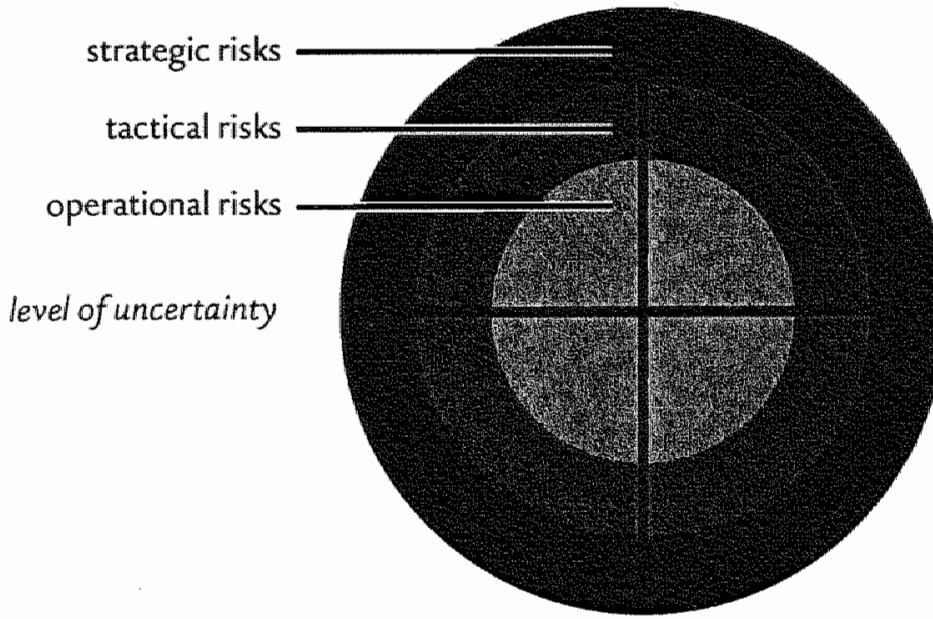

time horizon

spatial scope

FiCURE 3 Classification of types of risk

risk statements that can inform decision-making. In sum, integrated risk analysis is especially relevant in case of strategic risks ${ }^{\text {igz }}$.

"Risky decisions" are choices among options, each of which has a variety of relevant features ${ }^{18_{3}}$. Although there is no unique definition of 'risk', from the above it can be concluded that risk in strategic risk cases is a multidimensional notion, of which some dimensions can be expressed quantitatively and others not ${ }^{184}$. For our purpose, we are interested in a notion of 'risk' that integrates scientific, psychological and sociocultural dimensions. Integrated in this context means doing justice to the multiple dimensions in a balanced way so that it is more or less acceptable to experts, the public and decision-makers. An operational definition of risk thus should be ${ }^{88_{5}}$ i) logically sound, ii) reflective of scientific expertise, iii) reflective of public values, iv) responsive to social concerns and v) acceptable to experts, the public and decision-makers. Building upon the above, the end product of the integrated risk analysis processes is:

Risk statements that are the joint product of knowledge (i.e. judgements of facts, values and uncertainties) about the future and evaluation of desired prospects about a complex, incompletely known issue.

\footnotetext{
182 Compare Chapter 2 , in which we argue that integrated Assessment is especially rellevart in the first phases of the policy life cyctio.

183 (Fischhoff et all 1984i)

184 Compare (Giezondheidsrad: 1995)

185 Compare the requirements as proposed by (Whipple 1985 ).
} 
From the scholarly literature on risk it can be concluded that context-dependent riskdefinitions are more appropriate. Reasoning from this premise, we would like to arrive at a generic multi-climensional risk scheme that can be applied to different contexts. In this case, it suffices to indicate a general scheme that is as comprehensive as possible. Such a scheme can then serve as a starting point for defining risk in a compact way that is sufficiently comprehensive for the relevant risk issue ${ }^{186}$.

Which characteristics or dimensions 'define' risk? Otway and his associates ${ }^{187}$ characterise four clusters of risk attributes that could be useful, i.e.:

- economic and technical benefits factors

- environmental and physical risk factors

- psychological risk factors

- socio-political and cultural risk factors.

In order to be reflective of both public and expert knowledge, integrated risk estimates should indicate the relevant risk factors on these different attributes. In order to be relevant to decision-making processes, it is furthermore essential, although not sufficient, that risk analysis comprises options about "what to do", i.e. alternative policy options ${ }^{188}$. Furthermore, damages and benefits are distribured in time, space, as well as demographically distributed. This distribution may be inequitable and uneven. Decision-makers should be able to evaluate such trade-offs. It is therefore necessary that risk analysis addresses the question: risky to whom? How are the consequences distributed in terms of personal, collective, intergenerational, economic, sector-specific, societal, institutional and/or environmental impacts?

Risk statements should summarise insights with regard to the related questions $\mathrm{s}^{189}$;

i) What might happen?

ii) What consequences are imaginable if it happens, and are these consequences acceptable/desirable?

in terms of both possible benefits (i.e. effects valued as positive by at least one party in the risk debate) ${ }^{190}$ and possible damages (i.e. effects valued negatively by at least one party in the risk debate), further specified into:

- social (e.g. in terms of health and quality of life), economic (e.g. economic losses/gains), environmental (e.g. in terms of ecological value,

186 Compare (Wiak 1996)

187 (Otway and Fischbein 1977 ; Otway at al. 1978)

198 See (Cownello we al. 1991 ) for a synthesis that underpins this conclusion.

189 Compare Knaplan and Garrick (1981)

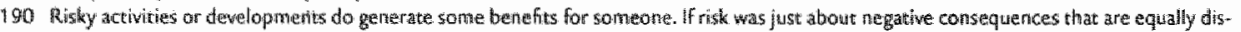

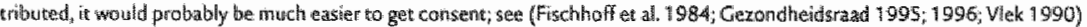


biodiversity and natural processes/functions) and institutional terms

- terms of distribution

- direct and indirect effects

iii) How plausible is the imagined event or series of events and how likely are the consequences?

iv) What can be done about it?

Answers to the above questions together in principle yield risk statements that comprise knowledge about the future and an evaluation of desired prospects. The first and third questions define what dimensions the assessment of knowledge about the future should address. The fourth question points to the evaluation of desired prospects. The second and fifth question involves both dimensions.

In addition to the above list of risk questions, the following list of key dimensions is compiled from social and behavioural research ${ }^{\text {ig? }}$ :

- equity

- cause: e.g. in terms of natural versus human-induced

- catastrophic potential or "maximum credible accident"

- invisibility and dread ${ }^{193}$

- controllability

- voluntariness

- familiarity: whether unfamiliar impacts are to be expected.

- accident history: whether activities have a history of major accidents. ${ }^{134}$

- reversibility

- delay: whether impacts will extend to future generations.

Consistent findings in statistical analysis of perceived risks are the following two correlations ${ }^{195}$ :

- a positive correlation between voluntariness and controllability

- a negative correlation between delay and familiarity ${ }^{196}$

These correlations enable us to condense the dimensions that can supplement or can enable to elaborate on the above questions.

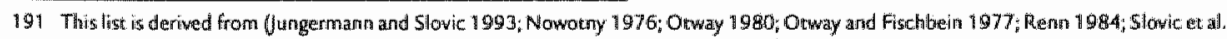

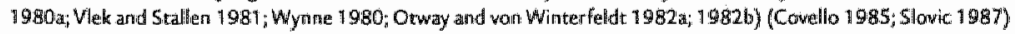

192 Both in objecsivist and constructivist (for example, Beck) circles, the importance of the 'maximum credible accident' in thisking and decidung about complex issues is brought forwart.

193 Social and betravioural research indicate that risk amalysis inwolving dread and uniknown risks need to be sensitive to lhigher order nisks (Sllowic 1991).

194 Accidents serve as sigmalss of how risky an activity or development is (Jungernamn and Slovic 1993)

195 E.g. (Whelk 1996; Vhek and Stallen 1980; 1981)

196 in other words in case impacts for future gernerations are expected, these impiacts ate considered to be unfamiliar. 
From the above the following list of questions, further referred to as risk dimensions ${ }^{157}$, can be deduced that may serve as heuristic in defining risk in specific contexts:

- what might happen?

- imaginable consequences?

- risky to whom?

- equity?

- cause?

- catastrophic potential?

- invisible dread?

- controllable? / voluntariness?

- familiarity?/delay?

- accident history? ?98 $^{198}$

- reversibility?

- how plausible/likely?

- acceptable/desirable?

- what can be done about it?

This risk scheme expresses the multi-dimensionality of risks. We do not argue that all these questions have to be addressed in any risk case. Because of the wealth of risk dimensions, selection will be anyhow needed in practical risk cases ${ }^{199,200}$. The character and features of the specific risk issue should frame the selection of risk dimensions to be considered in the risk analysis ${ }^{201}$. Differences in the selection of risk dimensions will lead to different risk definitions. Currently, these selections are implicit and opaque, and thereby obscure the risk discussions. The aim of the above risk scheme is to allow systematic and transparent selection of risk dimensions with the aim that different risk definitions can be shared, in order to enhance the chances for a meaningful communication.

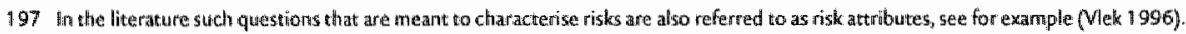

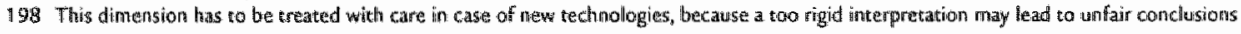
(Hoppe, persionat communication).

199 Comparte (Cimondilueidsrand 1995)

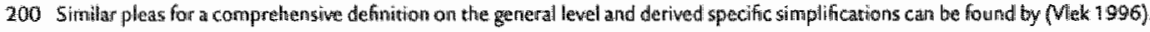

201 Compane (Gezondheidsraad 9995 ) 
The first step in integrated risk analysis is to consider which risk dimensions are crucial for the case. This can be done in a demand-driven or a supply-driven mode. Let us take the supply-driven approach, as Fischhoff et al. have adopted. They took into account the following 5 risk attributes:

- death risk for workers (risk attribute 1) and for the public (risk attribute 2) expressed in the expected number of deaths per Gigawatt year (Gwyr) of electricity generated or saved.

- morbidity risk expressed in expected person-days of incapacity per Gwyr of electricity (risk attribute 3).

- public concern in terms of the level of unknown (risk attribute 4) and dread (risk attribute 5). Psychometric methods are used to gauge these attributes.

How does this choice reflect the dimensions we have distinguished? The question 'what might happen?' is implicitly addressed by the choice of the 6 alternative technologies. The risk issue is thus brought down to the issue what are the risks associated with these particular technologies. The risk attributes chosen by Fischhoff $e t$ al. reflect the following risk dimensions either implicitly or explicitly:

\section{IMAGINABLE CONSEQUENCES}

- benefits: electricity generation

- damages: i) dead workers, ii) dead citizens, iii) ill workers, and iv) unhappy public

RISKY TO WHOM

- workers by electricity generation plants

- public

CAUSE

- human-induced (technology)

HOW LIKELY/PLAUSIBLE ARE THESE CONSEQUENCES

- implicitly comprised in the measures used for death and morbidity risks WHAT CAN WE DO ABOUT IT

- choice of technological option

Risk attributes 4 and 5 are evaluated by means of psychometric methods. With a survey, respondents are asked to score the 6 technologies on the following 
properties (scale 0-100, score of o implies that technological option has this property according to respondent) $)^{202}$ :

- observable

- known

- effect immediate

- old

- known to science

- controllable

- not global catastrophic

- consequences not fatal

- equitable

- individual

- low future risk

- can be easily reduced

- voluntary

- does not affect me

The scores of the sample on these properties are combined and aggregated ${ }^{203}$ into values for risk attribute 4 and 5 . In this way, the definition adopted by Fischhoffet al addresses the dimensions of desired prospects by means of gauging public perceptions.

The general multi-dimensional risk definition is in this way translated into measurable items that are appropriate for the case under concern. Fischhoff $e t$ al. do not specify their case in terms of scale, so the size of the sample, the profile of the respondents, and on the basis of what data (local, national global) morbidity and death risks are calculated are not specified. In a real case, it is necessary to further concretise the items in spatial and temporal terms. Nevertheless, it illustrates how the generic risk scheme proposed in this Chapter, can serve as a heuristic in specific cases.

202 Although (Fischhoff al. 1984 ) indicated that and how this dat a should be collected via a survey, they did not actually do such a survey. Is their puper they used fake data.

203 (Fischthoff et al. 1984) did not exipulicitly discuss how the scores were combined and agregregated. In a real case, it is necessasy to specify the agigregation procediune (see allso Clinapter 5 ). 


\section{Participatory risk analysis}

How to design participatory risk analysis? Four principal groups have to be involved ${ }^{204}$ :

- scientific experts, who generate required scientific and technical information.

- decision makers, who decide about risk issues.

- citizens and opinion leaders, who learn about risks through interactive communication and who, on that basis, formulate their risk judgements.

- interest group representatives, such as representatives of NGOs, who express interests associared with the risk issues.

The second step is to explore what tasks such a heterogeneous group comprising scientists and stakeholders should perform. What jobs are assigned to them? An answer to this question can be derived from a closer inspection of the risk dimensions. Reasoning from the characteristics of the different participants, we have attempted to indicate the likely expertise among scientists, decision-makers, citizens and interest group representatives (see Table 4).

The first responsibility of scientists is to indicate what is known and what not, and what seems to be possible and what not in the light of current knowledge. As a consequence scientists have a special role to play in highlighting facts, hypotheses and uncertainties with regard to the various dimensions. Taking account of the constructivist lessons, it is important that the scientists are aware of, and open about, their value judgements and perspectives. Building upon this profile of the scientists as participants in integrated risk analysis, it is possible to evaluate which dimensions in general require this kind of input (marked by ++ ), and for which dimensions this type of knowledge can be useful (marked by + ). Some of the risk dimensions cannot be addressed by scientists. For example, scientists do not possess any particular competence or expertise with regard to the question whether the consequences sketched are acceptable.

The knowledge scientists contribute is usually of a general and abstract character. Decision-makers, citizens and interest group representatives can provide local knowledge, i.e. knowledge that is situated, context-dependent and site specific. This understanding and insight can supplement, complement and elaborate the input of scientists. Citizens and interest group representatives have a special role to play in sketching societal aspirations and constraints that are important in view of the stakeholders. Starting from this profile, it is possible to assess where the input of the non- 
academic stakeholders is essential (for example, with regard to the equity) (marked with ++ ), where it would be welcomed (marked with + ), and in which cases decisionmakers, citizens and representatives of interest groups do not seem to possess particular competence of expertise.

\begin{tabular}{|c|c|c|c|}
\hline \multirow[b]{2}{*}{ RIS DIMENSION } & \multicolumn{3}{|c|}{ INVOLVES EXPERTISE OR INVOLVEMENT OF } \\
\hline & scientists & decision-makers & $\begin{array}{c}\text { citizens and interest group } \\
\text { representatives }\end{array}$ \\
\hline What might happen? & ++ & \# & + \\
\hline Imaginable consequences? & + & * & + \\
\hline Risky to whom? & ++ & + & + \\
\hline Equity? & & +4 & $+*$ \\
\hline Cause? & +4 & + & + \\
\hline Cat:astrophic potential? & +++ & & +4 \\
\hline Invisible \& dread? & & & $\pi+4$ \\
\hline Controllable volutitariness? & + & & +4 \\
\hline Pamiliaricy/delay? & $8+$ & & ++ \\
\hline Accident history" & ++ & & + \\
\hline Irreversibility? & ++ & & \\
\hline How plausible/likely? & + & + & + \\
\hline Acceptable desirable? & & ++ & +4 \\
\hline What carn be done about it? & + & +4 & $\#+$ \\
\hline
\end{tabular}

TABLE 4 Participants" llkkely expertise and knowledge related to tasks in integrated risk analysis

LECEND empty signifies no particular competence or expertis., * indicates relevant competence or expertise,

* Indicates outstanding competence or expertise

If we take the preliminary division of roles as sketched in Table 4 as starting point, the participatory process should be organised in such a way that scientists collect and communicate facts, hypotheses and uncertainties on the following dimensions: i) what can happen?, ii) imaginable consequences?, iii) distribution of risk?, iv) cause? v) catastrophic potential?, vi) delay?, viii) accident history?, ix) irreversibility?, $x$ ) platusibility/likelihood?, and xi) what can be done about it?. In this assessment process, they have to be aware of subjectivity and multi-interpretability. Scientists can furthermore use psychometric methods to estimate lay perceptions of: i) catastrophic potential, ii) invisibility \& dread, iii) controllability/voluntariness and iv) familiarity.

The set-up of participatory processes should stimulate decision-makers to consider especially equity issues, and options and strategies. The citizens and interest group representatives have a special role to play in expressing the perceived level of i) catastrophic potential, ii) invisibility and dread, iii) control and/or voluntariness, iv) 
familiarity and/or delay. Furthermore, these participants should be invited to express their local knowledge concerning the following dimensions: i) what can happen?, ii) imaginable consequences?, iii) distribution of risk?, iv) cause?, v) accident history?, vi) plausibility/likelihood?, and vii) what can be done about it?. Last but not least, the key role of these participants is to express which risks and imaginable consequences are acceptable and which are not. The participatory process should be organised in such a way that this role is appointed to the non-academic participants.

Inspection of Table 4 helps to articulate what we expect from participants in participatory risk analysis. Following this line, the tasks assigned to the participatory processes in a supplly-driven risk analysis involve:

- to structure, enrich and evaluate the scientific assessments ${ }^{205}$ :

- to articulate local, situated and case-specific knowledge.

- to formulate information needs with regard to imaginable developments and consequences that were not taken into account.

- to assess how likely the considered developments and consequences are from a societal point of view.

- to propose and evaluate policy and societal responses.

- to evaluate the considered developments and plausible consequences in terms of:

- equity

- the catastrophic potential associated with the consequences

- the level of dread and invisibility associated with the consequences

- the level of familiarity

- to express and assess societal constraints and aspirations both in terms of desirability of benefits and unacceptability of impacts.

- to evaluate trade-offs between societal constraints and aspirations, economic benefits, and technical and physical possibilities.

- to produce informed risk judgements.

In a demand-driven risk analysis, primary to the jobs described above, it is the responsibility of the participants to frame the risk analysis by determining what risk issues are most pressing in societall terms, what developments and consequences should be considered in the risk analysis, and how risk should be defined (i.e. so what risk dimensions should be considered).

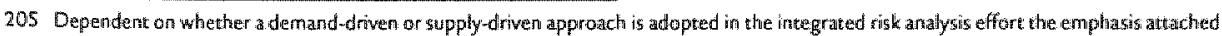
to these tusilks odiffer. 
Risk communication literature suggests conditions for participatory proc$\operatorname{esses}^{206}$. The first and most important is mutual respect among all participants in the process. The advantage of the participatory approach is that people stereotype less when they are dealing with someone they know ${ }^{207}$. In that sense, participatory processes may enhance trust building within the group, which in turn will stimulate the process.

Social and behavioural studies indicate that there is little chance that the participatory group formulates defmite risk statements without guidance ${ }^{208}$. The participants presumably disagree, because they are arguing from different perspectives. Real dialogue means adapting the strategies, institutions, procedures, etc. to one another's ideal ${ }^{209}$. To keep the dialogue going and to prevent deadlocks, the participatory processes should be structured in such a way that the participants are from time to time forced to put oneself in someone else's position ${ }^{2 t 0}$. Role games and/or explicit discussion guides for the facilitator may be suitable in this respect.

The above procedure for participatory risk analysis should not be regarded as a rigid blueprint. We just attempted to be clear about what kind of input can, and probably should, be expected from the various participants and in what way these expectations have implications for the structure of the participatory process, and for the roles and responsibilities ascribed to the participants. In doing so, we have tried to sketch some guidelines and heuristics that can be used in setting up participatory processes for integrated risk anallysis.

\section{CASE}

\section{PARTICIPATORY PROCESS}

With the first characterisation of the alternative technologies for electricity generation in terms of the five risk attributes, a participatory process could be set up. Taking into account the guidelines for participatory risk analysis as expressed earlier in this Chapter, four groups have to be involved:

- scientific experts: in this case we can think of engineers, who can explain the technical details of the diverse options, health experts, who can generate the required information with regard to the health risks associated with the various forms of electricity generation, life-style specialists as sociolo-

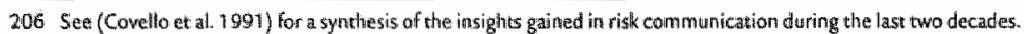

207 to should be noted that this only holds for the spokespersons actually participating hir the process $s_{4}$ and not for those the are representing

208 (jumgerinath and Slovic 1993 )

209 (Douglas and Wildawsiky 1982)

210 See, for example, Chapter 2 for gaming approaches to participation: 
gists and anthropologists, who can indicate the consumer patterns, economists, who can indicate the anticipated demand for electricity and the costs associated with electricity generation, and jurists, who can indicate the legal aspects. Furthermore, in order to be able to run the whole process, we need experts on participation and facilitators.

- decision-makers: in this case, representatives of local and national authorities, esp. for the department of Energy, Economy and Public Health and local and national members of parliament, and private decision makers in the energy sector.

- citizens: in this case, inhabitants of the area where electricity generation takes place (potential risk victims), and a random sample of residents of the country (both as electricity consumers and as indirectly involved).

- representatives of interest groups: in the case of electricity generation the following organisations seem to have both a stake in the issue and may provide relevant information: representatives of workers in energy utilities, the anti-nuclear movement, environmental movements which have experience in energy and resource issues, and labour unions.

Fischhoff $e t a l$ did not set up a participatory process. Nevertheless, taking into account what they did, the participatory process could have been helpful to evaluate the estimates of the various risk attributes. How would the participants estimate the risky properties of the different technologies for electricity generation? The participatory process could furthermore have helped to indicate whether all relevant technological options have been taken into account, or that, for example, representatives from the energy sector or members from the anti-nuclear movement consider that other alternatives are feasible. The group of participants could, for example, have reached the conclusion that electricity generation based on solar technology should be considered. Furthermore, a participatory conclusion could have been that also options for altering consumer behaviour should be included in the risk analysis. By changing life-styles the future demand of electricity may decrease, which affect the need for building electricity generation facilities.

Furthermore, the participatory process could have been used to assess societal constraints and aspirations. For example, the participants could have been asked to express whether nature area might be sacrificed for building new plants. And whether large-scale wind plants are acceptable from an aesthetic point of view. Or whether it is acceptable to rely on coal supply from countries 
that do not have legislation that guarantees that the coal-miners work under humane conditions. Such questions could have been addressed in the forms of role-plays or scenario-exercises, in which the participants are asked to 'paint' their desired future and the most undesirable future.

The above discussion illustrates how a participatory process in the case of electricity generation could have informed the risk analysis. It would have enabled to decide whether the adopted risk framework was able to address the issues that stakeholders consider relevant, so that the risk framework could have been adjusted in an earlier stage. Furthermore, insights into societal constraints and aspirations could have helped to put the multiple risk statements that the analysis delivers into a broader context. It may have helped Fischhoff et al, to build a bridge from integrated insights into concrete policy recommendations.

\section{Multiple risk assessments}

Using the risk scheme presented in the previous section in actual integrated risk analysis would involve the following steps (see also Figure 4$)^{21 !}$ :

- selection of the relevant risk dimensions

- identification and selection of measurable items (indicators) that adequately ${ }^{212}$ represent the various risk dimensions for the specific case under concern

- gathering of information/data/estimates to gauge the selected items/indicators, both in qualitative and quantitative terms, as well as in terms of quality and uncertainty.

- scoring with respect to each dimension

- evaluation of trade-offs and weighing of the various dimensions (i.e. assignment of importance weights)

- formulation of a multi-dimensional risk profile

Each of these steps involves value judgements. It is a question of ethics to determine which risks are to be considered, how risk is to be characterised, how the different dimensions of risk should be weighted, etc. This means, as is argued earlier in this Chapter, that we have to accommodate for multiple perspectives in such a risk analy-

211 Compare (Fischoff 1995; Gezondheidsratd 1996; Whek 1996)

212 Cirucial in the identification of risk itents/nedicators is to signify the appropriate spatial and scale 


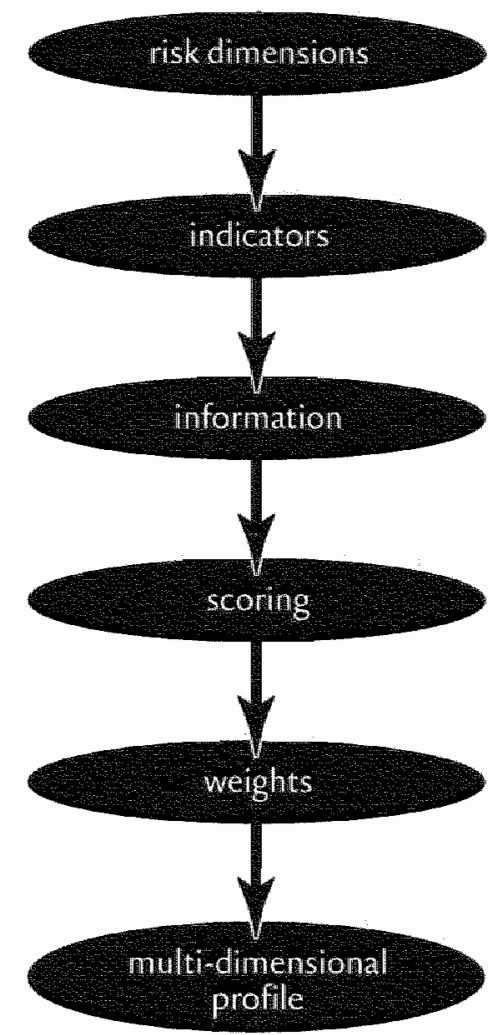

Ficurre 4 Steps in risk analysis

$\operatorname{sis}^{213}$. But how? Following social and cultural risk analysis, the various sets, scores and weights can be motivated by different risk perceptions. People interpret and estimate risk differently according to their perspective and their position with regard to the specific issue. With regard to the latter, the following classification of roles in the risk debates is of interest ${ }^{214}$ :

- the directly involved: the risk-taker(s) ${ }^{215}$, those gaining ${ }^{216}$, and the risk victim(s); revolting risk victims become risk protestors.

- the indirectly involved: risk regulators (i.e. authorities and institutions), the media, and the general public; both the media and the general public can play an important role as risk protestors.

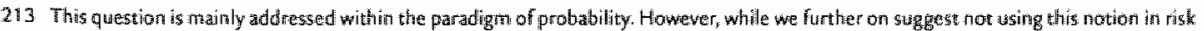
analysis, we will not explore the literature on subjective probability distributions.

214 (Cezondheidsrad 1996) Compare (Rawetz 2000)

215 Also referred to as risk imposer (havetz 2000)

216 This cam be ind widd alls, cominnumities, companies, institurions, etc 
Questions about risk management are societal questions. Ideas about the vulnerability of nature, about the responsibility towards future generations, and indiwidual freedom shape risk perceptions ${ }^{237}$. Cultural theory of 1 is ${ }^{2 * 8}$, a constructivist. theory, argues that it is not necessary to involve the endless number of individual perceptions to account for social and cultural variety ${ }^{219}$. Anthropology, which investigates meaning and actions against the background of implicit cultural biases, provides some structuring of the variety in risk attitudes. For example, a dichotomy indicating two paradigmatic world views, i.e. industrialists and environmentallists, provided by Cotgrove ${ }^{220}$ (see Table 2), the traditional dichotomies of political sciences (i.e. left-wing versus right wing, and materialistic versus post-materialistic) and the four risk cultures of Cultural Theory (see Table 3 ). The distinction by Cotgrove features two very specific categories, and is thus rather limited.

\begin{tabular}{|c|c|c|}
\hline Features of world wieus & Industrialists & Envirommentalises \\
\hline core values & $\begin{array}{l}\text { - material, economic growth } \\
\text { - natural environment is resource } \\
\text { - anthropocentric }\end{array}$ & $\begin{array}{l}\text { - spiritual growth } \\
\text { - ecocentric } \\
\text { - harmony with nature }\end{array}$ \\
\hline economy & $\begin{array}{l}\text { - market forces } \\
\text { - rewards for achievement } \\
\text { - differentials } \\
\text { - individual assurtnce }\end{array}$ & $\begin{array}{l}\text { - public system } \\
\text { - incomes related to needs } \\
\text { - egalitarian } \\
\text { - social security }\end{array}$ \\
\hline governance & - aurhoritative structures, technocratic & - participatory structures \\
\hline sociaty & $\begin{array}{l}\text { - centralised } \\
\text { - large-scale } \\
\text { - ordered } \\
\text { - institutionalised }\end{array}$ & $\begin{array}{l}\text { - decentralised } \\
\text { - small-scale } \\
\text { - flexiblle } \\
\text { - community-based }\end{array}$ \\
\hline nature & $\begin{array}{l}\text { - ample reserves } \\
\text { - environoment is controllable }\end{array}$ & $\begin{array}{l}\text { - resources limited } \\
\text { - nature in delicate balance }\end{array}$ \\
\hline knowldge & $\begin{array}{l}\text { - confidence im science and techmology } \\
\text { - ratomality of means }\end{array}$ & $\begin{array}{l}\text { - limits to science } \\
\text { - rationality of ends }\end{array}$ \\
\hline
\end{tabular}

TMOLIE 2 Features of pragnatic worldwiews proposed by Cotgrove

The typology derived from grid-group analysis, the so-called 'Cultural 'Theory', so far received most attention in risk analysis ${ }^{23}$. Cultural theory distinguishes four risk

217 (Gerondheidstatad 1996)

218 e.g. (Thompson at al. 1990; Rayner and Cantor 1987, Rayner 1987, Funcowicz and Ravetz 1985). A crucial publicantion in this context is (Krimsky and Colding 1992 ).

215: (Rhymer and Cantor 1987 ; R aynter 1987)

220 (Cotgrove 1981)

2215 ee footwote 218 for refferences. 
cultures, i.e. hierarchy, individualism, egalitarianism and fatalism, which allows a richer analysis than a dichotomy does. These positions are "extremes" that together they seem to expand the space of viable risk perceptions.

\begin{tabular}{|c|c|c|c|c|}
\hline $\begin{array}{l}\text { central fectures } \\
\text { of risk cultures }\end{array}$ & hierarchist & egalitarian & individualist & fatalist \\
\hline myth of nature & $\begin{array}{c}\text { robust whin limits } \\
\text { (nature perversel } \\
\text { tolerant) }\end{array}$ & $\begin{array}{c}\text { Cragile } \\
\text { (nature ephemeral) }\end{array}$ & $\begin{array}{c}\text { robust } \\
\text { (nature benign) }\end{array}$ & $\begin{array}{c}\text { lotcery } \\
\text { (nature capricious) }\end{array}$ \\
\hline $\begin{array}{l}\text { concept of } \\
\text { human nature }\end{array}$ & siniful & $\begin{array}{l}\text { born good, } \\
\text { malleable }\end{array}$ & self-seeking & $\begin{array}{c}\text { some are more lucky } \\
\text { than orhers }\end{array}$ \\
\hline treeds \& resources & $\begin{array}{l}\text { can manage } \\
\text { resources but } \\
\text { not needs }\end{array}$ & $\begin{array}{l}\text { can manage } \\
\text { needs but not } \\
\text { resources }\end{array}$ & $\begin{array}{c}\text { can manage } \\
\text { both needs and } \\
\text { resources, with } \\
\text { emphasis on manag- } \\
\text { ing resources upwards }\end{array}$ & $\begin{array}{l}\text { can mamage } \\
\text { neither needs } \\
\text { nor resources }\end{array}$ \\
\hline $\begin{array}{l}\text { management style } \\
\text { learning style }\end{array}$ & $\begin{array}{c}\text { control } \\
\text { anticipation }\end{array}$ & $\begin{array}{c}\text { preventive } \\
\text { trial without error }\end{array}$ & $\begin{array}{l}\text { adaptive } \\
\text { trial and error }\end{array}$ & luck \\
\hline saltent risters & $\begin{array}{c}\text { loss of control } \\
\text { (i.e. of public trust) }\end{array}$ & $\begin{array}{l}\text { catastrophic, } \\
\text { irreversible and } \\
\text { inequitable } \\
\text { developments }\end{array}$ & $\begin{array}{l}\text { threats } \\
\text { to functioning } \\
\text { of markets }\end{array}$ & 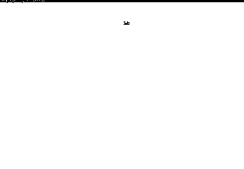 \\
\hline risk artitude & risk-accepting & risk-aversive & risk-seeking & risk-absorptive \\
\hline
\end{tabular}

TABLE 3 Features of four risk cultures associated with Cultural Theory ${ }^{223}$

The idea is to use a set of perspectives to develop:

- multiple sets of context-dependent risk items

- multiple syntheses of the information on risk items

- multiple sets of scores

- multiple sets of weights

- multiple risk profiles

in a consistent and transparent manner. It seems promising to explore whether and under which conditions the Cultural Theory typology is an appropriate scheme to be used ${ }^{224}$. The typology of perspectives provided by Cultural Theory is deductive, in the sense that general social scientific insights and arguments are used to arrive at an aggregated typology. In case such a simplification is not desirable or not acceptable for the risk issue under concern, an inductive, bottom-up approach is advocated. An 
inductive approach implies reasoning from empirical research in which the perspective and interests of individuals or groups involved in the particular risk issue are articulated. These responses can then be clustered to a limited set of perspectives.

\section{CASE MULTIPLE RISK ASSESSMENTS}

Fischhoff et al. did not propose a way to arrive at alternative syntheses of the available information, which would have led to different estimates for the five risk attributes. Their way of dealing with inherent uncertainty in knowledge on such a complex issue is to consider solely the worst case. In other words, the scientific data is interpreted from one wery specific point of view. An alternative would have been to interpret the dlata, which forms the basis for estimates on death risks and morbidity risks, also from other perspectives. For example, a more 'middle-ground' perspective that prefers to use the most-likely case as basis for the risk analysis. Or a more technocratic perspecrive, that interprets the historical accident data from the point of view that the present technology underlying the various options for electricity generation is much safer.

Psychometric data could also have been used to construct alternative estimates for the two risk attributes dealing with public support (i.e. the level of unknown and the level of dread). Fischhoff et al. have averaged the individual scores to arrive at a single value for these risk attributes. However, a more in-depth analysis of the psychometric data could have yielded groups of opinions reflecting different risk-attitudes. The risk-cultures proposed by Cultural Theory could have been used as heuristic device to guide such an analysis ${ }^{22}$. In that case, the survey questions on properties of the various technologies could have been complemented with questions that enable to characterise roughly the basic risk-attitude of groups of respondents. Such a clustered analysis of the data could then yield different valid estimates for the public support risk attributes.

Notwithstanding the lack of pluralism with regard to the synthesis of available, incomplete and uncertain, knowledge, Fischhoff $e t$ al. propose a pluralistic approach with regard to weighing the various risk attributes. They formulated four sets of weights that can be considered as reflections of four perspectives on the value of life. Let us assume that these particular sets of weights $(A, B, C$, and D) resulted out of the hypothetical participatory process, as described above. Together with the scores of the six technologies on the five risk 
atrributes, these sets of weights are used to compute risk estimates. The resulting risk estimates are shown in Figure 5 below.

FICURE 5 Multiple risk estimates

RISK ESTIMATES ACCORDING TO DIFFERENT SETS OF WEICHTS

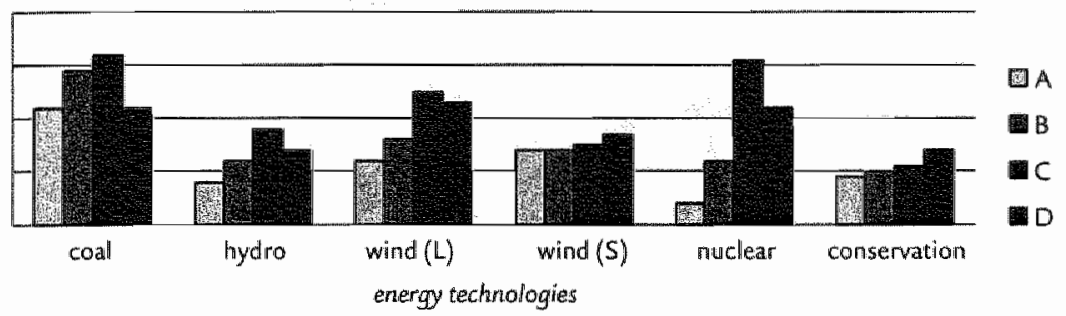

These estimates are used to indicate the relative riskiness of the six technologies according to the four sets of weights. The resulting characterisations of the alternative technologies for electricity generation in terms of riskiness are indicated in Table 5.

\begin{tabular}{l|c|c|c|c}
\multirow{4}{*}{ riskiness } & \multicolumn{4}{|c}{ Set of weights (perspective) } \\
& A & B & C & D \\
\hline \multirow{4}{*}{ low risk } & nuclear & conservation & conserwation & conservation \\
\cline { 2 - 5 } & hydro & hydro & small-scale wind & hydro \\
\cline { 2 - 5 } & Conservation & nuclear & hydro & small-scale wind \\
\cline { 2 - 5 } & large-scale wind & small-scale wind & large-scale wind & coal \\
\cline { 2 - 5 } & small-scale wind & large-scale wind & coal & nuclear \\
\hline high risk & Coal & coal & nudear & large-scale wind \\
\hline
\end{tabular}

TABLE 5 Multiple judgements of alternative technologies in terms of riskiness

The same information can be visualised with use of a multi-star representation $^{27}$, as is done in Figure 6.

225 Hoppe (personal commurtication)

226. Concrete suggestion on survey questions on Cuitural Theory can be fout in (Dake 1991; 1992; Dake and Thompson 1993) and (jaeger et al. 1999). Suggestions for how psychometric analyses and the ritsk cultures associated with Gultural Theory can be used in a conplementary manner can be found in (Marris et al. 1997). The author learned that just this idea on using Cultural Theory wass proposed thy 5 kewe Rayner to Paul 5 lovic in the mid 80 s, bart it was newer performed (5 teve Playner, personal communicalion).

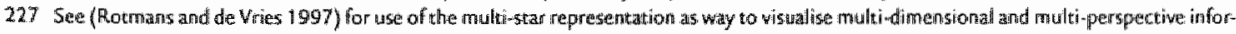
mation inta one Gigure. 


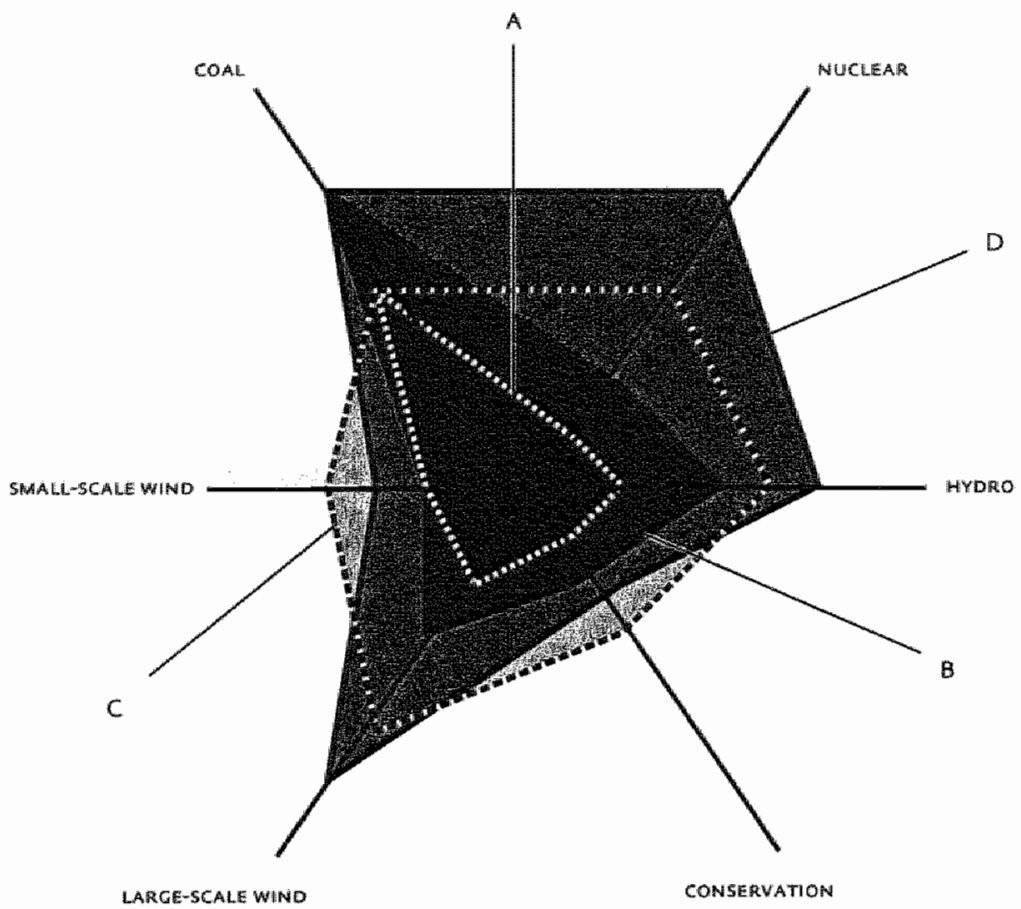

FICURE 6 Multiple star-representation of risk estimates

In case, multiple syntheses of the information on the risk attributes would have been used, the analysis would have increased with one dimension. Let us assume that the four risk-cultures associated with Cultural Theory are used to arrive at different sets of estimates for the five risk attributes. Such a risk assessment could have been performed using a matrix set-up (see Table 6). As a result of such a structure, the ultimate risk estimates would not only differ because different weights are used (as in Figure 5), but also because different estimates for the underlying risk attributes are used. Furthermore, it would have yielded more estimates due to the increased number of combinations.

\begin{tabular}{l|l|l|l|l}
\multirow{2}{*}{ Risk attribute } & \multicolumn{4}{|c}{ Perspective } \\
\hline death risk workers & hierarchist & egalitarian & individuallist & fatalist \\
\hline death risk public & & & & \\
\hline morbidicy risk & & & & \\
\hline public concern: unknown & & & & \\
\hline public concern: dread & & & & \\
\hline
\end{tabular}


This scoring and weighting could also have been done in a participatory effort. An example of more participatory risk assessment is the citizen panel approach adopted by the Environmental Protection Agency (EPA) in the US ${ }^{32}$. In these panels citizens develop rankings of risk over a period of time with considerable scientific support. Such citizen panels can in principle also be used to suggest alternative perspectives. This example shows that participatory risk assessment in the systematic way as proposed in this Chapter seems to be a possible avenue.

\section{Risk statements}

The ultimate goal of participatory risk analysis is to produce informed judgements and robust recommendations. In this context the following issues are crucial in the participatory risk analysis: i) how to communicate risk statements?, and ii) how to integrate the pluralistic risk estimates informed by participatory processes into robust risk statements that reflect insights relevant to societal decision-making on risk?

\section{I. HOW TO COMMUNICATE RISK STATEMENTS?}

It is generally observed that citizens do not know how to interpret probability ${ }^{229}$, especially not in case of extreme values like $\mathrm{I}$ in a million. Furthermore, also the "political decision-making processes do not take the probabilistic perspective of the risk analyst" ${ }^{330}$. If, as is suggested by many risk communication experts ${ }^{23:}$, we drop the use of probability, what is the alternative? We then need to find ways that are compatible with the essentially non-probabilistic orientation of decision-makers, stakeholders and the general public.

Does the scholarly literature on risk suggest alternatives to probabilistic statements? Both objectivist and constructivist scholars stress the importance of the 'maximum credible accident' in thinking and deciding about complex issues. To this

\footnotetext{
228 (EPA 1993$)$

229 among others (Cowello 19:84; Slowic et all. 1980ts; 5rarr and Whipgle 1980)

230 (Lathop 1980 )

231 For examplie, (Cokello 1985 ). See for a recent and comprehensive discussion on comanturication prothetsis concerning probalbilty (Kaplan 1997 .
} 
end scenario approaches ${ }^{23^{2}}$ may provide useful suggestions how such maximum credible accidents could be assessed.

Among the few principles that have come down to us from early risk analysis there is one that states that comparisons are more meaningful than absolute numbers or probabilities ${ }^{253}$. It should be noted that risks are difficult to compare, because risks are so diverse. So we do not plea for a comparison in the traditional sense, but we advocate comparative analysis in which participants arrange risk issues in mutual consultations. In this context risk-comparisons are only used in relative terms and in an illustrative manner. Comparisons that indicate the "rellative riskiness" ${ }^{134}$ can help to put risk estimates into perspective ${ }^{235}$. It should be noted that risk comparison does not necessarily imply a quantitative exercise. Qualitative comparison is equally valid.

Some comments have to be made: risk comparisons should in principle not be presented as argument to settle the question, such $\mathrm{as}^{2360}$ :

The risk of a (e.g. emissions from a plant or flooding) is lower than the risk of $\boldsymbol{b}$ (e.g. driving a car or smoking cigarettes). Because you find $\boldsymbol{b}$ acceptable you should also find a acceptable.

This argument has a basic flaw in its logic for the following reasons:

i) comparisons in terms of concentrations of hazardous substances seem to minimise and trivialise the problem, and they can be misleading because the porency of the various substances varies widely,

ii) because the risks fundamentally differ in character: risks of type a are not controllable and are usually not voluntarily taken, while the risks of type $b$ are controllable and voluntarily taken,

iii) people do not want to be forced in this way,

iv) because of accumulation of risks: "because I already accept b, which is risky, I do not want to take more risks".

Psychological research on risk communication indicates that risk comparisons that present unrelated risks (such as the risks associated with motorcycling versus the risk of flooding) do not influence risk perceptions ${ }^{237}$. The use of this type of risk comparisons can undermine the trust and credibility necessary to estimate risks. Not-

232 See Chapter 2 and chapter 3 A for disc lassions on scemario approweles.

233 E. (Roths ind 1979 sowby 1965 )

234 (Fischath of al. 1984 )

235 See ror example (Covello at al 1991 )

236 (Covetloet al. 1994 ; Rotheselhild 1979)

23 ) (Slovic 1991) 
withstanding these reservations, it may sometimes be useful to contrast risks in the above manner, to indicate the different ways in which they are treated in society ${ }^{238}$.

The challenge is to use risk comparisons that address related issues and that are not perceived as an effort to pre-empt judgements about acceptability. Covello et al. ${ }^{239}$ provide a ranking of risk comparisons. Relevant, appropriate and helpful risk comparisons are those that compare:

- the same risk at two different times: "The risk associated with $x$ is around $y \%$ less than $z$ years ago".

- with a standard: "Exposure to $x$ is well below the level that authority $y$ considers safe" ${ }^{n+240}$.

- different estimates of the same risk: "Our best estimate of the risk is $x$, whereas the worst case risk estimate we have calculated is $y$, on the basis of methodology 2 we arrive at estimate $z$, whereas that of organisation $A B C$ is $v$ ".

- the risk of doing something versus not doing it: "If measure $a$ is implemented the risk will be $x$, whereas if not, the risk will be $y$."

- alternative policy options: "The risks associated with option $a$ is $x$, and the risk associated with option $b$ is $y$ ".

- the same risk as experienced in other places: "The most serious problems associated with $x$ have been encountered in place $A$, while here the risk is only about $y \%$ from that in $A^{\prime \prime}$.

- risk from one source of a particular negative effect with the risk from all sources of that same adverse effect: "The risk on a posed by $x$ is roughly $y \%$ of the total risk on $a$ in this community".

In these comparisons it is important to be open about the uncertainties associated with the various risk estimates, so as to be able to evaluate the level of confidence that can be attached to these risk comparisons. They can be helpful in investigating the characrer and fearures of the different risks in order to be able to explore in the participatory process which risks seem to be the most risky.

Psychological research on risk reveals that in representing risk it is important to be aware of the possibility of so-called 'framing-effects': the views on risk can be easily manipulated by the presentation format ${ }^{241}$. Kaplan and Garrick ${ }^{24 x}$ were among the first to argue that risk should be represented graphically. Furthermore, not all

\footnotetext{
238 (Croweh and Witson 1982)

239 (Cowello ett. 1991)

240 This type of wish estimiates is not very helloful in risk contexts where authorities are rout trasted.

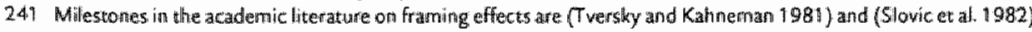

242 (Kaplanand Gartick 1981 )
} 
dimensions can be assessed in a quantitative way. The approach to risk as proposed here results in multi-dimensional, hybrid risk estimates, which by definition cannot be represented in a purely quantitative manner.

Risk estimates then cannot be expressed in one number. Notwithstanding the fact that the need for graphical representation was recognised so early, the risk literature does not provide an abundance of schemes that yield understandable risk figures $^{243}$. The ultimate challenge for the future is to integrate quantitative and qualitative estimates into a risk profile of certain pathways into the future. In this effort, risk analysis may benefit from advances made with regard to indicators and indices ${ }^{34}$ in other fields, such as Integrated Assessment.

\subsection{HOW TO INTEGRATE PLURALISTIC RISK ASSESSMENTS INTO ROBUST RISK STATEMENTS?}

The challenge we face is to integrate multiple risk estimates via comparisons in terms of relative riskiness, and ranking to robust risk statements that can inform societal decision-making processes. The above process yields for each strategy or activity plural perspective-based multi-dimensional risk profiles. One way to create robust conclusions is to evaluate which strategy seems to have the best risk profiles, taking into account the various risk comparisons. It does not imply that the so-called best alternatives' are the safest, or that it leads to an acceptable or desirable future. In terms of nature of the decision, robust risk statements involve exploring which strategies or activities seem to be acceptable or even desirable taking into account a wide variety of perspectives, and which are not. It is important that the risk statements reflect the process and the considerations to be of use in the decision-making proc$\operatorname{ess}^{245}$. The argumentation is as important as the output ${ }^{24}$.

\footnotetext{
244 The representation provided by (Fisclithof et all, 1984) that is thoroughly discussed in the following section is one of the rate examples in which riskis arre wistiallised in a qualitutive, understandable manner.

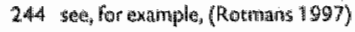

245 Conapare (Fischithoff 1996)

246 (Ceramdheds:at 19915)
} 
Mathematically speaking, there are 720 rankings $^{247}$ of the six alternative technologies, so it is rather likely that the rankings that result of the above process will differ. These rankings can also be represented using the multi-star representation; however, due to the number of 'stars' it will be rather 'crowded'. For that reason in this case an alternative representation may be more practical, such as the risk area ${ }^{248}$ presented in Figure 7. In this figure a dot in a row of one of the technologies represent that that option for electricity generation scores the associated level of riskiness in one of the rankings. In the Figure below we have just indicated dots corresponding with the four rankings provided by Fischhoff et al.

\begin{tabular}{|c|c|c|c|c|c|c|}
\hline \multirow[t]{2}{*}{ technology } & \multicolumn{6}{|c|}{ relative riskiness } \\
\hline & low ris & & & & & highrisk \\
\hline nuclear & 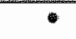 & & - & & $\bullet$ & 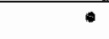 \\
\hline hydro & & $\cdots$ & - & & & \\
\hline conservation & 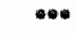 & & 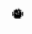 & & & \\
\hline large-scalle wind & & & & $\because$ & - & 6 \\
\hline small-scale winds & & - & $\bullet$ & - & - & \\
\hline coal & & & & $\bullet$ & $\bullet$ & 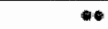 \\
\hline
\end{tabular}

TABLE 7 Risk area representation of multüple rarikings

The example on alternative technologies for electricity generation reasons from the beginning from a comparison between alternative options. In that sense, all the statements discussed above are, implicitly or explicitly, phrased as "The risk associated with option $\mathrm{a}$ is $\mathrm{x}$, and the risk associated with option $\mathrm{b}$ is $\mathrm{y}^{\prime \prime}$. As discussed in section 6.r, this is an appropriate and relevant way of communicating risks.

The multiple perspective-based risk estimates furthermore enable to compare different estimates of the same risk. Especially if also the assessment of risk attributes is pluralistic (as we recommended), risks can be compared in terms of: "Our best estimate of the risk is $\mathrm{x}$, whereas the worst case risk esti- 


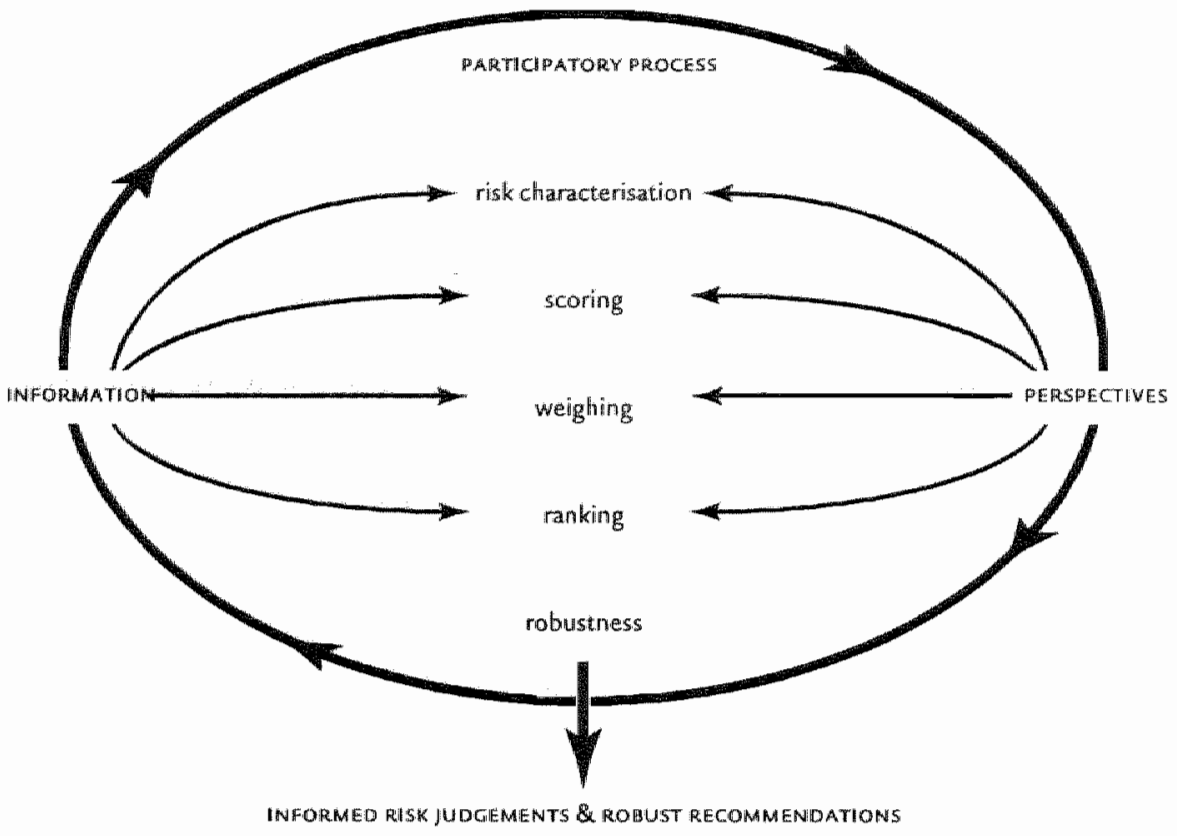

FicURe y Framework for participatory, intergated risk anallysis

mate we have calculated is y. On the basis of another methodology, we arrive at estimate $z$, while that of organisation $\mathrm{ABC}$ is $\mathrm{v}_{\text {." }}$

Nevertheless, it may be that participants in the risk analysis process are served with some other appropriate risk comparisons that complement the one used so far. In this particular case, the scientific experts may be asked to generate information that allows comparison of the risk of one technology over time. For example, what were the death risks associated with electricity generation based on coal 25 years ago? Last but not least, it may be helpful to allow comparison of the risks associated with the various technologies in the (nameless) country under concern with the risks as experienced in other countries. To that end, the scientific experts should try to collect available, reliable data on mortality and morbidity associated with electricity generations in other countries, as well as assess survey results on risks in other countries.

Fischhoff ex al explicitly state that they do not provide a definitive statement. "They underpin this lack of integration in the following way: "Even a definitive statement about risk would have no necessary implications for most policy-making". They are right in acknowledging the limits of every analytical endeavour that aims to support decision-making. However, with this argument they reduce any risk analysis to fighting a losing battle. We argue that it is possi- 
ble to go beyond multiple risk estimates, and to search for ways to integrate pluralistic risk estimates into robust risk statements. To illustrate our argument, we extend the case of electricity generation beyond what Fischhoff $e t a l$. did.

Our assessment of the risk estimates was helped by the various representations of the multiple rankings on riskiness, as provided in the previous section. Such integrated visualisations of the multiple risk assessments inspire integrative thinking in terms of concrete, robust policy recommendations. So such graphical representations are much more than just nice figures. They are helpful, may be even ind ispensable, tools in the integration exercise.

The evaluation in terms of relative riskiness indicates that conservation is the most preferred option by three perspectives, while at the same time it is not considered to be a high-risk option by the remaining perspective. This observation may then result in the robust statement that energy conservation is the most acceptable technology in balancing societal benefits and negative impacts. In terms of recommendation for policy, this statement implies that it is worthwhile to assess how energy conservation technologies can be stimulated. By RD\&D programs? Legislation? Financial incentives? This type of robust statements identifies how further analysis, and what kind of analysis, could shed light on the decision-making properties of the risk issue.

Another robust statement that results from the above risk analysis on electricity technology is that opting for nuclear power is likely to create societal tensions. This can be concluded from the observation that nuclear power is in one perspective considered to be the most risky and in another a low-risk technology. With regard to enlarging energy supply, hydropower seems to be the option for which societal support may be created most easily at the general level, although also in this case not-in-my-backyard tensions can be anticipated.

From the above hypothetical risk analysis, it is also clear that electricity generation is a controversial risk issue. A robust recommendation building upon this insight would be to explore which technological options for energy supply are most flexible, in the sense that they can be easily dismantled in case the energy demand did not increase in the way assumed in this scenario. Such a characterisation of the technological options would allow decision-makers to keep options open. This type of recommendations indicates how further analysis can clarify relevant aspects of the risk issue under concern.

The above hypothetical recommendations are presented to illustrate that notwithstanding the fundamental diversity in risk definitions and risk percep- 
tions the outcome of pluralistic participatory risk analysis is not necessarily a deadlock situation of dissent. It furthermore illustrates that clearly characterised disagreements, such as on nuclear energy, can still inform decision-making. It is even argued that a well-managed, mutually respectful process of participatory risk analysis may reveal some significant areas of agreement, even among diverse individuals from a wide variety of backgrounds, and that the result of such a process may be fewer, and better focussed, conflicts about risk $^{249}$.

\section{Conclusions}

The present Chapter proposes a theoretical outline for integrated risk analysis that can be used for the analysis of strategic risks, i.e. risks that are inherently uncertain, that are beyond the reach of individual controll, and that are far-reaching both in terms of temporal and geographical terms. According to the Dutch Health Coun$\mathrm{cil}^{250}$, strategic risk issues necessitate new forms of dealing with risk. Integrated participatory risk analysis aims to address this need. The proposed framework (see Figure 8 for a summary) synthesises shared premises and multi-disciplinary insights resulting from three decades of academic research on risk. In doing so, we aim to reconcile the strengths of scientific analysis with psychological, sacial and cultural values into one coherent paradigm. In this way, it may provide a bridge between the various groups within the risk community, as well as between risk analysts, decisionmakers and stakeholders.

The framework for integrated risk analysis should not be considered as a rigid blue print for risk analysis. It has never been the aim to provide a potential standard. The risk of standardising in the context of complex risk analysis is that essential unique aspects of actual risk cases are neglected in the analysis. The aim has been to sketch a general interdisciplinary framework that synthesises the multi-disciplinary insights and that can be used in a flexible way to organise integrated risk analysis in a manner that is theoretically sound.

This Chapter furthermore explores how this framework could be used. The challenge is to test the soundness of this proposed approach in concrete risk studies, also in comparison to existing approaches to risk issues. The key question ${ }^{25 n}$ is 
whether the proposed integrative approach offers something that could improve the current practise at public bodies, like the Ministry of Public Health, Planning and Environment (VROM) in the Netherlands, which currently apply a rigid standard setting and testing approach to risk management ${ }^{252}$, and the Environmental Planming Agency (EPA) in the US ${ }^{253}$, which already adopts participatory risk ranking approaches. To that end, in particular the potential value and limitations of the following suggestions have to be empirically tested:

- the proposed method for multi-dimensional risk characterisation

- the manageability and effectiveness of participatory processes structured around the proposed tasks.

- the proposed approach for multi-perspective risk analysis, e.g. the typology of risk cultures as tool to consider plural interpretations in different phases of risk analysis.

- the practical value of the proposed type of robust risk statements

The aim of the following Chapters is to use the proposed framework and insights on the concept of risk to develop a credible approach for risk analysis and uncertainty management in the context of Integrated Assessment of complex problems. From the current Chapter we can conclude that key notions for such an endeavour are ${ }^{254}$ :

- pluralism

- participation

- ROBUSTNESS

252 See (WROM et al. 1989) for a description of the curremt approach. See (Cezondheidsraad 1995; 1996) for a critical review.

253 (EPA 1993) See also (Cecondlitesdsrad 1995) for a su numary of EPA"s cexperiences.

254 The same key notions materialise from addlessing the above am of this thesis from our overview of the state-of-the-art in integrated Asse:ssment (Chapter 2), and from our philosophacall evaluation of the concept of "uncertainty' combined with a critical review of the currevts practise in uncertainty anallysis (Chapter $3 \mathrm{~A}$ ). 


\section{REFERENCES CHAPTER $3 B$}

- Adams, I. (1995), Risk, UCL Press, London, UK.

- Beck, U. (1986). Risk Society: Towards a New Modernity, Sage, London, UK.

- Beck, U. (1992), "From Industrial Society to the Risk Society: Questions of survival, social structure and ecological enlightenment." Theory, Culture and Sociery, 9(1), 97-123.

- Beck, U. (1995). "The Utopia of Self-restraint (in German)." Aesthetik \& Kommunilation, 24(May), 89.

- Beck, U. (1996). "World Risk Society, World Openess and Global Subpolitics: Ecological questions in the contex of produced uncertainties (in German)." Environmental Sociology (in German), A. Diekmann and C.C.jeger, eds., Opladen, Cermany.

- Beck, U. (1997a). "Fatalists in the labyrinth of the risk society." The World as Risk Society: Essays about the ecological crisis and the politics of progress (in Dutch), U. Beck, ed., De Balie, Amsterdam, the Netherlands.

- Beck, U. (1997b). "Tsernobyl and the anthropological shock (in Dutch)." The World as Risk Society: Essays about the ecologieal crisis and the pollitics of progress (in Dutch), U. Beck, ed., De Balie, Amsterdam, The Netherlands.

- Bernardo, fl, and Smith, A. (1994). Bayysian Theory, John Wiley and Sons, Chichester, USA.

- Burger, E. I. (1988). "How citizens think about risks to health." Risk analysis, 8(3), 305-314.

- Carlson, W. B., and Millard, A. J. (1987). "Defining risk within a business context. Thomas A. Edison, Elihu Thomsom, and the a.c.-d.c. controwersy $(1885-1900)$." The social and cultural construction of risk, B. B. Johnson and V. T. Covello, eds., Reidel, Dordrecht, the Netherlands.

- Clark, W. C. (1980). "Witches, floods, and wonder drugs: hístorical perspectives on risk management." Societal risk assessment: How safe is safe enough?, R. C. Schwwing and W. A. Albers Jr., eds., Plenum Press, New York, USA.

- Colson, J.P. (1977). The nuclear issue without the French people (in French), Maspero, Paris, France.

- Conrad, J. (ed.) (1980). Society, Technology and Risk Assessment, Academic Press, London, UK.

- Cotgrove, 5. (1981). "Risk, Value Conflict and Political Legitimacy." Dealing with Risk, R. F. Griffiths, ed, Manchester University Press, Manchester.

- Covello, V. (1984). "Uses of social and behavioural research on risk." Environment international, 4(June), 17-26.

- Covello, V.T. (1985). "Social and behavioural research on risk: Uses in Risk management decision-making." Enwironmental impact assessment, technology assessment and risk analysis, V. T. Covello, J. L. Mumpower, P. J. M. Stallen, and V. R. R. Uppuluri, eds., Springer Verlag, Berlin, Germany.

- Covello, V.T., Samdiman, P. M., and Slovic, P. (1991). "Guidelines for communicating information about chemical risks effectively and responsibly." Acceptable evidence: Science and values in risk management, D. G. Mayo and R. D. Hollander, eds., Oxford University Press, New York, USA.

- Crouch, E. A. C., and Wilson, R. (1982). Risk/Benefit antalysüs, Ballinger Publishing Company, Cambridge Massachusetts.

- Dake, K. (1991). "Orienting dispositions in the perception of risk: an analysis of contemporary world views and cuitural biasses." Journal of Cross-cultural Psychology, 22(1),61-82.

- Dake, K. (1992). "Myths of nature, culture and the social construction of risk." Joumal of Social Issues, 48(4)" 21-37.

- Dake, K., and Thompson, M. (1993). "The Meanings of Sustainable Development: Household strategies for Hanaging Needs and Resources." Human Ecology: Crossing Boundaries, S. D. Wright, T. Dietz, R. Borden, C. Young, and G. Guagnano, eds., The Society for Human Ecoliogy, Fort Collins, USA.

- de Finetti, N. (1974). Theory of probabillity, Wiley, New York, USA.

- Douglas, M. (1969). "Environments at risk." Ecology: The Shaping Enquiry, J. Beuthall, ed., Longman, London, UK.

- Douglas, M. (ed.) (1982). Essays in the Sociology of Perception, Routledge and Kegan Paul, London, U.K.

- Douglas, M., and Wildavsky, A. (1982). Risk and Culture: Essays on the Selection of Technical and Enwironmental Dangers, University of Callifornia Press, Berkley, USA.

- Earle, $T$, and Cvetovich, $G$. (1985). "Risk judgement and the communication of hazard information: Toward a new look in the study of risk perception. "Environmental impact assessment, technology assessment and risk analysis, V. T. Covello, J. L. Mumpower, P. J. M. Stallen, and V. R. R. U ppuluri, eds., Springer Verlag, Berlin, Germany.

- EPA. (1993). "Comparing Risks and Setting Envirommental Priorities.", Environmental Protection Agency, Washington D.C., USA.

- Fischer, W. F., Morgan, M. G., Fischhoff, B, Nair, I, and Lave, L. B. (1991). "What risks are people concerned about?" Risk Analysisis, 11(2), 303-314. 
- Fischhoff, B. (1995). "Ranking Risks." Rist: Health, safery andemwironment, 6(Summer) 191-201.

- Fischhoff, B. (1996). "Public Values in Risk Research." The Annals of the Anericati Academy, 545(May), 75-84.

- Fischhof, B, Bostrom, A, and Quadrel, M. I. (1997) "Risk Perception and Communication." Oxford Textbook of Public Health: The methods of public thealth, R. Detels, W. W. Hollard, J. McEwen, and C. S. Omenr, edss, Oxford University Press, Oxford.

- Fischhoff, B., Lichtenstein, S., Slovic, P., Derby, S. and Keeney, R. (1981). Acceptable Risk, Cambridge Uniwersity Press, Cambridge $U$,

- Fischhoff, B, Watsan, S. R, and Hope, C. (1984). "Defining Risk." Policy Sciences, 17, 123-139.

- Funtowicz, S. O., and Ravetz, J. R. (1985). "Three types of risk assersment: A methodological analysis." Riskik Analysis in the Private Sector, C. Whipple and V. T. Covello, eds., Plenum Piness, New York, USA.

- Funtowicz, S. O., and Ravetz, . R. (1990). Uncertainty and quality in science for polncy, Kluwer, Dordrecht, the Netherlands

- Funtowicz, S. O., and Ravetz J. R. (1992a). "Risk Maragement. as a Postnormal Science." Risk Analysis, 12(1), 95-97.

- Funtowicz, S. O., and Ravetz, \&. R. (1992b). "Three Types of Risk Assessment and the Emergence of Post-Normal Science." Social Theories of Risk, S. Krimsky and D. Goldimg, eds., Greenwood, Westpart.

- Funtowicz, S. O, and Ravetz, ). R. (1993a). "The Emergence of Post-normal Science." Science, Politics and Movality: Scientific uncertainty and decision-making, R. von Schomberg, ed., Klawer Academic Publishers, Dordrecht, the Netherlands.

- Funtowicz, S. O., and Ravetz, f. R. (19936). "Science for the Post-Normal Age." Futures, 25 (7), 739.755.

- Funtowicz, S. O, and Raverz, I. R. (1994). "The Worth of a Songbird: Ecological Economics as a Post-Normal Sci. ence." Ecological Ecanomics(10), $197-207$.

- Gamble, D. J. (1978) "The Berger linquiry." Science, 199(March), 946-951.

- Geurts, J. L. A., Hart, S. L., and Caplan, N. S. (1987). "Decision techniques and social research: a contingency frame. work for problem solwing." Hituman Systems Management, 5, 333-347.

- Geurts, J. L. A., and Mayer, 1. (1996). "Methods for Participatory Policy Analysis: Towards a conceptuall model fon research and devellopment." 96.12,008/3, Work and Organisation Research Centre (WORC), Tilburg, the Netherlands.

- Gezondheidsraad. (1995). "Not All Risks are Equall (in Dutch with an English summary):"1995/06, Health Council of the Netherlands, The Hague, the Netherlands.

- Gezondheidsraad. (1996). "Risk is More than Just a Number (in Dutch with an English summary)." 1996/03, Health Council of the Netherlands, The Hague, the Netherlands.

- Hacking, 1. (1975). The emergence of probability, Cambridge University Press, Cambridge, UK

- Hafele, W. (1976) "Benefit-risk tradeoffs in nu clear power generation." Energy and the environnent, $H$. Ashloy, F. Rudharn, and C Whipple, ed s. Pergamon Press, New York, USA, 141-184.

- Hajer, M, and Schwarz, M. (1997). "Contours of the Risk Saciety (in Dutch)," The World as Risk Soriety (in Duttich), De Balie, Amsterdam, the Netherlands.

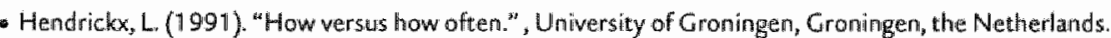

- Hilderink, H. B. M., and wan Asselt, M. B.A. (1997) "Popularion ard Health in Perspective." Perspectives on Global Change; The TARCETS approach, /. Rotmans and H. J. M. de Vries, ed.s., Cambridge Uniwersity Press, Cambridge, UK.

- Jaeger, C. C., Grendstad, G., van Asselt, M. B. A., Beck, A., Bieri, La, Durrenberger, $G_{\text {. }}$ Selle, P., and Stromsnes, K. (1999). "Environmental Risks and Myths of Nature: A Test Of The Cultural "Theory Of Risk." Risk Analysis (subinitted).

- Jasanoff, S. (1987). "Cultural aspects of risk assessment in Britain and the United States." The social and cultural construction of risk, B. B. Johnson and W. T. Covello, ed's, Reidel, Dordrecht, the Netheriands.

- Jasanoff, S. (1991)، "Acceptable evidence in a pluralistic society." Acceptable evidence: Science and walues in risk management, D. G. Mayo and R. D. Hollander, eds., Oxford University Press, New York, USA.

- Jasanoff, S. (1993). "Bridging the two cultures of risk analysis." Risk Anatysis, 13(2), 123-129.

- Johnson, B. B., and V. T. Covello (1987). The Social and Cultural Construction of Risk. Essays an risk selection and perception, Reidel Publishing Company, Dordrecht.

- Jungermann, H. (1985). "Psychological Aspects of Scenarios." NATO ASI serias, Vol G4f(Enwironmental Risk Assessment, Technology Assessment and Ristl Analysis). 
- Jungernann, H. (1993). "Risk (in Cerman)." Technology Controwersy. Actual key motions for public debates (in Gerrian, H. Schitz and W. P.M. eds., IMK, Frankfurt am Main, Cermany.

- Jungermann, $H_{\circ}$ and Femers, 5. (1995). "Multiple perspectives on risk: Measures and comparisons." European review of applied psychology, $45(1), 4,47$

- Jungermam, H, and Slovic, P. (1993). "Characteristics af individual risk perception." Rüskis a Construct, B. Rück, ed., Kriesebeck Verlag, Munchen, Curmany.

- Kahneman, D. and Tversky, A. (1982). "Variants of uncertainzy." Judgement under Uncertainty: heuristics and biases, D. Kahneman, P. Slwic, and A. Twersky, eds., Cambridge Unwersity Press, Cambridge, UK.

- Kamper E. (1998). "Sociology of risk. Implications for the analysis of enwironmental policy." hrtp://wwwiue.w4/ WCES/1S517/kaemper.h, European University Institute, Florence, italy.

- Kaplan, S. (1997) " "The words of rigk anailysis." Risk Analysis, 17(4), 407-417.

- Kaplan, 5. and Garrick, B. J. (1981) "On the quantitative definition of risk." Risk Analysis, 1, 11-27.

- Kaprow M. (1985). "Manufacturing danger: Fear and pollution in industrial society". American anthropologist, $87(2), 342,356$

- Kasper, R. G. (1980). "Perceptions of risk and their effects on decision-making" Sacietal nisk assessment: how safe is safe enough?, R. C. Schwing and W. A. Albers Jr, eds ", Plenum Press, New York, USA

- Krimsky, S, and Colding, D. (eds.).(11992). Social theories of risk, Praeger, Westport, USA.

- Krohn, W., and Kruecken, G. (1993). Risky technologies: Reflection and regulation (in Cerman), Suhrkamp, Frankfurt ant Main, Germany.

- Kunne uther, H. C., and Linnerooth, J. (1983). Risk Analysis and Decision Processes, Springer-Verlag, Berlin.

- Lathrop, ). W. (1980). "The role of risk assessment and facility siting: An example from California." WP-80-150, 11 A 5 , Laxenburg, Austria.

- Lindley, D, V. (1973). Making decisionts, Wiley, Nlew Vork, USA.

- LinneroothmBayer J $_{\text {" }}$ and Thompson, M. (1997). "Risk and Governance: Proposal to the European Science Foundation." IIASA, Laxenburg, Austria.

- Lowrance, W. W. (1976). Of acceptabie risk: Science and the determination of safety, Kaufman, Los Altos, USA.

- Lubbe, H. (1993) "Security: Risk perception in the civilisation process." Decision Science and Social Risk Management, BayerischeRisck, ed., Reidel, Dordrecht, the Netherlands.

- Marris, C., Langford, 1., Saunderson, T., and O'Riordan, T. (1997). "Exploring the Psychometric Paradigm: Comparisons between aggregate and individual analyses." Risk Analysis $17(3), 303-312$.

- Mayo, D. G., and Hollander, R. D. (eds.) (1991). Acceptable Ewidence: Science and wahues in risk management, Oxford University Press, New York, USA.

- Mazur, A. (1980). "Societal and scientific causes of the historical development of risk assessment." Society, technology and risk assessment ]. Conrad, ed, London, UK,

- McDaniels, T. Axelrod, L.)., and Slovic, P, (1996). "Perceived ecological risks of global change." Global Environmental Change. $6(2), 159.171$.

- Melchers, R. E., and Stewart, M. G. (eds.). (1995). Integrated risk assessment: Current practice and new directions, Balkerna, Ratterdam, The Netherlands.

- Morgan, G. M, and Henrion, M. (1990). Uncertainty - A Guide to Dealing with Uncertainty in Quantitative Risk and Policy Analysis, Cambridge University Press, New York, USA.

- Morgan, M. C. (1978). "Bad science and good policy analysis." Science, $201,971$.

- NationalResearch Council. (1983). Risk assessment in the fedenal gowernment: Managing the process, National Aca. demy Pres.s, Washington D.C, USA.

- Nelkin, D. (1982). "Blunders in the Business of Risk." Nature, 298, 775-776.

- Nowotny, H. (1976). "Social aspects of the nuclear power controversy:" RM-76-33, IIASA, Laxenburg, Austria.

- O'Riondan, T.(1982). "Risllk perception studies and policy priorities." Risk analysis, 2(2), 95-100.

- O'Riondar, T. (1985). "The impact of EIA on decision-making." Environmental Impact Assessment, Technology Assessiment and Risk Analysis, V. T. Covello, J. L. Mumpower, P. I. M. Stallen, and V. R. R. Uppuluri, eds., Springer Verlag, Berlin, Germany.

- Otway H. (1980). "Risk perception: A psychological perspectiwe." Technological risks: Its perception and handing in the European Community, M. Dierkes, 5. Edwards, and R. Coppock, eds, Oelgeschlager, Gunn and Hain, Boston, USA. 
- Otway, $\mathrm{H}$, and Fischbein, M. (1977). "Public attitudes and decision-making. RM-77.54, IASA, Laxenburg. Austria.

- Otway, H.J. Maurer, D., and Thomas, K (1978). "Nuclear Power: The question of public acceptance ${ }^{25}$ Futures $10(2), 109-118$.

- Otway, H.I, and won Winterfeldt, D. (1982a). "Bieyond acceptable risk: On the social acceptability of technologies." Policy sciences, 14,247-256.

- Otway, H. I, and von Winterfelitt, D. (1982b). "Risk management and acceptable risk criteria." Risk: A semina" seriles, H. Kunneuther, ed, IIIASA, Laxenburg, Austria.

- Perrow, C. (1984). Normal Accidents: Living with High-vish Technologies, BasicBooks, New York.

- Ravetz, J. (2000 (in press)). "Knowledge, Power and Participation in Environmentall Policy Analysis." Policy Studies Review Annual, 12 (special issue Hisschemoller, M, Hoppe, R, Dunn, W.N. and Ravetz, ).).

- Rayner, 5. (1992). "Cultural Theory and Risk Analysis." Social Theory of Risk, G. D. Preagor, ed., Westport, USA.

- Rayner, 5., and Cantor, R. (1987). "How fair is safe enough? The cultural approach to societal teclinology choice." Risto Analysis, 7(1), 3-9.

- Rayner, S. F. (1987). "Risk and rellativism in science for policy" The social and oultural construction of risk, B. B. Johnson and V. T. Covello, eds., Reidel, Dondrecht, the Netherlands.

- Renn, O. (1984). Risk Perception of Nuclear Energy (in Cerman), Campus, Frankfurt am Main, Germany.

- Renn, O., Webler, T, and Wiedemann, P. (eds.). (1995). Faimess and Competence in Citizen participation, Kluwer Academic Publishers, Dordrecht, the Netherlands.

- Rothschild, N. (1979). "Coming to grips with risk." Wall Street Journal, New' York.

- Rotmans, 1. (1997). "Indicators for Sustainable Development." Perspectives on Global Change: The TARGETS approach, ). Rotmans and $H_{n}$, . M. de Vries, ed $s_{\text {, }}$ Cambridge University Press, Cambridge, UK.

- Rotmans, ) (1998). "Methods for IA. The challenges and opportunities ahead." Enwironmental Modelling and" Assessment, 3(3, Special issue: Challenges and Opportumities for Integrated Enwironmental Assessment, ). Rotrrians and P. Vellinga, eds.), 155-179.

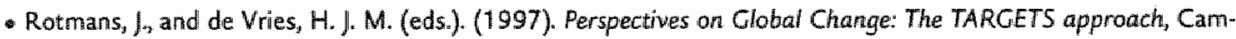
bridge University Press, Cambridge, UK.

- Rowe, W. D. (1977). An anatomy of risk, Wiley, New York, USA.

- RoyalSociety. (1992). "Rüsk: Analysis, perception and management", Royal Society, London, UK.

- Russel, M., and Cruber, M. (1987). "Risk Assessment in Environmental Policy Making." Science, 236, 286-290.

- Sandman, P. (1987). "Risk communication: Facing public outrage." Environmental protection journal(November,; 21-22).

- Savage, L. J. (195.4). The foundations of statistics, Willey New York, USA.

- Schneider, S. (1997). "Integrated Assessment Modeling of Climate Change: Transparent rational tool for policy making or opaque screen hiding value-laden assumptions?" Enwironmental Madelling and Assessmerit, 2(4), 229.250 .

- Schwarz, M., and Thompson, M. (1990). Divided We Stand. Redefining Politics, Technology and Social Choice, Harvester Wheatsheaf, Naw York, USA.

- Shrader-Frechette, K. (1991). "Reductionist Approaches to Risk." Acceptable Evidence Science and values in risk management, D. G. Mayo and R. D. Hollander, eds. Oxford University Presis, New York, USA.

- Slovic, P. (1987). "Perception of Risk." Science(236), $280-285$.

- Slovic P. (1991) "Beyond numbers: A broader perspective on risk perception and risk communication." Acceptable evidence: sicience and values in risk management, D. C.. Mayo and R. D. Hollander, eds, Oxford University Press, New York, USA.

- Slovic, P, Fischhoff, B, and Lichtenstein, S. (1980a). "Facts and fears: Understanding perceived risk." Societal risk assessment: How safe is safe enough?, R. Schwing and W. Albers, eds., Plenum, New York, USA.

- Slovic, P., Fischhoff, B, and Lichtenstein "S. (1980b), "Facts and Fears." Understanding perceived risks." Societal Risk Assessment: How safe is safe enough?", R. Schwing and J. W. Albers, eds, Plenum Press, New York, US.A.

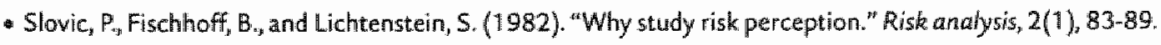

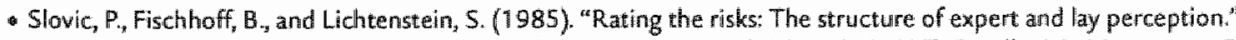
Environmental impact assessment, technology assersment and risk analysis, V. T. Cowello, J. L. Mumpower".P. J. M. Stallen, and V. R. R. Uppuluri, eds., Springer Verlag, Berlin, Heidelberg, Cermany.

- Somers, E. (1995). "Perspectives on risk management." Risk. Analysis, 15(6), 677-684. 
- Sowby, F. D. (1965). "Radiation and other risks." Health Physics, 11, 879-887.

- Starr ${ }_{n}$ C. (1969). "Social benefit wersus technological risk." Science, 165, 1232-1238.

- Starr, $C_{\text {. }}$ and Whipple, C. (1980). "Risks of risk decisions." Science, 208, 1114-1119.

- Stern, P. C, and Fineberg, H.V. (eds.). (1996). Understanding Risk: Informing decisions in democratic society, National Academy Press, Washington D.C., USA.

- Swart, R. (1994), "Climate change: Managing the risks," , Free University, Amsterdam, the Netherlands.

- Tarr, J. A., and Jacobson, C. (1987). "Environmental risk in historical perspective," The social and cultural construction of risk, V. T. Covello and B. B. Johnson, eds., Reidel, Dordrecht, the Netherlands.

- Thompson, M., Ellis, R, and Wildavsky, A. (1990). Cultural Theory, Westview Press, Boulder, USA.

- Tversky, A., and Kahnemarn, D. (1974). "Judgement under Uncertainty: Heuristics and Biases." Science, 185, 11241131.

- Tversky, A., and Kahneman, D. (1980). "Causal Schemes in judgements under Uncertainty. Progress in Social Psychology, M. Fishbein, ed., Lawrence Erlbaum Associates, Hillsdate, USA.

- Tversky, A., and Kahneman, D. (1981) "The Framing of Decisions and the Psychology of Choice." Science, 211, $453-458$.

- TweedeKamer. (1989). "Dealing with risks: the risk approach in enwironmental policy. Appendix to the Dutch National Environmental Policy Plan (in Dutch)." 21137-5, Tweede Kamer, The Hague.

- van den Daele, W. (1991). "Risk communication: Gene-technology (in German)." Risk controversies (in German), H. Jungermann, B. Rohrmann, and P. M. Wiedemann, eds., Springer, Berlin, Germany.

- van Eijndhowen, J. (1991). "Risk communications." The need for a broader perspective." Communicating risk to the public, R. E. Kasperson and P.J. M. Stallen, eds., Kluwer, Dordrecht, the Netherlands.

- van Eijndhowen, J. C.M. (1995). The unbearable lightniess of the debate: The contribution of Technology Assessment to the debate on science and technology (in Dutch), Rathenau Institute, The Hague, the Netherlands.

- Vlek, C. A. . (1990). "Decision-making about risk acceptance (in Dutch)." A90/10, Gezondheidsraad, The Hague, the Netherlands.

- Vlek ${ }_{n}$ C. A I. (1996). "A Multi-level, Multi-stage and Multi-attribute Perspective on Risk Assessment, Decisionmaking and Risk Control." Risk Decision and Policy, 1(1), S-31.

- Wlek, C. A. J., and Stallen, P.). (1980). "Rational and personal aspects of riisk." Acta Psychologica, 273-300.

- Vek, C. A J., and Stallen, P. J.M. (1981). "Judging risks and benefits in the small and the large." Organizational behaviour and human performance, 28, 235-271.

- von Winterfeldt, D. (1992) "Expert Knowledge and Public Values in Risk Management: The role of decision analysis." Social theories of risk, S. Krimsky and D. Golding, eds., Plenum, New York, USA.

- VROM, EZ, LNV and V\&W. (1989), "National Environmental Poliey Plan." 21137, nrs. 1-2, VROM, Dern Haag, The Netherlands.

- Weinberg, A. M. (1981). "Reflections on risk assessment." Risk Analysis, 1(1), 5-7.

- Weilnstein, N. D. (1984). "Why it won't happen to me: Perceptions of risk factors and susceptibility." Heal h P5ychology (3), 431.457

- Whipple, C. (1985). "Opportunities for the social sciences in risk anallysis: An engineer's viewpoint." Enwironmental Impact Assessment, Technology Assessment and Risk Analysis, V. T. Covello, J. L. Mumpower, P. J. M. Stalien, and W. R. R. Uppuluri, eds., Springer Verlag, Benlin, Cermany.

- Winner, L. (1982). "Pollution as Delusion." New York Times Book Review, New York, USA 8-18.

- Wyrne, B. (1978). "Nuclear debate at the crossraads." New Scientist(August), 349-360.

- Wynne, B. (1980). "Technology, risk and participation: On the social treatment of uncertainty." Society, Technollogy and Risk Assessment, , Conrad, ed., Academic Press.

- Wynne, B. (1982). Rationality and Ritual: The Windscale Inquiry and Nuclear Decisions in Britain, Biritish Society for the History of Science, Chalfont, St. Glies. 


\section{Uncertainy and risk in perspective}

So far, we have discussed the concepts 'uncertainty' and 'risk' as independent instances. However, the two concepts are related. In this Chapter, we will argue that uncertainty and risk are two sides of the same coin, i.e. the limited predictability of complex issues. Furthermore, as can be concluded from the previous Chapters, the key challenges uncertainty management and risk analysis face are comparable. Instead of considering uncertainty and risk as two separate concepts and viewing uncertainty management and risk analysis as two different branches, we think it is interesting to explore how the two concepts and the two methodologies can be used in a complementary manner in decision-support on complex issues. Our aim is thus to develop a framework for integrated uncertainty management and risk analysis.

This Chapter will first study in some more depth the interconnectedness between uncertainty and risk. Then we will move forward with the key challenges that resulted from the theoretical analyses as provided in the previous chapters. The first key notion is pluralism. Using the concept pluralism in developing an integrated framework for decision-support requires a better understanding of the notion of pluralism. To that end, this Chapter will study pluralism in some more depth in order to provide a basis for crystallising the ideas on pluralistic uncertainty management and risk analysis. We then discuss the role of participation and robustness in relation to our ambition to develop an integrated framework for uncertainty management and risk analysis. The Chapter will then conclude with a definition of integrated uncertainty management and risk analysis that synthesises the theoretical ingredients. 


\section{Uncertain risks and risky uncertainties}

The concept of 'risk' is closely connected with the prevalence of uncertainty. Risk deals with uncertain situations in which a number of possible undesirable outcomes might occur, of which at least one, but possibly more, is undesirable ${ }^{\natural}$. Personal, collective, societal and environmental risks and their evaluation as 'good' or 'bad' thus arise from the uncertainty surrounding the occurrence of particular events or series of events. We do only think and talk about risk in the face of uncertainty. Deciding about risk is deciding in uncertainty ${ }^{ \pm}$. So risk analysts do not discuss situations with certain outcomes, although uncertainties can arise in many different ways ${ }^{3}$. Some risks can, notwithstanding uncertainty, reasonably be calculated. To give an example 4 if a person crosses a crowded street blindfolded, there is obviously a high risk that the person will be killed or at least injured. In that sense, the outcome seems to be certain. Nevertheless, even in this clear case the risk analysis involves uncertainty. Part of the uncertainty is due to variability: the actual outcome will depend on where the individual precisely is when a car arrives, the actual speed of the car and to behavioural variability, such as whether the driver stop if he or she notices the person. Part of the uncertainty is due to lack of knowledge: the actual outcome will depend on the nature of the fenders and other features of the specific car.

The multitude of factors, dimensions and scales that trigger strategic risks cause inherent uncertainty ${ }^{5}$. So risk analysis concerned with strategic risks that involve inherent uncertainty and which are much more difficult to assess. Examples of cases in risk analysis for which no historical data or no analogies are available to determine risks are the release of a new chemical to the environment, the introduction of a new technology, and unprecedented human disturbance of natural processes. In these cases, the risks are difficult to estimate, primarily due to uncertainty associated with lack of knowledge. Uncertainties with regard to the complex relationships between causes and effects make it very difficult to assess what is likely to happen if a particular event or a concurrence of circumstances comes about. Furthermore, social and behavioural research on risk perceptions indicates that if the underlying mechanisms and processes are not well understood, lay estimates, especially concerning

1 (Merkhorer 1987")

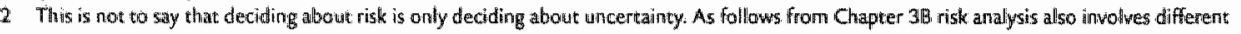
judgements of facts and certain outcomes ascociated with the risk issue under concerm.

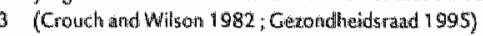

4 Thts illistration reasons from the examphe given by (Cirouch and wilson 1982)

5 (Gowatheidsrad 1995) 
involuntary risks, tend to be higher. ${ }^{6}$. The level of uncertainty is thus a risk dimension. So there is not only the problem that uncertainty violates the exactness of risk estimates, but also that the level of uncertainty co-determines the risk estimate itself. Uncertainty is thus central to risk analysis, but the paradox is that risk analysis is also complicated by the omnipresence of uncertainty.

Apart from the issues discussed above, there is another aspect that makes the relationship between risk and uncertainty intricate. As argued in Chapter $3 B$, risk perceptions differ, which yields a wide variety of risk definitions and risk estimates, especially in the case of strategic risk. This increases the uncertainty for those involved in the risk debate. On the other hand, the fact that risk estimates are thus uncertain, is on its turn revealed by the disagreement among experts?

The above thus reveals that uncertainty ${ }^{8}$ and risk are interrelated on the following levels:

- the uncertain reality of what may occur

- the uncertain analysis of assessing the uncertain risks

- the variable evaluations of the uncertain risk analysis

There are two major reasons that the risk concept is relevant to our endeavour. First, risk is a concept that is deployed in every day life, and thereby familiar to decisionmakers and the broad public. As argued by Luhmann" risk is the general form in which society describes and assesses its future. Ravetz ${ }^{\text {to }}$ argues that the political way of dealing with uncertainty appears to be to create a story about risks. In other words, communication of future outlooks in terms of risk is therefore likely to enhance understanding between science and society. Second, attempts to estimate risks also reveal where the greatest uncertainties lie ${ }^{\mathrm{tt}}$, and thereby provide valuable insights for uncertainty analysis. And vice versa: knowledge of uncertainty helps to indicate where risks are expected by exploring what-if situations.

Due to the nature of complexity, i.e. multidimensional, multi-scales and multiproblem $^{12}$, complex issues are inherently uncertain and involve strategic risks. Or to phrase it differently, complex problems are about radical uncertainty and strategic risk. In the face of complexity, we are facing both uncertain strategic risks and risky

6 (Covello 1984 )

7 (Jugermann and Slowic 1993; Beck 1986)

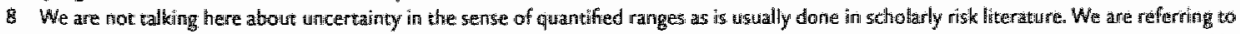

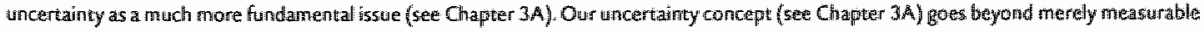
uncertaingy, and inclutes ignorance and indeteminaty.

9 (Lahmanan 1993)

10 (Ravetz 2000)

1 (Whipple 1985)

12 See Crapter: 
radical uncertainties. Complexity is complicated, because of inherent uncerrainty. Complexity is important, because of the strategic risks involved. If we would restrict ourselves to uncertainty, we will not understand the importance of complexity. On the orher hand, if we just focus on risk, we will never understand the features of complexity.

It is important to recognise that risk and uncertainty are interlinked concepts. Uncertainty and risk can be considered as the two sides of the same coin, i.e. the limited predictability as a result of complexity. 'Uncertainty' is generally associated with the rationality of science, while 'risk' is a notion that seems to correspond most with the rationality of decision-making. Figure $x$ indicates how the degree of uncertainty and the level of risk are related. From an integrated perspective, this means that the one cannot be adequately studied without considering the other, and vice versa. In case of operational risks and measurable uncertainties an adequate toolkit for decision-support is available in the form of quantitative risk assessment and methods for uncertainty anallysis. As follows from Chapters ${ }_{3} \mathrm{~A}$ and ${ }_{3} \mathrm{~B}$, those current decision support methods fail to address esp. radical uncertainties and strategic risks. This implies that applying current decision-support tools to complex issues can be compared to hammering a nail with a mixer. In current decision-support on complex issues we apply methods that are not geared to the essential fearures of complexity, which implies that scientific decision-support fails in addressing decisionmakers' need. So probably not so much is left to them than muddling along.

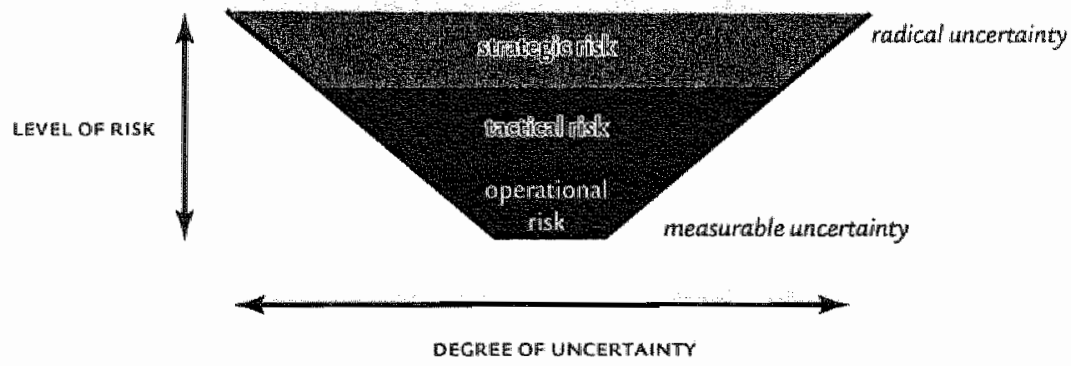

FIGURE, Level of uncertainty and type of risk

From a decision-support perspective, the challenge seems to be to use both concepts in a synergetic way in the analysis of what might be possible and seems to be plausible. Uncertainty management should yield insight in strategic risks, while risk analysis should involve a thorough analysis of the salient uncertainties. To that end, we would like to explore a framework for integrated uncertainty management 
and risk analysis that is theoretically sound. Such an integrated framework for uncertainty management and risk analysis would in principle be able to be used in decision-support on complex issues. Our line of reasoning is summarised in Figure 2.

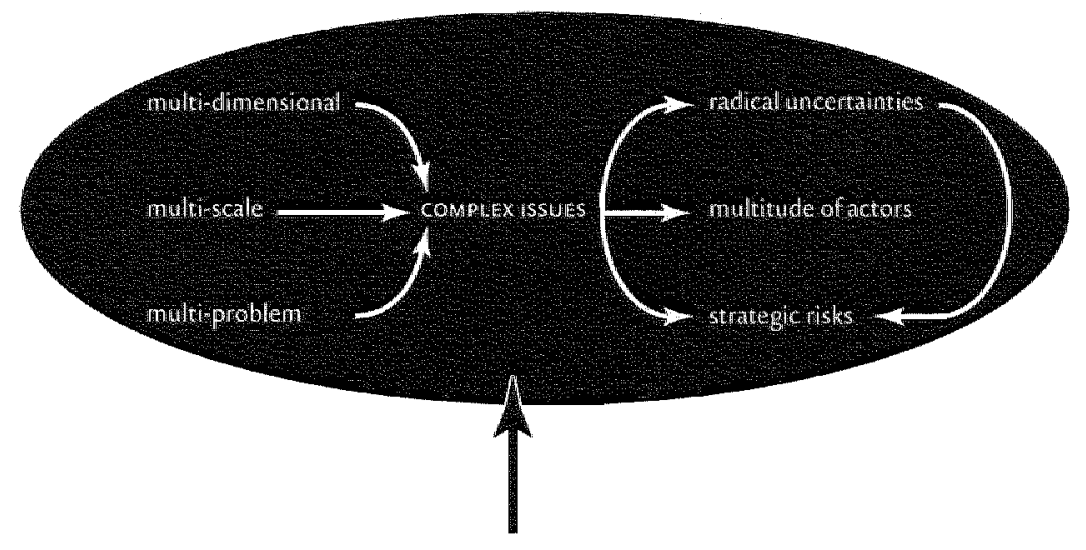

pluralistic and participatory integrated uncertainty management and risk analysis

FICURE 2 Principle of complexity and pluralism

\section{Pluralism ${ }^{13}$}

Complexity stimulates pluralism ${ }^{14}$. Due to inherent uncertainty there are plural legitimate interpretations. In case of strategic risk, there is divergence of risk perceptions. Furthermore, by the nature of complexity, complex issues involve a multitude of actors.

Pluralism thus means that different perspectives are legitimate and viable, also within science. Pluralism fundamentally conflicts with the positivist, singular, paradigm $^{15}$, because in this latter paradigm different explanations are accepted in the sense of necessarily provisional: in the long run 'pluralism' will disappear. Schools of thought that reason from inherent pluralism share that they all renounce the positivist principles. But they differ with regard to the question how far the significance of pluralism reaches. We will investigate the essence of the differences between pluralistic schools of thought by sketching a transition from positivist singularity to constructivist pluralism, in order to explore the consequences of the adoption of a certain perspective in pluralistic assessment endeavours. Based on these assumptions,

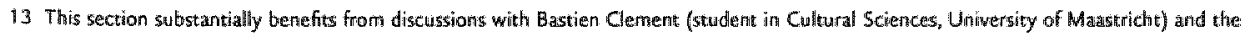
essays he pradwced during his internship at ICIS (Nowember 1998-March 1999).

14. Whille plaralism on tes tum increases uncertainty, as is discussed in Chapter $3 \mathrm{~A}$.
} 
we would like to assess questions which and how many perspectives are to be considered in the assessment and which uncertainties are included in the perspective-based analysis and evaluation, and which are not.

To see something from a certain perspective implies having a view on reality, and thereby presupposes that humans, as knowing subjects, visualise the foutside world'. This notion of a perspective presupposes objectifying the world and subjectifying the knowing individual: a distinction is made between object and subject. This can be illustrated by means of the turn in the art of painting in the $14^{\text {th }}$ and $15^{\text {th }}$ century. During the Renaissance, the perspective projection method came into use. This is a geometric method to draw objects so that it matches the way in which a spectator sees those objects from a certain position.

The first deviation from positivism can be compared to the perspective art of painting. In this school of thought, it is recognised that scientists observe the world from a certain perspective, which is determined by tradition, school of thought or culture. Different perspectives provide a kaleidoscopic view on the world. Observation is thus put into perspective. This line of reasoning can be traced back to Kant ${ }^{16}$. In his inquiry on the limits to reason, Kant asserted that we could not discern 'das Ding an sich". Hume ${ }^{17}$ also argued that knowledge does not simply result out of empiricism. A sequence of events is observed and scientists put into a causal order. In doing so, science projects its own framework onto the world, as the painters portray the panorama from their standpoint. Similar thoughts can be found by Popper ${ }^{18}$, who held that every statement about the world is 'theoretically mediated', which means that an observation is always an interpretation of findings in the light of a theory. Recognition of the perspective character of observation does not necessarily lead to relativism. The various partial perspectives on the 'world out there' can in principle complement as well as contradict each other. If the various perspectives complement each other, they allow drawing a richer image of reality. In case of contradiction, the partial perspectives highlight controversy.

The analogy between the concept 'perspective' in art and science goes further. With the projection method, the painters dissociate themselves from the world, which they attempt to reproduce in all dimensions. This can be compared by the above view on pluralism in science. One step further is to realise that a perspective

15 See chapter $3 \mathrm{~A}$ tor a basic discussion on positivilim.

16 (Kant edition 1997, Serwtom 1982)

17 See (Ayer 1980)

18 (Popper 1959; 1973; Corvi 1997) 
is dependent from the painter's position in the landscape, he or she is painting. In other words, a perspective is a relative and not an absolute notion. A perspective is not simply a representation of the landscape, but a perspective is also 'created' along with the landscape. Perspective and object thus interact. In the context of science this means that a perspective about the world is inseparable from the relation to that world.

Such an interpretation of perspective implies that the dualism between object and subject is questioned. Kuhn's thinking ${ }^{19}$ corresponds to this line of reasoning. According to Kuhn, a perspective is obtained in interaction with the world. The distinction between observation and interpretation is no longer drawn. Observations are considered to be interpretations about which agreement is reached within the scientific community. Facts exist, but only within what Kuhn refers to as a paradigm. A paradigm involves values and research styles shared by the researchers "socialised' within that paradigm. In that process of socialising, the exemplary archetypes of problem-solving, so-called 'exemplars' are crucial. Anomalies are problems that cannot be solved according to the archetypall exemplars, and thus observations that fall beyond the paradigm. Anomalies play a critical role in paradigm shifts: if the number of anomalies continues to increase, at a certain point of time the reigning paradigm will be questioned. Such a change of scientific perspective can be compared to what in psychology is called 'Gestalt-switch'. This can be illustrated by means of the example of the duck-rabbit-figure (see Figure 3). A paradigm shift implies that

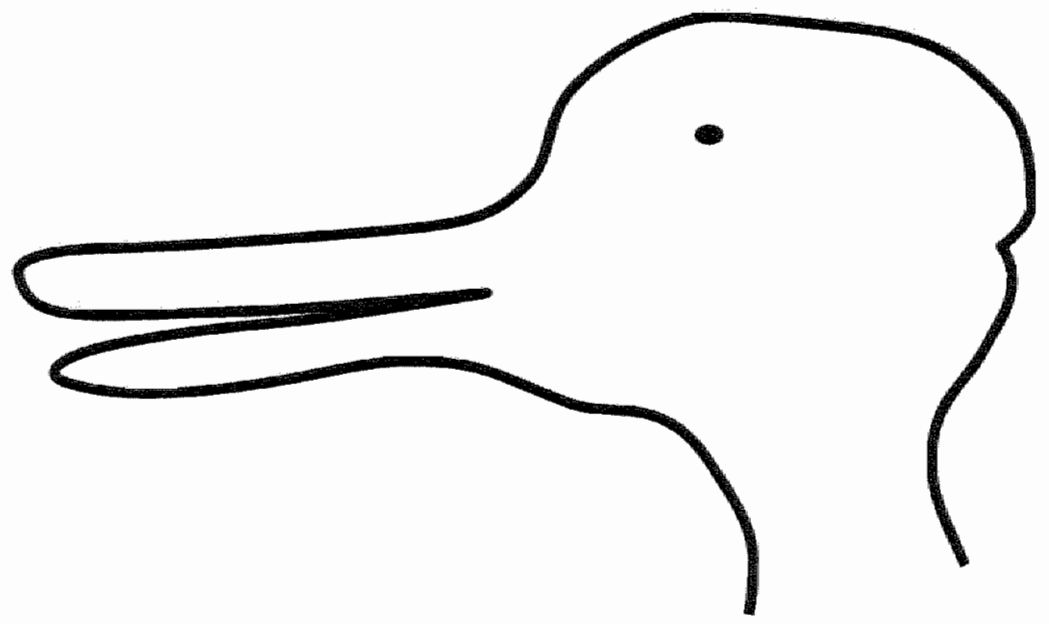

FIGURE 3 Durk or rabbit? 
what was seen as a duck is now considered to be a rabbit. Such a change of perspective cannot be analysed in terms of a transformation of observations, because the drawing itself remains the same. So perception seems to take place within a sociocultural context. With the concept of 'paradigm', Kuhn related cognitive changes to the culture of science and social interactions within science.

The above perspective can be considered as an internal explanation for pluralism in science, because it is focused on socio-cultural factors within science. Mannheim ${ }^{20}$ introduced another view on pluralism. He argued that cognitive knowledge is essentially connected to societal circumstances. The 'Edinburgh school ${ }^{21}$ goes further in assuming a causal relationship between social and cultural structures and science. This school of thought argues that the intellectual stand and scientific interpretation root in social and cultural structures outside science. This external explanation of pluralism is related to Durkheim's social theory ${ }^{22}$. This theory has it that there are collective perspectives, so-called 'representation collectives', that do not follow from interactions between actors, but which are social givens. An individual comes across such collective perspectives and will internalise such a perspective, consciously or, more often, unconsciously. In this 'external' explanation, pluralism in science thus arises from pluralism in society.

The above perspectives on perspective share that they distinguish between the world of science and the social world. Different movements within philosophy and social studies of science ${ }^{23}$ break out of this dichotomy between internal and external. This view stresses that science is interwoven with institutional, political and social interests, intentions and preferences. Intellectual conflicts are thus social conflicts, and pluralism within science is societal pluralism. This perspective on pluralism has it that knowledge is embedded in societal interaction patterns and the rules of the interwoven community, also referred to as 'societal field" ${ }^{24}$ or 'network" ${ }^{25}$. This perspective on pluralism has it that knowledge is not a statement about reality, but that reality is shaped by science. In this perspective, developing a scientific theory means painting a new version of the world.

We consider the above perspectives on pluralism as different viewpoints that constitute a spectrum between positivism and constructivist pluralism (see Figure 4 ).

$20 \mathrm{eg}$ (Mantrhein 9935 )

2: (18arnes 1977; Barnes and Mackenic 1979; Barner and Bloor 1996)

22 see (Lukes 1975 )

23 Eg post-modernism and radical social-constructivism; see for an overview (Hets 1999 )

24 (Bourdieu 1975)

25 (Latour and Woolgar 1979 ) 
POSITIVISIM

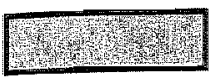

no perspectivie

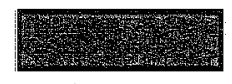

observation

in perspectiwe

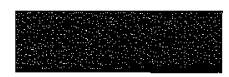

theory

im perspective

CONSTUCTVIST

PLURALASM

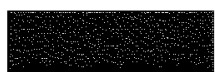

science

in perspective

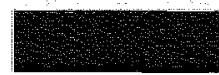

reality

in perspective

FICURE 4 Spectirum of perspectives on perspectives.

Changing point of wiew implies a paradigm shift in which fundamental assumptions change, so it cannot be considered as a continuous spectrum. The first deviation from positivism is associated with putting observation into perspective. This school of thought remains reasoning from one of the essential principles in positivism, i.e. the dichotomy berween object and subject. The major difference between the school of thought characterised as "observation in perspective" (e.g. Kant, Hume, Nietzsche, and Popper) versus "theory in perspective" (e.g. Kuhn) is that the latter transcends the dichotomy between object and subject. But the "theory in perspective"-perspective still contains another principle of positivism, i.e. the dichotomy between the cognitive and the social, and thus between science and societal structures. This dichotomy begins to disappear in the next viewpoint characterised as "science in perspective". This school of thought has it that science is part of society. The most extreme point of view does not even consider science to be something special. It is considered just to be another network or field. This "reality in perspective"-perspective goes hand in hand with methodological relativism, implying that 'facts' result out of social processes. This school of thought can thus be considered as the most fundamental form of constructivist pluralism ${ }^{26}$.

\section{Pluralism as a $\mathrm{fact}^{27}$}

Within physical science, there is still a large group of scientists adhering to the positivist paradigm, while the majority of contemporary philosophers of science seem to be at the other end of the spectrum. The presented views on pluralism are irreconcilable, but on the other hand they seem to co-exist. Furthermore, it would even be in conflict with the whole notion of pluralism, if we would argue that one of the above

26 st is interesting to mote that early research in this perspective on plaralism wonders why there is relatively little pluralism in science, set e. (Coullins 1985 )

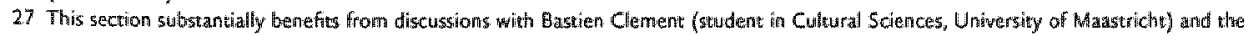

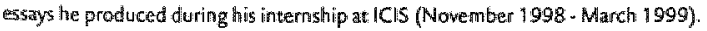


viewpoints is the one and only 'best'. In other words, there are different perspectives on perspectives, as a consequence of which there is pluralism about pluralism.

So notwithstanding our modesty about truth claims as expressed in the previous chapters, we arrive at a strong truth-claim about pluralism. This may seem an inconsistency, but it is a paradox: it is truth claim about discourse. In other words, we put pluralism forward as a fact on discourse that can easily be verified.

The distinction between reality and discourse touches upon another fierce debate between scientific practitioners and those practising social studies of science and philosophy. The first group generally has it that reality exists and can be studied. In this point of view reality is the starting point of scientific investigation. The latter argue that reality as such does not exist. Reality is the result of social processes and discourse. So the essence of something 'real' is not its physical existence, but the way it is interpreted. This point of view is beyond the head of scientific practitioners, and generally means that they turn their back on social scientists and philosophers. We would like to escape this deadlock, by arguing that to date both recognise that scientific discourse exists. This means that they in principle could agree on claims on this level, where agreement with regard to 'reality' is principally unattainable.

Above, we have attempted to prove that pluralism exists in the discourse, in order to provide some common ground for a collective endeavour in which we explore pluralistic ways of performing science. The existence of the different schools of thoughts about pluralism is only one example. Within all social sciences fundamentally different schools of thought can be observed. For example, within psychology we find behaviourism, which reasons from human behaviour and which ignores human thinking, versus cognitive psychology that aims to understand behaviour out of mental processes. Within sociology a gap can be observed between explanatory and interpretative sociology. Different schools of thought can also be observed within economics, i.e. neo-classical economics, Keynesian economics, ecological economics and evolutionary economics, but also within the natural sciences. In physics, we can discriminate between Newtonian physics and quantum physics. These schools of thought can in a certain way be considered to be complementary, because the one explains phenomena that cannot be explained by the other, but the two explanatory schemes are also incompatible. Within the Earth sciences, schools of thought can be discerned that ranges from viewing the world as one of order to that of chaos and complexity.

Although the enumeration is not exhaustive, it seems legitimate to conclude that fundamentally different schools of thought coexist within science. In view of 
inherent uncertainty, no objective criteria enable to decide which one is definitively the "right" one. As a result of debates and new insights, some schools of thought may disappear and others will see the light. The scientific discourse is and will continue to be disunited. On the level of discourse, we conclude that pluralism can be proved.

\section{Pluralism in perspective}

Pluralism implies cultivating a diversity of perspectives, without necessarily slipping into an indifferent relativistic tolerance of all view points. Which and how many perspectives are accepted depends on the viewpoint taken with regard to pluralism (see also Table 1 ). In the "observation-in-perspective"-perspective only scientific frameworks are accepted as legitimate perspectives, while the "theory-inperspective"-perspective acknowledges different scientific paradigms. In the "science-in-perspective" -perspective a typology of socio-cultural perspectives is welcomed. The "reality-in-perspective" -perspective recognises those perspectives that are observed in actual networks or societal fields. The latter viewpoint would never accept an a-priori classification of perspectives, because it holds that knowledge and interpretation are embedded in social interaction patterns.

\begin{tabular}{l|c|c|c|c}
$\begin{array}{l}\text { perspective } \\
\text { on pluralism }\end{array}$ & $\begin{array}{c}\text { observation- } \\
\text { in-perspective }\end{array}$ & $\begin{array}{c}\text { theory- } \\
\text { in-perspective }\end{array}$ & $\begin{array}{c}\text { science- } \\
\text { in-perspective }\end{array}$ & $\begin{array}{c}\text { reality- } \\
\text { in-perspective }\end{array}$ \\
\hline type ofperspectives & $\begin{array}{c}\text { scientific } \\
\text { hypotheses }\end{array}$ & $\begin{array}{c}\text { scientific } \\
\text { paradigms }\end{array}$ & $\begin{array}{c}\text { socio-cultural } \\
\text { perspectives }\end{array}$ & $\begin{array}{c}\text { observed in } \\
\text { actual netwarks }\end{array}$
\end{tabular}

TABLE I Perspectives on pluralism in relation to type of perspectives considered

The consequence of pluralism is that we have to realise that in exploring a pluralistic approach we, either explicitly or implicitly, take up a certain perspective on pluralism. As argued above, adopting a perspective on pluralism has serious implications for choosing a typology of perspectives and for dealing with different perspectives in decision-support endeavours. If we take pluralism and our own effort to render pluralism explicit, serious, this implies that we have to be transparent about the adopted perspective.

In this thesis, we obviously go beyond the positivist paradigm that fundamentally debars pluralism. In our earlier work ${ }^{28}$, we were not explicit about our perspec-

28 E. (wan Asseit et al. 1996; van Asselt and Rormans $7995 ; 1996 ; 1997 ; 1999$ ) 
tive on pluralism. With the above characterisation of the different viewpoints on pluralism, it is worthwhile to reflect in retrospect on our implicit principles. We reasoned that pluralism in science is inherent in view of uncertainty. The framework of science puts forward cognitive and rational standards. In a situation without uncertainty, it would in principle be possible to detect the most appropriate perspective for science. This also implies that, measured by its own yardsticks, pluralism in science in situations free of uncertainty would be unmasked as 'bad science'. However, in situations with inherent uncertainty, different perspectives are legitimate, also within science. This is a modest view point on pluralism that conflicts with the extreme constructivist pluralism that argues that in situations in which there is pluralism in society, this will always be mirrored in science.

The perspective on pluralism that underlies the methodology of perspecrivebased model routes ${ }^{29}$ comes close to both the "theory-in-perspective"-perspective and the "science in perspective" -perspective. Both views have it that observation and interpretation are intertwined and that the knowledge derived from observation and interpretation is perspective-dependent. In Rotmans et al..$^{\text {ja }}$, the earliest record of our pluralistic ambitions, a clear distinction was made between scientific perspectives (i.e. based on scientific hypotheses or theories) on the one hand, and cultural perspectives (i.e. characterising human attitudes) on the other. The initial idea was to use scientific perspectives (like the Gaia-perspective and the 'Expectation-of-the-unexpected'perspective) to address the scientific uncertainties, i.e. "uncertainties occurring in the environmental system which arise from the degree of unpredictability of global environmental change processes and which may be narrowed as a result of further scientific research or more detailed/appropriate modelling"'s'. Second, the cultural perspectives (i.e. hierarchist, egalitarian and individualist ${ }^{3^{2}}$ ) were thought to be related to social and economic uncertainties, i.e. "uncertainties occurring in the human system which arise from the degree of unpredictability of future geopolitical, socio-economic and demographic developments, and which are inherently "unknowable" or in practise unpredictable" ${ }^{\prime 3}$. In this view on perspectives, a clear distinction is made between science and non-science. The two are considered to be separate, independent domains. The starting point of our pluralistic approach to Integrated Assessment modelling thus closely corresponded with the "theory-in-perspective"-perspective.

29 (Var Asselt et at. 1995; van Asselt and Romans 1995; 1996; 1997; 1999)

30 (Riocmans et

31 Citation (Rotmans et al 1994 )

32 See Chapter $3 \mathrm{~A}$ and $3 \mathrm{~B}$ for short descriptions of these perspectives associated with Cultural Theory and a bibliography of $C$ ultivial Theory.

33 Citation (Rotmans et al 1994) 
However in the course of the research, a mental change can be observed. We first argued ${ }^{34}$, in line with Morgan and Henrion ${ }^{35}$, that different sources of uncertainty in modelling can be distinguished (i.e. statistical variation, variability, linguistic imprecision, approximation, subjectivity and disagreement among experts) and that these sources produce both the so-called scientific and the so-called socio-economic uncertainties. In this way, the distinction between scientific and socio-economic uncertainties faded into the background. Second, we put forward that a new approach to uncertainty analysis in IA models was necessary ${ }^{36}$ " because standard uncertainty analysis does not address uncertainty due to subjectivity and disagreement. Our main argument became that subjective judgement and disagreement occur due to the adoption of different (cultural) perspectives by scientists. It became our aim to develop a methodology "to analyse and clarify perspective-related uncertainties in Integrated Assessment models" ${ }^{n 37}$.

The above mental change implied that scientific judgement was at least partly related to cultural perspectives. The sharp division berween science and culture prevallent in the first phase has thus been transcended. In the practice of building and using perspective-based model routes in the TARGETS-model, the change became even more fundamental. Perspective-based model routes were used to address all selected uncertainties in the TARGETS model, while the starting point has been that perspective-based model routes should be used for a subset of uncertainties and that the method should be used in combination with other methods (such as probabilitybased methods).

An explanation for this extended use of perspective-based uncertainty analysis is that this new method also promised to solve two recognised shortcomings of standard uncertainty analysis, i.e. ${ }^{38}$ :

- the uncertainty estimates associated with standard methods for uncertainty analysis are difficult to understand by non-modellers

- standard uncertainty analysis neglects uncertainty in model structure ${ }^{39}$

With these promised advantages the multiple model route methodology turned out not to be just attractive for addressing uncertainties that were neglected so far. In

34 (wan Asselt ande Rotnars 1965 )

35 (Morgan and hen rion 1990 )

36 (wan Assett et al 1996; wan Asselt and Rotmans 1995; 1996; 1997)

37 (wan Asselt and hotmans 1995)

38 (van Assett ot al. 1996; wan H.sselt and Rotmans 1995; 1996; 1997)

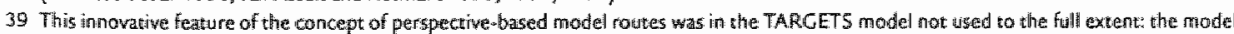

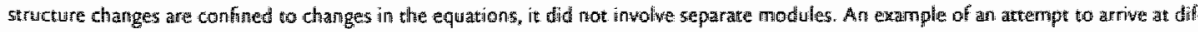

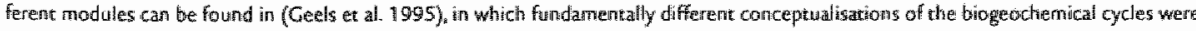
propased. 
practice, it began to serve as a full alternative for standard uncertainty analysis. The other methods for uncertainty analysis were used in a supportive mode, instead of a more complementary manner; sensitivity analysis was used to select the most important uncertainties in the submodels ${ }^{4}$ and allso to further analyse the model outcomes $^{4}$, and probability-based methods (i.e. Monte Carlo) have been used to generate uncertainty ranges for each perspective-based projection ${ }^{42}$. Available techniques such as Monte Carlo and sensitivity analysis were thus primarily used to enrich perspective-based uncertainty analysis.

Within the TARGETS project, the perspective-based model routes were thus used as the methodology for uncertainty analysis. Furthermore, using cultural perspectives ${ }^{43}$ to address the model uncertainties, marked the transformation from the original starting point "science and culture" into the standpoint "science as culture". It was not a cognitive mental change, but an implicit and probably unconscious shift in the course of the project. The final design of the (cultural) perspective-based model route methodology and its implementation clearly suffuse the "science-inperspective"-perspective, which has it that scientific judgement is culturally determined.

It is probably no surprise that this fundamental change with regard to the underlying epistemological principles resulted in a tension, or even an inconsistency, between the theoretical classification of uncertainty and the methodological framework. The current thesis dissolves this tension, by underpinning the methodology with a more fundamental typology of uncertainty. The typology of uncertainty used in earlier work did not really address uncertainty at the deepest level. The sources of uncertainty in models as provided by Morgan and Henrion ${ }^{44}$ are of a different kind. The classification is a mixture of ontological uncertainty (esp. variability), epistemological uncertainty (esp. approximation) and manifestations of uncertainty (esp. disagreement, subjectivity and linguistic imprecision). These unlike sources were in our earlier publications treated as if they were homogeneous. Thus arguing that disagreement and subjectivity are related to perspectives necessarily implied that

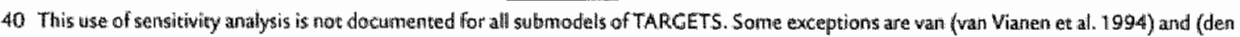
Elzen et al. 1995 )

41 See esp. (Hoekstrat at. 1997 )

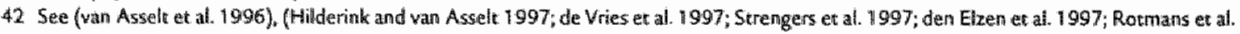
$1997)$

43. We lefe it in between whether this perspective is personat, or whether it is a collective giver that is adopted by the individual. Howewer, we followed the argument of for example, (Raymer 1991), who has it that in order to understand the staggering of perspectiwes (as opposed to

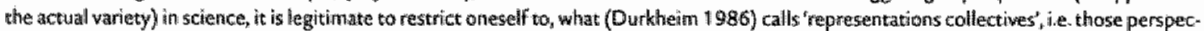

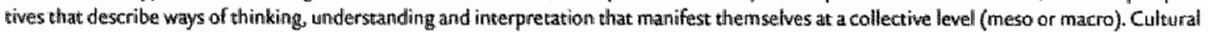
Theory correspondls to these assumptions.

44. (Morgan and thenrion 1990);
} 
the other uncertainties were "perspective-free". Notwithstanding this "perspectivefree" qualification, uncertainties in the model that arose out of either epistemological uncertainty (uncertainty due to lack of knowledge) and ontological uncertainty (uncertainty due to variability) were included in the perspective-based uncertainty analysis.

The typology of uncertainty as proposed in this thesis ${ }^{45}$ does not consider disagreement and subjectivity as sources of uncertainty. It explains why disagreement and subjectivity are likely to occur in science. In the context of our exploration which uncertainties are correctly included in perspective-based endeavours, the distinction between measurable and radical uncertainties is relevant ${ }^{46}$. Measurable uncertainties can be calculated. This implies that either margins (in case of unreliability) or seasonalities (in case of variability) can be established, so that the uncertainty can be described quantitatively (either in terms of a domain or as stochastic equation). The "theory-in-perspective"-perspective implies that these measurable uncertainties can be considered to be perspective-free. The interpretation of radical uncertainties, i.e. uncertainties that can at best just be roughly estimated, are perspective-dependent in both the "theory-in-perspective" and the "science-in-perspective"-perspective. This is an example of what fundamental implications the adoption of a certain perspective on pluralism carries with it for actual pluralistic assessment. Not only which and how many perspectives are considered in the assessment is dependent on the adopted stand on pluralism, but also which uncertainties are included in the perspective-based analysis and evaluation, and which are not.

We have learned from our experiences with pluralistic Integrated Assessment so far, that it is necessary to be explicit about the viewpoint on pluralism that guides the endeavour. In choosing one of the perspectives on pluralism we will lose those audiences that adhere to another. The stand implicitly adopted in our research so far $^{47}$ has been in between the "theory-in-perspective"- perspective and the "science in perspective" -perspective. In doing so, we were criticised by the scientific practitioners who thought that we went much too far, as well as by the social scientists and philosophers who thought that we went not far enough. This criticism was not directed towards our pluralistic approach, but it was targeted to the specific pluralistic stand. This problem cannot be solved due to the variety in perspectives on pluralism. Applying the notion of pluralism in the practise of decision-support neces- 
sitates choosing a position in the spectre ranging from 'observation-in-perspective' to 'reality-in-perspective'. In some cases, there may be clear arguments to choose one of the perspectives. Best practice in this context at least implies being aware of which view on pluralism is adopted and why, in order to facilitate communication and understanding.

It is not the aim of this thesis to defend a specific perspective on pluralism. Our major ambition is to allow scientific practitioners in decision-support to go beyond positivist 'monism', without neglecting the pluralism about pluralism. To that end, we have attempted to make the pluralism on pluralism explicit, in order to help practitioners to be conscious about their starting point. In order to facilitate scientific decision-support to go beyond positivism in a consistent way, our aim is furthermore:

- to explore the general features of a pluralistic approach

- to sketch the specific methodological choices associated with a certain perspective on pluralism.

\section{Towards pluralistic methods}

Pluralism means that different interpretations of uncertainty and different risk perceptions are legitimate. In the above, we have convincingly argued that our key hypothesis ${ }^{48}$ :

It is necessary to consider multiple perspectives in decision-support on complex societal issues

is scientifically sound. We thus want to make a virtue out of need. Our conclusion is that a pluralistic approach is both promising and necessary in the analysis of complex issues, and in particular in decision-support addressing complex issues. A pluralistic approach means that the uncertainties and risks associated with the issue are interpreted according to different perspectives and that these different interpretations and risk judgements are compared and confronted in order to draw a richer image of the issue under concern.

In the previous chapters and in the current one, we have provided a thorough. motivation and underpinning for our pluralistic starting point. And secondly, we have explained that uncertainty and risk are actually two sides of the same coin, and that synergy is welcomed between uncertainty management and risk analysis. Such 
an integrated, pluralistic approach seems in principle adequate to allow decision support on complex issues. We have furthermore argued that due to pluralism about pluralism we cannot end up with the pluralistic method. Our aim will be to develop an approach for pluralistic integrated uncertainty management and risk analysis that embraces different specific methods that share the basic pluralistic principles and the major procedural steps.

To that end, we will first briefly explore the two other key notions that resulted from Chapters ${ }_{3} \mathrm{~A}$ and ${ }_{3} \mathrm{~B}$, i.e. participation and robustness. Participation is related to pluralism. Participation is necessary if the required variety of perspectives extends beyond scientific points of view. As argued in Chapter 2, there are different levels of participation. Whether participation is necessary and to what extent it is practised, depends on the following:

- the character of the controversy/dilemma

- the sources and nature of the salient uncertainties

- the perspective on pluralism

- the aspired scope and nature of the insights

and it is furthermore important whether the decision-support activity as such is considered to be:

- a tool for social learning (i.e. a two way learning process between scientists, decision-makers, stakeholders and the general public)

- a method for improving the democratic character of policy formulation

In the latter two cases, which can be considered as forms of action research, participation seems to be a prerequisite ${ }^{49}$. With regard to the first four issues raised, participation is required to a greater or lesser extent in case one of the following descriptions apply:

- the controversy/dilemma involves complex issues ${ }^{50}$;

- the salient uncertainties are due to value diversity, behavioural variability and societal randomness";

- the salient uncertainties are related to psychological, socio-political and cultural risk factors ${ }^{5}$

\footnotetext{
49 See Chapter 38 for some reservations.

50 (Funtomirict and Ravere 1990 )

57 See Chapter $3 \mathrm{~A}$ for a discussion on sources of uncertainty.

52 See Chapter 38 for a discussion on ristik factors.
} 
- the adopted perspective on pluralism transcends the distinction between the world of science and the social world (i.e. the "science in perspective"-perspective and esp. the "reality in perspective"-perspective);

- the aim of the decision support endeavour is to deliver normative judgements;

- the decision support endeavour intends to provide recommendations that bear on public support.

Because of the features of the complex issues considered and the ambitions associated with Integrated Assessment, it is inconceivable that none of the above reasons for participation would apply. The process of integrated uncertainty management and risk analysis is thus not by definition participatory, although it can be expected that in the majority of the applications participation is highly recommended or even indispensable. This means that integrated uncertainty management and risk analysis in the context of IA will have to be a participatory endeavour.

The third key issue, i.e. robustness, is also closely related to pluralism. Due to inherent pluralism, the positivist ambitions of true and objective, and the modest version hereof, i.e. the most probable and the most plausible, are replaced by the ambition of robustness. Because it is impossible to arrive at a unique interpretation of uncertainty and one perception of risk, the challenge of decision support is twofold: to arrive at insights that hold irrespective of the adopted perspective,

to suggest strategies that i) appear to trigger a future that is acceptable, or even favourable, to different perspectives, ii) that seems to avoid those that one or more perspectives consider to be highly undesirable, and iii) that are flexible enough to be changed or reversed if new insights emerge.

This definition of the challenge for decision-support acknowledges that it is impossible to arrive at consensus with regard to worldviews ${ }^{53}$. The idea of a "shared perspective' composed of bits and pieces of the various perspectives assumes that a kind of meta-perspective exists, which assumption is fundamentally inconsistent with pluralism. Searching for robustness involves assessing which strategies are acceptable to different perspectives, without consensus on the underlying arguments. Such robust recommendations can inform decision-making on complex, and thus radically uncertain and strategically risky issues.

It thus follows from the above that integrated uncertainty management and risk analysis has to be pluralistic, at least partly participatory, and that it aims to deliver

53 for thie distinction between worldwiew and management scyle see Chapter $3 \mathrm{~A}$. 
robust recommendations. Building upon our elaboration so far, our challenge can be summarised as:

Integrated uncertainty management and risk analysis is an assessment process in which the salient uncertainties are interpreted according to different perspectives and structured into multiple risk judgements in such a way that robust insights can be deduced.

How to integrate uncertainty management and risk analysis? Uncertainty and risk are two sides of the same coin, but they have different features. As argued in Chapter ${ }_{3} \mathrm{~B}$, risk statements are the joint product of informed estimates about the future and the evaluation of desired and undesired prospects. Uncertainty management means an assessment of the knowledge base. In line herewith, we conclude that uncertainty management forms one of the bases for risk analysis. On the other hand, uncertainty management results in a wide variety of possible futures. As argued earlier, the output of uncertainty management is difficult to understand by decision-makers. Evaluation and translation is necessary in order to enable decision-makers to use this knowledge. Risk analysis can thus be considered as a logical next step after uncertainty management. The consequence is that uncertainty management can be used to improve the assessment of the knowledge about the future in risk analysis, while risk anallysis is used to transform and communicate the outcomes of uncertainty management into decision-relevant information.

Integrated uncertainty management and risk analysis can thus be considered as a two-step approach, with uncertainty management as the first step and risk analysis as the second. If this were it, it would be more appropriate to talk about coupled uncertainty management and risk analysis. In our point of view there are more opportunities to benefit from a synthesis of the two approaches. One of the crucial and most difficult steps in uncertainty management is the selection of salient uncertainties. Any selection implies weighing and evaluation. In Chapter $3 A$, we have argued how checklists and sensitivity analysis can be useful in this selection process. The NUSAP approach can also be of help to identify the degree of uncertainty. In the context of decision-support, the salience of uncertainty depends on whether the uncertainties are relevant in view of the decisions to be taken or the strategies to be developed. This is a typical chicken or egg problem: it is necessary to know the most important uncertainties before exploring decisions and strategies, while the importance of uncertainty can only be determined in view of the proposed decisions and strategies. 
How to deal with this mutual dependency? Pluralistic theories that consider perspectives as a-priori givens argue that a priori value patterns determine which uncertainties are relevant and which are not. In this case, the perspective framework can be used to filter which uncertainties are important. Other pluralistic theories do not reason from such a-priori perspectives. It both cases it seems important that integrated uncertainty management and risk analysis is an iterative effort. After a first cycle, it is necessary to evaluate the conclusions by checking whether the uncertainties that may have an crucial impact on the conclusions have all been considered. Second, the selection process can be informed by risk analysis. As argued in Chapter ${ }_{3} \mathrm{~B}$, risk is multidimensional. This multi-dimensional risk scheme can be used as another checklist to determine whether the uncertainty is salient in view of decisionsupport. The first step in risk analysis is to select the risk dimensions that are crucial in view of the dilemma or controversy under concern. The next step then would be to explore to what extent the identified uncertainties are related to the selected risk factors. This means that the uncertainties are characterised in terms of both scientific importance and policy relevance. This systematic approach and crosscheck increase the probability that the salient risky uncertainties and uncertain risks are captured in the assessment process from the early beginning on. 


\section{REFERENCES CHAPTER 4}

- Ayer, A. J. (1980), Hume; Hill and Wang, New York, USA.

- Bames, B. (1977). Interests and the Growth of Knowledge, Routledge, London, UK.

- Bames, $B$, and D. Bloor (1995). Scientific Knowfedge a Sociological Analysis, Athlone, London.

- Barnes, B., and D. MacKenzie (1979) "On the Role of Interests in Scientific Change." in: Wallis, R. (ed.) On the Margins of Science, Uniwersity of Keele Press, Keele, Staffordshire.

- Beck, U. (1986). Rusk Society: Towards a New Modernity, Sage, London, URK.

- Bourdieu. (1975). "The Specificity of the Scientific Field and the Sociall Conditions of the Progress of Reason." Social Scientific information, $1,4(6), 19.47$.

- Collims, H. M. (1985). Changing Order. Replication and induction in scientific practise, Sage, London, UK.

- Corvi (1997). An Introduction to the Thaught of Karl Popper, Routledge, London, UK.

- Cowello, V. (1984). "Uses of social and behavioural research on risk." Environment internatiomal, 4(June), 17-26.

- Crowch, E. A.C., and Wilson, R. (1982) Risk/Benefft arvalysis, Ballinger Publishing Company, Cambridge Massachusetts.

- de Vries, H. J. M., Beusen, A. H. W., and Jansen, M. A. (1997), "Energy systems in transition." Perspectives on Global Change: The TARGETS approach, J. Rotmans and B. de Vries, eds., Cambridge University Press, Cambridge, UK.

- "Len Elzen, M., Bewsen, A, and Rotmans, J. (1995). "Moddelling Global Biogeochemical Cycles. An üntegrated assessment approachi." 461502007, RIVM, Bilthoven.

- den Elzen, M. G.J., Beusen, A.H.W. Rotmans, J, and van Asselt, M. B. A. (1997). "Human disturbance of the global biogeachemical cycles." Perspectives on Globall Change: The TARGETS approach, J. Rotmans and B. de Vries, eds, Cambridge University Press, Cambridge, UK.

- Durkheim, E. (1986). The Rules of the Sociological Method, Presses Universitaires de France, Paris, France.

- Funtowicz, S. O., and Ravetz, I. R. (1990). Uncertainty and quality in science for policy, Kluwer, Dordirecht, the Netherlands.

- Geels, F. W. wan Asselt, M. B. A., and Rotmans, J. (1995). "Sulphate Aerosols and the Climate Debate: An uncertainty assessmemt." Gllobo working paper 4, RIVM, Bitthowen, The Netherlands.

- Gezondheid"sraad. (1995). "Wot All Risks are Equal (in Dutch with an English summary)." 1995/06, Health Council of the Netherlands, The Hague, the Netherlands.

- Hess, D. J. (1999). Science Studies: an Advanced Introdwction, New York Uniwersity Press, New York "USA.

- Hitderink, H. B. M., and van Asselt, M. B. A. (1997). "Population and Health in Perspective." Perspuectives on Global Change: The TARGETS approach, J. Rotmans and H. J. M. de Vries, eds, Cambridge University Press, Cambrìdge, UIK.

- Hoekstra, A. Y., Beusen, A. H. W., Hilderink, H. B. M., and van Assett, M. B. A. (1997) "Water in crisis?" Perspectives on Global Change: The TARGETS approach, J. Rotmans and H. H. M. de Vries, eds., Cambridge University Pres: Cambridge, UK.

- Jungermann, $H$, and Slowic, P. (1993). "Characteristics of individual risk perception." Risk is a Construct, B. Rtick, ed. Mnesebeck Verlag, München, Germany.

- Kant, I. (1997). Critique of practical reason (Kritik der Reinen Vernuft), Greigor, M., translator, Cambridge University Press, Cambridge (original edition: 1799).

- Kuhn, T. S. (1970). The Structure of Scientific Revolutions, Uniwersity of Chicago Press, Chicago, USA.

- Latour, B., and Woolgar, S. (1979). Laboratory Life: The social construction of scientific facts, Sage, Bewerly Hills, USA.

- Luhmann, N. (1993). Risk: A saciological theory, De Grijyter, Berlin, Germany.

- Lukes, S. (1975). Emile Durkheim, his life and work: Historical and Critical Study, Penguin Publishers, Harmandisworth.

由annheim, K. (1936). Ideology and Utopia, Routledge, London, UK. 
- Merlichofer, M. W. (1987). Decision science and societal risk management, Reidel, Boston, USA.

- Morgan, G. M. and Henrion, M. (1990). Uncertainty: A Guide to Dealing with Uncertainty in Quantitatiwe Risk and Pollicy Analysis, Cambridge University Press, New York, USA.

- Popper, K. (1959). The Logic of Scientific Discowery, Basic Books, New York, USA.

- Popper, Ko (1973). Objectrve Knowidedge, Clarendon Press, Oxford, UK.

- Raverz, J. R. (2000) "Models of Risk: An exploration." Effective Knowledge Use, Participation, and Power in Environmental and Risk Policy, M. Hisschemoller and R. Hoppe, eds., Transaction Books, New Brunswick, USA.

- Rayner, S. (1999). "A Cultural Perspective on the Structure and Implementation of Clobal Environmental Agree. ment: "Evaluation Review; $15(1), 75-102$.

- Rotmans, I, de Vries, H. J. M., van Asselt, M. B. A., Beusen, A. H. W. den Elzen, M. G. I. Hilderink, H. B. M., Hoekstra, A. Y., and Strenigers, B. J. (1997). "Towards Integrated Assessment of Clobal Change." Perspectives on Global Change: The TARGETS appraach, J. Rotmans and H. J. M. de Vries, eds., Cambridge Uniwersity Press, Cambridge, UK.

- Rotmans, I, van Asselt, M., B. A., de Bruin, A. J, den Elzen, M. G. J, de Greef, In, Hilderink, H, Hoekstra, A. Y, Janssen, M. A., Koster, H. W, Martens, W. J. M., Niesser, L. W., and de Vries, H. J. M. (1994). "Global Change and Sustainablle Development: A Modelling Perspective for the Nlext Decade." RVM-report no. 461502004, National Institute of Public Health and the Enwironment (RIVM), Bilthoven, The Netherlands.

- Scruton, R. (1995). A Short History of Modern Philosophy. From Descartes to Wittgenstein, Routledge, London.

- Strengers, B. I. den Elzen, M. G. J, Koster, H. W., Hilderink, H. B. M., and van Asselt, M. B. A. (1997). "Food for the future." Perspectives on Clobal Change: The TARGETS approach, J. Rotmans and $H_{1}$ J. M. de Vries, eds", Cambridge Uniwersity Press, Cambridge, UK.

- varn Asselt, M. B. A., Beusen, A. H. W., and Hilderink, H. B. M. (1996). "Uncertainty in Integrated Assersment: A Social Scientific Approach " Emvironmental Modelling and Assessment, 1(1/2), 71-90.

- van Asselt M. B. A, and Rotmans, J. (1995). "Uncertainty in Integrated Assessment Modelling: A Cultural Perspective-based Approach." RIVM-report no. 461502009, National Institute of Public Health and the Environment (RIVM), the Netherlands, Bilthowen.

- van Asselt, M. B. A., and Rotmans, J (1996). "Uncertainty in Perspective." Clobal Environmental Change, 6(2), 121-157.

- van Asselt, M. B. A., and Rotmans, J. (1997). "Uncertainties in perspective." Perspectives on Global Change: the TARGETS approach, J. Rotmans and B. de Vries, eds, Cambridge University Press, Cambridge, UK.

-van Asselt, M. B. A., and Rotmans, J. (1999). "Perspectives and the subjective dimension in modelling." Climate Change: an integrated perspectiwe, W. J. M. Martens and J. Rotmans, eds., Kh uwer, Dordrecht, the Netherlands.

- van Vianen, H. A. W., Willekens, F. J. Hutter, L., wan Asselt, M. B. A., Hillderink, H. B. M., Niessen, L. W., and Rotmans, J. (1994). "Fertillty Change: A Global Integrated Perspective." RIVM-Report no. 467502008, National Institute of Public Health and the Enwironment (RIVM), Bilthoven, The Netherlands. 


\section{Pluralistic framework for integrated uncertainy}

\section{management and risk analysis}

(PRIMA)

In line with the theoretical criteria and conditions discussed in the previous part of this thesis, a general framework for pluralistic integrated uncertainty management and risk analysis is proposed in this Chapter. The various steps will be discussed as concrete as possible. In the next part of the thesis, it will be explored in practice by means of the case of an example of an actual assessment process (Chapters 6-8). The aim is that by means of this testing, the theoretical outline can be developed into a more practically feasible framework (Chapter 9 ).

The aim is to provide a generic framework that is theoretically sound and that provides hints how these steps can be performed in practise. It should always be tailored to the specific case, adopted to the needs of those involved (both analysts and clients) and it should be possible to use it in a flexible manner in order to accommodate for the state of affairs and the actual running of things. The aim is that the general framework for pluralistic integrated uncertainty management and risk analysis, can be used as a kind of 'ideal plan', that inspires and challenges practitioners. The PRIMA framework is designed to help setting up pluralistic trajectories that enable practitioners to deal with uncertainty and risk in a way that acknowledges state-ofthe-art theorising on complexity, uncertainty and risk. Such a change of practice would in principle increase the analytical and methodological quality of the assessment and the decision-support ${ }^{\pi}$. 


\section{General framework}

How to come from a scattered complex problem to robust recommendations? In the previous Chapter, we concluded that:

Integrated uncertainty management and risk analysis is a participatory assessment process in which the salient uncertainties are interpreted according to different perspectives and structured into multiple risk judgements in such a way that robust insights can be deduced.

How can such an assessment process be set up? What steps have to be performed in any pluralistic approach to integrated uncertainty management and risk analysis? The major steps are visualised in Figure I. In view of the aim of the framework to serve as a kind of guide, this scheme of steps should not be interpreted as a rigid procedure, but as an attempt to structure the desired ingredients of pluralistic integrated uncertainty management and risk analysis.

The above scheme represents a very ambitious programme. In order to be able to see the connection between the various steps, the framework can also be described in terms of various stages. The first stage can be described as defining the overall perspective, both in terms of which perspective on pluralism is adopted and in terms of the controversy or dilemma being assessed. The next phase can be characterised as "uncertainties in perspective". In this stage the scan, selection and perspectivebased interpretation of uncertainties is the central task. In the following phase, it is assessed what scenarios seem to be possible and plausible. This involves scanning the future from a wide variety of perspectives. This stage can therefore be typified as "scenarios in perspective". The next challenge is to assess risks, taking into account the variety of perspective-based assessments gathered in the previous phases. Putting risk in perspective can yield robust insights. This stage is therefore characterised as "risks in perspective". It is very important to test the quality of the robust insights by reflecting on the previous steps, that means evaluating whether the uncertainties and risk factors relevant for these particular conclusions have be considered in an adequate manner. This stage of quality assessment can be considered as closing the assessment cycle (see Figure 2). This process then yields outputs that can be used as qualified recommendations in the decision-making community and as priorities for the research agenda in the scientific community. Building upon these new insights the process can be iterated with an adopted or new definition of the controversy or dilemma, or with another perspective on pluralism. 


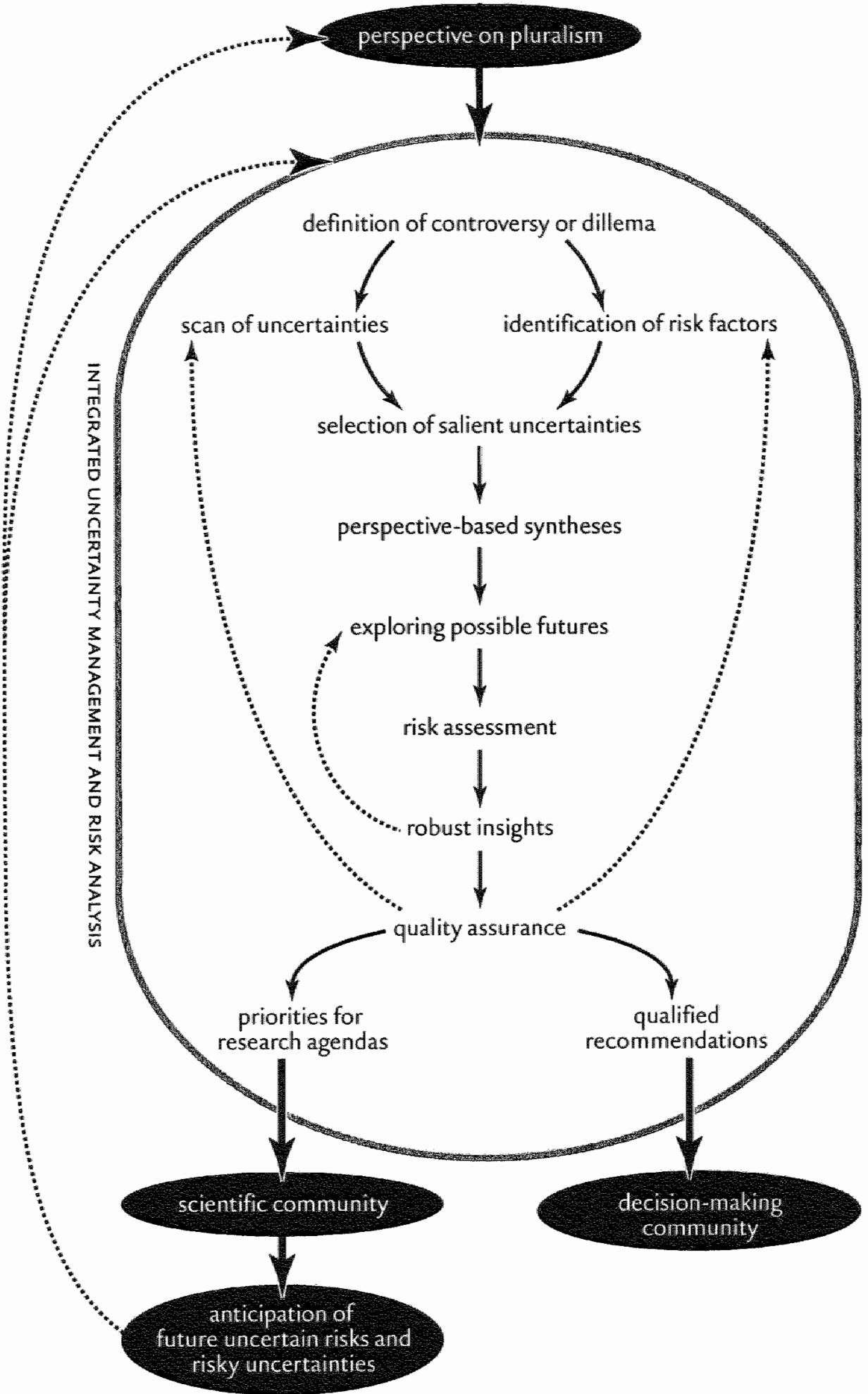

FGGURE i Genera framework for pluralistic integrated uncertainty management and risk analysis (PRHMA) 
In sum the following phases can be distinguished (see also Figure 2):

- definition of 'starting perspective'

- uncertainties in perspective

- scenarios in perspective

- risks in perspective

- quality assessment

- use of outputs

The various steps, including concepts, tools and methods that enable to perform these steps, are described stage-wise in the following sections.

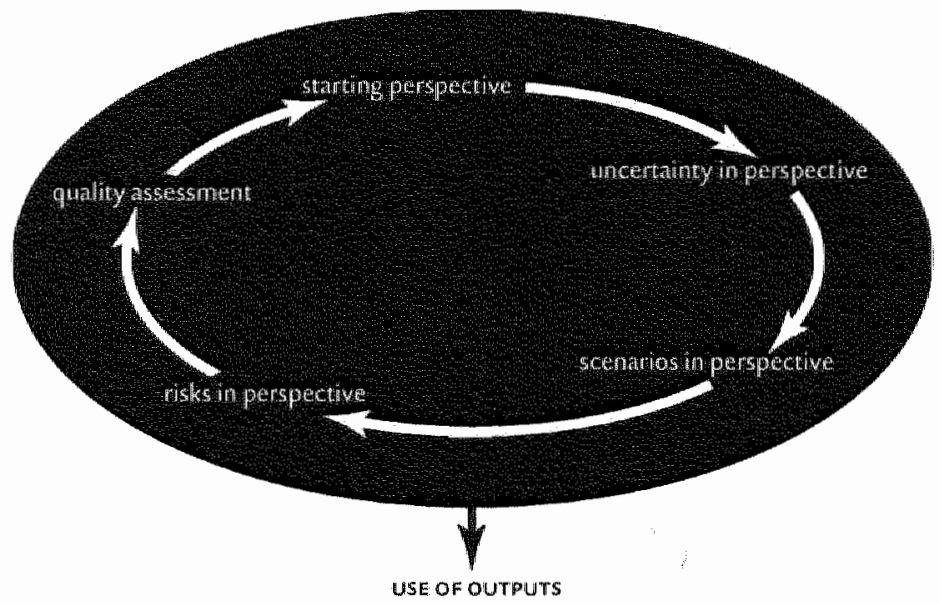

FICURE2 Multi-stage approach to pluralistic integrated uncertainty management and risk analysis (PRMA)

\section{Starting perspective}

As can be concluded from the previous Chapter, applying pluralism means taking up a certain stand with regard to pluralism. On the highest level of abstraction, we could argue that diverse types of pluralistic analyses have to be carried out. This would tally with the theoretical considerations, but it is clear that in being too far beyond current practise and in being too time-consuming, this would turn integrated uncertainty management and risk analysis into a mission impossible. We would advise that the first step is to choose that perspective on pluralism that corresponds most with the attitude of both the analysts and the clientele, and then to be consistent with this perspective during the assessment process. 


\section{PERSPECTIVE ON PLURALISM}

There are three crucial choices that are dependent on the choice for the pluralistic stand, i.e.:

- the type of uncertainties included in the pluralistic analysis

- whether a demand- or a supply-driven approach is advocated

- portfolio of methods for uncertainty analysis

- the perspective framework used

In the following we would like to address these issues from the various perspectives on pluralism. The aim is to help practitioners to decide in choosing which perspective on pluralism is most appropriate in their situation and to facilitate them in being consistent throughout the analysis. The feacures associated with the various perspectives on pluralism are summarised in Table $\mathrm{I}$ and are further explained and explored in the remaining of this section ${ }^{2}$.

\begin{tabular}{|c|c|c|c|c|}
\hline $\begin{array}{l}\text { perspective } \\
\text { design choice }\end{array}$ & $\begin{array}{l}\text { "observation } \\
\text { in perspective" }\end{array}$ & $\begin{array}{c}\text { "theory } \\
\text { int perspective" }\end{array}$ & $\begin{array}{c}\text { "scietuce } \\
\text { in perspective" }\end{array}$ & $\begin{array}{c}\text { "reality } \\
\text { in perspective" }\end{array}$ \\
\hline $\begin{array}{l}\text { uncertainties } \\
\text { included }\end{array}$ & radical uncertainties & radical uncertainties & $\begin{array}{l}\text { radical and measur- } \\
\text { able uncertainties }\end{array}$ & $\begin{array}{l}\text { everything is } \\
\text { uncertain }\end{array}$ \\
\hline $\begin{array}{l}\text { type of } \\
\text { assessment }\end{array}$ & supply-driven & $\begin{array}{l}\text { supply-driven \& } \\
\text { participatory }\end{array}$ & participatory & demand-driven \\
\hline $\begin{array}{l}\text { methods for } \\
\text { uncertainty } \\
\text { analysis }\end{array}$ & $\begin{array}{l}\text { standard methods } \\
\text { with } \\
\text { perspective-based } \\
\text { as supportive }\end{array}$ & $\begin{array}{l}\text { perspective-based } \\
\text { and standard methods } \\
\text { in a complementary } \\
\text { manner }\end{array}$ & $\begin{array}{l}\text { perspective-based } \\
\text { with standard } \\
\text { methods as } \\
\text { supportive }\end{array}$ & $\begin{array}{c}\text { fully } \\
\text { perspective-based }\end{array}$ \\
\hline $\begin{array}{l}\text { perspective- } \\
\text { framework }\end{array}$ & hypotheses & $\begin{array}{l}\text { scientific } \\
\text { paradigms }\end{array}$ & $\begin{array}{l}\text { socio-culctiral } \\
\text { perspectives }\end{array}$ & $\begin{array}{l}\text { perspectives result } \\
\text { out of participation / } \\
\text { observed in } \\
\text { actual networks }\end{array}$ \\
\hline
\end{tabular}

TABLE I Practical differences between perspectives on pluralism

The "observation-in-perspective"-perspective holds that observation is shaped by what the researcher wants to falsify or verify. This means that compering hypotheses are the basis for pluralism in this specific stand. A perspective in this context thus means a coherent set of hypotheses. The practical implication is that if this view on pluralism is accepted in the study on complex issues, the scientists have to infer competing sets of hypotheses, which are then used to interpret the salient uncer- 
tainties. This realist perspective implies an essentially supply-driven assessment, in which the perspective-based analysis is restricted to radical uncertainties.

The "theory-in-perspective"-perspective includes radical uncertainties in the perspective-based analysis, while measurable uncertainties are treated with standard methods. This perspective on pluralism advocates the supply-driven approach, although this does not exclude the possibility that some of the activities are participatory.

In case of the "theory-in-perspective"-perspective it would be appropriate to use different scientific paradigms to compose a set of perspectives. Even in disciplines in which the reigning paradigm is very dominant, it will be possible to discern at least one alternative, either by an analysis of the history of this discipline or by retrieving the line of thought of contemporary dissidents. As far as our knowledge extends, such a systematic analysis of paradigms in different disciplines and integration of disciplinary paradigms into interdisciplinary perspectives have never been performed. As a consequence developing a set of perspectives in this way seems to be a research programme in its own right.

A more pragmatic approach within the "theory-in-perspective"-perspective would be to reason from major dichotomies within science. Table 2 is a first attempt to highlight major constituting dichotomies. In this way, a perspective-framework can be developed that on an abstract level roughly describes major diverging viewpoints present within science. These scientific perspectives can then be used to interpret the salient uncertainties.

\begin{tabular}{|c|c|c|}
\hline sclentifo clusters & some majo & r dichotomies \\
\hline econtomic sctiences & $\begin{array}{l}\text { markeb-oriented } \\
\text { itcional artor \& equilibrium } \\
\text { need-oriented (demand) }\end{array}$ & $\begin{array}{l}\leftrightarrow \text { government-oriented } \\
\leftrightarrow \text { adaptive learning agents \& non-eguilibrium } \\
\leftrightarrow \text { resource-or hented (supply) }\end{array}$ \\
\hline social-cultural sciences & $\begin{array}{l}\text { individual } \\
\text { detarminism } \\
\text { cognition }\end{array}$ & $\begin{array}{l}\rightarrow \text { collective/social phenomena } \\
\rightarrow \text { voluntarism } \\
\rightarrow \text { buhaviour }\end{array}$ \\
\hline envinonthental sciences & $\begin{array}{r}\text { anthropocentric } \\
\text { scarcity } \\
\text { adaptive capaciry }\end{array}$ & $\begin{array}{l}\leftrightarrow \text { ecocentric } \\
\leftrightarrow \text { abundance } \\
\leftrightarrow \text { fragillity }\end{array}$ \\
\hline institutional sciences & $\begin{array}{l}\text { institutionalised politics } \\
\text { hierarchy/power structures }\end{array}$ & $\begin{array}{l}\leftrightarrow \text { subpolitics } \\
\leftrightarrow \text { egalitarian/democracy }\end{array}$ \\
\hline
\end{tabular}


A more bottom-up way to arrive at a set of perspectives that could be used in the "theory-in-perspective" mode would be to deduce perspectives from elicitation processes with scientific experts. That means that a representative set of scientists is asked to interpret the salient uncertainties. The various interpretations are compared in order to discern patterns of interpretation. These patterns can then be considered as empirically revealled scientific perspectives ${ }^{3}$.

As said before in the "science-in-perspective"-perspective a typology of sociocultural perspectives is welcomed, because pluralism in science results out of pluralism in society. Such a typology can be found in Cultural Theory ${ }^{4}$. It is clear that Cultural Theory organises some dichotomies that are important in social and cultural science conceptualisations, such as hierarchy versus egalitarianism, market versus government, centralised versus decentralised, and individualism versus social solidarity ${ }^{5}$. We advocate to adopt the three active perspectives inferred from Cultural Theory ${ }^{6}$, while bringing them a little more down to Earth through renaming and summarising them in terms of heuristic rules ${ }^{7}$. This pragmatic approach was inspired by our analysis of European scenarios, in which four different patterns of thinking about the future were clearly recognisable (i.e. the money-maker, the doom monger, think green, and wait and see ${ }^{8}$ ). Our experience was that this clustering was acceptable to experts that resist to Cultural Theory, while it to our opinion at the same time reflects the basic characteristics shaping the cultural theory perspectives. The complicated naming of the perspectives is one of the recognised obstacles ${ }_{n}$ also for them neutral or positive to Cultural Theory. The first adjustment thus involves a renaming , i.e.:

- the market optimist (instead of individualist)

- the environmental worrywart (instead of egalitarian)

- the controllist ${ }^{\mathrm{I}}$ (instead of hierarchist)

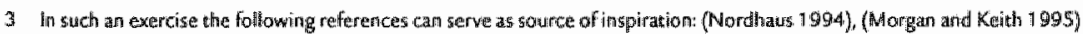

4 See Chapter 3A and 3B for short descriptions of these perspectives associated with Cultural Theory and a bibliography of Culural Theory. See Chapter 3 A for a discussion of otr experineres in ws ing the perspectives proposed by Cultural Theory. 5ee also Chaptur 4.

5 As argosed in (vall Asselt and Rotmans 1996, 1997)

5 We realise that we are not doing justice to Cultural Theory by just presenting their perspectine seheme. Cutural Theory is in fact a theory of

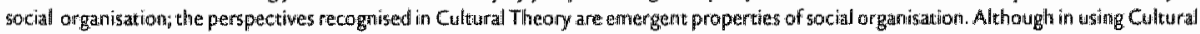
Theory we thave been aware of the dependence of perspectives on the relevant social organisation, this feature: of the Cuiturat theory persper.

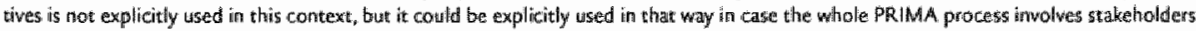
from different social contexts th the current thesis, the perspectives are ustext as sterectypes.

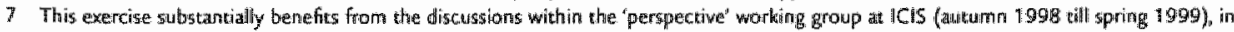
which apart from the author, Nicole Rijkens, Frank van Asten, Bastien Clement and josine Spierenburgh were involved, and the discussions

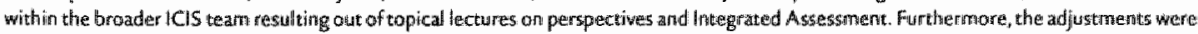
informed by the experiences of using Cultural Theory as perspectirwe frame inl wariows contex ss

8. (wan Asselt et al. 1998 )

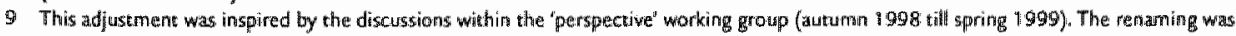
explicity advised by prof keses 5 chuyt in a wivid discussion alow the pros and cons of Cultural Theory.

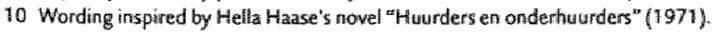


Furthermore, the practical experiences inspired us to propose summaries (see Table 3) comprising the heuristic rules that turned out to be critical in interpreting uncertainties according to the Cultural Theory perspectives. We have furthermore tried to prioritise these critical features. In doing so, the summarised characterisations can be used as heuristic schemes in quicklly applying the above perspectives with assessment practitioners and stakeholders not familiar with Cultural Theory.

\begin{tabular}{|c|c|c|c|}
\hline & masket-optinist & envirommental worrywart & controllist \\
\hline heuristic rule 1 & $\begin{array}{l}\text { Free market and } \\
\text { anti-regulation; Economic } \\
\text { growth and technological } \\
\text { development are progress; }\end{array}$ & $\begin{array}{l}\text { Nature is vulnerable, and } \\
\text { thus in need of protection } \\
\text { from excessive exploitation; } \\
\text { Aversive to environmental risks; } \\
\text { Prevention is better than cure. }\end{array}$ & $\begin{array}{l}\text { Societal stability through } \\
\text { reguliation, norms and } \\
\text { hierarchy; Acceptation of } \\
\text { inequalities }\end{array}$ \\
\hline heuristic rule? & $\begin{array}{l}\text { Individual development } \\
\text { and material self-interest } \\
\text { are the motives for action. } \\
\text { Success is a personal } \\
\text { responsibitily. }\end{array}$ & Equity. & $\begin{array}{l}\text { Risk-awersive; Anti abrupt } \\
\text { change; Easy doing } \\
\text { other wise the line } \\
\text { will break. }\end{array}$ \\
\hline heuristic rule 3 & $\begin{array}{l}\text { Narure is not fragile; it can } \\
\text { stand rough handling. }\end{array}$ & $\begin{array}{l}\text { The economy is a means } \\
\text { and not an aim. Conscious } \\
\text { consumption. }\end{array}$ & $\begin{array}{l}\text { Authority through } \\
\text { expertise and explerience. }\end{array}$ \\
\hline heuristic rulle 4 & $\begin{array}{l}\text { Problems are solwable; } \\
\text { Risks are challenges } \\
\text { and opportunities }\end{array}$ & $\begin{array}{l}\text { Human beings are essentially } \\
\text { solidary and act accordingly; } \\
\text { Collective interest. }\end{array}$ & $\begin{array}{l}\text { Power and status are the } \\
\text { motives for action. }\end{array}$ \\
\hline
\end{tabular}

TABLE 3 Features of sociomcultural perspectives

The above typology of perspectives can be used in the "science-in-perspective"mode. This typology may also be useful as source of inspiration in the "theoryin-perspective" - perspective, because, although this typology transcends scientific disputes, it inhibits particular combinations of stands taken with regard to the major dichotomies prevailing in science (compare Table 2). Within the "science-inperspective"-perspective a deductive strategy of deriving perspectives from the participatory process can also be considered. 
The "reality-in-perspective"-perspective only recognises those perspectives that are observed empirically in actual interactions. This viewpoint denies the possibility of any a priori classification of perspectives, because it holds that perspectives are embedded in social interaction patterns. Because science is granted no special role, adoption of the "reality-in-perspective"-perspective implies that the whole assessment process should be participatory. Interpretations of uncertainty arise out of the interactions in the participatory process. In its extreme form, this perspective has it that social interactions are unique, which implies that the assessment is not reproducible and that the results cannot be generalised. In a less post-modern variant, it is possible to infer patterns out of the empirical study of the interaction processes. So far, the constructivist literature does not provide a scheme that can be applied in pluralistic efforts. This implies that at the moment a pluralistic integrated uncertainty management and risk analysis in a "reality-in-perspective" mode involves that the assessment process is demand-driven and necessarily participatory.

\section{DEFINITION OF CONTROVERSY OR DILEMMA}

After having adopted a certain perspective on pluralism, the next step is to define the complex issue under concern in terms of a controversy or dilemma. This enables to define the problem, and to demarcate what is the focus of the assessment, what will be studied, and what not. The controversy or dilemma should be phrased broad enough to comprise various perspectives, while it should be concrete enough to serve as starting point for analysis. In view of the aim of integrated uncertainty management and risk analysis, the formulation has to be sensible, understandable and legitimate both from a scientific and a decision-makers' point of view.

This starting perspective stage results in decisions with regard to uncertainties included, the type of assessment, the portfolio of methods, the perspective-framework, and the problem formulation, which choices structure the further process. 


\section{Uncertainty in perspective}

This phase involves scanning the uncertainties and identifying the relevant risk factors. The taxonomy of sources and types of uncertainty provided in Chapter $3 \mathrm{~A}$ can be used to systematically assess and characterise the uncertainties involved (see Figure 3).

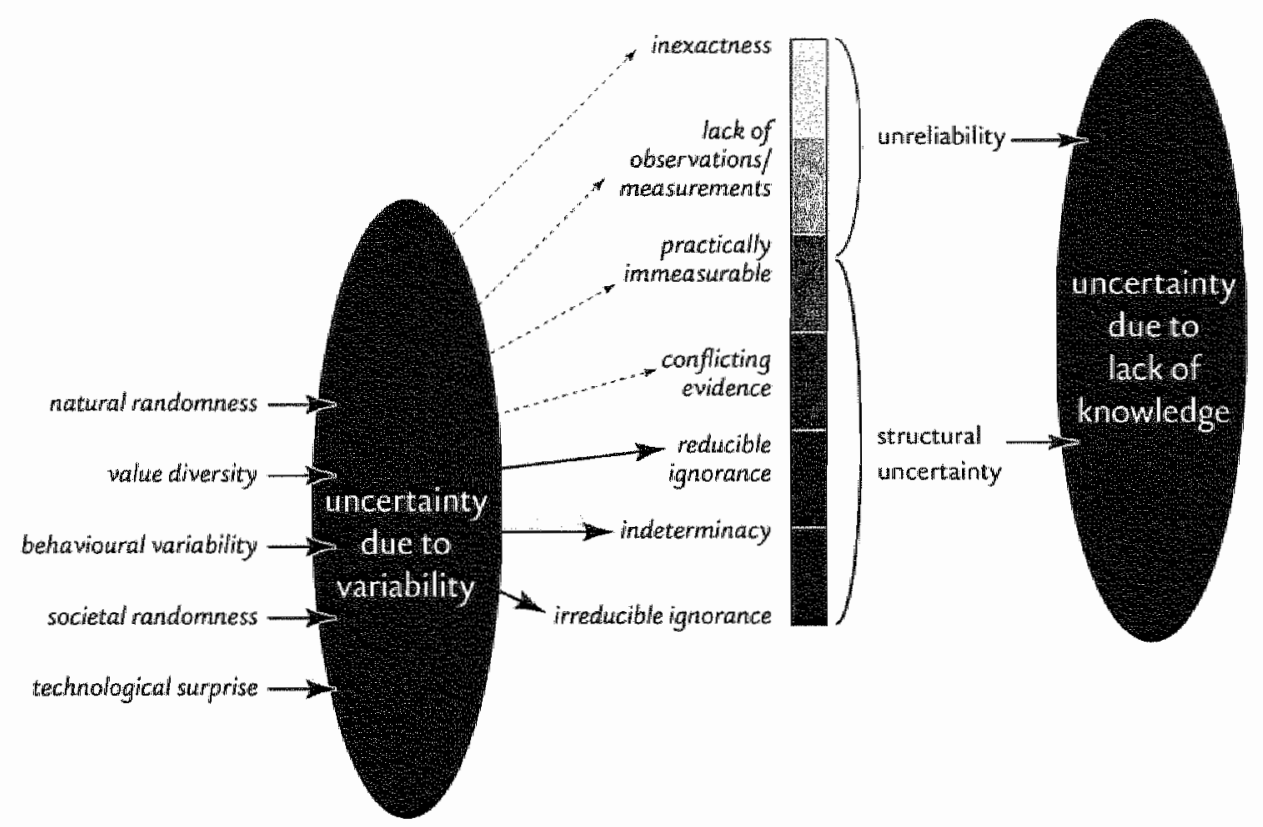

FICURE 3 Typology of uncertainty (see Chapter 3A)

The multidimensional risk scheme (see below) that is given in Chapter ${ }_{3} \mathrm{~B}$ can serve as a starting point for exploring risk factors in a structured manner:

- what might happen?

- imaginable consequences?

- risky to whom?

- equity?

- cause?

- catastrophic potential?

- invisible dread?

- controllable? / voluntariness?

- familiarity?/delay? 
- accident history?

- irreversibility?

- how plausible/likely?

- acceptable/desirable?

- what can be done about it

The characterisation and features of types of consequences can also be useful in this context, i.e. benefits (desired effects) and damages (undesired effects), further specified into:

- social (e.g. in terms of health and quality of life), economic (e.g. economic losses/gains), environmental (e.g. in terms of ecological value, biodiversity and natural processes/functions) and institutional terms

- terms of distribution

- direct and indirect effects

Both activities will be an iterative effort, i.e. going back and forth between the theoretical aspects of the two notions and the specifics of the issue under concern. Building upon these parallel steps, the salient uncertainties have to be selected. Salience in the context of decision support and Integrated Assessment implies that the degree of uncertainty is significant and that the policy relevance is high ${ }^{12}$. How to determine which uncertainties are salient? Taking into account that salience in this context has both a scientific and a decision-making dimension, the conclusion is that this step can best be done by means of a participatory process. Whether the degree of uncertainty is high and whether the uncertainties are highly policy relevant can then be determined in an intersubjective manner. It can also be decided that different sets of salient uncertainties are composed in relation to the various perspectives that are used in the specific assessment. Figure 4 sketches a participatory selection process. The taxonomy of uncertainty is useful to identify and characterise the uncertainties. Heuristics as checklists, sensitivity analysis and NUSAP may help to estimate the degree of uncertainty. By means of the identified risk factors, the uncertainties can also be characterised in terms of policy relevance. These two features of uncertainty, i.e. degree and policy relevance, in principle enable to select those uncertainties that are salient in view of the complex issue.

12 Compare (Funtowice and Ravetz 1990) 


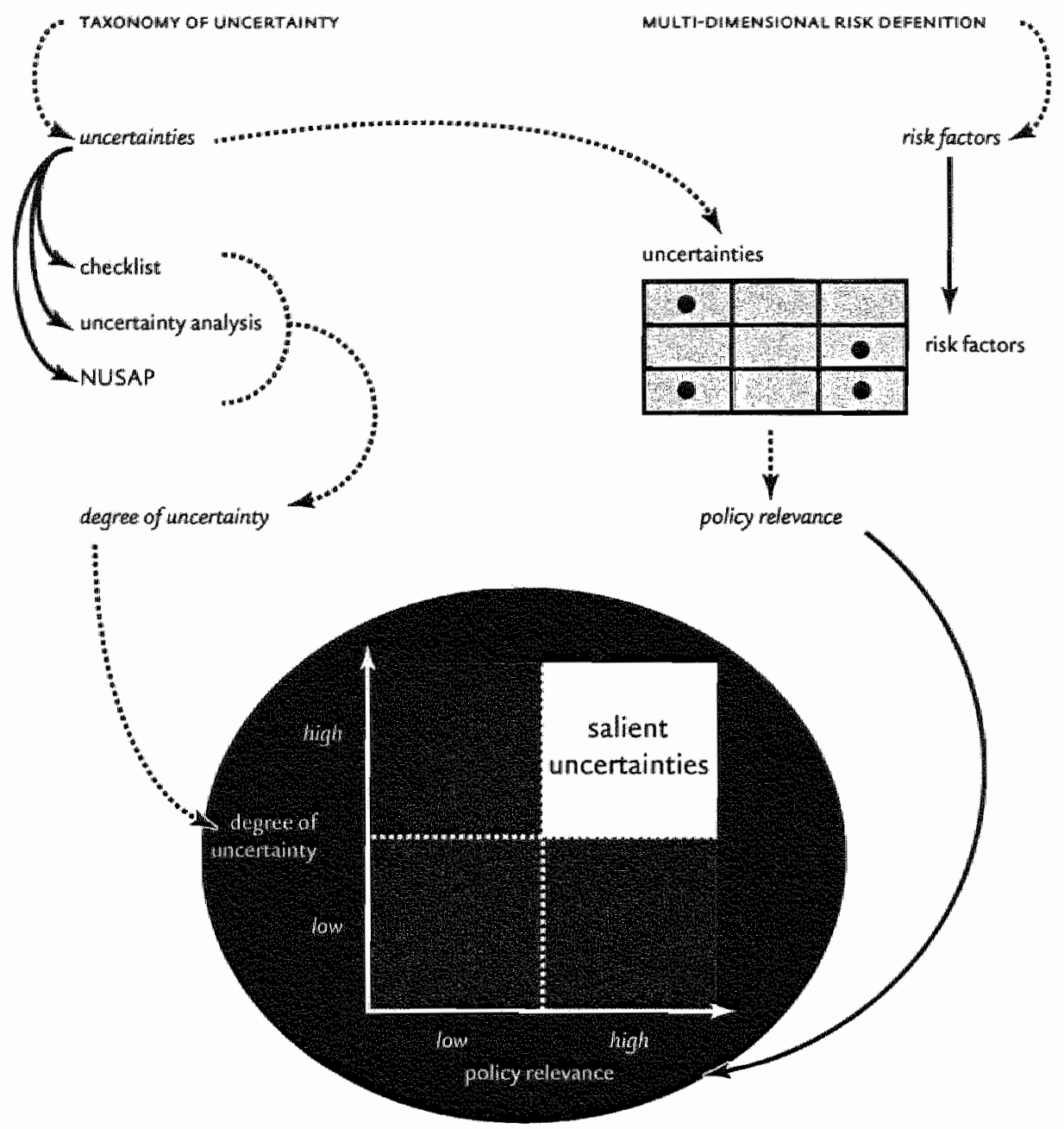

FHeURE 4 Routing for selection of salient uncertainties

Salient uncertainties can be clustered in terms of world view and management style $^{13}$. Uncertainties associated with worldview involve uncertainties pertaining to economic, environmental and socio-cultural processes. Uncertainties associated with management style deal with policy preferences in terms of strategies and options, and with institutional processes. The distinction between world view and management style is relevant in this interpretation phase. The salient uncertainties have to be interpreted according to different perspectives. The fleshing out of worldviews

13 This distinction reflects the conmon dichotonnies berween perceiving and areving, between autonomous and policy-driwen, and between trow it is and what we showld do. In tusing perspectives in decision-support this distinction is crucial, see (wan Asselt and Rotmans 1995; 1996; $1997)$ 
(see Table 4) can be done qualitatively, semi-quantitatively or quantitatively. The syntheses of the interpretation of "world view" uncertainties with factual information yield different conceptualisations of the dynamics underlying the relevant complex issue.

\begin{tabular}{l|l|l|l}
\multicolumn{1}{c|}{$\begin{array}{c}\text { perspective } \\
\text { uncertainty }\end{array}$} & perspective A & perspective B & perspective N \\
\hline uncertainty 1 & & & \\
\hline uncertainty 2 & & & \\
\hline uncercainty $\mathrm{x}$ & & & \\
\hline
\end{tabular}

TABLE 4. Unterpretation format for world view according to perspective

Interpreting the salient uncertainties associated with management style involves a scan of the strategies and options ${ }^{14}$ that have to be considered in the analysis. This can be done in different ways, for example i) by means of a participatory exercise in which the decision-makers and/or stakeholders participate, ii) by a review of strategic documents checked with the policy sciences literature, or iii) by using the perspectives for a structured and systematic brainstorm. Ideally the different approaches are combined to guarantee an adequate coverage both of options and strategies viable in the decision-making community and of innovative responses. This stage should result in fleshing out plural management styles (see Table 5).

\begin{tabular}{c|c|c} 
perspective A & perspective B & perspective $\mathbf{N}$ \\
\hline policy option r & policy option 3 & policy option $x$ \\
strategy 2 & strategy I & strategy $y$ \\
$\ldots$ & $\ldots$ & $\ldots$
\end{tabular}

TABLE 5 Interpretation format for management style peir perspective

The major outcome of this phase is a consistent perspective-based set of salient uncertainties, in which worldview and management style are distinguished. Table 6 illustrates the outcome of such a process with reference to the TARGETs project, in which endeavour the original Cultural Theory labels were used ${ }^{15}$. These worldviews and management styles form the building blocks for assessing the future. Furthermore, the intermediary product, i.e. the list of salient uncertainties that is deter-

14 Policy analysis literature prowides teclingiques for option generation, see for example (van Hieffera et al. 1999) and (Hoppe 1998 ). 15. For more detaills, see Chapter $3 \mathrm{~A}$. 
mined in a systematic and participatory manner, as such can already proven to be a valuable input to the decision-making process and can be used to set the scientific agenda.

\begin{tabular}{|c|c|c|c|}
\hline & Hieratchist & Egalitarian & Individualist \\
\hline economy & $\begin{array}{l}\text { moderate desiired } \\
\text { economic growth }\end{array}$ & $\begin{array}{l}\text { How desired } \\
\text { economic growth }\end{array}$ & $\begin{array}{l}\text { high desired } \\
\text { economicgrowth }\end{array}$ \\
\hline population \& liealth & $\begin{array}{l}\text { - physical limirs } \\
\text { - family planning programs } \\
\text { as driving force } \\
\text { - health as human capital } \\
\text { - health serwices }\end{array}$ & $\begin{array}{l}\text { - environmental and } \\
\text { social limits } \\
\text { - socieral developments } \\
\text { as driving rorce } \\
\text { - health as humarn asset } \\
\text { social-economic and } \\
\text { environmental health } \\
\text { determinants }\end{array}$ & $\begin{array}{l}\text { - no limirs } \\
\text { - ind ividual possibilities } \\
\text { as driving force } \\
\text { - he alth as constumption } \\
\text { good } \\
\text { - ageing }\end{array}$ \\
\hline energy & $\begin{array}{l}\text { moder ate } \\
\text { taclinalogy development }\end{array}$ & $\begin{array}{l}\text { environmental } \\
\text { rechnology }\end{array}$ & $\begin{array}{l}\text { energy fefficient } \\
\text { cechnology }\end{array}$ \\
\hline climate & $\begin{array}{l}\text { - mplifying effect of } \\
\text { geophysical reedbacks } \\
\text { moderate cooling of } \\
\text { aerosols }\end{array}$ & $\begin{array}{l}\text { - strong amplifying } \\
\text { effects of geophysical } \\
\text { feedbacks }\end{array}$ & $\begin{array}{l}\text { radiative effects are } \\
\text { strongly dampening } \\
\text { effects }\end{array}$ \\
\hline water & $\begin{array}{l}\text { - supply oriented } \\
\text { - stable runoff as potential } \\
\text { warer supply } \\
\text { - medium response to } \\
\text { dimate change }\end{array}$ & $\begin{array}{l}\text { - dernand oriented } \\
\text { clean fresh warer stock } \\
\text { as potential supply } \\
\text { - hight response to } \\
\text { climate change }\end{array}$ & $\begin{array}{l}\text { - market oriented } \\
\text { no limits } \\
\text { - low response to } \\
\text { climate change }\end{array}$ \\
\hline land \& food & $\begin{array}{l}\text { - present diet } \\
\text { - } 3.3 \text { Gha arable land } \\
\text { middle trecuperative } \\
\text { power of degraded land }\end{array}$ & $\begin{array}{l}\text { - vegetarian dier } \\
\text { - } 2.8 \text { Gha arable land } \\
\text { - low recuperative power } \\
\text { of degraded land } \\
\text { megative effect of } \\
\text { temperature increase }\end{array}$ & $\begin{array}{l}\text { - American diet } \\
\text { - } 3 . \text { Gha arable land } \\
\text { - high recuperarive power } \\
\text { of degraded land } \\
\text { - posicive } \mathrm{CO}_{3} \\
\text { fertilisation effect }\end{array}$ \\
\hline
\end{tabular}

TAB 6 A Example of perspective addescriptions in terths of worldview 


\begin{tabular}{|c|c|c|c|}
\hline & Herarchist & Egalitarian & Indiwidualist \\
\hline $\begin{array}{l}\text { population \& } \\
\text { health policy }\end{array}$ & $\begin{array}{l}\text { - family planning } \\
\text { - anti-abortion } \\
\text { - selective health care } \\
\text { policy (cure) }\end{array}$ & $\begin{array}{l}\text { - human development } \\
\text { (esp edtcation for } \\
\text { women) } \\
\text { - legislation of abortion } \\
\text { comprehensive health } \\
\text { care policy (prevention) }\end{array}$ & $\begin{array}{l}\text { - legalisarion of abortion } \\
\text { - market-oriented health } \\
\text { policy }\end{array}$ \\
\hline energy policy & $\begin{array}{l}\text { - no carbon tax } \\
\text { - moderate } R \& D \text { programs } \\
\text { for new energy supply and } \\
\text { - efficiency options }\end{array}$ & $\begin{array}{l}\text { - carbon tax rowands } \\
500 \$ / r C \text { in } 2020 \\
\text { constanr afterwards } \\
\text { - R\&D programson } \\
\text { renewable resources }\end{array}$ & - no carbontax \\
\hline water management & $\begin{array}{l}\text { - increasing charges } \\
\text { on water }\end{array}$ & $\begin{array}{l}\text { - warer-taxing } \\
\text { active policy on public } \\
\text { water stpply and coverage } \\
\text { - R\&D programs on } \\
\text { small-scale technology }\end{array}$ & $\begin{array}{l}\text { - marker pricing of water } \\
\text { - high-tech R D } \\
\text { programs if water gets } \\
\text { scarce (e.g. desalination) }\end{array}$ \\
\hline land management & $\begin{array}{l}\text { - reforestation policy } \\
\text { agricultural planning } \\
\text { (incl. irrigation, fertilisers }{ }_{\mu} \\
\text { deforestation, reforestation) }\end{array}$ & $\begin{array}{l}\text { eco-forestry } \\
\text { (e.g-reforestation) } \\
\text { eco-agriculture } \\
\text { (less clearing, } \\
\text { no fertilisers) }\end{array}$ & $\begin{array}{l}\text { - protection of wood } \\
\text { sectort } \\
\text { - intensiwe agriculinure } \\
\text { (ind genetic engineering) }\end{array}$ \\
\hline
\end{tabular}

TABLE 6B Example of perspective-descriptions in terms of management style

It should be noted that the above approach to flesh out plural perspectives is stylised, in the sense that it does not take into account the policy system and the associated balance of power. Each political system will tolerate and select particular management styles $^{16}$ or will prefer certain compromises ${ }^{17}$. However, our aim is not to mirror nor to replace the political process, but to indicate legitimate interpretations of uncertainties, both in terms of worldview and in terms of management style, as a decision-support endeavour. The actual evaluation of perspectives has to take place in the policy arena.

16 See, for example, (Miolenaters and Thompson 1999 ).

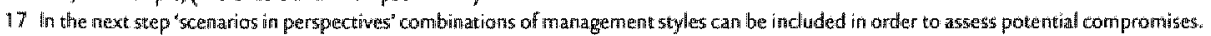




\section{Scenarios in perspective}

In this thesis, a scenario is defined as an alternative image of the future, created from mental maps or models that reflect a specific perspective on past, present and future developments ${ }^{\text {i8 }}$. A scenario is thus an assessment of the future reasoning from a particular interpretation of the salient uncertainties. In our approach, the perspectivebased interpretations that result from the previous step serve as starting point for scenario-analysis. In this way, scenarios are thus used as a tool to address uncertainty by systematically "thinking through" the consequences of different interpretations of the salient uncertainties. In view of the decision-support ambition, it is important that the scenarios involve the selected risk factors. In other words, the risk factors form a kind of content list for the images of the future.

The perspectives can be embodied into quantitative models (i.e. perspectivebased model routes) or in qualitative descriptions (i.e. perspective-based knowledge patterns). It is important here to distinguish between autonomous and policy-driven developments. To that end the various worldviews and management styles are systematically combined (see Figure 5) in order to explore different utopian and dystopian outlooks. In doing so, each scenario thus involves a particular management style (composed of policy options) and a particular interpretation of how the world functions.

In the context of the complex issue under concern, it might be interesting to go beyond the rigid management style and worldview scheme. Some extensions of this basic scheme are:

test a particular policy option or strategy against all world views

i) divide the worldviews into economic, socio-cultural, ecological and institutional clusters $^{11}$, ii) design interesting combinations and iii) test policy options and management styles against these combinations.

- introduce surprises and assess how the various perspective-based assessments of the future would change $e^{20}$

- explore the consequences of a future change of management style ${ }^{2 n}$

- combine these approaches

18 See Clyapter 2 for a summary of scholarly ideas and discursions on scienarios and scenario dewelopment. Herre we limit curselves to using the notions and conceptrs introd tuced in Chaptret 2.

19 This clustering is inspied by the distinction into economic capital, socio-cultural capital, ecalogical capitcal and institutional capical that is

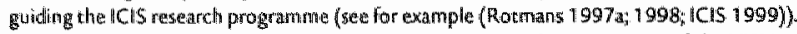

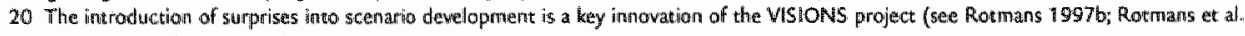
1999 ; van Asseti et al. 1998)

21 See (van Assatr and Rotmans 1996 ) and (jlanssen and de Wries 1996 ) for this kind of experiments with perspectiwe bazed madel routes. 
This systematic exploration of the future either yields quantitative forecasts or narratives dependent on the scenario method used. This phase thus results in a broad range of scenarios that covers the wide variety in legitimate interpretations of the underlying salient uncertainties and that comprises those risk dimensions relevant for the strategic debates. In doing so, this approach to scenario analysis puts uncertainty at the heart of the assessment. These scenarios show the range of possible futures constrained by current state-of-the-art knowledge. With integrated uncertainty management and risk analysis we scan what is possible. For complex issue, it is by definition impossible to come up with the most plausible or the most probable scenario. Scanning what is possible, and what not, is the relevant information integrated uncertainty management and risk analysis yield.

WORLD VIEW

MANAGEMENT STYLE

\begin{tabular}{|c|c|c|}
\hline perspective A & perspective B & perspective N \\
\cline { 2 - 3 } utopia & dystopia & dystopia \\
\hline dystopia & utopia & dystopia \\
\hline dystopia & dystopia & utopia \\
\hline
\end{tabular}

FIGURE 5 Scheme for utopian and dystopian experiments

\section{Risks in perspective}

The previous stage can be considered as a phase in which divergence was a key principle. In the present phase, convergence is the ambition. The challenge is to go beyond the multiple perspective-based "sprinkler' of "would-be-worlds" ment involves providing general insights relevant for decision-makers that are valid regardless of the preference for a certain perspective. The challenge is to analyse the scenarios in such a way that it enables to draw robust conclusions. In this process the notion of risk turns out to be useful, because it allows evaluating the scenarios.

In case of quantitative forecasts, we can assess how these outlooks score if we take two of the selected risk factors as indicators. These two indicators enable to define low-risk, moderate-risk and high-risk areas for the resulting two-dimensional 
space. The next step is to plot the outcomes of the set of scenarios in this two-dimensional space. The resulting picture indicates which policy options seem to be interesting to consider. On the other hand, thorough analysis of the scenarios that landed in the high-risk area may provide insights in which policy strategies may cause an undesirable future.

In this way, the scenarios can be compared and confronted. This step implies that the various scenarios (and thus images of the future) are assessed in terms of riskiness ${ }^{23}$. In Figure 6 it is illustrated how this can be done for a particular set of scenarios (e.g. scenarios associated with the same strategy) in the light of two unambiguous risk factors. Such an analysis of the scenarios in terms of risk areas can be done either qualitatively or quantitatively. The conclusion from the risk figures as shown in Figure 6 would be that the first strategy seems to be highly risky, while about the second one it is difficult to draw a similar robust conclusion. In this case, the conclusion would be that controversy about this strategy is to be expected.
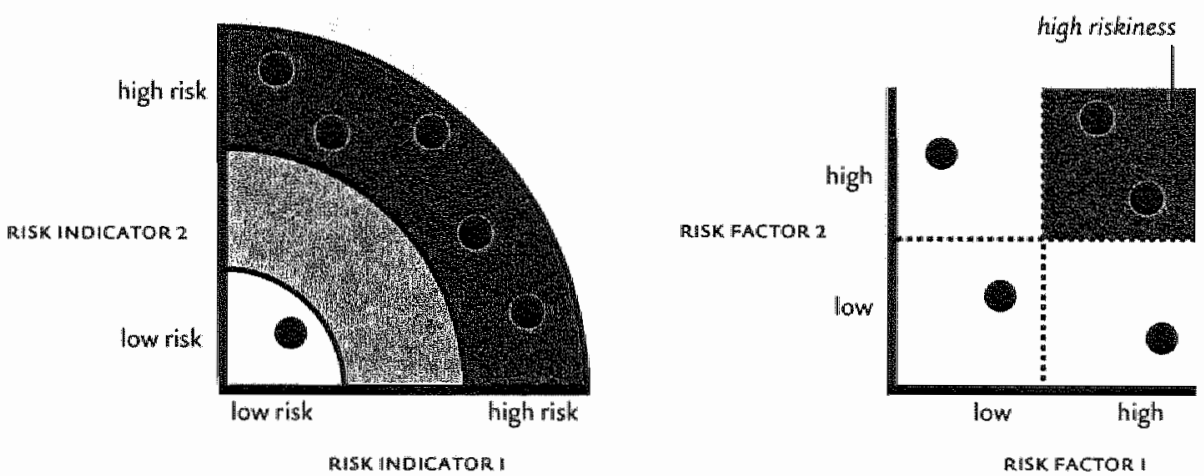

LECIEND Each bullet represents a scenario associated with a particular strategy/policy option. The bullets altogether repiresent different scenarios that perspective-based assessument of the particular strategy! policy option yields.

FGURe 6 Two ways to create risk areas signifying a set of scenarios characterised in terms of two risk in dicators

In case of more risk indicators similar exercises can be done by means of multidimensional visualisations such as the multi-star representation ${ }^{24}$ (see Figure 7) or by means of an aggregation procedure that enables to compose risk estimates pair-wise (see Figure 8$)$. 


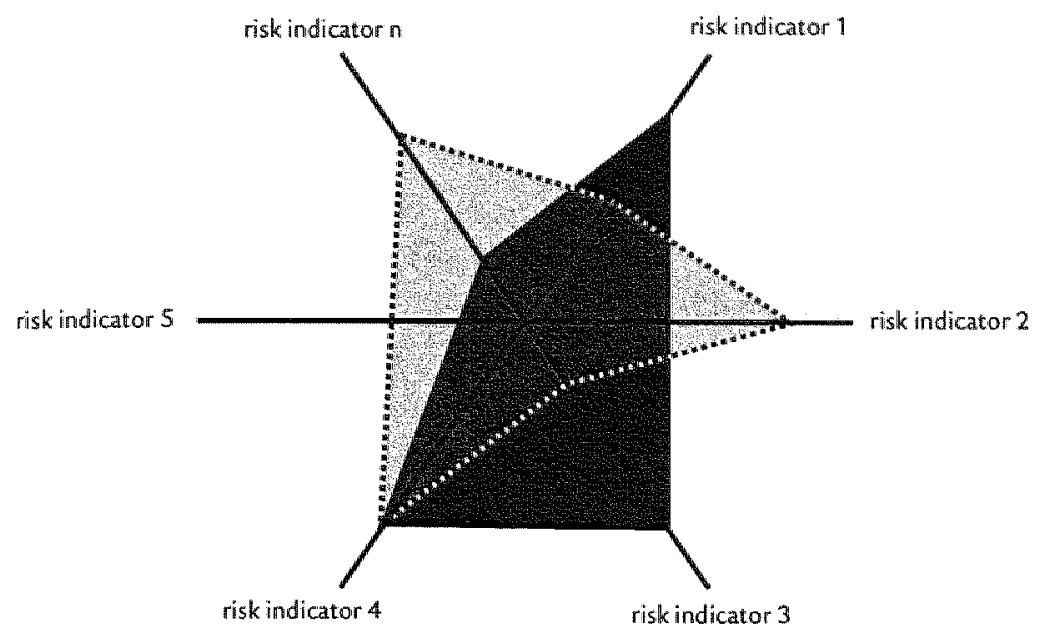

FicURE 7 Multi-star representation in which two scenarias are scored on warious risk indicators

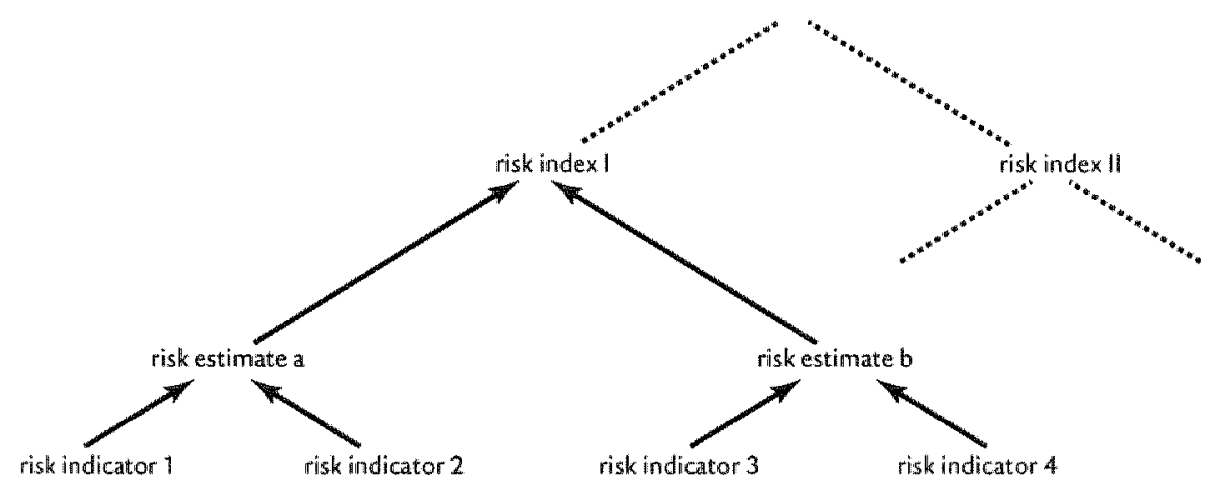

FICURE 8 AGGREGIATION PROCEDURE FOR COMPOSTE RISK ESTIMATES

By performing the assessment of risks in the above manner, it is possible to assess insights that are robust, i.e. insights that transcend the biased interpretations of uncertainty. Box I illustrates this type of insights that were derived from the integrated assessment of global change and sustainable development using the TARGETs model. This box provides examples both on the level of specific issues (i.e. population development and climate change) and on the integrated level. 
Box 1 Examples of robust insights

derived from pluralistic integrated assessment

\section{Popullation $^{25}$}

Population numbers and health status, expressed in life expectancy, are selected as the key indicators to assess population and health risks. Risk intervals are determined for both indicators, i.e.:

for population ${ }^{26}$ :

low-risk: population number below 7.7 billion people,

moderate-risk: population numbers between 7.7 billion and 12 billion people

high-risk: population numbers above 12 billion people. for human health ${ }^{27}$ :

low risk: health levels above a life-expectancy of 77 years

moderate risk: health levels with a life-expectancy between 66 and 77 years

high risk: health levels below a life expectancy of 66 years.

By implication, a future characterised by a population number below 7.7 billion with an average life-expectancy exceeding 77 years is considered a safe situation in demographic and epidemiological terms.

Analysis of Figure 10 shows that none of the utopian and dystopian futures is considered to be highly risky, although some of them are likely to enter the high-risk area in the course of the 22nd century. On the other hand, none of the management styles yields a future that would be safe in every case. The egalitarian utopia is the future closest to the desired state of the world. The analysis of dystopia and utopian experiments furthermore suggests that moderate population sizes and fairly good health are most likely where society is to a certain extent collectively 'makable', so that governing incentives might create favourable conditions. However, high population numbers are also reconcilable with an extremely good health in a market-oriented society. Figure 9 shows that the majority of countries in the future are not found in the area with deterioration of life expectancy (i.e. high-risk area with regard to health). In other words, referring to the question of whether a healthy life and popu- 
lation growth is irreconcilable, our experiments suggest that an improvement of the global life expectancy to a level comparable to the present situation in developed countries is most likely. Worth noting is that a healthy life seems reconcilable with significantly differing future population trajectories.

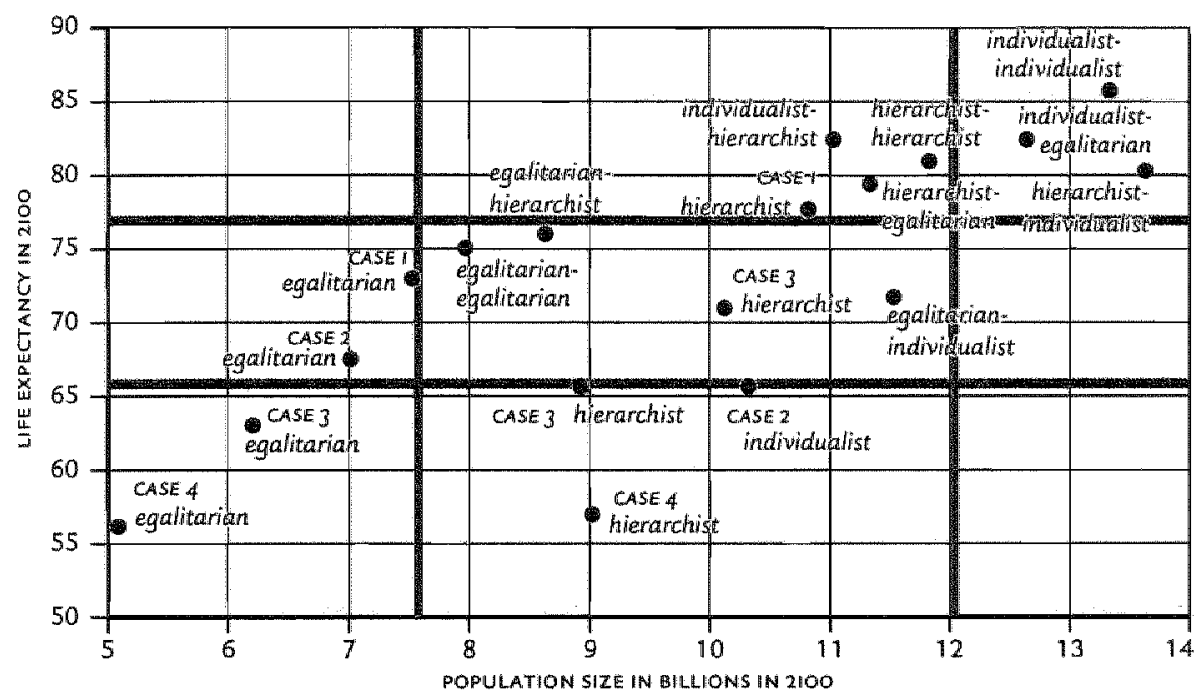

FICURE 9 Example of scenario assessment presented by means of risk areas
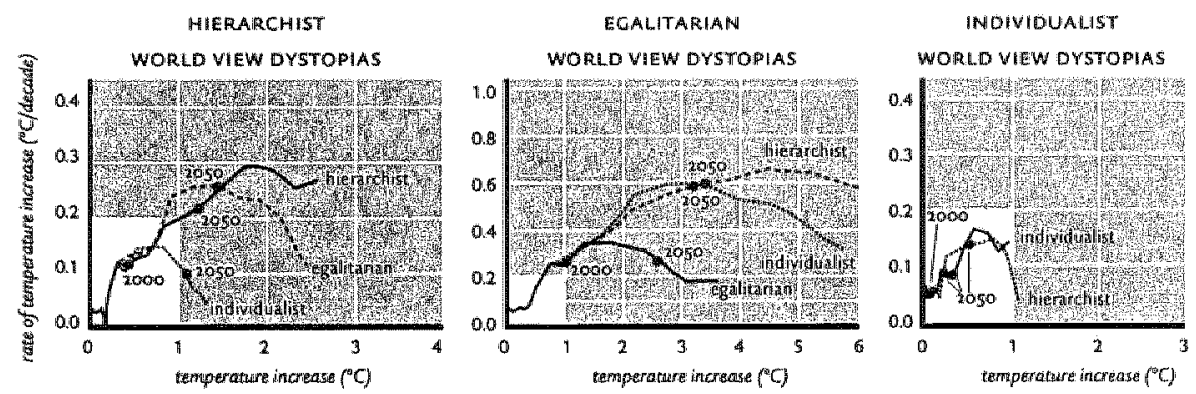

FIGURE to Simulation results presented by means of risth areas

What, in sum, do the utopian and dystopian experiments tell us with regard to the population and health controversy? A doomsday scenario featuring excessive population numbers in miserable health conditions is not very plausible. 
$\operatorname{sox} 1$

\section{Climate CHANGE ${ }^{28}$}

The outputs of the utopian experiments in terms of atmospheric $\mathrm{CO}_{2}$-concentration and temperature increase are presented in Figure to. Inspection of these graphs leads to the interesting conclusion that a high temperature increase (to about $3.5^{\circ} \mathrm{C}$ by the end of the next century) can be explained by a relatively low $\mathrm{CO}_{2}$-concentration (i.e. the egalitarian utopia). On the other hand, a concentration of $\mathrm{CO}_{2}$ in the atmosphere to about twice the present level (i.e. the individualistic projection) does not necessarily yield high temperature increases. The individualistic utopia features a temperature increase of about $1^{\circ} \mathrm{C}$ in the course of the $2 i^{\text {st }}$ century. Standard climate scenarios always show the concentration-temperature combinations low-low, middle-middle and high-high. How to explain the counter-intuitive results produced with multiple perspective-based model routes? Such an analysis of the climate controversy indicates by way of narratives how large the uncertainties are and how to understand outcomes in terms of interpretations of the underlying uncertainties. Comparing the egalitarian and individualistic utopia teaches us how crucial the uncertainties concerning amplifying and dampening feedbacks are in forecasting the future. The outcomes yield that if amplifying feedbacks dominate the biosphere-atmosphere response to initial warming signals, the absolute temperature increase will be significant, even if the $\mathrm{CO}_{2}$-emissions do not increase dramatically. On the other hand, if dampening feedbacks dominate, the future average climate will not be affected much, even by high $\mathrm{CO}_{2}$-emissions.

Another interesting observation is that it is not appropriate to consider the hierarchist as a middle-ground perspective. The utopian results with the CYCLES model show that the hierarchist is not always in the middle. The hierarchist utopia shows the highest atmospheric concentration of $\mathrm{CO}_{1}$. An explanation for this is that the hierarchist perspective is more pessimistic than the individualist concerning the development and penetration of energy-efficient technology and the market-mechanism with regard to alternative energy sources. On the other hand, the hierarchist does not expect severe life-style changes as the egalitarian perspective does. As a result the $\mathrm{CO}_{2}$ emissions, and thus the atmospheric $\mathrm{CO}_{2}$ concentration, in the hierarchist utopia are higher than in the two other utopian images of the future. 


\section{GLOBAL CHANGE AND SUSTAINABLE DEVELOPMENT ${ }^{29}$}

Some of the more illustrative dystopias are presented in Figure 11. The most catastrophic future is the one in which an egallitarian worldview is combined with an individualist management style. In this case, the world would be confronted with significant changes in the global climate and, partly as a consequence, with serious food and water shortages. Life expectancy only increases slightly compared to the present world average, and the resource base is squandered. The main conclusion is here that if policy-makers want to reduce the risks of such a catastrophic future, they should pursue an egalitarian policy that ailms at a high quality of human life (in particular health care and education for women), carbon tax, R\&D programs on renewable resources and small-scale technology, water taxing, public water supply policy, and eco-forestry and eco-agriculture policies. However, analysing the egalitarian management styles in general, it is obvious that they contain the potential risk of reducing socio-economic benefits in terms of a lesser improvement of quality of life and human health. An interesting observation is further that detrimental climate impacts are absent in a future where the world functions according to the individualistic world view and egalitarian policy measures are carried out. The counter-intuitive result means that an egalitarian government in combination with an adversative world view (that of the individualist), turns out to be more effective in terms of socio-economic and environmental prosperity than in case of the egalitarian utopia.

What kind of policy-relevant insights do the simulated utopian and dystopian futures teach us? At recent UN summits on sustainable development issues. (e.g. UNCED in Rio, 1992; the population and development summit in Cairo, 1994; the Earth Summit in New York, 1997), developed countries argued that developing countries should curb their population growth in order to reduce the world-wide environmental pressure. Expressing this pressure in the form of an anticipated climate change, our scenarios show that this dogmatic reproach is rather simpllistic. Figure 7 shows five futures where the population number exceeds 10 billion (about a doubling of the present number), while the rise of global-mean temperature is less than 2 degrees Celsius. On the other hand, however, the developing countries" argument that west-

see over

29. This assessment is derlwedt from (Rocrmans and van Asseln 1999; 2000 (in press)) which is an assessmext of the experianenty reported in (Rotmans and de Vries 1997 ). 


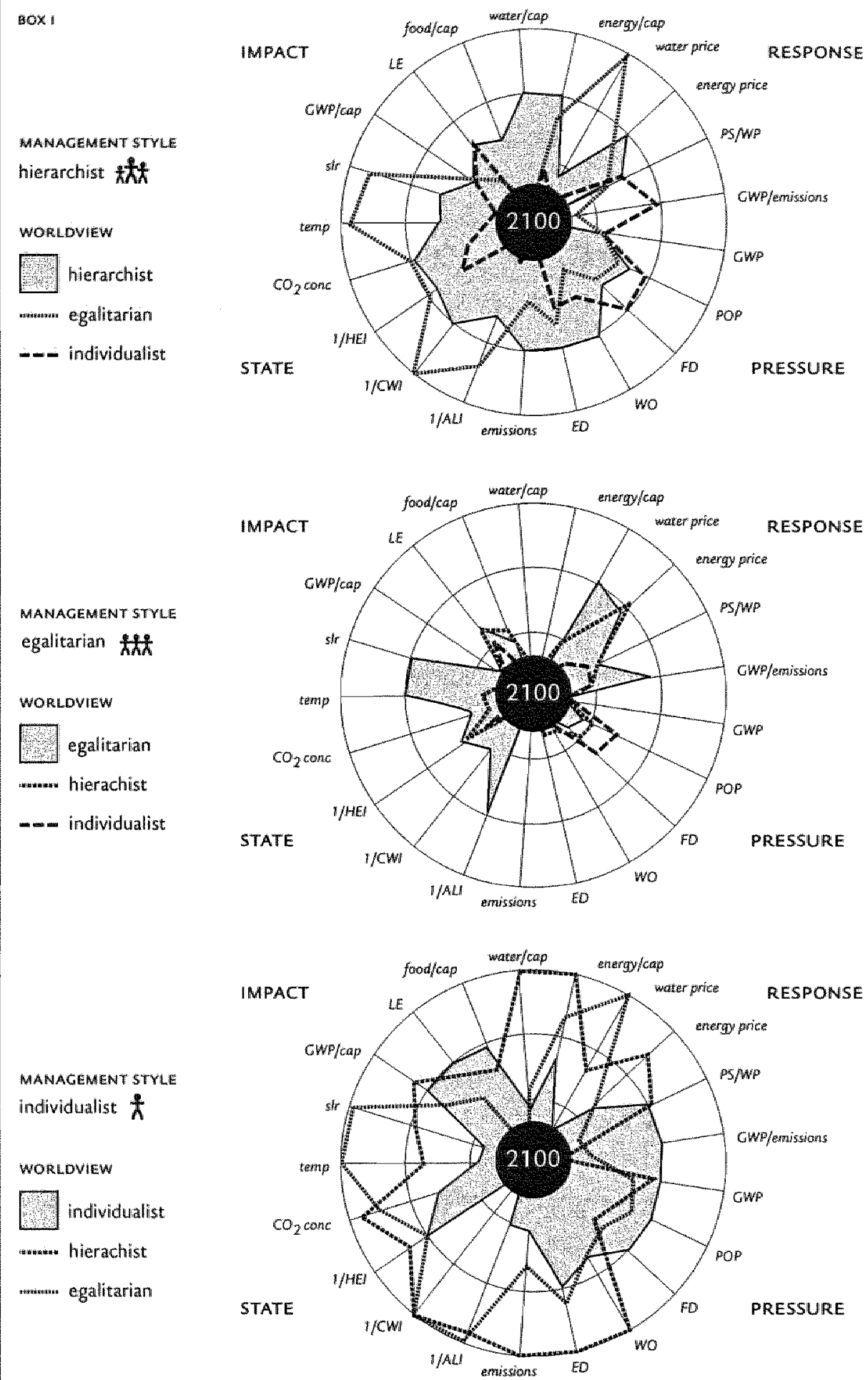

FIGURE ॥ Dystopian experiments represented by means of multi-star 
ern lifestyle of overconsumption, indulgence and dissipation will inevitably plunge the world into a climate catastrophe is also oversimplified. Analysing the whole range of scenarios, shows that a future in which high GWP levels and luxury diets are combined with small climate changes (i.e. the individualistic utopia) is as plausible as a future world that faces both an environmental and socio-economic catastrophe (i.e. the dystopia with an individualistic management style and an egalitarian world view). In sum, the way to sustainability is not simply a choice between population and consumption as it is quite often phrased in the policy makers' realm. Our assessment reveals further that:

- the individualistic management style (i.e. market-oriented health policy, market: pricing of water, high-tech R\&D programs, protection of industrial sectors, and intensive agriculture, incl. genetic engineering) is the most risky in terms of climate risks as global-mean temperature and sea level rises.

- the hierarchist management style (i.e. family planning, selective health care policy (e.g. cure), moderate R\&D programs for energy efficiency and new energy supply options, reforestation policy and agricultural planning) is least effective when evalluated in terms of improvements in resource efficiency.

- the observation that a transition to a less energy-intensive society is foreseen in the egalitarian and individualist utopia reveals that both a market-driven energy policy and a strict carbon-tax policy are potentially promising strategies to sup port such a shift. This result again underlines the importance of developing less energy-intensive technologies.

- the egalitarian management style (i.e. investments in human quality, taxing systems, R\&D programmes on new technologies, and eco-friendly policies) is the most effective in curbing population growth, although it should be noted that this is at the expense of a significant improvement in life expectancy.

The major conclusion is that a global catastrophe does not appear to be imminent. But the projections generated with the TARGETS model clearly indicate that pursuit of current trends is most unlikely to result in a sustainable future whatever the perspective is. Our major insight referring to the fundamental controversy on global change is that it seems possible to provide a future world population with more food per capita than the current level and that there are several potentials for a transition to a less energy-intensive, but healthy economy. It is most likely that the global popu- 
sox:

lation on average will live longer and healthier than today, which, however, does not mean an equitable distribution of health. The resource base is at risk, but there are many promising ways to safeguard the environment for future generations. However, there is a serious risk that water may become scarce ${ }^{30}$, even at the global level.

In sum, this assessment indicates huge potentials for rather robust policies, characterised by a balance in safeguarding natural resources, a transition towards clean and less resource-intensive technologies, while providing the world population with enough food and clean water, fulfilling the conditions for a healthy world population.

A more qualitative way to evaluate the riskiness of strategies, is to evaluate outlooks of the future in terms of the following risk questions:

- what might happen?

- how plausible?

- imaginable consequences?

- how likely?

- what can we do about it?

These risk questions can also be used to deepen the analysis in case the previous approach to risk analysis has been followed.

In the above, we have pretended as if in all cases the risk indicator can be unambiguously be determined. This may be the case in some cases, however in the majority of the cases the risk definitions differ. That means that the evaluation of desired/ undesired prospects is perspective-dependent: which scenarios seem to be most desirable and which are considered to be nightmarish is in many cases perspective-

\begin{tabular}{l|c|c|c}
$\begin{array}{c}\text { perspective } \\
\text { image of the future }\end{array}$ & Perspective A & Perspective B & Perspective N \\
\hline scenariol & ++ & + & ++ \\
\hline scenarioll & + & ++ & + \\
\hline scenario lll & - & - & $*$
\end{tabular}

LEGAEND (4+ most desirable, * desirable, - not preferred, - unacceptable)

TABLE 7 Evaluation of prospects according to perspective

30. See (Haelkstra 1998; Hoekstra et al. 1997 ) for a more extensiwe discussion of the water dimensiom of the utopian and dystopian futures. 
dependent. So pluralism may be also explicitly prevalent in this step: evaluation and weighing of the scenarios is done for different perspectives (see Table 7). The above approaches to risk analysis can then be used for each perspective to arrive at perspective-based estimates of prospects.

Using this perspective-based evaluation of the scenarios, we can assess whether there are scenarios, and thus strategies, that are to a more or less extent promising to all perspectives (in Table 7 scenario I), and which are considered to be unacceptable by the majority of them (in Table 7 scenario III). In assessing and comparing the various risk judgements, risk comparisons in terms of relative riskiness can be useful in this assessment phase (see Box 2 for appropriate risk comparisons $s^{33}$ ).

\section{BOX 2 Risk comparison schemes}

\section{- THE SAME RISK AT TWO DIFFERENT TIMES}

"The risk associated with $x$ is around $y \%$ less than $z$ years ago"

- WITH A STANDARD

"Exposure to $x$ is well below the level that anthoritative organisation $y$ considers safie".

- DIFFERENT ESTIMATES OF THE SAMIE RISIK

"Our best estimate of the risk is $x_{2}$ whereas the worst case risk estimate we have calculated is $y$, on the basis of methodology 2 we arive at estimate $z$, whereas that of organisation $A B C$ is $w^{20}$.

- THE RISK OF DOING SOMETHING VERSUS NOT DOINGIT "If measure a is implemented the risk will be $x_{2}$ whereas if not, the risk will be $y$."

- alternative policy options

"The risiks associated with option $a$ is $x$, and the risk associated with option $b$ is $y^{n \text {. }}$

- THE SAME RISK AS EXPERIENCED IN OTHER PLACES

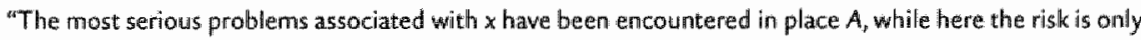
about $y$ \% from that in $A^{x}$.

- RISK FROM ONE SOURCE OF A PARTICULAR NEGATIVE EFFECT WITH THE RISK FROM ALL SOURCES OF THAT SAME ADVERSE EFFECT

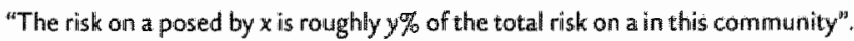


A comparison and confrontation of the various perspective-based scenarios, hence assessments of the future, enable to estimate what is possible or impossible, and what is desirable and what is not. Such an evaluation provides the basis for exploring whether insights about the complex issue can be discerned that hold in view of the different perspectives. In doing so, we can conclude whether the controversy or dilemma under concern inwolves significant risks, without adopting a specific risk definition. Risk in this case means that one or more perspectives, i.e. participants in the societal debate, are convinced that this controversy or dilemma may inhibit undesirable and unacceptable futures, and that the state-of-the-art knowledge does not allow excluding these futures.

This classification of the future outlooks in terms of risk allows us to evaluate which options and strategies seem to be most robust in terms of appearing to trigger a future that is acceptable, or even favourable, to different perspectives and in terms of avoiding those that one or more perspectives consider to be highly undesirable (see Figure 12 ). In this way, robust recommendations can be deduced. In the hypothetical outcome illustrated in Figure 12, decision 3 would be considered to be the most robust decision in view of the uncertainties and risks considered, while decision $\mathrm{I}$ is the most controversial considering the spread of riskiness estimates. In the latter case, controversy and disagreement is to be expected.

\begin{tabular}{|c|c|c|c|c|c|c|}
\hline \multicolumn{7}{|c|}{ policy option/strategy } \\
\hline & Low risk & & & & & high risk: \\
\hline decision ! & 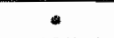 & & • & & $\cdot$ & $*$ \\
\hline decision 2 & & 0.0 & 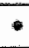 & & & \\
\hline decision 3 & 0 & & - & & & \\
\hline decision 4 & & & & $\because$ & 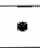 & 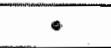 \\
\hline deciston 5 & & 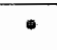 & - & - & $\bullet$ & \\
\hline
\end{tabular}

HEGEND Each bullet represents a scenario inwolving the particular decision

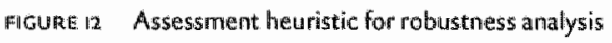

Another feature of robustmess is that the recommended strategies and options are flexible enough to be changed or reversed if new insights emerge. For this reason it is important which uncertain, but imaginable, developments potentially could undermine the effectiveness and adequacy of the proposed strategies and options. In other words, which signals will in the future make evident that we have to adapt the chosen strategy? This analysis will yield the salient uncertainties from a decision-makers viewpoint. It will indicate which uncertainties constitute policy 
risks. In this way, the value of uncertainty is made tangible to decision-makers. Some uncertainties will be resolved through time. An assessment in the way as sketched in this Chapter enables to indicate by which actual development it is necessary to adapt the chosen strategy. In doing so, the integrated uncertainty management and risk assessment can yield signals for sequential decision-making.

Central in this step is to explore how easy or how difficult it will be to change the proposed strategies. Robustness thus implies an evaluation of the flexible character of the recommended options and strategies. The consequence of this analysis will be that notwithstanding the recognised promises, some strategies are rejected, while others are transformed. Furthermore, the assessment of options and strategies may result in the creation of innovative strategies and options not considered so far. In order to test the robustness of these transformed and newly broad up strategies, it is necessary to test these against the possible futures. This implies a focused iteration of the previous steps.

The idea is that by means of putting uncertainties, scenarios and risks in perspective, robust insights pertaining to the formulated dilemma or controversy can be deduced. The outcomes associated with this last stage are different types of robust recommendations that are sensible and understandable to decision-makers. The following types of recommendations are imagined:

- strategy $x$ is more robust than strategy $y$, in the sense that it scores lower on more risk indicators

- strategy $x$ seems to be a robust way to reach policy target $a$

- the most risky future (i.e. the most undesired scenario) associated with strategy $x$ is a future in which ..., while the least risky future (i.e. the most acceptable scenario) is...

- a future in which ... is highlly impossible (i.e. outlooks beyond the variety of scenarios)

- compared to doing nothing strategy $x$ decreases/increases the risk of ...

- policy option 1 seems to be most effective (i.e. least risky) if accompanied by the following policy options.../embedded in the following strategy ...

- combining policy option $I$ with policy option 2 increases/decreases the risk of ...

- the following uncertain issues are crucial in addressing the controversy/ dilemma: ...

As the above list indicates, there are different ways to robustness. In case of agreement, i.e. the various valuations of the strategy result in a rather unequivocal opinion about the riskiness of the strategy, the robust conclusion involves a 
recommendation in terms of a recommendable strategy or a strategy that should be excluded from consideration. In case of disagreement, i.e. the riskiness estimates cover the whole range, the robust conclusion involves a kind of warning: this particular strategy is likely to involve a clash of opinions. The advantage of the integrated analysis is that it may enable to focus the debate by indicating what are the salient uncertainties and what are the key risk dimensions associated with this strategy. Analysis of the outlooks may also yield signals for decision-making. It should be noted that such an assessment is not a trick. The ideas presented in this Chapter enable to structure a creative process. The framework cannot guarantee the actual quality of the recommendations. The quality of the recommendations is heavily dependent on the quality of the people of involved (i.e. they should be able to use the framework for focussing and utilising their brainpower) and the actual process $^{33}$.

The major advantage of pluralistic integrated uncertainty management and risk analysis is that the level of robustness of the recommendations can be motivated, due to the comprehensiveness of the analysis, i.e. considering salient uncertainties and a wide variety of legitimate interpretations of the uncertainties which assessments are evaluated against different risk factors.

\section{Quality assessment}

Quality assurance ${ }^{35}$ is central to integrated uncertainty management and risk analysis. To that end, it is necessary to re-analyse the recommendations. It is important to check again wherher the crucial uncertainties and the critical risk factors pertaining to the recommendations have been adequately considered in the assessment process. It may be possible that uncertainties or risk factors that did not seem crucial in considering the broader complex issue are crucial now we have come down to particular conclusions. If such critical uncertainties or risk factors are discerned, it is important to test the recommendation against these uncertainties and risk factors. This can be done by a quick iteration of the assessment process. This procedure implies testing if uncertainty was treated adequately, or whether there are crucial uncertainties or risk factors, known or imaginable, which are undermining the robustness of the recommendations. 
In view of quality assurance, it is furthermore important that the assessment does not stop with recommendations for decision-making. Transparency about the analytical and methodological quality of the assessment is needed in order to allow clients themselves to make an informed judgement about the quality of the assessment. Building upon Chapter 2, it would therefore be recommendable to accompany the conclusions with a summary containing a review of the credibility of the data sources, the disciplinary quality of the used knowledge elements, the degree of interdisciplinarity of the assessment process, incl. the level of collaboration with disciplinary experts, and the level of participation ${ }^{34}$. For the first two issues the pedigree-qualifications proposed by Funtowicz and Ravet ${ }^{35}$ can be used (see Table 8).

\begin{tabular}{c|c|l|c} 
code & quality of model/fheoretical structure & quality of daca & deguree of peer acceptance \\
\hline 4 & Established theory & Experimental data & Total \\
\hline 3 & Theoretical model & Historicalfield data & High \\
\hline 2 & Computational model & Calculated data & Medium \\
\hline I & Statistical processing & Educared guesses & Low \\
\hline 0 & Definitions & Uneducated guesses & None
\end{tabular}

TABLE 8 Pedigree matrix

In summarising the other issues the following questions can be useful:

- who were involved and how were they selected?

- at what phases in the process and with what intensity?

- what has been done with the input of interdisciplinary experts and nonacademic participants?

- do they recognise themselves in the assessment?

The responsible investigators can do such an assessment of the quality ${ }^{36}$ of the process of integrated uncertainty management and risk analysis. However, it is advisable to involve peers or even an extended peer community in this effort. The output of this quality assessment involves qualified recommendations, i.e. recommendations of which the clients can also trace the robustness.

Apart from recommendations that aim to facilitate decision-support, it is advisable to explore what scientific insights can be deduced from the integrated uncer-

\footnotetext{
34 See (Rotmans and wan Asselt, 2000 (in press)) in which we report a first artempe ro pertorm such a quality assessment as the fnal step if ine Assessment process.

35 (Funtowicz and Raverz 1990 ), See also Chapter 3 A for a stumilnary of these ped hree quallification:

36 Cormpare Chapter 2.
} 
tainty management and risk analysis. Which salient risky uncertainties and uncertain risks would benefit from additional scientific research? In this way, the assessment can be used to set priorities for disciplinary and interdisciplinary research. This is also relevant in view of the robustness of decision-making, because it enables scientists to anticipate on uncertain risks and risky uncertainties that are crucial for future decision-making. Research always takes time. The consequence is that if research is initiated at the moment a controversy or dilemma is a topicality, it is to be expected that either time pressure corrupts the research results, or that the results arrive too late, which make them irrelevant to decision-making. Integrated uncertainty management and risk analysis can provide a basis for systematically anticipating furure controversies and decision-makers' dilemmas. The proposed approach to decision-support can be considered as an attempt to escape the time-quality wringer that constitutes a serious threat to the viability of (supply-driven) decision-support. Integrated uncertainty management and risk analysis can therefore also be considered an investment both in the future analytical and methodological quality by creating a time-span for research, and in the usability and timeliness of future supplydriven decision-support. In this way, supply-driven. Integrated Assessment would systematically build on lessons learned. 


\section{Conclusions}

Compared with the analytical steps that are considered to be essential in Integrated Assessment (see Chapter 2), it can be concluded that the above framework for pluralistic integrated uncertainty management and risk analysis provides a methodology for performing the following activities:

- selection of salient uncertainties and policy risks

- trend analysis and evaluation

- assessment of options for decision-making

Integrated uncertainty management and risk analysis is thus not a full Integrated Assessment. On the other hand, the above comparison implies that in principle the generic framework as presented above can be added to the IA toolkit.

In the previous Chapter the requirements for an integrated approach to uncertainty management and risk analysis have been studied. Building upon this analysis, a generic pluralistic framework was proposed in this Chapter. In this framework new ideas were blended with steps associated with uncertainty management and those comprised in risk analysis. As this framework complies with the hypotheses that are theoretically tested in the first part of this thesis, the proposed framework for integrated uncertainty management and risk analysis is theoretically sound. It was attempted to be as concrete as possible in describing the various steps by indicating how concepts, tools and methods can be used to implement the framework into actual decision-support.

The observed pluralism about pluralism and the state of the art in social sciences prevent that pluralistic assessment is a straightforward exercise. Due to the essential differences between the different perspectives on pluralism, it is fundamentally impossible to arrive at one set of perspectives that can be used by all pluralistic endeavours. Furthermore, the state of the art does not offer an extensive overview of the various paradigms prevalent within the science. There is no accepted typology of social-cultural perspectives. Nor is a specific method available that enables to derive perspectives from a participatory process in a systematic manner, and there is neither a categorising of societal interaction patterns that is in accordance with empirical analysis of societal interaction patterns pertaining to uncertainty and risk $^{37}$. So neither a particular set of perspectives for each of the pluralistic schools of

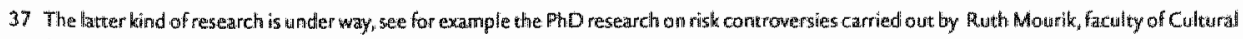
Sciences Uniwersity of Mastricht. 
thought, nor general methods to yield them can be recommended. This implies that any pluralistic approach is vulnerable, because of the inevitable lacked credibility of any perspective scheme used. Hopefully, this problem will be resolved in the course of time due to advancements in social sciences in general and in social studies of science in particular.

On the other hand, in view of the shared disapproval of positivism, every pluralistic endeavour whatever the level of sophistication, deserves credit. The consequence of recognising that uncertainty and risk are inevitably pluralistic is that it became our duty to put the notion of pluralism into practice. The first steps have been designing a generic framework for pluralistic integrated uncertainty management and risk analysis, and proposing warious legitimate and appropriate ways to apply this generic framework in a way internally consistent with the different perspectives on pluralism. The next step is to test and apply this theoretically sound methodology into actual decision-support.

From the description of the generic framework for integrated uncertainty management and risk analysis, it is clear that it is a demanding and time-consuming effort, even in case the most pragmatic route is chosen. We are convinced that it is worthwhile to invest intelligence, effort and time. First, because it is consistent to perform scientific decision-support in a way that is epistemologically right and thereby more valid. And second, because evaluated from a scientist perspective it in principal enables to improve the quality of decision-support. Radical uncertainty and strategic risk constitute the leitmotiv of the proposed framework. Due to this feature, the pluralistic framework for integrated uncertainty management and risk analysis in principle seems promising for decision-support on complex issues. 


\section{REFERENCES CHAPTER 5}

- Casti, ). L. (1997). Would-be worlds: How simulation is changing the frontiers of science, john Wiley \& Sons, New York, USA

- Cohen, J. E. (1995). How Many People Can the Earth Support?, W.W. Norton \& Company "New York, USA

- de Meere, F. (1996). You can go sleeping...: Ideas about technalogy, risk and society (in Dutch), Eburon, Delft, the Netherlands.

- den Elzen, M. G. J., Beusen, A. H. W, Rotmans, J, ard van Asselt, M. B. A. (1997), "Human disturbance of the global biogeochemical cycles." Perspectives on Clobal Change: The TARGiETS approach, J. Rotmans and B. de Vries, eds., Cambridge University Press, Cambridge, UK

- Funtowicz, S. O, and Ravetz, J. R. (1990). Uncertainty and quality in science for policy; Kluwer, Dordrecht, the Netherlands

- Hilderink, H. B. M., and van Asselt, M. B. A. (1997). "Population and Health in Perspective," Perspectives an Global Change: The TARGETS approach, J. Rotmans and H. J. M. de Wries, eds., Cambridge Uniwersity Press, Cambridge, UK

- Haekstra, A. Y. (1998). Perspectives on Water: An integrated model-based explaration of the future, International Books, Utrecht, the Netherlands

- Hoekstra, A. Y, Beusen, A. H. W., Hilderink, H. B. M., and van Asselt, M. B. A. (1997). "Water in crisis?" Perspectives on Global Change: The TARGETS approach, J. Rotmans and H.J. M. de Vries, eds., Cambridge University Press, Cambridge, UK

- Hoppe, R. (1998). Effective Policy Documents: A guide for successful decision support (in Dutch), Coutinho, Bussum, the Netherlands

- ICIS. (1999). "The Thinkmodel for POL (in Duteh).", ICIS, Maastricht

- Janssen, M., and de Vries, B. (1998). "The Battle of Perspectives: a Multi-agent Model with Adaptive Responses to Climate Change." Ecological Econamics, 43-65

- Molenaers, N., and Thompson, M. (1999). "The Cultural Conditions for Democracy and Their Implications for Transitional Societies." Cultural Theory as Political Science, M. Thompson, G. Grendstad, and P. Selle, eds., Routledge, Londan, UK

- Morgan, M. G., and Keith, D. W. (1995). "Subjectiwe Judgments by Climate Experts." Environmental Science and Technology, 29(10), 468-476

- Nordhaus, W. D. (1994), "Expert Opinion on Climate Change." American Scientist, 82, $45-51$

- Rotmans, J. (1997a). "Indicators, for Sustainable Development." Perspectives on Global Change: The TARGETS approach, J. Rotmans and H. J. M. de Vries, eds. Cambridge University Press, Cambridge, UK

- Rotmans, J. (1997b). "Integrated Wisions for a Sustainable Europe: An Integrated Assessment proposal.", Europeam Union, DC XII, Work Programme Environment and Climate (second phase); Brussels, Belgium

- Rotrnans, J. (1998). "Integrated thinking and acting a necessary good (in Dutch).", ICIS, Maastricht, the Netherllands

- Rotmans, J., and de Wries, H. J. M. (eds.). (1997). Perspectives on Global Change: The TARGETS approach, Cambridge Uniwersity Press, Cambridge, UK

- Rotrnans, I. and van Assselt, M. B. A. (1999). "Pepspectives on a Sustainable Future." International fournal for Sustainable Dewelopment, $1(3)$

- Rotmans, ), and van Asselt, M. B. A. (2000 (in press)), "Integrated Assessment: Current Practises and Challenges for the Future." Ecological Economics and Integrated Assessment: A participatory process for including equity, efficiency and scale in decisionmaking for sustaimability, R. Constanza and S. Tognetti, eds.y SCOPE, Paris, France

- Rotmans, J., wan Asselt, M. B. A., Peters, S., and Mellors, J. (1999). "WISIONS Progress Report." "KCIS, Maastricht

- Schwarz, M., and Thompson, M. (1990). Divided We Stand: Redefining Politics, Technology and Social Choice, Harvester Wheatsheaf, New York, USA 
- UNFPA. (1996). "World Population Report." "New York, USA

- van Ascelt, M. B. A, and Rotrians I) (1995). "Uncertainty in Integrated Assessment Modelling: A Cultural Perspec" twe-based Approach." RVM-report no. 461502009, National Institute of Public Health and the Environment ( $\mathrm{R}$ W WM), the Netherlands, Bilthower

- van Asselt, M. B. A., and Rotmans, ). (1996). "Uncertainty in Perspective." Global Environmental Change, 6(2), $121-157$

- van Asselt, M. B. A And Rotmans, l. (1997). "Uncertainties in perspective." Perspectives cn Global Change: the TARGETS approachy. Rotmans and B. de Wries, eds., Cambridge University Press, Cambridge, UK

- van Asselt, M. B. A., Storms, C. A. H. M., Rijkens.Klomp, N., and Rotmans, I. (1998), "Towards Visions for a Sustalinable Europe: An averview and assessment of the last decade of European scenario studies." 198-E001, $1 \mathrm{CIS}$, Mastricht, the Netheriands

- van Heffen, O, Masssen, P., and Rip, A. (1999), Social science: From design practise to design methodology, Twente University Press, Ensichede, The Netherlands. 


\section{Exploring the need for PRIMA} a case-study approach

The primary aim of this thesis is to propose a new approach to decision-support that is practically feasible as well as theoretically sound. We therefore want to explore in a real-life context whether the PRIm framework, outlined and theoretically underpinned in the previous part of this thesis, has something to offer to the practise of Integrated Assessment. The aim of this practical test is twofold. First, we want to evaluate whether there is a potential need for a new or complementary approach to uncertainty management amongst practitioners. To that end, it is proposed to perform a retrospective case study involving previous decision-support on complex issues. Second, we want to explore the potential added value of the proposed approach compared to present assessment strategies for decision-support. Therefore, the retrospective analysis will be followed by a prospective studly that enables to explore the practical feasibility of the Pruma-approach in a real life context. To do so, it is necessary to set up a mutual learning process, in which we, together with the analysts, explore whether and how the PrImA-approach is applicable in actual decisionsupport on complex issues.

\section{Selection of the case}

The ideal case is a decision-support practice that involves a series of comparable assessments produced on an ongoing, structural basis. Such a case would enable to carry out a retrospective analysis and explore the feasibility of the PR IMA-approach in the current assessment. An important pre-condition is that the analysts and the institute performing the assessments are interested in working with us. In the con- 
text of the present thesis, a decision-support endeavour that is explicitly meant to be an integrated assessment would be preferred as a case.

As argued in Chapter 2, Integrated Assessment is one of the more recent approaches to decision-support. That implies that it is not to be expected that an abundance of potential cases satisfies the above conditions. Taking the above into consideration, cases that can be thought of are, for example, the climate assessments of the Intergovermmental Panel of Climate Change (IPCC) and the Environmental Outooks produced by the Dutch National Institute of Public Health and the Environment (R rVM). The r cc process is very complex, involving many high-level scienlists who are spread all around the globe. In principle it would have been possible to carry out a case study on the previous IPCC assessments. However, it would have been clearly beyond the scope and the ambitions of this thesis to set up a mutual learning process with the IPCC, or even wich one of the IPCC working groups.

A case study on the Dutch Emvironmental Outlooks seems appropriate and more feasible. R IVM is considered to be one of the pioneering institutes in Integrated Assessment, and the institute characterises its work as being Integrated Assessment. The National Environmental Outlooks aim to be integrated assessments of the future with the explicit purpose to inform and support Dutch environmental. policy-making. Approximately every four years, wivm presents such a long-term assessment of the environment to the Dutch government. Since 1996 , R rvm is by law appointed to serve as the Environmental Planning Agency, and the production of the Environmental Outlook is one of the official structural tasks RIv has to fulfil. The first Envirommental Outlook was published in 1988 . Rrvm is curently preparing the fifth National Environmental Outlook that will be published in the course of 2000 .

The Environmental Outlooks aim to provide an assessment of the environmen. tal and health impacts in the Netherlands associated with the future state of the environment that results of a particular development of societal pressures in terms of economic growth, demographic developments, and consumption and production patrerns. Rrvm attempts to anticipate future developments in order to provide recommendations for environmental policy. The issue addressed in the Environmental Outlooks is complex ${ }^{2}$, due to the fact that not one problem is addressed, but a tangled web of related issues, multiple dimensions are involved - both environmental, economic, socio-cultural and institutional factors and processes matter - and che under lying processes interact on various scale levels and on different temporal scales. 
Taking this complex character into account, it is certain that uncertainty pertains to the assessment. This feature combined with the explicit policy support purpose of the Environmental Outlooks makes these Rrvm assessments an interesting case in the light of our objectives.

RIvM is considered to be one of the cradles of Integrated Assessment. Jan Rotmans developed the pioneering Integrated Assessment model for climate change, IMAGE, at RIVM. The IMAGE model is still further developed and maintained by

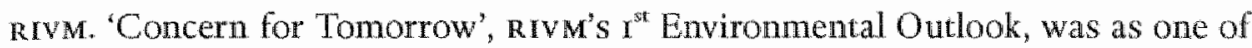
the first integrated environmental assessments in Europe that actually informed decision-makers. The Environmental Outlooks served as an example for the Global Environmental Outlook (GEO), produced under auspices of the United Nations Environment Progranme (UNEP) ${ }^{3}$. Rivm played an important supportive role in both GEO-I and GEO-2. Also the European Environmental Assessments produced by the European Environment Agency were inspired by r rv $\mathrm{M}^{\prime} \mathrm{s}$ assessment template. Rrvm's Environmental Outlooks fulfilled a model function in integrative decisionsupport. Because of this, the case study on the Environmental Outlooks is likely to yield insights relevant to other decision-support agencies as well.

The Environmental Outlooks constitute a series of integrated assessments that in principal allows for both a retrospective case study and a prospective analysis. The latter then would involve testing the PRIMA-approach interactively in the ongoing $5^{\text {th }}$ Environmental Outlook process. Last, but certainly not least, Rrvm's management had an expressed, but cautious interest in exploring alternative approaches for dealing with uncertainty in their assessment practise ${ }^{5}$. As said before, such an a priori interest in co-operation is a necessary pre-condition for testing the PRIMA-approach in the practise of decision support.

In line with the above considerations, we decided to carry out a multiple-case study on the Dutch Environmental Outlooks produced by RIV m. In this case study we want to analyse how uncertainty is managed in the previous environmental assessments (vertical analysis) and whether, and if so how, the approach to uncertainty has changed over time (horizontal analysis). In general, case studies are the preferred strategy if 'how' and/or 'why' questions are being asked about a contem-

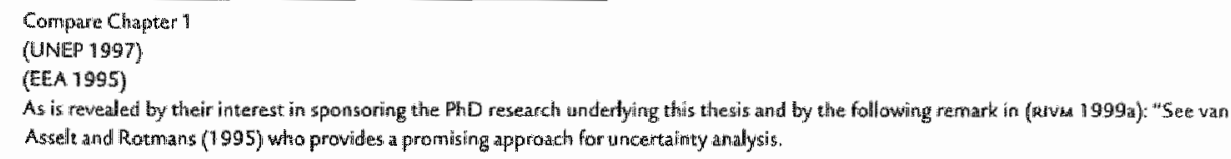


porary case over which the investigator has little or no control ${ }^{6}$. Building upon this retrospective, empirical analysis, we would like to explore whether there is a need for an alternative approach to uncertaincy management.

The aim of the prospective phase is to apply the PRIMA-approach in the practise of the $5^{\text {th }}$ Environmental Outlook. The aim of this phase is to explore together with the practitioners in an interactive manner whether the PRIMA approach can be of their use. Rrym did not commit itself beforehand to adopt the approach, bur it was willing to experiment with it as parc of their internal learning process. In this phase, we are not primarily observing and analysing. In a certain way, it acts as a kind of change agent? The major questions that are to be addressed in this phase are whether the PRIMA-approach is practically feasible, and whether, and in what way, it is considered to be useful by the practitioners.

The ultimate aim of the Environmental Outlook case is to analytically generalise from the case-specific conclusions to general recommendations concerning the practical feasibility of the PRIMA-approach as a new methodology for Integrated Assessment.

In this Chapter we will concentrate on the retrospective research. To that end, we will first introduce both Rivm and the Environmental Outlooks in some more detail than has been done so far to provide a sound description of the research context and subject. In the second part of this Chapter, the research methodology is described. The actual case study is reported in Chapter 7.

\section{RIVM $^{8}$}

Rıvm, the National Institute for Public Health and the Environment, is both a researche institute and a governmental planning agency that has the task of supplying the Dutch government with the information it requires for its health and environmental policies. Rrvm characterises its activities with the one-liner "research for human and the environment". Science and research lie at the heart of all Rrvm's activities. Rrvm aims to channel its expertise into different phases of environmental and health policy: alerting, controlling and consolidating. Eighty percent of its research concerns both structural and ad-hoc advise and reporting to the Dutch government.

\footnotetext{
Nin 1994 .

Sise Chapter 1 on the dopted researdi perspective

3. This section butds upon (wan Asten 2000). Major documents on rava used in the following description are: (Wan Zon 1990) and the most

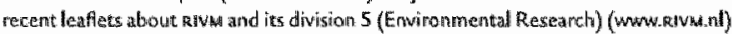


Its alerting task implies that nrvm initiates research on topics that may become important in the future. The latter type of research involves twenty percent of its budiget.

RIyM has a history that traces back to July roog, when the Central Laboratory for Public Health was set up. This laboratory came under the Ministry of Internal Affairs. Its aim was to perform policy-relevant research on public health. In the early days, 13 people were working in this nationall lab. Rrvm as it currently exists is the result of a history of mergers. In 1934 the Central Laboratory for Public Health merged with the Public Serological Institute into the National Institute for Public Health (Rrv). This was not a big step in practice, because the two institutes were already located on the same area in Utrecht. The new institute counted about 75 employees. In the 50's, a new building was realised with help of the Marshallplan, in Bilthoven, where Rrvm is still located. After 1950 the number of staff increased rapidly. In December $195^{\circ}$, Rrv) employed 200 people, in 1957 this number was more then doubled to 500 . In October 1965 the $1000^{\text {th }}$ employee was welcomed. In 1984 , RIV) merged with the Institute of Waste research (IVA) and the Public Institute for Water Supply (RID) into the National Institute for Public Health and the Environment (Rrvm). At the time of the merger, the institute employed about rnoo people. The institute came under the Ministry of Welfare, Public Health and Culture (w vc), but it had the explicit duty to carry out research for the Ministry of Regional Planning and the Environment (wrom). At the moment, Rrvm has about 7 oo employees.

Because we focus on RIvM's environmental research and services, it is interesting to explore how RIM became the governmental institute on the environment. The Central Laboratory for Public Health was a medical laboratory. However, apart from strict medical research, from the beginning on questions were addressed that nowadays would be characterised as environmental pollution issues, such as the health risks associated with water pollution due to industrial wastewater, and the quality of surface water in relation to swimming. The Serological Institute involved investigating samples of patients, control of food and medical drugs, and studies on the bacteriological pollution of water and air. In the Institute for Public Health that resulted out of the merger of these two institutes, the chemical-pharmaceutical department had the explicit task to estimate residues of insecticides and pesticides in relation to environmental pollution. In the late 30 , this research activity evolved into a research programme on the pollution of soil, air and surface water, although with emphasis on surface water. 
Where RIvm"s precursor in the pre-war period, during the Second World War and the early post-war period suffered from crisis, budget cuts and shortage of staff, after the 1950 ample resources were available. In addition the research attitude changed. The research activities became increasingly multidisciplinary and the attitude got increasingly society-oriented. In 1955, a separate laboratory within RIV for environmental research was established, i.e. the laboratory for research on soil, air and water. In the late sixties the political emphasis, both nationally and internationally, shifted to environmental pollution. As a response, RIV's board of directors argued that a coherent programme was needed to enable a systematic protection of the soil, water and air against microbiological, chemical and physical pollution. So far, research on the environment was carried out in the context of public health research. In the late sixties and the early seventies, environmental research got a more autonomous position within the institute. In this context, the institute formulated three decision-support instruments it aimed to develop: i) an overview of the type and degree of the pollution, ii) a continuous monitoring of pollution sources, and iii) an integrated approach to environmental pollution in the short and long term. "To that end, measuring nets were issued, with an emphasis on the registration of water and air pollution. The establishment of the Public Institute for Public Health and the Environment by Royal Decree marked the evolution the institute has gone through.

Since 1984 , it has been the explicit duty of RIV M to collect environmental data, to conduct research on the quality of the environment, and to inform the Dutch government. Rrvm's task is to identify and assess the state of the environment, the underlying processes, and the expected development of the environment, both in the short and in the long term. The furst Environmental Outook, i.e. 'Concern for Tomorrow', is considered to be a milestone in the realisation of RrVM's environmental mission. This I Environmental Outlook served as the scientific basis for the first. National Environmental Policy Plan (NMP), which appeared in 1989 ". Since 'Concern for 'Tomorrow', the Environmental Outlooks play a key role in Dutch environmental policy-making.

Since the publication of 'Concern for Tomorrow', RIvM was in the political practise considered as the governmental environmental institute, the counterpart of the Central Economic Planning Agency (CPB) and the Social-cultural Planning 
Agency (SCP). In 1996, RIVM got the legal status of environmental planning agency ${ }^{10}$, i.e. being the official governmental decision-support institute on environmental policy. One task assigned to Rrym in this capacity is the production of the National Environmental Outlooks in a four years cycle. Under ordinary circumstances, this means that each government receives one Environmental Outlook during their reigning period. Besides, RIVM produces every year an Environmental Account (in Dutch: Milieubalans). The Enwironmental Outlook is a long-term environmental assessment, while the Environmental Account is a detailed description of the current state-of-the-environment. While the Environmental Outlook serves as input to strategic policy-making, the Environmental Account has an evaluative aim. A recent development is that Rrvm is also responsible for the Nature Outlook (in Dutch: Natuurverkenningen)

At the moment 320 employees work in the environmental division, which comprises eight sectors. In Figure $\mathrm{r}$, the current organisation structure is provided. The department 'Environmental Assessment' (MNV) co-ordinates the environmental assessment activities, including the Environmental Outlooks, while the following laboratories are contributing to the analyses: the Laboratory for Waste Materials and Emissions (LAE), Soil and Groundwater Research Laboratory (LBG), Laboratory for Water and Drinking Water Research (LWD), Laboratory for Eco-toxicology (ECO), Department for Environmental Information Systems (CIM), Laboratory of Exposure Assessment and Environmental Epidemiology (LBM), Air Research Laboratory (LLO), Laboratory for Radiation Research (Lso), Centre for Substances and Risk Assessment (CSR), Laboratory for Health Effects Research (LEo), and Inspectorate Research and Environmental Incident Services (IEM).

In the beginning, the Central Laboratory conducted researches for both governmental organisations and non governmental organisations, in that time especially medical organisations, hospitals or individual doctors. Nowadays, Rrvm only serves the government, especially the ministries of vrom (Housing, Physical Planning and Enviromment) and of wrc (Welfare, Public Health and Culture) and it supports international organisations such as who (World Health Organisation), EU (European Union), UN (United Nations with special attention for the United Nations Environmental Programme (UNEP) and UNICEF) and the World Bank. Rrvm"s research activities have always extended beyond the national borders; people from RIVM actively participate in international research communities.

10. In Dutzin? Mffietplunbureaw 


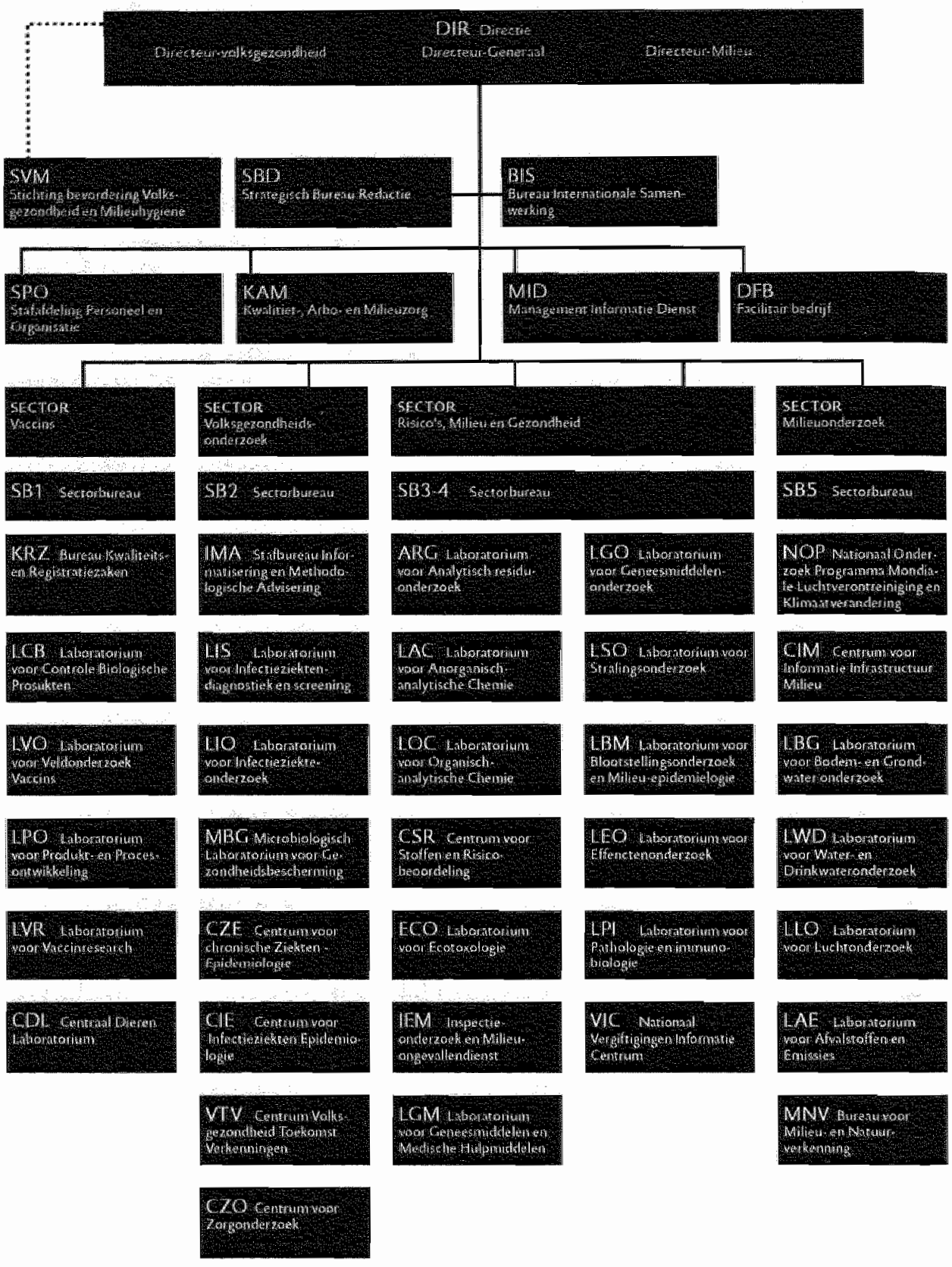

FICURE , Organisation structure of RIVM 


\section{Rivm's Environmental Outlooks}

The first Environmental Outlook was published in 1988 and was named 'Concern for Tomorrow". Its main message was: "the environment is getting worse at all scale levels despite all the efforts". This was a shock for the Dutch politicians, but also for society as a whole. In 199r, the second assessment, i.e. the 'Environmental Outlook 2 1990-2010 ${ }^{\prime 12}$ was produced, which is primarily an update of the first one: prior to the second national environmental policy plan, the government asked R rv $\mathrm{m}$ to produce a new environmental outlook that assessed the proposed environmental policies. The third Environmental Outlook ${ }^{13}$, published in 1994 , indicated the effectiveness of policy plans in relation to the environmental quality objectives as formulated in the first Environmental Policy Plan. The most actual Environmental Outlook, i.e. the 'Environmental Outlook $41997-2020^{\text {"14 }}$, was produced in 1997. Rrvm is currently preparing the fifth National Environmental Outlook, which will appear in the course of 2000 .

The aim of a National Environmental Outlook (NEO) is to provide an assessment of the environmental and health impacts in the Netherlands associated with the future state of the environment that results of a particular evolving of societal pressures in terms of economic growth, demographic developments, and changes in consumption and production patterns. An Environmental Outlook thus describes the cause-effect chains relevant to environmental change. It furthermore involves evaluation of adopted and proposed Dutch environmental policies. With the Environmental Outlook, RIVM attempts to anticipate future developments in order to provide recommendations for policy. One of its aims is to evaluate whether the future environmental targets can be reached by the current policy. The Environmental Outlooks are therefore long-term assessments. In general, the time-horizon of an Environmental Outlook is 25 years. Because an Environmental Outlook ultimately serves as an input to the preparation of the National Environmental Policy Plan ${ }^{15}$, its spatial focus is the Netherlands.

While knowledge accumulates over time, the relevant cause-effect relationships can be described in more detail and more comprehensively in the successive Environmental Outlooks. Looking backward, this is in general the case, except for the $3^{\text {rd }}$ 
Environmentall Outlook that focuses on the social developments and emissions, i.e. the starting-point of the environmental causal chains. The first two Environmental Outlooks are structured according to scale. The basic conviction behind this structure was that each scale level has its particular environmental problems. A typical global issue is climate change, acidification is a continental problem, pollution of the rivers pertains to a fluvial scale, waste disposal is a regional issue and noise and odour nuisance are examples of local problems. The $3^{\text {rd }}$ Environmental Outlook is structured according to environmental theme, such as acidification, eutrophication, dispersion, disposal, nuisance, desiccation, and squandering. "The $4^{\text {th }}$ Environmental Outlook aims to integrate the various aspects of environmental quality. Instead of a scale-based or theme-based structure, this assessment is structured into three types of environment, i.e. : i) urban area, ii) green area (which involves forests, nature reserves, recreation areas, agricultural area and ground water reserves) and iii) blue area, i.e. wet nature, like lakes, rivers and swamps.

To explore the next 25 years information is needed concerning possible future developments of particular exogenous factors. Such a relevant exogenous uncertainty to the Environmental Outlooks is economic development. The first Environmental Outlook was based on one possible economic future, i.e. the Medium Growth scenario developed by the Central Planning Office $(\mathrm{CPB})^{16}$ in 1985 . This scenario can be considered a surprise-free extrapolation of current trends. For the $2^{\text {nd }}$ Environmental Outlook, the Medium Growth scenario was updated by means of actual data. The $3^{\text {rd }}$ and $4^{\text {th }}$ Environmental Outlooks used a set of scenarios. In the $3^{\text {rd }}$ Environmental Outlook two scenarios were used that are derived from the CPB's "Scanning the Future" exercise ${ }^{17}$, in which four scenarios on the global economy were sketched, i.e. Balanced Growth (BG), Global Crisis (GC), European Renaissance (ER), and Global Shift (Gs). Because the prevailing environmental policy at that time differed fundamentally from the policy foreseen in the $\mathrm{B} G$ and $\mathrm{GC}$ scenario, only the European Renaissance and Global Shift scenarios were used in the $3^{\text {rd }}$ assessment. The $4^{\text {th }}$ Environmental Outlook made use of three scenarios, i.e. Divided Europe (DE), European Co-ordination (EC) and Global Competition (GC), which were derived from the new CPB scenario exercises ${ }^{18}$ and further enriched with the "Water System Outlook $^{\text {199 }}$ (REF) and the long-term assessment of the Physical Planning Agency ${ }^{20}$.

16 In Dutch: Centraal Plan Bureaw (cmas)

17 (cen 1992)

18 (ck 1996)

19 (你ijkwaterstant 1996 )

20. In Dutch: Rijkspitanologiscte Diengr (RPD) 
The assessment process underlying the Environmental Outlooks is informed by monitoring and measuring. Rrvm manages national measuring networks on air, soil, ground water, manure and radiation. Data related to surface water are obtained from the Department of Water Works and the Water Boards. RrvM furthermore participates in the Dutch network of ecological monitoring ${ }^{21}$. In this way, RIvM acquires environmental data on emissions, waste, land use, air-, soil- and water quality, manure, pesticides, noise, radiation, radioactivity and biodiversity. Relevant socio-economic and demographic data are obtained from the Economic Planning Agency (CPB), the Central Statistical Office (CBs) and the Social and Cultural Planning Agency (SCP). The Environmental Outlook process involves analysis of these data and measurements.

Models play an important role in the Environmental Outlook assessment process. Models are used to describe or explain environmental aspects in relation to other developments, to estimate future emissions, environmental quality and impacts from economic and technological scenarios, and to assess possible futures in relation to objectives and targets. Rrvm currently employs about thirty models ${ }^{23}$, ranging from global models (such as the IMAGE model to assess greenhouse gas emissions), distribution models (such as the OPS model to account for $\mathrm{SO}_{2}$ and $\mathrm{NO}_{\mathrm{x}}$ "import" emitted by other European countries), deposition models (like the DEADM model), water models (like the NLOAD, LGM and WATNAT models), and local models (like the CAR-VMK model for local air pollution) to models that assess effects, like the SMART/ MOvE model that assesses the impacts associated with environmental change on terrestrial ecosystems, the $\mathrm{PC}-\mathrm{Lake}$ and $\mathrm{PC}$-Ditch models for effects on aquatic ecosystems and the LVB model that calculates noise nuisance. These models are as far as possible calibrated and validated against available monitoring data. RIvm does not possess one fully integrated model, but it uses the available models in cascades in order to assess the relevant environmental cause-effect chains. The model calcula tions provide the major input to the assessments of the future.

The National Environmental Outlook reports can be considered as a product, because this document is the fnal output delivered to the government. On the other hand, the National Environmental Outlooks can also be considered from a process point of view. The 'booklet' results out of a development process that usually lasts between 6 months and 1.5 year. Negotiations take place about the goals, structure 
and contents both within RIVM as between RIVM and the government representatives, especially from the Ministry of Enwironment and Planning (in Dutch: vrom), from the Ministry of Economic Affairs (in Dutch: $E z$ ) and from the Ministry of Agriculture and Fishery (in Dutch: LNV). RIVM analyses and investigates the stateof-the-art science. Drafts are written, which are revised and reviewed, both within Rrvm and by external peers. This underlying assessment process involves different RIVM employees from different laboratories and departments with different responsibilities, as well as from other Dutch institutes (see Table r), and various government representatives from different ministries. In the $5^{\text {th }}$ Environmental Outlook process about 150 researchers from RIv are involved.

In general, the review process follows the following course ${ }^{23}$ : the laboratories responsible for the results first review the draft chapters. About rooo-r50o pages of copy are then handed over to the project-team, which usually involves about 15 people. These drafts are synthesised by the project-team into a draft document of about 200 pages. It is then circulated again within RIVM, and amongst the collaborating institutes. In the next round, external experts, such as academics from Dutch universities, review the next draft. The draft Environmental Outlook is also reviewed in the policy circuit, first by the so-called expert group (in Dutch: deskundigenoverleg), and then by the departmental task force, the steering group and the governmental commission for envirommental pollution (in Dutch: Rijksmilieuhygiëne-commissie). Finally, it is discussed in the council of ministers (in Dutch: Ministerraad), before it is published and presented to the Minister of Environment and the Parliament. In trying to reproduce how Rrym dealt with uncertainties in the previous Environmental Outlooks, ideally both the product and the process have to be analysed in order to get a fair comprehension. In the course of our analysis, RIvM employees mentioned that the way they are dealing with uncertainty heavily depends on what the expectations policy makers express and the guidelines they set. Although we are aware that the interplay with other institutes, external experts and the policy makers is an important aspect of the process, in this thesis we limited ourselves to the Environmental Outlook process within RIvM. It is beyond the scope of this thesis to address the interplay between Rrvm and politics in enough depth ${ }^{24}$. This thesis focuses on how uncertainty was dealt with in the internal scientific assessment process and how it was settled and communicated in the Environmental Outlook reports.

23 Source for aur description of the rewiew process: Rob hadas (personal communication) 24 see also Chapter 1 . 
Collaborating institute

Dutch name

Abreviation

\begin{tabular}{|c|c|c|}
\hline Advis ory board for traffic and trans port & Adviesdienst Verkeet en Verwoer & $A V N$ \\
\hline Central Statistical Office & Centraal Bureau voor de Statistiel & $\mathrm{CBs}$ \\
\hline Central Economic Plamning Agency & Centraal Planbureau & CPIS \\
\hline Energy research Centre the Netherllands & Energie-onderzoek Centrum Nederland & ECSN \\
\hline Knowledge Centre Nature Conservation & In formatie- en Kenniscentrum Natuubeheer & $\operatorname{IKC}-\mathrm{N}$ \\
\hline Royal Dutch Meteorological Insitutute & Koninklijk Nederlands Meteorologisch Institunt & RNMI \\
\hline Agricultural Economic Institute & Landbouw Economisch Institute & LETEDLCO \\
\hline National Aviation and Aerospace Laboratory & Nationaal Lucht- en Ruimtevart Laboratorím & NLL取 \\
\hline Public Institute for Coast and Sea & Rij̈ksinstitumt voor Kust en Zee & 取IKz \\
\hline $\begin{array}{l}\text { Public Institute for integ rative fresh water } \\
\text { management and waste water treatment }\end{array}$ & $\begin{array}{l}\text { Rijksinstituut voor Integraal Zoerwaterbeheer } \\
\text { en Afval waterbehandeling }\end{array}$ & 程.TZA \\
\hline Physicat planring angency & Rijksplanologische Dienst & $\mathrm{MOD}$ \\
\hline Staring Centre & Staring Centrium & SC-DLO \\
\hline Social and cultural plarning agency & Social en Cultureel Planbureau & SCP \\
\hline
\end{tabular}

TABLE I Collaborating institutes in the Environmental Outlook process

\section{The case-study methodology $\mathrm{y}^{25}$}

The overall aim of the retrospective analysis of the previous Environmental Outlooks was to assess whether there is a (potential) need for an alternative, probably complementary, approach for uncertainty management in decision-support. With a multiple-case case study we wanted to analyse how uncertainty is managed in RIVM's previous environmental assessments (vertical analysis ${ }^{26}$ ) and whether, and if so why and how, the approach to uncertainty has changed over time (horizontal analysis ${ }^{27}$ ). To this end, first a document analysis was performed, involving both argumentation analyses per Environmental Outlook and comparison of uncertainty management between the various Outlooks. To complement the document analyses were complemented by empirical research, in which Rrvm's practitioners were used as source of information. Interviews, a focus group and questionnaires were used to gather empirical data. The various materials for the case-study research are all described in more detail in the current section.

\footnotetext{
25 This seetion bstilds upon (Langendioncle 1999; wan Asselt et al. 2000)

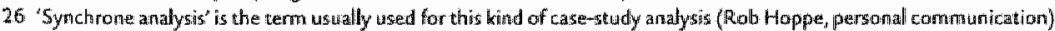

27 "Diadrone anallysis" is the term usually used for this kind of case-study analysis (Rob Hoppe, personal communication).
} 


\subsection{ARGUMENTATION ANALYSIS}

In order to investigate these research questions, we decided frst to perform a thorough argumentation analysis on major conclusions of the two most recent Environmental Outlooks. The aim of this vertical document analysis was to assess whether uncertainty affects the major conclusions, and if so how uncertainty is dealt with in the underlying analysis. The Summary chapters of the $3^{\text {rd }}$ and $4^{\text {th }}$ Environmental Outlook were screened in order to discern major conclusions RIvM wanted to convey to decision-making. It turned out beyond the scope of the study to single out every concluding statement and scrutinise the underlying information and justification. For that reason, we decided to select 6 conclusions per Environmental Outlook that could be considered to be representative for the addressed causal chains. To that end, we decided that the set of concluding statements per Environmental Outlook should involve statements pertaining to pressures (i.e. social, economic and technological driving forces that exert pressure on the environment), to states (i.e. physical, chemical and biological changes in the biosphere, or changes in the socio-cultural, natural and economic stocks) as well as to impacts. Apart from that criterion we did not use any selection heuristic, so that our selection of concluding statements can be considered as an a select sample.

The argumentation analysis involved the Environmental Outlook report, background reports ${ }^{28}$ and references provided in the Environmental Outlook report or in its background documents. The National Environmental Outlook booklets were used as the basic reference in which at first sources of evidence for the conclusions in terms of logical argumentation, figures, tables, footnotes, and further references were sought. Background documents and other related research reports ${ }^{29}$ were used as second set of reference. The selected conclusions were scrutinised along the lines of the following questions:

- How is the conclusion underpinned?

- Can uncertanties be recognised in the argumentation underlying the conclusion, and is so which ones?

- How are these uncertainties considered in the assessment underlying the conclusion?

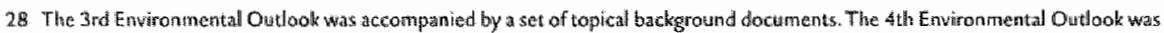
supplemented by a full barkground report, of which the aims was that it provided the scientific underpinning for the policy document 29 Such as those produced by the Central Planing Office and ather collaborating institutes.
} 
In addressing the first question, "Toulmin's ${ }^{30}$ definition of argumentation was used, i.e. an argument consists of a combination of i) information (I), ii) implicit or explicit justification (J) and iii) a statement (S). In the argumentation analysis of the Environmental Outlooks, the statement (S) served as starting point to investigate the underlying evidence (see Figure 2). The argumentation analysis on a specific statement continued until the basic underpinning was found, or until the analysis came to a deadlock, because neither the Environmental Outlook, nor the background documents nor the given references prowided any new clues.

The next step involved evaluation of argumentative components by means of the following questions ${ }^{3}$ :

- Is the information I solid?

- Is the justification J logical?

- Does the justification J match with the information I and the conclusion S?

- Is the conclusion $S$ based on the given argument (I and I) acceptable?

In doing so, we were able to assess whether the argumentation underlying a concluding statement is weak or strong. "Weak" implies that no underpinning evidence was found or that the given arguments were not solid, logical or did not match. In other words, a statement is classified as weak if one or more of the above questions are answered with 'no'. "Strong" implies that solid, in principle verifiable, evidence underpins the conclusion. A conclusion is thus adequately underpinned, and thus characterised as strong, in case all of the above questions are answered with 'yes'. We would like to underline that it was not our aim or intention to judge the correctness of any conclusion in the Environmental Outlooks; we wanted to explore whether the selected conclusions were acceptably underpinned.
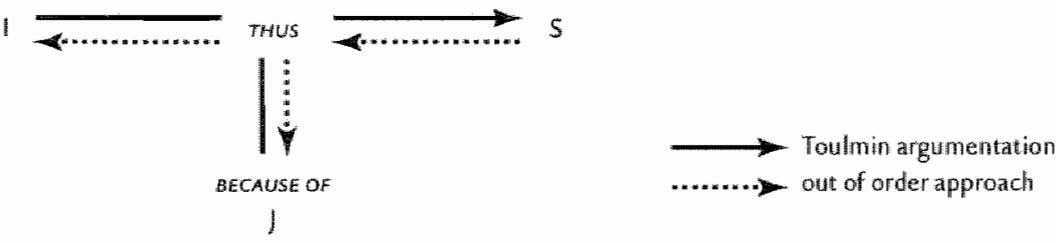

FIGURE a Basic arguimentation analysis scheme

30 (Schellens and Verhoeven 988 )

31 Compare (Schellens and Verhoewen 1988) 


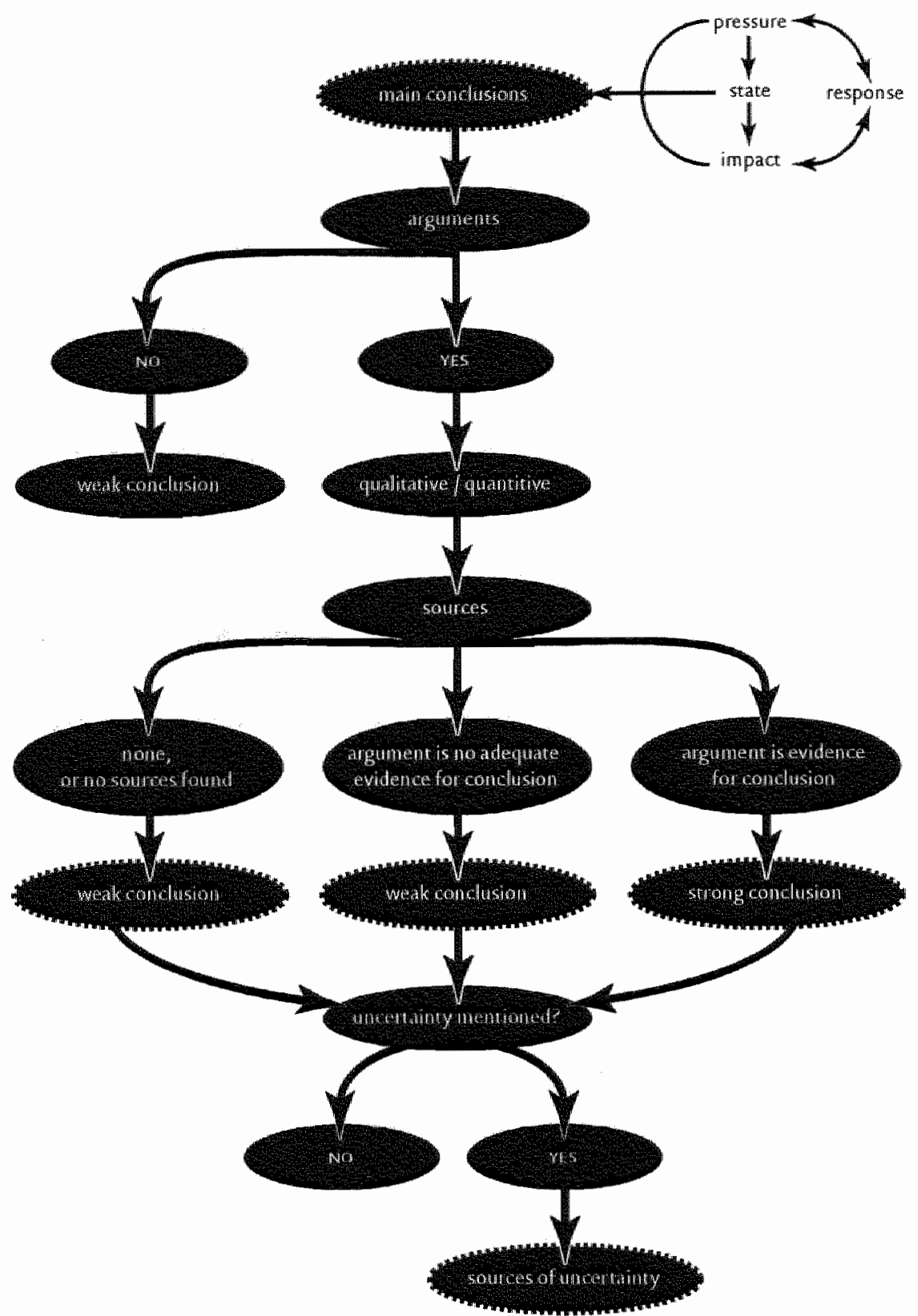

FIGURE 3 Analysis scheme for the argumentation analysis

However, 'strong' does not imply that no uncertainty is involved. 'Strong' implies that the associated uncertainties are mentioned and explicitly considered. In the case of strong statements, it is therefore a straight-forward exercise to identify whether uncertainties impact upon the conclusions, and if so, how they have been 
considered and interpreted in the underlying analysis. While 'strong' is not the same as certain, likewise 'weak' is not identical with uncertain. The weakness of a statement can also arise due to lack of transparency. It is thus much more difficult to figure out whether, and if so which, uncertainties impact upon the weak conclusions then in the case of strong conclusions. Nevertheless, 'weak' may serve as a kind of signal for hidden uncertainty. In principle one would and could expect that in case solid evidence was available or uncertainties would have been addressed systematically, it would have been used in the assessment.

The next step involves classifying the recognised uncertainties in terms of the sources of uncertainty as identified in Chapter $3 \mathrm{~A}$. Such a classification can be useful to characterise the uncertainties involved and to explore whether the adopted approach to deal with the uncertainty in the Environmental Outlook has been appropriate $^{32}$. The full argumentation analysis procedure is summarised in Figure 3 . To complement the latter analysis, we have taken the typology of sources of uncertainty as a starting point, and we have searched in the National Environmental Outlooks for concrete examples of each source of uncertainty. The purpose of this exercise was not to create a comprehensive overview, but it allows to indicate which sources of uncertainty in principle play a role in the environmental assessments. The results of the vertical document analysis including the latter exercises are reported in the next Chapter.

\subsection{HORIZONTAL DOCUMENT ANALYSIS}

The aim of the horizontal document analysis in the context of the current case-study was to investigate whether, and if so, how Rrvm's attitude and its approach to uncertainty management, as expressed in, or deduced from, the Environmental Outlook reports, have changed over time. In the horizontal document analysis (see Figure 4) all four Environmental Outlooks have been considered. The use of scenarios is one way to address uncertainty ${ }^{33}$. As discussed above the number of scenarios and the scenarios themselves as used in the Environmental Outlooks differ over time. We furthermore compared the relative magnitude of the margins in future assessments expanded by the scenarios among the four Environmental Outlooks (see Box r). In that way we can investigate whether the estimated degree of uncertainty for a specific issue differs between the various Outlooks. 


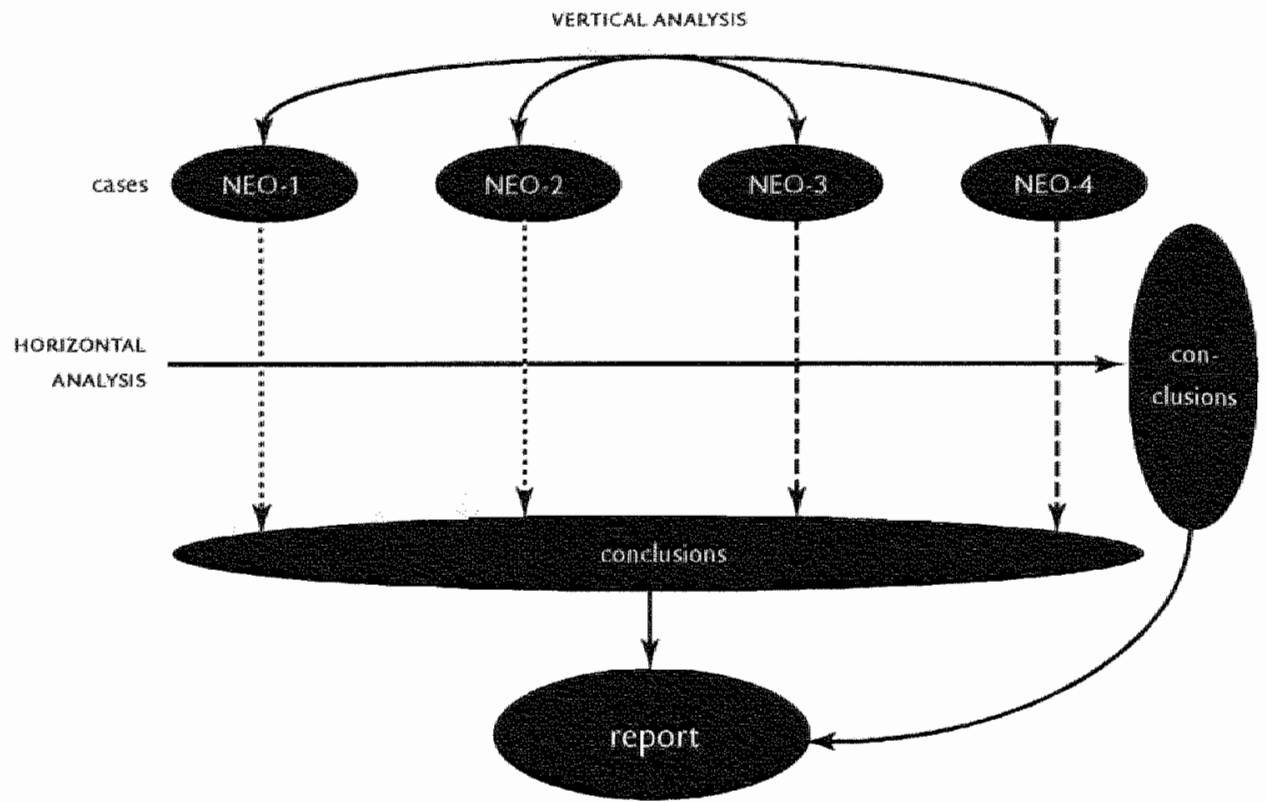

FIGURE \& Hotizontal and wertical idocument analysis

BOX I

Each scenario implies a trend line. The number of scenarios in a National Environmental Outlook is responsible for the number of trend lines. i.e. one scenario involves one trend line, two and more scenarios imply two lines (only the maximum and minimum values are visualised). For each issue, we compared the margins of the trend lines of the four National Environmental Outlooks. A margin is then the distance between a pair of trend lines of one Outlook at a certain time. This means that if the Envirommental Outlook employed just one scenario, no margins are expanded and as a consequence the calculated area is 0 . The total magnitude of a margin refers to all margins between a pair of trend lines over a distance of two year dates. In order to allow comparison the four National Environmental Outlooks, while taking the variability of the curves into account, we calculated the area between the pair of trend lines between two years. In general, the areas have been calculated for the year zooo and the last year that the trend lines have in common, often 2010 or 2015 . Furthermore, the total magnitude of the margins, i.e. the area of the field between a pair of lines and two year dates, was analysed in relative terms. Figure 5 visualises the area of a graph and Figure 6 indicates how the area was calculated. 


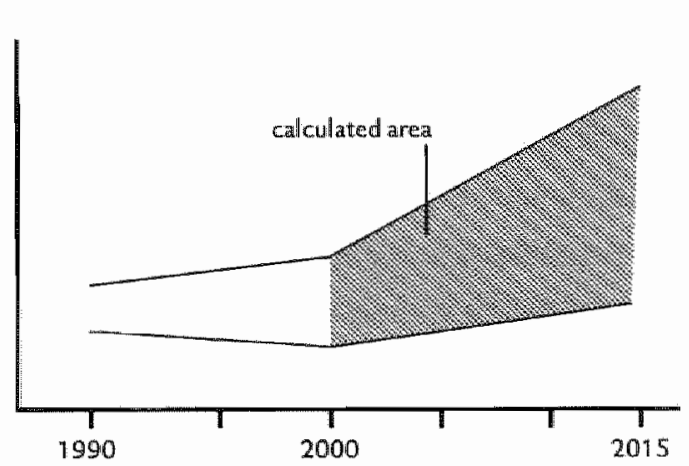

FICURE 5 Magnitude of margins between two trend lines

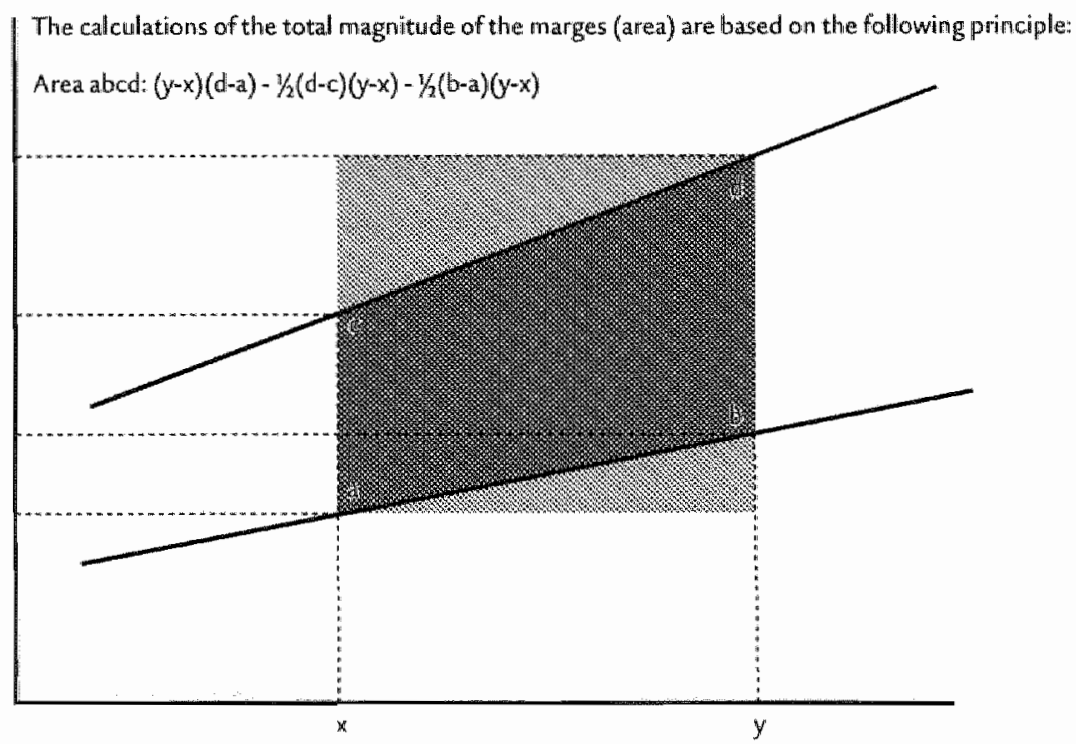

FIGURE 6 Method to calculate the area in a figure 
A third way to investigate Rrvm's attitude to, and management of, uncertainty over time by means of a document analysis is to analyse whether the number and type of linguistic expressions referring to the presence of uncertainty has changed over time. To that end, we distinguished between wordings indicating inexactness (e.g. 'about', 'approximately', or 'at least') and phrasings hinting at more structural uncertainty (such as 'uncertain/uncertainty' and 'it is expected/assumed'). It was beyond the scope of our study to perform such a complete, time-consuming analysis of the reports. Furthermore, because different issues are covered, such a full analysis would render the comparison more difficult. We therefore decided to perform such a linguistic screening for two issues that were discussed in all 4 Environmental Outlooks, i.e. demographic development and local air pollution. The first issue can be characterised as a pressure, where the second issue represents an environmental impact. We further counted the word 'uncertainty', and directly related words as 'uncertain' and 'not certain', in the summaries of the Environmental Outlooks. Because the surnmaries have a direct communicative aim, the latter analysis allows assessment of the importance attached to communication about uncertainty.

\subsection{INTERVIEWS}

Not all research questions can be addressed by means of the vertical argumentation analysis and the horizontal document analysis. Such analyses of the output of the assessment process do not fullly indicate how uncerrainties are dealt with in the underlying assessment process, and why uncertainties are managed in that way. For that reason, we decided to use practitioners from Rrym with experience in one or more Environmental Outlook processes as another source of information. To that end, we performed a number of interviews and a focus group. The aim of this part of the research was threefold:

- to validate the conclusions of the document analyses

- to assess the attitude towards uncertainty and uncertainty management among Rrvm practitioners

- to understand how uncertainty was managed in the assessment process, and why in this way

The interviewees and the participants to the focus group were selected in close interaction with RIVM. At the time of discussing which people to involve, uncertainty was considered to be a controversial topic that could easily confuse people participating in the current Environmental Outlook process, and thereby disturb the ongo- 
ing assessment activities. Uncertainty was identified as a topic for the $5^{\text {th }}$ Environmental Outlook, but among Rrvm's management there was a shared conviction that it should be handled carefully. On the other hand, we needed a set of respondents that covered experience and insight in Environmental Outlook assessment ever since 'Concern for Tomorrow'. In line with these two ambitions, we identified rr senior practitioners who were involved in at least one Environmental Outlook in a leading position (such as project leader, senior analyst, senior reviewer, project leader of modelling activities, chapter co-ordinator and integrated assessor), and who were known as conscious of, and open-minded towards, uncertainty in relation to the Environmental Outlooks (see Table 2). This selected, small group of respondents cannot be considered representative for Rrvm as a whole, which implies that statistical generalisations cannot be made. This is not a problem for our case-study research, because the ultimate aim is to understand the how uncertainty is managed. To that end, the selected 'elite' is a valuable and essential source of information.

We decided to carry out focused in-depth interviews, in which the respondents were asked for facts, opinions, insights and ideas ${ }^{34}$ about uncertainty and the Environmental Outlooks. In the interview three interview technicues were used ${ }^{35}$. An interview guide with open questions was used to structure the communication. In addition, a dozen closed questions were asked, in the form of statements on which the interviewees could agree or disagree on a five point scale. Some of the statements were on purpose phrased rather extreme in order to trigger a response and to be able to draw conclusions as sharp as possible. Finally, the interview involved a number of ranking exercises, in which they, for example, were invited to rank the sources of uncertainty in terms of importance for the Environmental Outlook. The interviews in generall took roughly an hour. Apart from some general introductory questions, such as about one"s involvement in the Environmental Outlook processes, the following topics were covered:

- general attitude towards science-knowledge-uncertainty

- attitude towards uncertainty in relation to the Environmental Oudlook

- sources of uncertainty in the Finvironmental Outlook

- RIYM's current uncertainty management

- prospects for the future

34 See (min 1994)

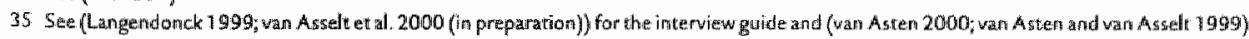
for the quiestionnaire. 


\begin{tabular}{|c|c|c|c|}
\hline $\begin{array}{l}\text { name } \\
\text { (in alphaberical order) }\end{array}$ & experience in NEO & $\begin{array}{l}\text { inter. } \\
\text { viewed }\end{array}$ & $\begin{array}{l}\text { participated } \\
\text { in focus group }\end{array}$ \\
\hline Romald Albers & $\begin{array}{l}\text { Since '90 at Rrw Author NEO-2. Chapter } \\
\text { co-ordinator NEO } 3 \text {. Project leader NEO } 4 \text {. } \\
\text { Current position: Head of the division of } \\
\text { policy analysis and scenatios. }\end{array}$ & $\mathrm{X}$ & $\begin{array}{l}\text { Invited, } \\
\text { other oblifictions }\end{array}$ \\
\hline Leon Braat & 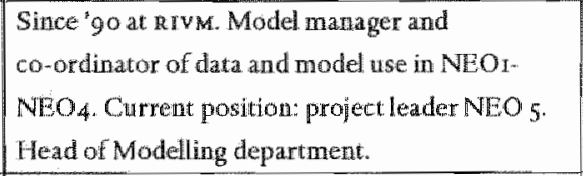 & $x$ & $\begin{array}{c}\text { Twited, } \\
\text { ather obligations }\end{array}$ \\
\hline Klas van Fgmond & 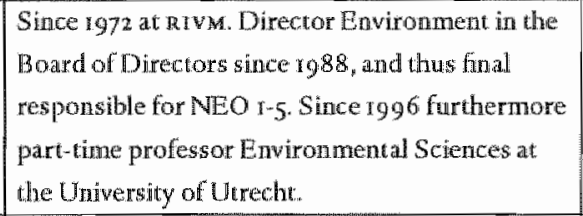 & - & $\mathrm{x}$ \\
\hline Anton wan der Giessen & 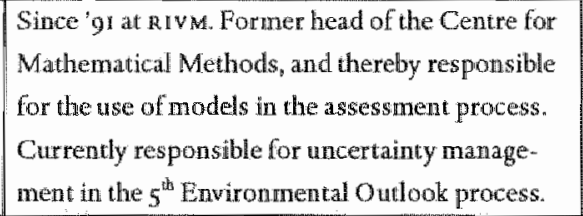 & - & $x$ \\
\hline Janneke Hoekstra & $\begin{array}{l}\text { Since " } 87 \text { at Rrvm. Statistician. Project leader } \\
\text { State of the Environment reports " } 97 \text { and " } 88 \text {. } \\
\text { Citrent position: }\end{array}$ & $x$ & $x$ \\
\hline Fred Langeweg & $\begin{array}{l}\text { Founding father of NEO. Deputy director of } \\
\text { the Environmental Planning Agency, } \\
\text { supervisor of NEO } 5\end{array}$ & $x$ & $\mathrm{x}$ \\
\hline Rob Maas & 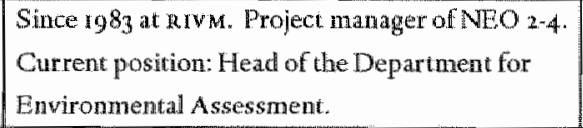 & $x$ & $x$ \\
\hline Ditk Ondlerdhtinden & $\begin{array}{l}\text { Since ' } 97 \text { inwolvad in NEO. Senior reviewer. } \\
\text { Integrated absessor. }\end{array}$ & $x$ & $\mathrm{X}$ \\
\hline Jan Rotmans & 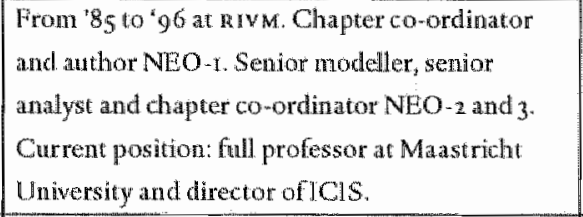 & $x$ & Not inviled \\
\hline Rob Swart & $\begin{array}{l}\text { Since } \mathrm{NEO} \text { - involved. Scenario analyst. } \\
\text { Chapter co-ordinator. }\end{array}$ & $x$ & Invited, abroat \\
\hline Keimpe Wieringa & 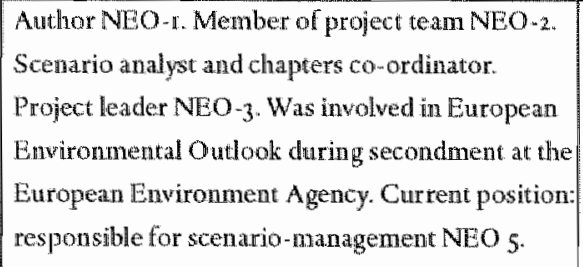 & $\mathrm{X}$ & $\begin{array}{l}\text { Anvited, interested } \\
\text { bun principal } \\
\text { abjection to } \\
\text { everwing session }\end{array}$ \\
\hline
\end{tabular}




\subsection{CHANGE OF CONTEXT-THE DE KWAADSTENIET AFFAIR}

The interviews were held in the period January - March 1999. The retrospective stady on the National Environmental Outlooks took off in September 1998, and was actually carried out 'behind the curtains'. A small group of people, especially at the top of the institute, knew about the project "Perspectives on uncertainty and risk", and followed it with some interest. Although uncertainty was a recognised agenda point for the $5^{\text {th }}$ Environmental Outlook, at that time it was not at the core of the assessment process. However, on Jamuary $20^{\text {th }}$ a national distinguished newspaper (Trouw) published a reader's letter from, and an interview with Hans de Kwaadsteniet, one of Rrvm's employees. This inside page content was announced on the front page with the screaming headline 'Environmental institute lies and cheats'. De Kwaadsteniet's had it that RIVm suggests a level of certainty in their environmental reports ${ }^{36}$ that cannot be justified. This publication arose a heated media affair that lasted for weeks and kept media attention during the course of r999. All Dutch newspapers, whether national or regional, as well as news bulletins, current affairs programs and discussion programs on radio and television reported the topic. A wide variety of scientists and policy analysts expressed their views via the so-called 'opinion pages' of the national newspapers ${ }^{37}$, or as opponents in media debates ${ }^{3^{8}}$. The boom of reactions can be roughly divided into two camps: those supporting De Kwaadsteniet's positivist's argument that measuring is knowing, versus those that acknowledge inherent uncertainty in decision-support on complex issues. The first group advocated more measurements and statistical methods as the way to improvement. The latter respondents usually argued that uncertainty is not a particular R rvM problem; other decision-support institutes struggle with the same problem. In line herewith, it was argued that science, decision-support institutes and politics should work out a new way to deal with uncertainty.

The De Kwaadsteniet affair also had a political impact. The Members of Parliament (MPs) were shocked by the criticism towards RIYM. They interrogated the Minister of Environment ${ }^{39}$. The minister first referred to RIvm for a reaction, but he was forced to come up with a written response, in which he defended RIvm. How-

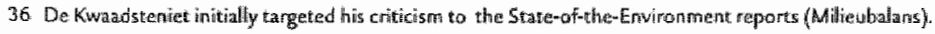

37 Also the author of twis thesis, topether whth her PhO supervisor, published an opinion article in which the nessage of this thes is "uncerta:nat

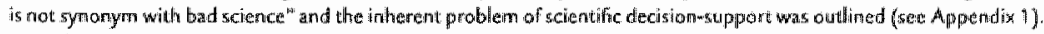

38 Examplites are Prof. Reinders, Prof. Hordijk, and Prot. Bomholf.

39 which was interesting because nuw legally belongs to the Min istry of Health.
} 
ever, the MPS were not satisfied by this ministerial reaction, and demanded a parliamentary debate about the Rivm case. In a second meeting between Minister and the Lower Chamber, all political parties supported a motion in which extra control on RIVM's research was requested. In his reaction to this motion, the Minister promised that he would communicate the Parliament's request to Rrv M"s supervisory board.

The media affair ${ }^{40}$ had an enormous impact on RIVM. Their reputation was seriously questioned. The adopted PR strategy can be characterised as defensive, and some serious PR mistakes were made (such as obtaining a court order forbidding De Kwaadsteniet to speak in public and a rather pathetic press conference), which weakened RIVM's image even more. It is no exaggeration to characterise the situation at rrvm in those days as panic. Of course this media affair impacted on our case-study, both in practical terms as well as with respect to the content. Our interviewees were busy, because they had to prepare or attend the press conference, they had to write reports to account for their work to inform the issued review process, or they had to attend internal crisis meetings. Furthermore, the whole affair distracted them from their usual activities, which (further) increased the workload, and impacted on their job satisfaction. Interview appointments were rescheduled or shortened up. We had problems entering the institute because the reception suspected us of being journalists and so on. Nevertheless, all planned interviews were held.

With regard to the contents, the affair had a multitude of effects. It is quite a unique situation that empirical research is crossed by such a public debate addressing the research topic. So far, the project. "Perspectives on uncertainty and risk" was looked upon as a theoretical endeavour of primarily scientific value. The advantage was that this affair illustrated the societal and the political importance of uncertainty. Our initial fear was that this whole affair could serve as a bomb, and thereby disrupt the research. De Kwaadsteniet's reproach expressed a positivist spirir ${ }^{4 r}$. It was quite likely, that this affair would push Rrvm towards monitoring and measuring at the expense of modelling and scenario activities. From the point of view defended in this thesis, that would have been a big step backward. However, the opposite happened. The media affair catalysed consciousness and awareness.

As a result of this momentum, the respondents were challenged to have an opinion about uncertainty in scientific decision-support, which increased their interest and their commitment to work with us. This explains why, notwithstanding the

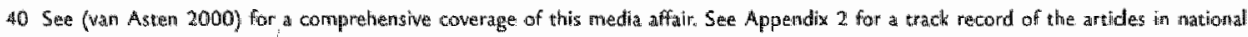
nespapers.

41 Compare Chaptiers $3 \mathrm{~A}$ and 4 .
} 
time pressure and panic, all interviews took place. The interviews seemed to have been considered an opportunity to channel their thoughts, opinions and ideas. The actual affair popped up in all interviews. Jokes were made about the timing of the interviews ('right time, right spot'). The affair could have either yielded a rather extremely critical attitude towards RIVM's practise, or a quite closed, even hostile atritude towards discussing the internal practise. The drawback would be that the answers, that should inform us about the state-of-the-art management of uncertainty, might involve either socially desired or 'cover-up' elements. In line with the above observation, our evaluation is that the latter does not correspond with the spirit of the interviews. However, it may be possible that the interviews are biased in a positive sense. The consequence would be that our conclusions deduced from the interviews might be more critical then R IV $M$ deserves.

The potential bias has been accounted for in several ways. As a response to all criticism, RIYM published a report and an addendum referred to as "Measurements, calculations and uncertainty: RIV M's environmental research methodology ${ }^{\text {p*42 }}$. These reports enabled to test the findings deduced from the document analyses and the interviews against RIVM's own account.

\subsection{FOCUS GROUP}

In addition to our comparison of the interview results concerning the actual practise and r rvm's official accounts, we decided to carry out a focus group. The term 'focus group" results from a combination of two social scientific research methods, i.e. the focused interview, in which an interviewer elicits information on a topic without a pre-fixed questionnaire, and the group discussion, in which a small rather heterogeneous, but carefully selected group of people discusses, facilitated by a skilled moderator ${ }^{43}$. The focus group is an established social scientific research method, originating from marketing research. The advantages of a focus group are that it in principle allows for collective thinking and that it in principle enhances richer argumentation, because the group members themselves raise questions and sharpen each other's arguments.

In our case, the value of a focus group was that it allowed us to test the robustness of the individual opinions against group pressure, and thereby a focus group

42 (RVM 1999\%; $1999 \mathrm{~b}$ )

43 (Durrenberger al. 1997) 
enabled us in a certain way to simulate Rrvm's forming of opinion. The focus group consisted of the interviewees (see Table 2) complemented with Rrvm's director Enviromment and the senior analyst responsible for uncertainty management in the $5^{\text {th }}$ Environmental Outlook. Such a focus group can provide insight in how the top of Rrym's environmental division as group thinks and discusses about the uncertaintyproblematic. 'This means that such a group process is likely to provide a more realistic reflection of the 'institute's thinking', then any picture that can be deduced from individual interviews. Furthermore, a confrontation with preliminary research results in the form of an in-depth interview could easily flow in a polarised discussion, in which the researcher/interviewer is too much involved. In this way, the researcher may become an obstacle in his or her own research. It is also difficult to have an external interviewer to hold such an interview, because it requires fullfledged knowledge of, and insight in, the research.

However, this does not mean that the interviews are superfluous. The interviews were a necessary step in the research process. They allowed a first impression and enabled to roughly draw the state-of-the-art in RIvm's uncertainty management. The interviews also served as a source of information to direct and inform the document analysis. On the one hand, the interviews served as a way to 'verify' the insights associated with the document analysis, while on the other hand, they turned out to serve as a preparatory step for the focus group. The results of the interviews were used to surface the discussion. The focus group was confronted with the preliminary conclusions and with tensions and conflicts that arose out of the whole set of interviews, and was invited to react. The input was provided in the form of transparencies presented to the focus group. This set of transparencies was also used as discussion guide. The discussion output, which can thus be considered as collective judgements and opinions, allowed us to clarify points in questions and ambiguities, and to reject, nuance or sharpen the preliminary conclusions.

\subsection{QUESTIONNAIRES}

In order to have a broader sample of RIvm's practitioners involved in the empirical phase, questionnaires were distributed among some twenty analysts involved in the current environmental assessment process that will result in the $5^{\text {th }}$ Environmental Outlook. Rrvm's analysis inwolved in the $5^{\text {th }}$ Environmental Oullook were invited by the project leader. It was explicitlycommunicated that the project leader and RIvm's environmental management considered participation important. The aim of the ques- 
tionnaires was to test the current attitude towards science, uncertainty and decisionsupport. In order to allow for comparison, the same closed questions used in the interviews were posed in the questionnaire. The respondents were confronted with a couple of statements and were asked to express their opinion on a 5-point scale.

\subsection{CASCADE OF RESEARCH METHODS}

The case-study methodology adopted in the multiple-case case-study on Ruvm's Environmental Outlooks is summarised in Figure 7. The various methods may yield conflicting or even inconsistent results. A key ambition is to highlight such conflicts and inconsistencies and to use them to ask further questions.

The cascade of research methods (i.e. document analyses, interviews, focus group and questionnaires) guaranteed a richer, and probably more realistic, picture of how uncertainty was managed in the four Environmental Outlooks. Such a description, accompanied by insight into the current attitude towards uncertainty as can be deduced from the interviews, the focus group and the questionnaires, then provides the basis for addressing the general research question, i.e.:

Is there a (potential) need for an alternative or complementary approach to uncertainty management in the decision support practice?

The above question is addressed in the case study in the following ways:

- by means of the argumentation analysis the quality of the conclusions is assessed, which results provides insights into the question whether the underlying assessment approach, including uncertainty management, adopted in the series of Environmental Outlooks seems to be problematic

- by means of the document analyses and the comparison over the series of Environmental Outlooks it is traced how uncertainty was addressed in the previous Environmental Outlooks.

- by means of empirical research it is analysed whether a need for an alternative approach to uncertainty management is felt by practitioners

Evaluation of the research results associated with the first two bullets against the theoretical insights into uncertainty management and risk analysis (as outlined in Chapters 3-5) allows to address whether their is a latent need for an alternative approach to uncertainty management. The empirical research among practitioners allows to assess whether their is also an overt need. If the current approach to uncertainty turns out to be problematic in view of the quality of the assessment and the data collected among practitioners indicate a positive attitude towards another 
approach to uncertainty management, the above general question can be answered with 'yes'. This 'yes' does not mean that there is a need for the PRIMA approach outlined in Chapter 5. However, the research results may allow to address whether the PR IMA approach in principle could address the observed (potential) need in the decision-support practice.

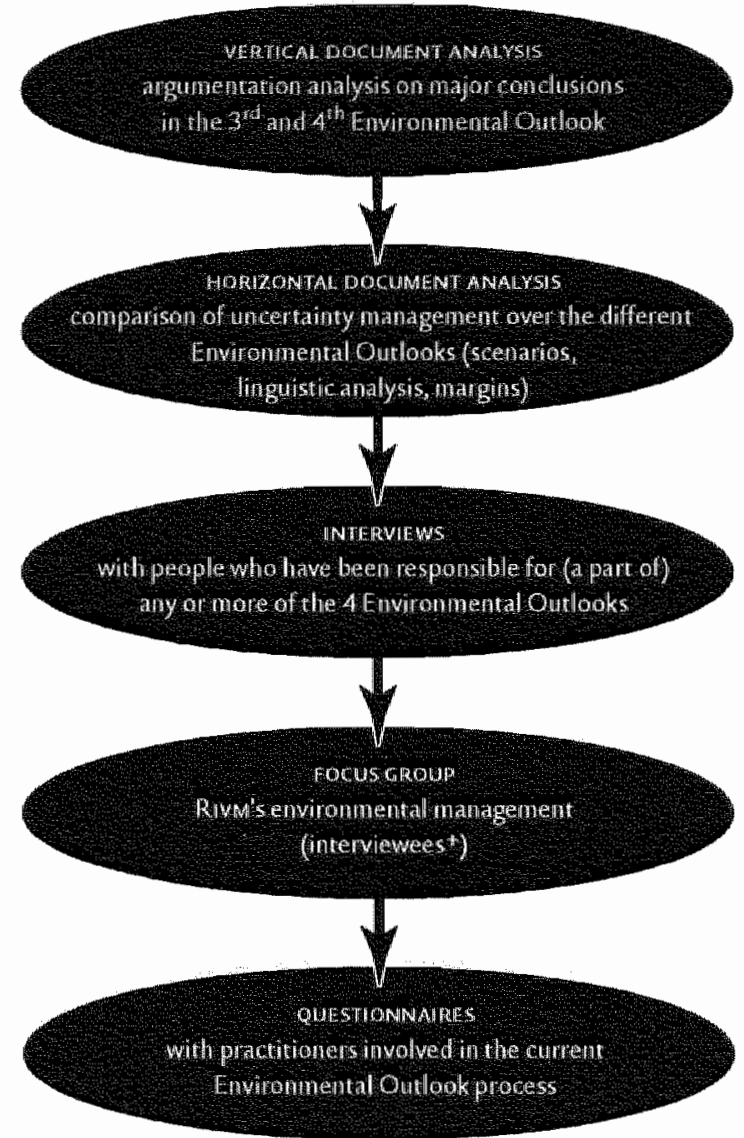

FarURE 7 Case study methodology 


\section{REFERENCES CHAPTER 6}

- CPB. (1992). Scanning the Future: A long term scenario study of the world economy 1990-2015, Sdu Uitgeverij, The Hagie, The Netherlands.

- CPB (1996). "Surroundings scenarios: Long term exploration 1995-2020." Working paper No.89, The Hague "The Netherlands.

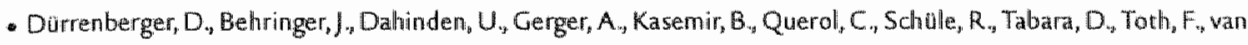
Asselt, M., Vassilarou, D., Willi, N, and jaeger, C. (1997). "Focus Groups in integrated Assessment: A Manual for a Participatory Tool." ULYSSSES working paper WP-97-2, Darmstadt University of Technology, Darmstadt, Germany.

- EEA. (1995). "Environment in the European Union: Report for the review of the fifth environmental action programme.", European Environment Agency, Copenhagen, Denmark.

- Langendonck, R. M. T. (1999). "Searching for Uncertainty: The case of the National Environtisental Outiooks," master thesis, ICIS, Maastricht, The Netherlands.

- Rijkswaterstaat (1996). "Water System Outlooks: A future for water. (in Dutchy)", Rijkswaterstaat, the Hague, the Netherlands.

- RIVM. (1988). Concern for Tomorrow, Samson H.D. Tjeenk Willink Alphen aan de Rijn, The Netherlands.

- RIVM. (1991). National Environmental Outlook 2 1990-2010, Samsom H.D. Tjeenk Willink, Alphen aan den Rijn, the Netherlands.

- RIVM. (1993). National Environmental Outlook 3 1993-2015, Samsom H.D. Tjeenk Willink, Alphern aan den Rijin, the Netherlands.

- RIVM. (1997). National Enwironmental Outlook 41997-2020 (in Dutch), 5ainsom H.D. Tjeenk Willink, Bilthoven, the Netherlands.

- RIVM. (1999a). "Addendum Measure, Calculate, and Uncertainties: The working method of RIVM's environmental research (in Dutch),", RUVM, Bilthoven, The Netherlands.

- RIVM (1999b). "Measure, Calculate and Uncertainties; The working method of RIVM's, environmental research (in Dutch)." Bilthoven, The Netherlands, RIVM.

- Schellens, P.), and Verhoeven, G. (1988). Argument and Counterargument (in Dutch), Martinus Nijhof, Leiden, The Netherlands.

- UNEP. (1997). Global Enwironmental Outlook, Oxford University Press, Oxford, UK.

- van Assell, M. B. A., Langendonck, R. M. T.n and van Asten, F. (2000 (in preparation)). "Searching for Uncertainty: A case-study on the Dutch National Enwironmental Outlooks.", ICIS, Maastricht, the Netherlands.

- van Asselt, M. B. A, and Rotmans, J. (1995). *Uncertainty in Integrated Assessment Modelling: A Cultural Perspective-based Approach:." RIVM report no. 461502009, National Institute of Public Health and the Environenent (RIVM), the Netherlands, Bilthovern.

- van Asten, F. (2000). "Uncertainty in Practice: Application of the PRIMA approach to the Sth Environmental Out. llook," master thesis, Maastricht University, Maastricht, the Netherlands.

- van Asten, Fu, and van Asselt, M. B. A. (1999). "Uncertainty and the 5 th Envirommental Outlook: Workshop report (in Dutch).", ICIS, Maastricht, the Netherlands.

- Van Zon, H. (1990). Eighty years RWM (in dutch), RIVM, Bitthoven, The Netherlands.

- VROM, EZ, LNV, and V\&W. (1989). "National Environmentall Policy Plam." 21137, nrs. 1-2, VROM „ Den Hatg, The Netherlands.

- Yin, R. K. (1994). Case Study Research: Design and method's, Sage Publications, Thousand Oaks, California. 



\section{Searching for uncertainty in RIVM's Environmental Outlooks ${ }^{1}$}

As outlined in the previous Chapter, a multiple-case case-study on Rrvm's Environmental Outlooks has been performed in order to address the research question whether there is a (potential) practical need for an alternative or complementary approach to uncertainty management. This Chapter reports the case-study research and the conclusions that can be deduced from this empirical research. The first part of the Chapter will focus on the document analyses, while in the second part the state-of-the-art in RIVm's uncertainty management is outlined, which description mainly builds on the interviews, the focus group and the questionnaires.

\section{Document analyses}

The aim of the document analyses was to figure out how uncertainty is dealt with in Rrvm's Environmental Outlooks ${ }^{2}$. The document analysis comprised the following two components:

- vertical analysis

- horizontal document analysis

The first type of analysis implied in-depth studies per Enwironmental Outlook. The main component of this vertical analysis involved argumentation analysis of selected conclusions. The second analysis, i.e. horizontal document analysis, was focused on the comparison among the four Environmental Outlooks.

1 This Chapter substantially bereffits from research carried owt by Rian Langendonck almd Frank wan Asten in ahe context of their andatter thesis. for the course Enwironmental Health Sciences. See also (Langendonck 1992; van Asselt 1999; wat Asselt et al. 1999 ; 2000 (in preparation); van Asten 2000; van Asten and van Asselt 19991).

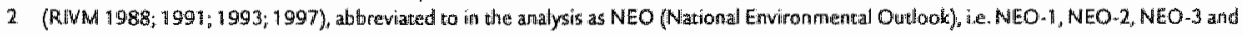
NEO-4 respectively. 
As argued in the previous Chapter, the aim of the argumentation analysis is to understand for some a-select conclusions how they are underpinned, whether uncertainties can be recognised in the underlying argumentation, and, if so, how these uncertainties are dealt with. The quality of the argumentation is evaluated in terms of weak or strong. Weak implies that no underpinning evidence was found or that the given arguments were not solid, logical or did not match with the conclusions. Strong implies that solid, in principle verifiable, evidence underpins the conclusion. We would like to underline that it was not our aim nor intention to judge the correctness of any conclusion in the Environmental Outlooks; we wanted to explore whether the selected conclusions were acceptably underpinned in order to get some insights whether uncertainty was, or may have been, involved.

\section{Argumentation analysis}

Box I outlines which concluding statements have been extracted from the Summary Chapters of the $3^{\text {rd }}$ and $4^{\text {th }}$ Environmental Outlook. These chapters in principle convey the major policy-relevant conclusions. It is beyond the scope of this thesis to report the analysis of all twelve statements. For the sake of brevity, we therefore limit ourselves here to the full description of the argumentation analysis of two illustrative conclusions, i.e. one conclusion that was characterised as weak and one other concluding statement that was classified as strong (next subsections). The other evaluation results are summarised in Box 2.

\section{BOX ॥ Concluding statements selected for argumentation analysis}

Our selection comprised both conclusions regarding pressures, and conclusions concerning states and impacts, in order to cover some relevant cause-effect chains.

The following quotation indicates the salient driving forces discussed in the $3^{\text {rt }}$ Environmental Outlook:

The following sections look at the social developments relewant to the environment, starting with the developments more or less exogenous to enwironmental policy, such as population growth and economic development. This is followed by an examination of the developments towards which enwironmental 
policy in a broad sense is primarily oriented: energy consumption, mobility, manure production ind water consumption' (NEO 3, P.36).

After screening the texts in the Summary Chapter on the underlined issues, the following "pressure conclusions" have been selected for further analysis:

\section{- population growth}

The Dutch population is expected to grow more than is assumed in the NEPP?. The level forecasted for 2000 was already reached in 1992. The population figures for 2010 in the ER and GS ${ }^{4}$ scenarios are about $10 \%$ higher than in the NEPP' (NEO-3, p. 12).

\section{- ECONOMIC DEVELOPMENT}

In the ER scenario GNP' remains somewhat lower than is assumed in de middle scenario until zooo, after which it increases more sharply. Economic growth in the GS scenario is significantly lower.' (NEO-3, p. 12).

\section{- mosilitr}

The policy that has now been formulated is expected to curb growth and thereby enables to reach the target for the year 2000. After 2000 car use will further increase' (NEO-3, p.12).

The following conclusions pertaining to state or impact issues have been selected:

- carbon dioxide emissions

'Depending on trends in energy prices, $\mathrm{CO}_{2}$ emissions in the ER scenario will rise by $5-10 \%$ between $1989 / 90$ and 2000 . In the $\mathrm{CS}$ scenario, $\mathrm{CO}_{2}$ emissions in the same period will rise by $5 \%$ if energy prices remain low until $2000^{\circ}$ (NEO-3, p.16).

- DEPOSITION OF ACID EQUIVALENTS.

The deposition target for 2010 of 1400 acid equivalents per hectare (average on woodland) will not be achieved with implementation of the proposed policy. Deposition will be able to fall to about zquo acid equivalents per hectare in $2010^{\prime}$ (NEO-3, p.r7).

- noise nuisance by road traffic

'Despite the increase in car traffic and the expansion of the road network, the proposed policy will reduce the number of people experiencing serious nuisance to $10.15 \%$ of the population, between 1990 and 2000 . The number of people experiencing some nuisance will fall less sharply. The targets for the year 2000 will easily be achieved. Howewer, the target for 2010 (a negligible level of serious nuisance) will not be achieved' (NEO-3, p.22).

see over 
aOx I

Three conclusions pertaining to pressures have been extracted and selected out of the Summary Chapter of the $4^{\text {th }}$ Environmental Outlook:

\section{- CONSUMPTION}

'It is expected that the consumption perhead will increase with $45 \%$-100\% loetween 1995 and $20020^{\circ}$ (NEO-4, p.12).

- production

'According to the economic long term scenarios on which this Environmental Outlook is based, the production will increase with $50 \%-125 \%$ in the next 25 years' (NEO -4, p.12).

\section{- Energy consumption}

'Between 1995 en 2020 the energy consumption will grow with $8 \%$ \% $45 \%$ '. (NEO $4,4.12)$.

In the $4^{\text {th }}$ Environmental Outlook, the theme 'environmental quality' is subdivided into three categories: the urban area, the green area and the blue area. in each category environmental state and impact issues are evaluated. From the Summary chapter we chose from each category one conclusion pertaining to state or impact issues:

\section{- phosphate concentration in the soll}

"With the adopted policy, the area with phosphate accumulation in the eastern, central and southern Sand Region will increase from $22 \%$ in 1990 to $50 \%$ in $2020^{\circ}$ (NEO-4 P. 16).

- IMPACt of FINE DUST ON HEALTH

"With the current policy, a slight improvennent is expected for photochemical air pollution (azone) and fine dust. However, this is not adequate to prevent health darmage (breathing problems)' (NEO-4, p.16).

- desiccation

Assuming an advisable rise of the ground water level of 25 centimetre and in case desiccation is adequately prioritised in land structure projects, the target for desiccation (in zoo: a decrease of the natural desiccated area with $40 \%$ in relation to 1985 ) will be almost reached in $2010-2020^{\circ}$ (NEO- 4, p.18).

see over

\section{I. EXAMPLE OF A WEAK CONCLUSION}

The analysis of the statement on economic development extracted from the $3^{\text {rd }}$ Environmental Outlook is discussed in more detail, as an example of a concluding statement that is ultimately characterised as weak:

In the ER scenario GNP remains sonewhat lower than is assumed in de middle scenario until 2000, after which it increases more sharply. Economic growth in the GS scenario is significantly lower' (NEO-3, p.12). 
It is argued that the growth in physical units is even more important to environmental assessments than monetary growth:

"The development of the GNP (the growth of the added value in guilders) is not as important to the environment as the growth in physical units. This physical growth of the economy is determined by the use of energy and raw materials, the end products and the level of recycling of waste products' (NEO-3, p.40). Statements, information and arguments on both indicators were analysed in further detail. Notwithstanding the explicit acknowiedgement of the importance of physical growth over monetary growth, GNP is used throughout the $3^{\text {rd }}$ Environmental Outlook as the reference indicator. The implication of using solely GNP is that this Environmental Outlook does not allow to assess whether so-called "de-coupling" of economic growth and pressure on the environment may be a realistic future outlook. In this Chapter, we limit ourselves to the analysis of the concluding statements on GNP7, which implies that only the left part of Figure $\mathrm{r}$ is discussed in detail here.

The first place in the $3^{\text {rd }}$ Environmental Outlook where we expected more specific information regarding the development of GNP is section 3.3, entitled "Economy". Here, the conclusion is repeated, but now in quantitative terms:

('...) the development of the GNP in ER is somewhat lower than in the Middle scenario (an annual average of $2.7 \%$ and $3 \%$, respectively, until the year 2000 ). (....) The GS scenario assumes a far more moderate growth (1.5\% per year)' (NEO-3, p.39).

Section 3.3 further comprises graph 3.3.I (NEO-3, p.39) (see Figure 2) indicating the development in GNP over the period 1970-2015 for the Middle scenario ${ }^{8}$, the European Renaissance (ER) and the Global Shift (GS) scenario. References indicate that these ER and GS trends are extracted from the document 'Scanning the Future A long-term study of the world economy 1990-2015' of the Central Economic Planning Agency (CPB) $)^{9}$. We tried to trace more information on and a justification for the GNP trends in this referred report. This 'Scanning the Future' report provides a thorough analysis of the global economy as the basis for scenario-development. Various perspectives on economic devellopment are distinguished and trends are studied. Furthermore, comparative strengths of the current state of the economy of major regions (especially the United States, Japan, Western Europe, Central Europe, dyna-

6 Sew (Molendific and Romans, 999 )

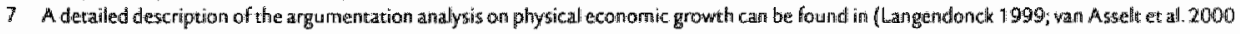
(in preparastion))

8 The scenario used in the 1 st and 2 nd Entritonmentad Oudooks. Added in this grapli for cormparison reasons.

9. (СPB 1992b) 

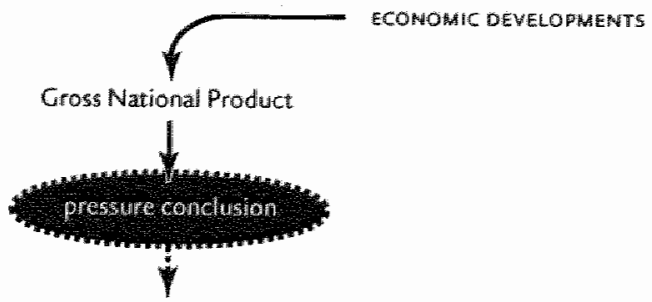

qual inative conclusion summary (NEO-3 p.12)

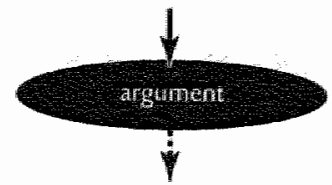

quatutative arginment

\$3.3 Economy (NEO-3 p.39)

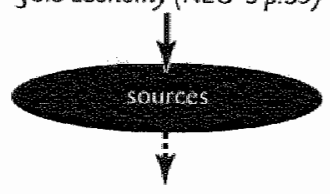

figure: development of

GNP 1970-2015

(NEO-3p.39)

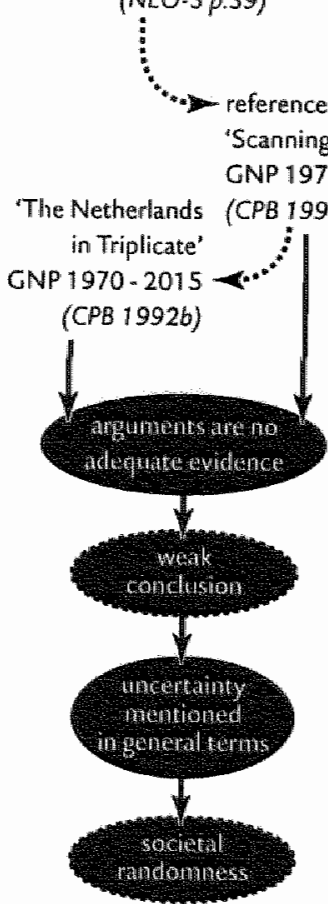

indirect quantitative

argument

(NEO-3p.40)

raw materials

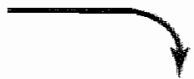

Growth Physical Units

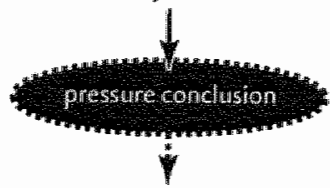

quantative conclusion

53.3 Economy (NEO-3 p.39)

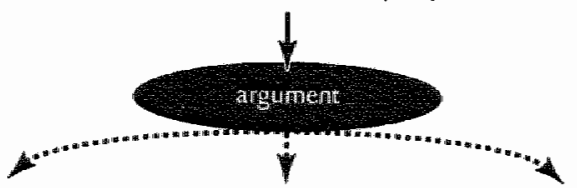

(and use of energy)

use of end products recycling level of waste
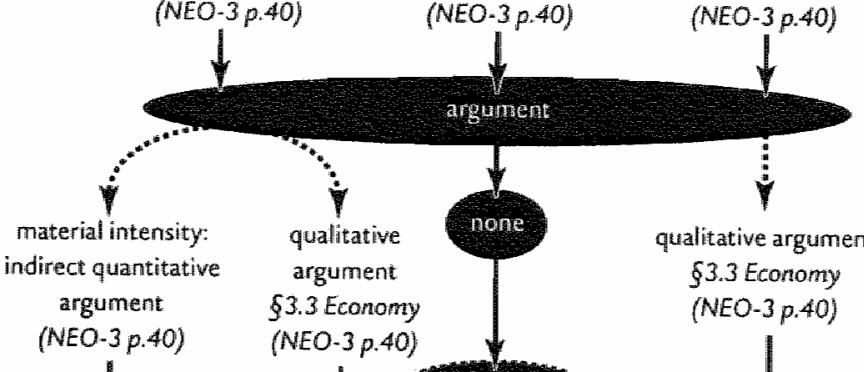

\$3:3 Eiconomy

argument

(NEO-3 $p .40$ )

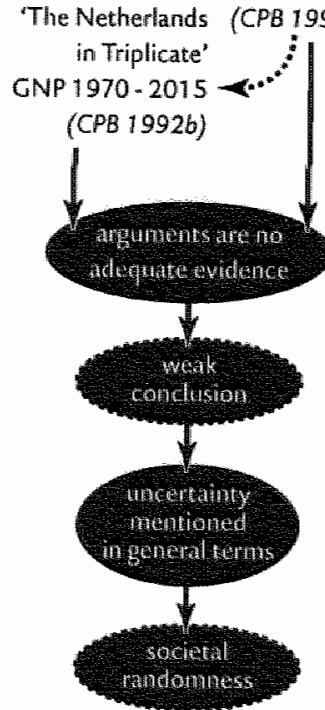

the future

b)

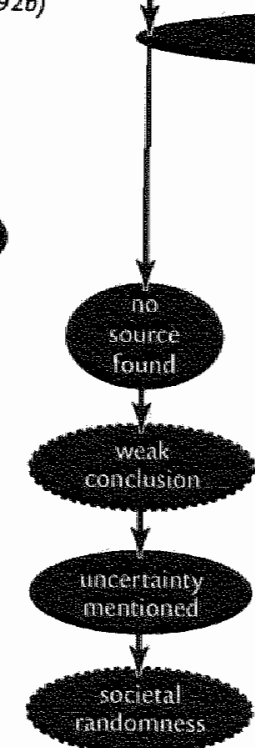

social developments

\$3:3 Economy

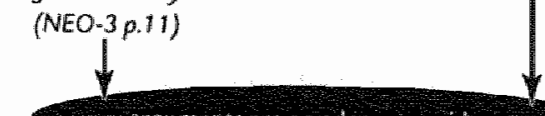

arguments are no adequate evidener

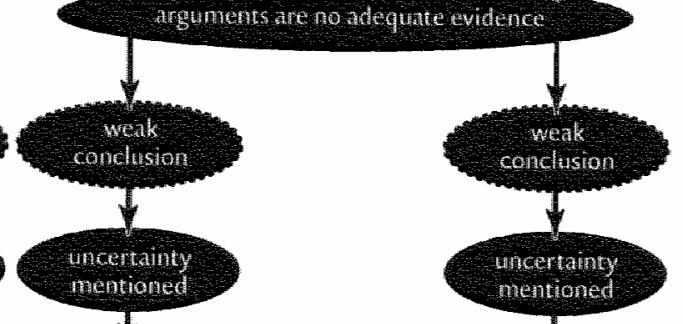

mish tionter

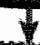

sorietrol lind on oness

sorcetel

lack of oluserwation

FICURE \& Analysis scheme of the argumentation analysis of the statement 'economic developments' 


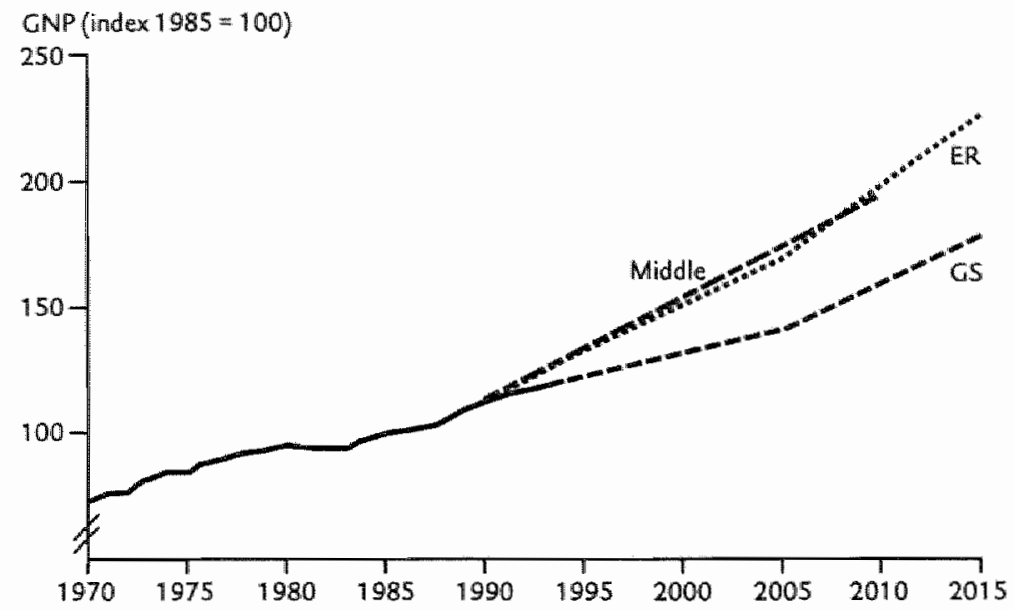

FIGURE 2 GNP trends (Source: National Environmental Outlook-3, figure 3.3.1)

mic Asian Economies, and a cluster of other less-developed countries) are analysed. Based on these analyses, four scenarios have been developed for each world region. The following scenarios were presented for Western Europe: European Renaissance, Global Shift, Balanced Growth and Global Crisis. However, it is not explicitly discussed, nor can it be extracted how the qualitative analysis is translated into quantitative developments in key indicators, such as GNP and use of raw materials. These quantitative trends may be the result of model experiments with the WorldScan model ${ }^{10}$, however this cannot be deduced from the report.

The CPB produced a follow-up scenario document "The Netherlands in Triplicate". Based on the European scenarios outlined in 'Scanning the Future', this second report discusses three of these scenarios for the Dutch economy. The GNP trends for the European Renaissance and the Global Shift scenario presented in "The Netherlands in "Triplicate" correspond with the trends used in the $3^{\text {rd }}$ Environmental Outlook. However, it is not made transparent how these GNP trends are generated. After a thorough comparison between 'Scanning the Future' and the 'The Netherlands in Triplicate', we conclude that it is most likely that the (unmotivated) quantitative trends for GNP development in Western Europe were down-scaled to the national level. However, it is not clear how this was done: it may be an extrapolation of the current Dutch 'distance' to the European average, or a model of the Dutch economy may have been used?

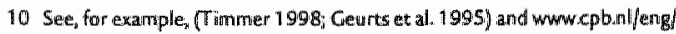

11 (CPB 1992a) 
It can be argued that because RIVM took the trends from a report published by the authoritative $\mathrm{CPB}$, the underpinning is strong. However, there are two counterarguments for this reasoning. First, RIVM provided anyhow the wrong reference: they referred to 'Scanning the Future' instead of the 'Netherlands in Triplicate', where the trends seem to have been taken from. Second, our analysis of the CPB reports indicates that no solid information or logic justification for the trends used in the Environmental Outlooks could be found in the two major documents. It can be deduced from the list of collaborators (see Chapter 6) that analysts from the CPB collaborated in the assessment process underlying the $3^{\text {rd }}$ Environmental Outlook. This implies that RIVM could have questioned the underpinning of the economic scenarios, which obviously played such a dominant role in the whole assessment effor ${ }^{12}$. We therefore conclude that the statement in the $3^{\text {rd }}$ Environmental Outlook regarding GNP development is weak, although the underpinning itself lied beyond RIVM's mandate.

The full argumentation analysis ${ }^{13}$ on economic development is summarised in Figure I. This Figure indicates that the conclusion on economic development as expressed in the Summary Chapter of the $3^{\text {rd }}$ Environmental Outlook is characterised as weak. In view of the importance of this pressure in the assessment process, the observed weakness is problematic, because it is propagated through the causal chains. This means that the weakness of the conclusion on economic development in principle undermines the quality of the full assessment.

In the present case, the observed weakness resulted from lack of underpinning information and justification, or the presented information could not be verified, so that it did not provide solid evidence. It may be that sources of evidence are present, but not further discussed or transparently referred to. 'Weak' is in the first place a judgement on the quality of argumentation, and as such it is not an indicator referring to uncertainty. However, it may be that the weakness of the analysed conclusion is (partly) due to uncertainty: it may be that the importance of the associated uncertainties was not fully recognised, and that as a consequence they were not systematically treated in the assessment process, thereby creating blind spots that could not be covered up in the reporting phase. To that end, it is

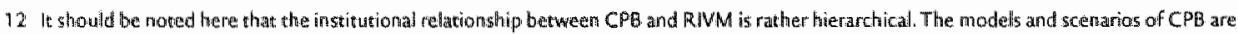
Lumbly used unquestioned by other decision-suppon instituses or ministrits. The above observation with regard to weaknesis of the selected

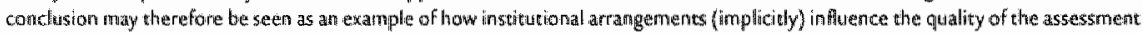

13 As said before, we have limired ourselves here to the argumentation analysis on CNP. becase it tumed out that CNP land not plysical

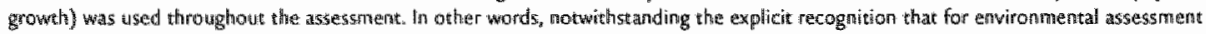

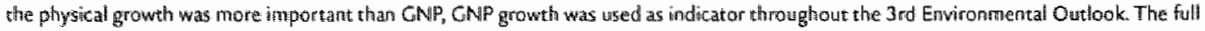
description of the antalysis summarised in the might side of Figure 1 can be fourd in (Langendonck 1999) and (war Assellt er al. 2000). 
relevant to investigate whether any uncertainties pertaining to GNP development are mentioned in the $3^{\text {rd }}$ Environmental Outlook.

Section 3.3 'Economy' of the $3^{\text {rd }}$ Environmental Outlook refers to uncertainty in general terms. The following quote indicates uncertainty in the economic scenarios impacting the assessment of future GNP development:

"Important uncertainties for the future of $($.$) the Dutch economy are formed$ by the development of world trade, European monetary and political unification, the rate of restructuring in Central and Eastern Europe (NEO-3, p.34).

The bold italic uncertainties refer to uncertain economic, institutional and socio-cultural dynamics. In terms of our typology of sources of uncertainty, it seems adequate to characterise the mentioned uncertainties associated with future GNP as uncertainty due to variability, and more specific societal randomness. In this case, the lack of knowledge resulting from this particular source of wariability can be considered structural. This implies that it is important to be explicit how these uncertainties are treated in the assessment, and what it implies for the robustness of the future outlooks sketched in the Environmental Outlook.

These obserwations combined seem to suggest that in this case it is reasonable to hypothesise that the weakness of the argumentation is partly due to unsystematic treatmenc of uncertainty.

\subsection{EXAMPLE OF A STRONG CONCLUSTON}

The number of people experiencing noise nuisance by road traffic is an example of an effect on human well being, and can thereby be considered as one of the ourputs of RrVM's assessment. The $3^{\text {rd }}$ Environmental Outlook features the following conclusion about noise pollution:

'Between 1985 and 1990 , the percentage of people experiencing noise nuisance as a result of road traffic rose from $59 \%$ to $6 \mathrm{r} \%$ and the percentage of people suffering serious nuisance rose from 19-20\% of the Dutch population. Despite the increase in car traffic and the expansion of the road network, the proposed policy will reduce the number of people experiencing serious nuisance to 10-15\% of the population between 1990 and 2000 . The number of people experiencing some nuisance will fall less sharply. The targets for the year 2000 will be easily achieved. However, the target for 20 ro (a negligible level of serious muisance) will not be achieved" (NEO-3, p.22). 
The conclusion in the specific section about noise pollution in Chapter 4 is more detailed than in the summary:

(".) the percentage of people experiencing noise nuisance or serious noise pollution between 1990 and 2000 will fall below the 1985 levels, which were $59 \%$ (nuisance) and $19 \%$ (serious pollution). In the ER scenario, these levels will drop to $56 \%$ and $15 \%$ and in the GS scenario to $51 \%$ and $12 \%$ (see Figure $4.6 .2 a$ ) $(\mathrm{NEO}-3$, p.r2o).

The $12 \%$ and $15 \%$ mentioned here roughly match with the $10 \%-15 \%$ range in the overall conclusion. The phrasing '... will fall...' is here quantitatively argued by the estimates that the level of noise nuisance will decrease from $59 \%$ to $51 \%$ or $56 \%$ respectively. Figure 4.6.2a (see Figure 3) further illustrates the described trend. However, neither the figure, nor the above quote, ind icates how these numbers were generated. Chapter 4 does not provide further justification or further references. Nevertheless, we decided to screen the background documents, of which the background document on traffic and transport ${ }^{14}$ seemed the most relevant one.

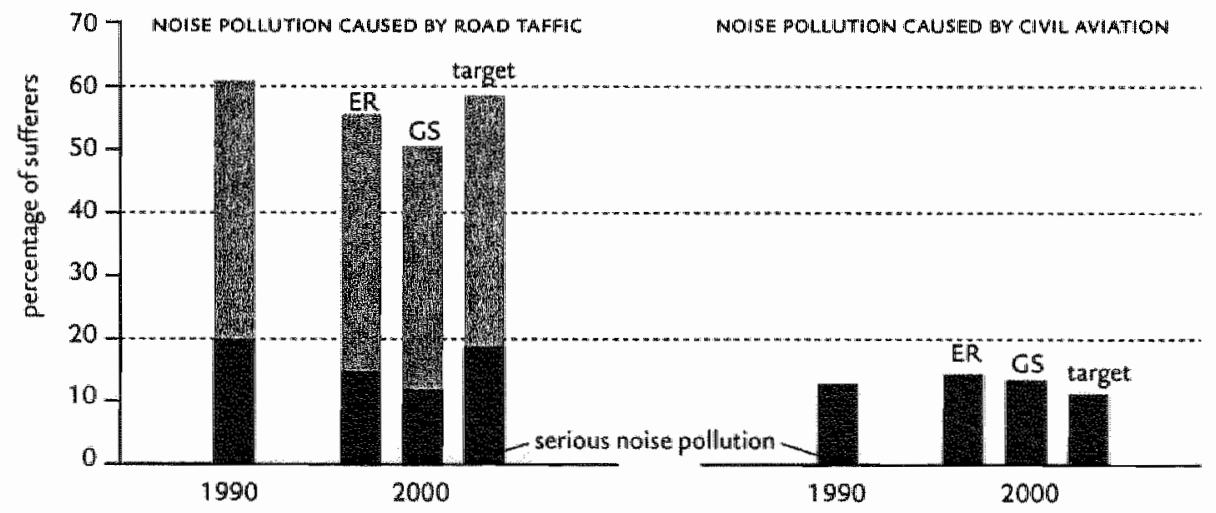

FHCupe 3 Trends in noise pollution (Source: National Environmental Outlook-3, figure 4.6.2)

This background document presented the necessary in formation and argumentation in a transparent manner. It provides comprehensive and motivated information pertaining to noise nuisance by road traffic that matches with the conclusion on the anticipated effects of policy measures in relation to set policy targets. Factors that determine noise pollution and nuisance are elaborated and assessed in a structured manner. Each step in the calculations, as well as assumptions and references, are made explicit. The report is transparent in a consistent way on the scientific ori- 
gins of methods and numbers. Although a specific reference in the $3{ }^{\text {rd }}$ Environmental Outlook to this particular background document in the relevant section would have been in place, we argue that the conclusion in the Summary Chapter on noise nuisance due to road traffic can be classified as strong (see also Figure 4).

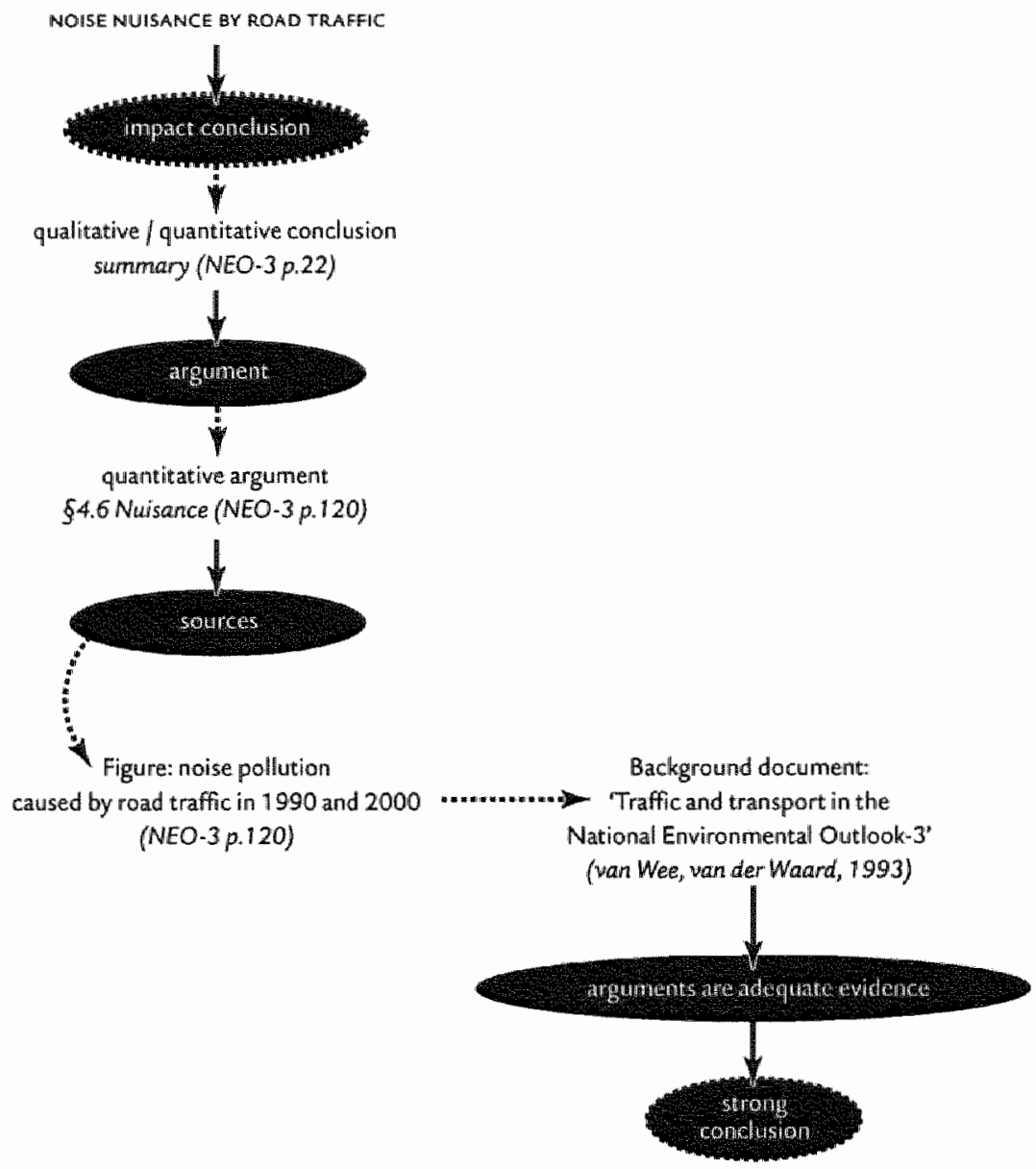

FIGURE 4 Analysis scheme of the argumentation analysis of the statement on 'noise nuisance by road traffic'

Strong is in the first place a quality judgement. It does not say that the conclusion is truth or false, or certain or uncertain. It says that the conclusion is built on a solid and transparent line of reasoning. In other words, strong does not mean that no uncertainty is involved. How can we use the quality judgement in our search to uncertainty? Strong implies that it in principle should be possible to recognise which uncertainties play a role and how they are considered in the underlying assessment. It can however be argued that argumentation that is judged as strong hides uncertainty; 
it may be that only experts in the field ${ }^{15}$ are able to recognise that the underlying arguments involve uncertainties that are not considered in the assessment. Nevertheless, in view of our aims, it is worthwhile to analyse whether uncertainties are mentioned in case of strong conclusions and how they are treated.

The $3^{\text {td }}$ Environmental Outlook itself does not mention uncertainties regarding noise pollution caused by road traffic. The many assumptions in the background document on transport and traffic signify uncertainties. The sources of uncertainties can in principle be deduced from the assumptions, which also hint how the uncertainties are interpreted. Such a detailed analysis was beyond the scope of this case study. Apart from being not crucial to the case-study questions and being too timeconsuming, it would have required expert knowledge and understanding of this particular topic, which was anyhow not available in the research team. We have limited ourselves to trace sources of uncertainty directly from the text. The background report on transport and traffic, for example, explicitly mentions conflicting evidence as a source of uncertainty:

'The data used in the noise calculations with respect to the composition of the traffic (see Table 6.3.4) are not fully in agreement with the data that would be gathered from chapter 3 based on the volume developments. In the first place, the volume of heawy goods transport in rural areas will be less than is expected; assumed is that the intensities of this category transport in the future will stabilise with respect to 1990 . Secondly, there is a difference between the definition of the transport categories in the mobility data and the prescription of noise calculations' (p.8i).

The case indicates that systematic treatment of uncertainty in the underlying assessment and in the actual report improves the quality of the argumentation, and enables interested readers to understand and accept the conclusion.

15 As opposed to the kind of generallists who performed the reported argurnentiation analyses. 


\subsection{SUMMARY OF THE VERTICAL DOCUMENT ANALYSIS}

The other ro selected concluding statements extracted from the Summary Chapters of the $3^{\text {rd }}$ and $4^{\text {th }}$ Environmental Ourlooks (see Box I) have been analysed according to the same procedure ${ }^{16}$. We limit ourselves here to a summary. In Box 2 the major findings are summarised per statement. The accompanying argumentation analysis schemes can be found in Appendix (3).

BOX 2 Main findings per selected concluding statement

POPULATION

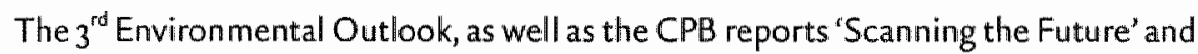
'The Netherlands in Triplicate', all utilise the same population trends without a reference and without explaining how these trends are generated. A thorough analysis of reports leads us to conclude that certain projections of the United Nations (without any proper reference) are used as starting point of the assessment in 'Scanning the Future', followed by an unmotivated downscaling to 'The Netherlands in Triplicate', which trends are adopted in the $3^{\text {rd }}$ Environmental Outlook. We did not find any proper justification for these trends, and therefore conclude that the concluding

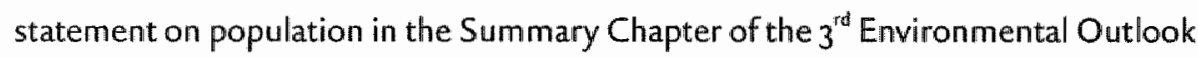
should be classified as weak.

USE OF PRIVATE VEHICLES

The statement on the use of private vehicles is comprehensively and solidly underpinned in the background document on traffic and transport ${ }^{7}$. The conclusion in the Summary Chapter of the $3^{\text {rd }}$ Environmental Outlook on the use of private vehicles can therefore be characterised as strong.

CARBON DIOXIDE EMISSIONS

A footnote in the section $4.1^{\prime}$ 'Changes in global biosphere' (NEO-3, p.67) refers to a background document on climate change. This report "Background document to 
BOX 2

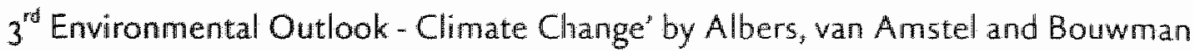
was, according to the reference list, still in preparation at the time the $3^{\text {rd }}$ Environmental Outlook was published (1993). However, at the time of our analysis (1999) this particular report could not be found, which lead us first to conclude that it had never been finished. While finishing our research, we found out that the report was eventually published, but the title and the authors had changed: "Greenhouse gas emissions in the Netherlands 1990,1991,1992 and projections for $1990-2010^{118}$ under authorship of van Amstel. This report mentions that the trend in energy prices is the most important uncertainty with regard to $\mathrm{CO}_{2}$-emissions. However, although the concluding statement seems to suggest that experiments have been carried out with the two scenarios and variations in energy prices, the background report does not document such experiments. It only says that the prices are higher in the ER than in the GS scenario. With regard to the ranges, the background report indicates a $4.3 \%$ increase in $\mathrm{CO}_{2}$-emissions for the ER scenario (opposed to the 5 -10\% range in the conclusions) and an increase of $2.7 \%$ in the GS scenario (as opposed to $5 \%$ in the concluding statement). The background report does indicate other experiments with additional policy; these experiments results into a decrease in $\mathrm{CO}_{2}$-emissions of $1.1 \%$ in the ER scenario and $2.7 \%$ in the $C 5$ scenario respectively. We therefore argue that the conclusion with regard to $\mathrm{CO}_{2}$-emissions is weak.

\section{DEPOSITION OF ACID EQUIVALENTS}

The scarce information on the deposition of acid equivalents involves a repetition of the conclusion with some, very limited, text on underlying causes. A potential source of information is Figure 4.2 .1 (NEO-3, p.77) in Chapter 4 (see Figure 5), in which the amounts mentioned in the conclusion are reflected. However, neither references nor footnotes refer to a background document that indicates how the conclusion, including the quantitative estimates, can be justified. The conclusion on deposition of acid equivallents in the Summary Chapter of the $3^{\text {nid }}$ Environmental Outlook is thus classified as weak. 


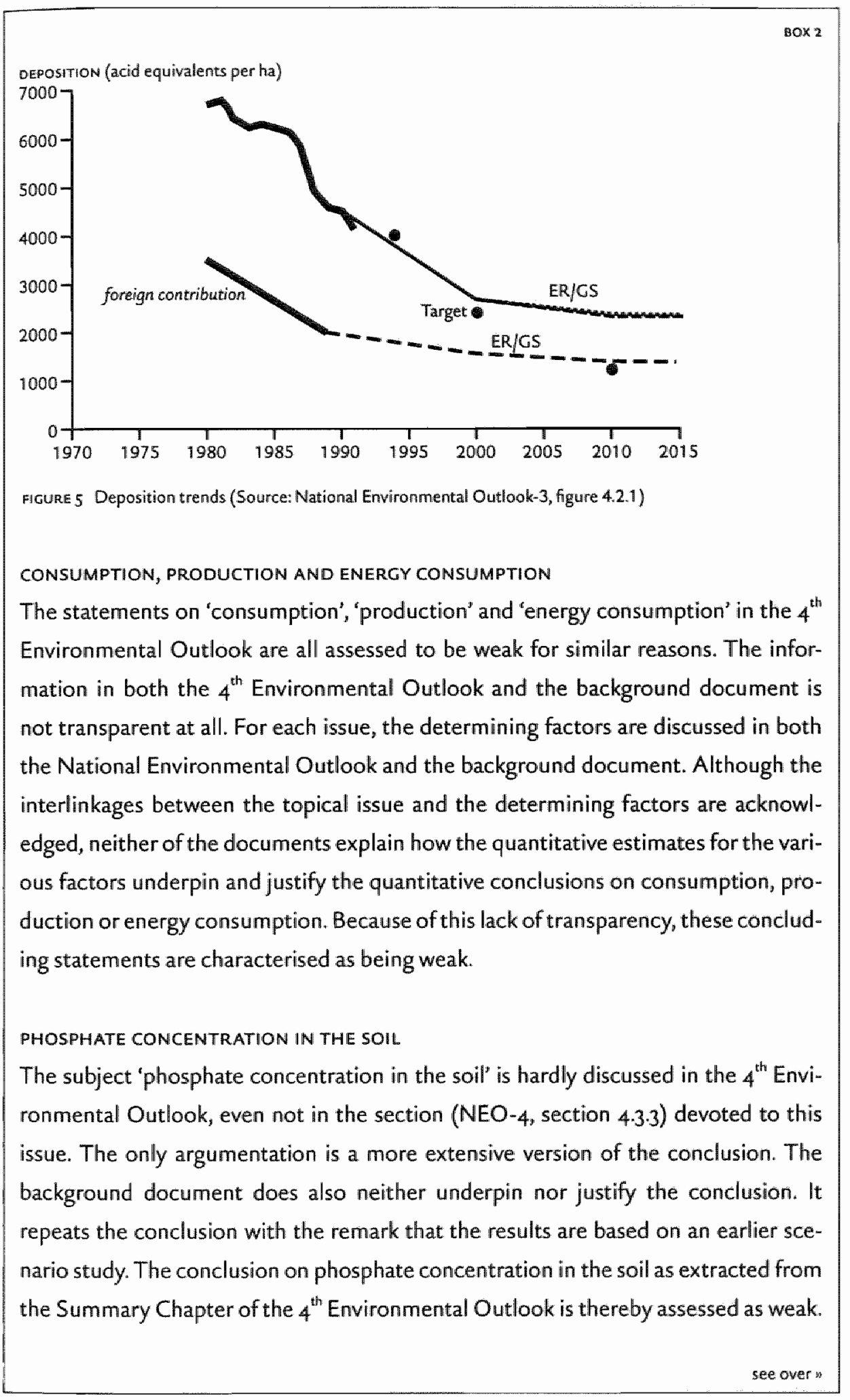


$\operatorname{BO} \times 2$

\section{HEALTH IMPACTS OF FINE DUST}

Despite the acknowledgement that little is known about the relation health impact versus fine dust, in section 4.2 .5 of the $4^{\text {th }}$ Environmental Outlook it is made transparent on what kind of information and which assumptions justify the conclusion on health impacts of fine dust. The background document presents the underlying assumptions and the associated uncertainties in a transparent and understandable way. The concluding statement on health impacts of fine dust can thus be classified as strong. The following quote indicate that the uncertainties associated with the issue under concern can be categorised as lack of measurements and ignorance:

'A lot of uncertainty still exists about the causality of the relationship between the aerosal air pollutiom and the different forms of health damage. (.) It is unclear which components of the mix are primary responsible for the heaith effects, and which mechanisrns play a role" (background document NEO-4,, .162 ).

\section{DESICCATION}

The $4^{\text {th }}$ Environmental Outlook (see section 4.3.4) contains little information on desiccation that can serve as argumentation for the conclusion. The background document, however, clarifies in a transparent way how the conclusion is generated. The discussed assumptions, determining factors and the additional information match with, and thereby justify, the conclusion. The conclusion on desiccation in the Summary Chapter of the $4^{\text {th }}$ Environmental Outlook can thus be classified as strong. With regard to uncertainty, the following quote matters:

\footnotetext{
"ll is unclear to what extent a rise in groundwater level with $25 \mathrm{~cm}$ would be enough to desiccation effects' (NEO-4, P.159).
}

This uncertainty can be classified as structural uncertainty (ignorance, indeterminacy), which may be due to variability in the natural system (i.e. natural randomness).

Table I provides a summarising overview indicating the quality of the argumentation, and whether uncertainties are mentioned, and if so, which sources.

Our argumentation analysis of the a-select extracted concluding statements of the $3^{\text {rd }}$ and 4 th Environmental Outlook indicate that 8 out of 12 can be characterised as weak, and that only 4 were classified as strong (see Table r). If we compare the classifications of the selected statements among the two Environmental Outlooks, we 


\begin{tabular}{|c|c|c|c|c|c|}
\hline \multirow[b]{2}{*}{ NEO-3 } & \multirow[t]{2}{*}{ Analysed Issues } & \multicolumn{2}{|c|}{ Ärgwmentation } & \multicolumn{2}{|c|}{ Uncertainties mentioned? } \\
\hline & & Weak & Strong & No & Yes: source \\
\hline \multirow[t]{3}{*}{ pressure } & Economy & $\mathrm{x}$ & & 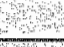 & - societal randomness \\
\hline & & & & 3 & $\begin{array}{l}\text { - lack of measurements / } \\
\text { obserwations }\end{array}$ \\
\hline & Population & $\mathrm{x}$ & & $\mathrm{x}$ & \\
\hline \multirow[t]{5}{*}{ state/impact } & Noise nuisance by road traffic & मी? & $x$ & $x$ & \\
\hline & Use of private vehicles & की & $x$ & $\mathrm{x}$ & \\
\hline & $\mathrm{CO}_{\mathrm{z}}$-emission & $\mathrm{X}$ & & 3 & - societal randomness \\
\hline & Deposition of acid equivalents & $\mathrm{X}$ & & $\mathrm{x}$ & \\
\hline & Total & $4 / 6$ & $2 / 6$ & $5 / 6$ & $3 / 6$ \\
\hline
\end{tabular}

NEO-4

\begin{tabular}{|c|c|c|c|c|c|}
\hline \multirow[t]{3}{*}{ pressure } & Consumption & $x$ & & $\mathrm{x}$ & \\
\hline & Production & $x$ & & $\mathrm{X}$ & \\
\hline & Energy consumption & $\mathrm{X}$ & & $\mathrm{X}$ & \\
\hline \multirow[t]{4}{*}{ state/intact } & Phosphate concentration in soil & $\mathrm{x}$ & & $\mathrm{X}$ & \\
\hline & Healith impacts of fine dust & & $x$ & & $\begin{array}{l}\text { - lack of nneasurements } \\
\text { - ignorance }\end{array}$ \\
\hline & Desiccarion & 4 & $\mathrm{x}$ & Has & $\begin{array}{l}\text { - indeterminacy } \\
\text { - natural randomness }\end{array}$ \\
\hline & Total & $4 / 6$ & $2 / 6$ & $4 / 6$ & $2 / 6$ \\
\hline
\end{tabular}

TABLE : Overview of the results of the argumentation analysis

can conclude that the picture does not differ between the two Outlooks. If the selected conclusions could be considered as representative for the whole Environmental Outlook, this observation would suggest that the quality of argumentation did not substantially improve over time. However, the rather random selection of statements, the number of statements selected, the limited broadness of the performed vertical analysis in view of the available text and the fact that we have limited ourselves to the two recent Environmental Outlooks, do not allow us to address this hypothesis in an acceptable manner.

In the case of strong conclusions, uncertainty is usually acknowledged. In some cases, uncertainties can be clearly identified in the text, in the other cases they can in principle be deduced from a detailed analysis of the assumptions. However, the latter type of analysis requires expert knowledge on the topic. In the context of this case study, this implied that it turned out to be beyond our reach to assess which uncertainties are salient in view of the robustness of the conclusions. Furthermore, the consequence is that it is beyond the average reader's capabilities to understand which uncertainties are considered in the assessment. 
In the case of weak conclusions, uncertainties are not recognised, with two exceptions; in the argumentation associated with the statement on economic development and on $\mathrm{CO}_{2}$-emissions uncertainties are mentioned, although it is unclear how they are treated. We can only wonder whether uncertainty played a role in the analysed weak argumentation. However, our analysis of the weak conclusion on economic development as well as our analyses of the strong conclusions indicate that it is sensible to postulate that a systematic treatment of uncertainty could provide a basis for improvement of the transparency and quality of the argumentation.

The argumentation analysis yields as a general picture that uncertainty is not explicitly nor consistently considered in the Environmental Outlook reports. The vertical analysis did not allow us to recognise which uncertainties are salient to the assessment and how this uncertainty was managed in the underlying assessment process. We thus conclude that the Environmental Outlook reports are not transparent with regard to uncertainty. That does not necessarily mean that uncertainty was not addressed in the assessment process. It only means that the vertical document analysis does not allow us to fulfil two of the key aspirations of the case-study, i.e. to describe the state-of-the-art in rivm's uncertainty management and to provide an overview of uncertainties salient to the Environmental Outlooks.

\section{Searching for sources of uncertainty}

The consequence of the design of the vertical argumentation analysis is that we only accidentally traced particular sources of uncertainty. To complement this analysis, we decided to scrutinise the Environmental Outlooks again, but this time with the ambition to find concrete examples for each source of uncertainty ${ }^{19}$. In this way we can roughly assess whether in principle all sources of uncertainty played a role in the previous Environmental Outlooks. Box 3 reports the concrete examples for the various sources of uncertainty.

19 Set Chapter J.A. 


\section{BOX 3 Sources of uncertainty}

\section{UNCERTAINTY DUE TO VARIABILITY}

\section{Randomness of nature}

- '() it is not clear to what degree processes such as deforestation, the loss of species variefy, acidification, desiccation, the spread of dust particles in the atmosphere, the damage to organisms by azone at ground level or by UW irradiation, and the introduction of numerous exotic substances into the enwironment may change the feedback mechanisms in the glabal climate system' (NEO-2, p.23).

- "It can therefore not be determined with sufficient certainty what those two trends (i.e. "check") imply for the number of days with summer smogin $2020^{\circ}$ (NEO-4. P.log).

\section{Behavioural variability}

- "There is a great deal of uncertainty as to the degree to which farmers will be prepared to purchase manuref from other farmers' (NEO-3, P.61)

- There is still little understanding of the degree to which provincial and local authorities (...) implement the adopted envirommental policy $(\ldots)^{\prime}($ NEO -3, P.34).

\section{Value diversity}

- All estimates of future costs in the Environmental Outlooks involve a level of discounting, which by def. nition reffect differences in norms and values.

\section{Societal processes}

- No prognoses have been made for the future, partly in wiew of the uncertainty associated with international developments' (NEO-3, p.122).

- "Future social developments are, of course, extremely uncertalin, particularly when they concerni a period of over a decade: (NEO-3, p. 33)

\section{Technological surprise}

- For trucks and busses it is assumed that emission levels are sharpened in 2000 (stage III). Hn view of technological uncertainties, stage IN levels have not been taken into account.' (NEO-4, p.42).

\section{UNCERTAINTY DUE TO LACK OF KNOWLEDGE}

\section{Inexactness}

- 'With the current measures, a red wetion of approximately 20 \% will therefore be possible' (NEO-2, p.231).

- "Agricultural products, foods and fertiliser hold a 40 to $45 \%$ shaure in domestic road haulage" (NEO-3, P.44).

- "The emission of phosphate increases in all senarios over the period 1995 -2000 with circa $20 \%$ " $(\mathrm{NEO}-4, \mathrm{p}, 86)$. 
$18 \times 3$

\section{Lack of observations/measurements}

- 'Since a complete overwiew of polluted locations does not exist, it is impossible to give a reliable picture of the size and costs of a soil cleanup operation' (NEO-3. p.21).

- In order to establish the current and future effects of the emission of gases at higher altitudes with more certainty, and particularly the impact of emissions of $\mathrm{NO}_{x}$ and $\mathrm{H}_{3} \mathrm{O}_{3}$ more information will have to be gathered about the processes (both chemical and physicaly involved and about emission levels. Imformation on both issues is limited at the present time" (NEO-3: P.47).

- "lengthy series of measurements of UV-radiation are not available" (NEO-4, p.163).

\section{Practically immeasurable}

- The health impacts of frne dust will decrease with $25 \%$ between 1995 and 2020 assuming that all components of fine dust are equally responsible for thealth impacts" ${ }^{120}$ (NEO-4, p.110).

\section{Conflicting evidence}

- 'The composition of the imported animal feed will also change as a result of efforts to reduce the average phosphorus and nitrogen content of roughage. A start was recently made, but the available data about the results vary widely $(\ldots, y)(\mathrm{NEO}-2$, p.108).

- 'It has been estimated that there may be 110.000 seriously polluted lacations, for which the total cleanup costs would be NLG 50 billion. However, recent data point to even higher costs' (NEO-3, p.21).

\section{Ignorance}

- 'A lot of uncertainty still exists about the causality of the relationship between the aerosol air pollution and the different forms of health damage. (..) It is unclear which components of the mix are primarily responsible for the health effects, and which mechanisms play a role' (background document NEO-4, p.162).

\section{Indeterminacy}

- Important uncertainties for the future of the Dutch environment involve the devellopment of world trade, European monetary and political unification, the rate of restructuring in Central and Eastern Europe and the expected internationall efforts to protect the environment' (NEO-3, p.34). 
This source-oriented document analysis indicates that all sources of uncertainty occur in RIVM's environmental assessments so far, although from such an analysis we cannot conclude whether all sources are salient ${ }^{21}$. The examples found for each source nevertheless seem to suggest that all sources of uncertainty at least to some degree matter in the environmental assessment, and may thus to a smaller or larger extent impact the policy conclusions. Furthermore, we did not find concrete examples of recognised uncertainty in any Environmental Outlook, which could not be straightforwardly classified according to our typology. This finding suggests that the typology of sources of uncertainty presented in this thesis has something to offer to the practise of decision-support.

\section{Horizontal document analysis}

As outlined in the previous Chapter, the aim of the horizontal document analysis was to compare the various Environmental Outlooks in order to understand whether and if so how, RIVM's approach to uncertainty management has changed over time. The horizontal document analysis comprised two types of analysis. First, we have compared the number and type of linguistic uncertainty expressions. Second, we have investigated the scenario approach applied in the four Environmental Outlooks.

\section{I. LINGUISTIC ANALYSIS}

The source-oriented document analysis as reported above already illustrates that linguistic expressions in the Environmental Outlook reports indicate uncertainty. Uncertainty due to inexactness is quantitatively expressed by margins, but linguistically by wordings such as 'roughly', 'approximately' and 'circa'. Phrasings like 'a possible trend', 'it is assumed' and 'it is not clear' indicate more structural uncertainty. Box 4 provides some illustrative quotes from the $3^{\text {ril }}$ and $4^{\text {th }}$ Environmental Outlook in which uncertainty is hinted at in a linguistic manner.

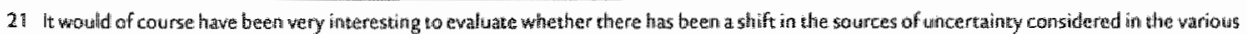

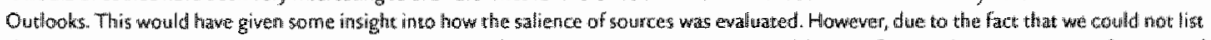

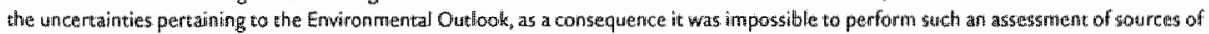
uncercainty treated ins the Environmental Ouklooks over time. 


\section{BOX 4 Examples of linguistic expressions indicating uncertainty}

\section{EXAMPLES FROM THE $3^{\text {ENVIRONMENTAL OUTLOOK }}$}

- 'There are also great umcertainties about the effectiveness of enforcement (...)' (NEO-3, p.43).

- There is still too little data to allow a reliable opinion of the dlegree to which the agreed objectives will actually be achiewed' (NEO-3, P.35).

- In ER, this growth is restricted to $35 \%$ between 986 and 2010 and in CS to 0 ver $25 \%$ (NEO-3, p.42-43).

- 'The ozone layer abowe the latitude of the Netherlands is expected to become at least $10 \%$ thinner' (NEO 3 , p.67)

- 'The banning of lead shot for hunting will cause a radical drop in lead (approximately $75 \%$ )' (NEO-3. p.102)

\section{EXAMPLES FROM THE 4 TH ENVIRONMENTAL OUTLOOK}

- 'The private car use will increase between 1995 and 2020 with roughly 25 till $35 \%$ (...)' (NEO-4, p. 39).

- 'the production volume of the whole livestock will decrease with circa 10\%' (NEO-4, P.4\%).

- In 2010 the emissions will be 5.2 to $55 \%$ less than in 1980 (...) (MEO-4, p. 85).

- The results of those two trends for the number of days with summer smog in zozo can therefore not be determined with sufficient certainty" (NEO-4, p.109).

- This concentration leads to approximately 400 cases of lung cancer $(\ldots)$ (NEO-4, p.113).

With the horizontal document analysis, we compared the use of linguistic expressions indicating uncertainty over the four Environmental Outlooks. We addressed this issue in two ways:

- we selected two representative issues addressed in all four Environmental Outlooks (i.e. demography (issue A) and local air pollution (issue B)) for which we compared the use of linguistic expressions hinting at uncertainty. We compared the average number of linguistic uncertainty expressions per effective page to investigate whether the relative use of linguistic uncertainty expressions varies over the different assessments. To that end, the total number of uncertainty expressions was divided by the number of effective text pages. The latrer implies that the number of pages was corrected for graphs, figures and tables (see Table 2). 


\begin{tabular}{|c|c|c|}
\hline & sections on issues $A$ and $B$ & total effective pages \\
\hline$N E O-I$ & $\begin{array}{l}\text { A Demographic developments p.14-17 } \\
\text { B. Air pollution inner city p.312-322 }\end{array}$ & $72 / 3$ \\
\hline $\mathrm{NEO}_{-2}$ & $\begin{array}{l}\text { A Demographic developments p.49-52 } \\
\text { B. Air pollurion in towns p.390-399 }\end{array}$ & $75 / 6$ \\
\hline $\mathrm{NEO}-3$ & $\begin{array}{l}\text { A Population p.37-38 } \\
\text { B. Local air pollution p.122-123 }\end{array}$ & $12 / 3$ \\
\hline $\mathrm{NEO}-4$ & $\begin{array}{l}\text { A Population and consumption p.25.28 } \\
\text { B Air pollurion (urbam area) p.108.110 }\end{array}$ & $31 / 3$ \\
\hline
\end{tabular}

TABLE 2. Location and number of effective text pages

- we counted the word "uncertainty", and other directly related words as 'uncertain', 'uncertainties' and 'not certain' in the Summary Chapter of each Environmental Outlook. We compared the relative occurrence of "uncertainty" per effective text page ("uncertainty density") for all four National Environmental. Outlooks.

Table 3 summarises the results of the linguistic analysis for the two selected issues, while Table 4 reports the analysis of uncertainty-expressions in the Summary Chapters. Furthermore, Figure 6 shows the uncertainty-density deduced from the latter analysis.

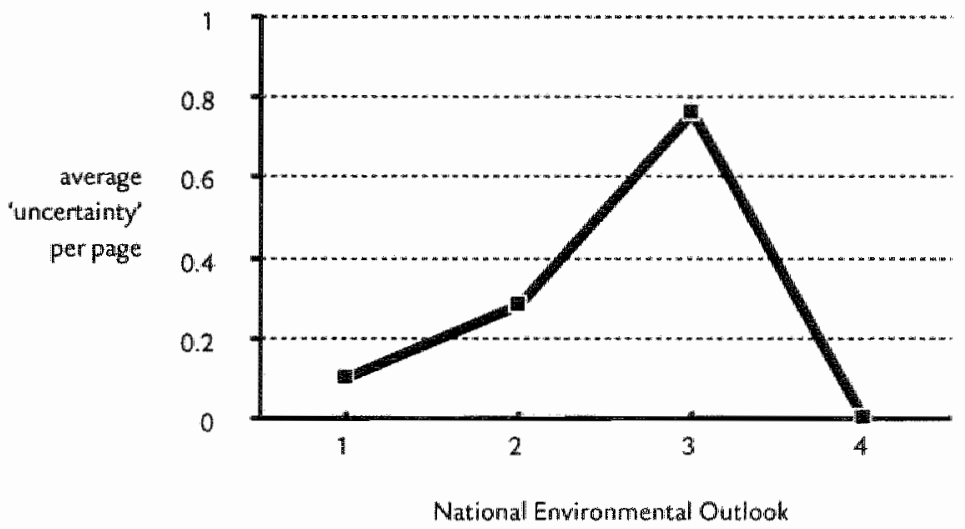

FHCURE 6 Uncertainty density in the summary chapters 


\begin{tabular}{|c|c|c|c|c|c|c|c|c|}
\hline \multirow{2}{*}{$\begin{array}{l}\text { Lingtistic expresstons which. } \\
\text {...indicate uncertainties }\end{array}$} & \multicolumn{2}{|c|}{ NEO-1 } & \multicolumn{2}{|c|}{$\mathrm{NEO}-2$} & \multicolumn{2}{|c|}{$\mathrm{NEO}-3$} & \multicolumn{2}{|c|}{$\mathrm{NEO}-4$} \\
\hline & $A$ & $B$ & $A$ & $B$ & $A$ & $B$ & $A$ & $B$ \\
\hline It is expected / expectation / expects & 2 & $r$ & 7 & & 3 & & 1 & \\
\hline It is estimated/festimation / estrmate & 2 & & & & 2 & 1 & & \\
\hline It is assumed / assumption / assume & 1 & & & 2 & & & & I \\
\hline $\begin{array}{l}\text {. can not be assessed with a } \\
\text { certain level of certainty }\end{array}$ & & & & & & & & I \\
\hline There is a great deal of uncertainty & & & & & & i & & \\
\hline It is diffcult to describe & & $\sqrt{1}$ & & & & & & \\
\hline It is hard to predict & & 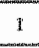 & & & & & & \\
\hline Not clear is & & 1 & & & & & & \\
\hline The uncertainty is & & $i$ & & & & & & \\
\hline total & 3 & 5 & 7 & 2 & 5 & 2 & $l$ & 2 \\
\hline total indications of uncertainties & & & & & & & & \\
\hline
\end{tabular}

\begin{tabular}{|c|c|c|c|c|c|c|c|c|}
\hline ...indicate estimations & $A$ & $B$ & $A$ & $B$ & $A$ & $\boldsymbol{B}$ & $A$ & $B$ \\
\hline Allmost & 1 & & 2 & & & & & \\
\hline Over & 1 & 2 & 2 & & 3 & & & \\
\hline Approximately & & & 4 & & $r$ & & & \\
\hline More than & & & 1 & & & & & \\
\hline Around & & & I & & & & & ॥ \\
\hline Probuably & & & 1 & & & 2 & 1 & \\
\hline Considerably & & & 1 & & & & & \\
\hline At least & & & & I & & & & \\
\hline At most & $\mathrm{I}$ & & & & & & & \\
\hline More than & & 2 & & 1 & & II & & \\
\hline Less than & & & & & & 1 & & \\
\hline Somewhere between & & & & & & $\|$ & & \\
\hline About & & & & 4 & & 3 & & \\
\hline Circal & & 5 & & & & & & 2 \\
\hline Roughy & & & & & & & & 2 \\
\hline total & 3 & 9 & $n$ & 6 & 4 & 8 & 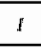 & 5 \\
\hline total indications of estimations & \multicolumn{2}{|c|}{$\sqrt{2}$} & \multicolumn{2}{|c|}{18} & & \\
\hline
\end{tabular}

\begin{tabular}{|c|c|c|c|c|c|c|c|c|}
\hline ratio "uncertaingy" versus 'estimations' & $5: 3$ & $5: 9$ & $7 \times 2$ & 2.6 & $5: 4$ & $2: 8$ & $n: 1$ & $2: 5$ \\
\hline ratio "uncertainty" wersus & \multirow{2}{*}{\multicolumn{2}{|c|}{$10: 12$}} & \multirow{2}{*}{\multicolumn{2}{|c|}{$9: 18$}} & \multirow{2}{*}{\multicolumn{2}{|c|}{$7: 12$}} & \multirow{2}{*}{\multicolumn{2}{|c|}{$3: 6$}} \\
\hline "escimations" $\mathbf{A}+\mathbf{B}$ & & & & & & & & \\
\hline
\end{tabular}

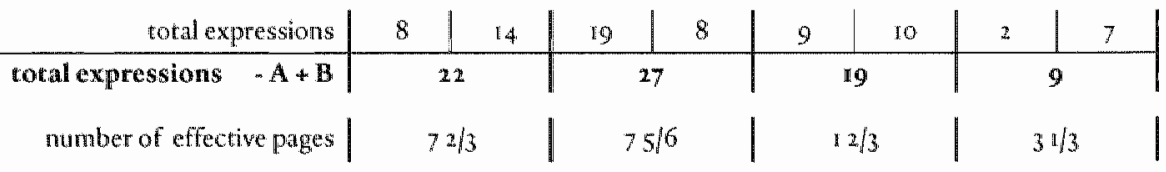

average number of linguistic expressions per page
2.9<smiles>C=[IH]</smiles>

$3 \cdot 4$

1
II

2.7 
In the issue-oriented linguistic analysis, we distinguished two sorts of linguistic expressions, i.e. estimations indicating unreliability, and uncertainty expressions hinting at structural uncertainty. Comparison of the ratio between 'indication of uncertainties' vs. 'indication of estimations' for the two issues together and the total indications of the two types of linguistic expressions seem to suggest that linguistic expressions involving estimations appear more often. However, this picture is not convincingly confirmed if we consider the ratios per Environmental Outlook per issue. In the case of local air pollution, unreliability is more often expressed then more structural uncertainty in all Environmental Outlooks. In the case of demographic developments such a conclusion cannot be drawn: the ratio of the sort of linguistic expressions suggests that structural uncertainty in the $\mathrm{I}^{\text {st }}$ and $3^{\text {rd }}$ Environmental Outlook slightly dominates, while the $2^{\text {tud }}$ Environmental Outlook indicates the opposite. These observations suggest that it seems impossible to infer from such a linguistic analysis which type of uncertainty is salient in the assessment of a particular topic.

If we take the Environmental Outlooks as adequate representations of the stateof-the-art knowledge, the results presented in Table 3 do not allow to judge from the number of linguistic expressions whether either demographic developments or local air pollution involve more uncertainty. The number of uncertainty expressions and the ratio between the two types of uncertainty expressions in the $2^{\text {nd }}$ Environmental Outlook suggest that demographic developments are more uncertain, while the outputs of the linguistic analysis of the other Environmental Outlooks would lead to the opposite conclusion.

Building upon the above observations, we argue that there has not been a consistent RIVm strategy whether and how often uncertainty is expressed in the literal text. The linguistic analysis seems to suggest that is more a matter of individual style and preference.

Table 3 reveals that both in absolute and in relative terms the $4^{\text {th }}$ Environmental Outlook involves significantly less linguistic expressions indicating uncertainty, whether unreliability or structural uncertainty, than the earlier Environmental Outlooks. This issue-oriented horizontal document analysis suggests that the $3^{\text {rd }}$ Environmental Outlook report is in its phrasing the most conscious about uncertainty. The average number of linguistic expressions per effective text page in the $3^{\text {ri }}$ Environmental Outlook is more than three times the uncertainty density of the previous Environmental Outlooks and is more than four times of its successor's uncertainty density. It is rather unlikely that the assessment at the time of the $3^{\text {rd }}$ 
Environmental Outlook was so much more uncertain than the other environmental assessments. If we compare the uncertainty density over time, we see a slight increase between the $\mathrm{r}^{\text {st }}$ and $2^{\text {nd }}$ Environmental Outlook, then an extraordinary peak, and then a decline to an uncertainty density below the level of the $\mathrm{I}^{\text {st }}$ Environmental Outlook.

The above picture is confirmed by the summary-oriented linguistic analysis (see Table 4 and Figure 6). In the summary of the $\mathrm{r}^{\text {st }}$ Environmental Outlook uncertainty was only once explicitly mentioned. The $2^{\text {nd }}$ Environmental Outlook contains 5 explicit uncertainty expressions in its summary, while II of such expressions where found in the summary of the $3^{\text {rd }}$ Environmental Ourlook. In the most recent Environmental Outlook no uncertainty-expressions were found. The $3^{\text {rd }}$ Environmental Outlook thus communicates uncertainty significantly more explicit than any of the other environmental assessments, both absolutely and relatively speaking.

\begin{tabular}{|c|c|c|c|c|}
\hline wacertainty-expressions & $\begin{array}{c}\text { NEO-I } \\
\text { 'Summary" } \\
\text { p.vIII-p.xx XItr }\end{array}$ & $\begin{array}{l}\text { NEO-2 } \\
\text { "Summary" } \\
\text { p.11-p.39 }\end{array}$ & $\begin{array}{c}\text { NEO-3 } \\
\text { "Summary" } \\
\text { p.9-p.27 }\end{array}$ & $\begin{array}{l}\text { NEO-4 } \\
\text { 'Summary' } \\
\text { p.11mp.19 }\end{array}$ \\
\hline Uncertainty & & 2 & & \\
\hline Uncertain & 1 & & 3 & \\
\hline Uncertaincies & & 3 & 8 & \\
\hline \multicolumn{5}{|l|}{ Not certain } \\
\hline $\begin{array}{l}\text { total number of } \\
\text { uncertainty-expressions }\end{array}$ & $\mathbf{I}$ & 5 & II & $\mathrm{o}$ \\
\hline
\end{tabular}

TABLE 4 Results of the linguistic analysis of the summaries

As already argued above, the results of horizontal linguistic analysis suggest that the number and the sort of linguistic expressions in the Environmental Outlooks is not indicative of the degree of uncertainty involved in the assessment. We conclude that the linguistic approach to uncertainty is not a systematic strategy employed by RIVM.

We might consider the number of linguistic expressions primarily as an indication of Rrvm's attitude towards uncertainty. This means that the horizontal analysis can be used to explore potential attitudinal change since the $\mathrm{I}^{\text {st }}$ Environmental Outlook. In case of an open attitude towards uncertainty, we would expect that the word 'uncertainty' would occur in the text of the Environmental Outlook. If we take that view, the above results suggest that RIVM was paying increasing attention towards uncertainty in its summary texts as well as in the selected issue text between 
1988 and 1993 . Both in the text on the selected cases and in the summary text of the $3^{\text {nt }}$ Environmental Outlook ( 1993 ), the average number of uncertainty expressions was about 3 times as high as in the other Environmental Outlooks. This suggests that in $3^{\text {rd }}$ Environmental Outlook, RIvm expressed an unusual openness and tolerance towards uncertainty in its phrasings. The upward trend broke after the $3^{\text {rd }}$ Environmental Outlook. Our analysis seems to suggest that, as a conscious or unconscious (over)reaction, uncertainty expressions were avoided in the $4^{\text {th }}$ Environmental Outlook. If we take the above numbers of uncertainty expression as indicator for attitude towards uncertainty, the results of our linguistic analysis suggest that RIVM at the time of the $4^{\text {th }}$ Environmental Outlook (1997) had a less open attitude towards uncertainty than about a decade earlier when 'Concern for Tomorrow' was produced. This observation sounds quite counter-intuitive, and it is not confirmed by the argumentation analysis ${ }^{22}$. The value of this inconsistency is that it indicates again that it is not at all straight forward to deduce uncertainties and how they are treated from the Environmental Outlook reports.

\subsection{ANALYSIS OF THE SCENARIOS}

So far, we have focused on argumentation and text analysis. Another way to get insights into RrVM's uncertainty management by means of document analysis is to focus on their scenario-approach and the quantitative outcomes associated with the scenario-analysis. As argued in Chapter $3 \mathrm{~A}$, scenario approaches are used in scientific assessments as method for uncertainty analysis ${ }^{23}$. Especially in the $3^{\text {rid }}$ and $4^{\text {th }}$ Environmental Outlook, it is argued that the scenarios cover the uncertainty concerning future societal developments, as is illustrated by the following quotes:

'The uncertainty concerning future social developments, including economicgrowth, is clearly shown in two contrasting future scenarios" (NEO-3, p.9).

'Given these uncertainties, a frame of reference is essential. $E R$ and GS determine this frame of reference within which the CPB suggests future economic developments are likely to take place (NEO-3, p.34).

'To do justice to the uncertainties, three scenarios are developed. The scenarios differ in assumptions pertaining to globaleconomic developments, demographic and socio-cultural developments, and technology development (NEO-4, p.21)

22 And also mor by the other docurneft aralyses reported th the remaining of the chapuer.

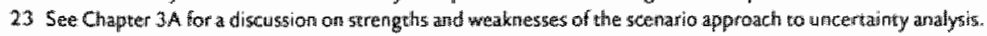


The key question is whether these scenarios cover the full range of scientifically legitimate interpretations of the salient uncertainties adequately. The next question is whether the scenarios have been systematically used to explore the uncertain future and to assess the robustness of conclusions and recommendations.

The use of scenarios in the four Environmental Outlooks has already been discussed in Chapter 6, because this overview was needed as background for the verti$\mathrm{cal}$ argumentation analysis. The essence of scenario-methodolog $\mathrm{y}^{24}$ is that in view of uncertainty multiple possible futures are developed and considered in the assessment. The $1^{\text {st }}$ and $2^{\text {nd }}$ Environmental Outlook did not employ a scenario-approach, because only one of possible pathways into the future was taken into account. In other words, uncertainty about future economic and technological development was acknowledged, but actually denied in the assessment itself. The (adapted) MediumGrowth scenario was in practise used as prediction, which is in full contrast with the argument underpinned in this thesis that prediction in case of complex issues is principally impossible.

Against that background, the scenario-approach adopted in the $3^{\text {rd }}$ Environmental Outlook was a more fundamental change in RIVM's uncertainty management, than we had assumed at first sight. In the $3^{\text {rd }}$ Environmental Outlook, two scenarios, i.e. tailored versions of the European Renaissance and Global Shift, were used throughout the assessment. This scenario-approach was explicitly motivated with reference to inherent uncertainty, as the following quote indicates:

'Future social developments are, of course, extremely uncertain, particularly when they concern a period of over a decade. However, possible coherent and consistent future scenarios can be sketched as the Central Planning Bureau (CPB) has shown in its recent long-term studies. The CPB has sketched four scenarios for the long-term development of the world economy, each based on a different vision of the economy and the role the government plays in it: Balanced Growth (BG), European Renaissance (ER), Global Shift (GS), and Global Crisis GC) (..) Current environmental policy is extremely different from the policy foreseen in this $B G$ global scenario, which makes BG less suitable as a reference scenario for policy assessment. The Global Crisis scenario is also less suitable in this respect, based as it is on a lack of international co-operation, as is Global Shift' (NEO-3, p.33) 
Still, scenarios were not used to assess policy options against a wide variery of possible futures. As follows from the above quote, the two scenarios were selected, because they were evaluated as the most likely. In that sense, the scenario-approach adopted in the $3^{\text {rd }}$ Environmental Outlook still suffuses positivist elements. The $4^{\text {th }}$ Environmental Outlook utilised 3 scenarios. It was explicitly recognised that two scenarios were not enough to manage uncertainty adequately throughout Rrvm's environmentall assessment, as can be inferred from the following quotation:

"To do justice to the uncertainties, three scenarios are developed. (.) The scenarios Divided Europe (DE), European Co-ordination (EC) and Glabal Competition (GC) (..)' (NEO-4, p.2x).

We thus observe that the number of scenarios has increased over the series of Environmental Outlooks, which means that a broader set of possible futures is taken into account. The next question is whether the scenarios used cover the range of possible futures relevant for the environmental assessment. The scenarios in the $3^{\text {nd }}$ and $4^{\text {th }}$ Environmental Outlook are predominantly oriented towards economy, population, and technology. These scenarios differ in assumptions pertaining to global economic developments, European economic and political developments, technology, and demographic as well as some social-cultural developments.

\begin{tabular}{l|c|c|c} 
Assumptions World & DE & EC & GC \\
\hline Economic main point & USA, Japan, DAE & EU, Japan, DAE & unchanged \\
\hline Liberalisation markets & only outside Europe & only inside blocks & global
\end{tabular}

Assumptions Europe

\begin{tabular}{l|c|c|c}
\hline European integration & slow fragmentation & more speds & a la carte \\
\hline European energyelaxes & no & 5 per barrel & no \\
\hline Migration to EU & low & relative high & moderate \\
\hline Technological development and diffusion & slow & moderate & fast \\
\hline Technological focus-felds & undhanged & social & marketorientated
\end{tabular}

TABLE 5 Main characteristics of the three scenarios

It is clear that the scenario-approach plays a crucial role in RIVM's uncertainty management. The key question then is whether the scenarios cover the social, economic and institutional uncertainties salient to RIVM's environmental assessment. An analysis of the scenarios developed by CPB in the context of a review of European scenarios ${ }^{26}$ indicated that the variety expressed by the set of scenarios is quite limited. 
The scenarios used in the $3^{\text {rd }}$ and $4^{\text {th }}$ Environmental Outlook presuppose a linear relationship between economic growth and technological development ${ }^{2}$. A high economic growth implies more funds for technology and thus more technology-improvement also in the realm of energy-efficient and environmental technology, which will cause the physical growth of the economy to stay behind the monetary growth rate. The postulated relationship implies that a lower economic growth is associated with fewer funds for technology, and thus less "eco-technology". "The consequence is that a low-economic-growth future is associated with a relatively high physical growth of the economy. This means that none of the scenarios developed by $C P B$ involves a future in which economic growth is not a condicion for technology improvement, but in which more environmental-friendly lifestyles are adopted, and available technology innovations are applied on large scales. This would result in a scenario with a low economic growth and a physical growth that is lower than assumed in the set of CPB-scenarios. The set of scenarios used in the previous Environmental Outlooks furthermore denies a future in which the physical economic grow th accelerates, because potential investment funds are not used for "eco-technology", but solely to increase the short-term wealth of the shareholders and to afford more materialistic lifestyles. Such a future would imply a scenario with a high economic growth, both in monetary and in physical terms. The latter two legitimate scenarios seem to be relevant for RrVM's environmental assessment, because of the severe implications in terms of envirommental impacts and thus in the policy recommendations.

Another problem with RIVM's scenario-approach can be deduced from the argumentation analyses on economic development. It was concluded that although physical growth is considered as the most relevant indicator for environmental pressure, it was the monetary growth (i.e. GNP) that was used throughout the Environmental Outlook. So apart from the problems with the scenarios, it seems that associated furtre outlooks in terms of physical growth are not adequately considered in the assessment.

We conclude that the scenario-approach adopted in $3^{\text {rit }}$ and $4^{\text {th }}$ Environmental Outlook did not systematically reason from the question which uncertainties are salient to assessing the state-of-the-environment. The scenario-approach seemed to be dictated by the CPB"s perspective on economic futures.

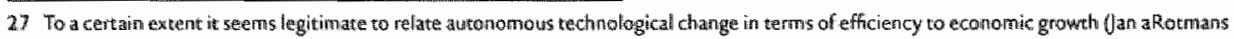
personal commuryication). What we question here is that all three scanarios involwe the assumpeion that all tedhnological development is a

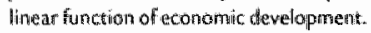


The consequence of a scenario-approach to assessment is that the quantitative conclusions are in principle expressed with margins, because of the difference between the outcomes associated with the various scenario runs. In order to understand whether uncertainty has increased or decreased over time, we compared the smallest and the largest uncertainty ranges found in the Summary Chapters in the four Environmental Outlooks. The following quotes indicate the extreme margins per Outlook:

\section{ENVIRONMENTAL OUTLOOK I}

- "With a high economic growth, an increase in the global energy use of $2-2.5 \%$ per year is expected." (NEO-I, p.2I)

- "To prevent health damage by ozone, it is necessary to achieve a drastic reduction of acidifying emissions of about 70-90\%." (NEO-I, p.22).

\section{ENVIRONMENTAL OUTLOOK 2}

- "In 2010 there will be an estimated 35\%-40\% less energy" (NEO-2, p.r2).

- "The consumption of energy and raw materials will increase by ro\%-20\%" (NEO-2, p.12).

\section{ENVIRONMENTAL OUTLOOK 3}

- "The number of private vehicle kilometres could end-up 10\%-15\% higher" (NEO-3, p.I2).

- "The number of breeding pigs and chickens will fall by $10 \%-40 \%$, depending on the amount of manure distributed within the Netherlands" (NEO-3, p.14).

\section{ENVIRONMENTAL OUTLOOK 4}

- "(..) the energy consumption of the households increases between 1995 and 2020 with $60 \%-140 \%$ in case of unaltered policy, the use of private cars increases with $15 \%-25 \%$, the aviation with $140 \%-300 \%$ and the total household waste with $15 \%=35 \% "$ (NEO-4, p.1.2).

The ranges reported in the $\mathrm{I}^{\text {si }}$ Environmental Outlook range from 0.5 to $10 \%$ (i.e. $2.5 \%-2 \%=0.5 \%$, and $75 \%-65 \%=10 \%$ ). In the $2^{\text {nd }}$ Environmental Outlook the spread in ranges is somewhat more condensed to $5 \%$ to $10 \%$ (i.e. $40 \%-35 \%=5 \%$, and $20 \%-10 \%=10 \%)$. In the Summary Chapter of the $3^{\text {rd }}$ Environmental Outlook, the smallest margin also comprised $5 \%$ (i.e. $15 \%-10 \%$ ), while the largest margin had grown to $30 \%$ (i.e. $40 \%-10 \%=30 \%$ ). The $4^{\text {th }}$ Environmental Outlook, however, denoted consequently larger ranges. The margins reported ranges from 10\% (i.e. $25 \%-15 \%=10 \%$ ) till $160 \%$ (i.e. $300 \%-140 \%=160 \%$ ).

This could mean that the uncertainty has increased over time. Testing this potential explanation is beyond the scope of the study. However, if such a dramatic 
increase in uncertainty in the underlying knowledge has occurred compared to the previous Outlook, one would expect that such a difference is explicitly acknowledged and explained. This is, however, not the case ${ }^{28}$.

To get more insight into the development of uncertainty ranges over time, we decided to further analyse the margins expressed for ten issues covered at least in the latter two Environmental Outlooks. To that end, we compared the distance between future trends in terms of total magnitude of the margin ${ }^{20}$. Because the $1^{\text {st }}$ and $2^{\text {nd }}$ Environmental Outloaks use only one scenario, and thus report only one pathway into the future, the total magnitude of the margin equals zero. The latter can also occur, if the outputs associated with the various scenarios overlap, as is, for example, the case in the quantitative estimates in the $3^{\text {rd }}$ Environmental Outlook concerning livestock volume, $\mathrm{NH}_{3}$-emissions and $\mathrm{CH}_{4}$-emissions. Table 6 reports the results of this comparison-exercise.

\begin{tabular}{|c|c|c|c|c|c|}
\hline \multirow[b]{2}{*}{ issue } & \multicolumn{4}{|c|}{ total magnicude of margin } & \multirow{2}{*}{$\begin{array}{c}\text { ratio } \\
\mathrm{NEO}_{-4} / \mathrm{NEO}_{3}\end{array}$} \\
\hline & NEO & $N E O^{\prime}-2$ & $\mathrm{NEO}_{3}$ & $\mathrm{NEO}_{-4}$ & \\
\hline Economic growth & 0 & o & 19 & 27 & 1.42 \\
\hline Energy consumption & 0 & 0 & 7483 & 9102 & 1.22 \\
\hline Transport volume & 0 & 0 & 413 & 825 & 2.00 \\
\hline Priwate car use & 9 & 0 & 65 & 83 & 1.28 \\
\hline Livestock volume & $\infty$ & - & 0 & 10375 & $(10375)$ \\
\hline $\mathrm{NH}_{3}$-emistion & 0 & 0 & 0 & 135 & $(135)$ \\
\hline $\mathrm{CH}_{4}$-emission & 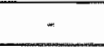 & - & 0 & 465 & 465 \\
\hline $\mathrm{CO}_{2}$-enission & - & 0 & 280 & 315 & 1.13 \\
\hline Deposition acid equivalents & 0 & 0 & 413 & 113 & 2.69 \\
\hline Noise rutsance by civil aviation & 0 & 0 & 1.9 & 7.5 & 3.95 \\
\hline
\end{tabular}

TABLE 6 Results of comparison of quantitatiwe forecasts over then selected issues

From this Table it can be concluded that the uncertainty ranges consistently increase between the $3^{\text {rd }}$ and $4^{\text {th }}$ Environmental Outlook. As the ratio in the last column indicates, the degree of uncertainty (as expressed by the total magnitude of the margins) increased over all selected issues. The increase differs from about $15 \%$ larger margins to four times the $3^{\text {rd }}$ Environmentall Outlook uncertainty range. The comparison of quantitative forecasts for the ten issues reinforces the observation that the uncertainty ranges expressed in the $4^{\text {th }}$ Environmental Outlook are significantly 
larger than in the previous Environmental Outlooks. It is interesting that this increase in quantitative uncertainty assessment is observed both on the level of the Summary as well as consistently for selected issues.

The increase in margins over time, i.e. the sprinkler-effect, has also a problematic dimension. Very large margins, such as the reported $140-300 \%$, become meaningless in communication terms. The increase in margins cannot continue indefinitely, because it will eventually deprive the Enwironmental Outlooks of its decisionsupport dimension. Uncertainty management should be more then ever-increasing margins; it should provide information on robust policy strategies.

To get some more insight into the above issue, we thought to compare uncertainty ranges in inputs versus those in outputs. The broader ranges are partly due to the larger set of input scenarios that have been considered in the $4{ }^{\text {th }}$ Environmental Outlook. Initially, our evaluation was that the uncertainty ranges associated with the outputs are consistently smaller than those of the inputs, of which the latter can be directly associated with the scenarios (see Box 5). At first sight, one would not expect that the output margins are smaller, due to accumulation of uncertainty throughout the causal chains. Because of delays and non-linearity, such as buffering effects, it is possible that the margins shrink during the analysis ${ }^{30}$. Ideally, the uncertainty ranges should have been explained in terms of causes (what is due to the scenario-input, and how much originates from uncertainty assessment in the environmental causal chains) in the Environmental Outlooks themselves. This is however not the case. This implies that an analysis of the increase in uncertainty ranges would necessitate at least analysis all underlying (model) calculations, a qualified assessment of the outputs, a sensitivity analyses on the full model chain and an overview of the outputs of the performed uncertainty analyses. Evaluation of the Environmental Outlooks and the background reports teaches that a detailed analysis of how much of the uncertainty ranges is due to the scenario-input implies that the assessment processes of the $3^{\text {rd }}$ and $4^{\text {th }}$ Environmental had to be repeated, which is of course practically impossible.

It seems legitimate to conclude that if the margins in the outputs are smaller than those associated with the scenario-input, that the scenarios predominantly explain the uncertainty ranges in the output, and that the contribution of uncertainty in the environmental assessment itself is marginal. This would imply that either the uncertainty pertaining to the environmental chains is marginal, or that

30 As argued by Rivht experts if the interwiews and in: the focus group. 
uncertainty pertaining to the environmental chains is not systematically and not adequately managed.

\section{BOX 5 Analysis of margins}

Figure $y$ indicates the margins presented for some representative pressure issues, which can be considered as inputs, and some state/impact issues, which can be considered as outputs, i.e. calculated in rivm's assessment process ${ }^{3}$. We have compared the relative uncertainty ranges, i.e. the absolute numbers and units were not taken into account. Table 7 summarises the comparison between the uncertainty ranges reported in the $3^{\text {ro }}$ and $4^{\text {th }}$ Environmental Outlook.

\begin{tabular}{|c|c|c|}
\hline \multirow{2}{*}{ issues } & \multicolumn{2}{|c|}{ uncertainty range } \\
\hline & $\mathrm{NEO}_{3} 3$ & $\mathrm{NEO}_{-4}$ \\
\hline \multicolumn{3}{|l|}{ pressure } \\
\hline Economic growth & $22.0 \%$ & $37.5 \%$ \\
\hline Energy consumption & $9.3 \%$ & $14.6 \%$ \\
\hline Transport volume & $7.8 \%$ & $12.1 \%$ \\
\hline Private car use & $3.1 \%$ & $2.0 \%$ \\
\hline Livestock volume & $0 \%$ & $11.3 \%$ \\
\hline$\overline{\text { mean }}$ & $8.4 \%$ & $15.5 \%$ \\
\hline \multicolumn{3}{|l|}{ state / impact } \\
\hline $\mathrm{NH}_{3}$-emission & $0 \%$ & $3.4 \%$ \\
\hline $\mathrm{CH}_{4}$-emission & $0 \%$ & $4.6 \%$ \\
\hline $\mathrm{CO}$-mission & $4.5 \%$ & $9.1 \%$ \\
\hline Deposhtion acid equivalents & $1.1 \%$ & $6.4 \%$ \\
\hline Noise nuisance by civil aviation & $1.8 \%$ & $14.3 \%$ \\
\hline mean & $1.5 \%$ & $7.5 \%$ \\
\hline
\end{tabular}

TAele 7 Uncertainty ranges for representatilye pressure issues ("inputs") wersus statefinpact issues ("outputs")

Both the graphs and Table 6 indicate that the reported uncertainty ranges associated with inputs are on average smaller than the uncertainty ranges reported on outputs. 


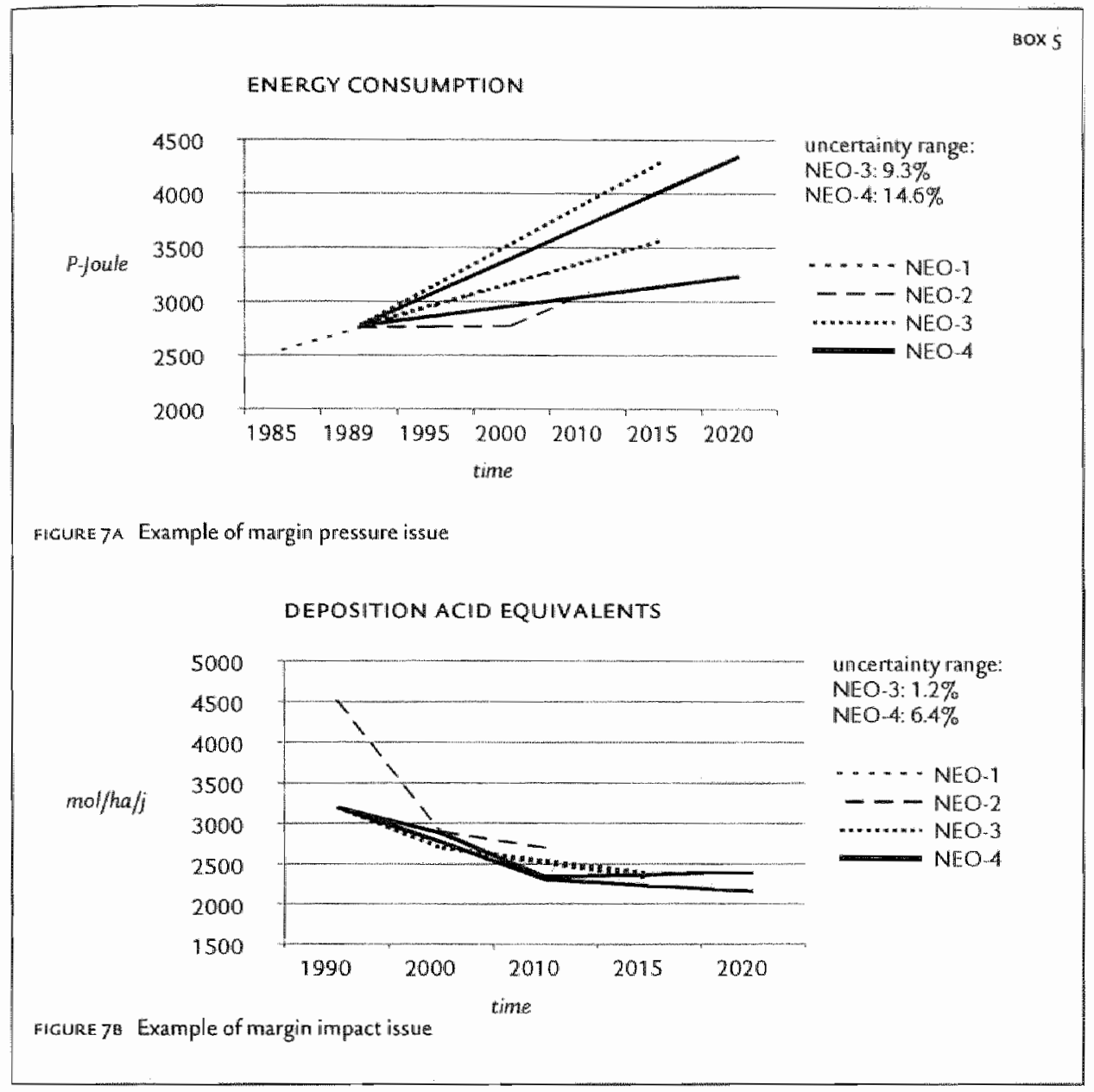

The analyses on the scenario-methodology, the scenarios employed and the evolution in quantitative uncertainty ranges seem to suggest that uncertainty pertaining to social and economic uncertainty is receiving more attention in RIVM's environmental assessment, which observation seems to be at odds with the results of the argumentation and linguistic analyses. Furthermore, the above analysis on the scenarios employed in the series of Environmental Outlooks also raises serious questions with regard to the adequacy of the actual scenario methodology as uncertainty method. It can be argued that after all the scenario methodology is not systemarically used as method for uncertainty management, but more as a way to consider some pathways into the future that are known in the Durch policy arena. The latter notwithstanding the explicit claim made in the Environmental Outlooks that the scenarios are employed to do justice to uncertainty. 


\subsection{RIVM"S UNCERTAINTY MANAGEMENT}

\section{AS DEDUCED FROM THE DOCUMENT ANALYSES}

The general questions framing the document analyses pertained to RrVM's attitude towards uncertainty and to the actual uncertainty management employed in the Environmental Outlook process. What picture do the above document analyses yield?

A change in attitude towards more uncertainty consciousness and tolerance is not consistently observed in our document analyses. As reported in the previous section, the text analyses indicate that the $4^{\text {th }}$ Environmental Outlook suffuses a less open attitude towards uncertainty than its successors. Also, the argumentation analysis does not reveal a significant increase in RrvM's atritude towards uncertainty. On the other hand, the investigation into scenarios and uncertainty ranges seem to suggest some attitudinal change to more uncertainty consciousness and tolerance. The result of this tension is that Rrvm's communication about uncertainty is very ambivalent, if not inconsistent. The messages on uncertainty expressed by linguistic expressions fundamentally conflicts with those associated with the quantitative conclusions. To give an example: the word 'uncertainty' is not even mentioned in the summary of the $4^{\text {th }}$ Environmental Outlook, whether it is at the same time expressing margins up to $160 \%$, which range in common language communicates that it is more uncertain than fully uncertain.

The conclusions with regard to RrvM's uncertainty management as deduced from both the horizontal and vertical document analyses of the four Environmental Outlooks are:

- the Environmental Outlooks involve weak argumentation (i.e. adequate argumentation and information justifying the conclusions is lacking) ${ }^{32}$

- the Environmental Outlooks are not transparent with regard to uncertainty; it is impossible to discover which uncertainties played a role for should have played a role) in the assessment and how they are managed throughout the underlying asses sment.

- uncertainty is not consistently, nor systematically treated in the Environmental Outlooks; there seems to be no strategy for uncertainty management.

32 This has just been proven for the 3rd and 4th Envirommental Outlooks, but it seems logical to suppose chat it also holds for the 1st and 2 nd Enwironmental Ourtiook. 
- the set of scenarios employed is inadequate in view of the aims associated with an Enwironmental Outlook.

- uncertainty is communicated in a confusing, and even inconsistent, manner.

- although the Environmental Outlooks show some traces of a growing uncertainty consciousness, the paradigm most associated with the Environmental Outlooks is clearly positivism.

In view of the above, we conclude that the way uncertainty is dealt with in the Environmental Outlooks is problematic. As a consequence, Rrvm is very vulnerable to criticism targeting uncertainty, even in cases the critic is wrong. Our document analysis thus provides an explanation why affairs like De Kwaadsteniet-affair could happen and could persist for such a long time. An environmental assessment that involves systematic, consistent and adequate treatment of uncertainty, transparent and clear communication on uncertainty, and strong argumentation is much more difficult to discredit.

\section{Empirical research}

From the extensive document analyses we concluded that uncertainty was not systematically treated in the four Environmental Outlook reports, but this doesn't necessarily mean that it was not systematically treated in the underlying assessment process. We could not deduce how uncertainty was managed in the assessment underlying the Environmental Outlook. We therefore decided to use practitioners in the previous Environmental Outlook processes as another source of information. As argued in the previous Chapter, a number of responsible RIVM people has been interviewed $^{33}$, a focus group session ${ }^{34}$ has been performed and questionnaires ${ }^{35}$ have been distributed among analysts in the current Environmental Outlook process, of whom the majority has participated in previous assessment processes. This empirical research output ${ }^{36}$ was analysed to address the following research questions:

- how was uncertainty managed in the previous environmental assessment processes?

- whether, and if so why and how, the attitude towards uncertainty and uncertainty management has changed over time?

\footnotetext{
33 See (Langendonck 1999; van Asselt et al. 2000)

34 See (van Asten 2000)

36 Preliminary analyses of the empirical outpuit were presented in (van Asselt et all. 1999) and wan (wan Astem and wan Assalt 1999)
} 
- which sources of uncertainty relevant to the assessment process are recognised by the experrs themselves?

- whether there is a (potential) need for a new or complementary approach for uncertainty management among RIVM practitioners?

\section{I. UNCERTAINTY IN THE ENVIRONMENTAL OUTLOOK PRACTISE}

Our respondents argued that it was an explicit choice of the management of the Environmental Outlook not to bother the readers too much with uncertainty. The interview data yielded that this attitude can be explained by the idea that policy-makers cannot handle uncertainty. As a consequence, the respondents argued, uncertainty is only mentioned in the Environmental Ourlook reports in case it is estimated by RrvM to be salient to the policy recommendations. Uncertainty ranges were thus only presented in the Environmental Outlooks in case RIvM was convinced that the uncertainties substantially influenced the conclusions, and thereby had consequences for the policy recommendations. There were no explicit criteria that facilitated this selection; in the interviews it was explicitly stated that the evaluation of the policy relevance of uncertainty was a rather intuitive process. Some heuristic rules involved that uncertainty is more important in case forecasts come close to the targets, and in case trends are unclear. The following examples were provided during the interviews:

- "In the time of the $\mathrm{I}^{\mathrm{st}}$ Environmental Outlook, the emission levels were so high. that they any how had to substantially decrease. At that moment, precision was not important i.e. in such cases it is not significant whether the emission have to decrease with $70 \%-80 \%$ or $83 \%$. (.) Now, for some substances $\left(\mathrm{SO}_{2}\right)$ for which targets are almost reached, it is interesting to assess whether it is efficient to continue with the policy. The last percentages of reduction have to be studied more precisely."

- "It is important to describe the trend correctly. (..) For example, an expectation is that the forest will decrease with $35-43 \%$. In this case this range is not important, because the conclusion is that the forest decreases. But when you are not sure about the direction of the trend, (..) the ranges become more important."

Furthermore, how uncertainty was dealt with also seemed to relate to the level of impact. The rule of thumb used seemed to be, as one of the interviewees phrased it: 
"you can better forecast something disastrous with a big uncertainty than something harmless with less uncertainty".

This implies that uncertainty is used as a kind of heuristic.

The above implies that almost by definition the Environmental Outlook reports do not reflect how uncertainty is dealt with in the assessment process. The interviews, the focus group and the Rrvm report describing its practice, which was produced during our case-study as RIVM's official response to the media and political pressure ${ }^{\text {*77 }}$ taught us that uncertainty in the Environmental Outlooks was addressed in the following ways:

\section{QUANTITATIVE METHODS FOR UNCERTAINTY ANALYSIS}

- economic-technological scenarios, sometimes complemented with specific model simulation runs (such as with low and high energy prices)

- sensitivity analysis on inputs ${ }^{38}$ for individual models ${ }^{39}$ (reported in research reports)

- uncertainties in parameter values are checked by means of standard uncertainty anallysis techniques

\section{QUALITATIVE APPROACHES}

- expert judgements

- consensus formation with other institutes (like the Central Economic Planning Office (CPB))

- contra-expertise, from external experts like the Royal Institute for Metrology (KNMI)

- internal and external reviews

\section{PRESENTATION APPROACHES}

- the word 'prediction' is taboo

- linguistic expressions

- graphical representations such as blocks instead of smooth curves and uncertainty ranges

- careful with the presentation of maps, because maps suggest certainty

With regard to statistical analysis, some of the respondents argued that pure statistics cannot be applied in a prognostic manner, and that therefore statistical methods

37 (RIVM 1999; 19996)

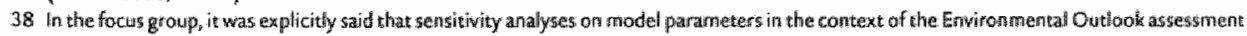
are rane.

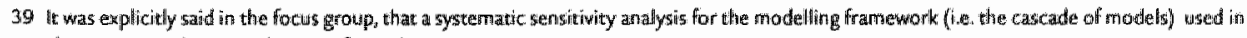
the assessment has never been performed. 
played a minor role in the assessment process underlying the Environmental Outlooks ${ }^{40}$.

The next question is how the above methods were applied. Expert judgements, internal expert discussions and consensus formation processes are usually not reported. There is a tendency to view the Environmental Outlooks as products of measurements and models; however, in the focus group it was argued that the most important ingredients are the brains and mental models of RIVM's analysts. Because of lateral thinking ${ }^{41}$, the brainwork is not a linear step-wise process, and is thus any how difficult to report. Nevertheless, it was agreed that lines of reasoning are not adequately reported. The focus group discussion concluded that the use of Rrvm's knowledge base and expertise is difficult to trace.

With regard to the actual use of quantitative methods, the discussions in the focus group made clear that within RIVM two groups of uncertainties are distinguished, i.e. societal tncertainties and uncertainties in the environmental system. Uncertainty in the environmental causal chains is not systematically addressed, which implies that accumulation of uncertainty is not analysed. The working hypothesis underlying the practise had it that because societal uncertainty dominates the major uncertainty with regard to the state-of-the-environment is already discounted for in the scenarios. From the focus group discussions, it can be concluded that this point of departure is currently highly debatable and questioned within RIVM. In the history of the Environmental Outlooks, it was never systematically analysed whether the models and theories utilised in the assessment process involved uncertainty. In the cases in which the impact of uncertainty in inputs was explored in the form of sensitivity analysis for particular models simulating parts of the environmental system, it has been done in isolation. In other words, interlinkages and interactions with other causal chains were not considered, nor were the cumulative effects of uncertainty throughout the whole environmental system addressed. In some cases, analysts experimented with worst-case scenarios beyond the CPB scenarios. However, full analysis of the consequences of such a worst case scenario was never performed. The respondents argued that the level of uncertainty is thus roughly known for the isolated components, in either qualitative or in quantitative terms. However, these uncertainties in the environmental system are not systematically accounted for in the overall assessment.

\footnotetext{
40 It is beyond the an of the study and the expercise of the researchers co discuss this argurnent in-depth. However, it should be noted that this

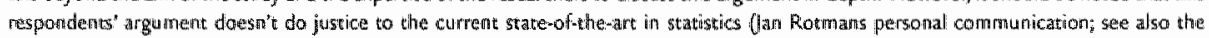
contributican of statisticians to the Dekwatadstenter aftaid.

41 (de Bono 1968; 1969; 1970)
} 
The document analysis yielded that scenarios were used as uncertainty method. This observation was confirmed by the interview data: the respondents argued that societal uncertainties are assessed by means of the scenarios. The document analyses taught us that the scenario method as employed turned out to be inadequate in view of the aims associated with the Environmental Outlooks. In the interviews, the question was therefore asked whether the respondents considered the scenarios used as an adequate treatment of the salient uncertainties. Both in the interviews and in the focus group, the adequacy of the CPB scenarios for the environmental assessment was questioned. A number of problems inherent to CPB's scenario methodology were brought to the fore. The CPB scenarios cover merely extrapolation of trends. Bifurcations and surprises are not considered, because the CPB models could not stand up to that kind of experiments. The resulting 'boring' character of the scenarios is questioned, as the following quote from the interviews yields:

"The past teaches us that developments are non-linear. The scenarios do not incorporate this lesson."

Furthermore, the CPB-scenarios reasoned from the consumption-side, which means that developments in the production sectors were derived from GNP calculations. However, not all sectors are sensitive to variations in GNP. An example is the agricultural sector. The implication is that the variety of futures for the agricultural sector as derived from the CPB scenarios is quite limited. According to the focus group, starting from the production side would yield a broader variety of scenarios, which would be more distinctive for the environmental assessment.

It is furthermore discussed that the CPB scenarios involved certain assumptions that caused a narrowing-down of the future outlooks in terms of physical growth and emission patterns. The fixed relationship between economic growth and technology development ${ }^{42}$ implies that the emission scenarios are condensed. Something similar holds for the assumed relationship between economic growth and population growth. Because of the actual Dutch population structure, the major uncertain variable is migration. $C P B$ postulated that a high economic growth in the Netherlands correlates with economic growth worldwidle, which will cause the economic stimulus for migration to weaken. As a consequence, the CPB forecasted either high economic growth - low population growth, or low economic growth and a relatively higher population growth. Such a set of scenarios implies that the range associated with the physical growth of the economy is narrowed down. A future that involves 
high economic and population growth combined with limited technological development, implying that a scenario featuring an increase in pressure on the environment was ignored in the set of scenarios. The same holds for a future characterised by low economic and population growth combined with substantial technological improvement, esp. concerning environmental-friendly technology. Another crucial issue in the environmental assessment involves deposition patterns. These patterns are not only dependent on Dutch emissions. Emissions in other European countries, but with regard to particular substances such as ozone even emissions in other continents, are relevant to the assessment of the state of the Dutch environment. The scenario methodology as applied in the previous Environmental Outlooks merely accounted for one emission scenario that was derived from the emission estimates from the countries themselves. This means that severe uncertainties associated with the societal development in other countries were not considered.

Some of the above limitations of the scenario-approach confirmed our conclusions derived from the document analysis. In sum, in the light of rIvm's job to assess the future state of the environment, the scenarios used in the previous Environmental Outlooks suffered from the following disadvantages can be deduced from the case-study research:

- extrapolative, linear character of the scenarios

- consumption-driven calculation of production trends

- rigid assumptions with regard to relationships between economic growth, population development and technollogical innovation

- limited discount of radical uncertainty abroad

- the dominance of the scenario indicator GNP growth over physical growth in the use of the scenarios throughout the assessment

As a result, the variety of scenarios used in the Environmental Outlooks is far too limited to account for an adequate treatment of economic-technological uncertainties, let alone for relevant socio-cultural uncertainties. Building upon the focus group discussions, it can therefore be concluded that the adopted scenarios appeared to be an inadequate approach for managing societal uncertainty in RrvM's assessment. This kind of problems was never systematically considered in the collaboration between RIVM and CPB. The respondents argued that so far RIVM has behaved rather authority abiding, which resulted into uncritical use of the $C P B$ scenarios in their environmental assessments ${ }^{43}$.

43 The particular argumentation analysis on economic development as rephorted in the first part of this Chapter also reveals such an uncritical use of the EPB input. 
The interviews and the focus group data (see Box 6) yield that the practitioners themselves concluded that uncertainty was not systematically managed in the Environmental Outlook assessment processes. This conclusion is reinforced by the output of the questionnaires among analyses involved in the $5^{\text {th }}$ Environmental Outlook process.

Box 6 Uncertainty in the assessment process: Interview, focus group and questionnaire data

\section{SINGULAR QUOTES FROM THE INTERVIEWS}

- "There could be more attention for uncertainty in the assessment".

- "We are not so attentive to uncertainty."

- "In all sincerity, uncertainty so far has played a minor role."

- "There is more sense about uncertainty than is written down in plain numbers and words."

- "If something is too uncertain, we don't mention it."

ANSWERS TO THE OPEN QUESTION:

Do you think uncertainty is adequately managed in the Environmental Outlook during the process and in the product?

- "We could do better. We talked about paying more attention to uncertainty in the Environmental Outlook, but you don't see that back. We are not real naturals in dealing with uncertainty. The Environmental Outlooks are in fact a summary of all available knowledge. (..) Also the other institutes (i.e. decision support institutes like the $(P B, M v A$ ) didn't find a way out either. It is not a matter of solution, but learning how to deal with it (i.e. uncertainty, MvA)."

- "In the Environmental Outlook, not enough. Maybe it is an unconscious fear to make them (i.e. uncertainties, MvA) explicit."

- "No, we can do better."

- "We think it can be cone better, and that it therefore should be done better."

- "Yes, but we can always do better. But taking into account the time and the financial means, we are doing OK." 
SINGULAR QUOTES FROM THE FOCUS GROUP IN THE ORDER OF THE DISCUSSION

- "It (i.e. paying explicit attention to uncertainty, MVA) indeed does not happen."

- "No, not systematically.

- "I know that it (i.e. how uncertainty is managed, MVA) is nat explicitly written somewhere, so it is rather unlikely that it (i.e. managing uncertainty, MvA) is done."

- "Uncertainty in models or theories is not systematically analysed."

- "I may bother too less about the theory behind it (i.e. uncertainty, MvA), we are working intuitively." "Very intuitively."

- "We can doubt to what extent uncertainties manifest themselves in the scenarios."

In the focus group it was argued that the statements in the interviews expressing that uncertainty was adequately addressed in the assessment process, should be explained by wishfull thinking.

THE LITERAL TEXT OF THE CONCLUDING REMARK IN THE FOCUS GROUP that was subscribed by all participants:

"It (i.e. managing uncertainty, MwA) is in any case not done in a systematic way, not explicitly either, I think..."

SCORES ON 5-POINT SCALE QUESTIONNAIRE ITEMS

Total number of respondents: 15

The questionnaire data ${ }^{44}$ below indicate that the analysts involved in the $5^{\text {th }}$ Environmental Outlook processes doubt that uncertainty was adequately managed in the previous Environmental Outlooks.

see over w

44. it could have been possitble to use statistical methods for small samples to calculate the signtificance of the scores. It can be argued that this would have inproved the argumentation, although hit cam be asked how much stronger it would have becone (pensonal communicanion with Prob Hoppe). Un other words, it is questionable whecher it would have been worth the effort. On the other band it would thawe suggested that the group of respondeats is a small, but representative sarnple, which is not at all the case. The absolute frequency distributions that we used in ou anislysis of the survey data do far more justice to the exploratony character of our research and they prowide enoughth information tio illustrate our agguments. 


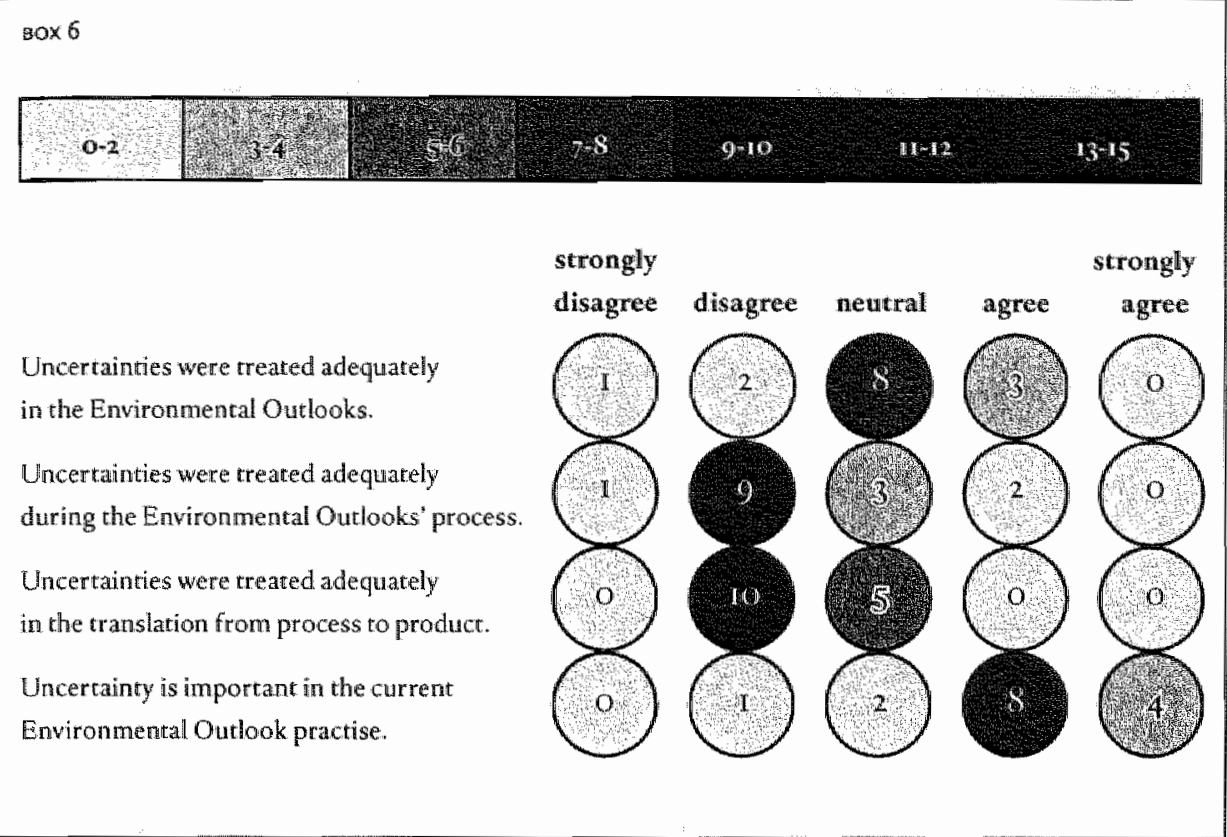

The document analysis alone did not provide enough evidence that systematic uncertainty management lacked in RIVM's assessment practise. However, building upon both the document analyses and the empirical data, we can conclude that uncertainty was not systematically managed in both the assessment process and in the Environmental Outlook reports. A framework for uncertainty management was lacking. There was not a coherent strategy towards applying the recognised approaches and techniques for uncertainty analysis. Not all approaches were used purposively, consequently and consistently. The scenario-approach was used consistently throughout the assessment, but serious concerns question the adequacy of the set of scenarios used. In sum, we conclude that uncertainty did not get systematic attention in the series of Environmental Outlooks.

\subsection{EXPRESSED ATTITUDE TOWARDS UNCERTAINTY}

From the document analysis we have tried to deduce RIVM"'s attitude towards uncertainty. The document analyses showed an ambiguous picture. Nevertheless, building upon the observed increase in margins and the development in scenario-methodology, we postulated that RIVM's attitude towards uncertainty changed towards more uncertainty consciousness and tolerance. One of the aims of the empirical research was to test whether the attitude towards uncertainty has changed over time, and if so, 
how and why. It is the first time, however, that RIVM's attitude towards uncertainty is addressed by empirical research. This means that no longitudinal data is available. For that reason, it is difficult, if not impossible, to sketch a reliable picture of attitudinal change over the Environmental Outlook history. In the context of the casestudy, wave followed two routes: i) the interviewees and the focus group were asked whether they perceived an attitudinal change over time, and ii) the current attitude towards uncertainty among practitioners involved in the Environmental Outlook assessments was tested in the interviews and questionnaires.

The interviewees agreed that uncertainty management had not fundamentally changed over time. Two of them saw no change at all, as is revealed by the following quote:

"I think nothing had changed, till two weeks ago (i.e. the beginning of the De Kwaadsteniet affair, MvA)."

The other respondents thought some minor change took place. It was argued that at the time of Concern for Tomorrow the analysts were convinced that what they wrote was certain. With regard to the present situation, the respondents observed more communication about uncertainty. They considered the development in scenario-methodology as a change in the attitude towards uncertainty. These respondents also mentioned the role of the media affair as catalyst in the current attitude towards uncertainty:

"We will pay more attention to uncertainty. The media affair has definitely contributed to this..."

These practitioners' assessment confirms the ambiguity revealed by the document analysis. This ambiguity may be interpreted as that uncertainty is bubbling under the surface and that it is becoming a theme in RIYM's assessments. This seems to imply that an attitudinal change is under way. With the available data, it is beyond the scope of this thesis to explain this postulated movement to change. In the following, we will focus on RIVM's current attitude towards uncertainty.

Table 8 shows the scores on a 5-points scale on items that tested the current attitude towards knowledge and uncertainty. The questions were derived from the theoretical detour reported in Chapter 3 to 5 of this thesis. The same closed questions were asked both in the interviews and in the questionnaire to allow for comparison.

From the Table, it can be concluded that the general attitude towards uncertainty and science as expressed by the respondents goes beyond the positivist attitude, because constructivist answers (i.e. "strongly disagree") dominate. On the other hand, the spread of the scores indicates that the collective expressed attitude involves 
Statement

Interwiews

Questionnaire Workshop

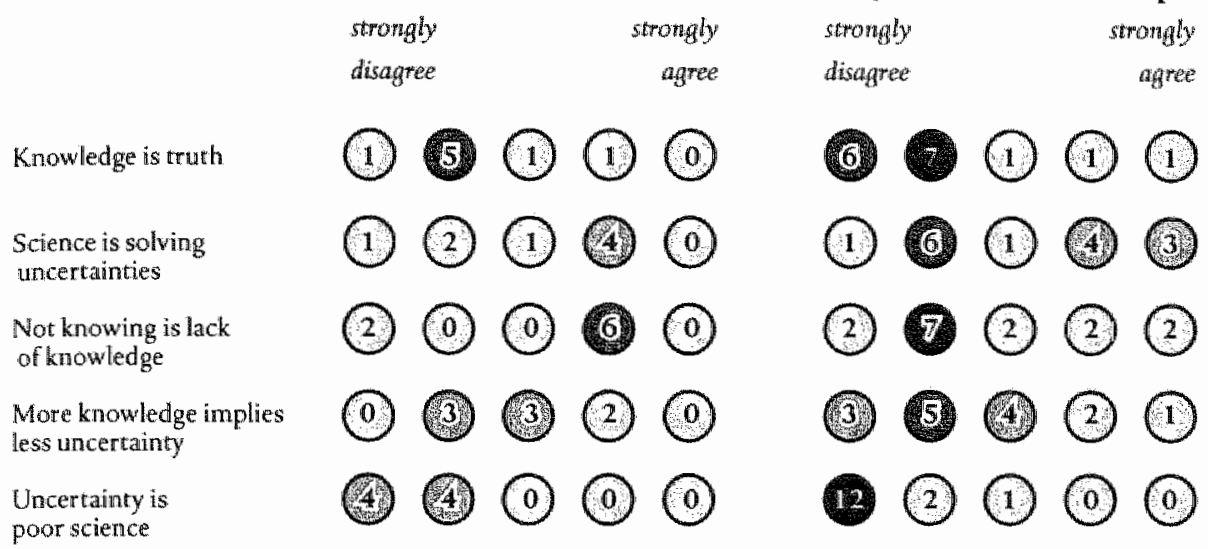

TABLE 8 Expressed attitudes towards uncertainty

positivist elements (i.e. "strongly agree"), although not one of the respondents gave pure positivist answers (as can be deduced from the zeros in the strongly agree columns). The expressed artitude prevailing among this sample of rovm practitioners involved can thus be characterised as rather constructivistic. This implies that recognition of uncertainty as inherent to science and scientific decision-support seems to be part of RIVM"s culture.

Apart from their general attitude, the attitude towards uncertainty and uncertainty management in relation to the Enwironmental Outlooks was explored. Table 9 summarises the empirical data gathered via the interviews and the questionnaires. Because the results of the interviews informed the design of the questionnaire, some new questions were added to the questionnaire handed out

From the scores on the opinion questions, it can be deduced that transparency towards uncertainty is considered to be a quality improvement. The majority of the respondents furthermore agreed that making uncertainty explicit is not in conflict with the policy relevance of the Environmental Outlook. This is in flat contradiction with the "publication strategy" that according to the respondents can be associated with the previous Environmental Outlooks. It was argued that with regard to the preceding assessments, it was the explicit choice not to bother the readers too much with uncertainty, because it was assumed that policy-makers cannot handle uncertainty. This implies that either the practitioners did disagree with the publication strategy, or there has been a fundamental change in reasoning about policy-makers, uncertainty and Environmental Outlook, or the respondents gave socially desirable answers in the survey. The fact that the majority of the respondents (see Box 6 ) 


\begin{tabular}{|c|c|c|c|c|c|c|c|c|c|c|}
\hline \multirow{3}{*}{$\begin{array}{l}\text { gtatememt } \\
\text { The more uncertainties are made explicit } \\
\text { the betuer the Environmental Outlook }\end{array}$} & \multicolumn{5}{|c|}{ interviews } & \multicolumn{5}{|c|}{ questionnaire workshop } \\
\hline & \multicolumn{3}{|c|}{$\begin{array}{l}\text { strongly } \\
\text { disagree }\end{array}$} & \multicolumn{2}{|c|}{$\begin{array}{r}\text { strongly } \\
\text { agree }\end{array}$} & \multicolumn{2}{|c|}{$\begin{array}{l}\text { stromgly } \\
\text { disagred }\end{array}$} & & \multicolumn{2}{|c|}{$\begin{array}{r}\text { strongly } \\
\text { adgree }\end{array}$} \\
\hline & 1 & 3 & 0 & 3 & I: & & & & & \\
\hline $\begin{array}{l}\text { Making uncertainties transparent in the } \\
\text { Environmental Outhook ts at che } \\
\text { expense of the quality }\end{array}$ & 5 & 3 & 0 & 0 & 0 & 8 & 4 & $\overline{3}$ & o & $a$ \\
\hline $\begin{array}{l}\text { An Enwirommental Outlook full of } \\
\text { uncertanties is itrelewant for the policy. }\end{array}$ & 0 & 5 & 0 & 3 & o & 4 & 4 & 3 & 4 & a \\
\hline $\begin{array}{l}\text { In the Environmental Ourlook, more } \\
\text { attention should be paid to uncertainty. }\end{array}$ & & & & & & 0 & 0 & 2 & 7 & 6 \\
\hline $\begin{array}{l}\text { Tt is possible to make uncertainty } \\
\text { explicit in the Enwronmental Outlook. }\end{array}$ & & & & & & 0 & (1) & 2 & 7 & 5 \\
\hline $\begin{array}{l}\text { More external rewiew is the solution } \\
\text { to the uncertanty problem. }\end{array}$ & & & & & & 8 & 5 & II & 1 & 0 \\
\hline Rrva should measture more. & & & & & & 1 & 7 & 5 & 2 & 0 \\
\hline $\begin{array}{l}\text { There is a need for another approach } \\
\text { to manage uncertainty in the } \\
\text { Environmental Outlook. }\end{array}$ & & & & & & $\Downarrow$ & 2 & $\mathbb{1}$ & 9 & 2 \\
\hline
\end{tabular}

TABLE 9 Expressed attitudes towards uncertainty in the light af the Environmental Outlooks

were not satisfied with the treatment of uncertainty in the actual reporting of the assessment in the Environmental Outlook report seems to provide some support for the first argument. On the other hand, we should not forget that the interviews and survey were held during the De Kwaadsteniet affair. It might be the case that inspired by the exchange of arguments in the debate, RIVM practitioners have, consciously or unconsciously, reconsidered their thinking about uncertainty. On the other hand, the same debate and the political pressure at that time on RIVM could also imply that the statement that expressing uncertainty does not conflict with the policy relevance was implicitly or" explicitly considered most socially preferred. As any interview or questionnaire research the empirical research discussed in the current Chapter also runs the risk of such biased responses. Nevertheless, the observed tension confirms RIVM's ambivalence towards uncertainty. It furthermore indicates how important the policy and political dimension of Rrvm's position is to the assessment process and product ${ }^{45}$.

45 As disseussied in Chapter 1 , it has been an explicit decision not to incorporate ithe policy and political dimension as research theme in the current PhD thesis: So we leave it with the above observation, and we do not go into any further reasoning about it. 
Table 9 indicates that the majority of the respondents consider uncertainty an important issue that should receive more attention in the assessment. This attitude is also reflected by answers to open questions in the interviews, as is illustrated by the following quote:

"More attention could be paid to uncertainty in the assessment, and right away more attention could be paid to communication uncertainty in the Environmental Outlooks. The latter is the easiest. Reliability can be reflected in documents as the Environmental Outlooks with simple, editorial means. Besides, I think more uncertainty research can be done, or more should be measured."

One of the research questions framing the empirical research has been our interest in identifying uncertainties salient to the Environmental Outlook assessment. It turned out that the document analysis of the series of Environmental Outlooks did not allow us to identify salient uncertainties. The source-oriented document analysis suggested that all sources of uncertainty play a role in the Environmental Outlook, however this analysis did not provide any clue which sources are crucial.

To that end, interviewees and the questionnaire respondents were asked to prioritise the sources of uncertainty in order of importance. Table to summarises the results.

\begin{tabular}{|c|c|c|c|c|c|c|c|c|c|c|c|c|c|c|c|c|c|c|c|c|}
\hline \multirow{2}{*}{$\frac{\text { sources of vincertainty }}{\text { Behavioural variability }}$} & \multicolumn{6}{|c|}{$\begin{array}{l}\text { ranking } \\
\text { in tincerv'tews }\end{array}$} & \multicolumn{14}{|c|}{$\begin{array}{l}\text { ranking } \\
\text { in questiomnatre* }\end{array}$} \\
\hline & 4 & 9 & 8 & 9 & 7 & 9 & 9 & 6 & $r$ & 7 & 7 & 2 & $i$ & 5 & 6 & 9 & 5 & 6 & 8 & 6 \\
\hline Societal randomness & 5 & 6 & 9 & 7 & 8 & 8 & 8 & 7 & $y$ & 7 & 7 & I & I & 4 & 6 & 5 & 6 & 9 & 7 & $r$ \\
\hline Technological surprise & 7 & 3 & 7 & 8 & 5 & 7 & 2 & 5 & 4 & 4 & 7 & 3 & 5 & $I$ & 4 & 7 & 7 & 8 & 3 & 2 \\
\hline Conflicting evidence & 9 & 5 & $r$ & 5 & 9 & 5 & 7 & $\mathbb{1}$ & 3 & 5 & 7 & 5 & 1 & 9 & 1 & 2 & 8 & 2 & 4 & 7 \\
\hline Natural randommess & 3 & 8 & 4 & 4 & 6 & 6 & 3 & 4 & $i$ & 7 & 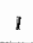 & 4 & 9 & 6 & 8 & 6 & I & 7 & 4 & 4 \\
\hline Value diversity & 8 & $i$ & 5 & $t$ & 4 & 4 & $\pi$ & 8 & 9 & 6 & 7 & 6 & $\pi$ & 3 & 4 & 8 & 9 & 5 & 9 & 8 \\
\hline nexactness & 6 & 7 & 2 & 3 & 2 & 1 & 4 & 2 & 6 & 4 & 4 & 9 & 5 & 8 & 2 & 3 & 2 & 3 & 6 & 3 \\
\hline $\begin{array}{l}\text { Lack of observations! } \\
\text { measurements }\end{array}$ & 2 & 4 & 6 & 2 & 3 & 3 & 5 & 3 & 9 & 5 & 2 & 8 & 9 & 7 & 2 & 1 & 3 & I & 2 & 5 \\
\hline Practically immeasurable & 1 & 2 & 3 & 6 & 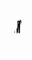 & 2 & 6 & 9 & 9 & 6 & 3 & 7 & 5 & 2 & 9 & 4 & 4 & 4 & 5 & 9 \\
\hline
\end{tabular}

LEGEND Scale 1-9, 1 highly important - 9 not important

*ne respondent did not answer this strvey question

TABLE IO Ranking af sources of uncertainty in the interviews and questionnaires. 
Taking the input of each respondent, whether manager, integrated assessor or disciplinary/sectoral expert, equally serious, each source has been ranked by one or more persons as being extremely important (i.e. Is in each row). The spread in the scores in Table 9 - each source was also scored as not important (i.e. an 8 and/or 9 in each row)- furthermore indicates that there is no consensus what so ever about the salience of the various sources. Building upon these two observations, it is at least legitimate to argue that all sources are seem to be relevant to RIVM's assessment of the future state of the environment.

\subsection{RIVM'S LEARNING PROCESS}

Both in the scholarly literature on uncertainty ${ }^{46}$ and in the interviews, it was noticed that consciousness on, and awareness of, uncertainty do not necessarily evoke that uncertainty is adequately addressed in the assessment. Taking this notion of phasing into account and in line with the steps proposed with the PRIMA-approach, it was postulated that uncertainty management involves a learning process in phases ${ }^{47}$. Taking the historical development on thinking about uncertainty and science into account, we sketched a transition from assessment in a positivist mood towards uncertainty management as central to the assessment (see Figure 8). In phase I uncertainty is qualified as 'bad work', which implies that uncertainty reduction is the key ambition. Awareness of uncertainty starts to develop in the second phase. In this phase uncertainty is becoming a theme on the assessment agenda, but it is not systematically addressed. Uncertainty is acknowledged, but it does not play a major role in the assessment. In the third phase, uncertainty is receiving more systematic attention. Instead of treating uncertainty as a black box, uncertainties are specified in terms of types and sources, which allows a more targeted use of available methods for uncertainty management. The $4^{\text {th }}$ phase features the learning process in which the degree of uncertainty can be systematically assessed, preferably in quantitative terms. This implies that experts are trained to express their knowledge in terms of qualitative statements, or in terms of quantitative uncertainty ranges. Furthermore, uncertainty is not just assessed at the level of components, but at the level of the full assessment. Building upon the previous phases, phase 5 features a situation in which the policy relevance of specific uncertainties is not any longer assessed intuiti- 


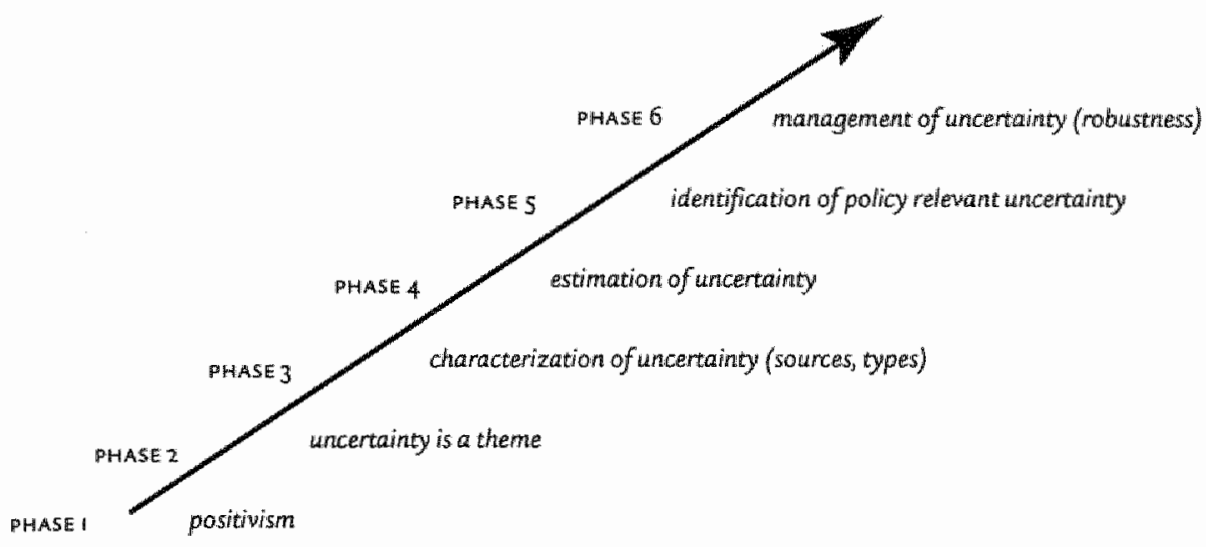

FiCURE 8 Learning curwe in dealing with uncertainity

vely, but in a systematic manner sufficiently informed by the underlying assessment. In the final phase, uncertainty management is fully integrated into the assessment methodology and framework.

Informed by the case-study research, we tried to characterise RIVM's current attitude towards uncertainty in terms of this learning transition. That does not mean that every single Rrvm practitioner is in that phase, but it indicates where RIV M's leading group is about. The expressed atritude as derived from the interview and questionnaire data implies that RIVM is beyond phase 1 . The document analysis and the empirical research indicate that uncertainty is acknowledged, but that it is not yet systematically treated in the assessment. As discussed above, the interviewees were confronted with the typology of sources of uncertainty. We hypothesise that they recognised the various sources and felt themselves able to prioritise the various sources ${ }^{48}$. The document analysis also indicated that the uncertainties considered in the assessment could quite straightforwardly be characterised in terms of sources. On the other hand, the interviewees were invited to estimate in qualitative terms the degree of uncertainty for the various components in the causal chains, but it turned out difficult or even impossible for them to assess the degree of uncertainty in relative terms. From this observation we conclude that RIVM is not (yet) in phase 4. From this induction, we can conclude that the current attitude towards uncertainty in the

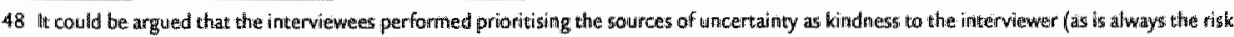
of interviews). In the same line of reasoning, it could be argued that the distribution of priority judgemento can bre considefed as a bad sigh for the respondents' ability to judge. Howewer, alliperwiewees except one refused to perform some of other rankings they were asked to do

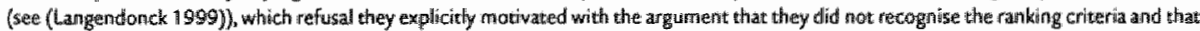

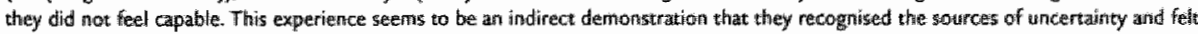
comfortable to rank them: Also the discussion in the focus group and the feedback on the workshop (sed Chapter B) wera the typology was preseanced, seent to prowide support for our hypothes. 
leading group of $\mathbb{R}$ IVM is possibly best characterised by phase 3 , while building upon our retrospective case-study the previous Environmental Outlooks can definitely be associated with phase 1 , or at maximum phase 2 .

\section{A need for the PRIMA approach?}

From the above multiple-case case-study research, we can conclude that both uncertainty due to variability and uncertainty due to lack of knowledge matter to RIV M's environmental assessment. However, both the document analyses and the empirical research consistently yield that uncertainty is not systematically managed in the assessment process and it is not transparently communicated in the Environmental Outlook reports. The relevant question is whether this implies that the quality of the policy recommendations is wiolated. It is beyond our expertise and capabilities to judge whether the conclusions that provided a basis for the pollicy recommendations in the four Envintonmental Outlooks lacked robustness. In the focus group, it was argued that with hindsight RIVM's environmental management does not regret any of the policy recommendations suggested in the series of Environmental Outlooks. This is explained by the rather conservative and no-regret atticude RIvm took; in view of uncertainty their concrete policy recommendations have been on the safe side in terms of $\operatorname{costs}^{49}$. In the last decade, only two of the many policy-relevant conclusions have been doubted afterwards, i.e. the environmental value of public transport and ploughing down of manure.

Notwithstanding the apparent robustness of the actual policy recommendations in the previous Environmental Outlook, the lack of systematic uncertainty management is problematic in view of RrvM's decision-support aim. Questions as to whether and how uncertainty was accounted for cannot be answered by means of reference to either the Environmental Outlook or the process documentation. This implies that Rrvm cannot prove by means of scientifically credible arguments that the robustness of conclusions is not violated by some salient uncertainties. This is not a problem as long as RrvM's authority is unquestioned. However, the De Kwaadsteniet affair teaches that in our current society authority is not (anymore) a solid basis. This media affair furthermore yielded that uncertainty management is not only relevant from a philosophical point of view, but that it is critical to Rrvm's deci-

49 it show be noted that conservative and mowegret attitude of RWM might have been wite to policy intervention in the assessment process on

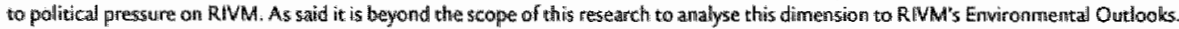


sion-support role in the policy arena. Reasoning from the political commotion that directly grew out of De Kwaadstenier's accusations, it is to be expected that Rrvm's future products will be accompanied by critical questions about uncertainty management. The recent media affair illustrated that RIvM's vulnerability due to lack of systematic uncertainty treatment is real. De Kwaadsteniet did not create the vulnerability; the media affair only brought it to the (public) fore ${ }^{50}$.

The retrospective case-study on the RrVM's Environmental Outlooks as discussed in this Chapter indicates that there is a potential need in the practice of Integrated Assessment for a methodology that allows to manage uncertainty in a systematic and adequate manner. There is a revealed need for improvement of Rrvm's uncertainty management (see also box 7 ). The next crucial question for the currrent thesis is whether this need could be satisfied with the Prima-approach as presented in this thesis. This question will be addressed in more detail in the next Chapter. Here we limit ourselves to summarising ideas for improvements that directly follow from the case-study research reported in the current Chapter:

- more systematic treatment of uncertainty in the argumentation underlying the policy conclusions (from weak to strong)

- a consistent linguistic strategy

- a broader set of scenarios that includes futures salient to the environmental assessment

- explanation of increase/decrease of uncertainty ranges compared to the previous environmental assessment

- a more transparent and accessible Environmental Outlook by means of a transparent policy summary accompanied by a scientific compendium, which is an extensive version of the policy summary in which the policy conclusions are justified at the right level of abstraction (which means that irrelevant details, but nevertheless interesting from a more sectoral or scientific view point do not occur in the scientific compendium).

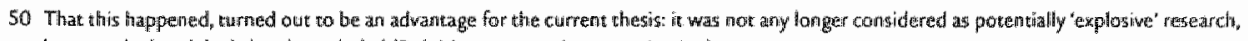
because the bomb tad already exploded (Rob Maas, personal communicazion). 


\section{$\mathrm{BO} \times 7$}

Furthermore, the interviewees were explicitly asked whether they see a need for another approach to uncertainty management in the Environmental Outlook practise. The interviewees answered:

- "It is interesting to explare the possibilities of other approaches, but I don't rule out that eventually we have to decide that a mone subjective approach doesn"t work. (..)"

- "I thimk there is a need to get to grips with uncertainty. There should come an easier and uniwocal way of communicating whertainty. Concepts like accuracy, uncertainty, reproducibility should be used unambigurousty defined. I don't really have an idea how this could be worked out. ."

- "Yes, in two ways. In explicitly considering uncertainty in the computations, as well as in communicating uncertainties in the final Environmental Outlook. To do so, more money should be invested in research imto wncertainty. Further , arV needs a protocol for managing uncertainty in a consistent manner. (..) it is a learning process."

- "(.) Another way' should be phased in. ( $)$ in fact it is a communication problem. There is an overload of infornation. In keeping the message simple, you attempt to communicate the message as clearly as possible.

(1.) It is aur duty to organise the underlying information, and there is yet quite a lot we should do about it."

- "Yes. (.) We should consider it in science-phlosophical terms. (..) It is a challenge (.). We should think more in narratives, imaginary futures that are coloured with some data."

- "It is my ideal. I hope there is also a need for another approach within the policy community. I would like to have more interaction and commumication with policy makers and politicians. I would like to explore strategies in gante-like sessions. There should be more creativity. We should think about potential surprises, so as to broadem scenarios: We need such interaction to decide which uncertainties are policy relevant."

- "It is wery difficult to teach policy waters in the Netherlands how to deal with the scenarios of the Rivw, but it is even more difficult to interest them in the models the RIVM applies and their potential arbitrary underlying assumptions. (.. ) For an effective contmunication you reed two parties. It is remarkable that this is lacking on national level. Within international relations there is a lot more bilateral communication. Maybe this originates from the CPB traditions. The CPB is placed on a pedestal and is independent of different parties. Because of that is is "not done" to deepen in the matter of the CPB and this has to be accepted. Now RIVM has acquired the status of environmental planwing agency, there is also no interest in deepening the understanding of the enwironmental models of the RIVH:"

- "y) more attention could be paid to communication uncertainty in the Environmental Outlooks. The Jatter is the asiest. Reliability cam be reflected in documents as the Environmental Outlooks with simple, editorial 
means. Besides, It think more uncertainty research can be done, or more showld be measured. An important issue in this context is the finances and the priorites. If there is not enough money, issues as uncertainty dre the first that go:

In the course of the interview, the interviewees expressed ideas and opinions on how uncertainty management could or should be improved:

- "Anyway, wa have to arrange that the models are validated and neviewed."

- " $($.$) to underpin the expert-judgements statistically and to rewiew them"$

- "The scientific rewiew and the metwork have to be better mobilised and reported"

- At the start (i.e societal developments and policy scenarios, MvA) and the end (he. effects on human environment, on ecosystems and on human heatth, MUA) of the causal chain, we have to invest extra work because there our models are least robust and least tested."

- "There should be more attention for the quality of the data and the scientific rewiew, and for the commurication with external knowledge institutes. It is also important how to communicate the information adequately to the press. (.) This all should be better organised."

- "The role of RIVM is to facilitate strategic decision-making. Models and measurements are means to achiowe this. One has to take care that the models are validated and reviewed. (.) The disadvantage is that this can turn into reductionism (..) The ultimate aim is to soar numbers and models, they are just means."

Building upon the interviews, two closed 5-point scale questions were formulated that were integrated in the questionnaire in order to get a richer understanding of RIVM's perception of the need for an alternative approach:

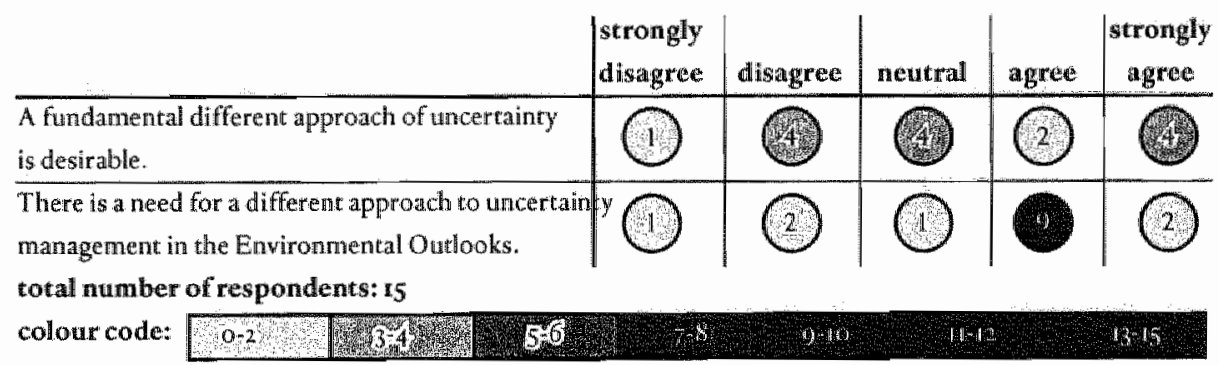


The above empirical interview and questionnaire data (see box 7 ) indicate that there is an interest in another approach for managing uncertainties in the Environmental Outlook. The analytical problems revealed with the multiple-case case study are to a more or lesser extent recognised by Rivm practitioners. However, the respondents differ with regard to the necessary lewel of change.It is clear that the majority of RIVM practitioners at this point in time does not advocate a fundamentally different approach to uncertainty management, notwithstanding some support for change found by some individual practitioners. The above is illustrated by the following:

- "any new approach should contain classical methods, or at least indicate the contribution of classical methods"

- "work that has already been done will not be thrown overboard"

Some see it primarily as a communication problem that can be solved relatively easily. Others see a more fundamental need, and refer to the need for uncertainty research and the need to explore new approaches. The respondents indicate that this has implications for priorities and financing; there is a risk that uncertainty management is considered a luxury that will be cut down in times of budget pressure. A clear conclusion that can be drawn from the interview data is that the success of any alternative approach to uncertainty in the Environmental Outlooks will ultimately be determined by the interaction with policy makers and their attitude towards uncertainty management.

It can be inferred from the empirical data that a "protocol" for uncertainty management should address the following issues in order to be able to satisfy RIVM's expressed need:

- data quality

- model validation and review

- transparent documentation of expert judgement and scientific review (i.e. documentation of the assessment process ${ }^{51}$ )

- creative scenario-development

- explanation of ranges

- relative importance of sources and types of uncertainties in relation to the conclusions

- reporting uncertainty in the Environmental Outlook report

- communication with other knowledge institutes

- interaction and communication with policy makers and politicians 
Some of the above issues also resulted from our document analysis, such as the transparency about uncertainty in the Environmental Outlook and the need for a broader set of scenarios. The first three issues involve onganisation of qualified information, the second cluster of three pertains to the assesment itself, while the last cluster pertains to the reporting and communication.

\section{Conclusions}

The case-study research discussed in this Chapter teaches us that there are fundamental limits to Rrvm's current management of uncertainty. The retrospective analytical study and the empirical data show that the way rrvm is currently dealing with uncertainty is problematic, both from a theoretical point of view and also from the practitioners' viewpoint. Extrapolation of the current practise implies that future Environmental Outlooks would feature 'sprinkling' margins that will violate the policy relevance of the Environmental Outlooks. Furthermore, there is not yet a legitimate set of scenarios available that is adequate in view of the Environmental Outlook ambitions. Last but not least, uncertainty can only be transparently communicated when it is systematically considered. Acknowledging uncertainty is just a first step. The latter two improvements thus require a significant change of the assessment methodology and process.

A systematic strategy and protocol for uncertainty management are currently lacking within RIYM. The empirical data indicate there seems to be a cautious openness towards an alternative approach for uncertainty management. In sum, we conclude that there is both a revealed and expressed need for improvement of RIVM's uncertainty management in the context of the Envirommental Outlooks. The next question is then whether the PRIMA-approach has something to offer to RIVM"s assessment practise. 


\section{REFERENCES CHAPTER 7}

- CPB (1992a), The Netherlands in Triplicate: a scenario study of the Dutch economy (In Dutch), Sou Uitgeverij. The Hague, The Netherlands.

- CPS. (1992b). Scanning the Future: A long term scenario study of the world economy 1990-2015, Sdu Uitgeverij, The Hague, The Netherlands.

- de Barro, $\mathrm{E}$ (1968). New Think The use of lateral thinking in the generation of new ideas, Biasic Books, New York, USA.

- de Bono, E. (1969). The Mecharism of Mind, Jonathan Cape, London, UK.

- de Bono, E. (1970). Lateral Thinking: Creativity step by step, Harper \& Row, New York, USA.

- Funtowicz, 5. O, and Ravetz, J. R. (1994). "The Worth of a Songbird: Ecological Economics as a Post-Normal Science." Ecological Economics(10), 197-207.

- Ceurts, B. M. E, Cielen, A. M. Mathuis, R., Tang, P. I. G., and Timmer, H. R. (1995). "Worldscan: An economic worldmodel for scenario analysis (paper for the Review of Worldscan) ${ }^{\text {" }}$, $C P B$, The Hague, the Netherlands.

- Langendonck, R. M. T. (1999). "Searching for Uncertainty: The case of the National Environmental Outlooks;" master thesis, ICIS, Maastricht, The Netherlands.

- Molendijk, $k_{n,}$ and Rotmans $s_{n}$ J. (1999). "De-coupling De-coupled (Internal paper for the Prowince of Limburg)"." $1 \mathrm{Cl5}$, Masastricht, the vetherlands.

- RWM. (1988). Concern for Tomorrow, Samison H.D. Tjeenk Willink, Alphen alan de Rijn, The Netherlands.

- RIVM. (1991). National Enwironmental Outlook 2 1990-2010, Samsom H.D. Tjeenk Willink, Alphen aan den Rijn, the Netherlands.

- RIVM. (1993). National Enwironmental Outlook 3 1993-2015, Samsom H.D. Tjeenk Willink, Alphen aan den Rijn, the Netherlands.

- RIMM. (1997). National Enwironmental Outlook 41997-2020 (in Dutch), Samsom H.D. Tjeenk Willink, Bilthoven, the Netherlands.

- RIVM. (1999a). "Addendurn Measure, Calculate, and Uncertainties: The working method of RIVM's environmentall research (in Dutch).", RIVM, Bithoven, The Netherlands.

- RIVM. (1999b). "Measure, Calculate and Uncertainties; The working method of RIVM's environmental research (in Dutch)." Bilthoven, The Netherlands, Dutch, ed, RIVM.

- Timmer, H. (1998). "Worldscan: A world model for long-term scenarios." CPB Report, 1998(3), 37.41.

- Van Amstel, A. R. (1993). "Greenhouse Gas Emissions in the Netherlands. 1990, 1991, 1992 and the Projections for 1990-2000" 77300100 J, RIVM, Bilthoven, The Netherlands.

- van Asselt, M. B. A. "Improving Decision-making under Uncertainty: An integrated approach to strategic risk analysis:" The 9th Anmual Conforence of the Society for' Risk Analysis "Facing the Mallenium", Rotterdam, the Nethertands.

- van Asselt, M. B. A., Langendonck, R. M. T, and van Asten, F. (2000 (in preparation)). "Searching for Uncertainty: A case-situdy on the Dutch National Enwironmental Outlooks." "ICIS, Maastricht, the Netherlands.

- van Asselt, M. B. A., Storms, C. A. H. M. R.jikens-Kliomp, N., and Rotmans, J. (1998). "Towards Visions for a Sustainable Europe: An overview and ascessment of the last decade of European scemario studies" 198-EO01, $\| C 15$, Mastricht, the Nietherlands.

- van Asselt, M. B. A, wan Asten, F, and Langendonck, R. M. T. "Uncertainty at Risk." The 1999 Open Meeting of the Muman Dimtensions of Global Enwironumental Change Research Community, Japam.

- van Asten, F. (2000). "Uncertainty in Practise: Application of the PRIMA approact to the 5 th Environmental Outlook," master thesis, Maastricht University, Maastricht, the Netherlands.

- van Asten, F, and van Asselt, M. B. A. (1999). "Uncertainty and the 5th Enwironmental Outlook: Workshop report (in Dutch), , 1CIS, Maastricht, the Netherlands. 


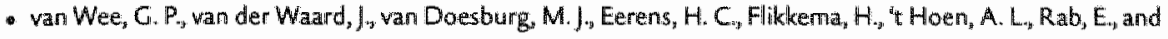
Thomas, R. (1993). "Transport in the 3rd Enwironmental Outlook and the 5 Wassesment 1993 (in Dutch)." 25 i 701014, RMVM, AVV, Bilthowen.

- WROM, EZ, LNV, and V\&W. (1989) "National Environmental Policy Plan." 21137, wrs. 1-2, VROM, The hague, The Netherlands. 



\section{Exploring PRIMA's first steps in practice}

the case of the $5^{\text {th }}$ Environmental Outlook

The retrospective study on RIVM's series of Environmental Outlooks as discussed in the previous Chapters indicated a potential need for a systematic framework for uncertainty management. One of the ambitions of this thesis is to test whether the proposed PRIMA approach can satisfy this need, not only theoretically, but also in practical terms. In the first part of this thesis we argued that from a theoretical, philosophical point of view applying the PRIMA approach would improve the quality of Integrated Assessment endeavours. In the current Chapter, we will explore whether and how this potential improvement can be realised in practise. "The key guestion addressed in this Chapter thus holds: Is it possible and if so in what way, to use the PRIMA approach in assessment practice in a practically feasible manner as to improve the quality of the assessment?

To this end, we explored how the Pruma approach could be implemented in RrMm's current environmental assessment process that will ultimately result in the $5^{\text {th }}$ Environmental Outlook. In this endeavour we restricted ourselves to the first two phases of PRIMA, i.e. definition phase and "uncertainties-in-perspective" phase. The RIVM case enables to get some insight into some practical constraints, conditions, expectations and ideals of practitioners. This kind of insights about assessment practise will help us to further develop the PRIMA approach as outlined in Chapter 5. 


\section{Research approach}

The retrospective case study on RrVM's Environmental Outlooks indicated that there is an observed need for an alternative mode of uncertainty management. Furthermore, there has been an a priori interest in the perspective-based approach to uncertainty management $t^{t}$, and the media-affair ${ }^{2}$ created a niche and momentum to experiment with the PRIMA-approach in the $5^{\text {th }}$ Environmental Outlook assessment process.

The flow chart of the PRImA-approach (see Figure r) ${ }^{3}$ served as starting point for the prospective research. It was clear from the beginning that within the scope and time frame of the $\mathrm{PhD}$ project, it would be impossible to explore the full cycle. We therefore decided to limit ourselves to phase I (the definition phase) and phase 2 (the "uncertainties-in-perspective" phase). It is argued in Chapter 5 that PRIMA was explicitly designed in such a way as to enable output of particular phases to serve as input to the assessment process, even if the cycle is not completed. Next to testing the two first phases in practise, we will therefore explore the implications of the associated output for the $5^{\text {th }}$ Environmental Outlook.

The PRIma framework outlines phases and provides some ideas about how these phases can be carried out in practise. The PRIMA approach is not a rigid methodology in which all successive steps are defined. It is explicitly meant to be a flexible framework that can serve as a heuristic for uncertainty management in assessment practises. In Chapter 5, we made clear that dependent on the context and the chosen perspective on pluralism specific design choices have to be made. In other words, there are different ways to carry out the PRIMA phases. So our first job was to design concrete steps that would allow carrying out the first two phases of PRIMA in the $5^{\text {th }}$ Environmental Outlook practise.

The first step involves definining the complex issue at stake and the perspective on pluralism that will be adopted throughout the pluralistic assessment process. Informed by the case-study research, we outlined the points of departure, which seemed to comply reasonably with RIVM's attitude and organisation culture. In the second part of the focus group ${ }^{4}$, the perspective on pluralism proposed to adopt for the $5^{\text {th }}$ Environmental Outlook process was shared with Rrvm's managers involved

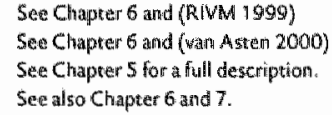




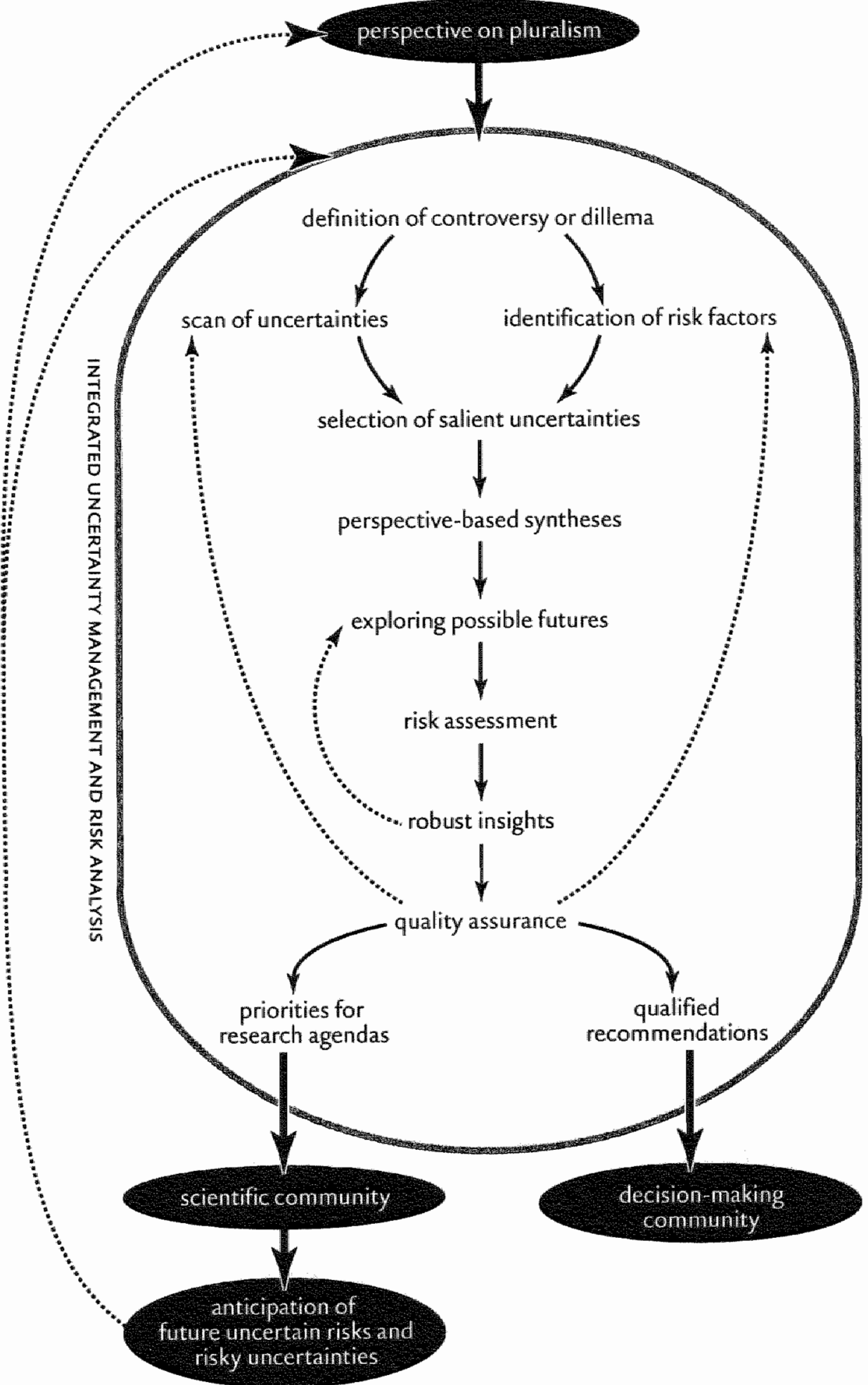


in, and responsible for, the Enwironmental Outlooks. It was discussed with the focus group wherher the proposed points of departure were considered to be appropriate in the eyes of the practitioners.

The retrospective research on the previous Environmental Outlooks has taught us that RIVM's expertise was needed to outline salient uncertainties. ${ }^{5}$. It was explicitly said that there is more knowledge on uncertainty in "the heads of the assessors" than in the assessment reports. Secondly, we were not interested in individual opinions, but we aimed to mobilise the collective expertise to arrive at a judgement on the salience of uncertainties. As a consequence we preferred a group research method above individual methods (as surveys and interviews). Thirdly, we were especially interested in studying whether practitioners were able to perform PRIMA activities. The aim of the "uncertainties-in-perspective" phase is to scan uncertainties and to interpret them from different perspectives. This implied that we were not so much interested in a group discussion, but that we wanted to create a group setting in which exercises are performed ${ }^{6}$, in the plenary and/or in facilitated subgroups. We therefore decided to carry out the second phase of PRIMA, i.e. "uncertainties-in-perspective", by means of a workshop with practitioners from the various departments and laboratories within RIVM involved in the $5^{\text {th }}$ Environmental Outlook assessment process. In its general form, a workshop involves an introduction and explanation of the work to be done, a central part in which the group does the exercises and a plenary closure, in which the results of the exercises are presented and discussed.

The workshop involved about 20 practitioners, and it lasted half a day. The PRIMA-workshop with RIVM practitioners involved the following exercises:

- brainstorm on uncertainties relevant for the $5^{\text {th }}$ Environmental Ourlook

- clustering of the uncertainties

- interpretation of the uncertainties from the view point of one perspective per subgroup

In the closing plenary, the subgroups presented their results, and the workshop and its output were discussed in view of the $5^{\text {th }}$ Environmental Outlook. Because of its character, a workshop results in a wealth of information involving notes of the workshop facilitators, audio or videotapes, pictures, and, most importantly, the material produced by the participants in the course of the workshop. The workshop was furthermore accompanied by two questionnaires. The participants filled out a question-

5 We tried to distract salient uncersainties by the andyses of the previous. Emvironmental Outlooks, but as discurssed in Chapter 7 dwe to the weallonesses observect in crucial lines of argument we could not induce sallent uncertainties in this way.

6 I owet this clear and appropriate definition of 'workshop' to Framk wain Asten. 
naire before the workshop', in order to be able to sketch the group profile and control for bias. A second questionnaire was completed after the workshop, in order to use the participants' evaluations to explore practical constraints, conditions, expectations and ideals ${ }^{8}$.

In sum, we tested the first two phases of PRIMA-approach, i.e. the definition phase and the "uncertainties in perspective" phase, in the following way:

- in the definition phase the major controversy guiding the environmental assessment was formulated and the approach to pluralism was chosen building upon the case study on the previous Environmental Outlooks. These preliminary choices were shared with and modified by the focus group.

- a representative group of practitioners involved in the $5^{\text {th }}$ Environmental Outlook process carried out the "uncertainties in perspective" phase through a workshop.

\section{Definition phase}

Building upon our analysis of the previous Environmental Ourlooks, we formulated the dilemma RIVM seems to address by way of the following central question that in principle spans different visions on the current and the future state of the environment:

Is a high environmental quality reconcilable with social-economic targets? And if so, to what extent can the government contribute to this? And if so, with what kind of policy measures?

This problem description was shared with, and discussed in, the focus group" consisting of people who are or have been in charge of one or more Environmental Outlooks. It was considered a good description of the problem description of the $3^{\text {rd }}$ and $4^{\text {th }}$ Environmental Outlook. One of the focus group participants brought forward that every phrasing inhibits a paradigm about society. He argued that Ruv $\mathrm{m}$ indeed presupposes that society can be influenced, or even managed, by policy. The issue would be defined differently from another perspective. Another participant argued that it is more realistic to say which environmental quality is attainable in the light of

7 Part of whe question raire ctata was at readly incorporated in Chapten 7.

8 See (van Asten and wan Astellt 1999) and (wan Asten 2000) for the full questionnarin responses: 
current economic and social goals. Someone else suggested that a way out could be to phrase the dilemma in a symmetric way. A phrasing in this spirit would be:

If and, if so, in what ways are environmental quality and social-economic targets reconcilable? And if so, to what extent can the government contribute to this? And if so, with what kind of policy measures?

Such a formulation of the dilemma in principle leaves room for the above interpretation of assessing which environmental quality is attainable in the light of current economic and societal goals. It also allows to emphasise the economic goals over environmental quality, as one of the participants would like to incorporate. In other words, the above formulation leaves room for fundamentally different perspectives. There was a slight preference in the group to define the starting point from different perspectives, instead of reasoning from one overarching dilemma. On the other hand, the focus group agreed that the proposed phrasing basically covers the crucial ingredients addressed in RIVM's environmental assessment endeavours. This experience yields that developing problem definitions for each perspective might be an alternative way to carry out the first PRIMA phase, next to the manner proposed in Chapter 5 (i.e. to formulate an overarching problem definition ${ }^{10}$ ).

The second step involved the proposition of an approach to pluralism. The spectrum of attitudes towards pluralism is discussed in Chapter 4. In order to figure out what perspective matches best with Rrvm's perspective, we further analysed the data from the interviews, the focus group and the questionnaires. From the attitudinal data towards knowledge and uncertainty discussed in the previous Chapter, it can be concluded that the attitude of the respondents goes beyond the objectivist perspective. Building upon the empirical data, it can be argued that either the "theory in perspective" or the "science in perspective" attitude seems to be most appropriate. Because Rrvm had gained experience with the "science in perspective" attitude via the TARGETS endeavour", we proposed the "science in perspective" attitude as philosophical starting point for the pluralistic exercise.

Consensus was achieved about the pluralistic starting point, as is illustrated by the following quote:

"I think it is a good proposal to cluster uncertainties you will never get rid of, with perspectives. (.) In this way you cluster the things you do not know. You then get some extreme variants. Then you vary: what if the pessimist is right in 
that the farmers will never co-operate. And in my policy instruments I reason from the assumption that human beings are in principle good, and that you have to inform them about the consequences for the Third World. Where do I get then? Nowhere. Maximal misfit.(.) This is a more sensible way of dealing with uncertainties (.) then to turn the handles of models."

The focus group also agreed that not only scientific perspectives should be considered; they were especially interested in societal perspectives, as follows from the following quotations:

- "I can imagine: there are some actors in society, which have a certain perspective? Wouldn't it be better to know these perspectives. (.) My question is thus whether it would be good to consider actual societal perspectives."

- "We could try to do something with the ministries (.) We could ask them what isyour worldview, what is your preferred management style. (.) The advantage of creating perspectives with ministries is that they are forced to think about their choices."

From these quotations, it follows that the focus group advocated a pluralistic attitude that goes beyond the "theory-in-perspective". This means that the proposed "science-in-perspective" perspective seems to be appropriate for a pluralistic exercise within RIVM. The next question is whether the perspectives have to be revealed empirically, as the above quotes suggested, or whether it would be acceptable to start with stereotypes. In the focus group discussion, it was argued that it is not so easy to reveal perspectives, and thus basic assumptions, from a discussion with societal actors. The discussion resulted in some consensus that the difference between the two approaches is not fundamental. In the end, the focus group supported the idea to experiment with pre-defined perspectives.

The next step is then to come up with a set of socio-cultural perspectives that could be used throughout the assessment. We proposed to use the three perspectives $^{12}$ associated with Cultural Theory ${ }^{13}$, i.e. the controllist, the market-optimist and the environmental worrywart. We proposed this scheme of perspectives to the focus group. One of the participants suggested other labels, i.e. the economist, the ecologist and the democrat or governor. The market optimist and the environmental worrywart were no point of discussion. The focus group had some problems with the controllist, as expressed by the following quotation:

12 Deduced from Cultural Theory See Clupters 4 and 5 .

13 See Chapter 5 
"I do not have so much sense for the controllist.I think this perspective is quite different from the other two. (.) The controllist is a strange figure. I can't associate it. (.) It seems to be a bit from this and a bit from that."

Notwithstanding the above reservations, after thorough discussion the majority of the focus group considered it worthwhile to test out the first steps of the PRIMAapproach in a workshop with RIVM practitioners along the lines of the proposed pluralistic stand and with the proposed set of perspectives.

\section{Uncertainty in perspective - workshop}

The aim of the workshop was to explore the phase "uncertainties in perspective" in practice. To that end, the workshop addressed practitioners in the $5^{\text {th }}$ Environmental Outlook process. The 18 participants were selected and invited by the project management of the $5^{\text {th }}$ Environmental Outlook ${ }^{14}$. The workshop took place on June $8^{\text {th }}$ 1999, at RIVM and lasted the afternoon. Prior to the workshop, the participants received a questionnaire and a discussion paper "Uncertainty and the $5^{\text {th }}$ Environmental Outlook" ${ }^{p 15}$, in which the major ideas underlying the PRIMA-approach were summarised.

The programme involved the following components:

- opening by Leon Braat, the project leader of $5^{\text {th }}$ Environmental Outlook, and Fred Langeweg, director of the Environmental division

- introduction to the workshop

- brainstorm on uncertainty and the Environmental Outlook

- clustering

- working groups per perspective

- plenary reporting

- closing discussion

In this section, we will focus on the heart of the workshop, i.e. the brainstorm and clustering, the working groups ${ }^{2}$ output and the closing discussion ${ }^{16}$.

\footnotetext{
14 see (vari Astern and varn Asseit 1999) and (van Astan 2000).

15 Ske (van Awstern and van Assels 1999). This discussion piper is a Dutch abstract of Chaprer 3 of this thesis

16 For the fill work hop report, see (van Asten and wan Asselt 1999) and (van Asten 2000).
} 


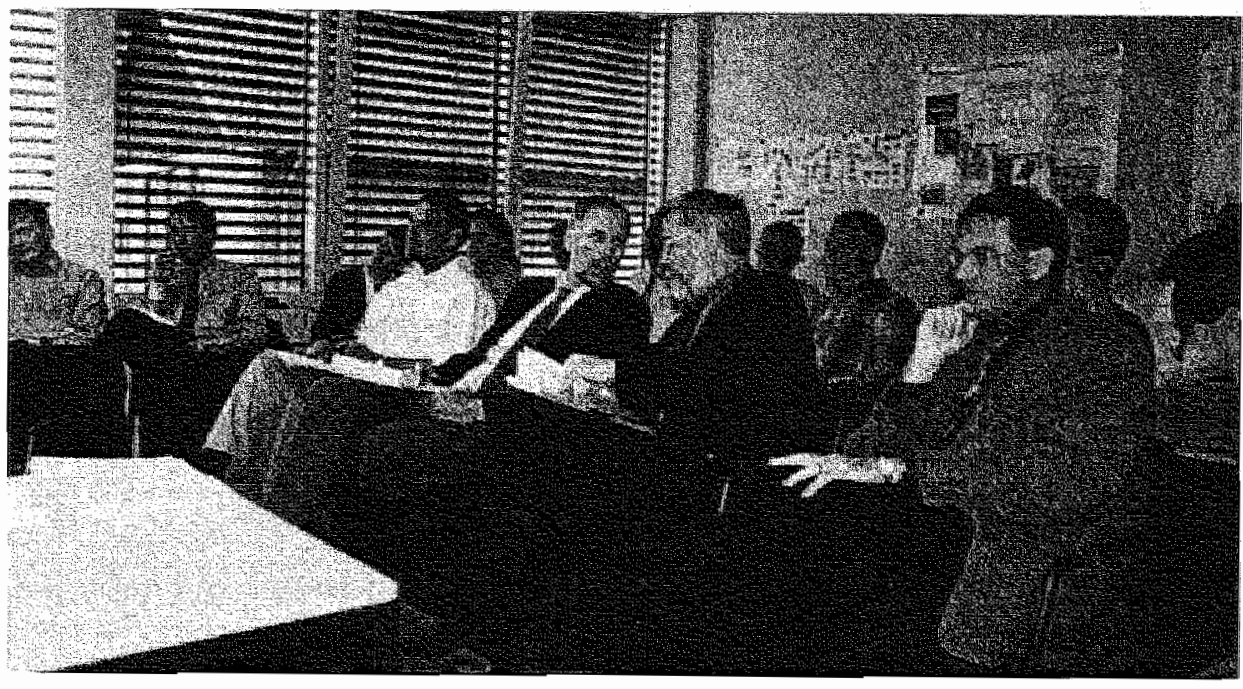

Workshop participants

\section{I SURFACING IMPORTANT UNCERTAINTIES}

The objective of the brainstorm and clustering was to get insight into uncertainties salient to the $5^{\text {th }}$ Environmental Outlook. To that end, each participant was given a number of Post-Its ${ }^{\mathrm{n}}{ }^{\text {, On }}$ One front of these, the participants wrote down which uncertainties they thought to be important and on the back they wrote the source of uncertainty and whether they could imagine a range. Next, the Post-Its were collected and divided into 4 categories: Institutional, Social-Cultural, Environment and Nature, and Economy ${ }^{\text {is }}$.

In total, the participants filled in 99 Post-Its $^{62}$. In the tables given below ${ }^{20}$, the various Post-Its have been clustered into the above categories. The number of Post Its addressing that uncertainty is given in the last column (\#). For 46 uncertainties, the source of the uncertainty was also given. On 29 Post-Its, an attempt was also made to give an accompanying range. The number shown in superscript shows to which range or source the mentioned uncertainty corresponds. Per cluster, the order is according to the number of times this particular uncertainty was mentioned.

17 These are small yetlow sheets of paper with a sticky strip on the back

18 This division is genenally used by ICIS for IA studie:s to structure the warious components of complex protems see for example; (1CIS 1998 ;

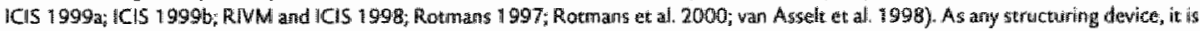

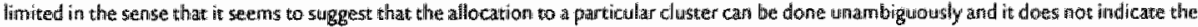

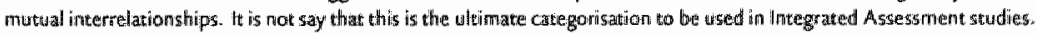

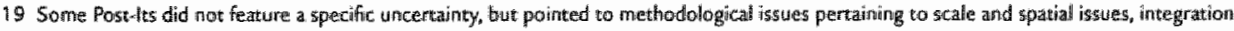

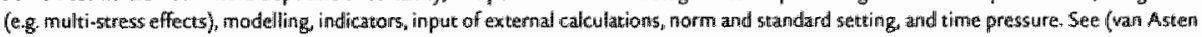
and van Asset 1999 ) fior liter al reporting of these posti-its.

20: We limit oumelwes here to the most important and dleamy expmessed uncertainties. For a full overview see (wan Asten and van Asgel 1999 ). 
INSTITUTIONAL

\begin{tabular}{|c|c|c|c|}
\hline wnceztainty & range & source & $\#$ \\
\hline $\begin{array}{l}\text { Effect and implementation of measures, degree } \\
\text { of molememtation/effectiveness of meastres } \\
\text { / effectiveness of policy /degnec of en forcement }\end{array}$ & & $\begin{array}{l}\text { Conflicting evidents" } \\
\text { Lack of measurements" }\end{array}$ & 5 \\
\hline 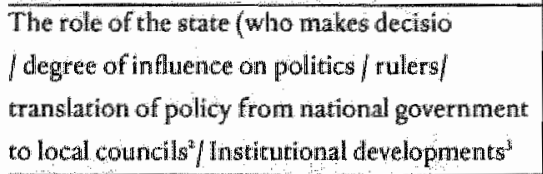 & $\begin{array}{l}\text { Large: a lot to Brussels" } \\
\text { Range, } 0-100 \%\end{array}$ & $\begin{array}{l}\text { Behaviour }{ }^{\text {" Lack of }} \\
\text { measurements/ in formation }\end{array}$ & 5 \\
\hline $\begin{array}{l}\text { Openness of Europe } 2030 \text { (bonders no longer } \\
\text { exist) / global agreements and EU policy / } \\
\text { foreign policy / lack of clarity in telationship } \\
\text { bueween intermational policy - national policy / } \\
\text { infuence of foreign environmental policy and } \\
\text { behaviour" }\end{array}$ & & $\begin{array}{l}\text { Lack of know hedge', } \\
\text { Unpredictable human actions }{ }^{2}\end{array}$ & 4 \\
\hline $\begin{array}{l}\text { Escalation of conflicts in the Third World / } \\
\text { instability (war) / discrete, once-only changes } \\
\text { disasters }{ }^{\text {tid }} / \text { Disconcinuty of sorial } \\
\text { developments }\end{array}$ & Small chance, $10-90 \%$ & Variabulity ${ }^{2}$ Human acrions ${ }^{*}$ & 4 \\
\hline $\begin{array}{l}\text { Policy objectives: Prevention versus } \\
\text { broad considerations }\end{array}$ & $\begin{array}{l}\text { Increasingly more } \\
\text { considerations }\end{array}$ & Policylbehaviour & $\mathrm{T}$ \\
\hline
\end{tabular}

TABLE \& Institutional uncertainties

\section{SOCHAL-CULTURAL}

\begin{tabular}{|c|c|c|c|}
\hline Uncertainty & Range & Source & $\#$ \\
\hline 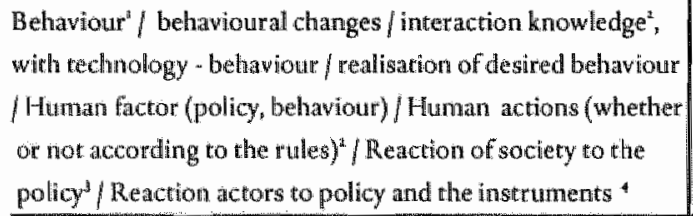 & $50 \%$ & $\begin{array}{l}\text { Human actions" } \\
\text { Latick of Unpredicta- } \\
\text { bility of human } \\
\text { actions "Variability* }\end{array}$ & 9 \\
\hline $\begin{array}{l}\text { Atritude of citizens to inmprovements in the quality of the } \\
\text { environment / response of people to the decline of the } \\
\text { environment }(+e c) \text { policy / Social preferences }\end{array}$ & Large" & $\begin{array}{l}\text { Shifting standards } \\
\text { and values }\end{array}$ & 3 \\
\hline $\begin{array}{l}\text { Consumer behaviour / pattern of consumption } 2030^{\circ} \text { / } \\
\text { reaction of producents and consumers to the consumption } \\
\text { pattern ( }+ \text { consumption of nature) }\end{array}$ & & $\begin{array}{l}\text { Unpredictability, } \\
\text { human behaviour }\end{array}$ & 2 \\
\hline Sociail development & $\begin{array}{l}\text { Strable to very un- } \\
\text { stable (ghettos rich) } \\
\text { poor), Range } 30 \%\end{array}$ & $\begin{array}{l}\text { Societal variability, } \\
\text { tnnpredictable human } \\
\text { actions }^{2}\end{array}$ & 2 \\
\hline Demography / Migration" & $\begin{array}{l}\text { Small, approximately } \\
\text { a couple of million } \\
\text { for the Netherlands }\end{array}$ & & 2 \\
\hline Inner cily trafhe problems & & & \\
\hline
\end{tabular}




\section{ENVIROONMENT AND NATURE}

\begin{tabular}{|c|c|c|}
\hline inty & Range & Source \\
\hline $\begin{array}{l}\text { Climate variability / climate system variability }{ }^{2} / \\
\text { occurrence of climate changes / Long term } \\
\text { (100-roooyears) fluctuations in the climate } \\
\text { and ecosystems }\end{array}$ & $\begin{array}{l}\text { Small for the Netherlands" } \\
\text { influence/no influence: } \\
\text { Range } 50 \%\end{array}$ & $\begin{array}{l}\text { Natur al randomness } \\
\text { lack of inaccurate objectives } \\
\text { lack of data }\end{array}$ \\
\hline $\begin{array}{l}\text { Collective (basic) emission (ERC) / predictability } \\
\text { of emissions / emissions, in particular spatial } \\
\text { differentiation / air emissions / emission } \\
\text { information, e.g. fine dust, ammonium }\end{array}$ & & $\begin{array}{l}\text { Inaccurate data, lack of data, } \\
\text { Lack of measurements, } \\
\text { pracrical workability" }\end{array}$ \\
\hline $\begin{array}{l}\text { Human + ecological effects }{ }^{2} \text {, Effects on humans } \\
\text { and ecosystern / Dose-effect relations }\end{array}$ & $>500 \%$ & $\begin{array}{l}\text { Practical immeasurability, } \\
\text { indeterminability }\end{array}$ \\
\hline $\begin{array}{l}\text { Response of ecosystem (fauna + flora) to bine de- } \\
\text { cline of qualiry of the environment }{ }^{\mathrm{t}} \text { Unfamiliar- } \\
\text { ity or uncertainty of funcrions of ecosystems } s^{2} / \\
\text { Environmental pressure } \rightarrow \text { ecosysterns }\end{array}$ & $30 \%$ & $\begin{array}{l}\text { Unpredictability of nature', } \\
\text { lack of knowledge of } \\
\text { long-term developments } \\
\text { of nature. }\end{array}$ \\
\hline $\begin{array}{l}\text { Speed of change of ecosysterns to climate changes } \\
\text { / feedback mechanisms climate-hydrology-ecology }\end{array}$ & & \\
\hline $\begin{array}{l}\text { Relation of } \mathrm{CO}_{2} \text { and threars via weather/climate, } \\
\text { influences of weather } \\
\text { Global supplies, water, energy, food production }\end{array}$ & Factor 2 & $\begin{array}{l}\text { Limited knowledge, } \\
\text { insufficient measurements }\end{array}$ \\
\hline $\begin{array}{l}\text { Natural variability (in contrast to highly } \\
\text { authorised indicators) }\end{array}$ & Depends on who asks & $\begin{array}{l}\text { System knowledge/ translation } \\
\text { between scale levels (variabitity) }\end{array}$ \\
\hline
\end{tabular}

TAELE 3 Nature and environmental uncertainties.

\section{ECONOMY}

\begin{tabular}{|c|c|c|c|}
\hline Uncertainty & Range & Source & $\#$ \\
\hline $\begin{array}{l}\text { Technology / technological development / } \\
\text { technological innowation (speed extent) }\end{array}$ & $\begin{array}{l}\text { Large porential effect, } \\
\text { large uncertainty }\end{array}$ & $\begin{array}{l}\text { Variability', technology } \\
\text { Indeterminacy }\end{array}$ & 6 \\
\hline $\begin{array}{l}\text { Technological developments in relation to } \\
\text { behaviour }{ }^{4}\end{array}$ & & & \\
\hline Econory, behaviour of the economic sectors & & & 3 \\
\hline Structure + size of Dutch industry & & $\begin{array}{l}\text { Unforeseen technological and } \\
\text { economic developments }\end{array}$ & 1 \\
\hline Occurrence of global economic recession. & & Unpredictable & 1 \\
\hline
\end{tabular}

TA.qL 4 Economic uncertainties

NOTE. Empty boxes imply that no remarks were made on the Poste-1ts regarding range and source. 
The sources of uncertainty ${ }^{2 t}$ mentioned on the Post-Its are given in Figure 2, with the number of times mentioned between brackets. It appears that many of the articulated uncertainties involve variability and structural uncertainty ${ }^{22}$ more than reliability. However, the document analyses as reported in Chapter 7 suggested that in those rare cases uncertainty was made explicit in previous Environmental Outlooks, the sources of uncertainty primarily referred to uncertainty due to unreliability (inaccurate measurement or calculations). This seems to imply that an 'articulation' of uncertainty by means of such a structured brainstorm yields sources of uncertainty that are overlooked or neglected in traditional assessment processes. This idea is confirmed by the results of the ex-ante questionnaire: 10 of the 15 respondents (out of the 18 participants) argued that the workshop helped them to systematically consider uncertainty ${ }^{23}$.

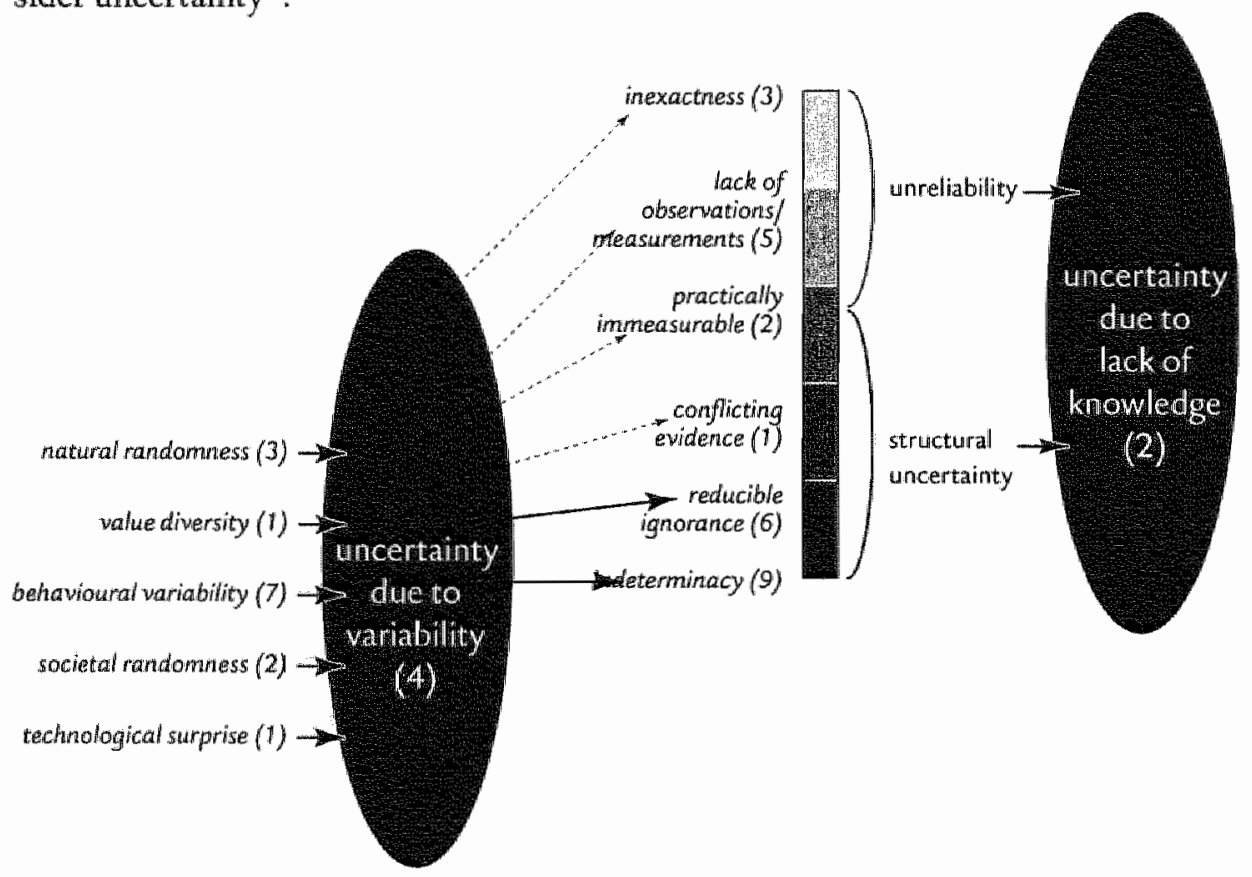

FIGuR 2 The number of times the sources of uncertainty were mentioned on Post-lits

The brainstorm and clustering surfaced an interesting list of uncertainties. The expressed variety is broader than that derived from the previous Environmental Outlooks. On the other hand, it has to be concluded that the uncertainties mentioned are on a high abstraction level and involve so-called 'container notions'. It is clear that

2.1 At the wime ol the workhop wa did not yet distinguish besween reducible and irfeducible ignomance (compare Chapter $3 \mathrm{~A}$ ).

23 See? (van Asten and vast Asselt 1999) and (van Asten 2000). 


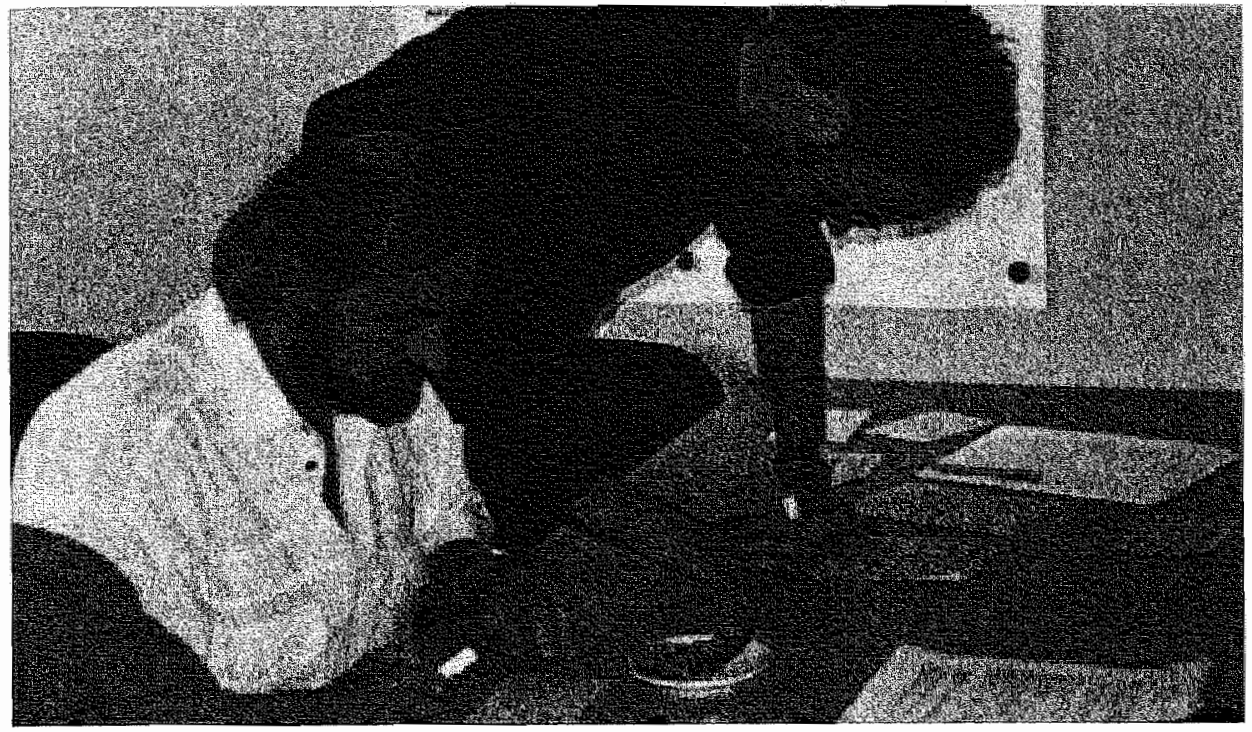

Brainstorming

a second check of the list is needed, before it can be decided whether the above of clusters are the most relevant, and whether the set of surfaced uncertainties is comprehensive enough in view of the dilemma the $5^{\text {th }}$ Environmental Outlook aims to address.

In the discussion following this brainstorm and clustering, it turned out that the participants considered the classification of uncertainties (economic, institutional, social-cultural, and nature and environment) useful. The same can be concluded on the typology of sources of uncertainty. We tested the typology as a tool to stretch thinking about uncertainty and as a means to facilitate communication about uncertainty. In the closing discussion of the workshop, it was concluded that the variety of uncertainties has been widened through this exercise. All respondents reported in the ex-post questionnaire that they considered the workshop useful and that about a $50 \%$ responded that the workshop helped in systematically thinking about uncertainty.

It was furthermore argued that the produced list of uncertainties, although it was a first attempt, enables to derive which uncertainties can be addressed through scenario analysis or with standard statistical methods, and which uncertainties will remain that must be addressed in another way. 


\subsection{UNCERTAINTIES IN PERSPECTIVE}

The aim of the second exercise was to interpret the surfaced uncertainties. As motivated above, we proposed to use the three perspectives derived from Cultural Theory (i.e. the controllist, the market-optimist and the environmental worrywart) as perspective framework. Following the PRIMA approach this implies that the surfaced uncertainties relevant for the Enwironmental Outlook had to be interpreted according to these three perspectives, with ultimately three internally consistent knowledge patterns as the result ${ }^{24}$.

How to arrive at perspective-based interpretations of the surfaced uncertainties? We had to design an exercise so that the RIVM practitioners would produce three perspective-based chains of interpretations of the surfaced uncertainties. We decided to divide the workshop group into three working groups. Each working group was assigned one of the three perspectives. The task for each working group was to interpret the most important uncertainties from the assigned perspective. In each group, key statements in line with the heuristic rules as outlined in Chapter 5 were used to introduce the perspective. In order to put themselves in the perspective, each group held a brainstorm about what their perspective was associated with. The idea was that through the brainstorm the participants had put themselves in the shoes of the perspective, from which 'standpoint' they then would interpret the uncertainties. The main task for the group was to attribute interpretations of uncertainties in line with the assigned perspective, through discussion. Facilitators famillar with the perspectives and the PRIMA-approach ${ }^{25}$ introduced the perspective to the participants and Eacilitated the group work; with regard to the latter, it was the explicit guideline not to interfere with the interpretations but just to enhance discussion and group thinking.

Below, the output of the three perspective working groups will be discussed. First, the associations with the assigned perspective will be given followed by the descriptions of the produced perspective-based chains of interpretations of uncertainty. Because the perspective-based patterns form the basis for further steps, they are described here in full length. At the end of each subsection the key lines of reasoning associated with the assigned perspective are summarised.

25 Marjolein vain Asselt. Frank war Asten and Nicole Rijkens, see (wan Astein and wan Asselt 1999). 


\subsection{OUTPUT OF THE CONTROLLIST WORKMNG GROUP}

Associations the working group participants had with the controllist are given in Box I.

Box I Associations with the controllist's key statements

- RIVM

- Conservative

- CDA (Christian Democratic Party)

- IPCC

- Agricultural sector

- No referendum

- Present emissions policy (environmental policy in a restricted sense)

- Prime Minister Kok

- EU

- Switzerland

- Water authorities

- Management of Directorate General Envirronment

- Big brother is watching you

The working group argued that if RIVM had to make an Enwironmental Outlook within a controllist society, it would pay special attention to measurements, gathering knowledge and measuring the policy objectives.

With regard to the Environmental Outlook, the controllist would make agreements with the institutions that provide information. These institutions should indicate which topics are uncertain and which ranges should be employed for this. This is very similar to the Environmental Outlook as it is being made now. According to the controllist, the 'Business as usual' scenario should be drawn up in the standard way and the other information should be included in the way that the other authorities have indicated.

In the vision of the controllist, science is based upon knowledge and experience. The starting point for the controllist is that aggregation and integration can be carried out to the highest level. 'The system' can be described in detail at various levels. 
The controllist will always try to gather more knowledge about uncertainties and will attempt to quantify uncertainty associated with estimates. Therefore all statistics are up-ro-date. The controllist believes in science's ability to solve problems $A$ lot of money is therefore needed for research. He cannot do anything with uncertain answers. He is only interested in uncertainties that can be quantified ("certain uncertainties $^{206}$ ). It is unscientific, if it cannot be calculated. The controllist is difficult to convince of the idea that uncertainties must be dealt with. Value is attached to validation, verification, explicit obserwations, and to statistics. The competence of the analysts is important, so certification and quality control play an important role. Both models and institutions have been decided upon by law. The controllist believes in the trustworthiness and the predictable nacure of models: models and institutions are beyond all doubt.

The controllist will try to make sure that the policy is roo\% effective. Policy objectives will always be formulated as clearly as possible and strict compliance will be demanded. To achieve this, the controllist will set up and enforce regulations to restrict uncertainties to a minimum. The controllist thus prefers traditional standards (in terms of high-low) to more functional standards. For the noise problem, for example, the peaks shall be removed, but the noise cover will possibly be accepted, if this lies below a certain level and if no demonstrable effects are attached. The controllist has typical end effect indicators, such as nature and health. The level is not so important since this is a question of necessity. He will always remain on the safe side (avoiding risk). An example of this is the MTR (Maximum Tolerable Risk) divided by 100. This is very much like the way in which we now deal with environmental policy in the restricted sense, such as emission policy.

The behaviour of people must be guided in fixed direction as much as possib]e. Not only will the behaviour of people be regulated, but also the behaviour of the economic sectors and the pattern of consumption. The controllist will try to regulate the pattern of consumption by, for example, placing levies on environmentally unfriendly products and products which are associated with health effects. The economic sector will not be allowed much freedom of movement. Covenants fit well into the image: they are used where strict rules do not work. Tolerance will definitely not fit into the controllist's perspective.

The controllist expects the translation of the national government's policy to the lower governments to work. In the controllist's perspective, the central govern- 


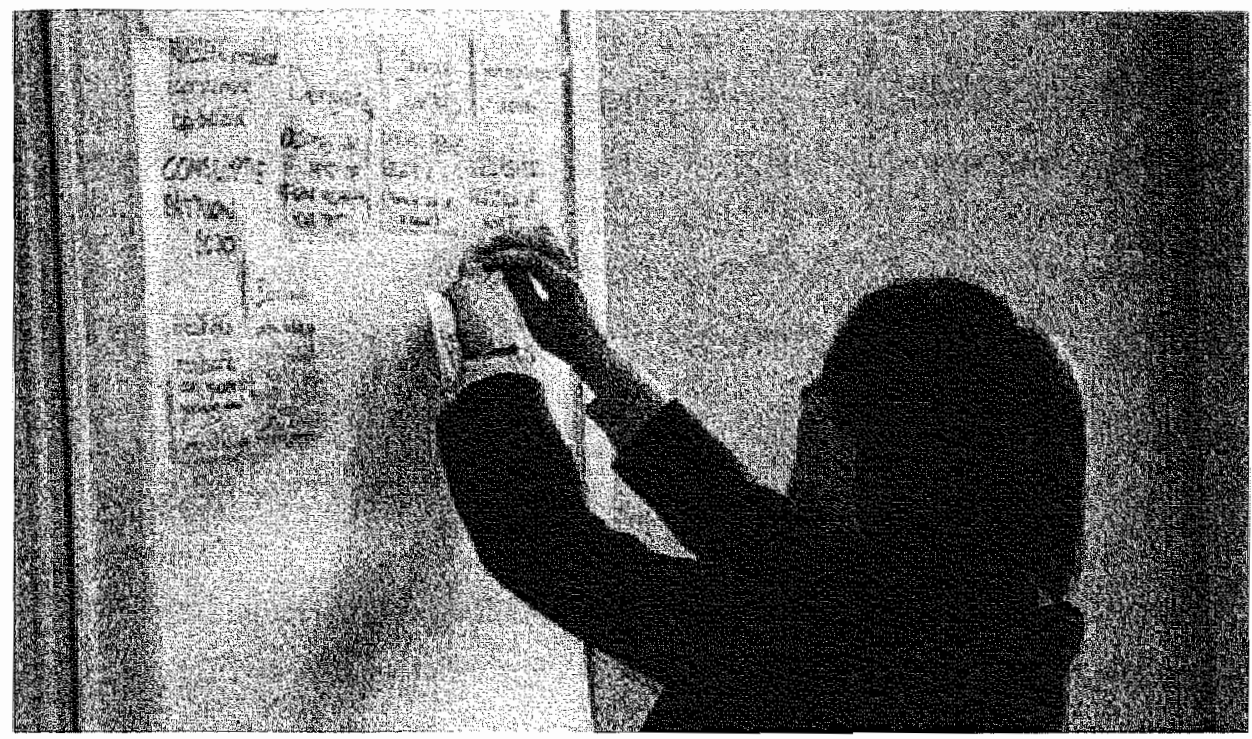

Clustering brainstrom outpust

ment can largely enforce its policy by making use of hierarchy. International policy, especially EU policy, is of increasing importance for the controllist. If an international policy is developed, then this will in principle be translated into national policy. Another point is that the society's reaction to national policy is very uncertain, but also very important. Inner cities are an example: the central government has ideas, but lower governments and/or commercial parties make most of the policy. The contollist worries in case no policy is introduced for a certain problem, or if the policy is delayed.

In the controllist's vision, continuity and stability play an important role. Sudden events, disasters, migration, wars and the occurrence of worldwide depressions do not fit into the controllist's perspective. The controllist generally tries to avoid surprises and discontinuicy, by drawing plans for dealing with exceptional situations. If a disaster will actually take place in the future and the plans cannot adequately deal with this, then the controllist does not know what he has to do.

Another example is the problem of Schiphol airport. The controllist will not move Schiphol to another location, or to the sea, because this does not reduce the (environmental) risks. Schiphol will be extended, and as a result, houses will be moved and be better insulated against the noise. In the project for the Betuwelijn (freight railway line from Rotterdam to Germany), the controllist is confronted with larger economic uncertainty than was expected. The initial research predicted that the Betuwelijn would not be so expensive and would fit in well as regards its effects. 
Fairly soon afterwards, however, it was known that the project would be considerably more expensive and that it would generate much less economical profits. Since an abrupt change of policy does not fit into the image of the controllist, the project will be slowly reduced. He will not take the decision to stop it abruptly.

According to the controllist, politics must be a constant, almost orderly, process. There should not be too many changes from left wing to right wing, because this creates risks. The fact that Paars $\mathrm{I}^{27}$ actually carried out the CDA' $\mathrm{s}^{28}$ policy is grist to the mill for the controllist.

Nature and climate are strongly regulated, which is why the controllist can reasonably estimate the emissions. The controllist is ambivalent as regards the climate problem. On the one hand, an attempt will be made to work out the system in fine detail, including all the uncertainties surrounding this. On the other hand, there will be inherent uncertainty, which makes it difficult for the controllist to deal with. The climate, especially its variability, is a large problem for the controllist. It is an external influence and little can be done to control it, except for taking preventive measures, such as reducing $\mathrm{CO}_{2}$ emissions, higher dykes, widening rivers, etc. The controllist sees climate change as a threat that develops gradually and which might only become acute at the end of the next century. He does not believe that the series of floods in the last few years has anything to do with climate changes. World supplies, such as (drinking) water, energy and food production, are long-term problems and should be strongly regulated now, so that they do not become risks in the future.

The controllist will invest in technology. He is forced to do so, because otherwise he will not be able to regulate certain problems. Radical innovations and breakthroughs, also in knowledge, however, do not fit into this image. Technological development is a gradual, almost evolutionary process in the eyes of the controllist. The controllist shall, therefore, continue to build on known principles and invest in these. In the course of time, innovations may possibly appear, but he keeps avoiding risks, so innovations will have to be tested thoroughly.

Spatial arrangements concerning human activities will be regulated and managed. On a national level, the controllist still does not know which direction it will take. Will the Netherlands become a delta-metropole or a large inter-connected city? These are questions to which the answers are still very unclear. On a local and regional level, the controllist stands for a strict spatial arrangement.

27 The first Dutch coalinion goverament ander prime ninister Kok whout the Christian themocratic party (1994-1998). 
Finally, society does not necessarily have to be materialistic for the controllist. Resources are needed as means to control.

In sum, the controllist perspective applied to uncertainties relevant for the Envi.ronmental Oudook involves the following interpretations of uncertainty, where risky uncertainties are those that are considered to be threatening to the perspective under concern:

\begin{tabular}{|c|c|}
\hline uncertainty & associated controllist's interpretation \\
\hline $\begin{array}{l}\text { Effectiveness of policy and } \\
\text { degree of en forcement }\end{array}$ & $100 \%$ effectiveness of policy; strict enforcement \\
\hline Intermational and EU policy & $\begin{array}{l}\text { Transtarion from higher levels (international, national) to lower governmerats } \\
\text { (national, local) works }\end{array}$ \\
\hline Instability, disasters & Risky turtertamin \\
\hline Who decides? & governments \\
\hline Type of policy & $\begin{array}{l}\text { Standard setting; Regulation of economic sectors and consumption patterns by } \\
\text { levies and converants; No drastic meastures/changes in policy: } \\
\text { no Schiphol in the sea; slowing down of Betuwelijn }\end{array}$ \\
\hline Behaviour & $\begin{array}{l}\text { Behaviour according to rules and fixed patterns. } \\
\text { risky uncertainty }\end{array}$ \\
\hline Consumption patterns & $\begin{array}{l}\text { Regulation of economic sectorsi and consunnption patrerns } \\
\text { by levies and convenants }\end{array}$ \\
\hline Dentograplay & Migration: risky uncertainuy \\
\hline Climate variability & Risky uncertanting; series of floods do nor relate to climare change \\
\hline Emissions & Strongly regulated, thus predictable \\
\hline Dose-effecrs & On the safe side \\
\hline $\begin{array}{l}\text { World wide supplies water, } \\
\text { energy and food }\end{array}$ & Strongly regulated to prevent future risks \\
\hline Technology & $\begin{array}{l}\text { No radical innovations and breakthroughs; gradual process; } \\
\text { innovations hawe to be tested }\end{array}$ \\
\hline $\begin{array}{l}\text { Behaviour of economic } \\
\text { sectors }\end{array}$ & $\begin{array}{l}\text { Regulation of economic sectors and consumption patterns } \\
\text { by leviles atnd conwenants }\end{array}$ \\
\hline Gllobal recession & Risky utlcentainty \\
\hline
\end{tabular}

TABLE 5 Summary of output of controllist working group 


\subsection{OUTPUT OF THE MARKET OPTIMIST WORKING GROUP}

Associations resulting out of the brainstorm in the market-optimist working group are given in Box 2.

Box 2 Associations with the market optimist

- Microsoft

- Enterprise/entrepreneurs/business

- Shell (large companies)

- Banks

- Favourite magazine: Elsevier

- Export promoting measures

- Ministry of Economic Affairs

- WD (Liberal Party)

- Government that negotiates and corrects market imperfections

The working group argued that the market optimist strongly believes in company dynamics and less in management by government. He is not necessarily interested in something that stops at the Dutch border. The fact that the EU has no economic borders must be taken into consideration. At the moment, the boundary is drawn at the Dutch border and foreign influences are only included to a limited extent. The uncertainties associated with foreign developments are not included. The environmental assessment should be drawn up much more in terms of risk contours, resulting in a sharper view of the local environment within the Netherlands and the rough contours outside the Netherlands. According to the market optimist, there is a market for an Environmental Outlook for Northwest Europe.

The market optimist believes in technological innovations. The necessary technology will appear by itself. The speed of technological development depends on investments in the form of time and money and this is clearly something that the market optimist can influence. Environmental technology will certainly arrive as a result of pressure from consumers.

The short-term economic situation is an important uncertainty in the market optimist's vision. The location of the production factors determines an important 
part of the market and, therefore, his possibilities. The risks that result from economic fluctuations, the changing of regions and the associated impacts, also for the enwironment, are very important in the market optimist's perspective. Additionally, it is uncertain how the world economy will develop until the year 2030 . Will this period of boom continue or will there be a recession? And when will this take place? For a market optimist, it is important that this kind of questions is included in the scenarios.

The role of multinationals and large investors in finding solutions causes uncertainty. A crucial question for the future is what multinationals situated in the Netherlands will do: will they stay or leave? The market optimist thinks that there should be less regulation in order to stimulate the multinationals to stay. The latest developments indicate that water companies, energy companies and waste companies are being purchased by Dutch companies as well as by foreign companies. For example, a French company has purchased Van Gansewinkel, a waste processing company. The question is to which rules this company will have to comply? The Dutch rules are stricter than the European or French rules. Multinationals do not have anything against standards if they are clear and if they are set on a European level, which means that they are the same in all European countries. The standards can be set fairly high, because then a competitive advantage can be obtained, The concept of effectiveness will have to be looked at from a completely different context, not only from the position of the government, but also from the position of business.

The market optimist is worried about taking risks concerning where to set up a business. It is not a problem that demands are placed on the location of a business in the Netherlands varying from average to high, as long as they are not exceptional or constantly changing. A pig farmer will not locate in the Netherlands with the present (environmental) regulations, but will migrate to Canada, unless he can sell the pork at the highest price here. The green market value is very important. The market optimist will want to know the intended policy and the uncertainties associated with it; for example, it is still uncertain to what extent companies can pay off national environmental regulations with environmental regulations in foreign countries. This can also have an influence on the Netherlands becoming a country in which to locate a business.

There must not be a threat from environmental risks, such as floods every year, to the location of a business. RIVM has a tendency to place the emphasis on accumulation in the Environmental Outlook, which results in the emphasis being placed on places in the Netherlands where the situation is really disastrous, for example the 


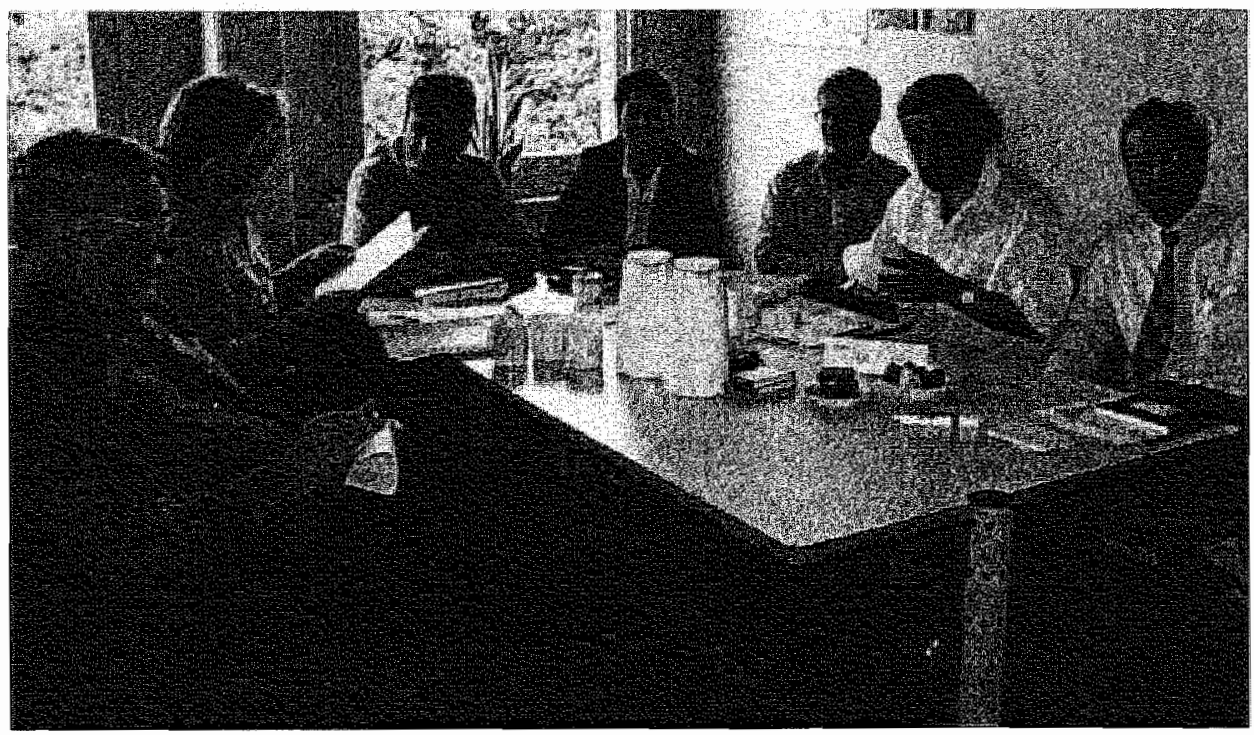

Working group in action

Randstad $^{25}$. This is not very interesting for the market optimist. He looks for areas where he can develop, where opportunities are and where his employees like to live. The market optimist wants to know which problems may occur and which policy will apply for a specific area. To prevent problems with the location of business, environmental risks must be mapped out in the Environmental Outlooks.

The location of business is also very important for the people who work there. On the other hand, people will become more mobile, they will choose to live in a different area to the one in which they work. Local councils can address this, for example, by refusing pig farmers so that it will be more pleasant to live there. Special attention is given to see whether it is nice to live there, if there is nature nearby and if there is not too much disturbance. It concerns not necessarily large areas such as the Hoge Veluwe ${ }^{30}$, but small nature areas surrounding cities. Biodiversity is nor valued, but nice trees are. People want to have good nature, but above all they want well-organised nature and there does not necessarily have to be any wild buffaloes walking around. Nature reflects our wellbeing. Companies can invest in it: nature and the consumption of nature will become a new market.

In sum, health, welfare and nature are very important. The spatial arrangement then becomes very important. It makes a difference where pressure on the environ-

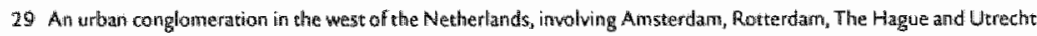

30 . Dutch nature reserve 
ment is placed in the Netherlands. However, a radius of $500 \mathrm{~m}$ around one's house will determine the perception. National averages lose their value as a result of this. The natural value in the Netherlands on the "Ten Brink" scale ${ }^{31}$ is well thought out, but what the direct surroundings are more important to people. As follows from the above, the emphasis will be placed more on local, human problems. The climate problem is of no interest whatsoever unless there is a good chance that the Netherlands will be flooded.

The Environmental Outlooks so far aimed address solutions associated with the government, but nothing is said about environmental programs initiated by business, such as eco-labelling and green programs by Albert Heijn ${ }^{32}$. The multinationals will look after the environment themselves if it suits them to do so. They can even fulfil a leadership role here. This possibility must not be underestimated; the market optimist will definitely want that the Environmental Outlook comprises an inventory of environmental initiatives taken by companies creating win-win situations. The controllist argues that the market can regulate itself: For Albert Heijn, for example, it is important that the Dutch govermment will not introduce strict rules on the country of origin of oranges, the use of packing materials, etc. Albert Heijn will respond that clearly telling the consumers what a product contains, where it comes from and what has happened to it, will have much more of an effect than if the government implements strict rules or even bans the product.

Uncertainties concerning the behaviour of citizens, the actions of people and the reaction of people to policy are important for the future. This is a weak link. The market optimist will be particularly interested in the consumption pattern of people and factors related to this. The environment as such will only be a small link in this. The appreciation of nature, however, does play a role here because people can adapt their behaviour to this. RIvm must also not be scared to say something about uncertainties in consumer behaviour.

The market optimist would like to know more about uncertainties in the perception of environmental problems. What causes social distrust in relation to environmental problems? He is not concerned about risks themselves, but more about the perception. For example, everybody thought that anybody who ate chickens that were infected with dioxin would die, but they had probably been eacing them for years. The market optimist asks from the Environmental Outlook to address about

31 (Schouten et al. 1999; ten Brink et al. 1998; wan Whiet et al. 2000)

32 A large Dutch supermarket chairt 
which issues people worry about and whether this is justified. The pure market optimist can profit from this and anticipate this sort of perception. The market optimist dislikes commotion about implausible disasters. They should not be ignored, but expressions such as "in fifry years time all the fossil fuels will be used up" and "in ten years time all the roads in the Randstad will be completely congested" should be dealt with carefully. Otherwise, it may cause a panic reaction and this can disturb the market.

In sum, the market optimist perspective applied to uncertainties relevant for the Enwironmental Outlook by the associated working group resulted in the following interpretations of uncertainty, where risky uncertainties are those that are considered to be threatening to the market optimist and important uncertainties those posing challenges:

\begin{tabular}{|c|c|}
\hline uncertainty & associated market optimist int erpretation \\
\hline $\begin{array}{l}\text { Effectiweness of policy and } \\
\text { degree of enforcement }\end{array}$ & Effectiveress should be considered on European leve:; market regulates itself. \\
\hline Who decides? & companies \\
\hline Type of policy & $\begin{array}{l}\text { Clear and competitive rules that do not change all the time; } \\
\text { preferably European regulation }\end{array}$ \\
\hline Behariout & Important uncertainty \\
\hline Consumption patterns & Important uncertainty \\
\hline Atritude towards environment & $\begin{array}{l}\text { Nature as commodity; mature close to cities; } \\
\text { perception of enwironmental problems is important }\end{array}$ \\
\hline Climate variabillicy & Nor important, unless the good chance that the Netherlands will be fooded \\
\hline Dose-effects & Emphasis on local humarn problems \\
\hline Tethology & $\begin{array}{l}\text { Technological innowations; can be influenced by time and money; } \\
\text { eco-technology will result out of consumer pressure }\end{array}$ \\
\hline Behaviour of economic sectors & Role of multinationals; environmental programs initiated by companies \\
\hline Global recession & Risky uncertatuty \\
\hline
\end{tabular}

TABLE 6 Summary of output of martket optimist working group 


\subsection{THE ENVIRONMENTAL WORRYWART}

Associations put forward by the third working group as regards the envirommental worrywart are given in $\mathrm{B}$ o 3 .

\section{BOX 3 Associations with the environmental worrywart's key statements}

- Preservation of mature / romance / llover of nature

- Deep ecology-submissive to nature

- Romantic Calvinist

- Respect for nature and humans

- Austerity

- Economy as a means of control

- Think global-act local

- Precautionary principlle

- Cautious with covenants and market orientated regulations.

- The environmental worrywart is nice to the person behind the consumer and strict with companies.

- Believe first, then command (information)

- Development aid is important (solidarity)

- Do not purchase emission rights in other countries

The environmental worrywart working group argued that this perspective would question the role of RIVM. In this view, RIVM collaborates with the enemy. This does not have directly to do with its competence, but more with the direct relationship with the gowernment and the implied protection of business: RIVM must constantly be aware of cabinet agreements and arrangements that the government makes with the business community. As a result, figures and statements are formum lated more carefully than is actually needed for the sake of the enviromment.

According to the environmental worrywart, nature is a very dynamic system that is difficult to understand. It is likely to be harmed by human interventions. It is therefore better to remain on the safe side. This means that people must consider the top of the uncertainty range in order to avoid environmental risks. The environmental worrywart takes nature as its starting point. He will always be concerned about 
nature, but more so if something abnormal takes place, such as an increase in temperature by a couple of degrees, despite high enforcement and world-wide agreements. The environmental worrywart emphasises the vulnerability of nature. Environmental pollution, such as air pollution, noise disturbance, disruption of the ecosystem and vulnerability, is an important theme about which the environmental worrywart is particularly concerned. The environmental worrywart is also anxious about spatial claims on nature and the irreplaceable stocks of natural resources. He tries to protect nature against threats, especially those caused by humans, of less known or unknown causes. He is worried about all sorts of unknown artefacts in the environment, such as genetically modified organisms, electromagnetic fields/ radiation, dioxins, etc, which involve threats that people cannot see or smell. It is better to make sure that they are not released, or better still, that they do not exist. "Fear the unknown, worry about the known". The environmental worrywart does not want artificial nature created by humans: he tries to have large, connected nature areas with high biodiversity that can sustain themselves.

The environmental worrywart is directly concerned about high dose-effect relationships. He will stay on the cautious side here. Dose-effect relationships cannot always be measured and this is where uncertainties appear. In face of uncertainty, the environmental worrywart will immediately introduce the doom scenario. The environmental worrywart always needs information, otherwise he does not know if there are new problems that need to be addressed. The environmental worrywart will therefore invest heavily in dose-effect research. This can be compared to DGM ${ }^{33}$ in the seventies. Strict standards must therefore be set. For example, the environmental worrywart worries about the dose-effect relationship between $\mathrm{CO}_{2}$ and the increase in temperature. Will a disaster take place and will there actually be any climatic changes?

The environmental worrywart will aim for a "limits to growth" policy, because the Earth's carrying capacity is physically limited. The environmental worrywart's greatest concern is that people continue to consume more space per capita and rhat this will take place at the expense of nature areas. He is worried about the unrestrained growth of cities. The environmental worrywart considers control of demography as important; this implies freezing the size of the population. "The environmental worrywart chooses prevention through information. For a "limits to growch" policy, the environmental worrywart tries to freeze the production acreage for agri-

33 Dinectomate General Enwinonment of the Ministry of Hausing Spatial Planning and Enviton ment (NROM). 


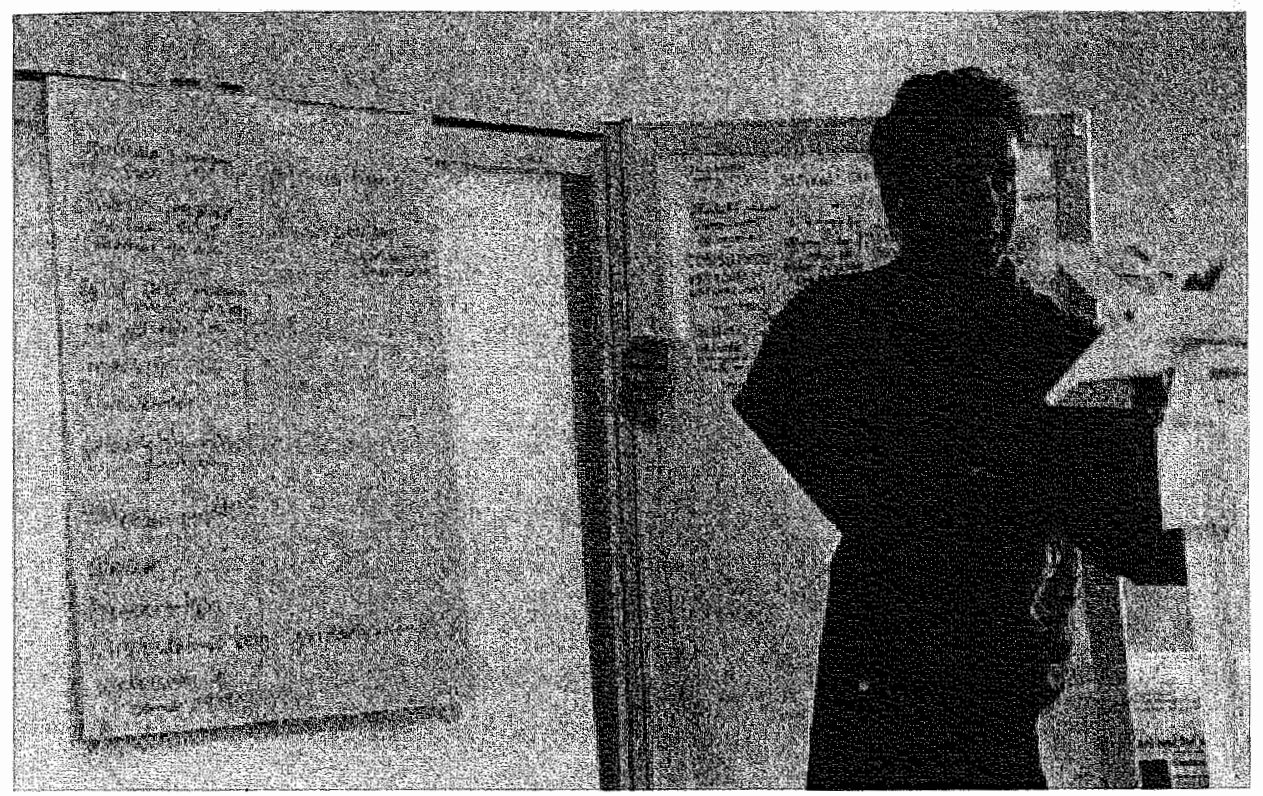

Reporting back

culture, tries to freeze the production of food, strives for a steady-state economy, sustainability and closed cycles. The environmental worrywart would try to introduce $\mathrm{CO}_{2}$ limits for each country or each type of industry.

The economy is a means, not an aim in itself. The environmental worrywart especially worries about the unrestrained speed of the economy. The environmental worrywart is concerned about consumption patterns. Consumption increases, because more people purchase the same things, want more appliances and replace and get rid of appliances more quickly. He has more a problem with the behavioural element of people and the controllability of this behaviour since this is unpredict able. If society develops as it did, there will probably be more cars, but more importantly, people will drive more. People also want to travel further on holiday and travel more often by plane. In short, growth in consumption should be restricted.

The environmental worrywart will aim for some technological innovation, because eco-technology is needed. Environmental technology is seen as a necessary evil: ideally environmental technology is unnecessary. A water purification company should not be needed at all. The water should not be polluted and a marsh should be created for the natural waste products, since this does exactly the same as a water purification company. An environmental worrywart does not believe that problems can be solved by technology. The environmental worrywart thinks it is very important that no deals are made: some industry is permitted, because a certain technol- 
ogy can (partly) undo the associated negative effect. An example of this is the car. In order to save energy, more efficient engines must be produced as well as clean cars, but this does not mean that more cars can then be driven. The environmental space must not be filled up again. The environmental worrywart is not in favour of end-ofpipe technology; he favours integrated process technology. The environmental worrywart will mainly be concerned with closing cycles, using natural processes, saving energy and recycling.

Enforcentent is an important principle for the enwironmental worrywart. Before environmental policy can be set, a lot of thought must be given to whether it can be carried out and/or enforced, if it can be cheated and whether it will completely disappear through pressure from the European Union. With regard to consumption patterns and spatial claims, the environmental worrywart is actually a pessimist: there is a natural tendency to growth, so it cannot be monitored strictly enough to prevent that. Environmental violations by both companies and individuals must be dealt with severely. Money earned through enforcement must primarily be used for even better enforcement and control, and secondly for other environmental policy.

The environmental worrywart is fairly locally oriented, but is also concerned with the 'outside world', because this influences his local community. The environmental worrywart, therefore, strives for global agreements. He places a lot of importance on the principle of justice. He will nor like it if other people emit the $\mathrm{CO}_{2}$ that he tries not to emit, or use pesticides that he refuses to use. He wants to make reliable agreements with the $G_{7}$ countries about the consumption pattern, demography, $\mathrm{CO}_{2}$ emissions and oil prices, even though he has doubts about whether this can be achieved. He would like to give development aid to preserve the Amazon rainforest.

In sum, the environmental worrywart perspective applied to uncertainties relevant for the Environmental Outlook was associated with the following interpretations of uncertainty, where risky uncertainties are those that are considered to be threatening to the perspective under concern: 


\begin{tabular}{|c|c|}
\hline wncertaincy & associated enwironmental worrywart"s interpretation \\
\hline $\begin{array}{l}\text { Effectiveness of policy and degree of } \\
\text { enforcement }\end{array}$ & $\begin{array}{l}\text { Effectiveness should be tested before ervirommental policy can be } \\
\text { set, environmental wiolations must be punislued. }\end{array}$ \\
\hline Inter marional and EU policy & Reliable global agrements; development aid to preserwe Amazon \\
\hline Type of policy & Environmentall policy \\
\hline Behaviour & Natural rendency to growth; Actors must be controlled; \\
\hline Consumption patterns & Risky wncertainty \\
\hline Attitude towards environment & $\begin{array}{l}\text { Nature as starting point; large connected areas } \\
\text { with high biodiver sity; no artificial narture }\end{array}$ \\
\hline Demography & Limits to growth; prewention \\
\hline Climate variability & Global problem \\
\hline Emissions & Will increase if the econorny continues ro grow \\
\hline Dose-effects & $\begin{array}{l}\text { Wortied about unkmown artefacts in the enviromment } \\
\text { (GMO, electromstress); Doom scenario; strict standards }\end{array}$ \\
\hline World wide supplies water energy and food & Freezing of producrion of food; closed cycles \\
\hline Technology & $\begin{array}{l}\text { Problems cannot be solved by technology ecomtechnology is } \\
\text { necessary evil; integrated process technology }\end{array}$ \\
\hline Behaviour of econonic sectors & Steady-state economy; economy is not an aim \\
\hline
\end{tabular}

TABLE 7 SUmmary of output of environmental worrywart working group

\section{Analysis of the workshop}

Analysis of the surfaced uncertainties yields that the output involves other uncertainties and other sources of uncertainty then usually considered in the Environmental Outlook. Examples of such uncertainties that have not been addressed in previous Environmental Outlooks $s^{34}$ are e.g. effectiveness of policy, foreign policy, instabilities (in terms of disasters and accidents), environmental attitude of citizens and actors, and inherent unpredictability of responses of humans and ecosystems related to environmental change. The list of uncertainties produced in the workshop questions the scenarios that so far have been used in RIVM's environmental assessments. It also indicates that there are uncertainties considered relevant that could not be addressed by statistical methods. On the other hand, the surfaced uncertainties are on a high level of abstraction and need further crystallisation.

The output of the working groups is rich, which implies that we should analyse it from different angles to do justice to this richness. In the following we will analyse the empirical data from two points of view: 
- review and analysis of the perspective-based interpretations in terms of consistency and bias (output-oriented)

- evaluation of the process in cerms of lessons to be learned for implementing PRIMA (process-oriented)

Furthermore, in Chapter 5 we argued that the intermediary product of the "uncertainties-in-perspectiwe phase" as such could provide a valuable input to the decisionsupport process. We will try to address this hypothesis by assessing how the output could be used for the Environmental Outlook.

\section{I. ANALYSIS OF THE WORKING GROUPS' OUTPUT}

Any interpretation exercise is biased. To be able to get insight into potential bias, we have explored the atritude towards the perspectives among the participants prior to the workshop. To that end, a perspective questionnaire comprising six statements (two per perspective) with a 5 -point scale had been included in the questionnaire that the participants completed in advance ${ }^{35}$. The answers have been decoded in order to characterise the expressed attitudes in terms of the three perspectives ${ }^{36}$. The results are presented in Table 8.

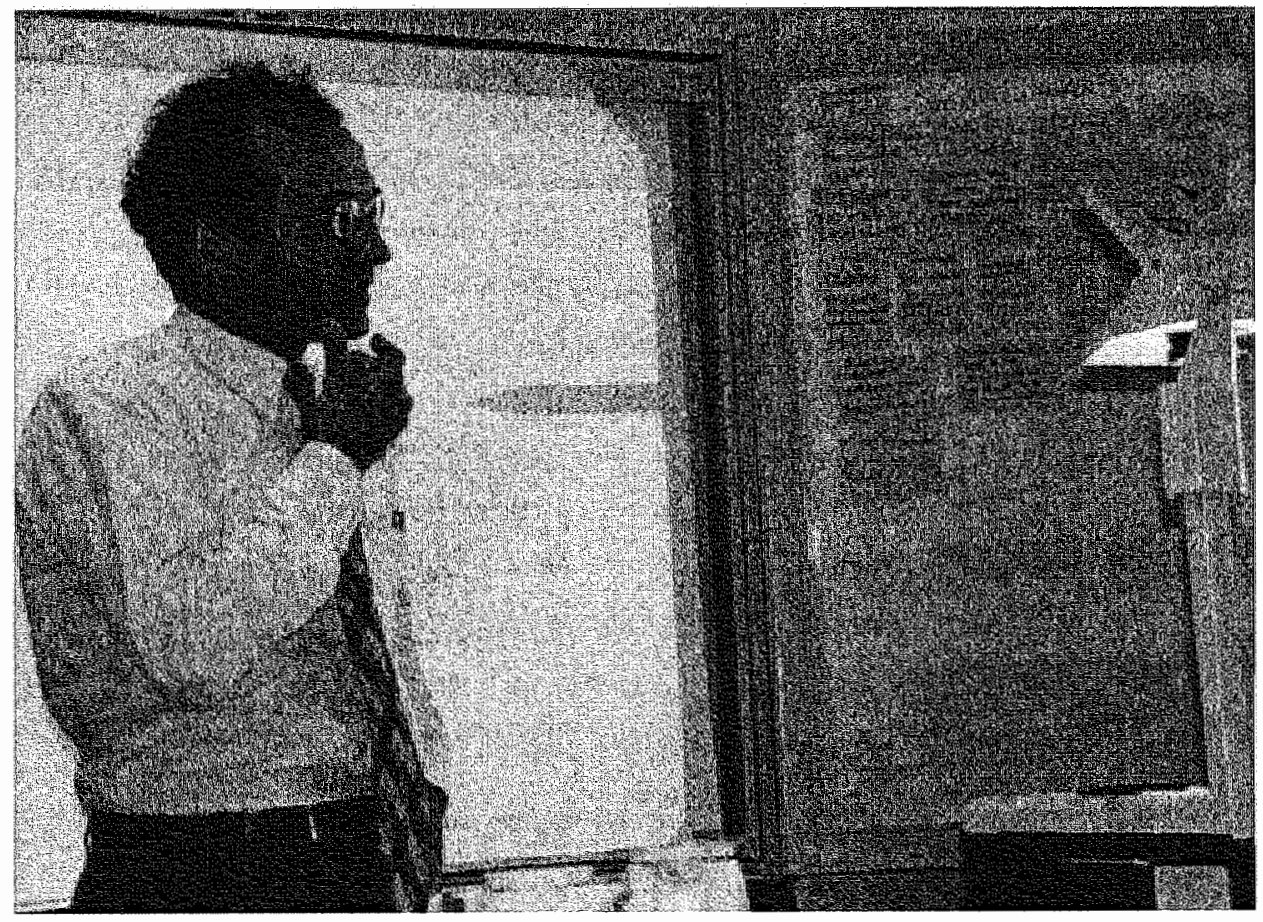




\begin{tabular}{|c|c|c|c|}
\hline Respondene & \% Contirollist & \% Market optimist & \% Environmental wortywart \\
\hline 1 & 17 & -33 & 50 \\
\hline 2 & -12 & . 38 & 0 \\
\hline 3 & 25 & -38 & 38 \\
\hline 4 & 40 & -20 & 40 \\
\hline 5 & 33 & 33 & 11 \\
\hline 6 & 20 & 40 & -40 \\
\hline 7 & 0 & -33 & 0 \\
\hline 8 & 0 & -50 & 50 \\
\hline 9 & 22 & $\cdot 33$ & 44 \\
\hline 10 & -50 & -25 & 25 \\
\hline 11 & $\because$ II & -33 & 33 \\
\hline 12 & 50 & 0 & 50 \\
\hline 13 & $3^{8}$ & -38 & 15 \\
\hline 14 & 29 & 0 & -14 \\
\hline 15 & 20 & -40 & 40 \\
\hline
\end{tabular}

TABLE 8 Characterisation of respondents' statements in terms of perspectives

NoTe A positive score implies conespondence with the key statements associated with that perspectiwe, whild a negative score indicates that the answers of the respondent showed opposing walues than those associated with that perspective. The thighest positive score of a respondent indicates which perspective is the most preferred.

If we consider the highest scores per respondent, we can conclude that all perspectives are present in the group of participants. The environmental worrywart perspective dominated in the responses (II out of 15 ), while two-third of the respondents also have a controllist orientation. A very small minority of the respondents positively approached the market-optimist perspective, while in respondents reject the market optimist perspective. The questionnaire results suggest that we can expect an 'environmental worrywart bias' in the whole perspective-exercise. To control for this bias, it would be theoretically interesting to repeat the exercise with a more balanced group and see whether there are significant differences in applying the Cultural Theory perspectives.

It is true that an environmental view can be observed from the workshop output. However, such a bias is not necessarily the consequence of preference for the environmental worrywart perspective, but is also due to the context of application, i.e. the Environmental Outlook. Furchermore, the value attached to environment and nature in the controllist and market-optimist patterns of interpretation cannot at all 
be characterised as "deeply green". The set of perspectives covers a spectrum of attitudes towards environment and nature $3^{38}$.

Tables 9 to $12^{3 y}$ summarise the perspective-based interpretations of uncertainty per category. Empty cells imply that the working group did not address that particular uncertainty in terms of a perspective-based interpretation or evaluation.

\begin{tabular}{|c|c|c|c|}
\hline uncertainty & controllist & market optimist & $\begin{array}{l}\text { enwironmental } \\
\text { worrywart }\end{array}$ \\
\hline $\begin{array}{l}\text { Effoctiventess of policy } \\
\text { and degree of } \\
\text { enforcement }\end{array}$ & $\begin{array}{l}100 \% \text { effectiveness of policy; } \\
\text { strict enforcement }\end{array}$ & $\begin{array}{l}\text { Effectiveness should be } \\
\text { considered on European } \\
\text { level marker regulates } \\
\text { irself. }\end{array}$ & $\begin{array}{l}\text { Effectiweness should be } \\
\text { tested biefore environ- } \\
\text { mental policy can be set; } \\
\text { enwironmental violations } \\
\text { must be punished. }\end{array}$ \\
\hline Who decides? & governments & companies & \\
\hline International and & Translation from higher levels & & Relliable global \\
\hline EU policy & $\begin{array}{l}\text { (international, national) to } \\
\text { lower gowernments (national, } \\
\text { local) works }\end{array}$ & & $\begin{array}{l}\text { agreements; development } \\
\text { aid to preserve Amazon }\end{array}$ \\
\hline Instability, disasters & Risky uncertainty & & \\
\hline Type of policy & $\begin{array}{l}\text { Standard setting; Regulation } \\
\text { of economic sectors and } \\
\text { consumption patterns by } \\
\text { levies and convenants; } \\
\text { No drastic measures/changes } \\
\text { in policy: no Schiphol in the sea; } \\
\text { slowing down of Betuwelijn }\end{array}$ & $\begin{array}{l}\text { Cleat and competitive } \\
\text { rules that do not change } \\
\text { all the time; preferably } \\
\text { European regulation }\end{array}$ & Enwironmental policy \\
\hline
\end{tabular}

LECEND Eimpty cells mean not addressed by working group

TALLE 9 Perspective-based interpretation of institutional uncertainties

38 In case PRIMA would be applited in a browder lintegrated Assessment endeavour, one wowld expect that mappang cut the perspectives would also yield partems of firter pretation in which enwiromment and nature are marginal.

39 The order of the uncertainties is the same as in Tables $1-4$. In the current tables the dissters of uncertainty are sunmmadised by key words in order to provide conwemient Tables. 


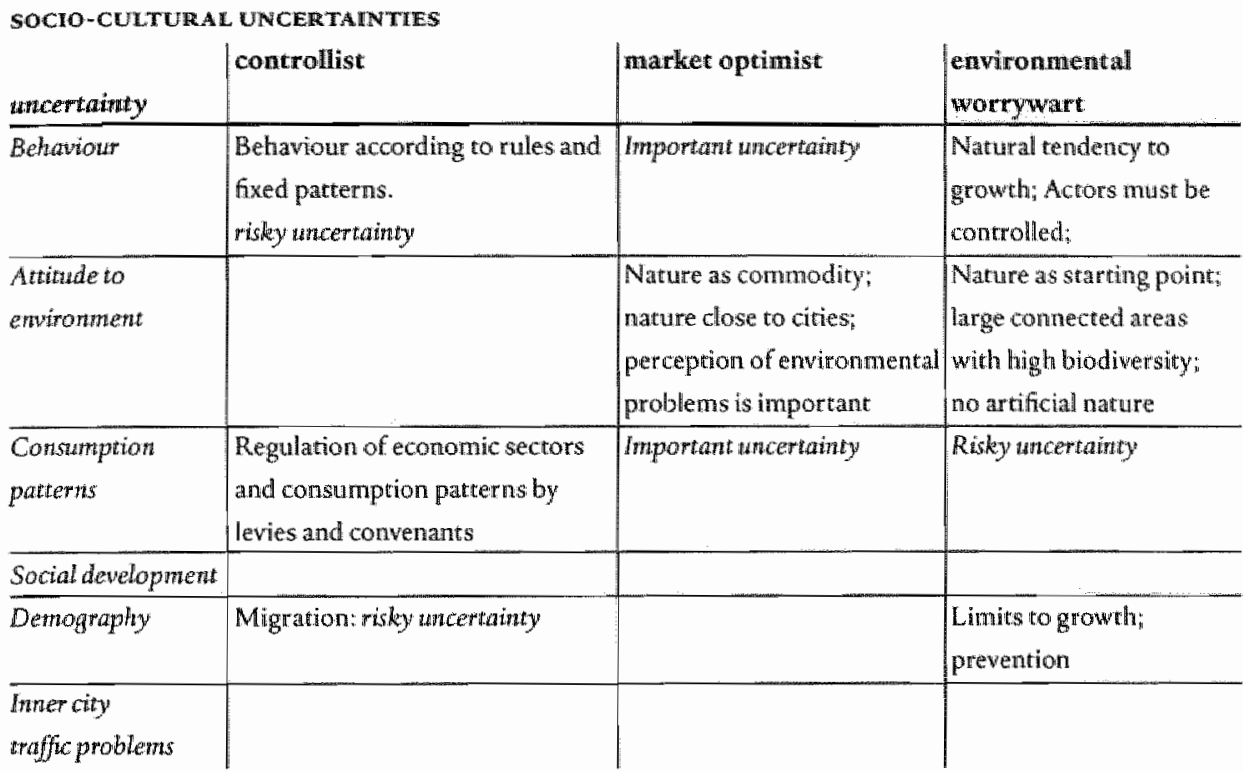

LEGEND Empty cells mean not addressed by warking group

TAELE to Perspective-based interpretation of socio-cultural uncertainties

\section{NATURE AND ENVIRONMENT UNCERTAINTIES}

\begin{tabular}{|c|c|c|c|}
\hline untcettainty & controllist & market optimist & $\begin{array}{l}\text { enwironmental } \\
\text { wortywart }\end{array}$ \\
\hline Climate wariability & $\begin{array}{l}\text { Risky uncertainty; series of floods } \\
\text { do not relate to climate change }\end{array}$ & $\begin{array}{l}\text { Not important, unless the } \\
\text { good diance that the } \\
\text { Netherlands will be flooded }\end{array}$ & Global problem \\
\hline Entissions & $\begin{array}{l}\text { Strongly regulated, } \\
\text { thus predictable }\end{array}$ & & $\begin{array}{l}\text { Will increase if the econ- } \\
\text { omy continues to grow }\end{array}$ \\
\hline Dose-effects & On the safe side & $\begin{array}{l}\text { Emphasis on local, } \\
\text { bumam problems }\end{array}$ & $\begin{array}{l}\text { Worried about unkmown } \\
\text { artefacts in the enwiron- } \\
\text { ment (CMO, electro- } \\
\text { stress), Doom scenario; } \\
\text { strict standards }\end{array}$ \\
\hline \multicolumn{4}{|l|}{ Feedback mechanisms } \\
\hline \multicolumn{4}{|l|}{ Response of ecosystems } \\
\hline $\begin{array}{l}\text { World wide supplies } \\
\text { water, energy and food }\end{array}$ & $\begin{array}{l}\text { Strongly regulated to prevent } \\
\text { furure risks }\end{array}$ & & $\begin{array}{l}\text { Freexing of production of } \\
\text { food; closed cycles }\end{array}$ \\
\hline
\end{tabular}

LECEND Empty cells mean nat addressed by working group

TABLE I Perspective-based interpretation of nature and enwironmental uncertainties 
ECONOMIC UNCERTAINTIES

\begin{tabular}{|c|c|c|c|}
\hline Hucertatinty & controlliste & market optimist & $\begin{array}{l}\text { environmentall } \\
\text { worrywart }\end{array}$ \\
\hline Technology & $\begin{array}{l}\text { No radical innovations and } \\
\text { breakthroughs; gradual } \\
\text { process; innowations hate } \\
\text { to be tested }\end{array}$ & $\begin{array}{l}\text { Technological innovations; } \\
\text { can be influenced by time } \\
\text { and money; eco-technology } \\
\text { will result cult of constmer } \\
\text { pressure }\end{array}$ & $\begin{array}{l}\text { Problems cannot be solved } \\
\text { by technology: } \\
\text { eco-rechnology is necessary } \\
\text { evil, integrated process } \\
\text { technology }\end{array}$ \\
\hline $\begin{array}{l}\text { Betudiour of } \\
\text { cconomic sectors }\end{array}$ & $\begin{array}{l}\text { Regullition of economic } \\
\text { sectors and consumption } \\
\text { patterns by levies and } \\
\text { convenants }\end{array}$ & $\begin{array}{l}\text { Role of multinarionals: } \\
\text { environmental programs } \\
\text { inidiated by companies }\end{array}$ & $\begin{array}{l}\text { Steady-state economy; } \\
\text { economy ils not an aim }\end{array}$ \\
\hline \multicolumn{4}{|l|}{$\begin{array}{l}\text { Structure and size } \\
\text { of Dutch industry }\end{array}$} \\
\hline Glabal recesstion & Risky uncertainty & Risky uncertainty & \\
\hline
\end{tabular}

LEG Ex En Empty cells mean not addressed by working group

ThiBLE 12 Perspectiwe-based interpretation of economic uncertainties

Analysis of the above summary of the interpretations of uncertainties by the three working groups yields that some of the uncertainties were not at all addressed by any of the working groups, i.e. feedback mechanisms, response of ecosystems, social development, inner city traffic problems, and structure and size of the Dutch industry. It cannot be deduced from the empirical material why exactly these uncertainties have been ignored in all three working groups. It could imply that these uncertainties are not salient after all, that these uncertainties are difficult to interpret, that expertise and knowledge about these particular uncertainties were lacking or that the time span available was too short. If we consider the number of times that a cluster of uncertainty was mentioned in the brainstorm session, all ignored clusters were not mentioned that often, just $\mathrm{I}-3$ times ${ }^{4 *}$. So there is some support for the argument that these uncertainties were not considered that salient after all. It is nevertheless surprising that issues that are considered to belong to Rrvm's competence, such as response of ecosystems and feedback mechanisms, were not addressed in the perspective exercise.

The second observation is that some uncertainties are left aside from a particular perspective, while they were addressed in the other working groups. These empty cells seem to suggest that these particular uncertainties are considered not that important for the assigned perspective. This especially holds for the market 
optimist, in which working group the following uncertainties were not addressed: international and EU policy, instability, demography, emissions, and global supplies of food, water and energy. These are all issues that are probably considered as solvable in the market optimist perspective, and thereby not seen as crucial uncertainties in future outlooks.

The output of the other working groups showed that uncertainties and risks preferably denied by the controllist are of significant rellevance and importance in the other perspective-based assessments. Where the controllist is not interested in any scenario about instabilities and disasters, the market optimist would like economic fluctuations, i.e. booms and recessions, to be considered in the scenarios. Where the controllist assumes $100 \%$ effectiveness, the other two perspectives, for different reasons, question this assumption and are interested in assessments that include partial or complete failure of implementation. The controllist is not interested in new risks that cannot be adequately calculated, while those risks associated with new anthropogenic artefacts or processes (such as genetically modified organisms and electrostress) are the central focus of the environmental worrywart.

It is remarkable that in the envirommental worrywart perspective it is not made clear who is taking decisions. The output of the environmental worrywart working group breathes a kind of fatalism, in which the environmental worrywart is seen as a kind of Don Quichotre fighting windmills. The controllist and market-optimist working groups produced patterns of interpretation that can be characterised as utopian in the sense that they imply a world that perspective would like to live in. The environmental worrywart chain of interpretation as produced in this workshop could be considered as dystopian in suggesting cloomsday outlooks. On the other hand, the output of the environmental worrywart working group could be filtered as to provide ingredients from which also a utopian outlook could be created.

In order to use the perspectives in the next phase of PRIMA, the distinction between world view and management style matters ${ }^{41}$ in order to assess utopian and dystopian outlooks in a systematic manner. If we consider the above uncertainties, most of them refer to uncertainties concer ning the underlying systems, which implies that the associated perspective-based interpretations delineate worldviews. The following two uncertain issues clearly refer to management style, i.e. "who decides?" and "type of policy". The output of the working groups involves management style issues, such as strict enforcement in the controllist perspective, business environ- 
mental programmes and investment in technology in the market-optimist perspective, and control of actor behaviour and strict regulation of new risks in the environmental worrywart perspectives. The policy options that can be derived from the output of the working groups are summarised in Table ${ }_{3}$.

\begin{tabular}{|c|c|c|}
\hline controllist & market optimist & emwironmentall worrywart \\
\hline Regulation by gowernments & Self wegulation by markets & Nature as starting point \\
\hline Strictenforowment & European regulation: dear and competitive & $\begin{array}{l}\text { Punishment of environmental } \\
\text { violations }\end{array}$ \\
\hline Standard secting & Nature close to cities & Control of actors \\
\hline $\begin{array}{l}\text { Strong regulation of } \\
\text { emissions and global suppliess }\end{array}$ & Emphasis on local luman problems & Preventive demographic policy \\
\hline Levies and convenanuts & Irvestment in technology & Reliable global agreements \\
\hline \multirow[t]{3}{*}{$\begin{array}{l}\text { No radical change of } \\
\text { prevaling policy }\end{array}$} & Business environmental programmes & $\begin{array}{l}\text { Strict standards towards new } \\
\text { environmental risks }\end{array}$ \\
\hline & & Closing of cycles \\
\hline & & Integrated process technology \\
\hline
\end{tabular}

TABLE 13 Policy options per perspective (derived from workshop output)

It has to be noted that articulation of management style was not an explicit exercise in this workshop. The above enumeration indicates the management style aspects that can be derived from this workshop, and that can be used as input to follow-up steps.

The workshop yielded an interesting set of internally consistent patterns. The assessment of the perspective-based interpretations does not yield specific statements that inherently conflict with the Cultural Theory description of that perspective. On the other hand, the interpretations are original as well, in the sense that these interpretations do not logically arise from the Cultural Theory descriptions. Examples of such original ideas are the suggestions that in the market optimist perspective environmental issues as such are not important, but the perception is, and the suggestion that eco-technology will result out of consumer pressure and that companies will initiate environmental programs. Also the ideas of the controllist working group that international, esp. European, policy will be implemented on the national and locall level and that the economic sectors are regulated by convenants are such creative applications of the abstract and aggregated Cultural Theory descriptions. Such fresh suggestions can also be found in the emvironmen- 
tal worrywart working group output, such as the ideas of development aid to preserve the Amazon or the concern on GMO. With hindsight these interpretations may seem not very difficult to consider and quite straightforward, however as far as our knowledge extends from Culcural Theory applications they are nevertheless "new".

The set of perspective-based chains of interpretation furthermore shows a wider variety of legitimate interpretations of uncertainty than the set of CPB scenarios employed in the previous Environmental Outlooks. For example, the environ. mental worrywart working group actually sketched a scenario in which economic growth results in higher emissions that cannot be counteracted by technological development. On the other hand, the market optimist scenario is also richer than a one-dimensional high economic growth scenario in which technology slows down environmental pressure. The market optimist working group described underlying developments, such as eco-technology arising from consumer pressure, leadership by multinationals resulting in environmental programs initiated by business and nature as a kind of pull factor, or even commodity, in the market mechanism. Finally, the output of the controllist workgroup indicates that the controllist is not just a middle-of-the-road way, but a perspective in its own right. The participants generally agreed that RrVM's current practise could be characterised as controllist. Furthermore, this perspective was assumed to be only interested in uncertainties that can be quantified and that can be reduced by plans and regulations. The working group actually associated the positivist/objectivist paradigm ${ }^{43}$ with the controllist perspective: lack of knowledge and uncertainty are considered to be a threat, but it is believed that this could be solved through research. These observations together suggest that the implicit controllist bias could (partly) explain the observed hesitation ${ }^{44}$ to address uncertainty in the previous Environmental Outlooks. From the plenary discussion and from the ex-post questionnaires it can be concluded that the uncertainties-inperspective endeavour made the participants (more) aware that the controllist perspective is just one way of considering uncertainty.

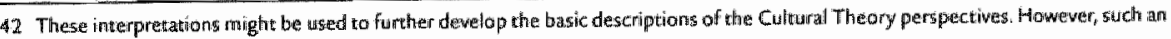
exererise goes beyond the scope of this thesis.

4.3. Siee Chapters 3a and $3 \mathrm{~b}$.

44. As extensively discussed in Chapter 7 .
} 


\subsection{EVALUATION OF THE PROCESS:}

\section{LESSONS FOR IMPLEMENTING PRIMA IN PRACTISE}

As argued before, salient uncertainties could not be derived from the case-study analysis, because RrM's expertise on environmental issues turned out to be vital. The workshop provided the floor to interact with experts and the exercises enabled to articulate tacit knowledge.

The experiences discussed in the current Chapter teaches us that a brainstorm session as included in the workshop is a valuable first step in an articulation process. Both the Post-It approach and the classifications of uncertainty turned out to be useful in facilitating a collective brainstorming. However, evaluation of the output yield that the uncertainties mentioned do not immediately translate into variables used in the assessment underlying the Environmental Outlook; uncertainty is articulated at a high level of abstraction and aggregation. Furthermore, it turned out to be difficult to attach ranges to the uncertainties, which could relate to the high level of abstraction. Next to that, both in the workshop and in the participants" feedback afterwards, it was made clear that approaches and techniques are needed that enable to articulate knowledge on uncertainty into estimates of ranges.

The above experience indicates that surfacing uncertainties in a prima process probably should be a three-step approach. In the first step uncertainties are articulated on a general level with a brainstorm approach as employed in the discussed workshop. In a second, more technical step, the uncertainties should be reviewed by specialists and further crystallised in terms of indicators and variables, and by means of quantitative ranges, qualitative estimates and/or an overview of diverse interpretations. Stich a second round could, for example, be done by means of expert elicitation. In this step sensitivity analysis may be used to assess whether the output is sensitive to the surfaced uncertainties ${ }^{45}$. Implementing PRIMA in practise also implies that techniques have to be found or developed that allow explicit articulation of tacit expert knowledge on ranges and legitimate interpretations of uncertainty ${ }^{4}$. Last but not least, a final round is necessary to prioritise in to order to arrive at a short list of uncertainties salient to the decision-support endeavour. Because this implies a collective judgement, it seems reasonable to do this again in the form of a workshop ${ }^{47}$.

45 See chapter 3 :

46 One of such qualitakive schenes was presented in Chapter 3 a. Technitulues used for axpert elicitation in the concexi of subjective probability functions cian also be usefuil (seo also Chapter 3 a).

47 As argued, see also (van der Sluiljs 1997) and Chapter 3a. 
The various risk dimensions as described in Chapter 5 can serve as a heuristic in assessing which uncertainties are key to the decision-support endeavour.

In view of the above lessons, the lisc of uncertainties as discussed in this Chapter should be considered as a first overview of uncertainties that practitioners involved in the assessment process consider important for RIVM's Environmental Outlook.

The second step in the uncertainty-in-perspective phase involved interpretation of the uncertainties from the point of view of the various perspectives. The exercise given to the working groups was to interpret the important uncertainties surfaced by the brainstorm session from the viewpoint of the assigned perspective. All working groups applied the assigned perspective to produce perspective-based. chains of interpretations, and they evaluated which uncertainties impose risks to the perspective's world view and management style (referred to as "risky uncertainties"). Furthermore, in the light of the assigned perspective remarks were made with regard to the organisation of the environmental assessment process.

As discussed above, the workshop yielded an interesting set of internally consistent patterns sketching three clearly distinctive perspectives on che uncertainties important to the $5^{\text {ih }}$ Environmental Outlook. The assessment of the perspectivebased interpretations does not yield specific statements that inherendy conflict with the Cultural Theory description of that perspective. In other words, the participants seemed to have applied the perspective scheme in their interpretation endeavours in line with the original Cultural Theory descriptions. From this angle, the set of perspectives and the procedure used seem to enhance a constructive process of creative discussion in which the degrees of freedom of interpretation of uncertainty are systematically explored. All working groups involved a creative process blended with knowledge on environmental issues. The participants thought of interpretations of uncertainties out of their usual mindset while still using their expertise and knowledge. In doing so, interpretations materialised that are consistent with Cultural Theory, but which are at the same time original as well.

The reactions in the plenary presentation of the working groups indicate that the developed narratives were all considered as plausible interpretations of uncertainty with some internal logic. From the workshop experience, we conclude that the perspectives facilitated the participants in focussing and questioning consistency in terms of internal logic. The perspectives seemed to frame the creative discussions, and thereby function as a kind of common benchmark. The workshop seemed to have created more awareness concerning the fundamental nature of uncertainty, risk and pluralism, which impression is confirmed by the responses to the $2^{\text {nd }}$ question- 
naire ${ }^{48}$. A third of the participants responded that the workshop has changed their thinking abour uncertainty. $50 \%$ of the respondents considered the workshop ser-up used as a good way to discuss uncertainty in relation to the Environmental Outlook. Concluding this implies that the chosen design seems to be at least effective in disseminating the major principles underlying PRIMA.

The chosen format turned out to be effective in the light of the aim to arrive at perspective-based interpretations of the surfaced uncertainties. From the facilitators' observations and from the output we can conclude that in none of the working groups any problems with reasoning from the assigned perspective were observed, nor were internal inconsistencies. In the questionnaire completed after the workshop, a large majority of the respondents (about $80 \%$ ) said that they were able to project oneself into the assigned perspective. The association brainstorm on the assigned perspective was just fed with four statements. Evaluation of the associations indicate that these four statements were effective in evoking conceptions that correspond quite well to the richer descriptions of perspectives found in Cultural Theory literature. The brainstorm served as a warming-up; it seemed to help the participants to affiliate with the assigned perspective and thereby facilitated the interpretation exercise.

In designing the workshop format, it was deliberately decided to have one assigned perspective per working group. This choice was motivated by the idea that such a form would make it easier for the participants to leave their own preferences behind, because it is close to role-playing. If the task had been to interprer all three perspectives, participants might have been inclined to associate themselves with one of the perspectives, which may have led to black and white interpretations and a polarised debate blocking the group process. The experience with the "one working group - one perspective format' allows to hypothesise that such a design contributes to producing the kind of output aimed at with the "uncertainties in perspective" plase. We therefore conclude that the chosen format - each working group works with just one perspective, four statements to introduce a perspective and brainstorm before interpretation - seems to be an effective way to yield perspective-based interpretations in a couple of hours with participants who are not familiar with Cultural Theory. The proposed format may also be useful in perspective-interpretation exercises in which another perspective scheme than Cultural Theory is used. 
The conclusion that can be drawn from the analysis of the working groups' output is that the perspective-based interpretation endeavour in PRIMA's uncertainties-in-perspective phase has to be a stepwise approach. An interpretation exercise in a workshop setting in which perspective-based interpretations are generated in a semi-structured brainstorm (like we did in the held workshop) constitutes the first step. The output has then to be structured (similar to the analysis in the previous section) to allow a systematic review. The structured chains of interpretations have then to be reviewed and enriched, either by the same the group that generated the first drafts, or by another group, or by a mixture of 'old' and 'new' 49 . In this step there should be special attention for the empty cells in tables as the ones presented above. Furthermore, in this phase the perspective-based interpretations have to be played out more systematically in terms of world view and management style. This stepwise approach would then result in resolute perspective-based chains of interpretations.

The perspective-based exercise suffered from the fact that the list of uncertainties was preliminary. This experience teaches us that either first the list of uncertainties has to be established through iteration before the perspective endeavour starts, or that the whole phase is an iterative integrated exercise, in which both mapping out the uncertainties and the perspective-based interpretations mature. The latter seems to make sense, because our experiment with the PRIMA approach in the Environmental Outlook setting suggests that the perspective-exercise may also yield insights into the salience of uncertainties. Furthermore, the obvious link with uncertainty also in the process design of applying the perspectives seems to help the participants to blend creative thinking with their scientific knowledge.

Insights with regard to the necessary step-wise approach to the uncertaintiesin-perspective phase that can be derived from the experiences discussed are summarised into a flowchart (Figure 3) suggesting a procedure for implementing the uncertainties-in-perspective phase.

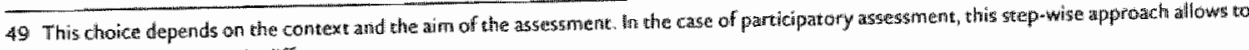
involwe different actors in diliferent ways. 


\section{uncertainties-in-perspective}

Sufacing uncertainties:

Wokks:Hop

- collective brain-storm

- clustering

$\downarrow$

INTELYWIEWING EXPEIRES

- review

- crystallisation

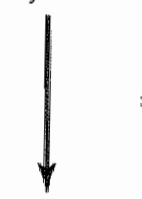

WORKSHOP

SENSITIVITY ANALLSITS

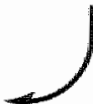

- prioritising

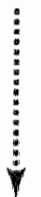

Output:

salient uncertainties

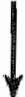

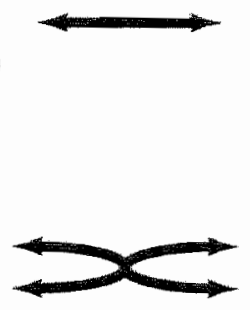

Perspetrive based interpretations

\section{WORKSHOP}

- working groups per perspective

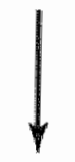

ASSESSHE TNT OF OUTPUT

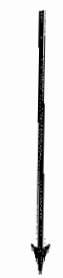

WORISHOP(S) /INTERVIEWS/WIRITTEM REVIEW

- review and enrichment

- world view \& management style

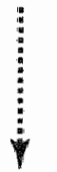

Output:

stable perspectiwe-based interpretations

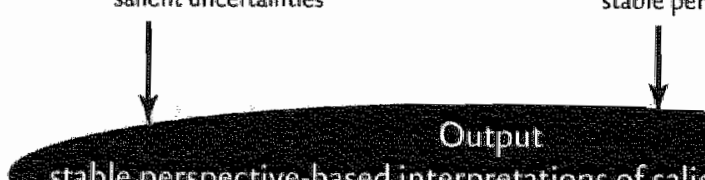

stable perspective-based interpretations of salient uncertainties
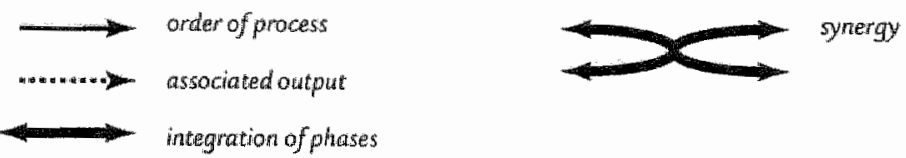

alcuke 3 Flow chant of set-up of uncertainties-in-perspective phase derived from experiences 


\subsection{USE OF PRIMA OUTPUT IN $5^{\text {TH }}$ ENVIRONMENTAL OUTLOOK}

The perspective-based chains of interpretations can in principle be used for carrying out the next phases of the prima approach. In the context of the $5^{\text {th }}$ Environmental Outlook applying the next steps ("scenarios in perspectives" and "risk in perspective") would imply that the qualitative interpretations of uncertainty are used:

- to develop a set of perspective-based input-scenarios on exogenous variables (such as economic and demographic developments, technological innovation and lifestyles)

- to develop perspective-based model routes in the model equipment used in RIVM's environmental assessment process

- as heuristic in expert judgement about uncertainties that are not implemented in models, but for which inter pretation is nevertheless needed in the assessment process.

This would enable to explore the future by systematically "thinking through" what-if questions. Doing so would yield a broad range of scenarios that covers the wide variety in legitimate and relevant interpretations of the underlying salient uncertainties. The next convergence step would then involve that insights relevant for decision making are extracted from the bunch of possible futures ${ }^{5 * x}$. As discussed in Chapter 5 such an assessment would yield insights in terms of the (relative) robustness of strategies. This would then provide a basis for motivated recommendations in the form of:

- advising in favour or advising against a particular strategy

- indicating the level of societal controversy to be expected with a certain proposal

- proposing flexible strategies and the associated indicators ("signals") that are then important for decision-making in the future.

Applying Prima in its full form would be to develop the $5^{\text {th }}$ Environmental Outlook from different perspectives in the way as described above. This implies that all uncertainties both in the pressures and in the causal chains have to be addressed, and that the choice of themes and scale levels is perspective-dependent. A less consequential, but still innovative way to use the idea of pluralistic uncertainty management in the Environmental Outlook would be to define the input-scenarios and other imputs per perspective, but the models are kept as they are and do not involve perspectivebased model routes. This implies that the pressures on the environmental system are 
put into perspective. Finally, even if PRIMA and/or the perspectives are not used in the assessment itself, these concepts and notions can be useful in reflecting on the assessment product. The set of perspectives can be used ex-post to identify important uncertainties and to review critical assumptions. For example, the dilemma that resulted out of the discussed definition phase, could be used to scope the assessment in terms of the introduction and concluding chapters of the Environmental Outlook. In this way, the conclusions can be put in a broader perspective, which could improve the quality of the assessment product.

The above discussion gives an idea how the PRIMA approach could have been used in the $5^{\text {th }}$ Environmental Outlook. However, apart from the fact that implementing and facilitating the full cycle was beyond the scope of our research. we here encountered also a conflict between theory and practise. The media affai ${ }^{51}$ created a niche and momentum for experiments around uncertainty. In their report on assessment methods $s^{52}$ produced as defence, Rrvm explicitly referred to pluralistic uncertainty management as a promising avenue. Although Rrv's's management as well as practitioners were willing to invest time and effort in participating in our research project, the PrIMA approach was not adopted as assessment methodology for the $5^{\text {th }}$ Environmental Outlook. The $5^{\text {th }}$ Environmental Outlook process was already fully planned and well on its way at the time our activities started. One argument not to switch to PRIMA was time-pressure. Other explicit or implicit arguments seemed to relate to the general attitude towards science-knowledge-uncertainty, the relationship between RrYm as decision-support institute and its client(s) (esp.the Minister of Environment and the professionals from the Directorate General Environment of the Ministry), and the (anticipated) expectations and ambitions of the client(s).

Our research did not involve a systematic inquiry into Rrv M's decision-making with regard to uncertainty management. We therefore leave it here with concluding that RIVM primarily experimented with pluralistic uncertainty management parallel to the $5^{\text {th }}$ Environmental Outlook process. The PRIMA activities described in this Chapter were not considered as an integral part of the process, but as complementary actions that were considered valuable in view of R IVM's learning process concerning uncertainty. These activities were only in second instance seen as exercises that might provide concrete input to the assessment process.

What insights do our first practical experiences with the PRIMA approach yield that could be of direct use in the $5^{\text {th }}$ Environmental Outlook, irrespective of the fact

51 See Chapter 6 and ( $\tan$ Asren 2000) 
that the PRIMA approach is not yet adopted as assessment methodology? In other words, how may the outputs and insights discussed in this Chapter be used in a sensible manner in the $5^{\text {th }}$ Environmental Outlook? With addressing this question, we would like to evaluate the idea that intermediary outputs associated with a particular phase in the PRIMA approach can also serve as a valuable input to the assessment process, and ultimately the decision-making process. Assessment of the workshop output suggests that the uncertainties-in-perspective phase yields relevant insights and interesting ideas on two levels:

- the scope of the Environmental Outlook

- critical uncertainties, issues and assumptions

Such insights and ideas can in principle be of direct use to the $5^{\text {th }}$ Environmental Outlook process. In the following the suggestions that can be derived from the workshop output will be discussed in more detail.

The working groups' output enables to raise interesting ideas about the Environmental Outlook and the underlying assessment process. The market optimist working group suggested that the scope should be broadened from a focus on the Netherlands to a wider Northwest European perspective. In line herewith, it is argued that the Environmental Outlooks' traditional focus on Dutch environmental policy should shift in three ways. On the one hand, an Environmental Outlook should address European environmental policy as well. On the other hand, the Environmental Outlook should not only focus on governments, but it should involve environmental measures that are taken, or can be taken by, other actors, such as multinationals and consumers. Thirdly, the Environmental Outlooks so far concentrated on accumulation of environmental and health impacts. It would be interesting to map out environmental and health profiles that enable to compare locations. Furthermore, the environmental worrywart working group brought to the fore that RIVM is not always regarded as an independent authority, but is sometimes seen as a continuation of government. If RrVm would be willing to consider the latter in the Environmental Outiook assessment process, this means that the assessment process has to be more participatory ${ }^{53}$.

The list of surfaced uncertainties can be used as input to the design of sensitivity analysis, and the choice of model experiments. Even in case the surfaced uncertainties are not addressed in the assessment itself, the list can be used in framing the 
scope of the assessment as well as the conclusions. Furthermore, it can be used as a checklist in writing about uncertainty in the ultimate report. It may serve as a checklist to those practitioners that have to integrate and edit the various contributions.

With the perspective exercise, specific uncertain areas are highlighted. The workshop output allows identifying which issues and assumptions are critical to societal debates (see Table 4 ). It was argued in the closing discussion at the workshop that if these issues are not addressed in the $5^{\text {th }}$ Environmental Outlook, whether numbers are available or not, Rrw can expect critical questions from societal actors. This insight in critical issues so far not addressed in the Environmental Outlook could be used to broaden the assessment or to develop a communication strategy. The workshop output can be used to develop or to evaluate the content list for the $5^{\text {th }}$ Environmental Outlook. Not all issues can be addressed quantitatively, but it may also be interesting to integrate qualitative evaluations and expert judgements in the assessment. The insight into critical assumptions may be used to reflect on the assessment and the assessment output, and can thereby help to perform some sort of ex-post evaluation of the robustness of the recommendations derived from the assessment.

\section{cruticical issues}

International ard EU policy:

Type of policy

Behaviour and consumprion paterns

Environmental programes/measures by non-governmental actors

Nisw environmental risks

Nature

\section{Critical assumptions}

stability, continutity

$100 \%$ effectiveness

Gradual rechnological change 


\section{Practitioners's view on PRIMA experience}

From the data gathered with the ex-post questionnaire ${ }^{54}$, it became clear that the participants considered the workshop useful for assessing which issues are welcomed in the Environmental Outlook and that it enabled them to explore uncertainty in a systematic manner. Two thirds of the respondents ${ }^{55}$ considered the workshop as a means to think (more) systematically about uncertainty. Half of the respondents furthermore argued that the workshop changed their thinking about uncertainty. In general, the workshop was considered as useful, even in case the workshop did not fully match the prior expectations. One respondent had expected a more concrete planning for the whole $5^{\text {th }}$ Environmental Outlook process, another had expected a more technical workshop and another respondent had expected a broader overview of different approaches to uncertainty. Notwithstanding these reservations, the overall evaluation of the workshop as derived from the closing discussion and the questionnaire data is rather positive: it was considered a well-organised workshop that breathed an open and unforced atmosphere in which quite a lot was done in a relatively short time period. Both the participants to the focus group and the participants to the workshop valued that the prospective research offered the opportunity to have fundamental discussions about uncertainty with an interesting selection of colleagues in an open atmosphere.

The next question is how the participants to the workshop evaluated and valued the perspective approach in the light of RIVM's practise. In the questionnaire prior to the workshop, the respondents expressed a neutral attitude towards a perspectiveapproach. In the questionnaire completed after the workshop, a $50 \%$ of the respondents expressed an interest in a more pluralistic approach to the Environmental Outlook in the associated closed question. Furthermore, all responded positively to the open question "In your opinion, does the perspective method seem to be a desirable method for dealing with uncertainties in the Environmental Outlook?".

54. See (wan Asten and wam Assett 1999) for a detalled report of the questionnaire nesults.

55. Of the 18 participants. 
The ex-post questionnaire data show an ambiguous picture with regard to the perspective-dimension of the workshop. With regard to the perspectives used the following remarks were found in the $2^{\text {nd }}$ questionnaire's response:

- more background for the choice of perspective is needed.

- whether all perspectives that play a role for RIvm have been put forward, or if more must be added in order to lay down a complete representation of society.

- how the mix of perspectives is in society.

Addressing the latter two issues would involve empirical research that is clearly beyond the scope of this thesis. It has been argued earlier in this thesis, that the perspectives used can be considered as generic stereotypes that are useful in a first fleshing out of perspectives. Nevertheless, these responses underline the importance of Pr rma's definition-phase and implicitly criticise the pragmatic approach adopted in the current case.

The majority of the respondents $(65 \%)$ stated that they would be able to apply the perspective approach, with only a $10 \%$ doubting whether they could. The majority of the respondents considered the perspective approach an interesting alternative to uncertainty management that can complement existing approaches. On the other hand, the answers to the open questions indicate that the perspective approach is evaluated by some of them as being not concrete enough to be applied as is illustrated by the following quotes:

" "The perspective method" does not (yet) have enough body, in my opinion.

- It remained unclear in what aspect the perspective approach provides a better view of uncertainty.

Nevertheless, only one respondent did explicitly state that the perspective approach is not a desirable method for the Environmental Outlook. Another argued that it is not a panacea:

In my opinion, one of the causes of all the unrest surrounding "De Kwaad. steniet" is the large anount of distrust from the public towands science (.). This combined with the inability to read fugures by the public and media. This distrust will not be removed by only mapping uncertainties. I think that the perspective method is only half the answer to how to deal with uncertainties in scientific decision-support.

To evaluate the prima approach through the eyes of practitioners it is useful to compare the experience so far with the articulated need as discussed in Chapter 7 . The prospective research yields that RIVM practitioners evaluate PRIMA primarily as a systematic and creative method for scenario development and evaluation: the com- 
bination of uncertainty and perspectives is primarily associated with 'societal uncertainties", or pressures, and much less with the causal chains. Although the PRuma approach is explicitly meant as a way to address uncertainty pertaining to data and model quality and adequacy, the practitioners involved in our testing did not perceive it like that. From their responses, it is also clear that the participants to the process did not view the PRIMA approach as an assessment methodology that could frame the assessment. It was perceived as a potential complementary method, not as framework in which current techniques and procedures could be integrated. As discussed in Chapters $1-5$ the PRIMA approach actually involves a fundamental change in thinking about uncertainty and risk. From that perspective, the above reactions also underlines that such a transformation costs time, probably years.

\section{Conclusions}

The prospective research discussed in this Chapter served to evaluate the first two phases of the PRIMA approach in an actwal decision-support practise. The $5^{\text {th }}$ Environmental Outlook functioned as a testing environment. By means of this case we aimed to evaluate the PRIMA approach as proposed in this thesis in the following terms:

- whether the PR IMA framework as proposed in Chapter 5 can serve as a heuristic for designing sensible assessment processes?

- and if so, which concrete activities are needed to realise the ambitions associated with the first two phases of PRIMA in practise?

In doing so, we evaluate the practical feasibility of the prima approach. In the previous Chapters we have convincingly argued that RIVM's current practise is problematic, both from a science-philosophical and from a decision-support point of view. We therefore would like to assess whether prima might address the observed need for another approach. This question provides a second angle to evaluate the potential practicall value of the PRIM approach as methodology for integrated uncertainty management and risk analysis in Integrated Assessment endeavours.

If we compare the output discussed in this Chapter with the ambitions of the PRIMA approach outlined in Chapter 5, how close is the practise to the theoretical ideal? The defunition phase involves making crucial design choices that structure the whole assessment endeavour. The course of the case shows that the practitioners consider these choices as critical and that support for those choices is needed to create the necessary commitment. From the empirical testing we can thus con- 
clude that the definition phase is not just a start of the process, but that it is an inherent essential part. In the Environmental Outlook case, we have chosen a pragmatic approach to avoid that the whole testing would get stuck in endless discussions about the problem definition and approach. In other words, we did test the relevance of that PR IMA phase, but we have not developed through the case a sensible procedure for how this phase can be carried out adequately in practise. The adopted approach worked in the sense that it enabled us to explore the science-in-perspective approach to PRIMA and the perspectives associated with Cultural Theory as perspective-scheme in practise. As a consequence of the set-up, it did not work in terms of the practitioners' necessary support for those choices.

The uncertainty-in-perspective phase aims at identifying the salient uncertainties and interpreting them from different perspectives. Salient is here described as cases in which the degree of uncertainty is significant and the policy relevance is high. The process so far has lead to a first articulation of important uncertainties; however, systematic estimation and selection have not yet been performed. So far, the risk dimensions have not explicitly been used in qualifying the uncertainties, although the working groups have signalled which uncertainties are considered to be risky to a particular perspective ${ }^{57}$. However, the risk concept is not addressed systematically and risk factors are not specified.

From the above analysis of the output and the evaluations, we can conclude that we did not fully succeed in producing some of the outputs associated with these first phases of PRIMA outlined in Chapter 5. However, we did succeed in producing a first set of distinctive qualitative perspective-based interpretations that are internally consistent without being straightforward. Where the scenario approach in the previous Environmental Outlook has degraded to evaluating impacts of extrapolations of the current situation ${ }^{53}$, the produced interpretation patterns provide a basis for a relevant broader assessment of the future. Instead of concentrating on what economists consider plausible futures, proceeding with a pluralistic approach would enable to incorporate equally possible futures that are relevant to consider in evaluating the robustness of recommended environmental policy.

The core of our prospective research endeavour has been devoted to the "uncertainties in perspective" phase. The experiences discussed in the current Chapter indicate that it seems possible to design a process and to carry it out along the lines 
of the PRIMA-framework. The framework as described in Chapter 5 turned out to be concrete enough to serve as guideline for practice, and flexible enough to be adapted to the specific features of the case. The experiences discussed in this Chapter suggest that the PRIMA framework as has been developed from theoretical, philosophical research could serve as a heuristic and benchmark for designing actual activities in a decision-support practise. Exploring the PRIMA approach in practise furthermore yields further suggestions how the uncertainties-in-perspective phase can be translated into concrete activities. It became clear that it is impossible to carry out this whole phase through one workshop. The experience taught us that a step-wise approach is needed. In Figure 3 the lessons in terms of process were summarised.

In sum, we conclude that it is in principle possible to carry out the first two phases of PRIMA in practise, although not in the full richness proposed in Chapter 5. Building upon the practical experience gained with the Environmental Outlook case, we are able to further concretise the first two phases of the PRIMA approach in terms of processes, activities and (intermediary) output and we have gained insight which methodological improvements have to be made. With regard to the latter, it has never been the intention to develop a rigid framework of procedures in which each step is outlined in details. However, from the experience it is clear that the PRIMA framework should ultimately encompass at least the following hints with regard to the first two phases:

- how to organise and facilitate the definition process among practitioners?

- methods and techniques for characterisation and mapping of uncertainty

- how to eventually involve stakeholders in the uncertainties-in-perspective phase?

A secondary aim of the prospective research was to evaluate whether PRIMA could satisfy the observed need for another approach to uncertainty management in Rrvm's Environmental Outlook process. The experiences with the PRIMA approach in the practise of the Environmental Outlook indicate that this approach seemed to evoke reflection and that it seemed to contribute to learning among practitioners. Furthermore, the output of the activities as discussed in this Chapter provide material and insights that in principle can contribute to the $5^{\text {th }}$ Environmental Outlook process. Next to that, no practical criterion has been encountered that would disqualify the PRIMA approach as assessment methodology for RrvM. Our experiences seem to suggest that the PRIMA approach has something to offer to RIVM"s assessment practise, both in view of theoretical considerations as well as in terms of practical needs and relevance. 
With regard to the practical feasibility of the PR rmA approach, we conclude that the prima framework as proposed in Chapter 5 can be used as heuristic to design concrete activities in the assessment process that allow to perform a (more) pluralistic assessment. Howewer, the experiences with the $5^{\text {th }}$ Environmental Outlook process also indicate that it does not lend itself easily to be implemented in practise. The empirical experiences gained resulted in improvernent of the uncertainties-in-perspective phase, both in terms of process and in terms of output(s) that can be produced with such process. If RIVM might be considered as representative for the current culture in decision-support, the experiences yield that the PRIMA approach is in the first place considered as a way to raise awareness and consciousness, and to evoke learning processes about uncertainty, risk and pluralism among decision-support practitioners. It was only in second instance, and just by some Rrvm practitioners, considered as an assessment methodology. The first experiences indicate that application of the PRIMA-approach as assessment methodology in the practise of decision-support anyhow requires a change in the way of thinking, that is fundamental and time-consuming. From Chapters $3-8$ we conclude that such a process seems to involve the following steps: i) consciousness raising about uncertainty, risk and pluralism among practitioners, ii) recognition of the importance of adequate integrated uncertainty management and risk analysis in their actual decision-support practise, iii) understanding the essence of integrated uncertainty management and risk analysis as well as understanding which and how methods and techniques can be used, iv) designing a context-dependent procedure, v) implementation in pilot-cases, and vi) incorporation in standard practise. 


\section{REFERENCES CHAPTER 8}

- Grendstad, G, and Selle, P., 1995, Paper presented at LIASA workshop on "August 1995, LOS-Center, Uniwersity of Bergen, Norway. "Ecology, Environmentalism and Political Cultures." Risk, Policy and Complexity, Laxen. burg, Austria.

- Grendstad "G., and Selle, P. (1997) "Cultural Theory, Postmaterialism and Environmental Attitudes." Culture Mat: ters: Essays in Memory of Aaron Wildavsly, R. J. Ellis and M. Thompson, eds., Westview Presi, Bioulder, USA.

- Hilderink, H., Mosselman, E, Bewsen, A. H. W., van Asselt, M. B. A. den Elzen, M. G. I. de Vink, P. J. Fo, and Rotmans, J. (1998). "TARCETS CD." Baltzer Science Publishers, Bussum, the Netheriands.

- ICIS. (1998). "Limburg in Perspective: A first inventory (im Dutch).", ICIS, Mastricht.

- ICIS. (1999a). "Future on its way: City vision and planning tool for Mlaastricht on its way to 2030." 1 CIS, Maas: tricht, the Netherlands.

- \|ClS. (1999b). "The Thinikmodel for POL (in Dutch)." ICIS, Maastricht:.

- RIMM. (1999). "Addendum Measure, Calculate, and Uncertainties: The working methode of RivM"s environmental research (in Dutch)." RVM, Bilthoven; The Netherlands.

- RIVM and ICIS. (1998). "The Green Heart in Broader Perspective: Initiation report scenarios and indicators for the visions workshop." , Maastricht.

- Rotmans, J, and H. J. M. de Wries (eds.). (1997), Perspectives on Global Change. The TARGETS approach, Cambridge University Press, Cambridge, UK.

- Rotmans, 1. (1997). "Inidicators for Sustainable Development." Perspectives on Global Change: The TARGETS approach, J. Rotmans and $H_{2}$. . M. de Vries, eds, Cambridge University Press, Cambridge, UK.

- Rotmans, J, wan Asselt, M. B. A., Anastasi, , C., Mellors, J., Peters, S., Rothman, D., and Rühkens, N. (2000). "Visions for a sustainable Europe." Futures (in press).

- Schouten, A. J, Bruere, A. M., Bloem, J., Didden, W, de Ruiter, P. C., and Siepel, H. (1999). ".ife Support Functions of the Soil: Operationalisation for biodiversity policy (in Dutch)." 607601003 , R.IVM, Bilthowen, the Netherlands.

- ten Brink, B., Hoogeveen, Y., van Strien, A, and Thissen, H. (1998). "Towards an Ecological Capital lndex: Measuring nature (in Dutch)." Bionieuws, 8(11).

- van Asselt, M. B. A Storms, C. A.H. M., Rijkens-Klomp, N., and Rotmans, ). (1998). "Towards Visions for a Sustain" able Europe: An overview and assessment of the lasit decade of European scenario studies." 198-EO0\%, ICIS, Maastricht, the Netherlands.

- wan Asten, F. (2000) "Uncertainty in Practise: Application of the PRIMA approach to the 5 th Environmental Outlook (in Dutch) " master thesis, Maastricht University, Masitricht, the Netherlands.

- wan Asten, Fs and van Asselt, M. B. A. (1999). "Uncertainty and the 5 th Enwironmental Outlook: Workshop report (in Dutch).", ICIS, Maastricht, the Netherlands

* wan der Sluijs, ). P. (1997). "Anchoring amid uncertainty", Utrecht Uniwers ity, Utrecht, the Netherlands.

- wan Wiet, A. J. H., Heunks, C., and ter Brink, B., . E. (2000). "Natural areas in Europe aund the change of some pressures." "RIVM, Bilthoven, The Netherlands. 



\section{Perspectives \\ on uncertainty and risk \\ conclusions and discussion}

Society is more and more confronted with complex issues. Decision-makers are ever more struggling with complexity. As argued in this thesis the features of today's complexity are that:

- there is not one problem, but a tangled web of related problems (multi-problem).

- it lies across, or at the intersection of, many disciplines (multi-dimensional).

- the underlying processes interact on various geographical and temporal scales (multi-scale).

In this thesis, we have argued that uncertainty and risk are fundamental, problematic but challenging issues in decision-support on complex issues. We have provided both theoretical arguments and empirical evidence for this claim, the latter by means of a case study on actual decision-support.

Taking the above features of current complexity into account, it is clear that an integrative approach is needed. Integrated Assessment (IA) involves an interdisciplinary process of synthesising pieces of knowledge gathered from various scientific disciplines and societal actors, with the explicit purpose to better inform policy and to support decision-making (Chapter 2). Integrated Assessment attempts to shed light on complex issues by illuminating different aspects: from causes to impacts, and from options to strategies. It is only recently that Integrated Assessment is increasingly recognised as a specific branch of science. The current state can be considered as the culmination of a process of decadles that involved both the 
changing nature of the issues on the societal agenda as well as the evolution from mono-disciplinary to multi-disciplinary and interdisciplinary research.

It is an explicit goal of Integrated Assessment to address complexity through highlighting uncertainty and different risk perceptions. However, methods and procedures for doing this in a legitimate and systematic manner are not yet part of the Integrated Assessment tool-kit. The ultimate objective of this thesis was to develop approaches that allow to manage uncertainty and to analyse risk adequately in order to improve Integrated Assessment as approach to scientific decision-support. In the current concluding Chapter, we will summarise the findings, reflect on the conclusions and discuss some challenges for the future.

\section{Summary of findings}

The first steps in the reported research involved study of the sources of uncertainty and risk. We tried to understand why uncertainty and risk occur in societal debates. Analogous to investigating a physical phenomenon, such as climate change, we have attempted to study the causes underlying uncertainty and risk. This part of the research yielded a typology of sources of uncertainty (Figure $\mathrm{I}$ ) that can improve our understanding of, and communication on, these abstract notions (Chapter $3 A$ ).

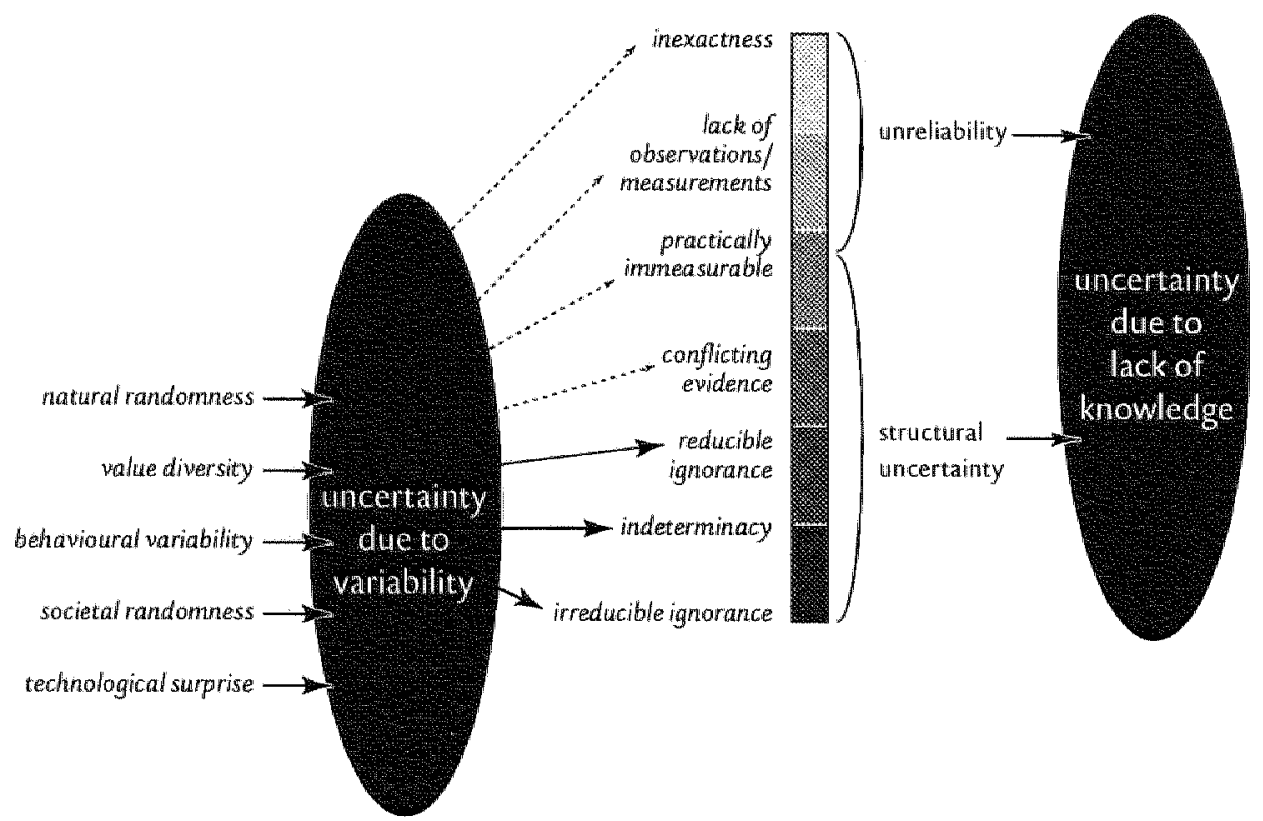

Ricure I Typology of sources of uncertainty 
Building upon our review of scholarly literature from various scientific disciplines on uncertainty and risk, we concluded that complexity means facing inherent, radical uncertainty, strategic risks and multiple risk perceptions. Radical uncertainty involves uncertainties that can at best be roughly assessed. Strategic risks are risks that cannot be controlled by individuals, nor can they be exactly located, and the time horizon usually transcends the short-term. We have argued in this thesis that uncertainty and risk are related concepts and that they can be considered two sides of the same coin, i.e. the limited predictability associated with complex issues. 'Uncertainty' is generally associated with the rationality of science (Chapter $3 \mathrm{~A}$ ), while 'risk' is a notion that seems to correspond most with the rationality of decision-making (Chapter $3 B$ ). Figure 2 indicates how the degree of uncertainty and the level of risk are related.

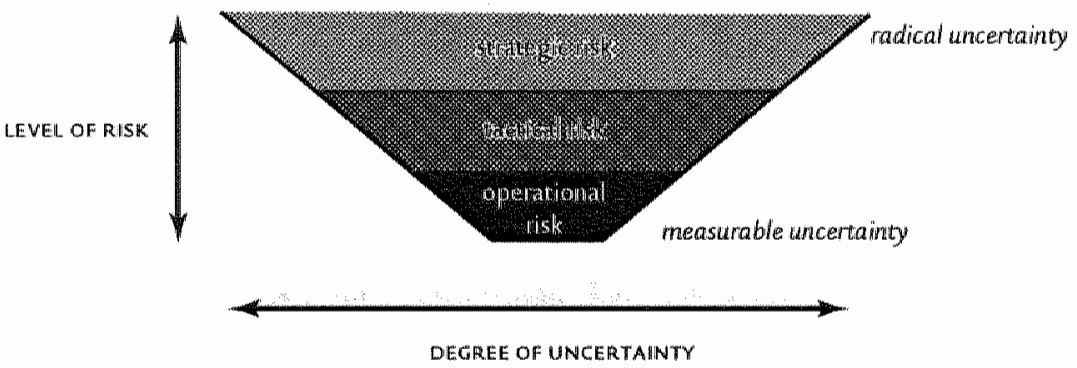

FIGURE 2 Lewel of uncertainty and type of risk

Complexity thus involves both uncertain risks and risky uncertainties. In other words, uncertainty and risk are symptoms of complexity (Chapter 4 ). This means that uncertainty cannot be adequately studied without considering risk, and vice versa. Traditionally, two separate research communities address uncertainty and risk. Notwithstanding this schism, the classical approach treating uncertainty and risk as mathematical and statistical artefacts has dominated both scientific communities for a long time, notwithstanding the increased recognition that:

- science is a creative, innovative process in which intellect, intuition and values interfere with facts and figures

- knowledge is not equivalent to truth and certainty

- experts perceive risk differently from lay people

- cultural factors affect the way people assess risk

The consequence of the above is that different perspectives on uncertainty and risk are legitimate and viable. 
Our research yields that the traditional approaches to uncertainty and risk are especially inadequate in the case of radical uncertainty and strategic risks (i.e. the upper part of Figure $r$ ), exactly those types of uncertainty pertaining to complex issues. The theoretical research led us to conclude that the challenge is to develop a decision-support heuristic that uses the two concepts in a synergetic way. Furthermore, our review of existing methods for uncertainty and risk analysis indicated that even in case an optimal combination of existing methods would be possible, the current tools and methods are by definition not sufficient. New integrated uncertainty and risk methodology is needed for decision-support on complex issues.

The aim of the present $\mathrm{PhD}$ research was to address the issue of analysis and management of uncertainty and risk in decision-support in an integrative way corresponding to the aims of Integrated Assessment. The ambition of our methodological endeavour was to develop an approach to uncertainty and risk that is theoretically sound and practically feasible. In this thesis, we have shown that such a method has to be pluralistic, in order to account for legitimate plural interpretations of uncertainty and multiple risk perceptions (Chapter 4). Our study of the concept of pluralism suggested that there is not one legitimate pluralistic starting point, but several. This means that there is not one unique approach that can satisfy the observed need, but that there is in principle a range of methods and tools that can contribute to adequate and effective pluralistic uncertainty management and risk analysis in decision-support endeavours. This means that the Pluralistic fRamework for Integrated uncertainty Management and risk Analysis (PRIMAy proposed in this thesis (Chapter 5 ) is but one possible approach to deal with uncertainty and risk in decision-support in a theoretically sound manner.

Building upon our theoretical study on uncertainty, risk and pluralism, we have attempted to develop an approach that can serve as a heuristic in designing pluralistic assessment processes centred around uncertainty and risk. The PR MA framework proposed in this thesis is not meant as a blueprint or a rigid methodology. We have designed prima as a flexible framework that comprises steps and stages that are theoretically sound and that appear to be useful to decision-support practice.

Central to the PRIMA heuristic is to disentangle controversies on complex issues in terms of radical uncertainties and strategic risks. The pluralistic approach adopted involves that the uncertainties and risks associated with the issue under concern are interpreted according to different perspectives. These different interpretations and risk judgements are compared and confronted in order to draw a richer image of the 
issue under concern. The essence of the prima approach is that the uncertainties, identified in a participatory process as salient, are 'coloured' according to watious perspectives, in which we used perspectives associated with Cultural Theory, i.e. controllist, market-optimist and environmental worrywart. Starting from these perspective-based interpretations, various legitimate and consistent narratives are developed as to assess what might happen in order to explore what are the key challenges for current decision-making. Integrated analysis (either qualitatively or by means of models) of the set of perspective-based chains of interpretation allows evaluation of autonomous and policy-driven developments in terms of risk. Informed by these integrated assessments, the ultimate aim is to assess the level of robustness of strategies in a systematic manner. The different stages associated with the PR MAapproach are summarised in Figure 3.

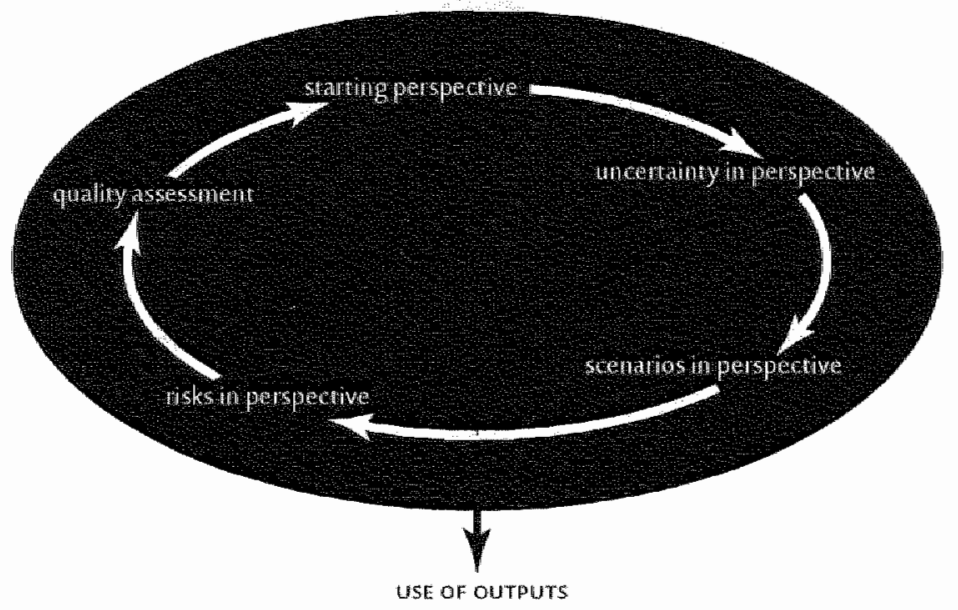

FIGURE 3 Multiostiage approach to plunal istic integrated uncertaimty management and risk analysiss

The next question is whether the framework is practically feasible. To that end, we have first performed a case-study on decision-support practice, in case the Environmental Outlooks produced by Rrvm (the Dutch Institute for public health and the environment) (Chapter 6). Our retrospective analysis of how uncertainty was dealt with in the four Environmental Outlooks indicated that the current practice is problematic and deficient, both from a theoretical and from an empirical perspective. The retrospective case study showed that Rrvm lacked a strategy and a framework for dealing with uncertainty in their assessment endeavours, which had serious consequences for the firmness and robustness of the conclusions. We concluded 
that RIvm is vulnerable to criticism: the assessment reports do not permit informed judgement of the robustness and quality of the conclusions and recommendations (Chapter 7 ). $\AA$ recent media affair, known as the De Kwaadsteniet affair, underlined this conclusion in a dubious, but forceful way.

RIvm, however, seems not unique in quarrelling with the issues of uncertainty and risk in their decision-support. Our case study suggested that other decisionsupport institures, so-called planning offices, are struggling with similar problems. The case-study research involved reports produced by other Dutch decision-support institutes, such as the $C P B$, and similar problems in terms of weak argumentation were encountered. Furthermore, in the media affair it was explicitly argued and recognised by various opponents that the criticism towards Rrym seemed to be valid for other decision-support institutes as well. There seem to be no reasons for which Rrvm cannot be considered as an example case of decision-support practice: the conclusions about Rrvm's practice seem to be generalisable to decision-support practice in general. Based on our research, we hypothesise that in view of increasing complexity of societal issues there is a general need for systematic approaches to uncertainty management and risk analysis. Our case study indicates that this need is more and more explicitly recognised by practitioners in decision-support themselves.

The next question is whether the PRIMA approach can serve as a heuristic in designing and implementing integrated uncertainty management and risk analysis in the practice of decision-support? To that end, we have explored the first two phases of the PRIMA approach (definition phase and "uncertainties-in-perspective" phase) in the practice of Rrvm's environmental assessment process underlying the $5^{\text {th }}$ Environmental Outlook (Chapter 8). We did prove the relevance of the definition phase, but we have not yet developed a procedure for carrying out this phase adequately. The core of our prospective research endeavour has been devoted to the uncertainties-in-perspective phase. We did not fully succeed in producing the outputs associated with the first phases of PRIMA, although we did produce a first set of distinctive qualitative perspective-based interpretations that are internally consistent without being straightforward. The experiences discussed in this thesis indicate that it seems possible to design a procedure that enables to run the uncertainties-inperspective phase along the lines of the PrImA-framework.

In sum, this thesis provides insights into the sources of uncertainty and risk, it discusses a pluralistic approach for systematically addressing uncertainty and risk in decision-support endeavours, and it gives a first evaluation of the potential 
practical value by discussing Rrvm's previous Environmental Outlooks as well as preliminary experiences with elements of the PRIMA approach in the context of the $5^{\text {th }}$ Environmental Outlook.

\section{Reflection}

The first two phases of the PRIMA approach have been explored in a real life decisionsupport context. Although we did not come as far as we would have liked, it was by no means clear from the start that we would get as far as we did. Notwithstanding scepticism and careful enthusiasm, all. practitioners who participated were very clear in concluding that we contributed to the learning process within RIVM, both on the individual and the collective level. The empirical data also indicate that a transition has been set in motion. It is unclear yet what this cultural change will imply for RIVM's practice in the broad sense and its ultimate decision-support products. It was clear that the potential progress in this transition is dependent on how the actual policy-analysts and decision-makers (i.e. Rrvm clients) will act and react, on what they expect and desire, and on how far they do (not) want to go with innovating decision-support. We purposively decided to demarcate the ambitions of this $\mathrm{PhD}$ research in such a way that this complex interplay between science, societal actors and decision-makers was not a research topic. Nevertheless, the awareness that this interplay is ultimately crucial for the whole endeavour has always been clearly in the back of our mind.

The experience with Rrym taught us that a step-wise, iterative approach to integrated uncertainty management and risk analysis is needed. The framework turned out to be a heuristic at least concrete enough to serve as guideline for practice, and flexible enough to be adapted to the specific features of the case. The experiences yield that application of the PRIMA-approach as assessment methodology in the practice of decision-support anyhow requires a change in the way of thinking, that is fundamental and time-consuming. From Chapters $3-8$ we concluded that such a process seems to involve the following steps: i) consciousness raising about uncertainty, risk and pluralism among practitioners, ii) recognition of the importance of adequate integrated uncertainty management and risk analysis in their actual decision-support practice, iii) understanding the essence of integrated uncertainty management and risk analysis as well as understanding which and how methods and techniques can be used, iv) designing a context-dependent procedure, v) implementation in pilot-cases, and vi) incorporation in standard practice. 
The overall ambition underlying this thesis was to contribute to the further development of Integrated Assessment and IA methodology. In discussing the state of the art of this relatively young branch of decision-support, we have shown that the treatment of uncertainty and the incorporation of multiple perspectives are vital issues to the quality of $I A$, but that it is yet unclear how this can be done. Besides, it could be concluded that IA lacks frameworks to use analytical and participatory methods in a sensible and credible complementary way. Finally, it was argued that the IA community wants to explore how IA could benefit from risk approaches. What did this thesis deliver in view of these challenges? The PRIMA approach proposed in this thesis involves a process structure in which it is highlighted when, why and how analytical methods, participatory processes or a particular combination of both are valuable means to the targeted end(s). The prima approach can thus be considered as proposing one possible methodological framework for IA. Because the proposed phases are discussed step by step and because concrete examples are provided, this thesis can be considered as a heuristic guide for those that would like to deal systematically with uncertainty and pluralism in IA endeavours. This thesis can be viewed as a first exploration of how $1 \mathrm{~A}$ may employ the risk concept and risk approaches. With regard to the latter, we hope that this thesis can serve as a scoping document for the IA community.

With the example of the perspective-based model routes implemented in the IA model TARGETS and with re-doing the classical example provided by Fischihoff and colleagues, we have tried to convincingly illustrate that the risk concept is essential to the Prima approach. Especially in terms of evaluating the policy relevance of the issues to be addressed in the assessment, in terms of fleshing out plural perspectives and in interpreting and communicating the assessment insights in a sensible and meaningful manner, the risk concept is crucial. Although the pRImA approach is meant as integrated framework to address uncertainty and risk in decision-support endeavour, so far it has been mainly considered and used as an alternative approach to uncertainty management.

\section{A look ahead}

Although we have tried to be comprehensive and to fasten loose ends, a PhD thesis is always both an end and a new beginning. The following two research challenges pertaining to the proposed PRImA approach can be easily derived from the current material and insights: 
- to test the whole PRIMA-framework in varying contexts through ex-ante case studies.

- to improve the current PRIMA methodology, which involves among others: to further develop theoretically sound sets of perspectives that can be used in the various pluralistic modes of PR IMA, to explore procedures and tools to highlight different legitimate and relevant perspectives through social processes in at practically feasible manner, to strengthen the risk dimension, which among others means developing and designing tools and procedures that allow to put risk more on the table in the assessment process

Integrated Assessment aims to facilitate a process in which insights on complexity are comproduced by scientists, stakeholders and decision-makers. This means that methodology should not only be valid in scientific terms, but it should also be an acceptable approach in view of the social and political context. This means that follow-up research should involve extensive literature review on policy sciences and ideally also empirical research in order to conceptualise the decision-naking contexts. These insights can then be used as another evaluation scheme for the PR IMA methodology.

Partly due to the complexity of the decision-making issues, the role of "knowledge transfer" changes: from "speaking-truth-to-power" to "mutual construction", and from given answers to highlighting uncertainty and risk, and evaluating robustness. This has consequences for institutes and organisations that have an intermediary role between science and decision-making. In the Netherlands, the planning offices, such as RIVM, CPB, RPD, SCP and CBS, are such intermediary institutions. In this thesis, we have focused on RIVM's assessment practice. For follow-up research, it would be interesting to involve other planning offices in the Netherlands, or similar intermediary institutions abroad. For such case-studies, we design developed

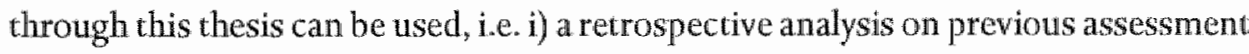
reports involving argumentation analysis, analysis of the argumentation in terms of uncertainty and risk perception, diachrone analysis, interviews and a focus group, and ii) an ex-ante study in which the PRIMA-framework serves as benchmark for the design. With regard to the latter, the challenge is to translate the proposed steps into procedures that fit into the context of practice, while still in line with the methodological principles. We learned from the research reported in this thesis that in order to do so a thorough analysis of the history and institutionalisation of the institute under concern, and an analysis of the organisational culture are needed to be able to put the ex-ante research in a broader context. 
Apart from PRIMA-related challenges, the current research yields that the ultimate challenge is to develop variants of IA procedures that integrate different methods and approaches into a coherent assessment strategy. Such a toolkit" can help practitioners to design and implement concrete assessment activities. Uncertainty and risk have been the explicit starting point in this thesis. If we look back, it is clear that we have touched upon other methodological branches. To further develop methodology for Integrated Assessment the following ideas for future research can be derived from this thesis:

- systematic survey and review of relevant fields of methodology, such as participatory methods, scenario methodology, modelling approaches, evaluation methods, policy analysis, technology assessment, etc.

- development of frameworks involving a sensible and useful mix and phasing of methods

- testing the practical feasibility of these methodological frameworks in view of goals and contexts via ex-ante case-studies

- development of an IA toolkit comprising heuristic frameworks that involve goal/context - mix-of-methods combinations

In sum, an agenda for a follow-up research programme on IA methodology addressing uncertainty, risk and pluralism would comprise the following issues:

- the methodological quality of integrated uncertainty management and risk analysis, through further use of advances in related methodological fields.

- the rationality of decision-making, through use of insights from policy analysis, policy sciences and empirical research.

- the practical feasibility and usefulness of proposed heuristics, through empirical testing in ex-ante cases

\section{Epilogue}

In outlining our research perspective in the beginning of this $\mathrm{PhD}$ thesis, we admitted that our ideal was to act as a change agent in the practice of decision-support. With the current $\mathrm{PhD}$ research we have focused our efforts towards practitioners and analysts in actual decision-support practice. The next challenge is to interest actors in the decision-making realm in learning about alternative perspectives on uncertainty and risk, in addition to continuing the interactive mutual learning process with practitioners, as those from RIVM. This thesis at least provides enough basis and food for thought to continue with improving decision-support from a scientific angle. 
We are well aware that this thesis may be evaluated as controversial. We realised that we played a risky game with an interdisciplinary thesis into issues fundamental to science and scientific advise. It is meant to encourage scientists, practitioners in decision-support, decision-makers and societal actors to put uncertainty and risk in another than their usual perspective and we hope to facilitate constructive communication among them about uncertainty, risk, robustness, participation and pluralism. With this thesis, we hope to sketch some more attractive perspectives to dealing with complexity than muddling along, which inadequate tools and methods. 



\section{Letter to the editor}

\section{by Rotmans and van Asselt (in Dutch)}

\section{Meten baadt niet bij RIVM-onderzoek}

\begin{abstract}
Onzeker zijn over de uitkotrusten is therentwan werenschappelik onderzoek, ook dat wan het RIWM. Onzekerheid is niat aan synoniem an slew te weterschap. Samenwerking tussen onderzoeksinstiuten kan een deel wat de onzekerheid wegnemen an maken dat de politiek toch tijdig op antwoorden kan rekenen.
\end{abstract}

Milieuroniderzoek

\section{Jan Rotmans en Marjolein wan Asselt}

Het RIWM is in opspraak: de betrouwbaarheid wan het rijjksinstituut werd de afgelopen week openlijk in twijfel getrokken, sinds Trouw een interview publiceerde met RIVM-werknemer De Kwardsteniet (2o januari).

De Kwaadsteniet beticht het RIVM ervan gegewens met een geringe betrouwbalarheid te presenteren met name in de jaarlijks werschijnende Milieubalans. De onderzoeksresultaten zouden onwoldoende gevalidecrd zijn en significant afwijken wan die werkelijiktheid.

Een van de problemen rondom dit soort onderzoek is de toenemende druk vanuit de politick op instituter als het $\mathbb{R}$ IVM, om "oplosisingen" aan te dragen. De politiek geeft instituten alls her RIVM als het ware de opdracht een onmogelijk moeilinke rekensom in een woek en een zuchr op re losiser. Dit leidt tor niet genoeg onderbouwde adwiezen met een sterk ad hockarakter, die continu worden bijgesteld in de tijd.

Op díc moment holt de politiek van rapport naar rapport zonder zichzelf en de adviserende onder zoeksinstituten de tijd te gunnen voor een grondige analyse. Slechis een dergelink grondige werkwifze kan uitmonden in een structureel advies war het beleid op langere termijn mee uit de voeten kon. Dit is geen pleidooi woor eindeloze onderzoekingen. Het karakter wan de politiek vragkt nu een. maal om rjjdige informatie.

Maar zo'n grondige analyse door samenwerkende ondierzoeksinstituten kan juist ook de basis bieden voor het snel en adequat beartwoorden wan ad hoc verzoken om informatie.

Vender geldt dat onzekertheid omtrent milien vens er ook gewoon bij hoort: inherent aan weten w schappelijke kennis is dat deze onvolkomen is. Een significant deel wan die onzekerheid kar niet worden weggenomen door hev vertichten van meer metingen, zoals De Kwaadsteniet woorstaat. Het is illusoir om te veronderstellen dat het de fundamentele lacumes in onze kernis zou opvullen. Dus 'meten is weren' (Willem Breedveld, Podiunt, 27 januari) is achterhasld.

\section{Politiek zet RIVM onder druk door een snel antwoord te wragen}

Wet werkelijke probleem dat schuilt achter de cijfers van het RIVM is dus niet zo zeer het grebrek an metingen. De cijters zijn beperkt betrou wbatr. ondat er grenzen zijn aan wat we kunnen weten. Om dit te onderbouwen moeten we de verschillende bronnen wan onzelkerheid tader analyserem. Een belangrijk onderscheid is dac russen 'onzeker. heid door gebrek aan kennis' en 'onzekerheid door variabiliteit:

Er zijn werschillende gradaties van gebrek aan kemnis, te weten meetroutten, gelorel aar metingen en warmemingen. Daurbijzijn er ook cijfers die in theor te te verzamelen $z$ gifn, maar in de praktijk niet. 
Het is bijwoorbeeld onmogelik te observeren hotveel afval el he Nederlander iedere dag produceert, of om op idere werkante meter de concentraties fosfaat en anmoniak te meter. Daaraast kunnen er verschillende cijerreeksen beschlikbat zijn die ruimte operaten wor tegenstijdige interpretaties.

Fundamenteler is bet gebrek aan kennis doordat wr zogenoemde variabiliteit optreedt " Variabiliteit betekent dat het systeem zich onvoorspelbaar kan gedragen en zichntutan wetten houdt. Belangrijke redenen warom die variabiliteit een rol speest in milieu-onderzosk is de ratumrlijke willekeur (denk ata the weer), de onvootspelbaarheid wan mensellijk gedrag en maatschappelijke en technologin sche verrassingen. Mer andere woorden, al zou het RTVM alles meten wat er metelly valt, darn nog zou de onzekerheid niet verdwinten. Opeenstapeling in thet onderzoek wan verschillende van dergelijke onwoorspelloarheden is een furdamenteel probleem, dat helaas niet opgetost kan worden door het opnemen wan betrouwbarheidsinterwallen en waarschijnlijkheidlswerdelingen, zoals de Kwaadsteniet suggereert. Zo'n interval is ondanks alle geavanceerde statistische methoden slechtsen schatting wan de mate van onzekerheid.

Daamaast tonen social-wetenschappers, vooral op het gebied van tisico-communicatie, keer op keer an dat niet-wetenschappers niet weten hoe waarschijnlijkheidswerdelinget en betrouwbarheidsink dat een dergelinke "statistische" communicatie ower onzekerheid de wer warring groter zou maken

Het werkelijhe probleem wan onzeketheid is dus a.anzienlijk complexer, en is ook geen typisch RIWM problem. Ander belleidsonderbouwende instituren zoals her CPB, het SCP en het CBS wor stelen met dezelfide problemen en produceren studies warwar de resultaten zinn omgeven met de nodige onzekertheid, maar deze vormen anderzijds een onmisbaar hulpmiddel in her proces van de beleidswoombereiding. Dir ontsatat de voornoemde instituten uiteraard niet wan de plicht orm de nodige zorgwuldigheid te berrachten bij cle presentatie van hun onderzoeksresultaten en beleidsadviezen.

De enige oplossing lijke ons te zijn am een nieuwe modus te vinden voor het ong gan met onzekerheid in onze maatschappij. Dus niet langer onzeker heid in onze maatschappij. Dus niet langer onzekerheid louter als een probleem beschouwen of als synomiem van slechte wetenschap, maatr ermee leren omgaan. Wie niet wil inzien dat onzekerheid onwermijdelijk is en schijnzekerheid gevaarlijk, zal tot in lengte van dagen steeds opnieuw geschokt zijn ower de beperkte betrouwbartheid van de ciffers in de rapporten van gerenommeerde onderzoksin. stituten.

Prof.driir. Jan Rotmans en ir. Marjolein wan Asselt, oud-werkmemers wan het RIVM, zijn directeur resp.

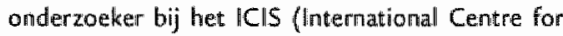
Integrative Studies) van de Uniwersite ${ }^{u}$ Maastricht 


\title{
Track record of media facts of DeKwaadsteniet affair
}

\author{
national newspapers and national radio and $T V$ \\ in chronological order \\ covered period: January 1999 - September 1999
}

- Lagendijk, A. Politically correct. De Volkskrant, 23 May 1998.

- Trouw. Environment institute lies and deceives. Trouw, 20 January 1999.

- De Kwaadsteniet, J.W. The society has a right to honest information. Trouw 20 January 1999.

- Engels, J. Then the truth is less important. Trouw, 20 January 1999.

- RIVM (Internet:www.rivm.nl/pr/pr9901.html). RIVM takes distance from assertions that environmental results would be dishonest. RIVM, 20 January 1999.

- Rijswijk, C. Conversation with RIVM Director Van Egmond. Tijdsein. EO-radioprogramme. 20 January 1999.

- De Volkskrant. Parliament shocked by criticism on reports RIVM. De Volkskrant, 21 January 1999.

- Reijnders. L. Publish RIVM-report together with criticism. Trouw, 21 January 1999.

- Telegraaf. Parliament wants inquiry into RIVM. Telegraaf, 21 January 1999.

- Trouw. RIVM has to highlight uncertainties in reports. Trouw, 21 January 1999.

- Trouw. The Schiphol- and ammonia-fugures from the RIVM. Trouw, 21 January 1999.

- Trouw (Comment). Environment, science and politics. Trouw, 21 January 1999.

- Trouw (Editorship Science). Fuss in Parliament after criticism on environmental figures. Trouw, 21 January 1999.

- Trouw (Editorship Science). RIVM: no malicious intent. Trouw, 21 January 1999.

- Borgman, W. Conversation with Minister of Environment Jan Pronk about RIVM. Tijdsein. EO-radioprogramme. 22 January 1999.

- Trouw (Editorship Politics). Parliament asks Pronk for elucidation. Trouw, 22 January 1999.

- Trouw (Editorship Politics). Pronk rejects criticism on environmental institute. Trouw, 22 January 1999. 
- Van Cooten, A. Accusation against reliability of RIVM hits agricultural sector directly. Agrarisch Dagblad, 22 January 1999.

- Van Houten, M. Unassailable figures in environmental research. Trouw, 22 January 1999.

- Verhoeven, R. Computer-models and the inflow of asylum seekers. Trouw, 22 January 1999.

- De Volkskrant. Monopoly position makes accused RIVM vulnerable. De Volkskrant, 23 January 1999.

- Trouw. Suspended official summons RIVM. Trouw 23 January 1999.

- Trouw (Editorship Politics). VVD: Pronk too laconic about criticism RIVM. Trouw, 23 January 1999.

- Buitenhof-Discussion with DeKwaadsteniet-Nederland 1 as TV programme, 24 January 1999.

- RIVM(Internet: www.rivm.nl/pr/pr9902.html). Irresponsible accusations not only harmful for RIVM. RIVM, 24 January 1999.

- ANP. RIVM-employee ignores ban on public statements. De Volkskrant, 25 January, 1999.

- De Volkskrant. Political Science. De Volkskrant, 25 January 1999.

- Conversation with Director Van Egmond and Professor Lucas Reijnders. Tijdsein. EO-radio-programme. 25 January 1999.

- Eindhovensdagblad. Parliament: clarification about Environmental-institute. Eindhovens dagblad, 26 January 1999.

- NRC-Handelsblad. RIVM blames criticism of employee. NRC-Handelsblad, 26 January 1999.

- Rijswijk, T. Conversation with RIVM-Director Van Noort of the RIVM. Tijdsein. EO-radio-programme. 26 January 1999.

- Wams, T RIVM operates in a minefield. De Volkskrant, 26 January 1999.

- Breedveld, W. The bankruptcy of the figures. Trouw, 27 January 1999.

- De Volkskrant. RIVM angry about accusations of employee. De Volkskrant, 27 January 1999.

- Trouw (Editorship Science). Fierce criticism of RIVM on accusation deceit. Trouw, 27 January 1999.

- Bomhoff, E.J. RIVM has to provoke competition. Trouw, 27 January 1999.

- Trouw. Chamber/Parliament wants to question Pronk about the RIVM. Trouw, 27 January 1999. 
- Rotmans, J., Van Asselt, M. Measurement is not enough for RIVM-assessment. Trouw, 28 January 1999.

- Pulles, T. Not everything can be scientifically sound. Trouw, 29 January 1999.

- Van Dobben, H., Verboom, J. en Wamelink, W. Computer model is always better than a crystal ball. De Volkskrant, 29 January 1999.

- Aarden, M., Trommelen, J. Kafka and the environmental figures. De Volkskrant, 30 January 1999.

- Bomhoff, E.J. Badly organised research. NRC, 30 January 1999.

- Hulsbosch, J.K. How controllable is scientific research? De Volkskrant, 30 January 1999.

- Van Dommelen, A., Van der Schot, J. Not method but model determines outcome. Trouw, 2 February 1999.

- Van Egmond, N.D. Models give meaning to measurement results. Trouw, 3 February 1999.

- Didde, R. en Mieras, M. Pure figures: Ten years after the environmental alarm: Intermediair, 4 February 1999.

- De Berg, J. (Trouw Editorship). Question also the other party. Trouw, 5 February 1999.

- Van de Sluijs, J., Schulte Fischedick, K. Crisis of authority about environmental figures. Trouw 6 February 1999.

- Quak, A. Government bases policy too often only on models. Trouw, 9 February 1999.

- Van Staalduinen, M. Wageningen tests unscientifically. Trouw, 10 Fiebruary 1999.

- Trouw (Editorship Politics). Parliament: RIVM tested externally. Trouw, 11 February 1999.

- Engels, J. Would competition not be better for RIVM? Trouw, 11 February 1999.

- Klein Molenkamp, J. H. Independent testing of environmental figures necessary. Trouw, 11 February 1999.

- Van der Steenhoven, J., Rabbae, M. Desired outcomes are easily bought. Trouw, 11 February 1999.

- Van der Burg, T. CPB has the wrong conclusions. Trouw, 12 February 1999.

- Trouw. Homage for the bell-ringer. Trouw, 12 February 1999.

- Trouw. (Editorship Politics). Work of RIVM more precisely reviewed. Trouw, 12 February 1999.

- Trouw. De Kwaadsteniet disappointed in Parliament. Trouw, 12 February 1999. 
- De Volkskrant. Suspended RIVM employee wants to go back to work. De Volkskrant, 19 February 1999.

- Trouw. RIVM want to get rid of scientist De Kwaadsteniet. Trouw, 19 February 1999.

- De Volkskrant. Judge declares that employee is right. De Volkskrant, 25 February 1999.

- Schoonen, W. De Kwaadsteniet has the wind in his back. Trouw, 25 February 1999.

- De Volkskrant. RIVM appoints confidential agent for employee. De Volkskrant, 26 February 1999.

- Trouw. RIVM purishes critical employee after all. Trouw, 26 February 1999.

- Trouw. (Editorship Politics) RIVM examined on qualitity of data. Trouw, 10 March 1999.

- Engels, J. The balance is missing. Trouw, 29 April 1999.

- Schoonen, W. The "Djöficering" of the Netherlands. Trouw, 29 April 1999,

- De Volkskrant. RIVM has to dispose of tasks due to less subsidies. De Volkskrant, 7 May 1999.

- Trouw. (Editorship Politics). To economise RIVM on the expense of research. Trouw, 7 May 1999.

- Van Dommelen, A., Van der Schot, J. RIVM retrains to be environmental detective. Intermediair, 9 September 1999. 
APPENDIX 3

Argumentation analysis schemes

ISSUES NATIONAL ENVIRONMENTAL OUTLOOK-3 ( 1 of 4)

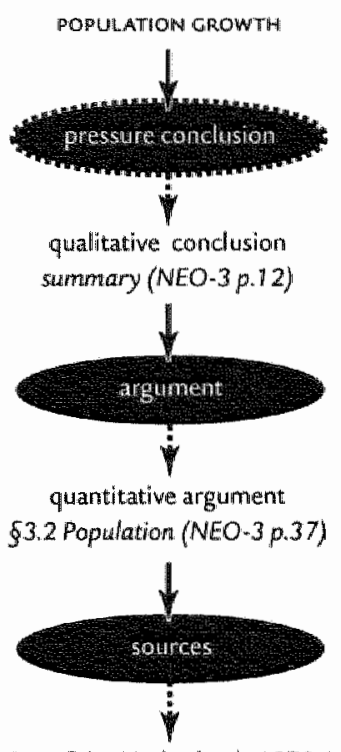

figure: total population of the Netherlands 1970-201.5 (NE O-3 p.37)

The Netherlands in Triplicate" \&....... reference: 'Scanning the Future." (CPB, 1992a) (CPB, 1992b)

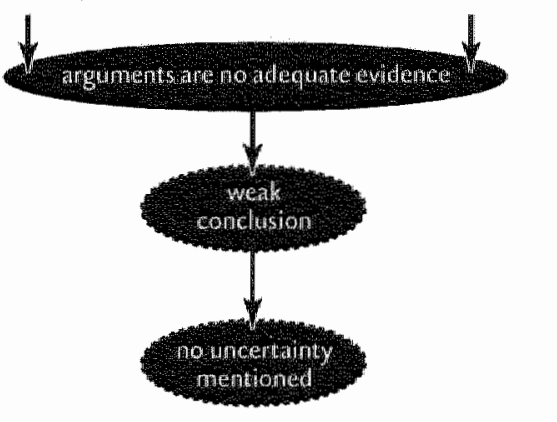




$$
\frac{\equiv}{\vdots}
$$




$$
\frac{\equiv}{\underline{\underline{D}}}
$$




$$
\bar{E}
$$


ARGIUHEWTATION AHALYSIS SCMEHWS

429

ISSUES NATYONAL ENVIRONMENTAL OUTLOOK-4 ( 1 of 6 )
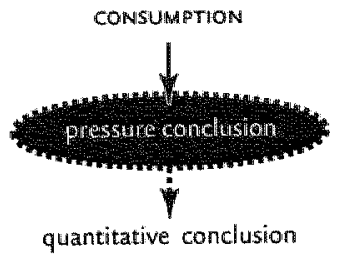

summary (NEO-4 p.12)

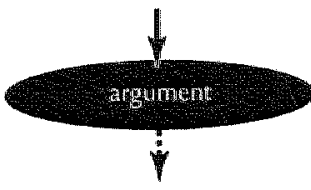

quantitative / qualitative argument

\$2.3.1 Population \& Consumption (NEO-4p.25.26)

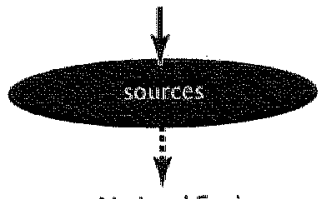

Background document National Environmental Outlook -4 (RIMM, 1997)

reference "Working document 89 " (CPB, 1996)

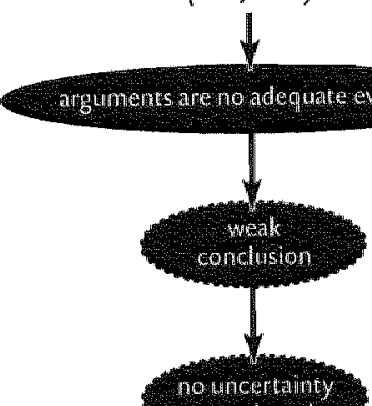

10Hisentim

ondatones 


$$
\frac{1}{3}
$$


ARGUMENTATiON ANALYSIS SCHEMES

$4 \mathbf{3}$

ISSUES NATIONAL ENVIRONMENTAL OUTLOOK-4 ( 3 of 6 )

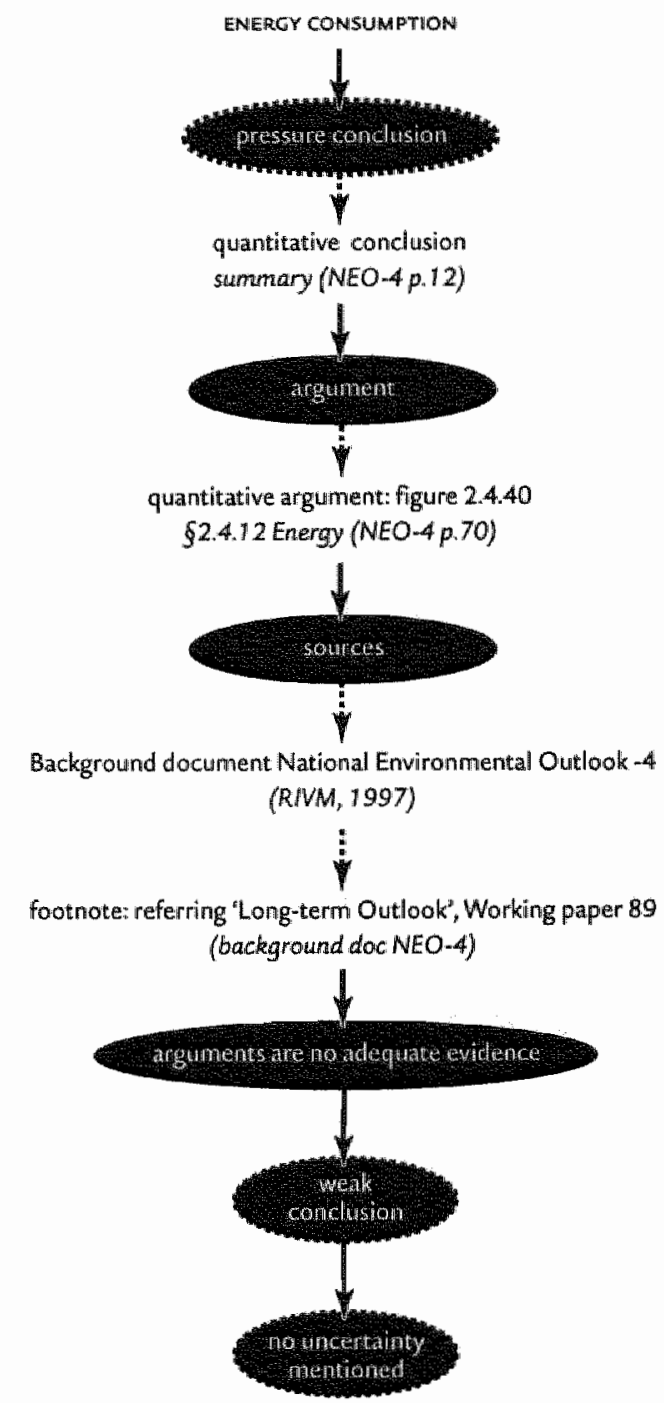


ISSUES NATIONAL ENVTRONMENTAL OUTLOOK-4 (4 OF 6$)$

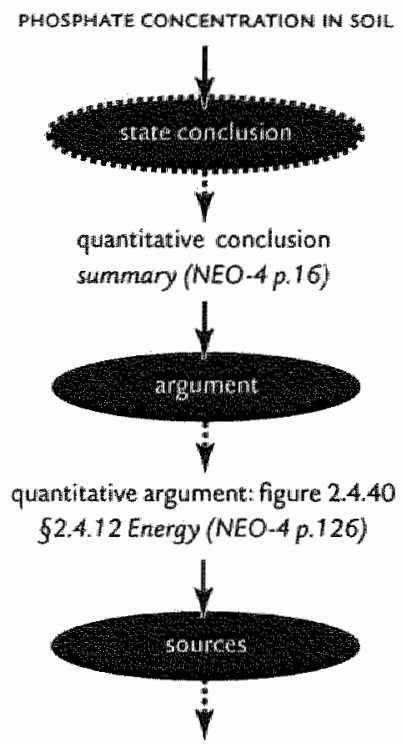

Background document National Environmental Outlook -4 (RIVM, 1997)

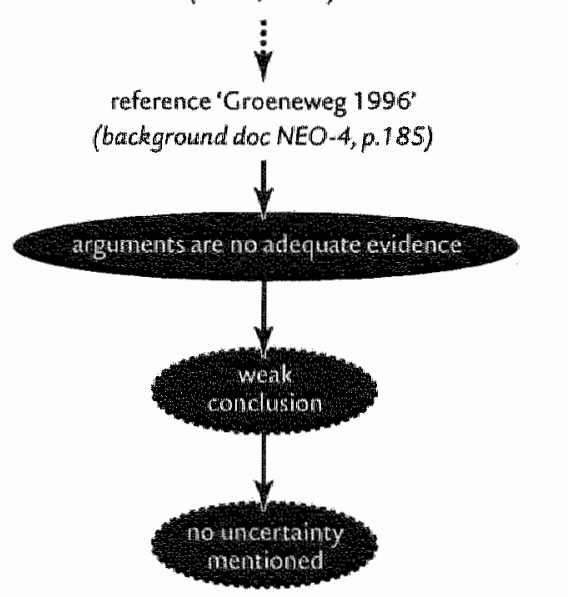


ISSUES NATIONAL ENWIRONMENTAL OUTLOOK-4 (5 Of 6 )

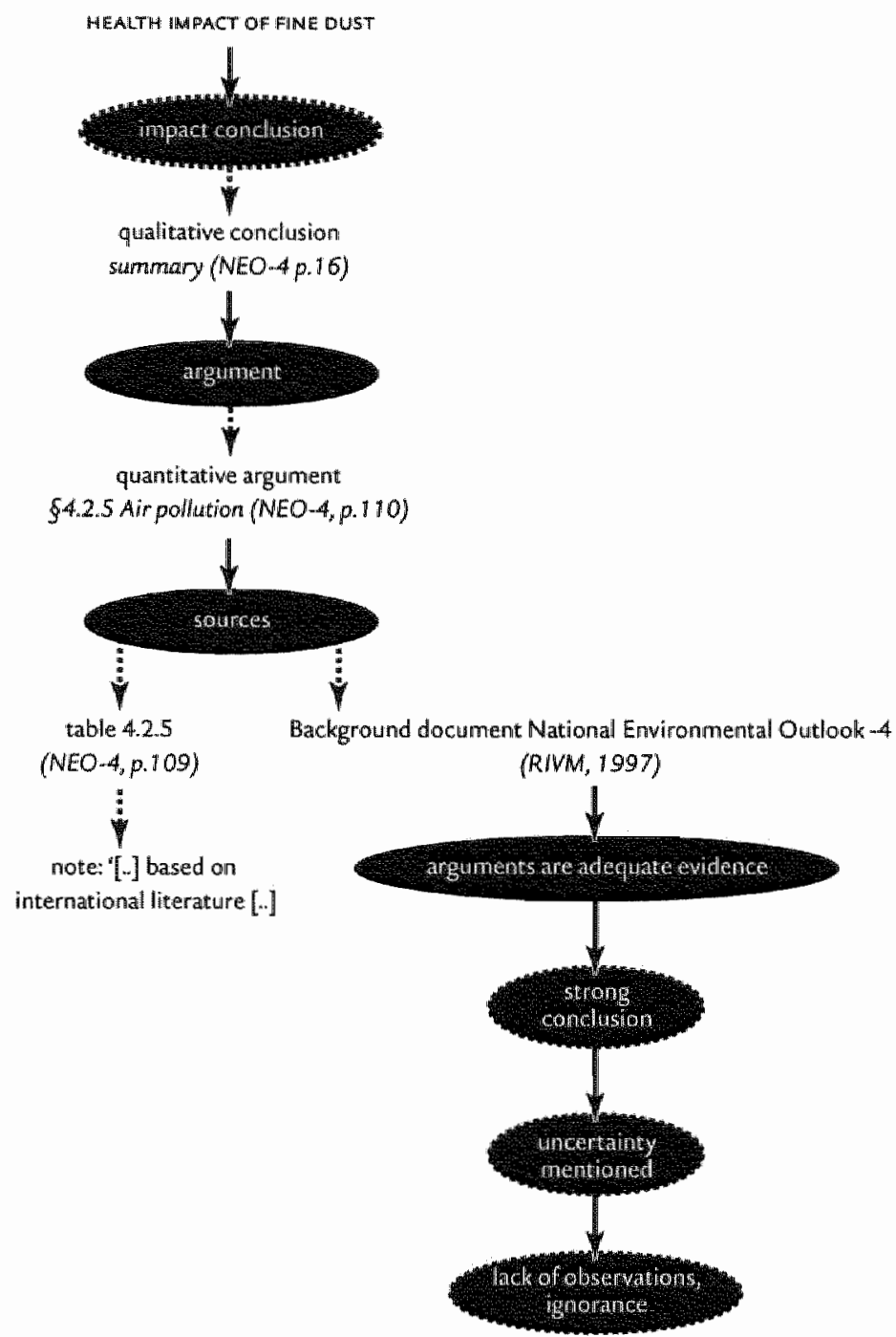




$$
\frac{5}{ \pm}
$$


Perspectives

on uncertainty

and risk

The PRIMA approach to decision-support

Marjolein B.A. van Asselt 


\section{Perspectives on uncertainty and risk}

The PRIMA approach to decision-support

\section{proefschrift}

ter verkrijging van de graad van doctor aan de Universiteit Maastricht op gezag van de Rector Magnificus, Prof. dr. A.C. Nieuwenhuijzen Kruseman volgens het besluit van het College van Decanen, in het openbaar te verdedigen

op donderdag 12 oktober 2000 om 16.00 unr

DOOR

ir. Marjolein B.A. van Asselt 
PROMOTORES

Prof. dr. ir. J. Rotmans

Prof dr. R. Hoppe Universiteit Twente

\section{BROOR DELINGSCOMMISSIE}

Prof. dr. ir. W.E. Bijker voorzitter

Prof. dr. C.C. Jaeger Potsdam Institute for Climate Impact Research, Germany Prof. dr. P. Kirschner

Prof. dr. T. O'Riordan University of East Anglia, United Kingdom

Prof. dr. W.F. Passchier

Prof. dr. S. Rayner Columbia University, USA. 


\section{Stellingen}

I. Onzekerheid en risico zijn met elkaar samenhangende symptomen van complexiteit. Een complexe maatschappij als de onze, waarin ongelijksoortige processen steeds meer verstrengeld raken, wordt dus in toenemende mate gekenmerkt door inherente onzekerheid en daaraan gekoppelde risico"s.

2. De analysemethoden die momenteel gebruikt worden in wetenschappelijk beleidsondersteunend onderzoek zijn ontoereikend om de meest cruciale onzekerheden en risico's adequat te adresseren, ondat ze geen inzicht geven in de verschillende bronnen en typen van onzekerheid.

3. Het interpreteren van onzekerheid en risico vanuit één perspectief is misleidend en fundamenteel onjuist. Het zichtbaar maken van plufalisme door het gebruik van verschillende perspectieven vormt de grote uitdaging woor beleidsondersteunend onderzoek.

4. De in dit proefschrift voorgeste]de benadering (PRIMA) om onzekerheid vanuit verschillende perspectieven te interpreteren, teneinde strategische risico's zo grondig mogelijk te verkennen met het doel robuuste strategieedn te ontwikkelen, is theoretisch juist, en lijkt hanteerbaar en nuttig voor de praktijk van beleidsondersteuning.

5. Door het fenomeen onzekerheid lange tijd niet echt serieus te nemen, hebben de planbureaus, waaronder het ruv, zich onnodig kwetsbaar gemaakt woor kritiek. De Kwaadsteniet legde alleen mar deze kwetsbatheid bloot, zonder te begrijpen waar de klepel hing: meer meten is geen oplossing. 
6. Het is heden ten dage eenvoudiger een torenhoog salaris en een leaseauto te regelen dan een echt interessante baan.

7. Het is onbegrijpelijk dat de universiteiten disciplinaire bastions blijven (waarvan de onneembaarheid in stand wordt gehouden door het NWOmechanisme van disciplinaire 'peer-review'), terwijl de maarschappij schreeuwt om een interdisciplinaire aanpak van complexe problemen. Op deze manier zijn de universiteiten tot leegloop en maatschappelijke irrelevantie gedoemd.

8. Ouders van nu betalen liever een oppas dan dat ze (kinderloze) vrienden inschakelen. Daarmee onthouden ze hun kinderen en hun vrienden onbetaalbare momenten.

9. Als een kosmopoliet iemand is voor wie geen bestemming te ver is, dan zijn de meeste Randstedelingen gezien hun perceptie van de afstand Amsterdam-Maastricht eersteklas provincialen.

10. Wetenschap bedrijven is bewust nadenken. De liefde bedrijven is bewuste sex. 


\title{
Perspectieven op onzekerheid en risico
}

\section{de PRIMA-benadering voor beleidsondersteuning}

\author{
Nederlcundse samematting
}

De maatschappij wordt in toenemende mate geconfronteerd met complexe problemen. De kenmerken van de hedendaagse complexiteit zijn:

- er is sprake van een web van met elkaar samenhangende problemen (multi-problem)

- de problematiek ligt op het snijvlak van verschillende disciplines en domeinen (multi-dimensional)

- de onderliggende processen spelen zich op verschillende schaalniveaus in ruimte en tijd af (multi-scale)

De huidige beleidsondersteunende praktijk is niet toegesneden op dergelijke complexe vraagstukken. In dit proefschrift wordt een poging gedaan een constructieve bijdrage te leveren aan de noodzakelijke innovatie in beleidsondersteuning door een nieuwe benadering voor het systematisch analyseren van onzekerheid en risico (PRIMA) te ontwikkelen. Met theoretische en empirische argumenten wordt aangetoond dat onzekerheid en risico fundamentele onderwerpen zijn wataan in beleidsondersteunende onderzoek tot nu toe nauwelijks serieuze atandacht wordt besteed. Het gevolg daarvan is dat de kwaliteit van beleidsondersteuning momenteel onder druk staat. 
Tegen de achtergrond van bet bovenstaande, stat in dit proefschrift de volgende vraag centraal (hoofdstuk I):

Wat zijn theoretisch jüste en praktisch bruikbare wetenschappelijke methoden die beleidsondersteunende onderzoekers in staat stellen om onzekerheid en risico op een adequate en effectieve manier te adresseren in beleidsondersteunende studies? Met andere woorden:

Hoe kan de kloof tussen het theoretische ideaal en de beleidsondersteunende praktijk overbrugd worden?

De onderliggende onderzoekshypothese is dat het daartoe nodig is nieuwe methoden te ontwikkelen. In dit proefschrift wordt onderbouwd dat dergelijke methoden pluralistisch moeten zijn; daarmee wordt bedoeld dat de methoden rekening houden met, en gebruik maken van, het voorkomen wan verschillende zienswijzen, normen- en waardenpatronen, percepties, paradigma's, culturen, wereldbeelden, etc.

Rekening houdend met de kenmerken van complexiteit, spreekt het voor zich clat een integrale benadering noodzakelijk is. Integrated Assessment (in het Nederlands: geintegreerd denken en handelen) is een interdisciplinaire aanpak die zich in toenemende belangstelling mag verheugen. Integrated Assessment (IA) kan het best omschreven worden als een interdisciplinair en participatief proces waarin relevante kenniselementen worden gecombineerd met als doel besluitvormingsprocessen beter te ondersteunen. Het doel van Integrated Assessment is om inzicht te verkrijgen in complexe problemen door oorzaken, effecten en mogelijke strategieen te werkennen. Het is explictet de bedoeling dat in geintegreerde studies onzekerheden en verschillende risico-inschattingen explicier gemaakt worden. Methoden en procedures om dit op een legitieme en adequate manier te doen ontbreken echter momenteel in de IA-gereedschapskist (hoofdstuk 2). Het is de ambitie van dit proefschrift om deze methodologische uitdaging op te pakken doot methoden te verkennen die het mogelijk maken om op een geïntegreerde manier onzekerheid te 'managen' en risico te analyseren. De 
bedoeling is om daarmee een bijdrage te leveren aan de verdere ontwikkeling van Integrated Assessment als aanpak voor wetenschappelijk beleidsondersteunend onderzoek.

\section{Prima}

Het eerste onderdeel van het promotie-onderzoek behelst een studie naar de bronnen van onzekerheid en risico. Analoog aan het onderzoeken vam een fysisch fenomeen, zoals klimatwerandering, hebben we geprobeerd de oorzaken die aan het voorkomen van onzekerheid en risico in maatschappelijke debatten ten grondslag liggen, te identificeren. Dit deelonderzoek mondt uit in een taxonomie van bronnen van onzekerheid (figurur 1), die gebruikt kan worden om het begrip te verhelleren en de discussie te verbeteren. Deze taxonomie is generiek, in de zin dat hij algemeen bruikbaar is voor het iden-

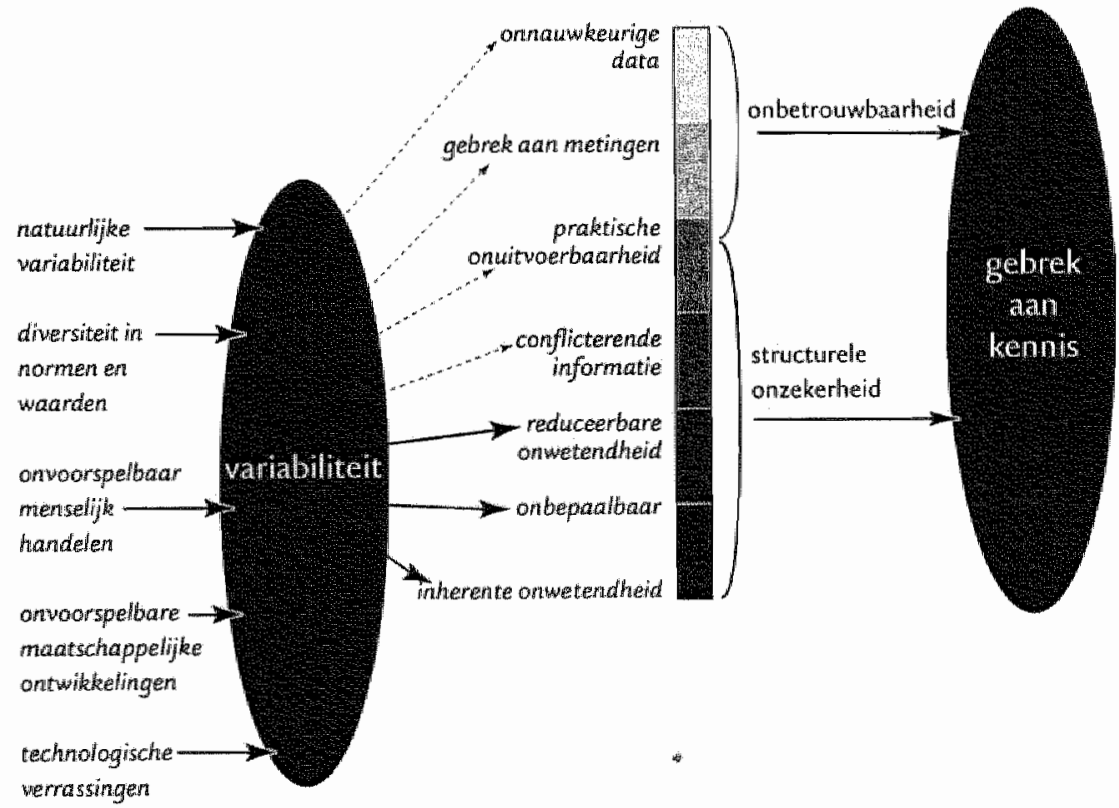

FGuUr ! Taxonomie wan bronnen wan anzekerheid 
tificeren en verkennen van bronnen van onzekerheid in studies naar complexe maatschappelijke problemen.

Op basis van de analyse van de wetenschappelijke literatuur uit verschillende disciplines (uiteenlopend wan wiskunde en economie tot filosofie en wetenschapsstudies) over onzekerheid en risico, concluderen we dat radicale onzekerheid, strategische risico's en meerdere perspectieven inherent zijn an complexiteit. Radicale onzekerheid betreft onzekerheden die op zijn best grof geschat kunnen worden. Strategische risico's zijn risico's die niet gecontroleerd kunnen worden door individuen, die niet exact gelokaliseerd kunnen worden, en het zijn risico's die spelen op de lange termijn (zowel wat oorzaken als effecten betreft). In dit proefschrift wordt beargumenteerd dat onzekerheid en risico aan elkalar gerelateerde concepten zijn, die beschouwd kunnen worden als twee zijden van dezelfde medaille: de beperkte voorspelbaarheid van complexiteit. Onzekerheid en risico zijn dus symptomen van complexiteit. 'Onzekerheid' (hoofdstuk $3 \mathrm{~A}$ ) wordt veelal geassocieerd met de wetenschappelijke rationaliteit, terwijl 'risico' een concept is dat in de eerste plaats geassocieerd wordt met de rationaliteit van beleidsmakers en besluitwormers (hoofdstuk $3^{3}$ ). In figuur Ir wordt weergegeven hoe de mate van onzekerheid en het type risico gerelateerd zijn.

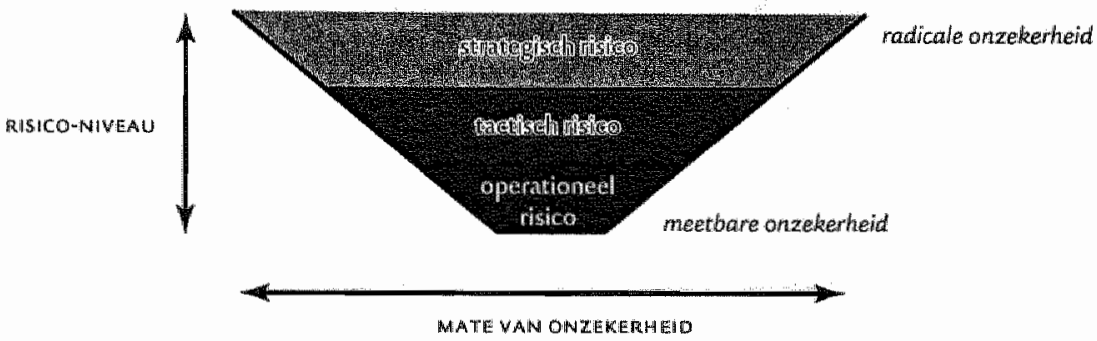

Fucun \# Mate van onzekerheid en type risico

Complexiteit impliceert dus zowel onzekere risico's als riskante onzekerheden. Dit betekent dat onzekerheid niet adequaat bestudeerd kan worden zonder risico daarbij te betrekken en vice versa. Tot nu toe houden 
veelal gescheiden onderzoeksgemeenschappen zich of bezig met risico of met onzekerheid. In deze onderzoekswelden domineerde tot woor kort de klassieke benadering warin onzekerheid en risico behandeld worden als mathematische en statistische artefacten. In deze onderzoeksgemeenschappen groeit het inzicht dat:

- wetenschap een creatief en innovatief proces is waarin intellect, intuitie, normen en waarden interfereren met feiten en cijfers

- kennis niet equivalent is met zekerheid en waarheid

- experts risico"s anders percipiëren dan 'leken'

- culturele factoren de manier waarop mensen risico's inschatten beïnvloeden

De logische consequentie wan deze gedeelde inzichten is dat verschillende perspectieven op onzekerheid en risico legitiem en valide zijn.

In dit proefschrift wordt aangetoond dat de huidige methoden voor onzekerheidsanalyse en risica-assessment vooral te kort schieten in geval van radicale onzekerheden en strategische risico's, precies die soorten onzekerheden en risico's die zo'n grote rol spelen bij complexe matschappelijke problemen. Op grond daarvan concluderen we dat er behoefre is a an nieuwe methoden, die gebruik maken van verschillende perspectieven teneinde pluralisme zichtbaar te maken en constructief te benutten. Een pluralistische aanpak impliceert dat verschillende legitieme interpretaties van de onzekerheden en divergerende risico-percepties worden meegenomen in de analyse. Onze analyse van het concept 'pluralisme' (hoofdstuk 4) mondt uit in de constatering dat er niet slechts én pluralistisclı uitgangspunt mogelijk is, maar meerdere. Dit betekent dat er niet éen unieke methode is waramee de geobserveerde behoefte vervuld kan worden, maar dat er in principe een variëteit aan methoden denkbaar is waarmee een bijdrage geleverd kan worden an effectief pluralistisch onzekerheidsmanagement en risico-analyse. Dat betekent dat het Pluralistic RRamework for Integrated uncertainty Management and risk Analysis (PRIMA), dat in het voorliggende promotieonderzoek wordt ontwikkeld, maar én manier is om onzekerheid en risico 
theoretisch adequat te adresseren in beleidsondersteunende studies. De PRMA-benadering is überhaupt niet bedoeld als blauwdruk. Het doel van de pRIMA benadering is om een heuristiek - een manier om een zoekproces te structureren - te bieden, die bestaat uit een aantal stappen en stadia, die theoretisch consistent zijn en praktisch bruikbaar lijken voor de beleidsonderstcunende praktijk.

Central in de PRIMA-benadering (hoofdstuk 5) staat de ambitie om controverses over complexe matschappelijke problemen te ontrafelen in termen van radicale onzekerheden en strategische risico's. De pluralistische aanpak impliceert dat de geïdentificeerde onzekerheden en risico's systematisch geïnterpreteerd worden aan de hand van verschillende perspectieven. Deze verschillende interpretaties en inschattingen worden met elkaar geconfronteerd met het doel om een rijker beeld te schetsen van de betreffende complexe problematiek.

De essentie van de PRIMA aanpak is dat onzekerheden die in een participatief proces als cruciaal met het oog op strategie-ontwikkeling worden aangeduid, wolgens verschillende perspectieven worden 'ingekleurd'. In het

\begin{tabular}{|c|c|c|}
\hline markt optimisit & milieu-doemdenker & controlist \\
\hline 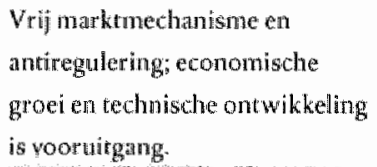 & $\begin{array}{l}\text { Natuur is kwersbaar, dus geery } \\
\text { milieurisico's nemen; } \\
\text { yoorkomen is beter } \\
\text { dan genezen. }\end{array}$ & 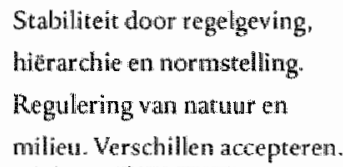 \\
\hline 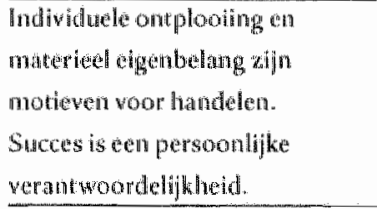 & Gelinklaxid & 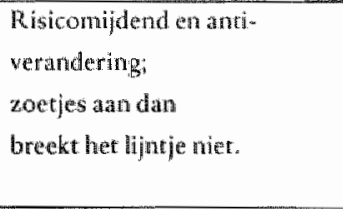 \\
\hline 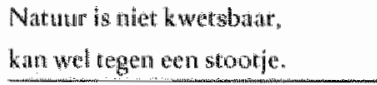 & 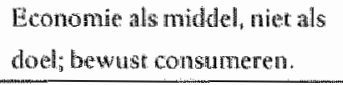 & $\begin{array}{l}\text { Auroriteit door expertise ery } \\
\text { erwaring. }\end{array}$ \\
\hline $\begin{array}{l}\text { Problemen xijo oplosbatr; } \\
\text { Risico's bieden mogelikheden, } \\
\text { virdaginger. }\end{array}$ & $\begin{array}{l}\text { Mensen xin solidin an } \\
\text { gedragen zich ook zo; } \\
\text { collectiof balang. }\end{array}$ & $\begin{array}{l}\text { Macht en alanzien zifin } \\
\text { de motieven woor actie. }\end{array}$ \\
\hline
\end{tabular}

TaabL I Eigenschappen van de drie gebnulkte perspactievery 
proefschrift maken we daartoe gebruik van drie perspectieven (de marktoptimist, de milieu-doemdenker en de controlist; zie tabel I) ontleend aan de Culturele Theorie.

De perspectivische interpretaties van onzekerheden worden vervolgens gebruikt om op een systematische manier verschillende scenario's te ontwikkelen. Geïntegreerde analyse (hetzij kwallitatief, hetzij gebruik makend van modellen) van deze fundamenteel verschillende scenario's biedt vervolgens de basis om autonome ontwikkelingen en beleidsstrategieën te evalueren in termen van risico. Scenario's worden in dit proefschrift gedefinieerd als coherente beschrijvingen van verschillende mogelijke toekomsten, dat wil zeggen dat een scenario een sequentie is van elkar opvolgende gebeurtenissen en processen over een bepaalde tijdsperiode. Een dergelijke geïntegreerde evaluatie stelt analisten in staat de mate van robuustheid van de a anbevelingen systematisch te verkennen, te onderbouwen en te communiceren. Deze verschillende fasen van de PRIMA-benadering zijn samengevat in figuur Irr.

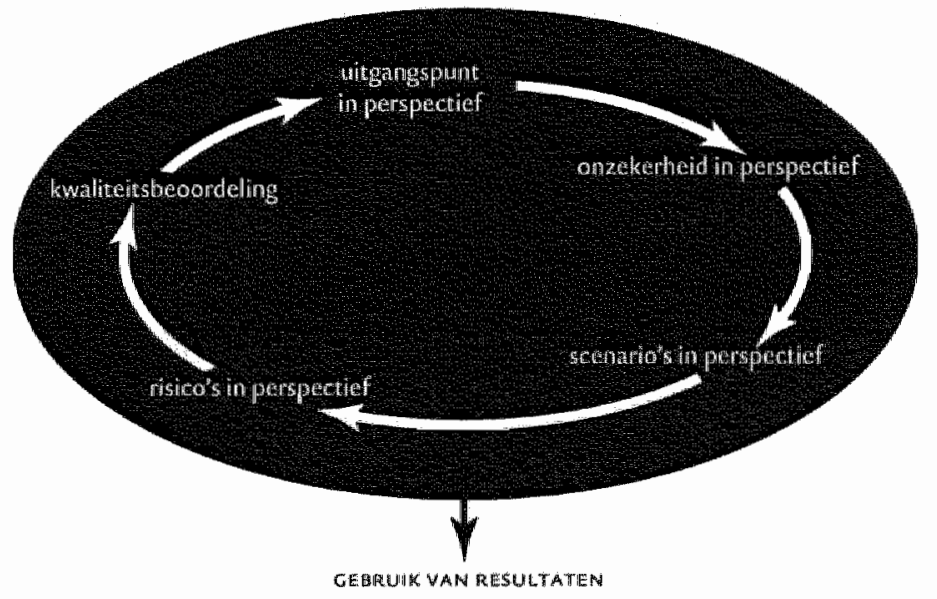

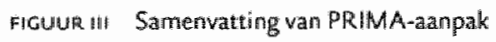




\section{Onzekerheid en RIvM's Milieuverkenningen}

De volgende vraag is of de voorgestelde prima-benadering ook potentiele waarde heeft voor de beleidspraktijk. Is het mogelijk de geformuleerde PRIMA-stappen uit te voeren? Zo ja, hoe en wat levert dat op? Met het oog op deze vragen hebben we een case-studie uitgevoerd betreffende de Milieuverkenningen van het Rijksinstituut woor Volksgezondheid en Milieu (FIVM). Het eerste onderdeel van deze case-studie behelst een retrospectieve analyse van de vier Milieuverkenningen die het Rrvm sinds 1988 heeft geproduceerd. In dit deelonderzoek is nagegaan hoe de belangrijkste conclusies onderbouwd worden en op welke manier in deze redenering wordt omgegaan met onzekerheden. Op basis van deze analyse kan geconcludeerd worden dat het RIVM een strategie en een kader ontbeert om in hun activiteiten op een systematische manier met onzekerheid om te gaan, wat consequenties heeft voor de robuustheid en de kwaliteit van de conclusies en beleidsaanbevelingen. De huidige manier van werken is met het oog op het fundamentele karakter van onzekerheid dus problematisch te noemen. Het RIVM is daardoor kwetsbaar voor kritiek, zoals de De Kwaadsteniet-affaire op een dubieuze, maar krachtige manier illustreerde. Het krym is niet het enige planbureau dat worstelt met het vraagstuk van onzekerheid. Uit het case-studie materiaal blijkt dat het aannemelijk is dat dit evenzeer geldt voor de andere planbureaus en beleidsondersteunende instituten. De conclusies aangaande de Milieuverkenningen lijken dan ook te gelden woor soortgelijke werkenningsactiviteiten. Op grond van onze case-studie concluderen we dus dat er in de wetenschappelijke beleidsondersteuning een latente behoefte is aan nieuwe methoden voor onzekerheidsmanagement. Uit onze data blijkt dat die behoefte ook meer en meer expliciet door de praktijk zelf wordt onderkend.

De volgende vraag is in hoeverre de PRIMA-aanpak de potentie heeft om in deze behoefte te voorzien. In dit proefschrift hebben we ons beperkt tot de vraag of en hoe het mogelijk zou zijn de eerste twee PRIMA-stappen 
uitvoeren. Deze vraag is verkend in de context van het Milieuverkenmingen 5 proces, waarbij we ons vooral toegespitst hebben op de "onzekerheid-in-perspectief fase. Vervolgens hebben we gekeken hoe de output van de PR MAactiviteiten (focusgroep, workshop, enquêtes en integrale analyse daarvan) bruikbaar zou kumnen zijn voor de Miliewwerkenningen 5, om op die manier het praktisch mut van de gezette stappen te verkennen. Dit empirische onderzoek mondt uit in een werkbare procedure voor de fase 'onzekerheid-inperspectief'. Daarnaast wordt door het empirische onderzoek de relevantie voor de praktijk van de fase 'uitgangspunt-in-perspectief' aangetoond.

De ervaringen opgedaan in deze prospectieve fase van het onderzoek suggereren dat het mogelijk en zinvol is om de PRrma-benadering in de praktijk wan beleidsondersteunend onderzoek in te zetten. Duidelijk is wel dat implementatie van de PRIMA-aanpak in de praktijk een fundamentele omslag in de manier van denken en handelen vergt en dat een dergelijke omslag ook de nodige tijd en moeite kost. De bij het prospectieve onderzoek betrokken RIVM-ers waren eensgezind in hun evaluatie dat de PR IMAactiviteiten tenminste een bijdrage geleverd hadden aan het individuele en collectieve leerproces binnen het RIVM.

\section{Conclusies}

Het promotie-onderzoek heeft tot doel inzicht te geven in de vratag of er theoretisch juiste en praktisch bruikbare alternatieve wetenschappelijke methoden denkbaar zijn die beleidsondersteunende onderzockers in staat stellen om onzekerheid en risico op een adequate en effectieve manier te adresseren in beleidsondersteunende studies. In dit proefschrift wordt bear gumenteerd dat er zowel een theoretische behoefte als een behoefte vanuit de beleidsondersteunende praktijk is aan pluralistische methoden waarin onzekerheid en risico in hun onderlinge samenhang worden beschouwd. De woorgestane PR IMA-benadering is ontwikkeld conform deze eisen. De ecrste ervaringen beschreven in dit proefschrift geven an dat het mogelijk en 
zinvol likt de prima-benadering in de praktik te gebruiken. Daarmee zou de kloof tussen het theoretische ideaal en de praktijk zeker niet gedicht zijn, maar er zouden met het verder ontwikkelen en toepassen van de PrImAbenadering wel belangrijke stappen op weg maar een theoretisch onderbouwde innovatie in beleidsondersteuning gezer kumnen worden.

De ambitie die tèn grondslag ligt aan dit proefschrift is om een methodologische bijdrage te leveren aan de ontwikkeling van Integrated Assessment als aanpak voor wetenschappelijk beleidsondersteunend onderzoek. Wat heeft PRIMA Integrated Assessment te bieden? De PRIMA aanpak geeft een proces-structuur waarin zowel analytische als participatieve methoden gebruikt worden. De prima-benadering kan dus beschouwd worden als een methodologisch kader voor geintegreerde studies. Daarnaast kan het als heuristiek gebruikt worden om in Integrated Assessment meer systemarisch met onzekerheid, risico en pluralisme om te gaan.

Een proefschrift is altijd zowel een eindpunt als een nieuw begin. Uit het voorliggende materiaal en de gegenereerde inzichten kunnen de volgende uitdagingen voor verwolgonderzoek worden afgeleid:

- verdere methodologische ontwikkeling van prima door kennis en inzicht met betrekking tot participatieve methoden en scenarioontwikkeling, en inzichten ontleend aan aanverwante velden zoals beleidsanalyse en technology assessment (nog) beter te benutten

- het erbij betrekken van de rationaliteit van beleid en beleidsprocessen, door gebruik te maken van beleidsanalyse, beleidswetenschappen en politicologie en middels empirisch onderzoek

- het toetsen van het praktische nut van prima door empirische toetsing in een serie van ex-ante case-studies ten aanzien van beleidsondersteunende activiteiten

Een interclisciplinair proefschrift is nog steeds een curiositeit. Daarnaast stelt dit proefschrift fundamentele vragen over de interactie tussen wetenschap en beleid. Het is duidelijk dat dit proefschrift daarom door deze en gene als controversieel beschouwd zal worden. Her is wooral de bedoeling 
dat dit proefschrift wetenschappers, beleidsondersteuners, beleidsmakers, maatschappelijke actoren en geïnteresseerde individuen uitdaagt om onzekerheid en risico eens in een ander perspectief te platsen om op die manier een noodzakelijke discussie over de toekomst van wetenschappelijk beleidsondersteuning aan te jagen. 


\title{
Curriculum vitae
}

\author{
Marjolein B.A. van Asselt
}

Marjolein van Asselt (1969) has an evident interest in interdisciplinary research. She is interested in the fundamental question how theories and knowledge from natural sciences and social sciences can be brought together in such a way that it is both scientifically valid and useful to society. In that sense the young research area of Integrated Assessment fits perfectly with her research interests. Marjolein can be characterised as someone building bridges in various ways: between disciplines, between process and product, and between science and society.

Marjolein van Asselt did her undergraduate in Computer Science at Twente University in the Netherlands. She finished the master course Philosophy in Science, Technology and Society (Twente University) in 1994. In 1993, she was awarded with the Stork UT prize: an annual award for a student who combines good study results with an active, recognisable role in student and university life. She was the first female prize winner ever and the first laureate from a non-technical department.

In 1993, she entered the Global Dynamics and Sustainable Develop ment group of prof. Jan Rotmans at nuv (Bilthoven, the Netherlands) as intern studying the gap between Integrated Assessment modellers and their targeted users (i.e. decision-makers). After her graduation, she stayed with this team till June 1996. Together with Jan Rotmans she developed the concept of perspective-based model routes as an approach to highlight inherent uncertainty and subjectivity in Integrated Assessment Models. Through team-work, the concept was implemented in the IA model TARGETS. 
Since the beginning of her research carreer, Marjolein has tried to use insights from philosophy and sociology of science to improve methodology for interdisciplinary decision-support. Although she acqainted a fair level of knowledge on a variety of issues related to global change and sustainable development through working in Integrated Assessment projects, her main interest is still methodological.

From July 1996 to June 1997. Marjolein van Asselt worked in Swirzerland, in the Human Ecology Group at the Swiss Institute for Environmental Science and Technology (EAWAG). Supervised by prof. Carlo Jaeger, she particpated in two large IA projects, i.e. the urysses project and the Clrar project. Both projects aimed to find ways to use models and participatory methods in a complementary manner in the assessment effort. In this way, Marjolein gained experience with participatory assessment processes.

In July 1997, she returned to the Netherlands. She was invited by Jan Rotmans to assist him in establishing a new research team at Maastricht University. In January 1998, the International Centre for Integrative Studies (ICIs) opened her doors. Marjolein van Asselt is currently deputy director of ICIS and team leader of the ICrs' research programme IA methodology. Next to that, she is co-director of ICIS-BV, a consultancy frrm that has been developed as a spin-off from the ICIS' research activities.

Next to her $P h D$ research, Marjolein has been involved in a number of innovative research projects, such as the visions project in which integrated multi-level scanerios for Europe are developed, and a Nop/rrma project in which perspective-based scenarios are used to develop integrated watermanagement strategies for the Rhine and Meuse. She furthermore plays a leading role in the lA consultancy projects, for clients such as the Prowince of Limburg, the city of Maastricht, RIVM and Dutch Ministries. 
Marjolein van Asselt has initiated and organised the first international advanced study course in Integrated Assessment (August - Seprember 1999): a 3 -week course featuring leading scientists in the field of Integrated Assessment, in which 25 post-graduates from 17 nationalities and from a wide range of disciplines participated. This course "Tools and methods for Integrated Assessment" was organised under the auspices of the European Commission-DG Research and the European Forum on Integrated Environmental Assessment (BFIEA). She is furthermore co-organisot" and host of the EFIEA workshop on scaling issues in Integrated Assessment (July 2000 ) as well as of the workshop "Dealling with uncertainty in environmental decision-making" (November 2000) within the European Science Foundation TERM II programme.

Marjolein is an active member of the European Forum on Integrated Envirommental Assessment (EFIEA). She is furthermore member of the editorial board of the international journal Integrated Assessment and associate of the International Jourmal of Risk Assessment and Management (IJRAM). 


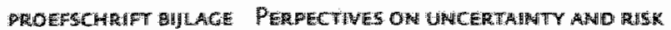




\title{
Overview of publications
}

\author{
Marjolein B.A. van Asselt
}

July 2000

\section{Journal articles}

- wan Asselt, M.B.A. and Rotmans, J. (1995). "Letter to the editor." Science and Public Policy, 22(6), 4.5.

- wan Asselt, M.B.A. and Rotmans, J. (1996). "Uncertainty in Perspective." Global Environmental Change, $6(2), 121-157$

- wan Asselt, M.B.A.x Beusen, A.H.W., Hilderirk, H.B.M. (1996). "Uncertainty in Integrated Assessment: A social scientific perspectiwe." Enwironmental Modelling and Assessment, 1(1), 71.90.

- Ratmans, l, and var Asselt, M.B.A. (1996). "Integrated Assessment: A growing child on its way to maturity." Climatic Change, 34, 327-336.

- Rotmans, I, and wan Asselt, M.B.A. (1999). "Perspectives on a sustainable future." International journat for sustainable development, $1(3), 25-60$.

- Kasemir, B., van Asselt, M. B. A., Dürrenberger, G., and jaeger, C. C. (1999). "Integrated Assessment: Multiple Perspectives in Interaction." International journal of Environment and Poillation, 11(4), $407-425$.

- Rotmans, J. and van Asselt, M.B.A, (2000). "Decision support in the public sector: towards an integrated planning tool', Journal of Multi-criteria Decision Analysis, (in print)

- Rotmains, I. and van Asselt, M.B.A. (2000). "Integrated Assessment Models: Uncertainty, quality and use", Environmental Monitoring and Assessment, (in print).

- Rotmanas, I, Van Asselit, M.B.A., Vellinga, P. (2000). "An integrated planining tool for sustainable citites", Environmental Impact Assessment Review 20 (2000), $165-276$.

- Rotmans, J. van Asselt, M.B.A. Anastasi, C. Greeuw, S., Mellors, J. Peters, S., Rothmaa, D., Rijkens, N. (2000). "Visions for a Sustainable Europe" Futures (in print)

- Var Asselt, M.B.A. (2000) "Uncertainty in Decision-support. From problem to chatlenge", Risk analysis. (accepted with revisions).

- Rotmans, f., Van Asselt, M.B.A. (2000). "Uncertainty in Integrated Assessment Modeling: A slippery path". Integrated Assessment, speciol issue edited by RMNO (accepted). 


\section{Books}

- Van Asselt; M.B.A. (2000). Perspectrues on Uncertalinty and Riste: The PRMA approach to decision support, Kluwer; Dordrecthe The Netherlands (in print,

- Van Asselt, W.B.A and Rotmans, J (eds.) (2000). Puzzle-solwing for policy: A prowisional hand book for Integrated Astessment, (publisher - to be decided) (in preparation).

- Rotmans, J. and van Asselt, M.B.A. (eds.) (2001). Scaling issues in lntegrated Assessmerit, (publisher - to be decidedy (in preparation).

\section{Book chapters}

- Rotmains, J, van Asselt. M. B. A, and de Vries, H. I. M. (1997). "Global Change and Sustainable Dewelopment." Perspectives on Clobal Change: The TARGETS approach, J. Rotmans, and H. J. M. de' Wries, eds., Cambridge Uniwersity Press, Cambridge, UK.

- Rotmants, l., de Vries, H. J. M. and van Asselit, M. B. A. (1997). "Concepts." Perspectives on Clobal Charge: The TARGETS approach, ). Rotmans and H. J. M. de Vries, eds., Cambridge University Press, Cambridge, UK.

- Rotmans, ل. de Vries, H. I. M. van Asselt, M. B. A., Beusen, A. H. W." den Elzen, M. G. J, Hilderink, H. B. M. Hoekstra, A. Y, and Strengers, B. I. (1997). "Towards Integrated Assessment of Cllobal Change." Perspectives on Glabal Change: The TARGETS approach, J. Rotmans and H.J. M. de Vries, eds., Cambridge University Press, Cambridge, UK.

- Rotmans, J, van Asselt, M. B. A.y de Vries, H. J. M., Beusen, A. H. W, den Elzen, M. G. J. Hilderink, H. B. M., Hoekstra, A. Y, Janssen, M. A., Koster H. W., Niessen, L. W, and Strengers, B.). (1997). "The TARGETS model." Perspectives on Global Change: The TARGETS approach, J. Rotmans and H.J. M. die Wries, eds.

- van Asselt, M. B. A., and Rotmans, J. (1997). "Uncertainties in perspective." Perspectives on Global Change: the TARGETS approach, J. Rotmans and B. de Vries, eds., Cambrigde University Press, Cambridge, UK.

- Elzen, M. G. J., Beusen, A. H. W., Rotmans, J., and wan Asselt, M. B. A. (1997). "Human disturbance of the global biogeochemical cycles." Perspectives on Global Change: The TARGETS approach, I. Rotmans and H. J. M de Vries, eds, Cambridge University Press "Cambridge, UK.

- Hitderink, H. B. M, and wan Asselt, M. B. A. (1997). "Population and Health in Perspective." Perspectives on Global Change: The TARGETS approach, J. Rotmans and H. J. M. de Vries, eds., Cambridge University Press, Cambridge, UK.

- Hookstra, A. Y. Beusen, A. H. W., Hilderink, H. B. M., and wan Asselt, M. B. A. (1997), "Water in crisis?" Perspectives on Global Change: The TARGETS approach, J Rotmans and H. J. M. de Vries, eds. Cambridge Uniwersity Press, Cambridge, UK.

- Strengers, 8. I, den Elzen, M. G. J. Koster, H. W., Hilderink, H. B. M. and van Asselt, M. B. A. (1997). "Foad for the future." Perspectives on Global Change: The TARGETS approach, I. Rotmans and H. I. M. de Vries, eds., Cambridge University Press, Cambridge, UK. 
- de Vries, H. J. M. Rotmans, J, Beusen, A. H. W. den Elizen, M. G. J. Hilderink, H. B. M., Hoeksta., A. Y, Janssen, M. A. Niessen, L. W. Strengers, B. J., and wan Asselt, M. B. A. (1997), "Clobal Change: Fresh insights, no simple answers." Perspectives an Clobal Change: The TARCETS approach, J. Rotmans and H. J.M. de Vries, eds, Cambridge University Press, Cambridge, UK.

- Rotmans 1., Dowlatabadi, H, Parson, E. A, war . Asselt, M.B.A., and Janssen, M.A.I. (1998) "Integrated Assessment of Climate Change: Evaluation of Methods and Strategies." Human Choice and Climate Change: An International Social Science Assessment, S. Rayner and E. Malone, ads.n Battelle Press, Washington, USA.

- Pahl-Wosti, C. Jaeger, C., Raymer, 5., Schaer, C, van Asseli, M. B. A., Imboden, D, and Vekovski, A, (1998). "Regional Integrated Assessment and the Problem of lindeterminacy." In: Views from the Alps. Regional perspectives on climate change, P. Cebon, Dahinden, U., H. Davies, D. Imboden, and $C$. jaeger, (eds), Cambridge, England.

- Rotmans, J, and van Asselt, M. B. A. (1999). "integrated Assessment Modelling." Clinnate Change: an integrated perspective, D. lanssen, W. J. M. Martens, J. Rotmans, and O. J. Vrieze, eds., Kluwer, Dordrecht, the Netherlands.

- van Asselt, M. B. A., and Rotmans, J. (1999). "Perspectives and the subjective dimension in modelling," Clinate Change: an integrated perspectiwe, D. Janssen, W. J. M. Martens, J. Rotmans, and O.J. Vrieze, eds., Kluwer, Dordrecht, the Netherlands.

- Jager, W., van Asselt, M.B.A., Rotmans, l., Vlek, C., (1999). "Consunner behaviour: A modelling perspective in the context of Integrated Assessment of Global Change" In: Sustainability in question. The research for a conceptual framework, J. Kơhn. . . Gowdly, F. Hinterberger and In w. d. Straatern, eds., Advances in ecological economics series, Edward Elgar Publishing, UK.

- Ratmans, J. and van Asselt, M. B. A. (2000). "Integrated Assessment: Current Practices and Challenges for the Future." In: UNEP-publications, R. Costanza and S. Tognetit, eds., SCOPE, Paris, USA, in preparation.

\section{Research reports}

- yan Asselt, M. B. A. (1994). "Gilobal Integrated Assessment Modells as Policy Support Tools: A Triangular Approach." University of Twente, Enschede, the Netherlands.

- Rotmans, I. van Asselt, M. B. A, de Bruin, A. J, den Elzen, M. Ci. J., de Greef, J, Hilderink, H. Hoekstra, A. Y., Janssen, M. A., Koster, H. W. Martens, W. J. M., Niliessen, L. W., and de Vries, H. J. M. (1994). "Global Charge and Sustainable Dewelopmemt: A Modelling Perspective for the Next Decade." RIVM-report no, 461502004, Globo report series, National Institute of Public Health and the Enwironment (RIVM), Bilthoven, The Netherlands. 
- wan Asselt, M. B. A, and Rotmans, (1 995) "Uncertainty in Integrated Assessment Modelling: A Cutural Perspective-based Approacri, National Institute of Public Health and Environmental Protection (RIWM), RUMA report no. 461502009, Clobo Report Series; Bithowen, the Netherlands.

- Durrenterger, D, Behringer, , Dahindsn, U., Gerger, A Kasemir, B, Querol, C., Schiole, R., Tabara, D.

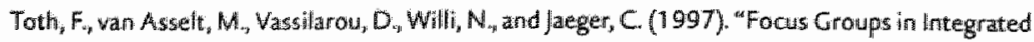
A.ssessment: A Manual for a Participatory Tool." ULYSSES working paper WP.97-2, Darrnstadt University of Techndogy, Darmitadt, Germany.

- Jager W, Wan Asselt, M. B. A., Rotmans, I, Vlek, C. A. I, and Boodt, C (1997). "Consumer behaviour: A modelling perspective in the context of integrated assersment of global change. 461502017 , RlWM, Bilthoven, the Netherlands.

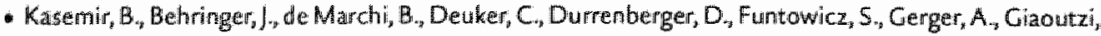
M. Haftner, Y, Nitlson, Mo, Querol, C. Schule, R., Tabara, D., van Asselt, M.B.A., Vassilafou, D, Wilit ${ }_{1} N_{\text {. }}$ and jaeger $C_{\text {. }}$ (1997). "Focus Croups in integrated Assessment: The ULYSSES pilot experience." ULYSSES WP-97-4, Darmstadt University of Technology, Darmstadt, Germany.

- wan Asselt, M.B.A. (1997) "TARGETS for ULYSSES: work package" "ULYSSES research report, EAWAC, Switzerland, the Netherlands.

- Van Asselt, M.B.A., Storms, C.A.H.M., Rijkens-Klomp, N., and Rotmans, J. (1998). "Towards Visions for a Sustainable Europe: An overview and assessment of the last deciade of European scenario. studies", 1C15, ICIS working paper 198-E001, Maastricht, The Netherlands.

- Rotrnans, J., Rijkens-Klomp, N., van Asselt, M.B.A.A (1998). "Limburg in perspectief: Een cerste aanzet", 1CIS, ICIS working paper 198-D002, Malastricht, Nederland.

- Rotmans, I. van Asselt, M.B.A., Rijkens-KKlomp, N., (1998). "Een denkmodel van kapitaalswormen, voorraden en stromen", ICIS, ICIS working-paper 198-D003, Maastricht, Nederland.

- Van Asselt, M.B.A, de Niet, R, Peters, S, Rijkens-Klomp, N., Rotmars, J., Slooff, W, (1998). "Het Groene Hart in breder perspectief. Startnotitie scenario"s en indicatoren t.b.v. VISIONS-workshop", ICIS en RIVM, Maastricht, Nederland.

- Van Asselt, M.B.A., Rijkerns-Klomp, N., Rotmans, I. (1999). "Input bedrijventerreinen schets Limburg". ICIS, Maastricht, Nedlerland.

- Rotmans, J., war Asselt, M.B.A. Rijkens-Klamp, N. (1999), "Het denkmodel woor POL", ICIS, ICIS working paper 199 -D004, Maastricht, Nederland.

- Van Assell, M. B.A. (1999). "Uncertainty in decision-5upport. From probtem to challenge" "ICIS working paper 199-E006, Maastricht, The Netherlands.

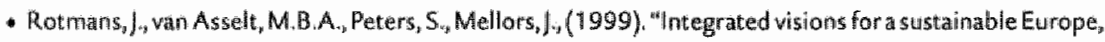
VISIONS progress report March 1998-February 1999", ENV44CT97-0462, 1CIS, Maastricht the Natherlands.

- Van Asgelit, M.B.A., Greeuw, S, de Niet, R, Rijkens-Klomp, N, Rotmant, J, Slooff, W. (1999). "Op weg matar scenario's woor het Groene Hart. Stof voor verhalen ", KCIS en RIVM, Maastricht, Nedentand.

- Amelung, B., Beers, P.J., Rotmans, J, van Asselt, M. B. A., Hogervorst, J., (1999). "Global tourism Towards an integrated approach", ICIS, Working paper 199-E007, Maastricht, Nederland. 


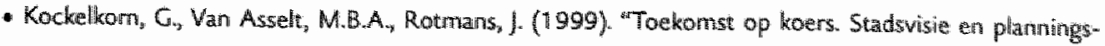
instrument voor Maastricht op weg naar 2030. Plan wan aanpalk in opdracht wan de gemeente Maastricht" "ICIS, Maastricht, The Netherlands.

- Varn Asselit, M.B.A., Greeuw, S, de Niet, R., Rotmans, J „1999). "VISIONS for the Green heart". Interim Report, Maastrichit, The Netherlands

- Rotmans, I, Anastasi, C, Van Asselt, M.B.A., Peters, S., Mellors, J. Creeuw, S.y Rothman, D. (1999). "VISIONS for Europe". interime report, Maastricht, The Netherlands

- Anastasi, C., Rotmans, J, wan Asselt, M. B.A.A, Greeuw, S., Mellors, ., Peters, S. Rothman, D. (1999) "Global Format". Position Faper, Maastricht, The Netherlands

- Van Asselt, M.B.A, Van Asten, F., (1999). "Onzekerheid \& Milieuwerkenningen 5." Workshop-report. ICIS, Maastricht, The Mletherlands.

- Van Asselt, M.B.A. Rijkens-Klomp, N. and Molendijk, K.G.P. (2000) (in Dutch). "Working with the SCENE-model". ICIS, Maastricht, the Netherllands.

- Van Cemert, N.M. en Van Asselt, M.B.A. (2000) (in Dutch) "Futures for the Rhine and Meuse.", Workshop-report. ICIS, Maastricht, the Netherlands.

- Van Asselt, M. B. A., Langendonck, R. M. T., and Van Asten, F. (2000), "Searching for Uncertanty: A case-study on the Dutch National Environmental Outlooks", ICIS, Maastricht, the Netherlands.

\section{Conference papers}

- Jager, W., Asselt, M.8.A. van, Rotmans, I. and Vlek, C.A.J. (1996) "Modelling Consumptive Behaviour in the cantext of Clobal Change". Human Dimensions of Clabal Environmental Change symposium, 20-22 september 1995, Geneva, Switzerland.

- Rotmans, J., and van Asselt, M. B. A. (1997) "From scenarios to visions. A long way to go. Lessons learned from two decades scenario development." Open meeting of the Human Dimensions of Clobal Enwronmental Change Research Community, Laxenburg, Austria.

- Van Asselt, M.B.A., (1999), "Uncertainty at risk: Learning from the Dutch environnental assessments", Paper prepared for the open meeting of the human dimensions of global environmental change research, Japan.

- Varn Asselt, M. B. A., Rotmans, I, (1999), "Uncertainty in Integrated Asses.sment Modelling. A bridge over troubled water". Paper presented at the 1999 Matrix Workshop on Uncertainty, EFIEA and Stockholim Enwironmental Institute, 10.18/uly 1999, Baden bei Wien, Austria.

- Van Asselt, M.B.A. (1999). "improwing decision-making under uncertainty. Ain integrated approach to strategic risk analysis". Paper prepared for the $9^{\text {in }}$ A murual Conference of the Society for Risk Analysis 'Facing the New Millennium, 10-13 October 1999, Rotterdam, the Netherlands. 


\section{CD-Roms}

- Hidernk, H.B.M., Moxselman, E, Beusen, A.H.W.- van Asseht, M.B.A., den Elzen, M.G.J, de Vink, P.J.F. Rotmans, 1. (1998). "Targets 1.0" ESIAM, vol. 1, Battzer Science Publishers, Bussum, The Netherlands.

\section{Other}

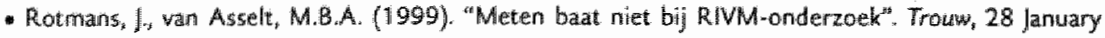
1999.

- Van Asselt, M. B. A, Molendijk, Ku, Rijkens-Klomp, No, Rotmans, J., (1999) (in Dutch) aReader: Starterstraining SCENE mode:", background material to training Province of Limburg, ICIS, Maastricht, The Netherlands.

- Van Assett, M. B. A. Molendijk, K., Rijkens-Klomp, N., Ratmans, J., (1999) (in Dutch) "Reader. Training SCENEmodel", background material to training Telos (Brabants instituut woor duturaamheidswraagstukken) 1 C15, Maastricht, the Netherlands.

- Van Asselt, M.B.A. and Rotmans, I, (2000) "Politici moeten wrees van burgers serieus nemem". Volkskrant, 17 May 2000.

- Rotmans, I., Van Asselt, M.B.A., Rijkensikllomp, N., van de Lindt, M., (2000) (in Dutch) "Reader: Integrated Assessment", background material to training Gemeente Maastricht, $1 \mathrm{CIS}$, Maastricht, the Netherlands. 
$\begin{array}{ll}-\ldots & -\end{array}$ 
the road ahead is empty

paved with miles of the unknown

whatever seems to be your destination

take uncertainty as your guide 